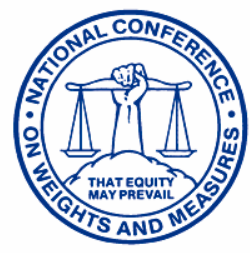

NIT

National Institute of

Standards and Technology

U.S. Department of Commerce

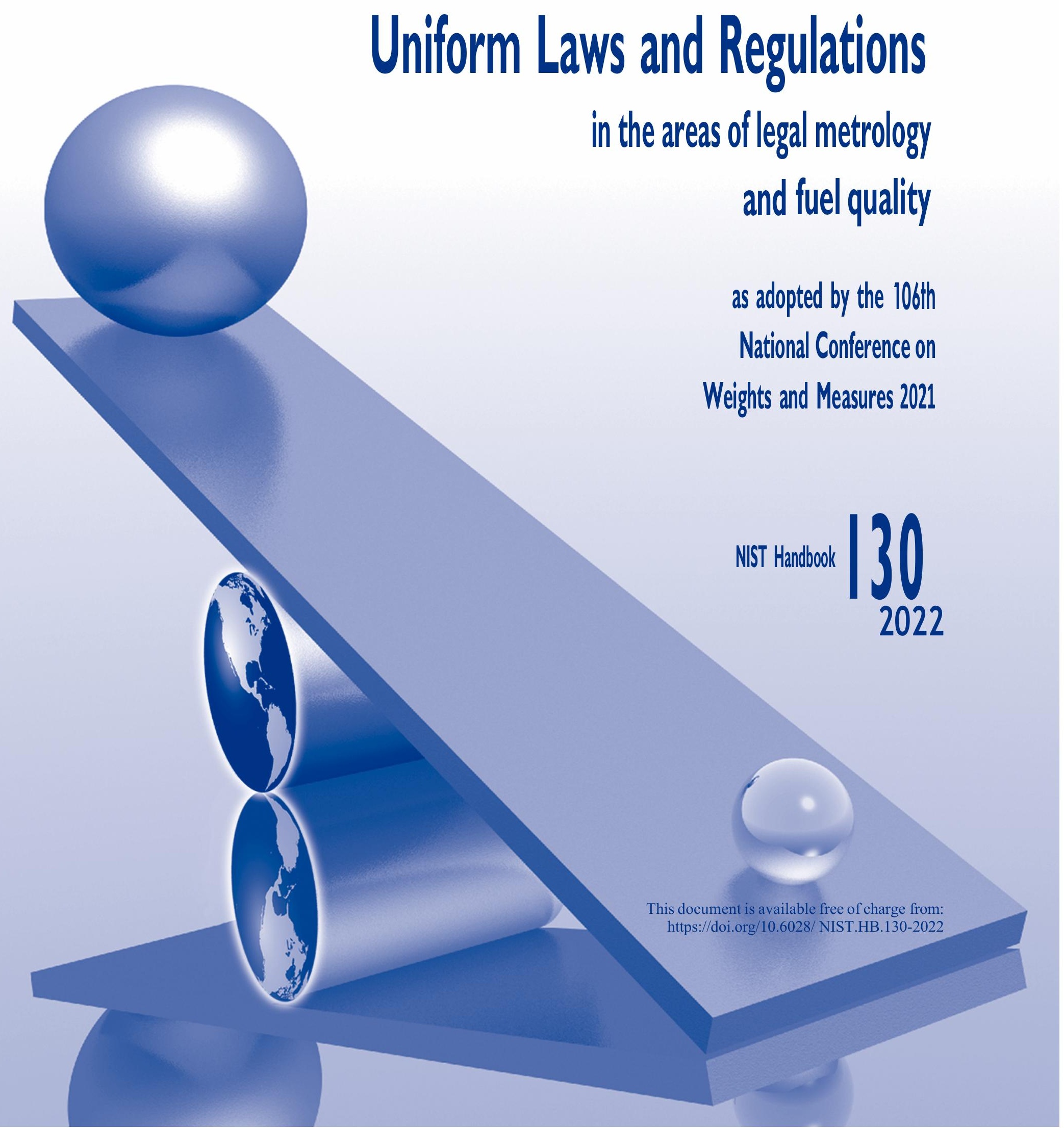

Uniform Laws and Regulations in the areas of legal metrology and fuel quality as adopted by the 106th National Conference on Weights and Measures 2021

NIST Handbool 


\section{Uniform Laws and Regulations in the Areas of Legal Metrology and Fuel Quality}

as adopted by the 106th National Conference on Weights and Measures 2021

Editors:

Shelby Bowers

David Sefcik

Lisa Warfield

Dr. Katrice Lippa, Chief Office of Weights and Measures Physical Measurement Laboratory

This publication is available free of charge from:

https://doi.org/10.6028/NIST.HB.130-2022

December 2021

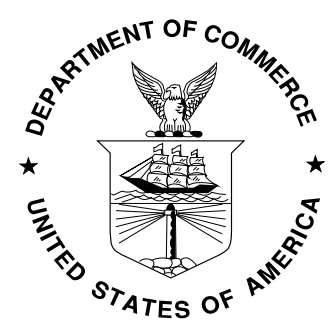

U.S. Department of Commerce Gina M. Raimondo, Secretary

National Institute of Standards and Technology James K. Olthoff, Performing the Non-Exclusive Functions and Duties of the Under Secretary of Commerce for Standards and Technology \& Director, National Institute of Standards and Technology

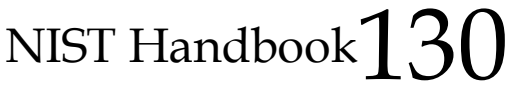


Certain commercial entities, equipment, or materials may be identified in this document in order to describe an experimental procedure or concept adequately. Such identification is not intended to imply recommendation or endorsement by the National Institute of Standards and Technology, nor is it intended to imply that the entities, materials, or equipment are necessarily the best available for the purpose.

National Institute of Standards and Technology Handbook 130 Natl. Inst. Stand. Technol. Handbook 130, 307 pages (December 2021)

This publication is available free of charge from: https://doi.org/10.6028/NIST.HB.130-2022 


\section{Foreword}

This handbook compiles the latest Uniform Laws and Regulations and related interpretations and guidelines adopted by the National Conference on Weights and Measures, Inc. (NCWM). At the 1983 Annual Meeting, the NCWM voted to change the title of Handbook 130 and the title of the Laws and Regulations compiled in this handbook. The former title of the handbook was "Model State Laws and Regulations." "Model State" was to be changed to "Uniform" in the title to reflect that these Laws and Regulations are (a) intended to be standards rather than just guidelines, and (b) intended for adoption by political subdivisions other than states when deemed appropriate.

NIST Handbook 130 is published in its entirety each year following the Annual Meeting of the National Conference on Weights and Measures (NCWM). As a result of circumstances surrounding the COVID-19 pandemic, a 2021 edition of NIST Handbook 130 was not published. The Committee on Laws and Regulations of the NCWM developed the 2022 edition with the assistance of the Office of Weights and Measures (OWM) of the National Institute of Standards and Technology (NIST). This handbook includes amendments endorsed by the $105^{\text {th }}$ and $106^{\text {th }}$ National Conference on Weights and Measures during its Annual Meetings in 2021. The NCWM recommends adoption and promulgation by weights and measures jurisdictions of these Uniform Laws and Regulations as updated in this handbook.

The National Institute of Standards and Technology (NIST) has a statutory responsibility to promote "cooperation with the states in securing uniformity in weights and measures laws and method of inspection." In partial fulfillment of this responsibility, the Institute is pleased to publish these recommendations of the NCWM.

This handbook promotes the primary use of the International System of Units (SI) by citing SI units before U.S. customary units where both units appear together, and by placing separate sections containing requirements for SI units before corresponding sections containing requirements for customary units. In some cases, however, trade practice is currently restricted to the use of U.S. customary units; therefore, some requirements in this handbook will continue to specify only U.S. customary units until the NCWM achieves a broad consensus on the permitted metric units. 
THIS PAGE INTENTIONALLY LEFT BLANK 


\title{
Committee Members
}

\section{Committee on Laws and Regulations of the $105^{\text {th }}$ Conference}

\author{
Ethan Bogren, New York \\ Mauricio Mejia, Florida \\ John McGuire, New Jersey \\ Doug Rathbun, Illinois \\ Tim Elliott, Washington
}

Associate Membership Committee Representative: Prentiss Searles, American Petroleum Institute Canadian Technical Advisor: Lance Robertson, Measurement Canada

NIST Technical Advisors: Lisa Warfield, David Sefcik

NIST Technical Advisor on the Uniform Regulation for National Type Evaluation: Tina Butcher

\section{Committee on Laws and Regulations of the $106^{\text {th }}$ Conference}

\author{
John McGuire, New Jersey \\ Mauricio Mejia, Florida \\ Doug Rathbun, Illinois \\ Tory Brewer, West Virginia \\ Timothy Elliott, Washington
}

Associate Membership Committee Representative: Prentiss Searles, American Petroleum Institute
Canadian Technical Advisor: Lance Robertson, Measurement Canada
NIST Technical Advisors: Lisa Warfield, David Sefcik
NIST Technical Advisor on the Uniform Regulation for National Type Evaluation: Tina Butcher 


\section{Past Chairs of the Committee}

$\begin{array}{cl}\text { Conference } & \text { Chair } \\ 41 & \text { G. H. Leithauser, MD } \\ 42-43 & \text { F. M. Greene, CT } \\ 44 & \text { G. L. Johnson, KY } \\ 45 & \text { R. Williams, NY } \\ 46-49 & \text { J. H. Lewis, WA } \\ 50-51 & \text { L. Barker, WV } \\ 52 & \text { M. Jennings, TN } \\ 53 & \text { W. A. Kerlin, CA } \\ 54-55 & \text { J. F. Lyles, VA } \\ 56-58 & \text { S. D. Andrews, FL } \\ 59 & \text { R. M. Leach, MI } \\ 60 & \text { R. L. Thompson, MD } \\ 61-62 & \text { C. H. Vincent, Dallas, TX } \\ 63 & \text { J. T. Bennett, CT } \\ 64 & \text { R. W. Probst, WI } \\ 65 & \text { D. I. Offner, MO } \\ 66-68 & \text { J. J. Bartfai, NY } \\ 69 & \text { W. R. Mossberg, CA } \\ 70 & \text { E. Skluzacek, MN } \\ 71 & \text { D. Stagg, AL } \\ 72 & \text { A. Nelson, CT } \\ 73-74 & \text { K. Simila, OR } \\ 75 & \text { S. B. Colbrook, IL } \\ 76 & \text { A. Nelson, CT } \\ 77 & \text { B. Bloch, CA }\end{array}$

$\begin{array}{cl}\text { Conference } & \text { Chair } \\ 78 & \text { F. Clem, OH } \\ 79 & \text { B. Bloch, CA } \\ 80 & \text { S. Rhoades, AZ } \\ 81 & \text { L. Straub, MD } \\ 82 & \text { S. Millay, ME } \\ 83-84 & \text { K. Angell, WV } \\ 85 & \text { S. Morrison, CA } \\ 86 & \text { R. Williams, TN } \\ 87 & \text { P. D’Errico, NJ } \\ 88-89 & \text { D. Johannes, CA } \\ 90 & \text { J. Gomez, NM } \\ 91 & \text { J. Benavides, TX } \\ 92 & \text { J. Cassidy, MA } \\ 93 & \text { Vicky Dempsey, OH } \\ 94 & \text { Joe Gomez, NM } \\ 95 & \text { Joe Benavides, TX } \\ 96 & \text { John Gaccione, NY } \\ 97-98 & \text { J. Cardin, WI } \\ 99 & \text { R. Johnson, NM } \\ 100 & \text { T. Lloyd, MT } \\ 101 & \text { R. Lewis, GA } \\ 102-103 & \text { Ethan Bogren, NY } \\ 104 & \text { Michelle Wilson, AZ } \\ 105 & \text { Ethan Bogren, NY } \\ 106 & \text { John McGuire, NJ }\end{array}$




\section{Table of Contents}

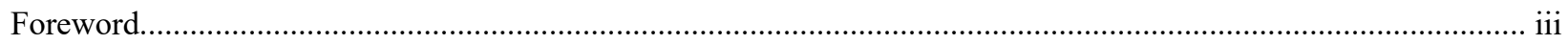

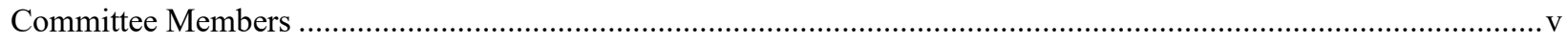

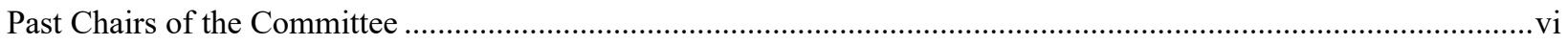

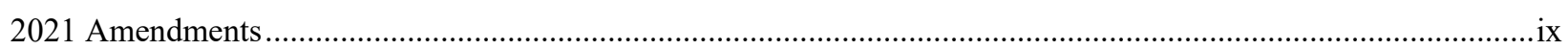

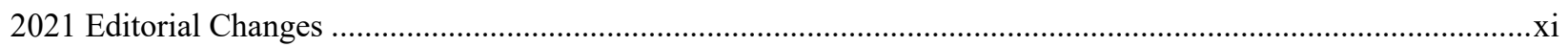

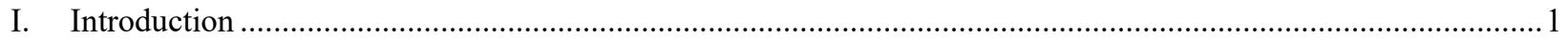

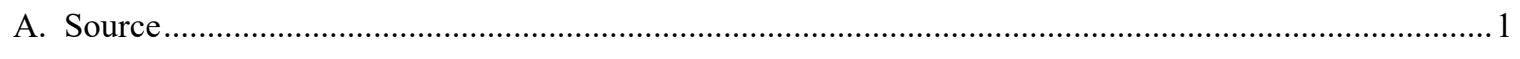

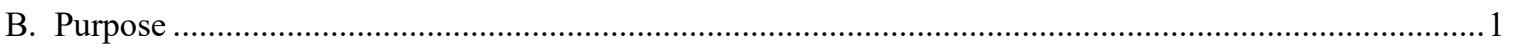

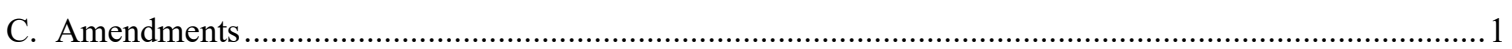

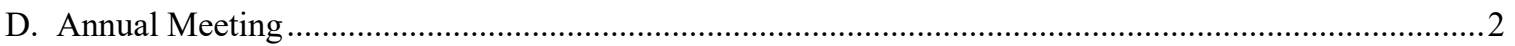

E. Final Committee Reports and Conference Action ..................................................................................

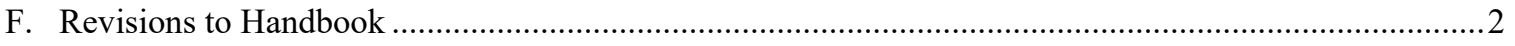

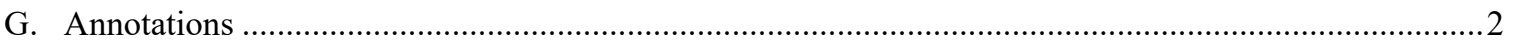

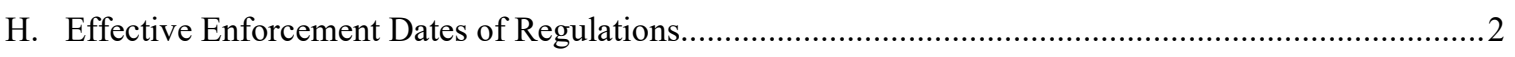

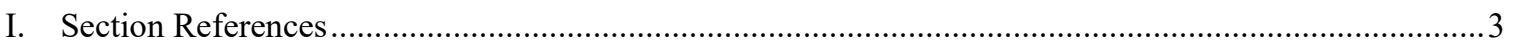

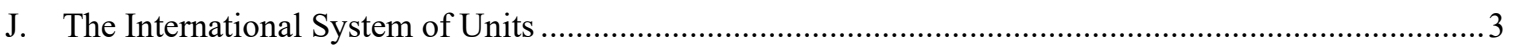

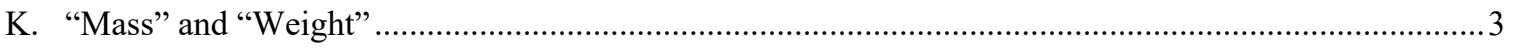

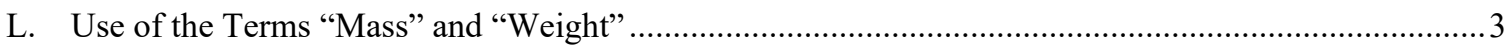

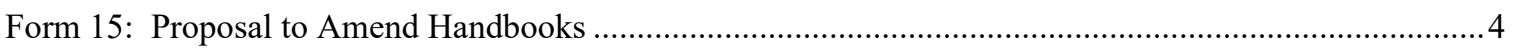

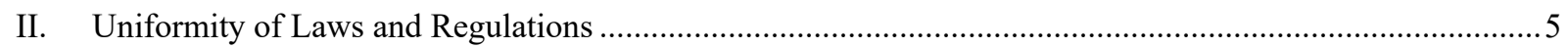

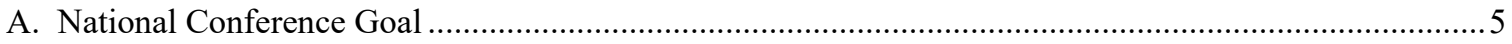

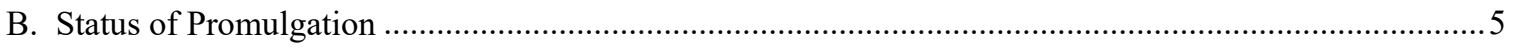

C. Summary of State Laws and Regulations in Weights and Measures ......................................................5

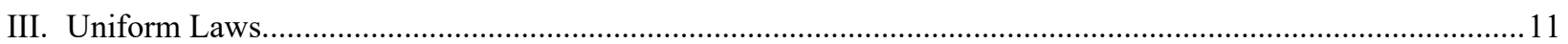

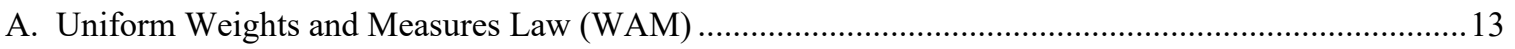

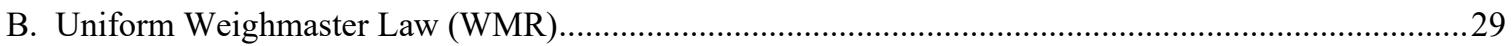

C. Uniform Fuels and Automotive Lubricants Inspection Law (FLL) .................................................... 41

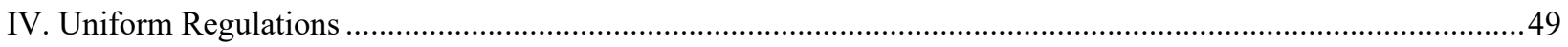

A. Uniform Packaging and Labeling Regulation (PAL) .....................................................................

B. Uniform Regulation for the Method of Sale of Commodities (MOS) ……….......................................99

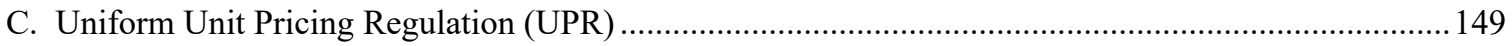

D. Uniform Regulation for the Voluntary Registration of Servicepersons and Service Agencies for

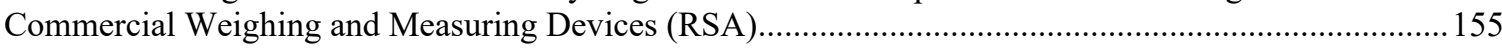




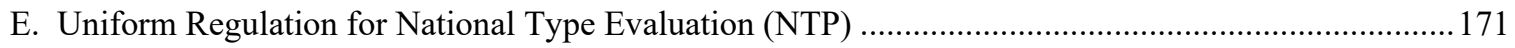

F. Uniform Fuels and Automotive Lubricants Regulation (FLR) ……................................................ 179

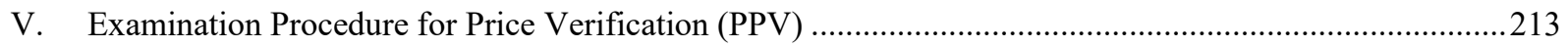

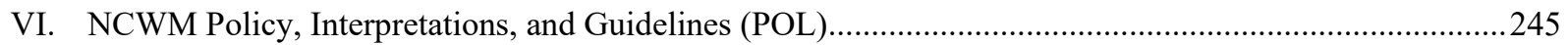




\section{Amendments}

The following table lists the laws and regulations amended by the $105^{\text {th }}(2020)$ and $106^{\text {th }}(2021)$ National Conference on Weights and Measures (NCWM). As appropriate, the text on the cited pages indicates the changes to the law or regulation, section, or paragraph as "Added 2021" or "Amended 2021." Unless otherwise noted, the effective date of the regulations added or amended in 2021 is January 1, 2022.

*Laws and Regulations (L\&R) item numbers designated with “(2020 Item)" appeared on the NCWM L\&R Committee's 2020 Agenda; these items were voted on at the $105^{\text {th }}$ NCWM Annual Meeting held in January 2021 and ratified at the $106^{\text {th }}$ NCWM Annual Meeting held in July 2021. Items without this designation appeared on the L\&R Committee's 2021 Agenda and were voted on at the $106^{\text {th }}$ NCWM Annual Meeting held July 2021.

\begin{tabular}{|c|c|c|c|c|}
\hline Law or Regulation & $\begin{array}{c}\text { L\&R } \\
\text { Committee } \\
\text { Item No. }\end{array}$ & Section & Action & Page \\
\hline $\begin{array}{l}\text { C. Uniform Fuels and } \\
\text { Automotive Lubricants } \\
\text { Inspection Law }\end{array}$ & $\begin{array}{c}\text { FLL-18.1 } \\
(2020 \text { Item)* }\end{array}$ & $\begin{array}{l}\text { Section 8. Prohibited Acts, Section } \\
\text { 8.6. }\end{array}$ & Amended & 47 \\
\hline \multirow{2}{*}{$\begin{array}{l}\text { A. Uniform Packaging } \\
\text { and Labeling Regulation }\end{array}$} & \multirow{2}{*}{ PAL-21.1 } & 11.19. Margarine & Amended & 84 \\
\hline & & 11.34. Bacon & Added & 87 \\
\hline \multirow{11}{*}{$\begin{array}{l}\text { B. Uniform Regulation } \\
\text { for the Method of Sale of } \\
\text { Commodities }\end{array}$} & $\begin{array}{l}\text { MOS-18.2 } \\
(2020 \text { Item })^{*}\end{array}$ & $\begin{array}{l}\text { Method of Sale of Commodities - } \\
\text { 1. Background Information }\end{array}$ & Amended & 97 \\
\hline & \multirow{3}{*}{ B3: MOS-18.1 } & $\begin{array}{l}\text { 2.33.1.3.2. Inactive or Obsolete } \\
\text { Service Categories. }\end{array}$ & Amended & 134 \\
\hline & & $\begin{array}{l}\text { 2.33.1.4. Tank Trucks or Rail } \\
\text { Cars. }\end{array}$ & Amended & 134 \\
\hline & & 2.33.1.5. Documentation & Amended & 134 \\
\hline & \multirow[t]{5}{*}{$\begin{array}{l}\text { B2: MOS-20.1 } \\
(2020 \text { Item)* }\end{array}$} & $\begin{array}{l}\text { 2.39.1. Products for Use in Lubri- } \\
\text { cating Tractors. }\end{array}$ & Amended & 140 \\
\hline & & 2.39.2.1.(e) Container Labeling & Amended & 141 \\
\hline & & $\begin{array}{l}\text { 2.39.2.2.(e) Identification on Doc- } \\
\text { umentation }\end{array}$ & Amended & 141 \\
\hline & & $\begin{array}{l}\text { 2.39.2.3.(e) Identification on Ser- } \\
\text { vice Provider Documentation }\end{array}$ & Amended & 142 \\
\hline & & 2.39.5.(a) Storage Tank Labeling & Amended & 142 \\
\hline & \multirow[t]{2}{*}{ B7: MOS-21.2 } & 2.39.2.1.(e) Container Labeling & Amended & 141 \\
\hline & & $\begin{array}{l}\text { 2.39.2.2.(e) Identification on Doc- } \\
\text { umentation }\end{array}$ & Amended & 141 \\
\hline
\end{tabular}




\begin{tabular}{|c|c|c|c|c|}
\hline & & $\begin{array}{l}\text { 2.39.2.3.(e) Identification on Ser- } \\
\text { vice Provider Documentation }\end{array}$ & Amended & 142 \\
\hline & $\begin{array}{l}\text { MOS-20.3. } \\
(2020 \text { Item)* }\end{array}$ & 2.40. Diesel Fuel & Added & 143 \\
\hline \multirow{14}{*}{$\begin{array}{l}\text { G. Uniform Fuels and } \\
\text { Automotive Lubricants } \\
\text { Regulation }\end{array}$} & $\begin{array}{l}\text { B5: FLR-20.4 } \\
\left(2020 \text { Item }^{*}\right.\end{array}$ & $\begin{array}{l}\text { Fuels and Automotive Lubricants } \\
\text { Regulation }-1 \text {. Background Infor- } \\
\text { mation }\end{array}$ & Amended & 169 \\
\hline & \multirow{2}{*}{$\begin{array}{l}\text { B2: FLR-20.1 } \\
\left(2020 \text { Item }^{*}\right.\end{array}$} & 1.31. Hydraulic Fluid & Amended & 179 \\
\hline & & $\begin{array}{l}\text { 2.22. Products for Use in Lubricat- } \\
\text { ing Tractors }\end{array}$ & Amended & 186 \\
\hline & \multirow{3}{*}{ B3: FLR-18.1 } & 2.14. Engine (Motor) Oil. & Amended & 185 \\
\hline & & $\begin{array}{l}\text { 3.13.1.4. Tank Trucks or Rail } \\
\text { Cars. }\end{array}$ & Amended & 193 \\
\hline & & 3.13.1.5. Documentation. & Amended & 193 \\
\hline & \multirow{4}{*}{$\begin{array}{l}\text { B3: FLR-20.1 } \\
(2020 \text { Item)* }\end{array}$} & 3.17.(e) Tractor Hydraulic Fluid & Amended & 196 \\
\hline & & $\begin{array}{l}\text { 3.17.1.2.(e) Identification on Doc- } \\
\text { umentation }\end{array}$ & Amended & 196 \\
\hline & & $\begin{array}{l}\text { 3.17.1.3.(e) Identification on Ser- } \\
\text { vice Provider Documentation }\end{array}$ & Amended & 198 \\
\hline & & 3.17.1.5.(a) Storage Tank Labeling & Amended & 198 \\
\hline & \multirow{3}{*}{ B7: FLR21.3 } & 3.17.1.1.(e) Container Labeling & Amended & 196 \\
\hline & & $\begin{array}{l}\text { 3.17.1.2.(e) Identification on Doc- } \\
\text { umentation. }\end{array}$ & Amended & 196 \\
\hline & & $\begin{array}{l}\text { 3.17.1.3.(e) Identification on Ser- } \\
\text { vice Provider Documentation. }\end{array}$ & Amended & 198 \\
\hline & B3: FLR-18.1 & $\begin{array}{l}\text { 7.2.3. SAE Viscosity Grades for } \\
\text { Engine Oils }\end{array}$ & Amended & 201 \\
\hline
\end{tabular}




\section{Editorial Changes}

The following items were deemed editorial in nature based on the following criteria: 1) the modified text did not change the meaning or procedure outlined, 2) modified text corrected an omission or clarified how the text was written, or 3 ) the item itself was reformatted and relocated in the text to make the organization of the content more meaningful.

Editorial Note: Notes are now identified by the Section number as opposed to page number.

Note: For the purposes of this table, the bold, underscored text indicates new language added and bold, strikeott text indicates deleted text.

\begin{tabular}{|c|c|c|c|}
\hline Law or Regulation & Section & Action & Page \\
\hline \multirow[t]{4}{*}{ Introduction } & \multirow[t]{3}{*}{$\begin{array}{l}\text { H. Effective Enforcement } \\
\text { Dates of Regulations }\end{array}$} & $\begin{array}{l}\text { Deleted } \\
\text { 5. Uniform-Open Dating Regula- } \\
\text { tion }\end{array}$ & 3 \\
\hline & & $\begin{array}{l}\text { Renumbered } \\
\text { 65. Uniform Regulation for Na- } \\
\text { tional Type Evaluation }\end{array}$ & 3 \\
\hline & & $\begin{array}{l}\text { Renumbered } \\
\text { 7‥ Uniform Fuels and Automotive } \\
\text { Lubricants Regulation }\end{array}$ & 3 \\
\hline & Form 15 & Updated Form & 4 \\
\hline \multirow[t]{2}{*}{$\begin{array}{l}\text { II. Uniformity of Laws } \\
\text { and Regulations }\end{array}$} & \multirow[t]{2}{*}{$\begin{array}{l}\text { C. Summary of State Laws } \\
\text { and Regulations in Weights } \\
\text { and Measures }\end{array}$} & $\begin{array}{l}\text { Editorial } \\
\ldots \text {..see Sections } 4 \text { through } \mathbf{1 0 9} \text { and } \\
\text { paragraph } \mathbf{1 2 1 1}(\mathrm{m})\end{array}$ & 5 \\
\hline & & $\begin{array}{l}\text { Deleted } \\
\text { Regulation - Open Dating }\end{array}$ & 6 \\
\hline \multirow{7}{*}{$\begin{array}{l}\text { A. Uniform Weights and } \\
\text { Measures Law }\end{array}$} & 1. Background & $\begin{array}{l}\text { Editorial change in (a) and (b) } \\
\text { Section 4. through } \mathbf{1 0} \underline{\mathbf{9}} \ldots .\end{array}$ & 13 \\
\hline & $\begin{array}{l}\text { Section } 4 \text {. Technical Require- } \\
\text { ments for Weighing and } \\
\text { Measuring }\end{array}$ & $\begin{array}{l}\text { Editorial change in (a) and (b) } \\
\text { Section 4. through } \mathbf{1 0} \underline{\mathbf{9}} \ldots . .\end{array}$ & 20 \\
\hline & \multirow[t]{5}{*}{ Sections $9-30$} & $\begin{array}{l}\text { Deleted } \\
\text { Section 9. Requirement for Open } \\
\text { Dating }\end{array}$ & 21 \\
\hline & & $\begin{array}{l}\text { Editorial change } \\
\text { Section } \mathbf{9} 10 \text {. Requirements for } \\
\text { Type Evaluation }\end{array}$ & 21 \\
\hline & & $\begin{array}{l}\text { Section 110. State Weights and } \\
\text { Measures Division }\end{array}$ & 21 \\
\hline & & $\begin{array}{l}\text { Section 121. Powers and Duties of } \\
\text { the Director }\end{array}$ & 21 \\
\hline & & Section 132.Special Police Powers & 23 \\
\hline
\end{tabular}




\begin{tabular}{|c|c|c|c|}
\hline Law or Regulation & Section & Action & Page \\
\hline & & $\begin{array}{l}\text { Section } 143 \text {. Powers and Duties of } \\
\text { Local Officials }\end{array}$ & 24 \\
\hline & & $\begin{array}{l}\text { Section } 15 \underline{4} \text {. Misrepresentation of } \\
\text { Quantity }\end{array}$ & 24 \\
\hline & & $\begin{array}{l}\text { Section } 1 \mathbf{6} \underline{\mathbf{5}} . \text { Misrepresentation of } \\
\text { Pricing }\end{array}$ & 24 \\
\hline & & Section 17‥ Method of Sale & 24 \\
\hline & & Section 18‥ Sale from Bulk & 24 \\
\hline & & $\begin{array}{l}\text { Section 19.8. Information Required } \\
\text { on Packages }\end{array}$ & 25 \\
\hline & & $\begin{array}{l}\text { Section 2019. Declarations of Unit } \\
\text { Price on Random Weight Packages }\end{array}$ & 25 \\
\hline & & $\begin{array}{l}\text { Section 21ㅁ. Advertising Packages } \\
\text { for Sale }\end{array}$ & 25 \\
\hline & & Section 22포. Prohibited Acts & 26 \\
\hline & & Section 232. Civil Penalties & 26 \\
\hline & & Section 24․․ Criminal Penalties & 26 \\
\hline & & $\begin{array}{l}\text { Section } 2 \mathbf{5 4} \text {. Restraining Order and } \\
\text { Injunction }\end{array}$ & 27 \\
\hline & & $\begin{array}{l}\text { Section 2.65. Presumptive Evi- } \\
\text { dence }\end{array}$ & 27 \\
\hline & & Section 27ㅁ․ Severability Provision & 27 \\
\hline & & $\begin{array}{l}\text { Section 287. Repeal of Conflicting } \\
\text { Laws. }\end{array}$ & 27 \\
\hline & & $\begin{array}{l}\text { Section } 29 \text {. Regulations to be Un- } \\
\text { affected by Repeal of Prior Ena- } \\
\text { bling Statue. }\end{array}$ & 27 \\
\hline & & Section 3029. Effective Date & 27 \\
\hline & $\begin{array}{l}\text { Section } 11 . \text { Powers and Du- } \\
\text { ties of the Director }\end{array}$ & $\begin{array}{l}\text { Removed } \\
\text { (d)...... "and establish require- } \\
\text { ments for open dating infor- } \\
\text { mation;"” }\end{array}$ & 21 \\
\hline $\begin{array}{l}\text { B. Uniform Weighmaster } \\
\text { Law }\end{array}$ & $\begin{array}{l}\text { Section 23. Separability Provi- } \\
\text { sion }\end{array}$ & $\begin{array}{l}\text { Editorial } \\
\text { Sepaverability }\end{array}$ & 39 \\
\hline \multirow{2}{*}{ IV Uniform Regulations } & $\begin{array}{l}\text { E. Uniform Regulation for } \\
\text { National Type Evaluation }\end{array}$ & $\begin{array}{l}\text { Reordered } \\
\text { EF. Uniform Regulation for Na- } \\
\text { tional Type Evaluation }\end{array}$ & 161 \\
\hline & $\begin{array}{l}\text { F. Uniform Fuels and Auto- } \\
\text { motive Lubricants Regulation }\end{array}$ & $\begin{array}{l}\text { Reordered } \\
\text { FG. Uniform Fuels and Automo- } \\
\text { tive Lubricants Regulation }\end{array}$ & 169 \\
\hline
\end{tabular}




\begin{tabular}{|c|c|c|c|}
\hline Law or Regulation & Section & Action & Page \\
\hline $\begin{array}{l}\text { A. Uniform Packaging and } \\
\text { Labeling Regulation }\end{array}$ & $\begin{array}{l}\text { 11.33. U.S. Customary Units, } \\
\text { Exemptions - Consumer Com- } \\
\text { modities }\end{array}$ & (see UPLR Appendix C....) & 84 \\
\hline \multirow{6}{*}{$\begin{array}{l}\text { B. Uniform Regulation for } \\
\text { the Method of Sale of } \\
\text { Commodities }\end{array}$} & $\begin{array}{l}\text { 1.7.2. Pelletized Ice Cream } \\
\text { and Similar Pelletized Frozen } \\
\text { Desserts }\end{array}$ & $\begin{array}{l}\text { Deleted } \\
\text { NOTE: This method of sale for } \\
\text { pelletized ice cream shall be en- } \\
\text { forceable after April 17, 2010, } \\
\text { and after August } 2,2011, \text { for } \\
\text { similar pelletized frozen desserts. }\end{array}$ & 108 \\
\hline & 2.4.3. Quantity. & $\begin{array}{l}\text { Editorial } \\
\text { (a)(1) liters, to include fractions of } \\
\text { a liter, and may also include a dec- } \\
\text { laration of quantity in terms of cu- } \\
\text { bic foot or feet to include fractions } \\
\text { of a cubic foot. } \\
\text { (d) (1) liters, to include fractions of } \\
\text { a liters, and may also include a dec- } \\
\text { laration of quantity. }\end{array}$ & 114 \\
\hline & 2.10. Softwood Lumber & $\begin{array}{l}\text { Editorial } \\
\text { Voluntary Product Standards PS } \\
\text { 20-1520, "American Softwood } \\
\text { Lumber Standard" }\end{array}$ & 117 \\
\hline & $\begin{array}{l}\text { 2.10.1.13. Minimum Dressed } \\
\text { Sizes (width and thickness) }\end{array}$ & $\begin{array}{l}\text { Editorial } \\
\text { Voluntary Product Standards PS } \\
\text { 20-1520, "American Softwood } \\
\text { Lumber Standard" }\end{array}$ & 118 \\
\hline & 2.23. Animal Bedding. & $\begin{array}{l}\text { Removed } \\
\text { NOTE: This method of sale for } \\
\text { animal bedding shall be enforce- } \\
\text { able after Jantary } 1,2020 \text {. }\end{array}$ & 129 \\
\hline & 2.35. Diesel Exhaust Fluid & $\begin{array}{l}\text { Removed } \\
\text { Effective date shall be January } 1 \text {, } \\
2016\end{array}$ & 136 \\
\hline $\begin{array}{l}\text { E. Uniform Open Dating } \\
\text { Regulation }\end{array}$ & $\begin{array}{l}\text { E. Uniform Open Dating Reg- } \\
\text { ulation }\end{array}$ & $\begin{array}{l}\text { ODR-2 (2019 Item) - Effective } \\
\text { January } 1,2022 \text { this regulation is } \\
\text { removed in its entirety }\end{array}$ & \\
\hline $\begin{array}{l}\text { G. Uniform Fuels and Au- } \\
\text { tomotive Lubricants Reg- } \\
\text { ulation }\end{array}$ & $\begin{array}{l}\text { 4.4.2. Declaration of Meaning } \\
\text { of Color Code }\end{array}$ & $\begin{array}{l}\text { Editorial } \\
\text { "API Recommended Practice } \\
1637, \text { Using the API Color-Sym- } \\
\text { bol System to Identify Equip- } \\
\text { ment, Vehicles, and Transfer } \\
\text { Points for Petroleum Fuels and } \\
\text { Related Products at Dispensing } \\
\text { and Storage Facilities and Distri- } \\
\text { bution Terminals" }\end{array}$ & 199 \\
\hline
\end{tabular}




\begin{tabular}{|c|c|c|c|}
\hline Law or Regulation & Section & Action & Page \\
\hline $\begin{array}{l}\text { V. Examination Proce- } \\
\text { dure for Price Verification }\end{array}$ & $\begin{array}{l}\text { 2.23. Universal Product Code } \\
\text { (UPC). }\end{array}$ & $\begin{array}{l}\text { Updated } \\
\text { (937) } 435-3870 \text { or (609) 620-0200. } \\
\text { You-can-visit them-on the web at } \\
\text { www.gs1 us.org. }\end{array}$ & 209 \\
\hline $\begin{array}{l}\text { VI. NCWM Policy, Inter- } \\
\text { pretations, and Guidelines }\end{array}$ & $\begin{array}{l}\text { 2.6.3. Octane Posting Regula- } \\
\text { tions. }\end{array}$ & $\begin{array}{l}\text { Updated } \\
\text { Telephone: (877) 382-4358 (202) } \\
\underline{\text { 326-2222. }}\end{array}$ & 250 \\
\hline
\end{tabular}




\section{Introduction}

\section{A. Source}

The Uniform Laws and Regulations ${ }^{1}$ in this handbook comprise all of those adopted by the National Conference on Weights and Measures, Inc. (NCWM). Contact NCWM at:
1135 M Street, Suite 100
Phone: (402) 434-4880
Lincoln, NE 68508
Fax: (402) 434-4878
E-mail: info@ncwm.com
URL: www.ncwm.com

The NCWM is supported by the National Institute of Standards and Technology (NIST), which provides its Executive Secretary and publishes its documents. NIST also develops technical publications for use by weights and measures agencies; these publications may subsequently be endorsed or adopted by the NCWM or its members.

All of the Uniform Laws and Regulations given herein are recommended by NCWM for adoption by states when reviewing or amending their official laws and regulations in the areas covered. A similar recommendation is made with regard to the local jurisdictions within a state in the absence of the promulgation of such laws and regulations at the state level.

(Amended 2015 and 2019)

\section{B. Purpose}

The purpose of these Uniform Laws and Regulations is to achieve, to the maximum extent possible, uniformity in weights and measures laws and regulations among the various states and local jurisdictions in order to facilitate trade between the states, permit fair competition among businesses, and provide uniform and sufficient protection to all consumers in commercial weights and measures practices.

\section{Amendments}

Proposed amendments to NIST Handbook 130 are deliberated and developed by NCWM's Committee on Laws and Regulations before presentation to the general membership for vote. In some instances, amendments that significantly affect other NIST Handbooks may be processed jointly by two or more committees.

Amendments to the handbooks are made in accordance with NCWM procedures and policies. The process begins at the regional weights and measures association meetings in the fall of each year and it is culminated at the NCWM Annual Meeting in July. After passing through one or more of the regional associations, the proposed amendment is placed on the agenda of the appropriate NCWM committee for consideration at the NCWM's Interim Meeting in January, and after final deliberation and development by the committee the amendment may be presented to the membership for a vote at the annual NCWM meeting in July. NCWM policy provides for exceptions to the process to accommodate urgent or priority items. NIST staff provides technical assistance and advice throughout the process.

\footnotetext{
${ }^{1}$ When referring to the Uniform Laws and Regulations in Handbook 130, Laws and Regulations will be capitalized.
} When referring to general federal or state laws and regulations, no capitalization will be used. 
The policy is available on the NCWM website at www.ncwm.com. For information on the regional weights and measures associations, visit www.ncwm.com/meetings.

(Amended 2015 and 2019)

\section{Annual Meeting}

1. The Committee will hold a public hearing at the Annual Meeting to discuss items on its agenda.

2. Those who want to speak on an item during the public hearing should request time from the Committee Chairman. The Committee Chairman may impose time limits on presentations, the discussion of a question, or the discussion of a proposed amendment.

\section{E. Final Committee Reports and Conference Action}

1. Following the public hearings, the Committee will prepare its final report for action by the voting membership of the Conference. Copies of the final report will be provided to the membership prior to the voting session for that report.

2. The Chairman of the Committee will present the final report of the Committee to the Conference body. A vote will be taken on items, proposals, or sections in the report as circumstances require. The Conference will vote on the entire final report as presented in accordance with established Conference voting procedures. Parliamentary procedures according to Robert's Rules of Order, as amended by NCWM Bylaws, must be adhered to in the presentation of, and any action on, a Standing Committee report.

(Amended 1998)

\section{F. Revisions to the Handbook}

NIST may not publish a new edition if it determines that it is reasonable to forego an annual publication (e.g., amendments were minor or editorial in nature) to save printing, mailing, and other costs. If this occurs, NIST will issue a notice that the current edition is still valid and will explain its action. (NOTE: Section numbering may be changed from one edition of the handbook to another to accommodate additions or deletions.)

(Amended 2008)

\section{G. Annotation}

Beginning in 1971, amendments or additions to sections in the Uniform Laws and Regulations are delineated at the end of each section (e.g." "amended 1982") as a service to those states that are planning to update their own laws or regulations. The references to each revision and the year will enable legislators and rule makers to study the actual wording and rationale for changes (appearing in the Annual Report of NCWM for that year) and subsequently adopt changes in their own laws and regulations, modeling them after the Uniform Laws and Regulations.

\section{H. Effective Enforcement Dates of Regulations}

Unless otherwise specified, the new or amended regulations listed in this section are intended to become effective and subject to enforcement on January 1 of the year following adoption by NCWM.

1. Uniform Packaging and Labeling Regulation

2. Uniform Regulation for the Method of Sale of Commodities 
3. Uniform Unit Pricing Regulation

4. Uniform Regulation for the Voluntary Registration of Servicepersons and Service Agencies for Commercial Weighing and Measuring Devices

5. Uniform Regulation for National Type Evaluation

6. Uniform Fuels and Automotive Lubricants Regulation

(Added 1992) (Amended 2021)

\section{Section References}

In most references made to specific sections or subsections in this handbook, the word "Section" is used, followed by the section number.

\section{J. The International System of Units}

The "International System of Units," "SI," or "SI Units" means the modernized metric system as established in 1960 by the General Conference on Weights and Measures (CGPM). In 1988, Congress amended the Metric Conversion Act of 1975 (refer to Section 5164 of Public Law 100-418) to declare that it is the policy of the United States to designate the metric system of measurement as the preferred measurement system for U.S. trade and commerce, and it further defined "the metric system of measurement" to be the International System as established by the CGPM and as interpreted or modified for the United States by the Secretary of Commerce. [refer to Metric Conversion Law 15 U.S.C. 205, NIST Special Publication 330 "The International System of Units (SI)"; NIST Special Publication 814 "Metric System of Measurement; and, Interpretation of the International System of Units for the United States" in Federal Register of May 16, 2008, ("Federal Register" Vol. 73, No. 96) or subsequent revisions]. In 1992, Congress amended the Federal Fair Packaging and Labeling Act to require certain consumer commodities to include the appropriate SI units along with the U.S. customary units in their quantity statements.

(Added 1993) (Revised 2008 and 2019)

\section{K. "Mass" and "Weight." [see Section K. NOTE]}

The mass of an object is a measure of the object's inertial property, or the amount of matter it contains. The weight of an object is a measure of the force exerted on the object by gravity, or the force needed to support it. The pull of gravity on the earth gives an object a downward acceleration of about $9.8 \mathrm{~m} / \mathrm{s}^{2}$. In trade and commerce and everyday use, the term "weight" is often used as a synonym for "mass." The "net mass" or "net weight" declared on a label indicates that the package contains a specific amount of commodity exclusive of wrapping materials. The use of the term "mass" is predominant throughout the world, and is becoming increasingly common in the United States.

(Added 1993)

Section K. NOTE: When used in this law (or regulation), the term "weight" means "mass." (see paragraphs K. "Mass" and "Weight" and L. Use of the Terms "Mass" and "Weight" in Section I. Introduction of NIST Handbook 130 for an explanation of these terms.) (Note Added 1993)

\section{Use of the Terms "Mass" and "Weight." [see Section K. NOTE]}

When used in this handbook, the term "weight" means "mass." The term "weight" appears when U.S. customary units are cited or when both U.S. customary and SI units are included in a requirement. The terms "mass" or "masses" are used when only SI units are cited in a requirement. The following note appears where the term "weight" is first used in a law or regulation. 
National Conference on Weights and Measures / National Type Evaluation Program

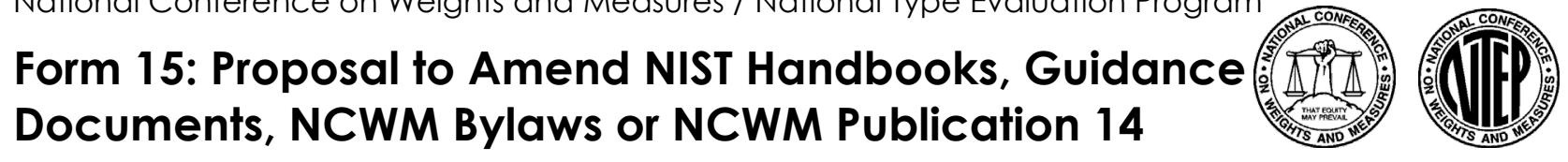

Submit proposals by August 15, 2022. See meeting dates at www.ncwm.com/meetings. If the item is deemed by a region to have merit, that region will forward the item to NCWM for national consideration. For more information on the Form 15 process, visit www.ncwm.com/standards-dev.

Submit in Microsoft Word Format to the NCWM Executive Director via email at don.onwiler@ncwm.com for review and dispersal to selected regions.

\section{General Information}

\begin{tabular}{l|l} 
1. Date: & $\begin{array}{c}\text { 2. Regional Association(s): (Not applicable for proposals to the Board of Directors or NTEP Committee) } \\
\text { Central (CWMA) _ _ Northeastern (NEWMA) _ _ Southern (SWMA) _ _ Western (WWMA) }\end{array}$
\end{tabular}

\begin{tabular}{l} 
3. Standing Committee: \\
\hline Laws \& Regulations $\quad$ Specifications \& Tolerances $\quad$ _ Professional Development _ _ Board of Directors _ NTEP \\
Committee
\end{tabular}

\begin{tabular}{|l|l|} 
4. Submitter's Name: & Submitter's Organization: \\
\hline
\end{tabular}

\section{Address:}

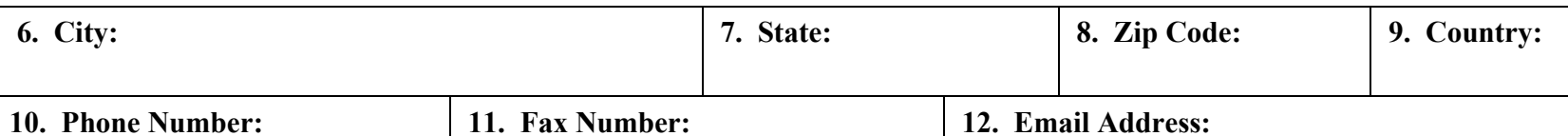

\section{Proposal Information}

13. Purpose: Concise statement as to the intent or purpose of this proposal, such as problem being fixed. (Do not include justification here.)

14. Document to be Amended:

NIST Handbook 44
NCWM Bylaws NIST Handbook $130 \_$NIST Handbook $133 \ldots$ NCWM Guidance Document

15. Cite portion to be Amended: Please file a separate Form 15 for each code, model law or regulation to be amended. Section:

Paragraph:

16. Proposal: Please use strikeout to show words to be deleted and underline to show new words. (Do not use track changes.)

17. Justification: Please include national importance, background on the issue, and reference to supporting data or documents.

18. Possible Opposing Argument's: Please demonstrate that you are aware and have considered possible opposition.

\section{Requested Action if Considered for NCWM Agenda:}

_ Voting Item _ _ Developing Item _ Informational Item _ Other (Please Describe):

\section{List of Attachments:}




\section{Uniformity of Laws and Regulations}

\section{A. National Conference Goal}

The goal of the National Conference on Weights and Measures (NCWM) with respect to these Uniform Laws and Regulations is to achieve their acceptance in all states and local jurisdictions that have authority over such matters. The Conference stands ready to assist any jurisdiction in any way possible in securing adoption.

\section{B. Status of Promulgation}

The following pages list, by state, information regarding the adoption of the Uniform Laws and Regulations. The tabulated data indicates if the state has adopted the Uniform Law or Regulation by reference, including subsequent amendments (thereby operating under the most recent version of the recommended regulation in this handbook), or if the state has used some version of the NCWM recommended law or regulation as guidance in developing a similar law or regulation.

The information is verified with each state annually; the entries represent the status of the state adoption at the time of the survey.

Unless a state adopts the recommended regulations and subsequent amendments and revisions, there may be variation in the actual degree of adoption. Adoption, implementation, and clarification may be determined by comparing a state law with the Uniform Law, section-by-section, or by contacting the state.

(Amended 1997 and 1998)

\section{Summary of State Laws and Regulations in Weights and Measures (as of Novem- ber 1, 2021)}

This is an overview of the status of adoption of NCWM standards by the states. In earlier editions of Handbook 130, state laws and regulations were compared to the NCWM standard from the prior year. This did not indicate whether the standard as printed in the current edition had been adopted by any given state. The table lists those states that adopt NCWM-recommended updates automatically ("YES"); see Sections 4 through 9 and paragraph 11.(m) of the Uniform Weights and Measures Law. This means the state's regulations are current with those printed in this edition of the handbook. If a state has adopted an NCWM recommendation in whole or in part from a particular year, but updates are not incorporated automatically, a lower case "yes" is shown. For additional information on the status of adoption, please contact the appropriate state officials. 


\begin{tabular}{|c|c|c|c|c|c|c|c|c|c|c|c|c|}
\hline \multirow[b]{2}{*}{ State } & \multicolumn{3}{|c|}{ Laws } & \multicolumn{9}{|c|}{ Regulations } \\
\hline & 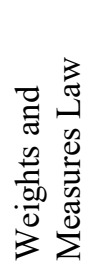 & 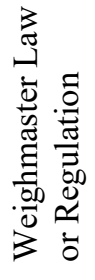 & 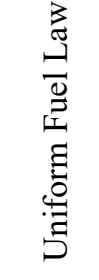 & 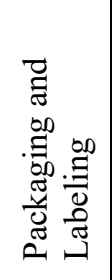 & $\begin{array}{l}\frac{0}{\pi} \\
\tilde{N} \\
4 \\
0 \\
\overrightarrow{0} \\
0 \\
\overrightarrow{0} \\
\Sigma\end{array}$ & 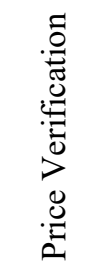 & 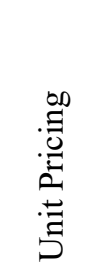 & 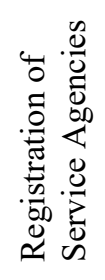 & 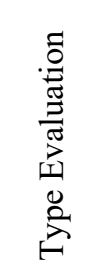 & 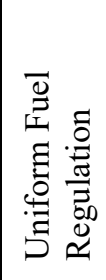 & 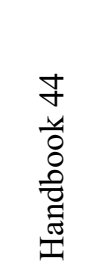 & 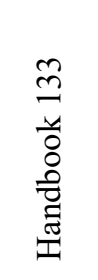 \\
\hline Alabama & yes & yes & yes & yes & yes & YES & NO & yes & yes & yes* & YES & YES \\
\hline Alaska & yes & NO & NO & yes & yes & yes & NO & NO & yes & NO & YES & yes \\
\hline Arizona & yes & yes & yes* & yes & yes & yes & NO & yes & yes & yes* & yes & yes \\
\hline Arkansas & YES & NO & YES & YES & YES & YES & YES & YES & YES & YES & YES & YES \\
\hline California & yes* & yes* & yes* & YES & yes* & yes* & yes* & yes* & yes* & yes* & YES & YES \\
\hline Colorado & yes & yes & yes* & yes & yes & yes & NO & yes & yes & yes* & YES & YES \\
\hline Connecticut & yes & yes & yes* & YES & YES & YES & yes* & yes* & yes & yes & YES & YES \\
\hline Delaware & yes & yes & yes* & yes & yes & yes & no & yes* & yes & yes* & YES & YES \\
\hline $\begin{array}{l}\text { District of } \\
\text { Columbia }\end{array}$ & yes & yes & yes & yes & yes & yes & yes* & NO & yes & yes & yes & yes \\
\hline Florida & yes & NO & yes* & yes & yes & yes & yes* & yes & yes & yes* & yes & yes \\
\hline Georgia & yes & yes & yes* & yes & yes & YES & NO & yes & yes & yes* & YES & YES \\
\hline Hawaii & yes & yes & yes* & yes & yes & yes & yes & yes & yes & yes* & yes & yes \\
\hline Idaho & yes & yes & yes* & yes & yes & yes* & no & yes & yes & yes* & YES & yes \\
\hline Illinois & yes & NO & yes* & YES & YES & NO & NO & yes & yes & yes & YES & YES \\
\hline Indiana & yes & yes* & yes* & yes & yes & NO & NO & NO & yes & yes* & yes & yes \\
\hline Iowa & yes & yes* & yes* & yes & yes & YES & NO & yes* & yes & yes* & yes & yes \\
\hline Kansas & NO & NO & NO & yes & yes & yes* & NO & yes* & yes & yes & yes & yes \\
\hline $\begin{array}{ll}\text { Key: } & \text { YES } \\
& \text { yes } \\
& \text { yes* } \\
& \text { NO } \\
& \text { no }\end{array}$ & $\begin{array}{l}\text { Adop } \\
\text { Law } \\
\text { Law } \\
\text { No la } \\
\text { No la }\end{array}$ & $\begin{array}{l}\text { or regul } \\
\text { or regul } \\
\text { W or re } \\
\text { W or re }\end{array}$ & $\begin{array}{l}\text { ion in } \\
\text { ions in } \\
\text { lation } \\
\text { lation }\end{array}$ & $\begin{array}{l}\text { n an } \\
\text { rce, } \mathrm{N} \\
\text { orce, }\end{array}$ & $\begin{array}{l}\text { WM } \\
\text { it not }\end{array}$ & $\begin{array}{l}\text { is. } \\
\text { ndard } \\
\text { sed on }\end{array}$ & $\begin{array}{l}\text { sed as b } \\
\text { NCWM }\end{array}$ & $\begin{array}{l}\text { sis of a } \\
\text { standarc }\end{array}$ & loption & out fro & an eal & er year. \\
\hline
\end{tabular}




\begin{tabular}{|c|c|c|c|c|c|c|c|c|c|c|c|c|}
\hline \multirow[b]{2}{*}{ State } & \multicolumn{3}{|c|}{ Laws } & \multicolumn{9}{|c|}{ Regulations } \\
\hline & 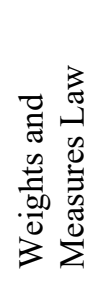 & 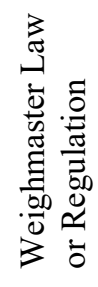 & 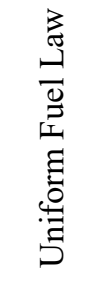 & 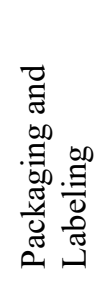 & $\begin{array}{l}\frac{0}{\pi} \\
\tilde{n} \\
4 \\
0 \\
0 \\
0 \\
\frac{0}{0} \\
\Sigma\end{array}$ & 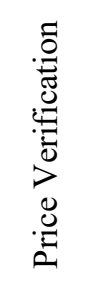 & 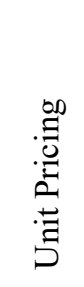 & 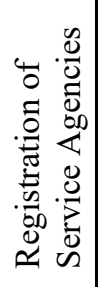 & 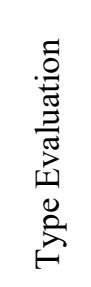 & 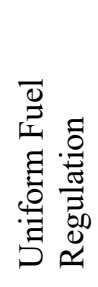 & 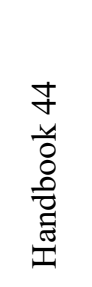 & 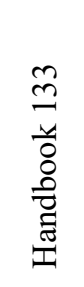 \\
\hline Kentucky & yes & NO & yes* & yes & yes & yes & NO & yes* & yes & yes* & YES & yes \\
\hline Louisiana & yes* & yes* & yes* & yes* & NO & YES & NO & yes* & yes* & yes* & YES & no \\
\hline Maine & yes & yes & yes* & YES & YES & YES & NO & yes & yes & YES & YES & no \\
\hline Maryland & yes & NO & yes* & YES & yes & no & yes* & yes* & yes & yes* & YES & YES \\
\hline Massachusetts & yes* & yes* & yes* & yes & yes* & YES & yes* & NO & yes & yes* & YES & no \\
\hline Michigan & yes & yes* & yes* & yes & yes & NO & $\mathrm{NO}$ & yes & yes & yes* & yes & no \\
\hline Minnesota & yes & NO & yes* & yes* & yes* & NO & NO & yes* & yes & yes* & yes & yes \\
\hline Mississippi & yes & yes & yes* & yes & yes & yes & yes & yes & yes & yes* & YES & YES \\
\hline Missouri & yes & NO & yes & YES & YES & YES & no & YES & YES & yes & YES & YES \\
\hline Montana & yes & NO & yes & yes & yes & NO & yes & yes & yes & yes & yes & yes \\
\hline Nebraska & yes & NO & NO & yes & yes & yes* & NO & yes & yes* & NO & yes & yes \\
\hline Nevada & yes & yes & yes* & YES & YES & YES & YES & YES & YES & yes* & YES & YES \\
\hline $\begin{array}{l}\text { New } \\
\text { Hampshire }\end{array}$ & yes & yes* & NO & YES & YES & no & no & yes* & YES & no & YES & no \\
\hline New Jersey & yes & yes & yes* & yes & yes & yes* & yes* & yes* & yes* & YES & YES & NO \\
\hline New Mexico & yes & yes & yes* & yes & yes & yes* & NO & yes & no & yes* & YES & YES \\
\hline New York & yes & yes & yes* & yes & yes & yes & yes* & NO & yes & yes* & yes & yes \\
\hline North Carolina & yes & yes* & yes* & YES & YES & yes & NO & yes & yes & yes* & YES & YES \\
\hline
\end{tabular}

Key: YES Adopted and updated on an annual basis.

yes Law or regulation in force, NCWM standard used as basis of adoption, but from an earlier year.

yes* Law or regulations in force, but not based on NCWM standard.

NO No law or regulation.

no No law or regulation, but NCWM standard is used as a guideline. 


\begin{tabular}{|c|c|c|c|c|c|c|c|c|c|c|c|c|}
\hline \multirow[b]{2}{*}{ State } & \multicolumn{3}{|c|}{ Laws } & \multicolumn{9}{|c|}{ Regulations } \\
\hline & 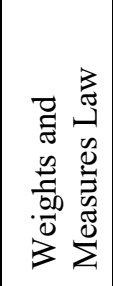 & 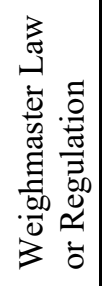 & 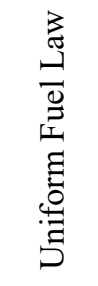 & 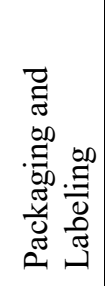 & $\begin{array}{l}\frac{0}{\pi} \\
\tilde{n} \\
4 \\
0 \\
0 \\
0 \\
\frac{E}{0} \\
\sum\end{array}$ & 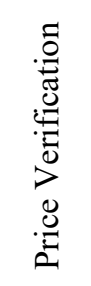 & 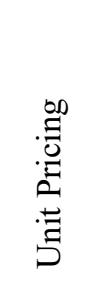 & 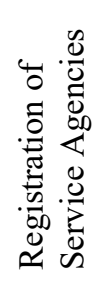 & 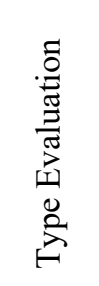 & 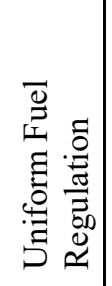 & 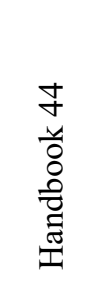 & 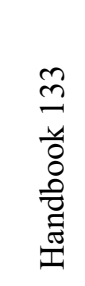 \\
\hline North Dakota & YES & NO & NO & NO & yes* & NO & NO & yes* & NO & yes* & yes* & $\mathrm{NO}$ \\
\hline Ohio & yes & NO & NO & yes & yes & YES & NO & yes & yes & NO & YES & YES \\
\hline Oklahoma & YES & NO & yes* & YES & YES & yes* & NO & yes* & YES & yes* & YES & YES \\
\hline Oregon & yes* & NO & yes* & yes & yes & yes & yes* & NO & yes* & yes* & yes & yes \\
\hline Pennsylvania & yes & yes & NO & yes & yes & yes & NO & yes & YES & NO & YES & YES \\
\hline Puerto Rico & yes & yes & yes* & yes & yes* & yes* & yes* & yes & yes & yes* & YES & YES \\
\hline Rhode Island & no & no & yes* & yes* & YES & no & yes* & NO & no & no & YES & no \\
\hline South Carolina & yes & yes* & yes* & YES & YES & NO & NO & YES & YES & yes* & YES & YES \\
\hline South Dakota & yes & NO & yes & yes & yes & yes & NO & yes & yes & yes & yes & yes \\
\hline Tennessee & yes & yes & yes & YES & YES & YES & NO & yes & YES & yes & YES & YES \\
\hline Texas & yes & yes* & yes* & YES & YES & yes* & NO & yes & NO & yes* & YES & YES \\
\hline Utah & yes & NO & yes* & YES & YES & YES & NO & yes & YES & yes & YES & YES \\
\hline Vermont & yes* & yes & yes* & YES & YES & yes & yes* & yes & no & NO & YES & yes \\
\hline Virginia & yes* & yes* & yes* & YES & YES & YES & NO & yes* & YES & YES & YES & YES \\
\hline Virgin Islands & yes & NO & yes* & yes & NO & NO & yes & NO & NO & yes & YES & no \\
\hline Washington & yes & yes & yes & YES & YES & YES & NO & yes & YES & yes & YES & YES \\
\hline West Virginia & YES & NO & YES & YES & YES & YES & YES & YES & YES & YES & YES & YES \\
\hline $\begin{array}{ll}\text { Key: } & \text { YES } \\
& \text { yes } \\
& \text { yes* } \\
& \text { NO } \\
& \text { no }\end{array}$ & $\begin{array}{l}\text { Adopte } \\
\text { Law or } \\
\text { Law or } \\
\text { No law } \\
\text { No law }\end{array}$ & $\begin{array}{l}1 \text { and up } \\
\text { regulati } \\
\text { regulati } \\
\text { or regu } \\
\text { or regu }\end{array}$ & $\begin{array}{l}\text { dated o } \\
\text { on in fo } \\
\text { ons in f } \\
\text { ation. } \\
\text { ation, b }\end{array}$ & $\begin{array}{l}\text { an ann } \\
\text { e, NCV } \\
\text { ce, but }\end{array}$ & $\begin{array}{l}\text { al basi } \\
\mathrm{T} \text { star } \\
\text { not bas }\end{array}$ & $\begin{array}{l}\text { ard us } \\
\text { on } \mathrm{N}\end{array}$ & $\begin{array}{l}\text { as ba } \\
\text { WM st }\end{array}$ & $\begin{array}{l}\text { s of adc } \\
\text { ndard. }\end{array}$ & tion, $\mathrm{b}$ & it from a & an earli & r year. \\
\hline
\end{tabular}




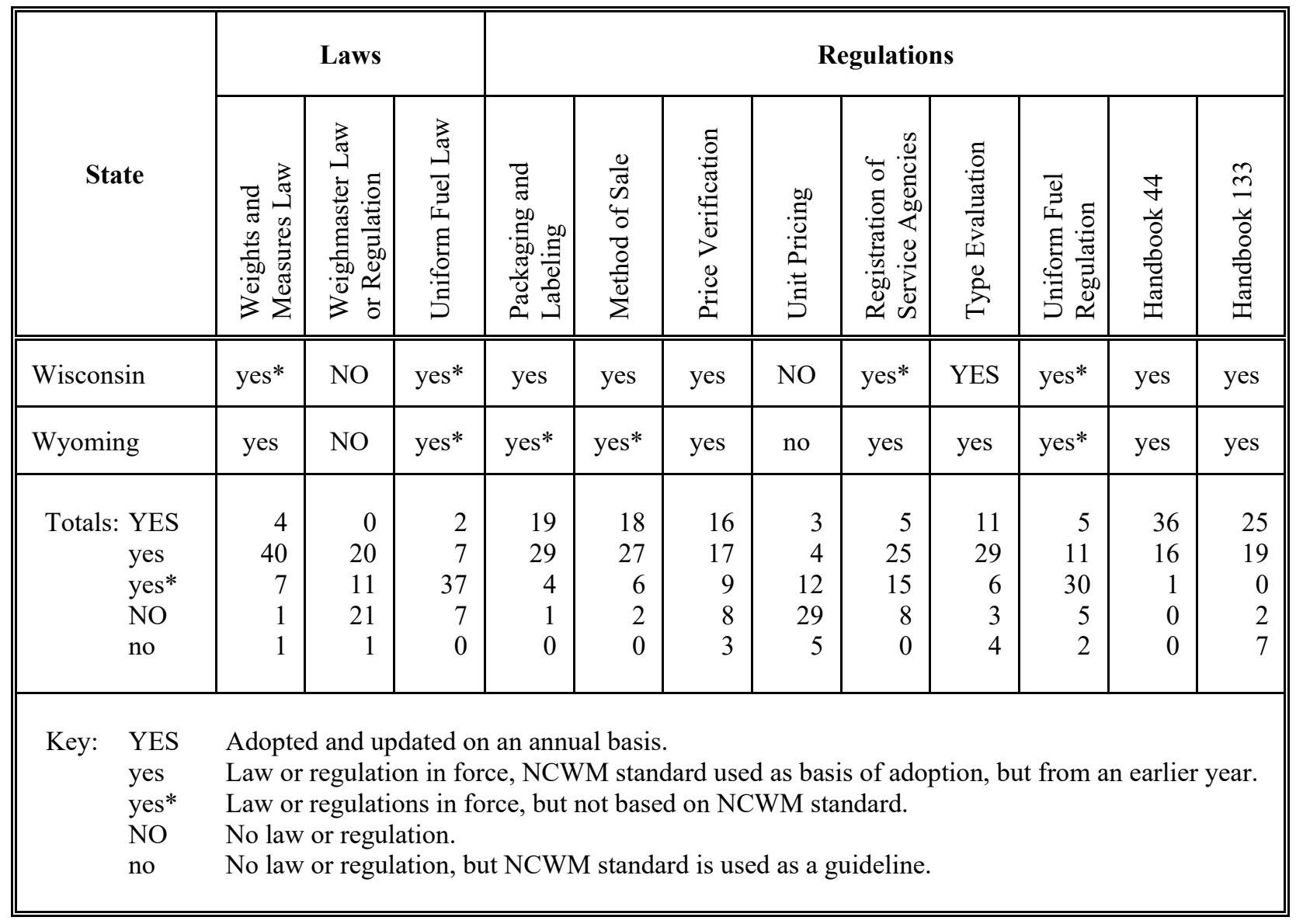


THIS PAGE INTENTIONALLY LEFT BLANK 


\section{Uniform Laws}

\section{Section}

Page

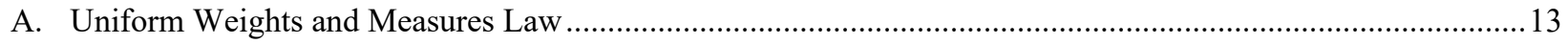

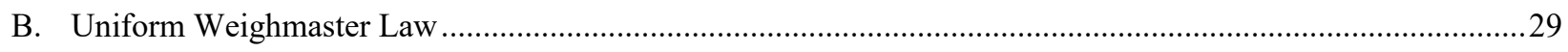

C. Uniform Fuels and Automotive Lubricants Inspection Law ...................................................................... 


\section{THIS PAGE INTENTIONALLY LEFT BLANK}




\title{
A. Uniform Weights and Measures Law
}

\author{
as adopted by \\ The National Conference on Weights and Measures*
}

\section{Background}

Recognition of the need for uniformity in weights and measures laws and regulations among the states was first noted at the second Annual Meeting of the National Conference on Weights and Measures (NCWM) in April 1906. In the following year, basic outlines of a "Model State Weights and Measures Law" were developed. The first "Model Law," as such, was formally adopted by the Conference in 1911.

Through the years, almost without exception, each state has relied upon the NCWM Weights and Measures Law when the state first enacted comprehensive weights and measures legislation. This has led to a greater degree of uniformity in the basic weights and measures requirements throughout the country.

The original Law was regularly amended to provide for new developments in commercial practices and technology. This resulted in a lengthy and cumbersome document and the need for a simplification of the basic weights and measures provisions. The 1971 NCWM adopted a thoroughly revised, simplified, modernized version of the "Model State Weights and Measures Law." This Law now can serve as a framework for all the many concerns in weights and measures administration and enforcement.

The title of the Law was changed by the 1983 NCWM. Amendments or revisions to the Law since 1971 are noted at the end of each section.

Sections 4 through 9 of the Uniform Weights and Measures Law adopt NIST Handbook 44 and the Uniform Regulations in NIST Handbook 130 by citation. In addition, these sections adopt supplements to and revisions of Handbook 44 and the Uniform Regulations "except insofar as modified or rejected by regulation." Some state laws may not permit enacting a statute that provides for automatic adoption of future supplements to or revisions of a Uniform Regulation covered by that statute. If this should be the case in a given state, two alternatives are available:

(a) Sections 4 through 9 may be enacted without the phrase “. . . and supplements thereto or revisions thereof .."; or

(b) Sections 4 through 9 may be enacted by replacing ". . . except insofar as modified or rejected by regulation ..." with the phrase ". . a as adopted, or amended and adopted, by rule of the director."

(Amended 2021)

Either alternative requires action on the part of the Director to adopt a current version of Handbook 44 and each Uniform Regulation each time a supplement or revision is made by the NCWM.

*The National Conference on Weights and Measures (NCWM) is supported by National Institute of Standards and Technology (NIST) in partial implementation of its statutory responsibility for "cooperation with the states in securing uniformity in weights and measures laws and methods of inspection." 


\section{Status of Promulgation}

See the table beginning on page 6, Section II. Uniformity of Laws and Regulations of NIST Handbook 130 for the status of adoption of the Uniform Weights and Measures Law. 


\section{A. Uniform Weights and Measures Law}

\section{Table of Contents}

Section $\quad$ Page

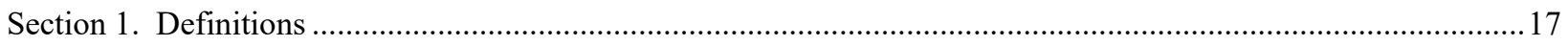

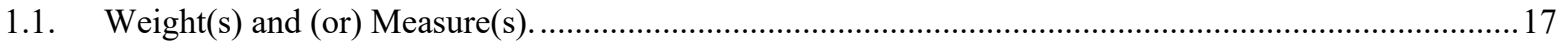

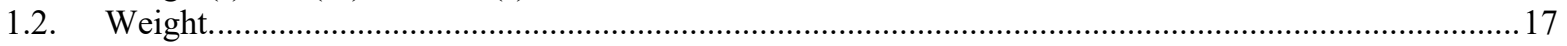

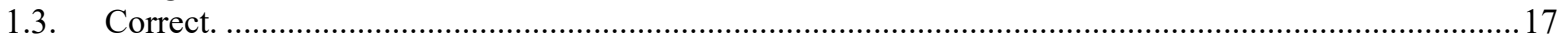

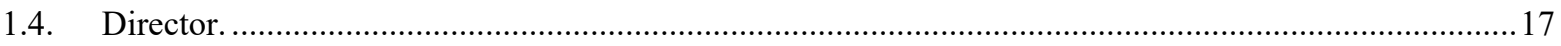

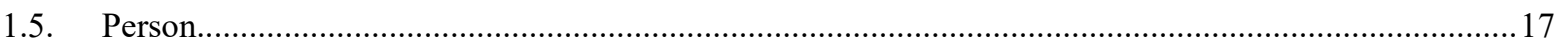

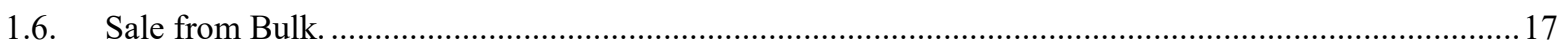

1.7. Package.

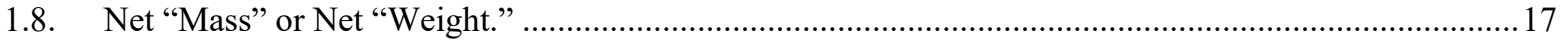

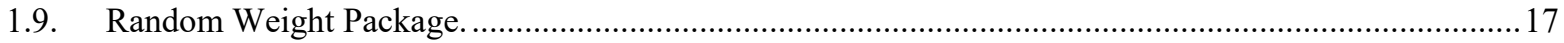

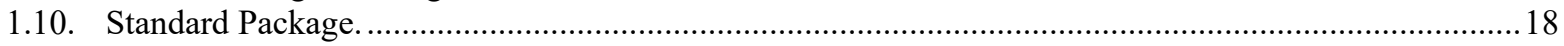

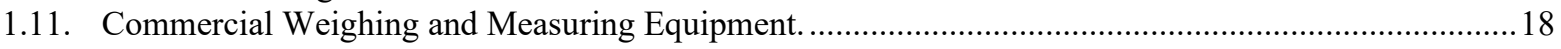

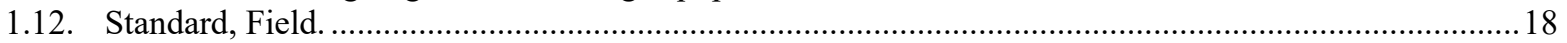

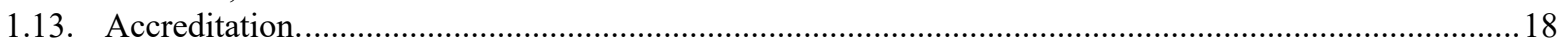

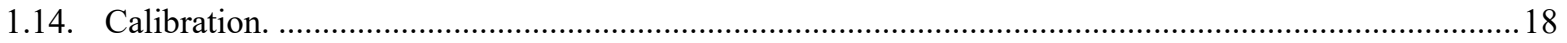

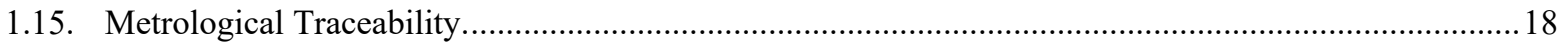

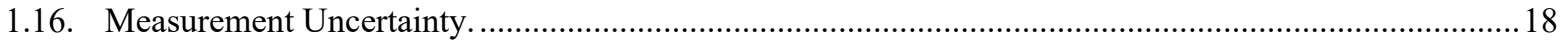

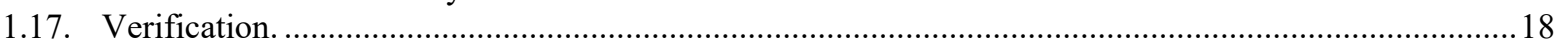

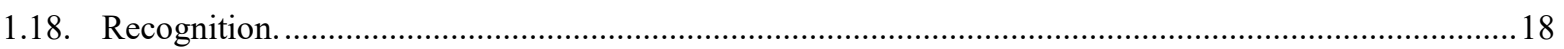

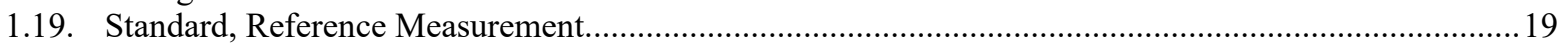

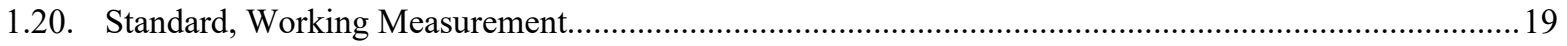

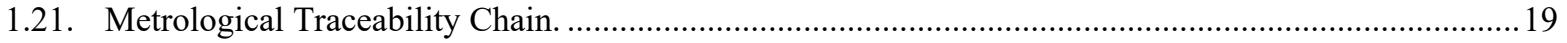

1.22. Metrological Traceability to a Measurement Unit. …….....................................................................19

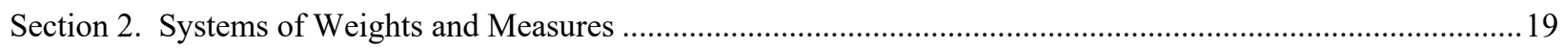

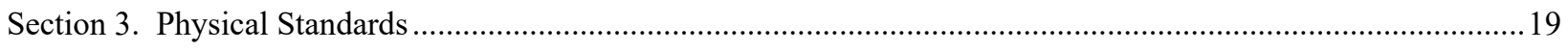

Section 4. Technical Requirements for Weighing and Measuring Devices..........................................................20

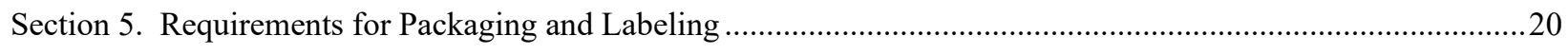

Section 6. Requirements for the Method of Sale of Commodities ........................................................................20

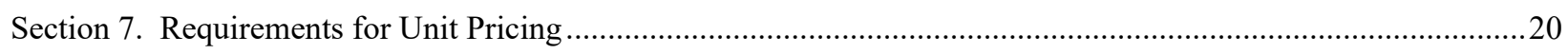

Section 8. Requirements for the Registration of Servicepersons and Service Agencies for Commercial Weighing

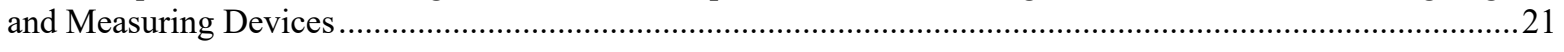

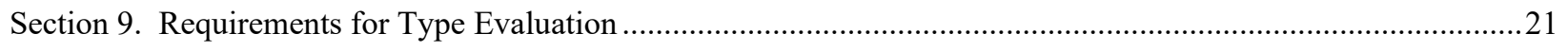

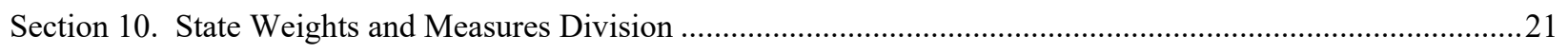

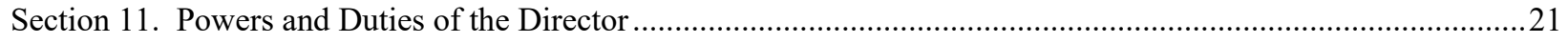

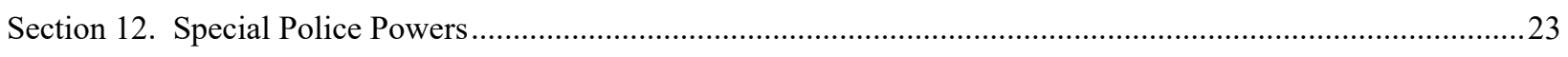

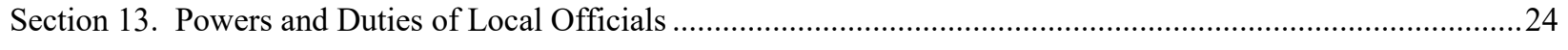

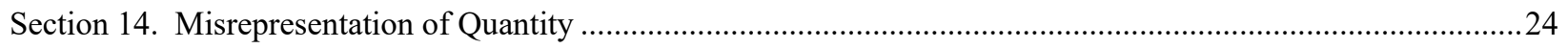




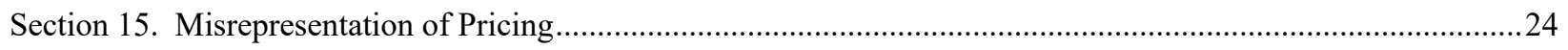

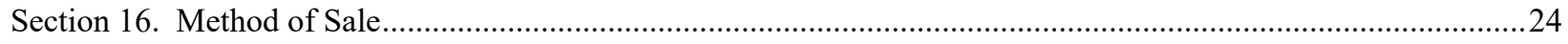

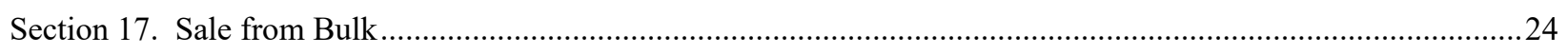

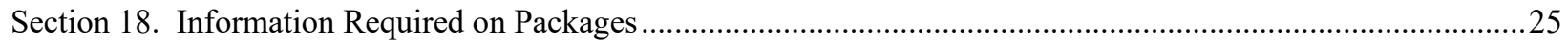

Section 19. Declarations of Unit Price on Random Weight Packages....................................................................25

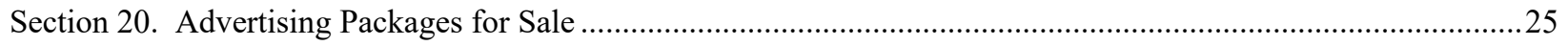

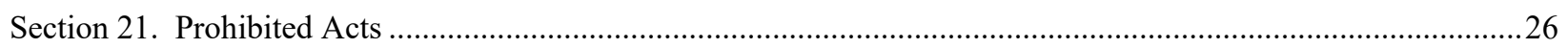

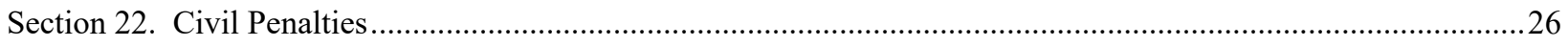

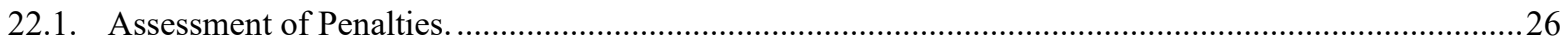

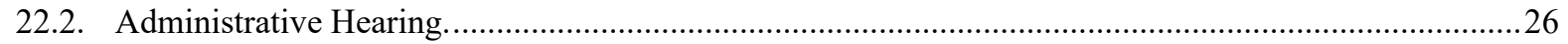

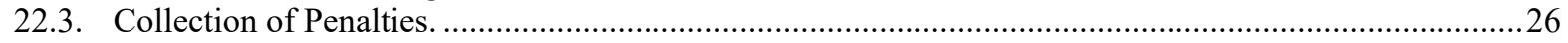

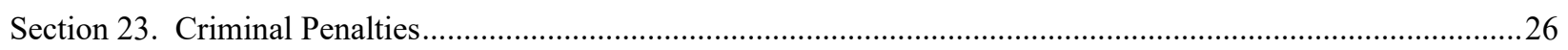

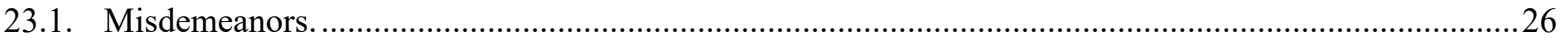

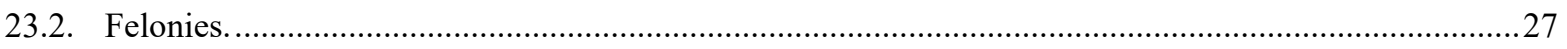

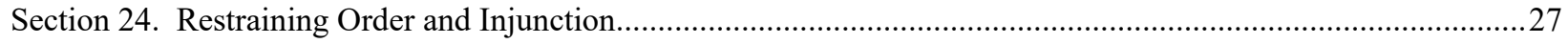

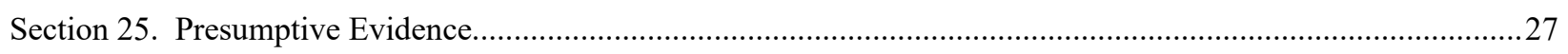

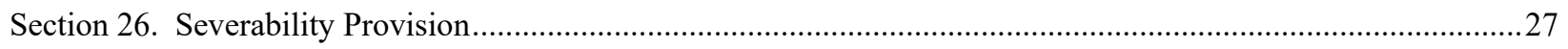

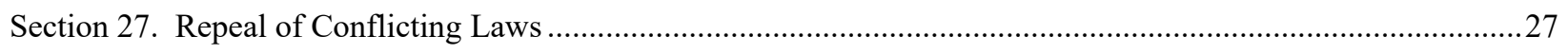

Section 28. Regulations to be Unaffected by Repeal of Prior Enabling Statute ………...........................................2

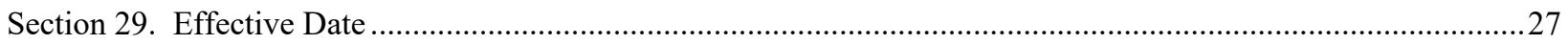




\title{
A. Uniform Weights and Measures Law
}

\section{Section 1. Definitions}

\author{
When used in this Act:
}

1.1. Weight(s) and (or) Measure(s). - The term "weight(s) and (or) measure(s)" means all weights and measures of every kind, instruments and devices for weighing and measuring, and any appliance and accessories associated with any or all such instruments and devices.

1.2. Weight. - The term "weight" as used in connection with any commodity or service means net weight. When a commodity is sold by drained weight, the term means net drained weight.

(Amended 1974 and 1990)

1.3. Correct. - The term "correct" as used in connection with weights and measures means conformance to all applicable requirements of this Act.

1.4. Director. - The term "director" means the of the Department of

1.5. Person. - The term "person" means both plural and the singular, as the case demands, and includes individuals, partnerships, corporations, companies, societies, and associations.

1.6. Sale from Bulk. - The term "sale from bulk" means the sale of commodities when the quantity is determined at the time of sale.

1.7. Package. - Except as modified by Section 1. Application of the Uniform Packaging and Labeling Regulation, the term "package," whether standard package or random package, means any commodity:

(a) enclosed in a container or wrapped in any manner in advance of wholesale or retail sale; or

(b) whose weight or measure has been determined in advance of wholesale or retail sale.

An individual item or lot of any commodity on which there is marked a selling price based on an established price per unit of weight or of measure shall be considered a package (or packages).

(Amended 1991)

1.8. Net "Mass" or Net "Weight." - The term "net mass" or "net weight" means the weight [see Section 1.8. NoTE] of a commodity excluding any materials, substances, or items not considered to be part of the commodity. Materials, substances, or items not considered to be part of the commodity include, but are not limited to, containers, conveyances, bags, wrappers, packaging materials, labels, individual piece coverings, decorative accompaniments, and coupons, except that, depending on the type of service rendered, packaging materials may be considered to be part of the service. For example, the service of shipping includes the weight of packing materials.

(Added 1988) (Amended 1989, 1991, and 1993)

Section 1.8. NOTE: When used in this law (or regulation), the term "weight" means "mass." (See paragraphs K. "Mass" and "Weight" and L. Use of the Terms "Mass" and "Weight" in Section I. Introduction of NIST Handbook 130 for an explanation of these terms.)

(Note Added 1993)

1.9. Random Weight Package. - A package that is one of a lot, shipment, or delivery of packages of the same commodity with no fixed pattern of weights.

(Added 1990) 
1.10. Standard Package. - A package that is one of a lot, shipment, or delivery of packages of the same commodity with identical net contents declarations.

\section{Examples:}

$1 \mathrm{~L}$ bottles or $12 \mathrm{fl} \mathrm{oz} \mathrm{cans} \mathrm{of} \mathrm{carbonated} \mathrm{soda}$

$500 \mathrm{~g}$ or $5 \mathrm{lb}$ bags of sugar

$100 \mathrm{~m}$ or $300 \mathrm{ft}$ packages of rope

(Added 1991) (Amended 1993)

1.11. Commercial Weighing and Measuring Equipment. - The term "commercial weighing and measuring equipment" means weights and measures and weighing and measuring devices commercially used or employed in establishing the size, quantity, extent, area, or measurement of quantities, things, produce, or articles for distribution or consumption, purchased, offered, or submitted for sale, hire, or award, or in computing any basic charge or payment for services rendered on the basis of weight or measure.

(Added 1995)

1.12. Standard, Field. - A physical standard that meets specifications and tolerances in NIST Handbook 105 -series standards (or other suitable and designated standards) and is traceable to the reference or working standards through comparisons, using acceptable laboratory procedures, and used in conjunction with commercial weighing and measuring equipment (1.13. Accreditation).

(Added 2005)

1.13. Accreditation. - A formal recognition by a recognized Accreditation Body that a laboratory is competent to carry out specific tests or calibrations or types of tests or calibrations. NOTE: Accreditation does not ensure compliance of standards to appropriate specifications.

(Added 2005)

1.14. Calibration. - An operation that, under specified conditions, in a first step, establishes a relation between the quantity values with measurement uncertainties provided by measurement standards and corresponding indications with associated measurement uncertainties and, in a second step, uses this information to establish a relation for obtaining a measurement result from an indication.

(Added 2005) (Amended 2013)

1.15. Metrological Traceability. - The property of a measurement result whereby the result can be related to a reference through a documented unbroken chain of calibrations, each contributing to the measurement uncertainty.

(Added 2005) (Amended 2013)

1.16. Measurement Uncertainty. - A non-negative parameter characterizing the dispersion of the quantity values being attributed to a measurand, based on the information used.

(Added 2005) (Amended 2013)

1.17. Verification. - The formal evaluation of a standard or device against the specifications and tolerances for determining conformance.

(Added 2005)

1.18. Recognition. - A formal recognition by NIST Office of Weights and Measures that a laboratory has demonstrated the ability to provide traceable measurement results and is competent to carry out specific tests or calibrations or types of tests or calibrations.

(Added 2005) 
1.19. Standard, Reference Measurement. - A measurement standard designated for the calibration of other measurement standards for quantities of a given kind in a given organization or at a given location. The term "reference measurement standards" usually means the physical standards of the state that serve as the legal reference from which all other standards for weights and measures within that state are derived.

(Added 2005) (Amended 2013)

1.20. Standard, Working Measurement. - A measurement standard that is used routinely to calibrate or verify measuring instruments or measuring systems. The term "working measurement standards" means the physical standards that are traceable to the reference standards through calibrations or verifications, using acceptable laboratory procedures, and used in the enforcement of weights and measures laws and regulations.

(Added 2005) (Amended 2013)

1.21. Metrological Traceability Chain. - Sequence of measurement standards and calibrations that is used to relate a measurement result to a reference.

(Added 2013)

1.22. Metrological Traceability to a Measurement Unit. - Metrological traceability where the reference is the definition of a measurement unit through its practical realization.

(Added 2013)

\section{Section 2. Systems of Weights and Measures}

The International System of Units (SI) and the system of weights and measures in customary use in the United States are jointly recognized, and either one or both of these systems shall be used for all commercial purposes in the state.

The definitions of basic units of weight and measure, the tables of weight and measure, and weights and measures equivalents as published by NIST are recognized and shall govern weighing and measuring equipment and transactions in the state.

(Amended 1993)

NOTE: SI or SI Unit. - means the International System of Units as established in 1960 by the General Conference on Weights and Measures (CGPM) and interpreted or modified for the United States by the Secretary of Commerce. Refer to "Interpretation of the International System of Units for the United States" in "Federal Register" (Volume 73, No. 96, pages 28432 to 28433) for May 16, 2008, and 15 United States Code, Section 205a - 205l "Metric Conversion." Also refer to NIST Special Publication 330, "The International System of Units (SI)," 2019 edition and NIST Special Publication 811, "Guide for the Use of the International System of Units (SI)," 2008 edition or subsequent revisions that are available at www.nist.gov/pml/weights-and-measures/publications/metricpublications or by contacting TheSI@nist.gov.

(Added 1993) (Revised 2019)

\section{Section 3. Physical Standards}

Weights and measures that are traceable to the U.S. prototype standards supplied by the Federal Government, or approved as being satisfactory by NIST, shall be the state reference and working standards of weights and measures, and shall be maintained in such calibration as prescribed by the NIST as demonstrated through laboratory accreditation or recognition. All field standards may be prescribed by the Director and shall be verified upon their initial receipt and as often thereafter as deemed necessary by the Director.

(Amended 2005) 


\section{Section 4. Technical Requirements for Weighing and Measuring Devices [see Section 4. NOTE]}

The specifications, tolerances, and other technical requirements for commercial, law enforcement, data gathering, and other weighing and measuring devices as adopted by the NCWM, published in the National Institute of Standards and Technology Handbook 44, "Specifications, Tolerances, and Other Technical Requirements for Weighing and Measuring Devices," and supplements thereto or revisions thereof, shall apply to weighing and measuring devices in the state, except insofar as modified or rejected by regulation.

(Amended 1975)

Section 4. NOTE: Sections 4 through 9 of the Uniform Weights and Measures Law adopt NIST Handbook 44 and Uniform Regulations in NIST Handbook 130 by citation. In addition, these sections adopt supplements to and revisions of NIST Handbook 44 and the Uniform Regulations "except insofar as modified or rejected by regulation." Some state laws may not permit enacting a statute that provides for automatic adoption of future supplements to or revisions of a regulation covered by that statute. If this should be the case in a given state, two alternatives are available:

(a) Sections 4 through 9 may be enacted without the phrase “. . . and supplements thereto or revisions thereof ..."; or

(b) Sections 4 through 9 may be enacted by replacing ". . except insofar as modified or rejected by regulation ..." with the phrase ". . . as adopted, or amended and adopted, by rule of the director."

(Amended 2021)

Either alternative requires action on the part of the Director to adopt a current version of Handbook 44 and Uniform Laws or Regulations each time a supplement is added or revision is made by the NCWM.

\section{Section 5. Requirements for Packaging and Labeling [see Section 4. NOTE]}

The Uniform Packaging and Labeling Regulation as adopted by the NCWM and published in the National Institute of Standards and Technology Handbook 130, "Uniform Laws and Regulations," and supplements thereto or revisions thereof, shall apply to packaging and labeling in the state, except insofar as modified or rejected by regulation.

(Added 1983)

\section{Section 6. Requirements for the Method of Sale of Commodities [see Section 4. NOTE]}

The Uniform Regulation for the Method of Sale of Commodities as adopted by the NCWM and published in National Institute of Standards and Technology Handbook 130, "Uniform Laws and Regulations," and supplements thereto or revisions thereof, shall apply to the method of sale of commodities in the state, except insofar as modified or rejected by regulation.

(Added 1983)

\section{Section 7. Requirements for Unit Pricing [see Section 4. NOTE]}

The Uniform Unit Pricing Regulation as adopted by the NCWM and published in the National Institute of Standards and Technology Handbook 130, "Uniform Laws and Regulations," and supplements thereto or revisions thereof, shall apply to unit pricing in the state, except insofar as modified or rejected by regulation.

(Added 1983) 


\section{Section 8. Requirements for the Registration of Servicepersons and Service Agencies for Commercial Weighing and Measuring Devices [see Section 4. NOTE]}

The Uniform Regulation for the Voluntary Registration of Servicepersons and Service Agencies for Commercial Weighing and Measuring Devices as adopted by the National NCWM and published in the National Institute of Standards and Technology Handbook 130, "Uniform Laws and Regulations," and supplements thereto or revisions thereof, shall apply to the registration of servicepersons and service agencies in the state, except insofar as modified or rejected by regulation.

(Added 1983)

\section{Section 9. Requirements for Type Evaluation ${ }^{\text {[see Section 4. NOTE] }}$}

The Uniform Regulation for National Type Evaluation as adopted by the NCWM and published in National Institute of Standards and Technology Handbook 130, "Uniform Laws and Regulations," and supplements thereto or revisions thereof, shall apply to type evaluation in the state, except insofar as modified or rejected by regulation.

(Added 1985)

\section{Section 10. State Weights and Measures Division}

There shall be a State Division of Weights and Measures located for administrative purposes within the Department of (agency, etc.). The Division is charged with, but not limited to, performing the following functions on behalf of the citizens of the state:

(a) Assuring that weights and measures in commercial services within the state are suitable for their intended use, properly installed, and accurate, and are so maintained by their owner or user.

(b) Preventing unfair or deceptive dealing by weight or measure in any commodity or service advertised, packaged, sold, or purchased within the state.

(c) Making available to all users of physical standards or weighing and measuring equipment the precision calibration and related metrological certification capabilities of the weights and measures facilities of the Division.

(d) Promoting uniformity, to the extent practicable and desirable, between weights and measures requirements of this state and those of other states and federal agencies.

(e) Encouraging desirable economic growth while protecting the consumer through the adoption by rule of weights and measures requirements as necessary to assure equity among buyers and sellers.

(Added 1976)

\section{Section 11. Powers and Duties of the Director}

The Director shall:

(a) maintain traceability of the state standards as demonstrated through laboratory accreditation or recognition; (Amended 2005)

(b) enforce the provisions of this Act; 
(c) issue reasonable regulations for the enforcement of this Act, which regulations shall have the force and effect of law;

(d) establish labeling requirements, establish requirements for the presentation of cost per unit information, establish standards of weight, measure, or count, and reasonable standards of fill for any packaged commodity.

(Added 1973) (Amended 2021)

(e) grant any exemptions from the provisions of this Act or any regulations promulgated pursuant thereto when appropriate to the maintenance of good commercial practices within the state;

(f) conduct investigations to ensure compliance with this Act;

(g) delegate to appropriate personnel any of these responsibilities for the proper administration of this office;

(h) verify the field standards for weights and measures used by any jurisdiction within the state, before being put into service, tested annually or as often thereafter as deemed necessary by the Director based on statistically evaluated data, and approve the same when found to be correct;

(Amended 2005)

(i) have the authority to inspect and test commercial weights and measures kept, offered, or exposed for sale; (Amended 1995)

(j) inspect and test, to ascertain if they are correct, weights and measures commercially used:

(1) in determining the weight, measure, or count of commodities or things sold, or offered or exposed for sale, on the basis of weight, measure, or count; or

(2) in computing the basic charge or payment for services rendered on the basis of weight, measure, or count.

(k) test all weights and measures used in checking the receipt or disbursement of supplies in every institution, the maintenance of which funds are appropriated by the legislature of the state;

(1) approve for use, and may mark, such commercial weights and measures as are found to be correct, and shall reject and order to be corrected, replaced, or removed such commercial weights and measures as are found to be incorrect. Weights and measures that have been rejected may be seized if not corrected within the time specified or if used or disposed of in a manner not specifically authorized. The Director shall remove from service and may seize the weights and measures found to be incorrect that are not capable of being made correct;

(Amended 1995)

(m) weigh, measure, or inspect packaged commodities kept, offered, or exposed for sale, sold, or in the process of delivery, to determine whether they contain the amounts represented and whether they are kept, offered, or exposed for sale in accordance with this Act or regulations promulgated pursuant thereto. In carrying out the provisions of this section, the Director shall employ recognized sampling procedures, such as are adopted by the NCWM and are published in the National Institute of Standards and Technology Handbook 133, "Checking the Net Contents of Packaged Goods;"

(Amended 1984, 1988, and 2000)

(n) prescribe, by regulation, the appropriate term or unit of weight or measure to be used, whenever the Director determines that an existing practice of declaring the quantity of a commodity or setting charges for a service by weight, measure, numerical count, time, or combination thereof, does not facilitate value comparisons by consumers, or offers an opportunity for consumer confusion;

(Amended 1991) 
(o) allow reasonable variations from the stated quantity of contents, which shall include those caused by loss or gain of moisture during the course of good distribution practice or by unavoidable deviations in good manufacturing practice only after the commodity has entered intrastate commerce;

(p) provide for the training of weights and measures personnel, and may establish minimum training and performance requirements, which shall then be met by all weights and measures personnel, whether county, municipal, or state. The Director may adopt the training standards of the National Conference on Weights and Measures' National Training Program and the laboratory metrology standards specified by the NIST accreditation and/or recognition requirements; and

(Added 1991) (Amended 2005)

(q) verify advertised prices, price representations, and point-of-sale systems, as deemed necessary, to determine:

(1) the accuracy of prices and computations and the correct use of the equipment; and

(2) if such system utilizes scanning or coding means in lieu of manual entry, the accuracy of prices printed or recalled from a database. In carrying out the provisions of this section, the Director shall:

i. employ recognized procedures, such as are designated in National Institute of Standards and Technology Handbook 130, Uniform Laws and Regulations in the Areas of Legal Metrology and Fuel Quality, "Examination Procedures for Price Verification;"

ii. issue necessary rules and regulations regarding the accuracy of advertised prices and automated systems for retail price charging (referred to as "point-of-sale systems") for the enforcement of this section, which rules shall have the force and effect of law; and

iii. conduct investigations to ensure compliance.

(Added 1995)

\section{Section 12. Special Police Powers}

When necessary for the enforcement of this Act or regulations promulgated pursuant thereto, the Director is:

(a) Authorized to enter any commercial premises during normal business hours, except that in the event such premises are not open to the public, he/she shall first present his/her credentials and obtain consent before making entry thereto, unless a search warrant has previously been obtained.

(b) Empowered to issue stop use, hold, and removal orders with respect to any weights and measures commercially used, stop sale, hold, and removal orders with respect to any packaged commodities or bulk commodities kept, offered, or exposed for sale.

(c) Empowered to seize, for use as evidence, without formal warrant, any incorrect or unapproved weight, measure, package, or commodity found to be used, retained, offered, or exposed for sale or sold in violation of the provisions of this Act or regulations promulgated pursuant thereto.

(d) Empowered to stop any commercial vehicle and, after presentation of his credentials, inspect the contents, require the person in charge of that vehicle to produce any documents in his possession concerning the contents, and require him to proceed with the vehicle to some specified place for inspection.

(e) With respect to the enforcement of this Act, the Director is hereby vested with special police powers, and is authorized to arrest, without formal warrant, any violator of this Act. 


\section{Section 13. Powers and Duties of Local Officials}

Any weights and measures official appointed for a county or city shall have the duties and powers enumerated in this Act, excepting those duties reserved to the state by law or regulation. These powers and duties shall extend to their respective jurisdictions, except that the jurisdiction of a county official shall not extend to any city for which a weights and measures official has been appointed. No requirement set forth by local agencies may be less stringent than or conflict with the requirements of the state.

(Amended 1984)

\section{Section 14. Misrepresentation of Quantity}

No person shall:

(a) sell, offer, or expose for sale a quantity less than the quantity represented; nor

(b) take more than the represented quantity when, as buyer, he/she furnishes the weight or measure by means of which the quantity is determined; nor

(c) represent the quantity in any manner calculated or tending to mislead or in any way deceive another person. (Amended 1975 and 1990)

\section{Section 15. Misrepresentation of Pricing}

No person shall misrepresent the price of any commodity or service sold, offered, exposed, or advertised for sale by weight, measure, or count, nor represent the price in any manner calculated or tending to mislead or in any way deceive a person.

\section{Section 16. Method of Sale}

Except as otherwise provided by the Director or by firmly established trade custom and practice,

(a) commodities in liquid form shall be sold by liquid measure or by weight; and

(b) commodities not in liquid form shall be sold by weight, by measure, or by count.

The method of sale shall provide accurate and adequate quantity information that permits the buyer to make price and quantity comparisons.

(Amended 1989)

\section{Section 17. Sale from Bulk}

All bulk sales in which the buyer and seller are not both present to witness the measurement, all bulk deliveries of heating fuel, and all other bulk sales specified by rule or regulation of the director shall be accompanied by a delivery ticket containing the following information:

(a) the name and address of the buyer and seller;

(b) the date delivered; 
(c) the quantity delivered and the quantity upon which the price is based, if this differs from the delivered quantity for example, when temperature compensated sales are made;

(Amended 1991)

(d) the unit price, unless otherwise agreed upon by both buyer and seller; (Added 1991)

(e) the identity in the most descriptive terms commercially practicable, including any quality representation made in connection with the sale; and

(f) the count of individually wrapped packages, if more than one, in the instance of commodities bought from bulk but delivered in packages.

(Amended 1983 and 1991)

\section{Section 18. Information Required on Packages}

Except as otherwise provided in this Act or by regulations promulgated pursuant thereto, any package, whether a random package or a standard package, kept for the purpose of sale, or offered or exposed for sale, shall bear on the outside of the package a definite, plain, and conspicuous declaration of:

(a) the identity of the commodity in the package, unless the commodity is a food, other than meat or poultry, that was repackaged in a retail establishment and the food is displayed to the purchaser under either of the following circumstances:

(1) its interstate labeling is clearly in view or with a counter card, sign or other appropriate device bearing prominently and conspicuously the common or usual name of the food; or

(2) the common or usual name of the food is clearly revealed by its appearance.

(Amended 2001)

(b) the quantity of contents in terms of weight, measure, or count; and,

(c) the name and place of business of the manufacturer, packer, or distributor, in the case of any package kept, offered, or exposed for sale, or sold in any place other than on the premises where packed.

(Amended 1991)

\section{Section 19. Declarations of Unit Price on Random Weight Packages}

In addition to the declarations required by Section 18. Information Required on Packages of this Act, any package being one of a lot containing random weights of the same commodity, at the time it is offered or exposed for sale at retail, shall bear on the outside of the package a plain and conspicuous declaration of the price per kilogram or pound and the total selling price of the package.

(Amended 1986)

\section{Section 20. Advertising Packages for Sale}

Whenever a packaged commodity is advertised in any manner with the retail price stated, there shall be closely and conspicuously associated with the retail price a declaration of quantity as is required by law or regulation to appear on the package.

(Amended 1993) 


\section{Section 21. Prohibited Acts}

No person shall:

(a) use or have in possession for use in commerce any incorrect weight or measure;

(b) sell or offer for sale for use in commerce any incorrect weight or measure;

(c) remove any tag, seal, or mark from any weight or measure without specific written authorization from the proper authority;

(d) hinder or obstruct any weights and measures official in the performance of his or her duties; or

(e) violate any provisions of this Act or regulations promulgated under it.

\section{Section 22. Civil Penalties}

22.1. Assessment of Penalties. - Any person who by himself or herself, by his or her servant or agent, or as the servant or agent of another person, commits any of the acts enumerated in Section 21. Prohibited Acts may be assessed by the a civil penalty of:

(a) not less than $\$$ nor more than $\$$ for a first violation;

(b) not less than $\$$ nor more than $\$$ for a second violation within from the date of the first violation; and

(c) not less than $\$$ nor more than $\$$ for a third violation within from the date of the first violation.

22.2. Administrative Hearing. - Any person subject to a civil penalty shall have a right to request an administrative hearing within days of receipt of the notice of the penalty. The Director or his/her designee shall be authorized to conduct the hearing after giving appropriate notice to the respondent. The decision of the Director shall be subject to appropriate judicial review.

22.3. Collection of Penalties. - If the respondent has exhausted his or her administrative appeals and the civil penalty has been upheld, he or she shall pay the civil penalty within days after the effective date of the final decision. If the respondent fails to pay the penalty, a civil action may be brought by the Director in any court of competent jurisdiction to recover the penalty. Any civil penalty collected under this Act shall be transmitted to

(Added 1989) (Amended 1995)

\section{Section 23. Criminal Penalties}

23.1. Misdemeanors. - Any person who commits any of the acts enumerated in Section 21 . Prohibited Acts shall be guilty of a Class misdemeanor and upon a first conviction thereof shall be punished by a fine of not less than $\$$ nor more than $\$$ or by imprisonment for not more than months, or both. Upon a subsequent conviction thereof, he or she shall be punished by a fine of not less than $\$$ nor more than $\$$ or by imprisonment for up to , or both. 
23.2. Felonies. - Any person who:

(a) intentionally violates any provisions of this Act or regulations under it;

(b) is convicted under the misdemeanor provisions of Section 23(a) more than three times in a two-year period; or

(c) uses or has in his or her possession a device which has been altered to facilitate fraud shall be guilty of a Class felony and upon a first offense shall be punished by a fine of not less than $\$$ or by imprisonment for not more than , or both.

(Added 1989)

\section{Section 24. Restraining Order and Injunction}

The Director is authorized to apply to any court of competent jurisdiction for a restraining order, or a temporary or permanent injunction, restraining any person from violating any provision of this Act.

(Retitled 1989)

\section{Section 25. Presumptive Evidence}

Whenever there shall exist a weight or measure or weighing or measuring device in or about any place in which or from which buying or selling is commonly carried on, there shall be a rebuttable presumption that such weight or measure or weighing or measuring device is regularly used for the business purposes of that place.

\section{Section 26. Severability Provision}

If any provision of this Act is declared unconstitutional, or the applicability thereof to any person or circumstance is held invalid, the constitutionality of the remainder of the Act and the applicability thereof to other persons and circumstances shall not be affected thereby.

\section{Section 27. Repeal of Conflicting Laws}

All laws and parts of laws contrary to or inconsistent with the provisions of this Act are repealed except as to offenses committed, liabilities incurred, and claims made there under prior to the effective date of this Act.

\section{Section 28. Regulations to be Unaffected by Repeal of Prior Enabling Statute}

The adoption of this Act or any of its provisions shall not affect any regulations promulgated pursuant to the authority of any earlier enabling statute unless inconsistent with this Act or modified or revoked by the Director.

\section{Section 29. Effective Date}

This Act shall become effective on 
THIS PAGE INTENTIONALLY LEFT BLANK 


\title{
B. Uniform Weighmaster Law
}

\author{
as adopted by \\ The National Conference on Weights and Measures
}

\section{Background}

The "Model State Weighmaster Law" was first proposed by the $35^{\text {th }}$ National Conference on Weights and Measures (NCWM) in 1950. It was formally adopted by the NCWM and recommended to the states in 1951.

Over the years, very few changes have been made to the Weighmaster Law until 1965. In that year, the format of the Weighmaster Law was revised to be in full accord with the Weights and Measures Law. The name was changed to "Uniform Weighmaster Law" in 1983. The law was again completely revised and updated in 1989. It was editorially revised in 1990.

It provides a registration, licensing, and enforcement program for "public weighmasters" or third-party measurers in commercial transactions.

\section{Status of Promulgation}

See the table beginning on page 6, Section II. Uniformity of Laws and Regulations of Handbook 130, Uniform Laws and Regulations in the Areas of Legal Metrology and Fuel Quality, for the status of adoption of the Uniform Weighmaster Law. 
III. Uniform Laws

B. Uniform Weighmaster Law
Handbook 130 - 2022

\section{THIS PAGE INTENTIONALLY LEFT BLANK}




\section{B. Uniform Weighmaster Law}

\section{Table of Contents}

Section

Section 1. Purpose

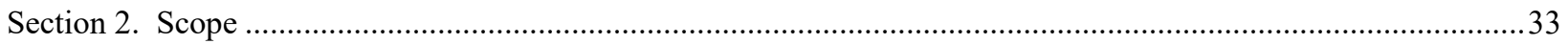

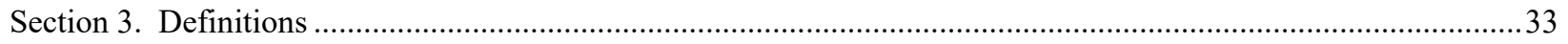

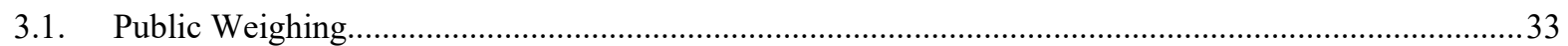

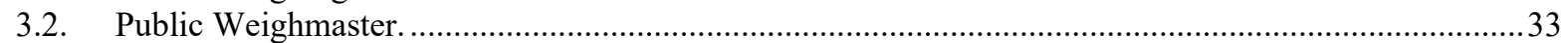

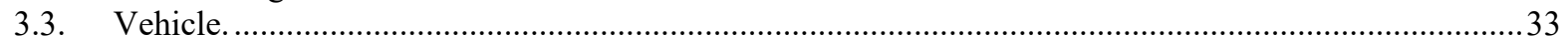

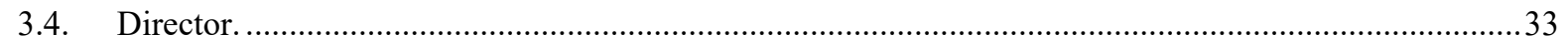

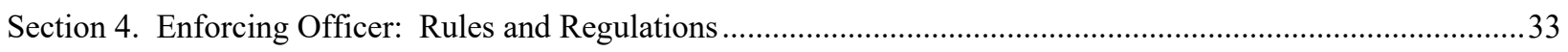

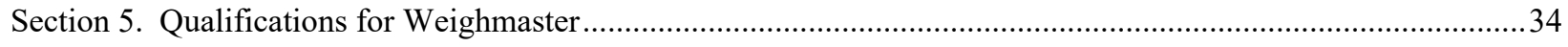

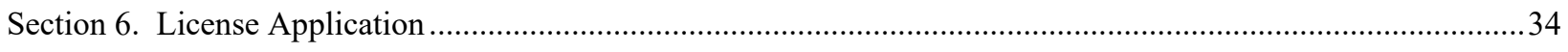

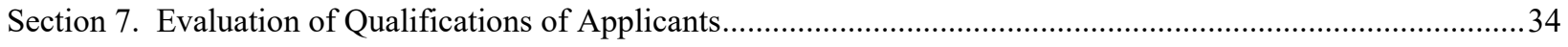

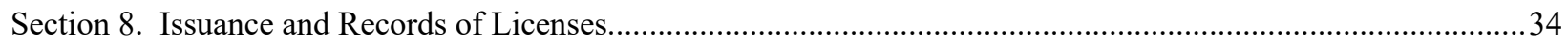

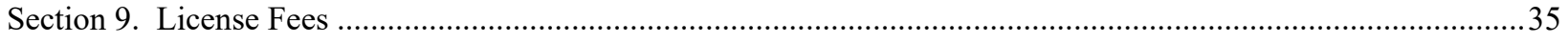

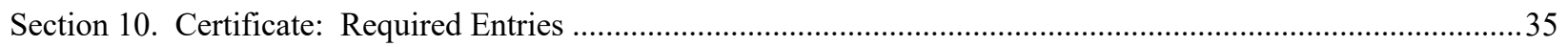

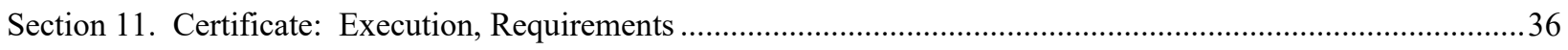

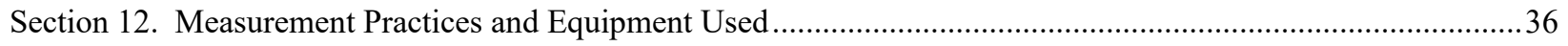

Section 13. Scale Used: Capacity, Platform Size, One-Draft Weighing.........................................................36

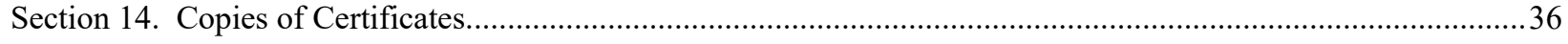

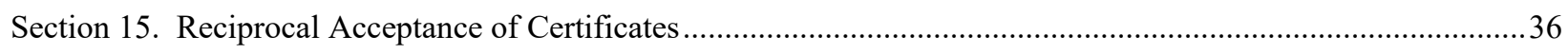

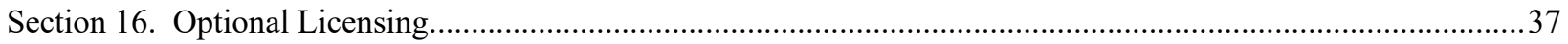

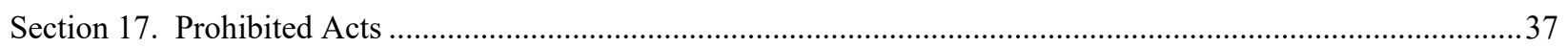

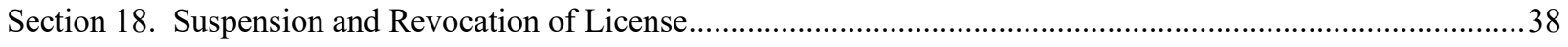

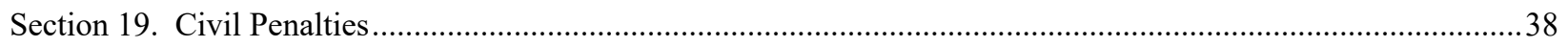

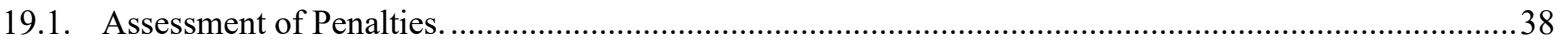

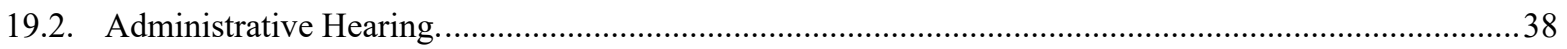

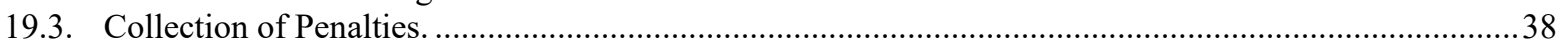

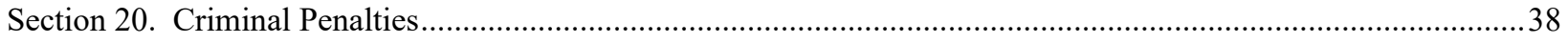

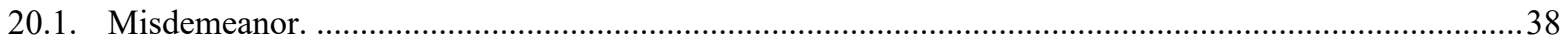

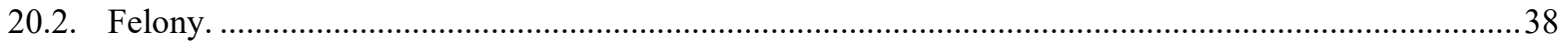


B. Uniform Weighmaster Law

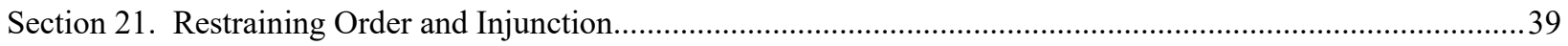

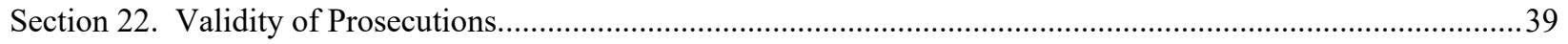

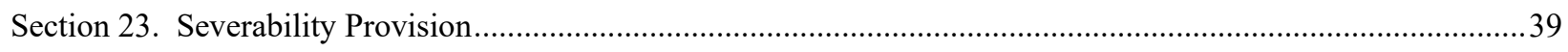

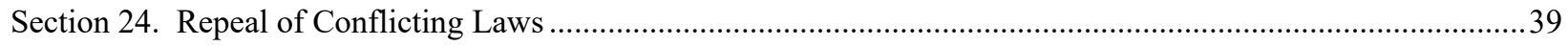

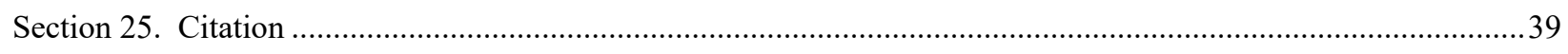

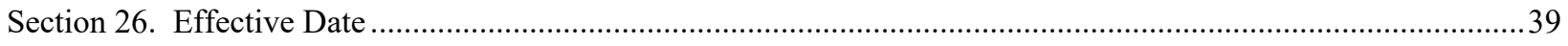




\section{B. Uniform Weighmaster Law}

\section{Section 1. Purpose}

The purpose of this Act is to ensure accurate measurements by public weighmasters.

\section{Section 2. Scope}

This Act:

(a) establishes a registration, licensing, and enforcement program;

(b) provides authority for license fee collection;

(c) empowers the state to promulgate regulations as needed to carry out the provisions of the Act;

(d) provides for optional or voluntary licensing when the employing organization or other organizations require it as part of the condition for employment; and

(e) provides for civil and criminal penalties.

\section{Section 3. Definitions}

As used in this Act:

3.1. Public Weighing. - The weighing, measuring, or counting, upon request, of vehicles, property, produce, commodities, or articles other than those that the weigher or his/her employer, if any, is either buying or selling.

3.2. Public Weighmaster. - Any person who performs public weighing as defined in 3.1. Public Weighing.

3.3. Vehicle. - Any device (except railroad freight cars) in, upon, or by which any property, produce, commodity, or article is or may be transported or drawn.

3.4. Director. - The of the Department of

\section{Section 4. Enforcing Officer: Rules and Regulations}

The Director is authorized to:

(a) enforce the provisions of this Act;

(b) issue reasonable regulations for the enforcement of this Act that shall have the force and effect of law; and

(c) adopt rules that include, but are not limited to, determining:

(1) the qualifications of the applicant for a license as a public weighmaster;

(2) renewal or refusal of a license; 
B. Uniform Weighmaster Law

(3) the period of license validity;

(4) measurement practices that must be followed, including the measurement or recording of tare;

(5) the required information to be submitted with or as part of a certificate; and

(6) the period of recordkeeping.

\section{Section 5. Qualifications for Weighmaster}

To receive authorization to act as a public weighmaster, a person must receive a license from the Director. In order to qualify for a license, a person must:

(a) be able to weigh or measure accurately;

(b) be able to generate correct certificates; and

(c) possess other qualifications required by regulations promulgated under the Act.

\section{Section 6. License Application}

Using a form provided by the Director, the applicant for a license as a public weighmaster shall furnish evidence that he/she has the qualifications required by Section 5. Qualifications for Weighmaster of this Act and regulations promulgated under the Act.

\section{Section 7. Evaluation of Qualifications of Applicants}

The Director will determine the qualifications of the applicant based on:

(a) the information provided on the application; and

(b) supplementary information as determined by the Director.

The Director may also determine the qualifications of the applicant based on the results of an examination of the applicant's knowledge.

\section{Section 8. Issuance and Records of Licenses}

The Director will:

(a) grant licenses as public weighmasters to qualified applicants;

(b) keep a record of all applications submitted and of all licenses issued; and

(c) establish the period of validity of licenses issued. 


\section{Section 9. License Fees}

The Director shall have the authority to set fees for the administration and effective enforcement of the provisions of this Act. Before the issuance of a new license or renewal of a license as a public weighmaster, the applicant must pay a fee of $\$$ to the Director.

\section{Section 10. Certificate: Required Entries}

(a) The certificate, when properly filled out and signed shall be prima facie evidence of the accuracy of the measurements shown.

(b) The design of and the information to be furnished on a weight certificate shall be prescribed by the Director and will include, but not be limited to, the following:

(1) the name and license number of the public weighmaster;

(2) the kind of commodity weighed, measured, or counted;

(3) the name of the owner, agent, or consignee of the commodity;

(4) the name of the recipient of the commodity, if applicable;

(5) the date the certificate is issued;

(6) the consecutive number of the certificate;

(7) the identification, including the identification number, if any, of the carrier transporting the commodity and the identification number or license number of the vehicle;

(8) other information needed to distinguish or identify the commodity from a like kind;

(9) the number of units of the commodity, if applicable;

(10) the measure of the commodity, if applicable;

(11) the weight $[$ see Section 10. NOTE] of the commodity and the vehicle or container (if applicable) broken down as follows:

i. the gross weight of the commodity and the associated vehicle or container;

ii. the tare weight of the unladened vehicle or container; or

iii. both the gross and tare weight and the resultant net weight of the commodity;

(12) signature of the public weighmaster who determined the weight, measure, or count.

Section 10. NOTE: When used in this law (or regulation), the term "weight" means "mass." (See paragraphs K. "Mass" and "Weight" and L. Use of the Terms "Mass" and "Weight" in Section I. Introduction of NIST Handbook 130 for an explanation of these terms.)

(Note added 1993) 
B. Uniform Weighmaster Law

\section{Section 11. Certificate: Execution, Requirements}

(a) When filling out a certificate, a public weighmaster shall:

(1) enter the measurement values to clearly show that the measurements were actually determined;

(2) enter only the measurement values personally determined; and

(3) not enter measurement values determined by other persons.

(b) If the certificate provides for entries of gross, tare, or net, the public weighmaster shall:

(1) strike out or otherwise cancel the printed entries for the values not determined; or

(2) enter the scale and date on which the values were determined on the certificate if the values were not determined on the same scale or on the same date shown on the certificate.

\section{Section 12. Measurement Practices and Equipment Used}

A public weighmaster shall use measurement practices and equipment:

(a) in accordance with the requirements of the latest edition of NIST Handbook 44, "Specifications, Tolerances, and Other Technical Requirements for Weighing and Measuring Devices"; and

(b) examined, tested, and approved for use by a weights and measures officer of this state.

\section{Section 13. Scale Used: Capacity, Platform Size, One-Draft Weighing}

(a) A public weighmaster shall not weigh a vehicle, or combination of vehicles, when part of the vehicle or connected combination, is not resting fully, completely, and as one entire unit on the scale.

(b) When weighing a combination of vehicles that will not rest fully, completely, and as one complete unit on the scale platform:

(1) the combination shall be disconnected and weighed in single drafts; and

(2) the weights of the single drafts may be combined in order to issue a single certificate for the combination, provided the certificate indicates that the total represents a combination of single draft weighings.

\section{Section 14. Copies of Certificates}

A public weighmaster shall keep and preserve for the period specified in the regulations a legible copy of each certificate issued by him or her. The certificates shall be available for inspection by any weights and measures officer of this state during normal office hours.

\section{Section 15. Reciprocal Acceptance of Certificates}

The Director is authorized to recognize and accept certificates issued by licensed public weighmasters of other states that recognize and accept certificates issued by licensed weighmasters of this state. 


\section{Section 16. Optional Licensing}

The following persons shall be authorized, but are not required, to obtain licenses as public weighmasters:

(a) a law enforcement or weights and measures officer or other qualified employee of a state, city, or county agency or institution when acting within the scope of his/her official duties;

(b) a person weighing property, produce, commodities, or articles:

(1) that he/she or his/her employer is either buying or selling; or

(2) in conformity with the requirements of federal statutes or the statutes of this state relative to warehousemen or processors.

\section{Section 17. Prohibited Acts}

It is a prohibited act for any person

(a) without a valid license to:

(1) assume the title of public weighmaster or any title of similar import;

(2) perform the duties or acts to be performed by a public weighmaster;

(3) hold himself or herself out as a public weighmaster;

(4) issue any certificate, ticket, memorandum, or statement for which a fee is charged; or

(5) engage in full-time or part-time business of measuring for hire.

(b) to use or operate any device for certification purposes that does not meet, nor in a manner not in accordance with, the requirements of the latest edition of NIST Handbook 44, "Specifications, Tolerances, and Other Technical Requirements for Weighing and Measuring Devices";

(c) to falsify a certificate or to falsely certify any gross, tare, or net weight or measure required by the Act to be on the certificate;

(d) to refuse without cause to weigh or measure any article or thing which it is his/her duty to weigh or measure, or refuse to state in any certificate anything required to be therein;

(e) to hinder or obstruct in any way the Director or his/her authorized agent in the performance of the Director's official duties under this Act;

(f) to violate any provision of this Act or any regulation promulgated under this Act;

(g) to delegate his/her authority to any person not licensed as a public weighmaster;

(h) to request a false certificate or to request a public weighmaster to weigh, measure, or count any vehicle, property, produce, commodity, or article falsely or incorrectly;

(i) to issue a certificate simulating the certificate in the Act; or

(j) to use or have in his/her possession a device which has been altered to facilitate fraud. 


\section{Section 18. Suspension and Revocation of License}

The Director is authorized to suspend or revoke the license of any public weighmaster:

(a) when, after a hearing held following 10 days' notice to the licensee, he/she is satisfied that the licensee has violated any provision of this Act or any regulation under this Act;

(b) when the licensee has been convicted in any court of competent jurisdiction of violating any provision of this Act or any regulation under this Act; or

(c) when the licensee is convicted of any felony.

\section{Section 19. Civil Penalties}

19.1. Assessment of Penalties. - Any person who by himself or herself, by his or her servant or agent, or as the servant or agent of another person commits any of the acts enumerated in Section 22. Validity of Prosecutions may be assessed by the a civil penalty of:

(a) not less than $\$$ nor more than $\$$ for a first violation,

(b) not less than $\$$ nor more than $\$$ for a second violation within from the date of the first violation, and

(c) not less than $\$$ nor more than $\$$ for a third violation within from the date of the first violation.

19.2. Administrative Hearing. - Any person subject to a civil penalty shall have a right to request an administrative hearing within days of receipt of the notice of the penalty. The Director or his/her designee shall be authorized to conduct the hearing after giving appropriate notice to the respondent. The decision of the Director shall be subject to appropriate judicial review.

19.3. Collection of Penalties. - If the respondent has exhausted his or her administrative appeals and the civil penalty has been upheld, he or she shall pay the civil penalty within days after the effective date of the final decision. If the respondent fails to pay the penalty, a civil action may be brought by the Director in any court of competent jurisdiction to recover the penalty. Any civil penalty collected under this Act shall be transmitted to

(Added 1989) (Amended 1995)

\section{Section 20. Criminal Penalties}

20.1. Misdemeanor. - Any person who by himself/herself, by his/her servant or agent, or as the servant or agent of another person commits any of the acts enumerated in Section 17. Prohibited Acts or violates any other provision of this Act shall be guilty of a Class misdemeanor and upon conviction shall be punished by a fine not less than $\$$ , nor more than $\$$ or by imprisonment for not less than nor more than , or both fine and imprisonment.

20.2. Felony. - Any person who by himself/herself, by his/her servant or agent, or as the servant or agent of another person intentionally commits any of the acts enumerated in Section 17. Prohibited Acts or repeatedly violates any other provision of this Act shall be guilty of a Class felony and upon conviction shall be punished by a fine not less than $\$$ and/or by imprisonment for not less than , nor more than , or more than 


\section{Section 21. Restraining Order and Injunction}

The Director is authorized to apply to any court of competent jurisdiction for a restraining order, or a temporary or permanent injunction, restraining any person from violating any provision of this Act.

\section{Section 22. Validity of Prosecutions}

Prosecutions for violation of any provision of this Act are declared to be valid and proper notwithstanding the existence of any other valid general or specific Act of this state dealing with matters that may be the same as or similar to those covered by this Act.

\section{Section 23. Severability Provision}

If any provision of this Act is declared unconstitutional, or the applicability thereof to any person or circumstance is held invalid, the constitutionality of the remainder of the Act and the applicability thereof to other persons and circumstances shall not be affected.

\section{Section 24. Repeal of Conflicting Laws}

All laws and parts of laws contrary to or inconsistent with the provisions of this Act, and specifically , are repealed insofar as they might operate in the future; but as to offenses committed, liabilities incurred, and claims now existing there under, the existing law shall remain in full force and effect.

\section{Section 25. Citation}

This Act may be cited as the "Public Weighmaster Act of ."

\section{Section 26. Effective Date}

This Act shall become effective on 
III. Uniform Laws

B. Uniform Weighmaster Law
Handbook 130 - 2022

\section{THIS PAGE INTENTIONALLY LEFT BLANK}




\title{
C. Uniform Fuels and Automotive Lubricants Inspection Law
}

\author{
as adopted by \\ The National Conference on Weights and Measures*
}

\section{Background}

In 1984, the National Conference on Weights and Measures (NCWM) adopted a section in the Uniform Regulation for the Method of Sale of Commodities requiring that motor fuel containing alcohol be labeled to disclose to the retail purchaser that the fuel contains alcohol. The delegates deemed this action necessary since motor vehicle manufacturers were qualifying their warranties with respect to some gasoline-alcohol blends, motor fuel users were complaining to weights and measures officials about fuel quality and vehicle performance, and the American Society for Testing and Materials (ASTM) had not yet finalized quality standards for oxygenated (which includes alcoholcontaining) fuels. While many argued that weights and measures officials should not cross the line from quantity assurance programs to programs regulating quality, the delegates were persuaded that the issue needed immediate attention.

A Motor Fuels Task Force was appointed in 1984 to develop mechanisms for achieving uniformity in the evaluation and regulation of motor fuels. The Task Force developed the Uniform Motor Fuel Inspection Law and the Uniform Motor Fuel Regulation (see the Uniform Regulations section of this Handbook) to accompany the Law. The recommended Law required registration and certification of motor fuel as meeting ASTM standards. It established a motor fuel quality testing capability by the state. Funding for the installation and support of the testing facility was established by a fee per liter or per gallon on all fuel marketed within the state.

In 1992, the NCWM established the Petroleum Subcommittee under the Laws and Regulations Committee. The Subcommittee recommended major revisions to the Law that was adopted at the $80^{\text {th }}$ NCWM in 1995 . The scope of the Law was expanded to include all engine fuels, petroleum products, and automotive lubricants, and its title was changed accordingly. Other changes included expansion of the definitions section, limitation of the scope of the registration section to engine fuels designed for special use, and addition of sections on administrative and civil penalties and on criminal penalties.

In 2007, the Fuel and Lubricants Subcommittee (formerly the Petroleum Subcommittee) undertook a review of this uniform law to update it to eliminate reference to "petroleum products" and reflect the addition of new engine fuels to the marketplace. The amendments included new provisions to provide officials with the authority to review delivery records and grant waivers of requirements adopted under the law in times of emergency or natural disasters.

At the 2008 NCWM Interim Meeting, the Laws and Regulations Committee changed the Petroleum Subcommittee's name to the Fuels and Lubricants Subcommittee (FALS) in recognition of its work with a wide variety of fuels including petroleum and biofuels.

${ }^{*}$ The National Conference on Weights and Measures (NCWM) is supported by the National Institute of Standards and Technology (NIST) in partial implementation of its statutory responsibility for "cooperation with the states in securing uniformity in weights and measures laws and methods of inspection." 
III. Uniform Laws

Handbook $130-2022$

C. Uniform Fuels and Automotive Lubricants Inspection Law

\section{Status of Promulgation}

The current Uniform Fuels and Automotive Lubricants Inspection Law was recommended for adoption by the Conference in 2008. The table beginning on page 6, Section II. Uniformity of Laws and Regulations of Handbook 130 shows the status of adoption of the law.

(Amended 2008) 


\section{Uniform Fuels and Automotive Lubricants Inspection Law}

\section{Table of Contents}

Section $\quad$ Page

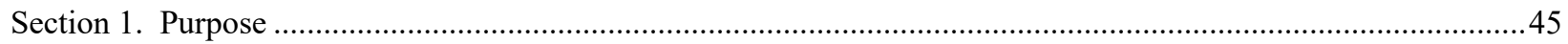

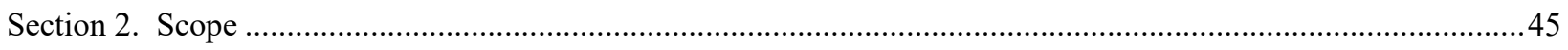

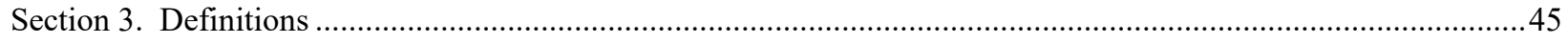

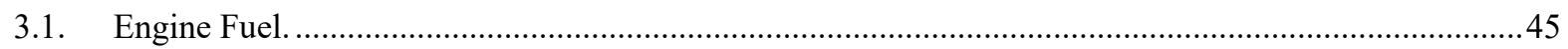

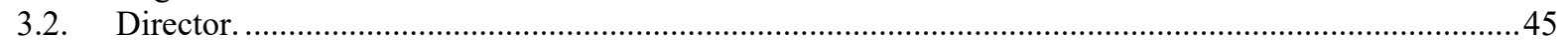

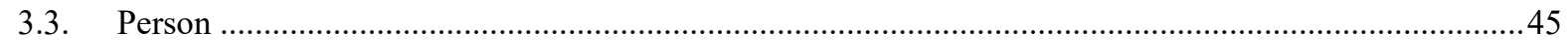

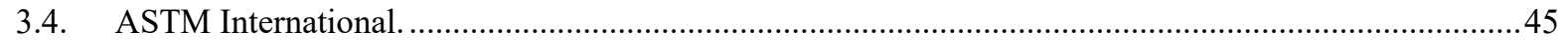

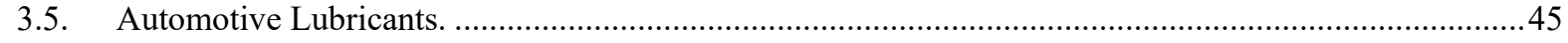

3.6. Engine Fuel Designed for Special Use......................................................................................... 45

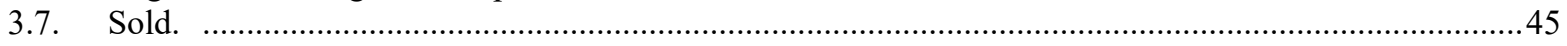

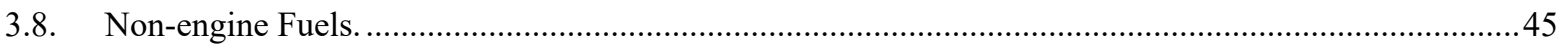

Section 4. Administration, Adoption of Standards, and Rules ……........................................................................45

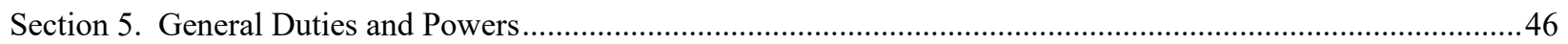

Section 6. Registration of Engine Fuels Designed for Special Use …...................................................................46

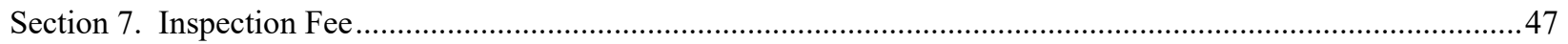

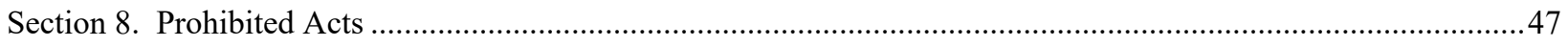

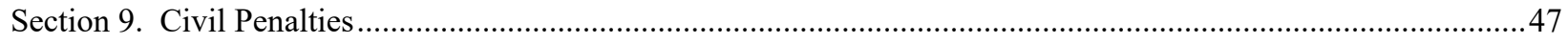

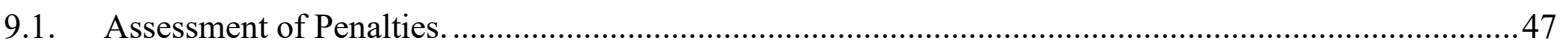

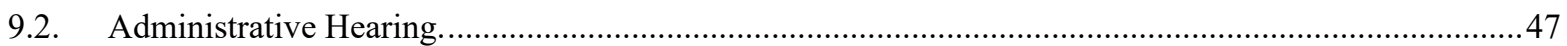

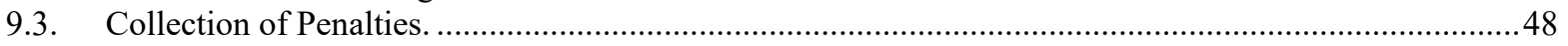

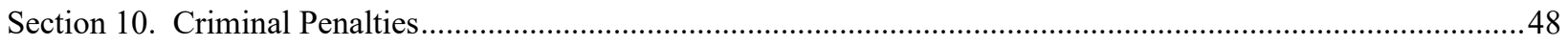

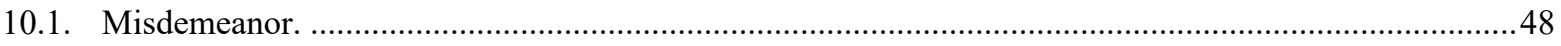

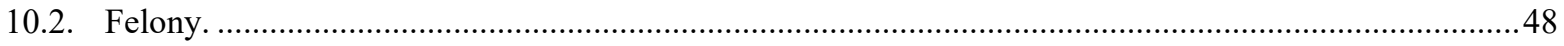

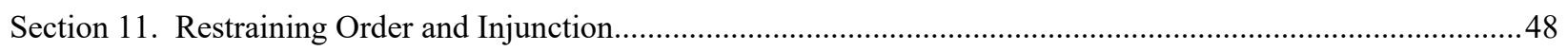

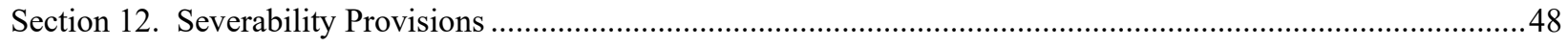

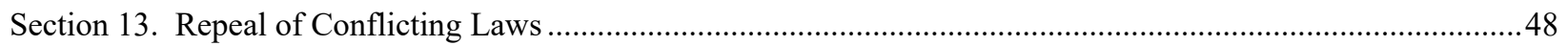

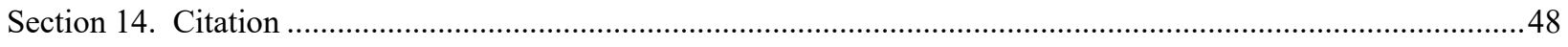

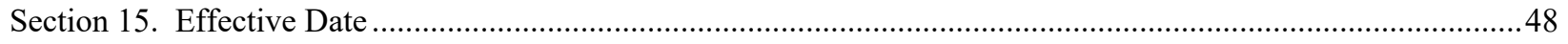


III. Uniform Laws

Handbook $130-2022$

C. Uniform Fuels and Automotive Lubricants Inspection Law

THIS PAGE INTENTIONALLY LEFT BLANKT 


\section{Uniform Fuels and Automotive Lubricants Inspection Law}

\section{Section 1. Purpose}

There should be uniform requirements for engine fuels, non-engine fuels, and automotive lubricants among the states. This Act provides for the establishment of quality specifications for these products.

(Amended 2008)

\section{Section 2. Scope}

The Act establishes a sampling, testing, and enforcement program, provides authority for fee collection, requires registration of engine fuels, and empowers the state to promulgate regulations as needed to carry out the provisions of the Act. It also provides for administrative, civil, and criminal penalties.

\section{Section 3. Definitions}

As used in this act:

3.1. Engine Fuel. - Any liquid or gaseous matter used for the generation of power in an internal combustion engine.

3.2. Director. - The of the Department of and designated agents.

3.3. Person. - An individual, corporation, company, society, association, partnership, or governmental entity.

3.4. ASTM International. (www.astm.org) - An international voluntary consensus standards organization formed for the development of standards on characteristics and performance of materials, products, systems, and services, and the promotion of related knowledge.

3.5. Automotive Lubricants. - Any material interposed between two surfaces that reduces the friction or wear between them.

3.6. Engine Fuel Designed for Special Use. - Engine fuels designated by the Director requiring registration. These fuels normally have no ASTM or other national consensus standards applying to their quality or usability; common special fuels are racing fuels and those intended for agricultural and other off-road applications.

3.7. Sold. - Kept, offered, or exposed for sale.

3.8. Non-engine Fuels. - Any liquid or gaseous matter used for the generation of heat, power, or similar uses. (Added 2008)

\section{Section 4. Administration, Adoption of Standards, and Rules}

The provisions of this Act shall be administered by the Director. For the purpose of administering and giving effect to the provisions of this Act, the specification and test method standards set forth in the most recent version available of ASTM International standards as published on its website www.astm.org are adopted except as amended or modified as required by the Director to comply with federal and state laws. When no ASTM standard exists, other generally recognized national consensus standards may be used. The Director is empowered to write rules and regu- 
C. Uniform Fuels and Automotive Lubricants Inspection Law

lations on the advertising, posting of prices, labeling, standards for, and identity of fuels, non-engine fuels, and automotive lubricants and is authorized to establish a testing laboratory.

(Amended 2008)

\section{Section 5. General Duties and Powers}

The Director shall have the authority to:

5.1. Enforce and administer all the provisions of this Act by inspections, analyses, and other appropriate actions.

5.2. Have access during normal business hours to all places where engine fuels, non-engine fuels, and automotive lubricants are kept, transferred, offered, exposed for sale, or sold for the purpose of examination, inspection, taking of samples, and review of fuel storage, receipts, transfers, sales records, or delivery records for determining compliance with this Act. If such access is refused by the owner, agent, or other persons leasing the same, the Director may obtain an administrative search warrant from a court of competent jurisdiction.

(Amended 2008)

5.3. Collect, or cause to be collected, samples of engine fuels, non-engine fuels, and automotive lubricants marketed in this state, and cause such samples to be tested or analyzed for compliance with the provisions of this Act.

(Amended 2008)

5.4. Define engine fuels for special use and refuse, revoke, suspend, or issue a stop-order if found not to be in compliance and remand stop-order if the engine fuel for special use is brought into full compliance with this Act.

5.5. Issue a stop-sale order for any engine fuel, non-engine fuels, and automotive lubricant found not to be in compliance and remand a stop-sale order if the engine fuel, petroleum product, or automotive lubricant is brought into full compliance with this Act.

(Amended 2008)

5.6. Refuse, revoke, or suspend the registration of an engine fuel, petroleum product, or automotive lubricant.

5.7. Delegate to appropriate personnel any of these responsibilities for the proper administration of this Act.

5.8. The Director is empowered to waive specific state requirements adopted under this Act or may establish alternative requirements for fuels as determined to be necessary in the event of an emergency or a natural disaster for a specified period of time.

(Added 2008)

\section{Section 6. Registration of Engine Fuels Designed for Special Use}

All engine fuels designed for special use must be registered with the Director. Such registration shall include:

6.1. Name, brand, or trademark under which the fuel will be sold.

6.2. Name and address of person registering the engine fuel.

6.3. The special use for which the engine fuel is designed.

6.4. A certification, declaration, or affidavit stating the fuel specifications. 


\section{Section 7. Inspection Fee}

There shall be a fee of $\$$ per appropriate unit of measure on all products covered under the scope of this Act marketed within this state for the purposes of administering and effectively enforcing the provisions of this Act.

\section{Section 8. Prohibited Acts}

It shall be unlawful to:

8.1. Represent engine fuels, non-engine fuels, or automotive lubricants in any manner that may deceive or tend to deceive the purchaser as to the nature, brand, price, quantity, and/or quality of such products.

(Amended 1996 and 2008)

8.2. Fail to register an engine fuel designed for special use.

8.3. Submit incorrect, misleading, or false information regarding the registration of an engine fuel designed for special use.

8.4. Hinder or obstruct the Director in the performance of the Director's duties.

8.5. Represent an engine fuel, non-engine fuels, or automotive lubricant that is contrary to the provisions of this Act.

(Amended 2008)

8.6. Misrepresent automotive lubricants with an SAE (SAE International) viscosity grade or performance categories as provided in the latest version of SAE J183, "Engine Oil Performance and Engine Service Classification (other than "Energy Conserving")," API 1509 "Engine Oil Licensing and Certification System," European Automobile Manufacturer Standards (ACEA), "European Oil Sequences," or other "Vehicle or Engine Manufacturers Standards" as applicable, to the purchaser service classification other than those specified by the intended purchaser.

(Added 1996) (Amended 2021)

\section{Section 9. Civil Penalties}

9.1. Assessment of Penalties. - Any person who, by himself or herself, by his or her servant or agent, or as the servant or agent of another person commits any of the acts enumerated in Section 8. Prohibited Acts may be assessed by the a civil penalty of:
(a) not less than $\$$ nor more than $\$$ for a first violation;
(b) not less than $\$ \_$nor more than $\$$ the date of the first violation; and
(c) not less than $\$$ date of the first violation. nor more than $\$$ for a third violation within from the

9.2. Administrative Hearing. - Any person subject to a civil penalty shall have a right to request an administrative hearing within days of receipt of the notice of the penalty. The Director or his/her designee shall be authorized to conduct the hearing after giving appropriate notice to the respondent. The decision of the Director shall be subject to appropriate judicial review. 
C. Uniform Fuels and Automotive Lubricants Inspection Law

9.3. Collection of Penalties. - If the respondent has exhausted his or her administrative appeals and the civil penalty has been upheld, he or she shall pay the civil penalty within days after the effective date of the final decision. If the respondent fails to pay the penalty, a civil action may be brought by the Director in any court of competent jurisdiction to recover the penalty. Any civil penalty collected under this Act shall be transmitted to

\section{Section 10. Criminal Penalties}

10.1. Misdemeanor. - Any person who violates any provision of this Act or regulations promulgated thereto shall be guilty of a Class or both. nor more than $\$$ misdemeanor and upon conviction shall be punished by a fine of not less than

10.2. Felony. - Any person who intentionally violates any provision of this Act or regulations promulgated thereto or is convicted under the misdemeanor provisions of this section more than three times in a two-year period shall be guilty of a Class felony and upon conviction shall be punished by a fine of not less than $\$$ nor more than $\$$ , or imprisonment for not less than nor more than , or both.

\section{Section 11. Restraining Order and Injunction}

The Director is authorized to apply to any court of competent jurisdiction for a restraining order or a temporary or permanent injunction restraining any person from violating any provision of this Act.

\section{Section 12. Severability Provisions}

If any word, phrase, provision, or portion of this Act shall be held in a court of competent jurisdiction to be unconstitutional or invalid, the unconstitutionality or invalidity shall apply only to such word, phrase, provision, or portion, and for this purpose the provisions of this Act are declared to be severable.

\section{Section 13. Repeal of Conflicting Laws}

All laws and parts of laws contrary to or inconsistent with the provisions of this Act are repealed except as to offense committed, liabilities incurred, and claims made there under prior to the effective date of this Act.

\section{Section 14. Citation}

This Act may be cited as the "Fuels and Automotive Lubricants Inspection Act of (Amended 2008)

\section{Section 15. Effective Date}

This Act shall become effective on 


\section{Uniform Regulations}

\section{Section}

Page

A. Uniform Packaging and Labeling Regulation..................................................................................

B. Uniform Regulation for the Method of Sale of Commodities...........................................................

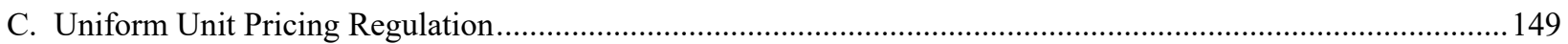

D. Uniform Regulation for the Voluntary Registration of Servicepersons and Service Agencies for Commercial

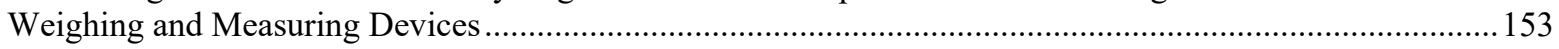

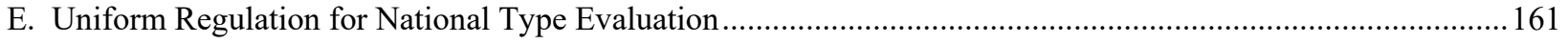

F. Uniform Fuels and Automotive Lubricants Regulation ...................................................................... 169 


\section{THIS PAGE INTENTIONALLY LEFT BLANK}




\title{
A. Uniform Packaging and Labeling Regulation*
}

\author{
as adopted by \\ The National Conference on Weights and Measures*
}

\section{Background}

The Uniform Packaging and Labeling Regulation was first adopted during the $37^{\text {th }}$ Annual Meeting of the National Conference on Weights and Measures (NCWM) in 1952. Reporting to the Conference, the Committee on Legislation stated:

The National Conference should adopt a model package regulation for the guidance of those states authorized to adopt such a regulation under provisions of their weights and measures laws. Since so much of the work of weights and measures officials in the package field concerns food products, the importance of uniformity between the Federal (FDA) regulations and any model regulations to be adopted by this Conference cannot be overemphasized.

Since its inception, the Uniform Packaging and Labeling Regulation has been continually revised to meet the complexities of an enormous expansion in the packaging industry - an expansion that, in late 1966, brought about the passage of the Fair Packaging and Labeling Act (FPLA). Recognizing the need for compatibility with the Federal Act, in 1968 the Committee on Laws and Regulations of the $53^{\text {rd }}$ Annual Meeting of the National Conference amended the "Model Packaging and Labeling Regulation" (renamed in 1983) to parallel regulations adopted by federal agencies under FPLA. The process of amending and revising this Regulation is a continuing one in order to keep it current with practices in the packaging field and make it compatible with appropriate federal regulations. Amendments and additions since 1971 are noted at the end of each section.

The revision of 1978 provided for the use of the metric system (SI) on labels as well as allowing SI-only labels for those commodities not covered by federal laws or regulations. "SI" means the International System of Units as established in 1960 by the General Conference on Weights and Measures and interpreted or modified for the United States by the Secretary of Commerce. [See the "Interpretation of the International System of Units for the United States" in the "Federal Register" (Volume 73, No. 96, pages 28432 to 28433) for May 16, 2008, and 15 United States Code, Section 205a - 2051 "Metric Conversion." See also NIST Special Publication 330 "The International System of Units (SI)" 2019 edition and NIST Special Publication 811 "Guide for the Use of the International System of Units (SI)" 2008 edition that are available at www.nist.gov/pml/weights-and-measures/publications/metricpublications or by contacting TheSi@nist.gov.] In 1988, Congress amended the Metric Conversion Law to declare that it is the policy of the United States to designate the International System of Units of measurement as the preferred system of weights and measures for U.S. trade and commerce. In 1992, Congress amended the federal FPLA to require the most appropriate units of the SI and the U.S. customary systems of measurement on certain consumer commodities. The 1993 amendments to NIST Handbook 130 require SI and U.S. customary units on certain consumer commodities in accordance with federal laws or regulations. Requirements for labeling in both units of measure were effective February 14, 1994, under FPLA and as specified in Section 15. Effective Date; except as specified in Section 11.32. SI Units, Exemptions for Consumer Commodities.

*The National Conference on Weights and Measures (NCWM) is supported by the National Institute of Standards and Technology (NIST) in partial implementation of its statutory responsibility for "cooperation with the states in securing uniformity in weights and measures laws and methods of inspection." 
In 2015, the Federal Trade Commission (FTC) conducted a periodic review of its regulations issued under the FPLA and recently published several revisions which go into effect on December 17, 2015. [See the "Rules, Regulations, Statements of General Policy or Interpretation and Exemptions Under the Fair Packaging and Labeling Act] Final Rule" in the "Federal Register" (Volume 80, No. 221, pages 71686 to 71689) dated Tuesday, November 17, 2015. In response to comments from the NCWM's Packaging and Labeling Subcommittee, the FTC amended its regulations to clarify that exponents may be used in conjunction with U.S. customary units and recognized that with today's online resources the location of a business can be readily obtained in lieu of using a printed telephone directory. The FTC amended its regulations on the Declaration of Responsibility to allow the street address to be omitted if it is accessible in a printed or online telephone directory, or any readily accessible, widely published and publicly available resource. In response to a concern that the existing regulation included a limited table of metric conversions, the FTC decided to incorporate the more comprehensive metric conversion tables to provide users with the wide range of factors in NIST Handbook 133 (2015) "Checking the Net Contents of Packaged Goods," Appendix E, General Tables of Units of Measurements. The FTC also revoked regulations on certain retail price sale representations, since they are no longer used in the marketplace. The regulation was also amended to aid state and local compliance efforts by alerting users of the role of the states in regulating packages that fall outside the scope of the FTC's purview under the FPLA.

(Added 2016)

Nothing contained in this regulation should be construed to supersede any labeling requirement specified in federal law or to require the use of SI units on non-consumer packages.

\section{Status of Promulgation}

The table beginning on page 6, Section II. Uniformity of Laws and Regulations of Handbook 130 shows the status of adoption of the Uniform Packaging and Labeling Regulation. 


\section{A. Uniform Packaging and Labeling Regulation}

\section{Table of Contents}

Section

Preamble

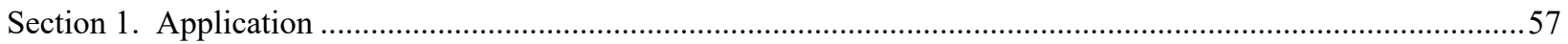

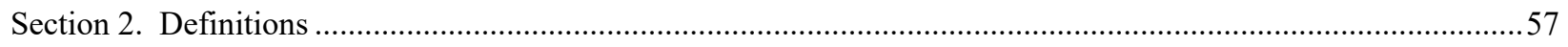

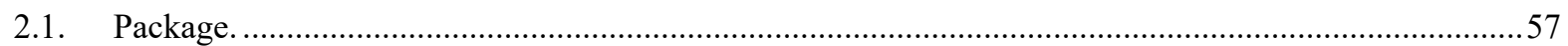

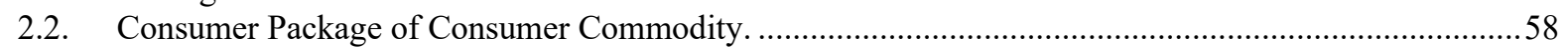

2.3. Non-Consumer Package: Package of Non-Consumer Commodity......................................................58

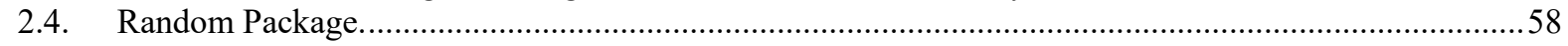

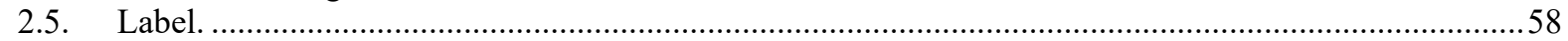

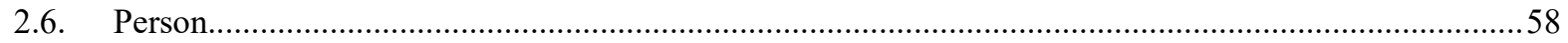

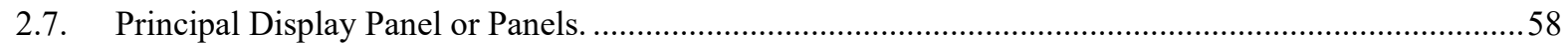

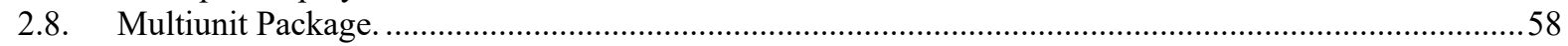

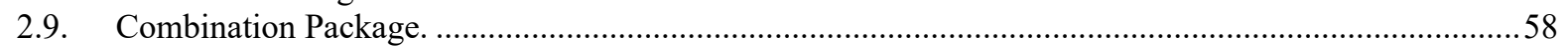

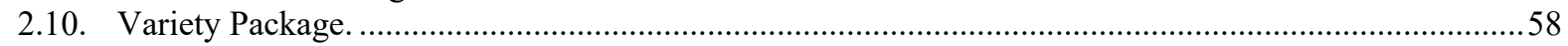

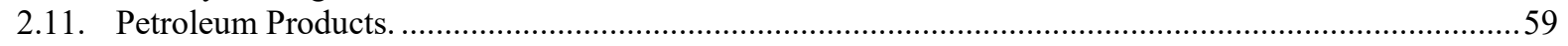

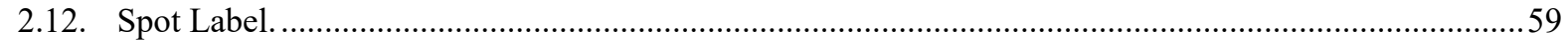

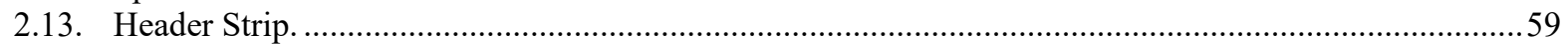

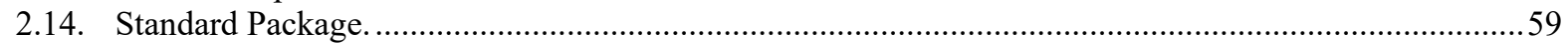

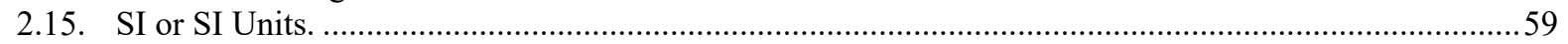

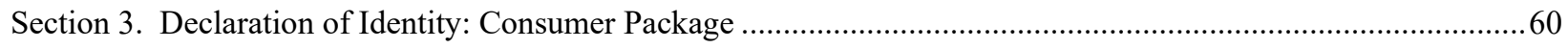

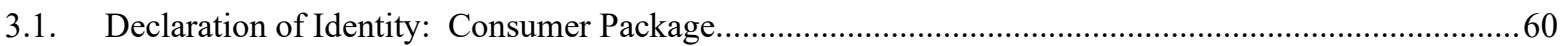

3.1.1. Parallel Identity Declaration: Consumer Package. .............................................................60

Section 4. Declaration of Identity: Non-Consumer Package .....................................................................60

Section 5. Declaration of Responsibility: Consumer and Non-Consumer Packages ........................................60

Section 6. Declaration of Quantity: Consumer Packages ..............................................................................61

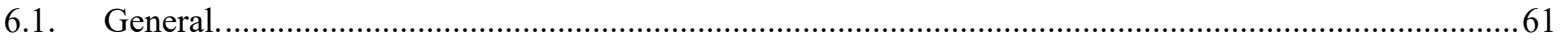

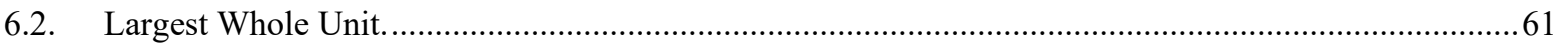

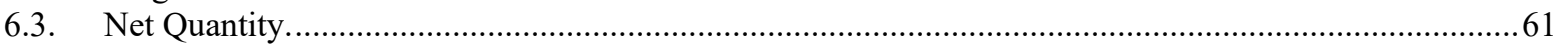

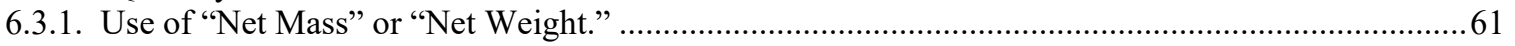

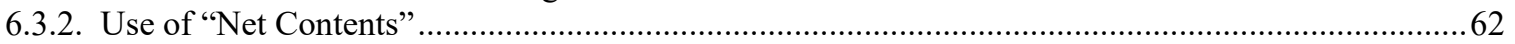

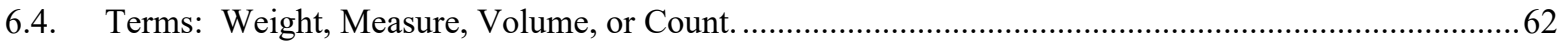

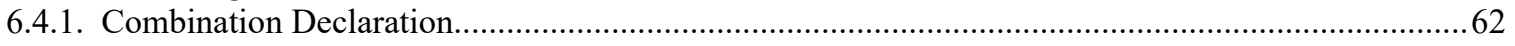

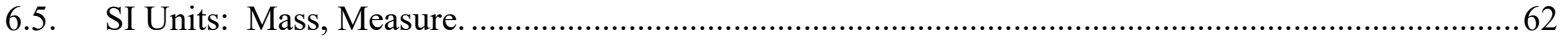

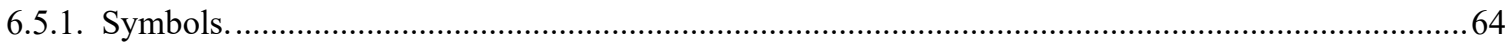

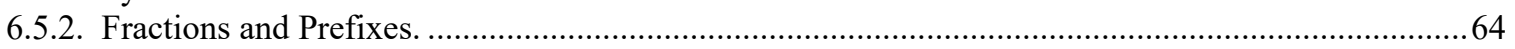

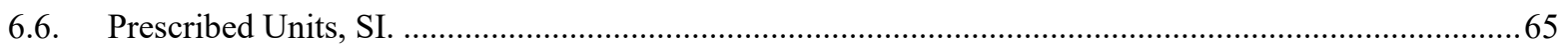

6.6.1. Less than 1 Meter, 1 Square Meter, 1 Kilogram, 1 Cubic Meter, or 1 Liter..................................65

6.6.2. One Meter, 1 Square Meter, 1 Kilogram, 1 Liter, 1 Cubic Meter, or More.................................6 65

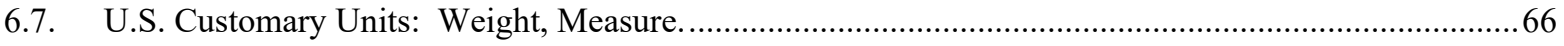

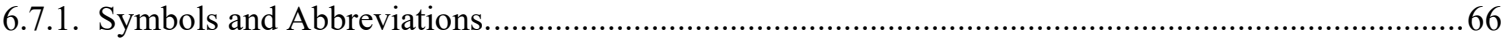

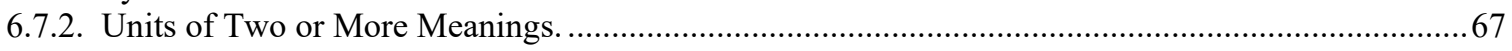

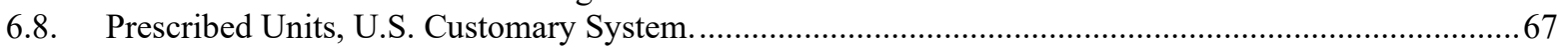


A. Uniform Packaging and Labeling Regulation

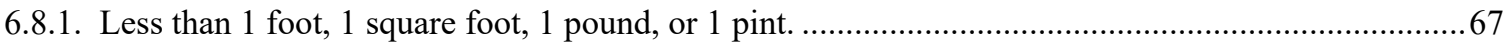

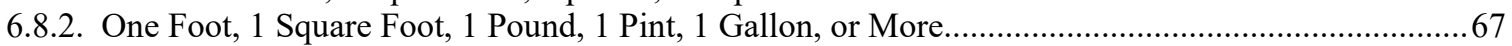

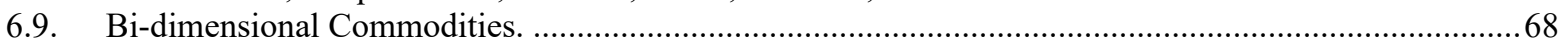

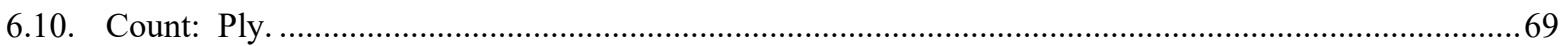

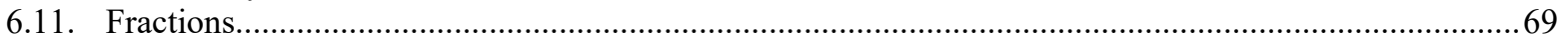

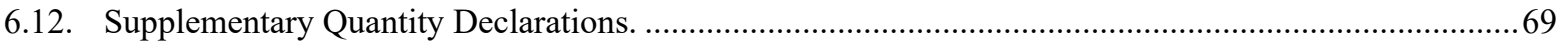

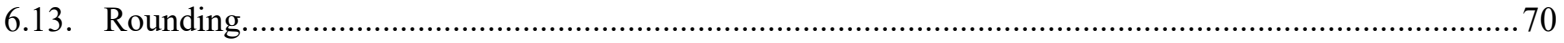

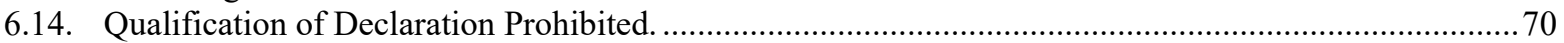

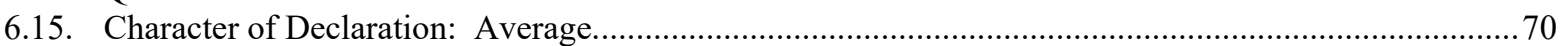

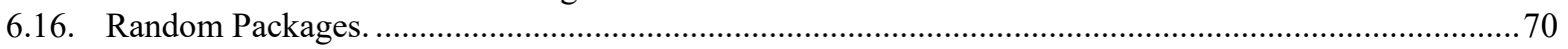

Section 7. Declaration of Quantity: Non-Consumer Packages ......................................................................... 70

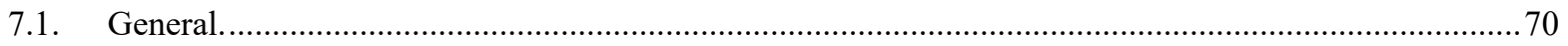

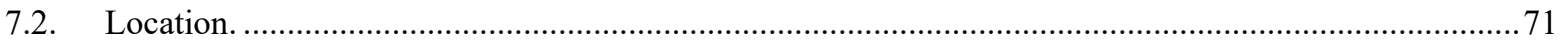

7.3. Terms: Weight, Liquid Measure, Dry Measure, or Count. ………................................................... 71

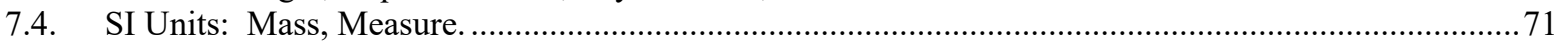

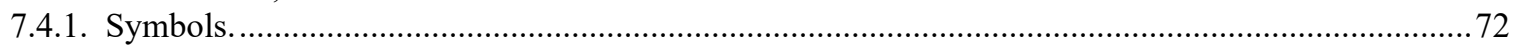

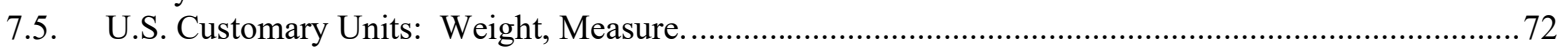

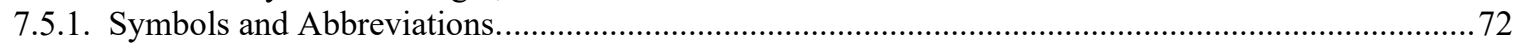

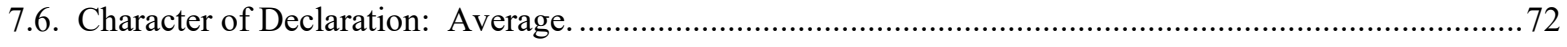

Section 8. Prominence and Placement: Consumer Packages...............................................................................72

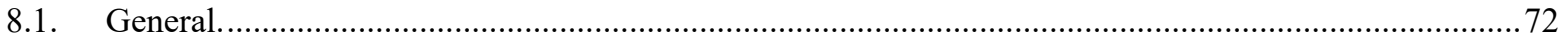

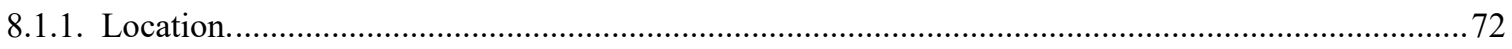

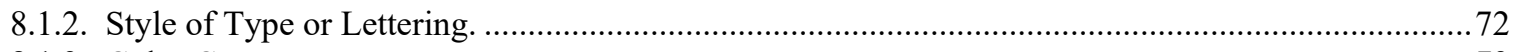

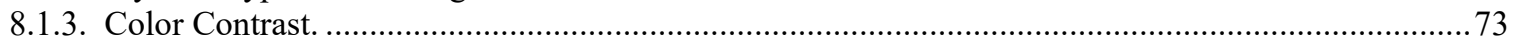

8.1.4. Free Area.

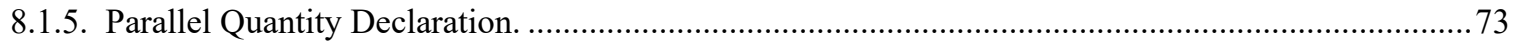

8.2. Calculation of Area of Principal Display Panel for Purposes of Type Size ............................................73

8.2.1. Minimum Height of Numbers and Letters................................................................................. 74

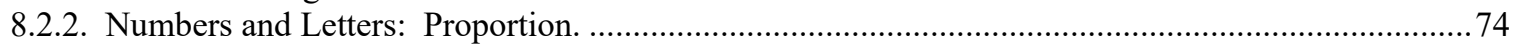

Section 9. Prominence and Placement: Non-Consumer Packages.........................................................................75

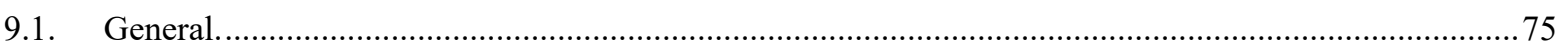

Section 10. Requirements: Specific Consumer Commodities, Non-Consumer Commodities, Packages, Containers

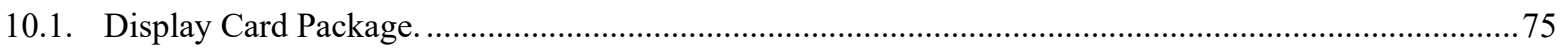

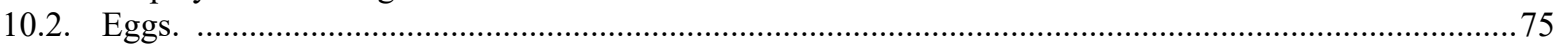

10.3. Aerosols and Other Pre-pressurized Containers Dispensing Product Under Pressure ...........................75

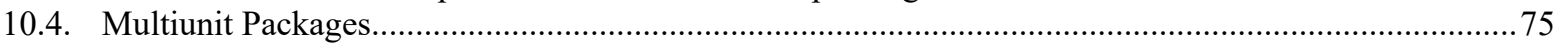

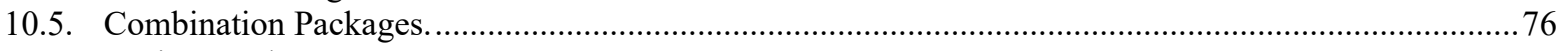

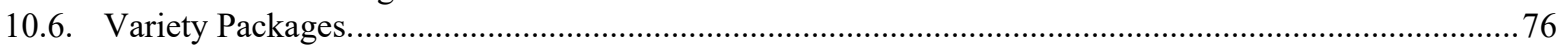

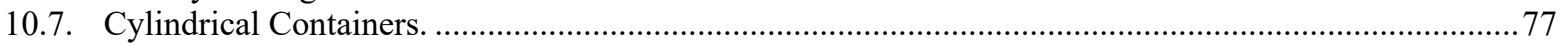

10.8. Measurement of Container-Type Commodities, How Expressed..........................................................77

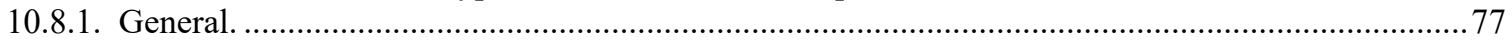

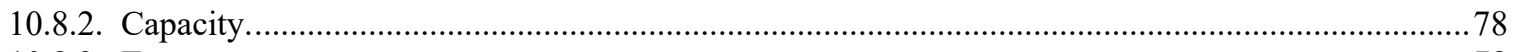

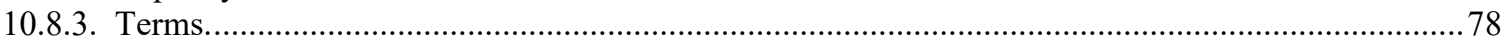

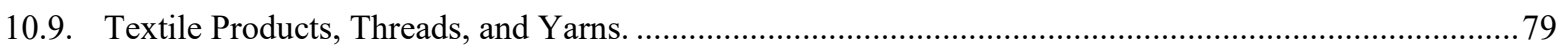

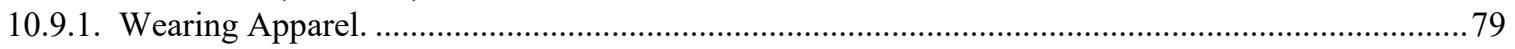

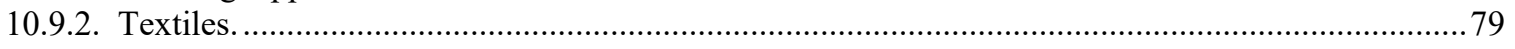

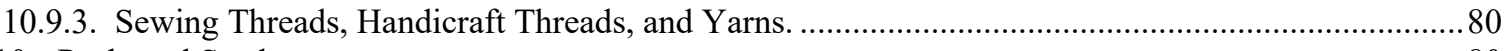

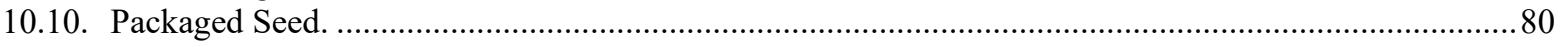




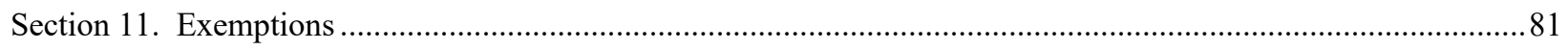

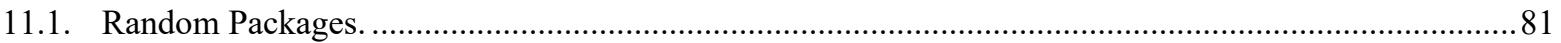

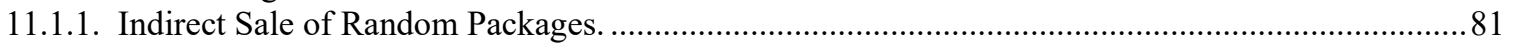

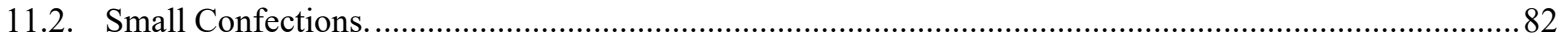

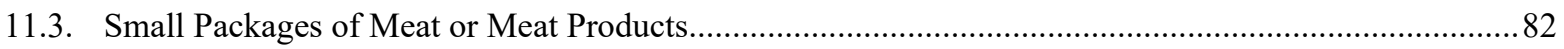

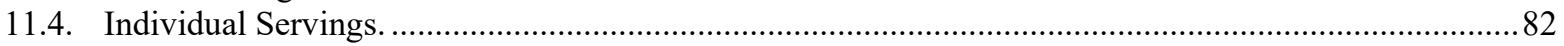

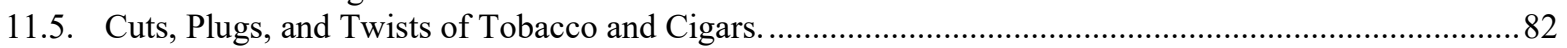

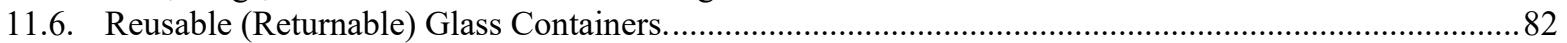

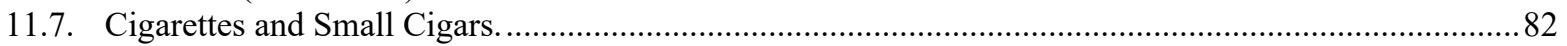

11.8. Packaged Commodities with Labeling Requirements Specified in Federal Laws and Regulations. ........82

11.9. Fluid Dairy Products, Ice Cream, and Similar Frozen Desserts..........................................................82

11.10. Single Strength and Less than Single-Strength Fruit Juice Beverages, Imitations thereof, and Drinking

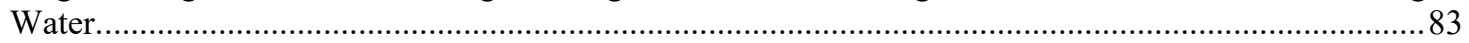

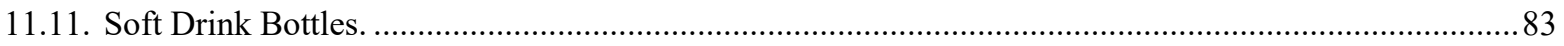

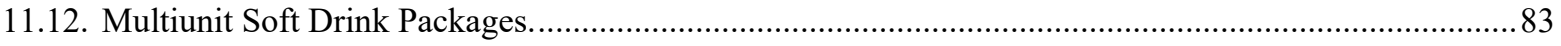

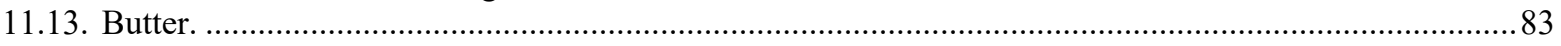

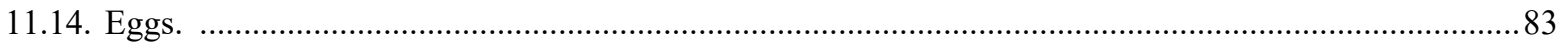

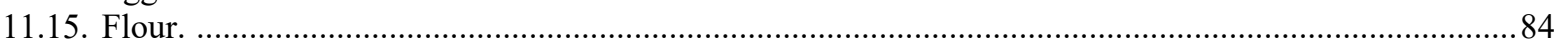

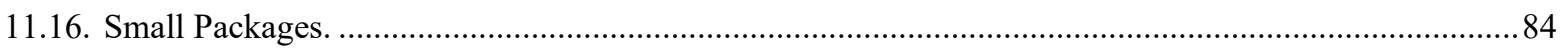

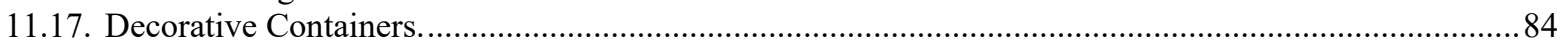

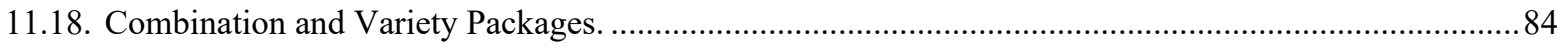

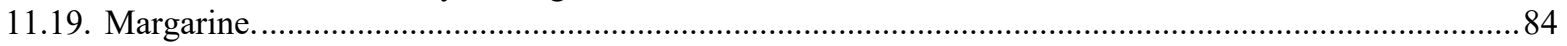

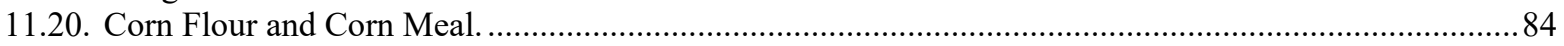

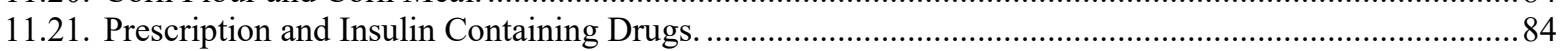

11.22. Camera Film, Video Recording Tape, Audio Recording Tape, and Other Image and Audio Recording

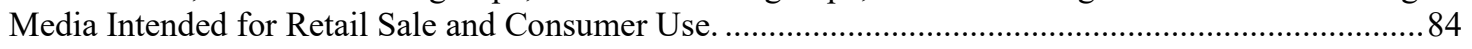

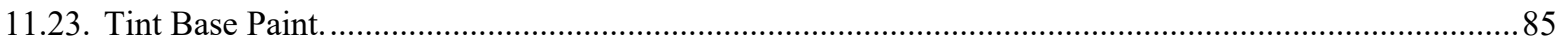

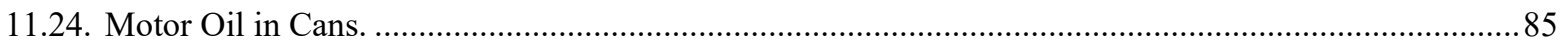

11.25. Pillows, Cushions, Comforters, Mattress Pads, Sleeping Bags, and Similar Products.............................85

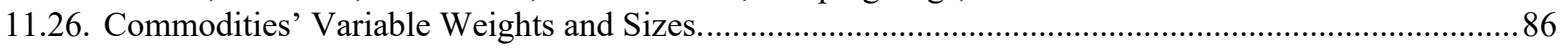

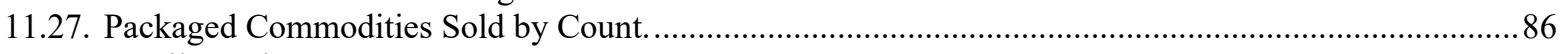

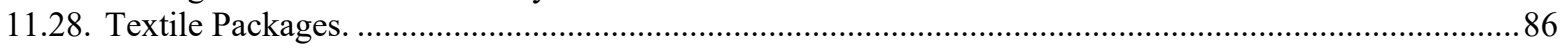

11.29. Spot Label.

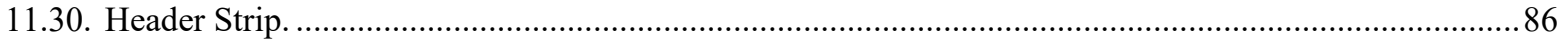

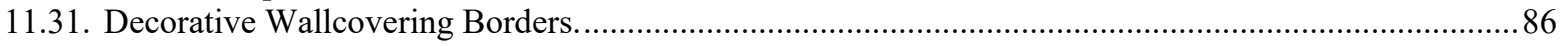

11.32. SI Units, Exemptions - Consumer Commodities. …….....................................................................8

11.33. U.S. Customary Units, Exemptions - Consumer Commodities. ………............................................... 87

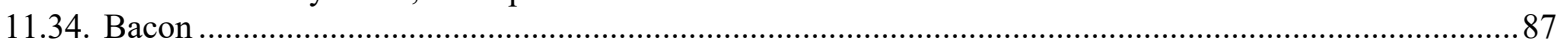

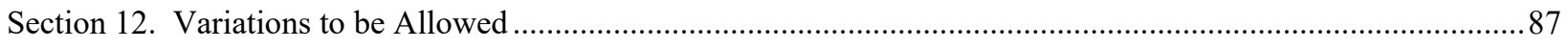

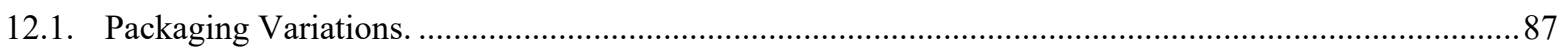

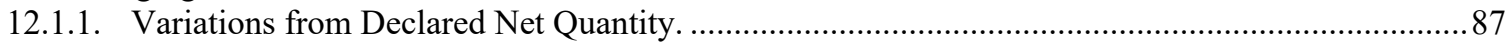

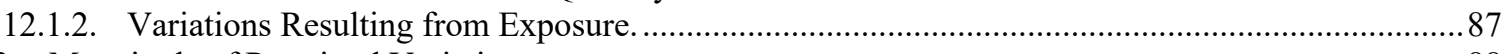

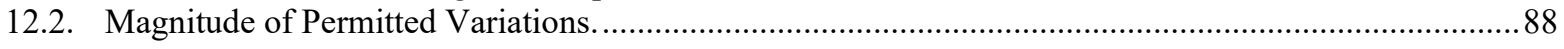

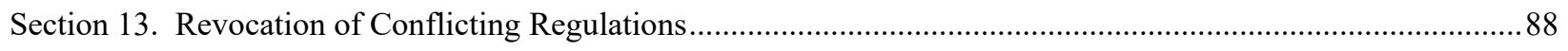

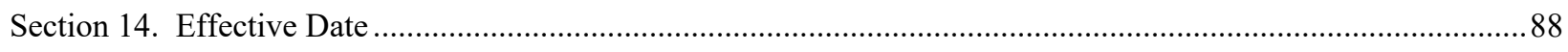

UPLR Appendix A: SI/U.S. Customary Conversion Factors** ............................................................................ 89

UPLR Appendix B: Converting U.S. Customary Units to SI Units for Quantity Declarations on Packages .............91

Appendix C: Reference Information for Packaged Commodities with Labeling Requirements Specified in Federal

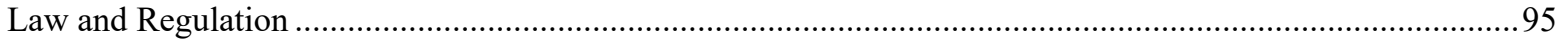


A. Uniform Packaging and Labeling Regulation

\section{THIS PAGE INTENTIONALLY LEFT BLANK}




\section{A. Uniform Packaging and Labeling Regulation}

\section{Preamble}

The purpose of this regulation is to provide accurate and adequate information on packages as to the identity and quantity of contents so that purchasers can make price and quantity comparisons.

(Added 1989)

\section{Section 1. Application}

This regulation shall apply to packages, but shall not apply to:

(a) inner wrappings not intended to be individually sold to the customer;

(b) shipping containers or wrapping used solely for the transportation of any commodities in bulk or in quantity to manufacturers, packers, or processors, or to wholesale or retail distributors, but in no event shall this exclusion apply to packages of consumer or non-consumer commodities as defined herein;

(Added 1971)

(c) auxiliary containers or outer wrappings used to deliver packages of such commodities to retail customers if such containers or wrappings bear no printed matter pertaining to any particular commodity;

(d) containers used for retail tray pack displays when the container itself is not intended to be sold (e.g., the tray that is used to display individual envelopes of seasonings, gravies, etc., and the tray itself is not intended to be sold);

(e) open carriers and transparent wrappers or carriers for containers when the wrappers or carriers do not bear any written, printed, or graphic matter obscuring the label information required by this regulation; or

(f) packages intended for export to foreign countries.

(Amended 1994 and 1998)

\section{Section 2. Definitions}

2.1. Package. - Except as modified by Section 1. Application, the term "package," whether standard package or random package, means any commodity:

(a) enclosed in a container or wrapped in any manner in advance of wholesale or retail sale; or

(b) whose weight ${ }^{\text {[see Section 2.1. NOTE] }}$ or measure has been determined in advance of wholesale or retail sale. An individual item or lot of any commodity on which there is marked a selling price based on an established price per unit of weight or of measure shall be considered a package or packages.

(Amended 1988 and 1991)

Section 2.1. NOTE: When used in this law (or regulation), the term "weight” means "mass." (See paragraphs K. "Mass" and "Weight" and L. Use of the Terms "Mass" and "Weight" in Section I. Introduction of NIST Handbook 130 for an explanation of these terms.)

(Note added 1993) 
2.2. Consumer Package of Consumer Commodity. - A package that is customarily produced or distributed for sale through retail sales agencies or instrumentalities for consumption or use by individuals for the purposes of personal care or in the performance of services ordinarily rendered in or about the household or in connection with personal possessions.

(Amended 1988 and 1991)

2.3. Non-Consumer Package: Package of Non-Consumer Commodity. - Any package other than a consumer package, and particularly a package intended solely for industrial or institutional use or for wholesale distribution.

(Amended 1988 and 1991)

2.4. Random Package. - A package that is one of a lot, shipment, or delivery of packages of the same consumer commodity with no fixed pattern of net contents.

(Amended 1988 and 1990)

2.5. Label. - Any written, printed, or graphic matter affixed to, applied to, attached to, blown into, formed, molded into, embossed on, or appearing upon or adjacent to a consumer commodity, or a package containing any consumer commodity, for purposes of branding, identifying, or giving any information with respect to the commodity or to the contents of the package, except that an inspector's tag or other non-promotional matter affixed to or appearing upon a consumer commodity shall not be considered a label requiring the repetition of label information required by this regulation.

(Amended 1988)

2.6. Person. - The term "person" means either singular or plural and shall include any individual, partnership, company, corporation, association, or society.

(Amended 1988)

2.7. Principal Display Panel or Panels. - That part, or those parts, of a label that is, or are, so designed as to most likely be displayed, presented, shown, or examined under normal and customary conditions of display and purchase. Wherever a principal display panel appears more than once on a package, all requirements pertaining to the "principal display panel" shall pertain to all such "principal display panels."

(Amended 1988)

2.8. Multiunit Package. - A package containing two or more individual packages of the same commodity, in the same quantity, intended to be sold as a multiunit package, but where the component packages are labeled individually in full compliance with all requirements of this regulation.

(Amended 1988)

2.9. Combination Package. - A package intended for retail sale, containing two or more individual packages or units of dissimilar commodities.

Examples:

antiquing or housecleaning kit

sponge and cleaner

lighter fluid and flints

(Added 1989)

2.10. Variety Package. - A package intended for retail sale, containing two or more individual packages or units of similar, but not identical, commodities. Commodities that are generically the same, but that differ in weight, measure, volume, appearance, or quality, are considered similar, but not identical.

\section{Examples:}

two sponges of different sizes

plastic tableware, consisting of 4 spoons, 4 knives, and 4 forks

(Added 1989) 
2.11. Petroleum Products. - Gasoline, diesel fuel, kerosene, or any product (whether or not such a product is actually derived from naturally occurring hydrocarbon mixtures known as "petroleum") commonly used in powering, lubricating, or idling engines or other devices, or is labeled as fuel to power camping stoves or lights. Therefore, sewing machine lubricant, camping fuels, and synthetic motor oil are "petroleum products" for the purposes of this regulation. Brake fluid, copier machine dispersant, antifreeze, cleaning solvents, and alcohol are not "petroleum products."

(Added 1987) (Amended 1988)

2.12. Spot Label. - A spot label is a label clearly defined by means of a border, indentation, or other means that covers only a small portion of the surface of a principal display panel of a package; the entire portion of the principal display panel outside the area of the label contains no printed or graphic matter of any kind. A spot label may contain all required labeling information (identity, responsibility, and net contents), but it must at least indicate the identity and net contents. See Exemptions, Section 11.29. Spot Label for net contents placement exemption for a spot label.

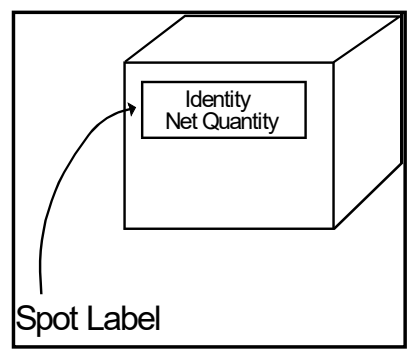

(Added 1990) (Amended 1991)

2.13. Header Strip. - A header label or header strip is a label that is attached across the top of a transparent or opaque bag or other container that bears no other printed or graphic material. See Exemptions, Section 11.30. Header Strip for net contents placement exemptions.

(Added 1990)

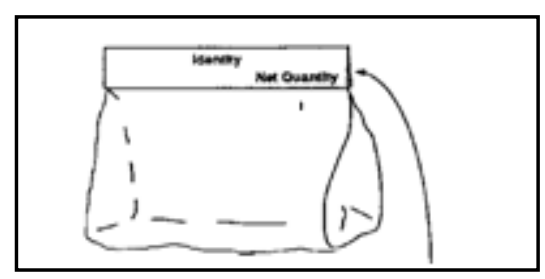

Header Strip

2.14. Standard Package. - A package that is one of a lot, shipment, or delivery of packages of the same commodity with identical net contents declarations.

Examples:

$1 \mathrm{~L}$ bottles or $12 \mathrm{fl} \mathrm{oz}$ cans of carbonated soda

$500 \mathrm{~g}$ or $5 \mathrm{lb}$ bags of sugar

$100 \mathrm{~m}$ packages of rope

(Added 1991)

2.15. SI or SI Units. - SI or SI Units means the International System of Units as established in 1960 by the General Conference on Weights and Measures (CGPM) and interpreted or modified for the United States by the Secretary of Commerce. See the "Interpretation of the International System of Units for the United States" in the "Federal Register" (Volume 73, No. 96, pages 28432 to 28433) for May 16, 2008, and 15 United States Code, Section 205a - 2051 "Metric Conversion." See also NIST Special Publication 330, The International System of Units (SI), 2019 edition and NIST Special Publication 811, Guide for the Use of the International System of Units (SI), 
2008 edition that are available at www.nist.gov/pml/weights-and-measures/publications/metric-publications or by contacting TheSI@nist.gov.

(Added 1993) (Revised 2019)

\section{Section 3. Declaration of Identity: Consumer Package}

3.1. Declaration of Identity: Consumer Package. - A separate declaration of identity [see Section 3.1. NOTE] on a consumer package shall appear on the principal display panel and shall not be misleading or deceptive. The identity shall be in terms of:

(a) the name specified in or required by any applicable federal or state law or regulation or, in the absence of this;

(b) the common or usual name or, in the absence of this;

(c) the generic name or other appropriate description, including a statement of function (such as "cleaning powder").

(Amended 1990) (Note added 1986)

3.1.1. Parallel Identity Declaration: Consumer Package. - A declaration of the identity on a consumer package shall appear generally parallel to the base on which the package rests as it is designed to be displayed.

Section 3.1. NOTE: Section 19.(a) of the Uniform Weights and Measures Law (and 21 CFR 101.100(b)(3) for nonmeat and non-poultry foods) specifically exempts food packages from identity statements if the commodity is a food, other than meat or poultry, that was repackaged in a retail establishment and the food is displayed to the purchaser under either of the following circumstances: "(1) its interstate labeling is clearly in view or with a counter card, sign, or other appropriate device bearing prominently and conspicuously the common or usual name of the food, or (2) the common or usual name of the food is clearly revealed by its appearance."

(Added 1986) (Amended 2001)

\section{Section 4. Declaration of Identity: Non-Consumer Package}

A declaration of identity [see Section 3.1. NOTE] on a non-consumer package shall appear on the outside of a package and shall not be misleading or deceptive. The identity shall be in terms of:

(a) the name specified in or required by any applicable federal or state law or regulation or, in the absence of this;

(b) the common or usual name or, in the absence of this;

(c) the generic name or other appropriate description, including a statement of function (such as "cleaning powder").

(Amended 1990) (Note added 1986)

\section{Section 5. Declaration of Responsibility: Consumer and Non-Consumer Packages}

Any package kept, offered, or exposed for sale, or sold at any place other than on the premises where packed shall specify conspicuously on the label of the package the name and address of the manufacturer, packer, or distributor. The name shall be the actual corporate name, or, when not incorporated, the name under which the business is conducted. The address shall include street address, city, state (or country if outside the United States), and ZIP Code (or the mailing code, if any, used in countries other than the United States); however, the street address may be omitted 
if it is listed in any readily accessible, well-known, widely published, and publicly available resource, including but not limited to a printed directory, electronic database, or website.

(Amendment effective December 17, 2015)

If a person manufactures, packs, or distributes a commodity at a place other than his principal place of business, the label may state the principal place of business in lieu of the actual place where the commodity was manufactured or packed or is to be distributed, unless such statement would be misleading. Where the commodity is not manufactured by the person whose name appears on the label, the name shall be qualified by a phrase that reveals the connection such person has with such commodity, such as "Manufactured for and packed by ,"Distributed by ___, or any other wording of similar import that expresses the facts.

(Amended 2016)

\section{Section 6. Declaration of Quantity: Consumer Packages}

6.1. General. [see Section 6.1. NOTE] - The International System of Units (SI), known as the metric system and the U.S. customary system of weights and measures are recognized as proper systems to be used in the declaration of quantity. Effective February 14, 1994, appropriate units of both systems shall be presented in a declaration of quantity except as specified in Section 11.32. SI Units, Exemptions for Consumer Commodities and Section 11.33. U.S. Customary Units, Exemptions - Consumer Commodities.

(Amended 1985, 1990, 1993, and 1999)

Section 6.1. NOTE: Packages subject to this Section and/or the Federal Fair Packaging and Labeling Act shall be labeled in units of the International System of Units (SI) and the U.S. customary system of measure effective February 14, 1994, [except for seed (see Section 10.10. Packaged Seed) and camera film and recording tape (see Section 11.22. Camera Film, Video Recording Tape, Audio Recording Tape and Other Image and Audio Recording Media Intended for Retail Sale and Consumer Use), and as specified in Section 11.32. SI Units, Exemptions Consumer Commodities]. SI units may appear first.

(Note Added 1982) (Amended 1990 and 1993)

6.2. Largest Whole Unit. - Where this regulation requires that the quantity declaration be in terms of the largest whole unit, the declaration shall, with respect to a particular package, be in terms of the largest whole unit of weight or measure with any remainder expressed (following the requirements of Section 6.5.2. (a) Fractions and Section 6.11. Fractions):

(a) SI Units. - in decimal fractions of such largest whole unit.

(b) U.S. Customary Units.

(1) in common or decimal fractions of such largest whole unit; or

(2) in the next smaller whole unit or units with any further remainder in terms of common or decimal fractions of the smallest unit present in the quantity declaration.

6.3. Net Quantity. - A declaration of net quantity of the commodity in the package, exclusive of wrappers and any other material packed with such commodity (except as noted in Section 10.3. Aerosols and Other Pre-pressurized Containers Dispensing Product Under Pressure), shall appear on the principal display panel of a consumer package and, unless otherwise specified in this regulation (see Sections 6.6. Prescribed Units, SI, through 6.9. Bi-dimensional Commodities), shall be in terms of the largest whole unit.

6.3.1. Use of "Net Mass" or "Net Weight." - When stating the net quantity of contents in terms of weight a quantity declaration may stand alone [e.g., "200 g (7 oz)" or "1 lb (453 g)"] or may include the term "net mass" 
or "net weight" either preceding or following the declaration. The term "net" by itself may be used on food labels. However, the quantity of contents shall always declare the net quantity of contents even when such terms are not used.

(Amended 1993)

6.3.2. Use of "Net Contents" - When stating the net quantity of contents in terms of fluid measure or numerical count, a quantity declaration may stand alone [e.g., " $177 \mathrm{~mL}(6 \mathrm{fl} \mathrm{oz})$ "] or may include the term "net" or "net contents" either preceding or following the declaration.

(Amended 2019)

6.3.3. Lines of Print or Type - A declaration of quantity may appear on one or more lines of print or type. (Amended 1982)

6.4. Terms: Weight, Measure, Volume, or Count. - The declaration of the quantity shall be expressed in terms of Table 6.4. Weight, Measure, Volume or Count:

\begin{tabular}{||l|l||}
\hline \multicolumn{2}{|c|}{ Weight, Measure, Volume, or Count } \\
\hline \hline If the commodity is: & $\begin{array}{l}\text { The declaration of the quantity of a particular } \\
\text { commodity shall be expressed in terms of: }\end{array}$ \\
\hline $\begin{array}{l}\text { (a) solid, semisolid, viscous, or a mixture of solid } \\
\text { and liquid }\end{array}$ & weight or mass \\
\hline (b) liquid & fluid volume measure \\
\hline (c) dry & dry measure \\
\hline (d) or labeled by linear measure or area & linear measure or area \\
\hline (e) or labeled by numerical units (count) & numerical count \\
\hline
\end{tabular}

However, if there exists a firmly established general consumer usage and trade custom with respect to the terms used in expressing a declaration of quantity of a particular commodity, such a declaration of quantity may be expressed in its traditional terms, provided such traditional declaration gives accurate and adequate information as to the quantity of the commodity. Any net content statement that does not permit price and quantity comparisons is forbidden.

(Amended 1989 and 2015)

\subsubsection{Combination Declaration.}

(a) A declaration of quantity in terms of weight or volume shall be combined with appropriate declarations of the measure, count, and size of the individual units unless a declaration of weight alone is fully informative.

(b) A declaration of quantity in terms of measure shall be combined with appropriate declarations of the weight, volume, count, and size of the individual units unless a declaration of measure alone is fully informative.

(c) A declaration of quantity in terms of count shall be combined with appropriate declarations of the weight, volume, measure, and size of the individual units unless a declaration of count alone is fully informative.

(Added 1971)

6.5. SI Units: Mass, Measure. ${ }^{[\text {see Section 6.3. NOTE] }}$ - A declaration of quantity shall be expressed in terms of Table 6.5. SI Units: Mass, Measure, and the requirements in 6.5.(f), (g), and (h): 


\begin{tabular}{|c|c|}
\hline \multicolumn{2}{|c|}{$\begin{array}{l}\text { Table } 6.5 \text {. } \\
\text { SI Units: Mass, Measure }\end{array}$} \\
\hline If a declaration of quantity is in units of: & The units shall be in: \\
\hline (a) mass & kilogram, gram, or milligram \\
\hline (b) liquid measure & $\begin{array}{l}\text { liter or milliliter and shall express the volume at } \\
20^{\circ} \mathrm{C}^{*} \text {, except for: } \\
\text { (1) petroleum products or distilled spirits for } \\
\text { which the declaration shall express the } \\
\text { volume at } 15.6^{\circ} \mathrm{C} \text {; } \\
\text { (2) a commodity that is normally sold and } \\
\text { consumed while frozen for which the } \\
\text { declaration shall express the volume at the } \\
\text { frozen temperature; and } \\
\text { (3) malt (beer) beverages that must be } \\
\text { maintained in the refrigerated state for which } \\
\text { the declaration shall express the volume at } \\
4{ }^{\circ} \mathrm{C} \text {. } \\
\text { (4) refrigerated food (e.g., milk and dairy } \\
\text { products labeled "keep refrigerated") for } \\
\text { which the declaration shall express the } \\
\text { volume at } 4{ }^{\circ} \mathrm{C} \text {. } \\
\text { *Other liquids and wine (e.g., for immediate } \\
\text { consumption that do not require, but may be } \\
\text { refrigerated [shelf stable] such as soft drinks, } \\
\text { bottled water) at } 20^{\circ} \mathrm{C} \text {. }\end{array}$ \\
\hline (c) linear measure & meter, centimeter, or millimeter \\
\hline (d) area measure & $\begin{array}{l}\text { square meter, square decimeter, square centimeter, } \\
\text { or square millimeter }\end{array}$ \\
\hline (e) volume other than liquid measure & $\begin{array}{l}\text { liter or milliliter, except that units cubic meter and } \\
\text { cubic centimeter shall be used only when specifi- } \\
\text { cally designated as a method of sale }\end{array}$ \\
\hline (f) Rule of 1000 . & $\begin{array}{l}\text { The selected multiple or submultiple prefixes for SI } \\
\text { units shall result in numerical values between } 1 \text { and } \\
\text { 1000. This rule allows centimeters or millimeters } \\
\text { to be used where a length declaration is less than } \\
100 \text { centimeters. } \\
\text { Examples: } \\
500 \mathrm{~g} \text {, not } 0.5 \mathrm{~kg} \\
1.96 \mathrm{~kg} \text {, not } 1960 \mathrm{~g} \\
750 \mathrm{~mL} \text {, not } 0.75 \mathrm{~L} \\
750 \mathrm{~mm} \text { or } 75 \mathrm{~cm} \text {, not } 0.75 \mathrm{~m} \\
\text { (Added } 1993 \text { ) }\end{array}$ \\
\hline
\end{tabular}


A. Uniform Packaging and Labeling Regulation

\begin{tabular}{|l|l|}
\hline (g) SI declarations should be shown in three digits & $\begin{array}{l}\text { Except where the quantity is below } 100 \text { grams, } \\
\text { milliliters, centimeters, square centimeters, or cubic } \\
\text { centimeters, where it may be shown in two digits. } \\
\text { In either case, any final zero appearing to the right } \\
\text { of the decimal point need not be shown; and } \\
\text { (Added 1993) }\end{array}$ \\
\hline (h) The declaration of net quantity of contents shall not \\
be expressed in mixed units. \\
$\begin{array}{l}\text { Example: } \\
1.5 \mathrm{~kg}, \text { not } 1 \mathrm{~kg} 500 \mathrm{~g} \\
\text { (Added 1993) }\end{array}$ \\
\hline
\end{tabular}

(Amended 2015)

6.5.1. Symbols. - Any of the following symbols for SI units, and none other, may be employed in the quantity statement on a package of commodity:

\begin{tabular}{|l|c||l|c||}
\hline \multicolumn{1}{|c|}{ Unit } & \multicolumn{1}{c|}{ Symbol } & \multicolumn{1}{c|}{ Unit } & Symbol \\
\hline \hline centimeter & $\mathrm{cm}$ & cubic meter & $\mathrm{m}^{3}$ \\
\hline cubic centimeter & $\mathrm{cm}^{3}$ & kilogram & $\mathrm{kg}$ \\
\hline meter & $\mathrm{m}$ & gram & $\mathrm{g}$ \\
\hline milligram & $\mathrm{mg}$ & millimeter & $\mathrm{mm}$ \\
\hline liter & $\mathrm{L}$ or 1 & square meter & $\mathrm{m}^{2}$ \\
\hline milliliter & $\mathrm{mL}$ or $\mathrm{ml}$ & cubic decimeter & $\mathrm{dm}^{3}$ \\
\hline square centimeter & $\mathrm{cm}^{2}$ & square decimeter & $\mathrm{dm}^{2}$ \\
\hline micrometer & $\mu \mathrm{m}$ & microgram & $\mu \mathrm{g} \mathrm{or} \mathrm{mcg}$ \\
\hline
\end{tabular}

(a) Symbols [see Section 6.5.1. NOTE], except for liter, are not capitalized unless the unit is derived from a proper name. Periods shall not be used after the symbol. Symbols shall always be written in the singular form. Adding "s" to an SI symbol to express the plural of the symbol is prohibited.

(b) The "L" symbol and the "mL" symbol are preferred; however, the "l" symbol for liter and "ml" symbol for milliliter are permitted.

(Amended 1980 and 1993)

Section 6.5.1. NOTE: The "e" mark shall not be considered to be a qualifying word or phrase and may be used as part of the statement of the net quantity of contents where warranted. When used, the " $e$ " mark shall be at least $3 \mathrm{~mm}$ (approximately $1 / 8$ in) in height. The term " $e$ " mark refers to the symbol " $e$ " used in connection with the quantity declarations on labels of some consumer commodities marketed primarily in the European Union (EU) and South Africa. The " $e$ " mark constitutes a representation by the packer or importer that the package to which it is applied has been filled in accordance with the average system of quantity specified by the EU. The average system is a method of declaring package fill in the EU and other countries of the world, including the United States.

(Added 1993)

\subsubsection{Fractions and Prefixes.}

(a) Fractions: An SI statement in a declaration of net quantity of contents of any consumer commodity may contain only decimal fractions.

(b) Prefixes: The following chart indicates SI prefixes that may be used on a broad range of consumer commodity labels to form multiples and submultiples of SI units: 


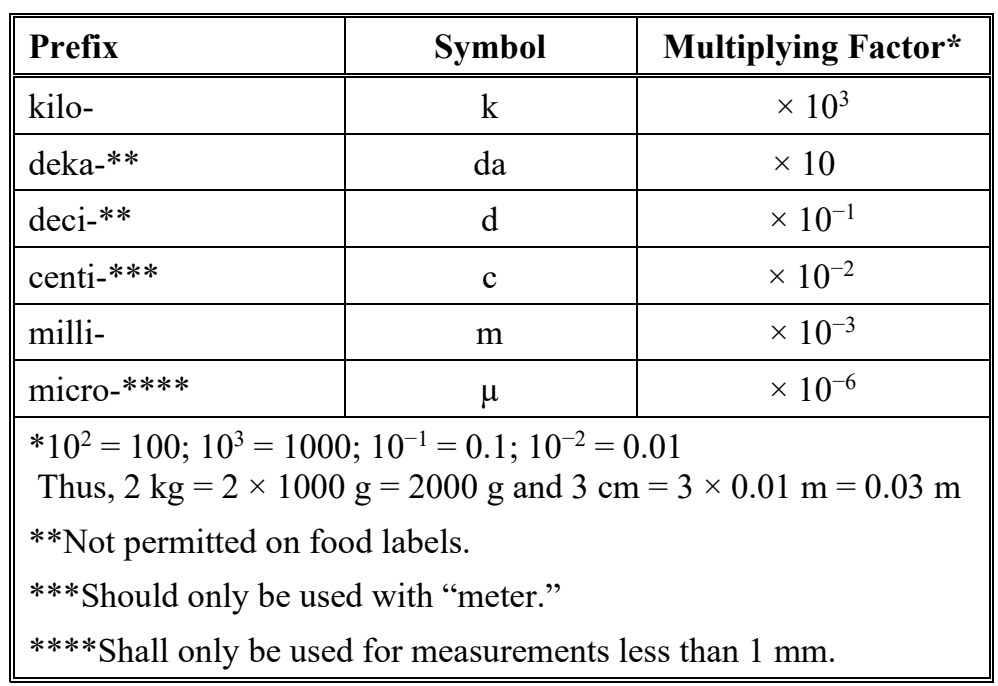

(Amended 1993)

\subsection{Prescribed Units, SI. [see Section 6.1. NOTE]}

6.6.1. Less than 1 Meter, 1 Square Meter, 1 Kilogram, 1 Cubic Meter, or 1 Liter. - The declaration of quantity shall be expressed as follows:

(a) length measure of less than 1 meter: in centimeters or millimeters; (Amended 1979)

(b) area measure of less than $1 \mathrm{~m}^{2}$ : in square decimeters and decimal fractions of a square decimeter or in square centimeters and decimal fractions of a square centimeter;

(c) mass of less than $1 \mathrm{~kg}$ : in grams and decimal fractions of a gram, but if less than $1 \mathrm{~g}$, then in milligrams;

(d) liquid or dry measure of less than $1 \mathrm{~L}$ : in milliliters; and

(e) cubic measure less than $1 \mathrm{~m}^{3}$ : in cubic centimeters or cubic decimeters (liters); (Added 1993)

provided the quantity declaration appearing on a random mass package may be expressed in units of decimal fractions of the largest appropriate unit, the fraction being carried out to not more than three decimal places. (Amended 1980 and 1993)

6.6.2. One Meter, 1 Square Meter, 1 Kilogram, 1 Liter, 1 Cubic Meter, or More. - In the case of:

(a) length measure of $1 \mathrm{~m}$ or more: in meters and decimal fractions to not more than three places;

(b) area measure of $1 \mathrm{~m}^{2}$ or more: in square meters and decimal fractions to not more than three places;

(c) mass of $1 \mathrm{~kg}$ or more: in kilograms and decimal fractions to not more than three places;

(d) liquid or dry measure of $1 \mathrm{~L}$ or more: in liters and decimal fractions to not more than three places; and (Added 1986) (Amended 1993)

(e) cubic measure of $1 \mathrm{~m}^{3}$ or more: in cubic meters and decimal fractions to not more than three places. (Added 1993) 
A. Uniform Packaging and Labeling Regulation

6.7. U.S. Customary Units: Weight, Measure. - A declaration of quantity shall be expressed in terms of Table 6.7. U.S. Customary Units: Weight, Measure:

Table 6.7.

U.S. Customary Units: Weight, Measure

\begin{tabular}{||l|l|}
\hline If a declaration of quantity is in units of: & The unit shall be in: \\
\hline (a) weight & avoirdupois pound or ounce \\
\hline (b) liquid measure & $\begin{array}{l}\text { U.S. gallon of } 231 \mathrm{in}^{3} \text { or liquid quart, liquid pint, or } \\
\text { fluid-ounce subdivisions of the gallon and shall express } \\
\text { the volume at } 68^{\circ} \mathrm{F}^{*}, \text { except in the case of: }\end{array}$ \\
\hline
\end{tabular}

(1) petroleum products or distilled spirits for which the declaration shall express the volume at $60^{\circ} \mathrm{F}$;

(2) a commodity that is normally sold and consumed while frozen for which the declaration shall express the volume at the frozen temperature; and

(3) malt (beer) beverages that must be maintained in the refrigerated state for which the declaration shall express the volume at $39.1^{\circ} \mathrm{F}$; and

(4) refrigerated food (e.g., milk and dairy products labeled "keep refrigerated") for which the declaration shall be expressed at $40^{\circ} \mathrm{F}$.

*Other liquids and wine (e.g., for immediate consumption that do not require, but may be refrigerated [shelf stable] such as soft drinks, bottled water) at $68^{\circ} \mathrm{F}$.

\begin{tabular}{|l|l|}
\hline (c) linear measure & yard, foot, or inch \\
\hline (d) area measure & square yard, square foot, or square inch \\
\hline (e) volume measure & cubic yard, cubic foot, or cubic inch \\
\hline (f) dry measure & $\begin{array}{l}\text { U.S. bushel of } 2150.42 \mathrm{in}^{3} \text {, or peck, dry quart, and dry } \\
\text { pint subdivisions of the bushel }\end{array}$ \\
\hline
\end{tabular}

(Amended 2015)

6.7.1. Symbols and Abbreviations. - Any of the following symbols and abbreviations, and none other, shall be employed in the quantity statement on a package of commodity:

\begin{tabular}{|c||c||c|c||}
\hline Symbol & Abbreviation & Symbol & Abbreviation \\
\hline \hline avoirdupois & $\mathrm{avdp}$ & ounce & $\mathrm{oz}$ \\
\hline piece & $\mathrm{pc}$ & count & $\mathrm{ct}$ \\
\hline pint & $\mathrm{pt}$ & cubic & $\mathrm{cu}$ \\
\hline pound & $\mathrm{lb}$ & each & $\mathrm{ea}$ \\
\hline feet or foot & $\mathrm{ft}$ & quart & $\mathrm{qt}$ \\
\hline fluid & $\mathrm{fl}$ & square & $\mathrm{sq}$ \\
\hline gallon & $\mathrm{gal}$ & weight & $\mathrm{wt}$ \\
\hline
\end{tabular}




\begin{tabular}{|c||c||c|c|}
\hline Symbol & Abbreviation & Symbol & Abbreviation \\
\hline \hline inch & in & yard & yd \\
\hline liquid & liq & drained & $\mathrm{dr}$ \\
\hline diameter & dia & \multicolumn{2}{|}{} \\
\hline
\end{tabular}

A period should not be used after the abbreviation. Abbreviations should be written in singular form; and "s" should not be added to express the plural. (For example, "oz" is the symbol for both "ounce" and "ounces.") Both upper and lowercase letters and exponents are acceptable.

(Amendment effective December 17, 2017)

(Added 1974) (Amended 1980, 1990, 1993, and 2016)

6.7.2. Units of Two or More Meanings. - When the term "ounce" is employed in a declaration of liquid quantity, the declaration shall identify the particular meaning of the term by the use of the term "fluid;" however, such distinction may be omitted when, by association of terms (for example, as in "1 pint 4 ounces"), the proper meaning is obvious. Whenever the declaration of quantity is in terms of the dry pint or dry quart, the declaration shall include the word "dry."

(Amended 1982)

\subsection{Prescribed Units, U.S. Customary System.}

6.8.1. Less than 1 foot, 1 square foot, 1 pound, or 1 pint. - The declaration of quantity shall be expressed in the following terms:

(a) in the case of length measure of less than $1 \mathrm{ft}$, in inches and fractions of inches;

(b) in the case of area measure of less than $1 \mathrm{ft}^{2}$, in square inches and fractions of square inches;

(c) in the case of weight of less than $1 \mathrm{lb}$, in ounces and fractions of ounces; and

(d) in the case of liquid measure of less than $1 \mathrm{pt}$, in fluid ounces and fractions of fluid ounces, provided, the quantity declaration appearing on a random package may be expressed in terms of decimal fractions of the largest appropriate unit, the fraction being carried out to not more than three decimal places.

(Amended 1984)

6.8.2. One Foot, 1 Square Foot, 1 Pound, 1 Pint, 1 Gallon, or More. - The declaration of quantity shall be expressed in the following terms (see Section 6.2. Largest Whole Unit and Section 6.11. Fractions):

(a) Linear Measure. - If $1 \mathrm{ft}$ or more, expressed in terms of the largest whole unit (a yard or a foot) with any remainder expressed in inches and fractions of the inch or in fractions of the foot or yard, except that it shall be optional to include a statement of length in terms of inches.

(b) Area Measure.

(1) If $1 \mathrm{ft}^{2}$ or more, but less than $4 \mathrm{ft}^{2}$, expressed in square feet with any remainder expressed in square inches and fractions of a square inch or in fractions of a square foot; and

(2) If $4 \mathrm{ft}^{2}$ or more, expressed in terms of the largest whole unit (e.g., square yards or square feet) with any remainder expressed in square inches and fractions of a square inch or in fractions of the square foot or square yard.

(c) Weight. - If $1 \mathrm{lb}$ or more, expressed in terms of the largest whole unit with any remainder expressed in ounces and fractions of an ounce or in fractions of the pound. 


\section{(d) Liquid Volume.}

(1) If 1 pt or more, but less than 1 gal, expressed in the largest whole unit (quarts, quarts and pints, or pints, as appropriate) with any remainder expressed in fluid ounces or fractions of the pint or quart, except that 2 qt may be declared as $1 / 2$ gal, and it shall be optional to include an additional expression of net quantity in fluid ounces; or

(2) If 1 gal or more, expressed in terms of the largest whole unit (gallons followed by fractions of a gallon or by the next smaller whole unit or units [for example, quarts and pints]) with any remainder expressed in fluid ounces or fractions of the pint or quart, except that it shall be optional to include an additional expression of net quantity in fluid ounces.

(e) Dry Measure. - If 1 dry pt or more, expressed in terms of the largest whole unit with the remainder expressed in fractions of a dry pint, dry quart, peck, or bushel, provided the quantity declaration on a random package may be expressed in decimal fractions of the largest appropriate unit carried out to not more than three decimal places.

(Amended 1993)

6.9. Bi-dimensional Commodities. - For bi-dimensional commodities (including roll-type commodities) the quantity declaration shall be expressed in both SI and U.S. customary units of measurement as follows:

(a) if the area is less than $929 \mathrm{~cm}^{2}\left(1 \mathrm{ft}^{2}\right)$, in terms of length and width (expressed in the largest whole unit for SI and in linear inches and fractions of linear inches for U.S. customary);

\section{Example:}

$20.3 \mathrm{~cm} \times 25.4 \mathrm{~cm}(8 \mathrm{in} \times 10 \mathrm{in})$

(b) if the area is at least $929 \mathrm{~cm}^{2}\left(1 \mathrm{ft}^{2}\right)$, but less than $37.1 \mathrm{dm}^{2}\left(4 \mathrm{ft}^{2}\right)$, in terms of area (expressed in the largest whole unit for SI and in square inches for U.S. customary), followed by a declaration of the length and width in terms of the largest whole unit:

\section{Example:}

$31 \mathrm{dm}^{2}(49 \mathrm{~cm} \times 64 \mathrm{~cm}) 3.36 \mathrm{ft}^{2}(1.6 \mathrm{ft} \times 2.1 \mathrm{ft})$, provided:

(1) bi-dimensional commodities having a width of $10 \mathrm{~cm}$ (4 in) or less, the declaration of net quantity shall be expressed in terms of width and length in linear measure; no declaration of area is required;

(2) an U.S. customary dimension of less than $2 \mathrm{ft}$ may be stated in inches;

(3) commodities consisting of usable individual units (e.g., paper napkins) require a declaration of unit area but not a declaration of total area of all such units (except roll-type commodities with individual usable units created by perforations, for which see Section 6.10. Count: Ply); and

(4) U.S. customary declarations may include after the statement of the linear dimensions in the largest whole unit a parenthetical declaration of the same dimensions in inches.

\section{Example:}

$25 \mathrm{ft}^{2}(12$ in $\times 8.33 \mathrm{yd})(12$ in $\times 300$ in $)$

(c) if the area is $37.1 \mathrm{dm}^{2}\left(4 \mathrm{ft}^{2}\right)$ or more, in terms of area (expressed in the largest whole unit for SI and in square feet for U.S. customary), followed by a declaration of the length and width, in terms of the largest whole unit, provided:

(1) no declaration of area is required for a bi-dimensional commodity with a width of $10 \mathrm{~cm}$ (4 in) or less; 
(2) bi-dimensional commodities with a width of $10 \mathrm{~cm}$ (4 in) or less, the U.S. customary statement of width shall be expressed in terms of linear inches and fractions thereof, and length shall be expressed in the largest whole unit (yard or foot) with any remainder in terms of fractions of the yard or foot, except that it shall be optional to express the length in the largest whole unit followed by a statement of length in inches or to express the length in inches followed by a statement of length in the largest whole unit;

\section{Examples:}

$5 \mathrm{~cm} \times 9.14 \mathrm{~m}(2$ in $\times 10 \mathrm{yd})$

$5 \mathrm{~cm} \times 9.14 \mathrm{~m}(2 \mathrm{in} \times 10 \mathrm{yd})(360 \mathrm{in})$

$5 \mathrm{~cm} \times 9.14 \mathrm{~m}(2 \mathrm{in} \times 360 \mathrm{in})(10 \mathrm{yd})$

(3) an U.S. customary dimension of less than $2 \mathrm{ft}$ may be stated in inches; and

(d) no declaration of area is required for commodities for which the length and width measurements are critical in terms of end use (such as wallpaper border) if such commodities clearly present the length and width measurements on the label.

6.10. Count: Ply. - If the commodity is in individually usable units of one or more components or plies, the quantity declaration shall, in addition to complying with other applicable quantity declaration requirements of this regulation, include the number of plies and total number of usable units.

Roll type commodities, when perforated so as to identify individual usable units, shall not be deemed to be made up of usable units; however, such roll type commodities shall be labeled in terms of:

(a) total area measurement;

(b) number of plies;

(c) count of usable units; and

(d) dimensions of a single usable unit.

(Amended 1988)

\subsection{Fractions.}

(a) U.S. Customary: An U.S. customary unit statement of net quantity of contents of any consumer commodity may contain common or decimal fractions. A common fraction shall be in terms of halves, quarters, eighths, sixteenths, or thirty-seconds, except that:

(1) if there exists a firmly established general consumer usage and trade custom of employing different common fractions in the net quantity declaration of a particular commodity, they may be employed; and

(2) if linear measurements are required in terms of yards or feet, common fractions may be in terms of thirds.

(b) Common fractions: A common fraction shall be reduced to its lowest term.

\section{Example:}

$2 / 4$ becomes $1 / 2$

(c) Decimal fractions: A decimal fraction shall not be carried out to more than three places.

(Amended 1986 and 1993)

6.12. Supplementary Quantity Declarations. - The required quantity declaration may be supplemented by one or more declarations of weight, measure, or count, such declaration appearing other than on a principal display panel. Such supplemental statement of quantity of contents shall not include any term qualifying a unit of weight, measure, 
or count that tends to exaggerate the amount of commodity contained in the package (e.g., "giant" quart, "larger" liter, "full" gallon, "when packed," "minimum," [see Section 6.12. NOTE] or words of similar import).

(Amended 2018)

Section 6.12. NOTE: Packages of products subject to the labeling requirements under the EPA, Federal Insecticide, Fungicide, and Rodenticide Act (FIRFA) under 40 CFR 156.10 are permitted to display the term "minimum" in conjunction with the net quantity of contents declaration. The packer may choose to fill the packages under the minimum or average systems of fill. However, if the minimum system is declared, variations above minimum quantity is permissible only to the extent that it represents deviation unavoidable in good manufacturing practice and no variation below the stated minimum quantity is permitted.

(Added 2018)

6.13. Rounding. ${ }^{[\text {see Section 6.13. NOTE] }}$ - In all conversions for the purpose of showing an equivalent SI or U.S. customary quantity to a rounded U.S. customary or SI quantity, or in calculated values to be declared in the net quantity statement, the number of significant digits retained must be such that accuracy is neither sacrificed nor exaggerated. Conversions, the proper use of significant digits, and rounding must be based on the packer's knowledge of the accuracy of the original measurement that is being converted. In no case shall rounded net contents declarations overstate a quantity; the packer may round the converted values down to avoid overstating the net contents.

(Amended 1993)

Section 6.13. NOTE: When as a result of rounding SI or U.S. customary declarations the resulting declarations are not exact, the largest declaration (either metric or U.S. customary) will be used for enforcement purposes to determine whether a package contains at least the declared amount of the product.

6.14. Qualification of Declaration Prohibited. - In no case shall any declaration of quantity be qualified by the addition of the words "when packed," "minimum," [see Section 6.12. NOTE] or "not less than" or any words of similar import (e.g., "approximately"), nor shall any unit of weight, measure, or count be qualified by any term (such as "jumbo," "giant," "full," or the like) that tends to exaggerate the amount of commodity.

(Amended 1998 and 2018)

6.15. Character of Declaration: Average. - The average quantity of contents in the packages of a particular lot, shipment, or delivery shall at least equal the declared quantity, and no unreasonable shortage in any package shall be permitted even though overages in other packages in the same shipment, delivery, or lot compensate for such shortage.

(Added 1981)

6.16. Random Packages. - A random weight package must bear a label conspicuously declaring:

(a) the net weight;

(b) unit price; and

(c) the total price.

In the case of a random package packed at one place for subsequent sale at another, neither the price per unit of weight nor the total selling price need appear on the package, provided the package label includes both such prices at the time it is offered or exposed for sale at retail.

(Added 1999)

\section{Section 7. Declaration of Quantity: Non-Consumer Packages}

7.1. General. - The SI and U.S. customary systems of weights and measures are recognized as proper systems to be used in the declaration of quantity. Units of both systems may be combined in a dual declaration of quantity. "[see Section 7.1. NOTE] (See Section 6.3. Net Quantity, and Section 6.3.1. Use of "Net Mass" or "Net Weight.") 
Section 7.1. NOTE: Although non-consumer packages under this Regulation may bear SI declarations only, this Regulation should not be construed to supersede any labeling requirement specified in federal law.

7.2. Location. - A non-consumer package shall bear on the outside a declaration of the net quantity of contents. Such declaration shall be in terms of the largest whole unit (see Section 6.2. Largest Whole Unit; for small packages, see Section 11.16. Small Packages).

7.3. Terms: Weight, Liquid Measure, Dry Measure, or Count. - The declaration of the quantity of a particular commodity shall be expressed in terms of liquid measure if the commodity is liquid, in terms of dry measure if the commodity is dry, in terms of weight if the commodity is solid, semisolid, viscous, or a mixture of solid and liquid, or in terms of numerical count. However, if there exists a firmly established general consumer usage and trade custom with respect to the terms used in expressing a declaration of quantity of a particular commodity, such declaration of quantity may be expressed in its traditional terms if such traditional declaration gives accurate and adequate information as to the quantity of the commodity.

7.4. SI Units: Mass, Measure. - A declaration of quantity:

(a) in units of mass shall be in terms of the kilogram, gram, or milligram;

(b) in units of liquid measure shall be in terms of the liter or milliliter, and shall express the volume at $20^{\circ} \mathrm{C}$, except in the case of petroleum products or distilled spirits, for which the declaration shall express the volume at $15.6^{\circ} \mathrm{C}$, and except also in the case of a commodity that is normally sold and consumed while frozen, for which the declaration shall express the volume at the frozen temperature, and except also in the case of malt beverages or a commodity that is normally sold in the refrigerated state, for which the declaration shall express the volume at $4{ }^{\circ} \mathrm{C}$;

(Amended 1985)

(c) in units of linear measure shall be in terms of the meter, centimeter, or millimeter;

(d) in units of area measure shall be in terms of the square meter, square decimeter, square centimeter or square millimeter;

(e) in units of volume other than liquid measure shall be in terms of the liter and milliliter, except that the terms cubic meter, cubic decimeter, and cubic centimeter will be used only when specifically designated as a method of sale;

(f) Rule of 1000. - The selected multiple or submultiple prefixes for SI units shall result in numerical values between 1 and 1000. This rule allows centimeters or millimeters to be used where a length declaration is less than 100 centimeters;

\section{Examples:}

$500 \mathrm{~g}$, not $0.5 \mathrm{~kg}$

$1.96 \mathrm{~kg}$, not $1960 \mathrm{~g}$

$750 \mathrm{~mL}$, not $0.75 \mathrm{~L}$

$750 \mathrm{~mm}$ or $75 \mathrm{~cm}$, not $0.75 \mathrm{~m}$

(Added 1993)

(g) SI declarations should be shown in three digits except where the quantity is below 100 grams, milliliters, centimeters, square centimeters, or cubic centimeters where it can be shown in two digits. In either case, any final zero appearing to the right of the decimal point need not be shown; and

(Added 1993) 
A. Uniform Packaging and Labeling Regulation

(h) the declaration of net quantity of contents shall not be expressed in mixed units.

\section{Example:}

$1.5 \mathrm{~kg}$, not $1 \mathrm{~kg} 500 \mathrm{~g}$

7.4.1. Symbols. - Only those symbols as detailed in Section 6.5.1. Symbols, and none other, may be employed in the quantity statement on a package of commodity.

\subsection{U.S. Customary Units: Weight, Measure. - A declaration of quantity:}

(a) in units of weight shall be in terms of the avoirdupois pound or ounce;

(b) in units of liquid measure shall be in terms of the United States gallon of 231 cubic inches or liquid quart, liquid pint, or fluid ounce subdivisions of the gallon and shall express the volume at $68^{\circ} \mathrm{F}$, except in the case of petroleum products or distilled spirits, for which the declaration shall express the volume at $60^{\circ} \mathrm{F}$, and except also in the case of a commodity that is normally sold and consumed while frozen, for which the declaration shall express the volume at the frozen temperature, and except also in the case of a commodity that is normally sold in the refrigerated state, for which the declaration shall express the volume at $40^{\circ} \mathrm{F}$, and except also in the case of malt beverages, for which the declaration shall express the volume at $39.1^{\circ} \mathrm{F}$;

(Amended 1985)

(c) in units of linear measure shall be in terms of the yard, foot, or inch;

(d) in units of area measure shall be in terms of the square yard, square foot, or square inch;

(e) in units of volume measure shall be in terms of the cubic yard, cubic foot, or cubic inch; and

(f) in units of dry measure, shall be in terms of the United States bushel of $2150.42 \mathrm{in}^{3}$, or peck, dry quart, and dry pint subdivisions of the bushel.

7.5.1. Symbols and Abbreviations. - Any generally accepted symbol and abbreviation of a unit name may be employed in the quantity statement on a package of commodity. (For commonly accepted symbols and abbreviations, see Section 6.7.1. Symbols and Abbreviations.)

7.6. Character of Declaration: Average. - The average quantity of contents in the packages of a particular lot, shipment, or delivery shall at least equal the declared quantity, and no unreasonable shortage in any package shall be permitted, even though overages in other packages in the same shipment, delivery, or lot compensate for such shortage.

\section{Section 8. Prominence and Placement: Consumer Packages}

8.1. General. - All information required to appear on a consumer package shall appear thereon in the English language and shall be prominent, definite, plain, and conspicuous as to size and style of letters and numbers and as to color of letters and numbers in contrast to color of background. Any required information that is either in hand lettering or hand script shall be entirely clear and equal to printing in legibility.

8.1.1. Location. - The declaration or declarations of quantity of the contents of a package shall appear in the bottom $30 \%$ of the principal display panel or panels. For cylindrical containers, see also Section 10.7. Cylindrical Containers for additional requirements. For small packages, see Section 11.16. Small Packages.

(Amended 1975)

8.1.2. Style of Type or Lettering. - The declaration or declarations of quantity shall be in such a style of type or lettering as to be boldly, clearly, and conspicuously presented with respect to other type, lettering, or graphic material on the package, except that a declaration of net quantity blown, formed, or molded on a glass or plastic surface is permissible when all label information is blown, formed, or molded on the surface. 
8.1.3. Color Contrast. - The declaration or declarations of quantity shall be in a color that contrasts conspicuously with its background, except that a declaration of net quantity blown, formed, or molded on a glass or plastic surface shall not be required to be presented in a contrasting color if no required label information is on the surface in a contrasting color.

8.1.4. Free Area. - The area surrounding the quantity declaration shall be free of printed information:

(a) above and below, by a space equal to at least the height of the lettering in the declaration; and

(b) to the left and right, by a space equal to twice the width of the letter " $\mathrm{N}$ " of the style and size of type used in the declaration.

8.1.5. Parallel Quantity Declaration. - The quantity declaration shall be presented in such a manner as to be generally parallel to the declaration of identity and to the base on which the package rests as it is designed to be displayed.

8.2. Calculation of Area of Principal Display Panel for Purposes of Type Size. - The area of the principal display panel shall be:

(a) in the case of a rectangular container, one entire side that properly can be considered the principal display panel, the product of the height times the width of that side;

For Figure 3, the area of the principal display panel is $20 \mathrm{~cm}(8 \mathrm{in}) \times 15 \mathrm{~cm}(6 \mathrm{in})=300 \mathrm{~cm}^{2}\left(48 \mathrm{in}^{2}\right)$.

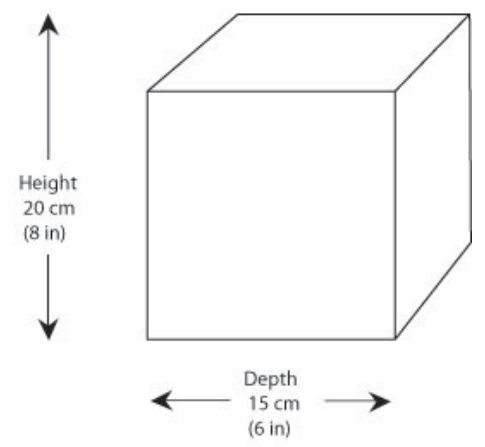

Figure 3. Calculation of the Area of the Principal Display Area of a Rectangular Container

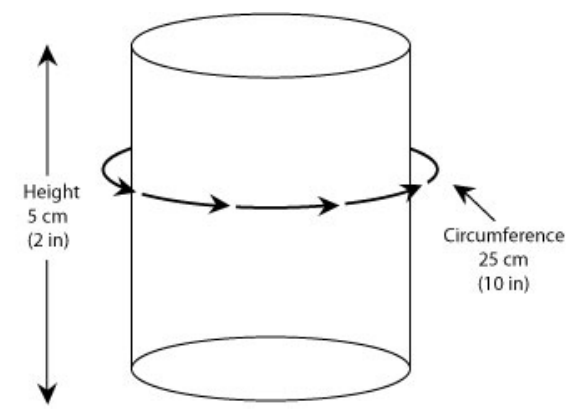

Figure 4. Calculation of the Area of the Principal Display Area of a Cylindrical Container

(b) in the case of a cylindrical or nearly cylindrical container, $40 \%$ of the product of the height of the container times the circumference;

For Figure 4. Calculation of the Area of the Principal Display Area of a Cylindrical Container, the area of the principal display panel is:

$25 \mathrm{~cm}(10$ in $) \times 5 \mathrm{~cm}(2 \mathrm{in})=125 \mathrm{~cm}\left(20 \mathrm{in}^{2}\right) \times 0.40=50 \mathrm{~cm}^{2}\left(8 \mathrm{in}^{2}\right)$

(see also Section 10.7. Cylindrical Containers).

The area of the principal display panel is the same in both examples. The declaration of net quantity of contents must be of the same height in both cases. It is not the size of the label that is used to determine the minimum type size of the quantity statement, but the size of the surface of the package exposed to view to the customer. The package on the right side of the figure has a spot label (see Section 2.12. Spot Label and Section 11.29. Spot Label); and 
(c) in the case of any other shaped container, $40 \%$ of the total surface of the container, unless such container presents an obvious principal display panel (e.g., the top of a triangular or circular package of cheese, or the top of a can of shoe polish), in which event the area shall consist of the entire such surface.

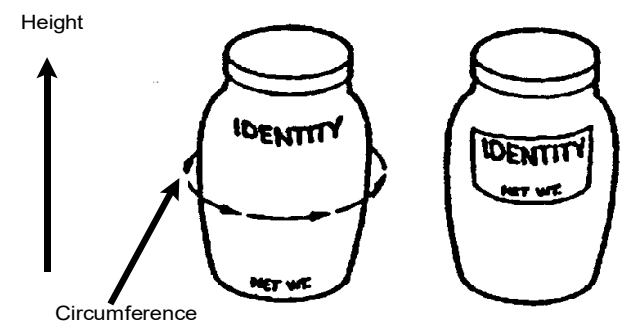

Figure 5. Other Shaped Containers.

Determination of the principal display panel shall exclude tops, bottoms, flanges at tops and bottoms of cans, and shoulders and necks of bottles or jars.

8.2.1. Minimum Height of Numbers and Letters. - The height of any letter or number in the required quantity declaration shall be not less than that shown in Table 1 with respect to the area of the panel, and the height of each number of a common fraction shall meet one-half the minimum height standards. When upper and lowercase or all lowercase letters are used, it is the lowercase "o" or its equivalent that shall meet the minimum height requirement. When upper and lowercase or all lowercase letters are used in SI symbols, it is the uppercase "L," lowercase "d," or their equivalent in the print or type that shall meet the minimum height requirement. However, no letter shall be less than $1.6 \mathrm{~mm}(1 / 16$ in) in height. Other letters and exponents must be presented in the same type style and in proportion to the type size used.

(Amended 1993)

8.2.2. Numbers and Letters: Proportion. - No number or letter shall be more than three times as high as it is wide.

Table 1. Minimum Height of Numbers and Letters

\begin{tabular}{|c|c|c|}
\hline $\begin{array}{c}\text { Area of } \\
\text { Principal Display Panel }\end{array}$ & $\begin{array}{l}\text { Minimum Height of } \\
\text { Numbers and Letters }\end{array}$ & $\begin{array}{c}\text { Minimum Height; Label Information } \\
\text { Blown, Formed, or Molded on Surface } \\
\text { of Container }\end{array}$ \\
\hline $\begin{array}{l}\leq 32 \mathrm{~cm}^{2} \\
\left(5 \mathrm{in}^{2}\right)\end{array}$ & $\begin{array}{l}1.6 \mathrm{~mm} \\
(1 / 16 \mathrm{in})\end{array}$ & $\begin{array}{l}3.2 \mathrm{~mm} \\
(1 / 8 \mathrm{in})\end{array}$ \\
\hline $\begin{array}{l}>32 \mathrm{~cm}^{2} \\
\left(5 \mathrm{in}^{2}\right) \leq 161 \mathrm{~cm}^{2}\left(25 \mathrm{in}^{2}\right)\end{array}$ & $\begin{array}{l}3.2 \mathrm{~mm} \\
(1 / 8 \mathrm{in})\end{array}$ & $\begin{array}{l}4.8 \mathrm{~mm} \\
(3 / 16 \mathrm{in})\end{array}$ \\
\hline $\begin{array}{l}>161 \mathrm{~cm}^{2} \\
\left(25 \mathrm{in}^{2}\right) \\
\leq 645 \mathrm{~cm}^{2} \\
\left(100 \mathrm{in}^{2}\right)\end{array}$ & $\begin{array}{l}4.8 \mathrm{~mm} \\
(3 / 16 \mathrm{in})\end{array}$ & $\begin{array}{l}6.4 \mathrm{~mm} \\
(1 / 4 \mathrm{in})\end{array}$ \\
\hline $\begin{array}{l}>645 \mathrm{~cm}^{2} \\
\left(100 \mathrm{in}^{2}\right) \leq 2581 \mathrm{~cm}^{2}\left(400 \mathrm{in}^{2}\right)\end{array}$ & $\begin{array}{l}6.4 \mathrm{~mm} \\
(1 / 4 \mathrm{in})\end{array}$ & $\begin{array}{l}7.9 \mathrm{~mm} \\
(5 / 16 \mathrm{in})\end{array}$ \\
\hline $\begin{array}{l}>2581 \mathrm{~cm}^{2} \\
\left(400 \mathrm{in}^{2}\right)\end{array}$ & $\begin{array}{l}12.7 \mathrm{~mm} \\
(1 / 2 \mathrm{in})\end{array}$ & $\begin{array}{l}14.3 \mathrm{~mm} \\
(9 / 16 \mathrm{in})\end{array}$ \\
\hline
\end{tabular}

Symbols: $\leq$ means less than or equal to; $<$ means less than; $>$ means greater than.

NOTE: The type size requirements specified in this table do not apply to the "e" mark [see Section 6.5.1. NOTE]. 


\section{Section 9. Prominence and Placement: Non-Consumer Packages}

9.1. General. - All information required to appear on a non-consumer package shall be definitely and clearly stated thereon in the English language. Any required information that is either in hand lettering or hand script shall be entirely clear and equal to printing in legibility.

\section{Section 10. Requirements: Specific Consumer Commodities, Non-Consumer Commodities, Packages, Containers}

(Title amended 1979)

10.1. Display Card Package. - For an individual package affixed to a display card, or for a commodity and display card together comprising a package, the type size of the quantity declaration is governed by the dimensions of the display card.

10.2. Eggs. - When cartons containing 12 eggs have been designed so as to permit division in half by the retail purchaser, the required quantity declaration shall be so positioned as to have its context destroyed when the carton is divided.

10.3. Aerosols and Other Pre-pressurized Containers Dispensing Product Under Pressure. - The declaration of quantity on an aerosol and on other pre-pressurized containers dispensing products under pressure shall disclose the net quantity of the commodity (including propellant, where applicable) in terms of weight that will be expelled when the instructions for use as shown on the container are followed.

(Amended 2014)

10.4. Multiunit Packages. [see Section 10.4. NOTE] - Any package containing more than one individual "commodity in package form" (see Section 2.1. Package) of the same commodity shall bear on the outside of the package a declaration of:

(a) the number of individual units;

(b) the quantity of each individual unit; and

(c) the total quantity of the contents of the multiunit package.

Example:

soap bars, 6 Bars, Net Wt $100 \mathrm{~g}(3.53 \mathrm{oz})$ each

total Net Wt $600 \mathrm{~g}(1.32 \mathrm{lb})$.

(Amended 1993)

(d) A multiunit package containing unlabeled individual packages which are not intended for retail sale separate from the multiunit package may contain, in lieu of the requirements of section (a), (b) and (c), a declaration of quantity of contents expressing the total quantity of the multiunit package without regard for inner packaging. For such multiunit packages, it shall be optional to include a statement of the number of individual packages when such a statement is not otherwise required by the regulations.

\section{Examples:}

Deodorant Cakes -

5 cakes, Net Wt 113 g (4 oz) each, Total Net Wt 566 g (1.25 lb); or

5 cakes, Total Net Wt $566 \mathrm{~g} \mathrm{(1} \mathrm{lb} 4 \mathrm{oz})$ 
Soap Packets -

10 packets, Net Wt $56.6 \mathrm{~g}(2 \mathrm{oz})$ each, Total Net Wt $566 \mathrm{~g}(1.25 \mathrm{lb})$; or Net Wt $566 \mathrm{~g}(1 \mathrm{lb} 4 \mathrm{oz})$; or 10 packets, Total Net Wt $566 \mathrm{~g}(1 \mathrm{lb} 4 \mathrm{oz})$

The term "total" or the phrase "total contents" may precede the quantity declaration.

(Amended 1993)

Section 10.4. NOTE: For foods, a "multiunit" package means a package containing two or more individually packaged units of the identical commodity in the same quantity, intended to be sold as part of the multiunit package but labeled to be individually sold in full compliance with this regulation. Open multiunit retail food packages under the authority of the FDA or the USDA that do not obscure the number of units or prevent examination of the labeling on each of the individual units are not required to declare the number of individual units or the total quantity of contents of the multiunit package if the labeling of each individual unit complies with requirements so that it is capable of being sold individually. (See also Section 11.11. Soft Drink Bottles and Section 11.12. Multiunit Soft-Drink Bottles.) (Added 1984)

10.5. Combination Packages. - A combination package is a package intended for retail sale, containing two or more individual packages or units of dissimilar commodities. The declaration of net quantity for a combination package shall contain an expression of weight, volume, measure, or count or a combination thereof, as appropriate, for each individual package or unit, provided the quantity statements for identical packages or units shall be combined. This section does not apply to food or other commodities subject to the Federal Food, Drug, and Cosmetic Act (21 USC).

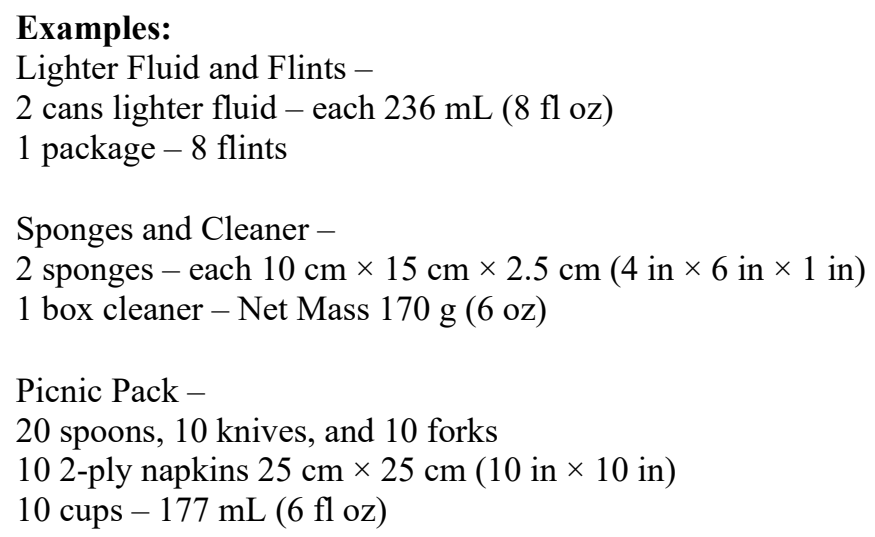

10.6. Variety Packages. - A variety package is a package intended for retail sale, containing two or more individual packages or units of similar but not identical commodities. Commodities that are generically the same but that differ in weight, measure, volume, appearance, or quality are considered similar but not identical. This section does not apply to foods or other commodities subject to the Federal Food, Drug, and Cosmetic Act (21 USC). The declaration of net quantity for a variety package will be expressed as follows:

(a) the number of units for each identical commodity followed by the weight, volume, or measure of that commodity;

(b) the total quantity by weight, volume, measure, and count, as appropriate, of the variety package. The statement of total quantity shall appear as the last item in the declaration of net quantity and shall not be of greater prominence than other terms used.

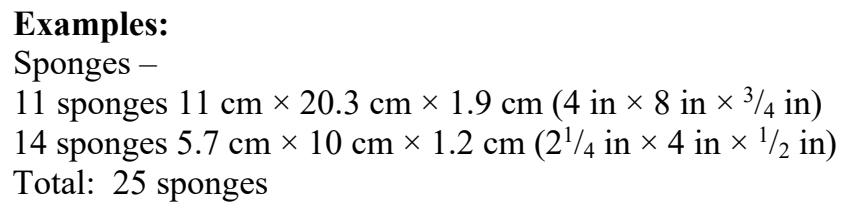




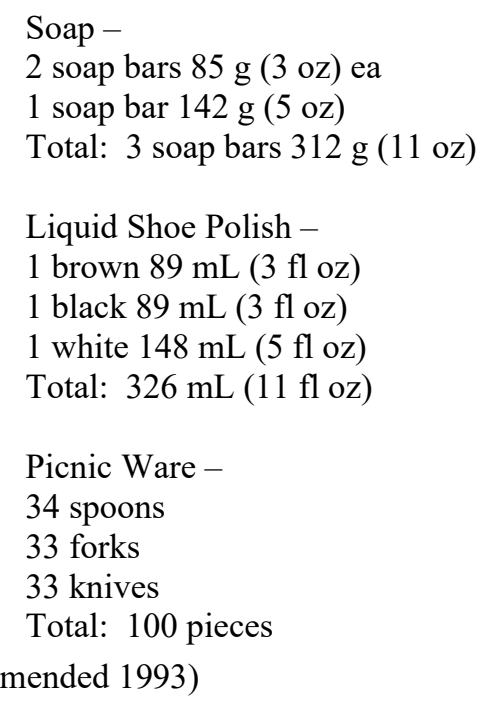

When individual units in a variety package are either packaged or labeled and are intended for retail sale as individual units, each unit shall be labeled in compliance with the applicable sections of this regulation.

10.7. Cylindrical Containers. - In the case of cylindrical or nearly cylindrical containers, information required to appear on the principal display panel shall appear within that $40 \%$ of the circumference which is most likely to be displayed, presented, shown, or examined under customary conditions of display for retail sale.

\subsection{Measurement of Container-Type Commodities, How Expressed.}

10.8.1. General. - Commodities designated and sold at retail to be used as containers for other materials or objects, such as bags, cups, boxes, and pans, shall be labeled with the declaration of net quantity as follows:

(a) For bag-type commodities, in terms of count followed by linear dimensions of the bag (whether packaged in a perforated roll or otherwise). The linear dimensions shall be expressed:

(1) in SI units: in millimeters or centimeters, except that a dimension of 1 meter or more will be expressed in meters with the remainder in terms of decimal fractions of the meter; and

(2) in U.S. customary units: in inches, except that a dimension of $2 \mathrm{ft}$ or more will be expressed in feet with any remainder in terms of inches or common or decimal fractions of the foot.

(b) When the unit bag is characterized by two dimensions because of the absence of a gusset, the width and length will be stated.

\section{Examples: \\ 25 bags, $12.7 \mathrm{~cm} \times 10 \mathrm{~cm}(5$ in $\times 4$ in $)$ or \\ 50 bags, $75 \mathrm{~cm} \times 1.2 \mathrm{~m}(2.5 \mathrm{ft} \times 3.9 \mathrm{ft})$}

(c) When the unit bag is gusseted, the dimensions will be expressed as width, depth, and length.

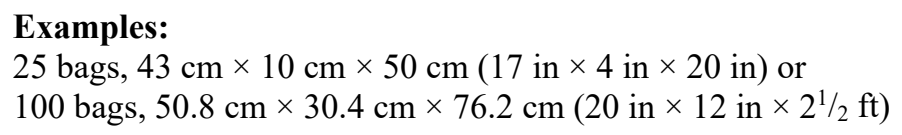

(d) For other square, oblong, rectangular, or similarly shaped containers, in terms of count followed by length, width, and depth, except depth need not be listed when less than $5 \mathrm{~cm}$ or 2 in. The linear dimensions shall be expressed as specified in Section 10.8.1.(a). 


\title{
Example:
}

bag-type commodities: 2 Pans, $20 \mathrm{~cm} \times 20 \mathrm{~cm}(8 \mathrm{in} \times 8$ in $)$

(e) For circular or other generally round-shaped containers, except cups and the like, in terms of count followed by diameter and depth, except depth need not be listed when less than $5 \mathrm{~cm}$ or 2 in.

\section{Example:}

4 pans, $20 \mathrm{~cm}(8 \mathrm{in})$ diameter $\times 10 \mathrm{~cm}(4$ in $)$

(f) Cups - Notwithstanding the above requirements, the net quantity statement for containers such as cups will be listed in terms of count and liquid capacity per unit.

\section{Example:}

24 cups, $177 \mathrm{~mL}$ (6 fl oz) capacity

10.8.2. Capacity. - When the functional use of the container is related by label references in standard terms of measure to the capability of holding a specific quantity of substance or class of substances such references shall be a part of the net quantity statement and shall specify capacity as follows:

(a) in SI units: in terms of volume for all containers and liners. The expressed capacity will be stated in terms of milliliters, except that a quantity of 1 liter or more shall be expressed in liters with the remainder in terms of decimal fractions of the liter; and

(b) in U.S. customary units:

(1) In terms of liquid measure for containers that are intended to be used for liquids, semisolids, viscous materials, or mixtures of solids and liquids. The expressed capacity will be stated in terms of the largest whole unit (gallon, quart, pint, fluid ounce) with any remainder in terms of common or decimal fractions of that unit.

\section{Example:}

Freezer Boxes -

4 Boxes, $946 \mathrm{~mL}$ capacity, $15 \mathrm{~cm} \times 15 \mathrm{~cm} \times 10 \mathrm{~cm}(1$ qt capacity, 6 in $\times 6$ in $\times 4$ in)

(2) In terms of dry measure for containers that are intended to be used for solids. The expressed capacity will be stated in terms of the largest whole unit (bushel, peck) with any remainder in terms of common or decimal fractions of that unit.

\section{Example: \\ Leaf Bags - \\ 8 bags, $211 \mathrm{~L}$ capacity, $1.21 \mathrm{~m} \times 1.52 \mathrm{~m}(6$ bu capacity, $4 \mathrm{ft} \times 5 \mathrm{ft})$}

(3) Where containers are used as liners for other more permanent containers, in the same terms as are normally used to express the capacity of the more permanent containers.

\author{
Example: \\ Garbage Can Liners - \\ 10 liners, $76.2 \mathrm{~cm} \times 93.9 \mathrm{~cm}$, fits up to $113 \mathrm{~L}$ cans $(2 \mathrm{ft} 6 \mathrm{in} \times 3 \mathrm{ft} 1 \mathrm{in}$, fits up to 30 gal cans)
}

10.8.3. Terms. - For purposes of this section, the use of the terms "capacity," "diameter," and "fluid" is optional. 


\subsection{Textile Products, Threads, and Yarns.}

10.9.1. Wearing Apparel. - Wearing apparel (including non-textile apparel and accessories such as leather goods and footwear) sold as single unit items, or if normally sold in pairs (such as hosiery, gloves, and shoes) sold as single unit pairs, shall be exempt from the requirements for net quantity statement by count, as required by Section 6.4. Terms: Weight, Liquid Measure, Dry Measure, or Count of this regulation.

10.9.2. Textiles. - Bed sheets, blankets, pillowcases, comforters, quilts, bedspreads, mattress covers and pads, afghans, throws, dresser and other furniture scarves, tablecloths and napkins, flags, curtains, drapes, dishtowels, dishcloths, towels, facecloths, utility cloths, bathmats, carpets and rugs, potholders, fixture and appliance covers, nonrectangular diapers, slipcovers, etc., shall be exempt from the requirements of Section 6.9. Bi-dimensional Commodities of this regulation, provided:

(a) The quantity statement for fitted sheets and mattress covers shall state, in centimeters and inches, the length and width of the mattress for which the item is designed and the size designation of the mattress if the item is intended to fit a mattress identified as "twin," "double," "queen," "king," "California king," etc.

\section{Example:}

double sheet for $137 \mathrm{~cm} \times 190 \mathrm{~cm}(54 \mathrm{in} \times 75$ in) mattress

(Amended 1987)

(b) The quantity statement for flat sheets shall state, in centimeters and inches, the length and width of the mattress for which the sheet is designed, followed in parentheses by a statement, in centimeters and inches, of the length and width of the finished sheet. The quantity statement shall also state the size designation of the mattress for which the sheet is designed, such as "twin," "double," "queen," "king," "California king," if the item is intended to fit such a mattress.

\section{Example:}

twin flat sheet for $99 \mathrm{~cm} \times 190 \mathrm{~cm}(39$ in $\times 75$ in) mattress, $167 \mathrm{~cm} \times 244 \mathrm{~cm}(66 \mathrm{in} \times 96$ in) finished size

(Amended 1987)

(c) The quantity statement for pillowcases shall state, in centimeters and inches, the length and width of the pillow for which the pillowcase is designed, followed in parentheses by a statement, in centimeters and inches of the length and width of the finished pillowcase. The quantity statement for pillowcases shall also state the size designation of the pillow for which the pillowcase is designed, for example, "youth," "standard," "queen," etc., if the item is intended to fit such pillows.

\section{Example:}

standard pillowcase for $51 \mathrm{~cm} \times 66 \mathrm{~cm}(20$ in $\times 26$ in $)$ pillow, $51 \mathrm{~cm} \times 76 \mathrm{~cm}(20$ in $\times 30$ in $)$ in finished size

(Amended 1977 and 1987)

(d) The quantity statement for blankets, comforters, quilts, bedspreads, mattress pads, afghans, and throws shall state, in centimeters and inches, the length and width of the finished item. The quantity statement shall also state the length of any ornamentation and the size designation of the mattress for which the item is designed, if it is intended to fit, for example, a "twin," "double," "queen," "king," "California king," etc., mattress.

(Amended 1988)

(e) The quantity statement for tablecloths and napkins shall state, in centimeters and inches, the length and width of the finished item. The quantity statement also may state parenthetically, in centimeters and inches, the length and width of the item before hemming and be properly identified as such. 
A. Uniform Packaging and Labeling Regulation

(f) The quantity statement for curtains, drapes, flags, furniture scarves, etc., shall state, in centimeters and inches, the length and width of the finished item. The quantity statement also may state parenthetically, in centimeters and inches, the length of any ornamentation.

(g) The quantity statement for carpets and rugs shall state, in meters and feet, with any remainder in decimal fractions of the meter for SI sizes or common or decimal fractions of the foot or in inches for U.S. customary sizes, the length and width of the item. The quantity statement also may state parenthetically, in centimeters and inches, the length of any ornamentation.

(h) The quantity statement for woven dishtowels, dishcloths, towels, facecloths, utility cloths, bathmats, etc., shall state, in centimeters and inches, the length and width of the item. The quantity statement for such items, when knitted, need not state the dimensions.

(i) The quantity statement for textile products such as potholders, fixture and appliance covers, slipcovers, non-rectangular diapers, etc., shall be stated in terms of count and may include size designations and dimensions.

(j) The quantity statement for other than rectangular textile products identified in Sections (a) through (h) shall state the geometric shape of the product and the dimensions that are customarily used in describing such geometric shape.

\section{Examples:}

round scarf, $190 \mathrm{~cm}(74 \mathrm{in})$ in diameter;

oval tablecloth, $177 \mathrm{~cm} \times 254 \mathrm{~cm}(70 \mathrm{in} \times 100 \mathrm{in})$ representing the maximum length and width in this case.

(k) The quantity statement for packages of remnants of textile products of assorted sizes, when sold by count, shall be accompanied by the term "irregular dimensions" and the minimum size of such remnants.

(Added 1971)

10.9.3. Sewing Threads, Handicraft Threads, and Yarns. - Sewing and handicraft threads shall be labeled as follows:

(a) The net quantity for sewing and handicraft threads shall be expressed in terms of meters and yards.

(b) The net quantity statement for yarns shall be expressed in terms of mass or weight.

(c) Thread products may, in lieu of name and address, bear a trademark, symbol, brand, or other mark that positively identifies the manufacturer, packer, or distributor provided such marks are filed with the Director.

(d) Each unit of industrial thread shall be marked to show its net length in terms of meters and yards or its net weight in terms of kilograms or grams and avoirdupois pounds or ounces, except that ready-wound bobbins that are not sold separately shall not be required to be individually marked to show the number of bobbins contained therein and the net meters and yards of thread on each bobbin.

10.10. Packaged Seed. - Packages of seeds intended for planting with net contents of less than $225 \mathrm{~g}$ or 8 oz shall be labeled in full accord with this regulation except as follows:

(a) The quantity statement shall appear in the upper $30 \%$ of the principal display panel.

(b) The quantity statement shall be in terms of:

(1) the largest whole SI unit for all packages with weights up to $7 \mathrm{~g}$; and 
(2) in grams and ounces for all other packages with weights less than $225 \mathrm{~g}$ or $8 \mathrm{oz}$.

(Amended 1995)

(c) The quantity statement for coated seed, encapsulated seed, pelletized seed, pre-planters, seed tapes, etc., shall be in terms of count.

(Added 1972) (Amended 1975 and 1993)

\section{Section 11. Exemptions [see Section 11. NOTE]}

Section 11. NOTE: Exemptions include several requirements that refer only to the historic use of U.S. customary units or are direct restatements of exemptions contained in federal laws or regulations which do not include SI units. SI equivalents are omitted in most of these requirements because the SI units would not be meaningful or useful.

(Added 1993) (Amended 1995)

11.1. Random Packages. - A random package bearing a label conspicuously declaring:

(a) the net weight;

(b) unit price; and

(c) the total price

shall be exempt from the SI units, type size, location, and free area requirements of this regulation. In the case of a random package packed at one place for subsequent sale at another, neither the price per unit of weight nor the total selling price need appear on the package, provided the package label includes both such prices at the time it is offered or exposed for sale at retail.

This section shall also apply to uniform weight packages of fresh fruit or vegetables labeled by count, in the same manner and by the same type of equipment as random packages exempted by this section, and cheese and cheese products labeled in the same manner and by the same type of equipment as random packages exempted by this section.

(Amended 1989)

11.1.1. Indirect Sale of Random Packages. - A random package manufactured or produced and offered for indirect sale (e.g., e-commerce, online, phone, fax, catalog, and similar methods) shall be exempt from the labeling requirements of:

(a) unit price

(b) total price

when the following requirements are met:

At the time of the delivery, each package need only bear a statement of net weight, provided that:

(a) the unit price is set forth and established in the initial product offering;

(b) the maximum possible net weight, unit price, and maximum possible price are provided to the customer by order confirmation when the product is ordered; and

(c) when the product is delivered, the customer receives a receipt bearing the following information: identity, declared net weight, unit price, and the total price. 
Indirect Sales: For the purpose of Section 11.1.1. Indirect Sale of Random Packages, indirect sales are sales where the customer makes a selection and places an order, but cannot be present when the determination of the net quantity is made. Examples of such indirect methods include, without limitation, Internet or online sales, sales conducted by telephone or facsimile, and catalog sales.

(Added 2001) (Amended 2002)

11.2. Small Confections. - Individually wrapped pieces of "penny candy" and other confectionery of less than $15 \mathrm{~g}$ or $1 / 2$ oz net weight per individual piece shall be exempt from the labeling requirements of this regulation when the container in which such confectionery is shipped is in conformance with the labeling requirements of this regulation. Similarly, when such confectionery items are sold in bags or boxes, such items shall be exempt from the labeling requirements of this regulation, including the required declaration of net quantity of contents, when the declaration of the bag or box meets the requirements of this regulation.

11.3. Small Packages of Meat or Meat Products. - Individually wrapped and labeled packages of meat or meat products of less than $15 \mathrm{~g}$ or $1 / 2 \mathrm{oz}$ net weight, which are in a shipping container, need not bear a statement of the net quantity of contents when the statement of the net quantity of contents on the shipping container is in conformance with the labeling requirements of this regulation.

(Added 1987)

11.4. Individual Servings. - Individual serving size packages of foods containing less than $15 \mathrm{~g}$ or $1 / 2 \mathrm{oz}$ or less than $15 \mathrm{~mL}$ or $1 / 2 \mathrm{fl}$ oz for use in restaurants, institutions, and passenger carriers, and not intended for sale at retail, shall be exempt from the required declaration of net quantity of contents specified in this regulation.

11.5. Cuts, Plugs, and Twists of Tobacco and Cigars. - When individual cuts, plugs, and twists of tobacco and individual cigars are shipped or delivered in containers that conform to the labeling requirements of this regulation, such individual cuts, plugs, and twists of tobacco and cigars shall be exempt from such labeling requirements.

11.6. Reusable (Returnable) Glass Containers. - Nothing in this Regulation shall be deemed to preclude the continued use of reusable (returnable) glass containers, provided such glass containers ordered after the effective date of this regulation shall conform to all requirements of this regulation.

11.7. Cigarettes and Small Cigars. - Cartons of cigarettes and small cigars, containing ten individual packages of twenty, labeled in accordance with the requirements of this regulation shall be exempt from the requirements set forth in Section 8.1.1. Location, Section 8.2.1. Minimum Height of Numbers and Letters, and Section 10.4. Multiunit Packages, provided such cartons bear a declaration of the net quantity of commodity in the package.

11.8. Packaged Commodities with Labeling Requirements Specified in Federal Laws and Regulations. Packages of alcoholic beverages (i.e., beer, distilled spirits, and wine), cosmetics, catfish (Siluriformes), meat and meat products, medical devices, over-the-counter drugs, poultry products, tobacco and tobacco products, and pesticides shall be exempt from those portions of these regulations specifying location, and minimum type size of the net quantity declaration, provided net quantity of contents and other required labeling requirements (i.e., identity, responsibility) for such products are specified in federal law or regulation so as to follow reasonably sound principles of providing consumer information. (Refer to Section 11.32. SI Units, Exemptions - Consumer Commodities and Appendix C. Reference Information for Packaged Commodities and Labeling Requirements Specified in Federal Laws and Regulations.)

(Amended 2018)

\subsection{Fluid Dairy Products, Ice Cream, and Similar Frozen Desserts.}

(a) When packaged in $1 / 2$ liq pt and $1 / 2$ gal containers, are exempt from the requirements for stating net contents of $8 \mathrm{fl} \mathrm{oz}$ and $64 \mathrm{fl} \mathrm{oz}$, which may be expressed as $1 / 2 \mathrm{pt}$ and $1 / 2$ gal, respectively.

(b) When measured by and packaged in measure containers as defined in "Measure Container Code" of the NIST Handbook 44, "Specifications, Tolerances, and Other Technical Requirements for Weighing Measuring 
Devices" are exempt from the requirements of Section 8.1.1. Location that the declaration of net contents be located within the bottom $30 \%$ of the principal display panel.

(c) Milk and milk products when measured by and packaged in glass or plastic containers of $1 / 2 \mathrm{pt}, 1 \mathrm{pt}, 1 \mathrm{qt}$, $1 / 2$ gal, and 1 gal capacities are exempt from the placement requirement of Section 8.1.1. Location that the declaration of net contents be located within the bottom $30 \%$ of the principal display panel, provided other required label information is conspicuously displayed on the cap or outside closure and the required net quantity of contents declaration is conspicuously blown, formed, or molded on, or permanently applied to that part of the glass or plastic container that is at or above the shoulder of the container.

(Amended 1993)

11.10. Single Strength and Less than Single-Strength Fruit Juice Beverages, Imitations thereof, and Drinking Water.

(a) When packaged in glass, plastic, or fluid milk type paper containers of $8 \mathrm{fl} \mathrm{oz}$ and $64 \mathrm{fl} \mathrm{oz}$ capacity, are exempt from the requirements of Section 6.2. Largest Whole Unit to the extent that net contents of $8 \mathrm{fl} \mathrm{oz}$ and $64 \mathrm{fl} \mathrm{oz} \mathrm{(or} 2 \mathrm{qt}$ ) may be expressed as $1 / 2 \mathrm{pt}$ (or half pint) and $1 / 2$ gal (or half gallon), respectively.

(b) When packaged in glass or plastic containers of $1 / 2 \mathrm{pt}, 1 \mathrm{pt}, 1 \mathrm{qt},{ }^{1} / 2$ gal, and 1 gal capacities, are exempt from the placement requirements of Section 8.1.1. Location that the declaration of net contents be located within the bottom $30 \%$ of the principal display panel, provided other label information is conspicuously displayed on the cap or outside closure and the required net quantity of contents declaration is conspicuously blown, formed, or molded into or permanently applied to that part of the glass or plastic container that is at or above the shoulder of the container.

(Amended 1993)

11.11. Soft Drink Bottles. - Bottles of soft drinks shall be exempt from the placement requirements for the declaration of:

(a) identity when such declaration appears on the bottle closure; and

(b) quantity when such declaration is blown, formed, or molded on or above the shoulder of the container and when all other information required by this regulation appears only on the bottle closure.

11.12. Multiunit Soft Drink Packages. - Multiunit packages of soft drinks are exempt from the requirement for a declaration of:

(a) responsibility when such declaration appears on the individual units and is not obscured by the multiunit packaging or when the outside container bears a statement to the effect that such declaration will be found on the individual units inside; and

(b) identity when such declaration appears on the individual units and is not obscured by the multiunit packaging.

11.13. Butter. - When packaged in $4 \mathrm{oz}, 8 \mathrm{oz}$, and $1 \mathrm{lb}$ packages with continuous label copy wrapping, butter is exempt from the requirements that the statement of identity (Section 3.1.1. Parallel Identity Declaration: Consumer Package) and the net quantity declaration (Section 8.1.5. Parallel Quantity Declaration) be generally parallel to the base of the package. When packaged in $8 \mathrm{oz}$ and $1 \mathrm{lb}$ units, butter is exempt from the requirement for location (Section 8.1.1. Location) of net quantity declaration.

(Amended 1980 and 1993)

11.14. Eggs. - Cartons containing 12 eggs shall be exempt from the requirement for location (Section 8.1.1. Location) of net quantity declaration. When such cartons are designed to permit division in half, each half shall be exempt from the labeling requirements of this regulation if the undivided carton conforms to all such requirements. 
A. Uniform Packaging and Labeling Regulation

11.15. Flour. - Packages of wheat flour in conventional 2, 5, 10, 25, 50, and $100 \mathrm{lb}$ packages shall be exempt from the requirement in this regulation for location (Section 8.1.1. Location) of the net quantity declaration.

(Amended 1980 and 1993)

11.16. Small Packages. - On a principal display panel of $32 \mathrm{~cm}^{2}\left(5 \mathrm{in}^{2}\right)$ or less, the declaration of quantity need not appear in the bottom $30 \%$ of the principal display panel if that declaration satisfies the other requirements of this regulation.

(Amended 1980)

11.17. Decorative Containers. - The principal display panel of a cosmetic marketed in a "boudoir-type" container, including decorative cosmetic containers of the "cartridge," "pill box," "compact," or "pencil" variety, and those with a capacity of $7.4 \mathrm{~mL}(1 / 4 \mathrm{oz})$ or less, may be a tear-away tag or tape affixed to the decorative container and bearing the mandatory label information as required by this regulation.

(Amended 1980)

11.18. Combination and Variety Packages. - Combination and variety packages are exempt from the requirements in this regulation for:

(a) location (see Section 8.1.1. Location);

(b) free area (see Section 8.1.4. Free Area); and

(c) minimum height of numbers and letters (see Section 8.2.1. Minimum Height of Numbers and Letters). (Amended 1989)

11.19. Margarine. - Margarine in $1 \mathrm{lb}$ rectangular packages, except for packages containing whipped or soft margarine or packages containing more than four sticks, shall be exempt from the requirement in this regulation for location (see Section 8.1.1. Location) of the net quantity declaration. The statement of net quantity shall appear in a clear and conspicuous manner on the principal display panel. (see 9 CFR 317.2)

(Amended 1980, 1993, and 2021)

11.20. Corn Flour and Corn Meal. - Corn flour and corn meal packaged in conventional 5, 10, 25, 50, and $100 \mathrm{lb}$ bags shall be exempt from the requirement in this regulation for location (see Section 8.1.1. Location) of the net quantity declaration.

(Amended 1978 and 1980)

11.21. Prescription and Insulin Containing Drugs. - Prescription and insulin containing drugs subject to the provisions of Sections 503(b)(1) or 506 of the Federal Food, Drug, and Cosmetic Act shall be exempt from the provisions of this regulation.

11.22. Camera Film, Video Recording Tape, Audio Recording Tape, and Other Image and Audio Recording Media Intended for Retail Sale and Consumer Use. - Image and audio media packaged and labeled for retail sale are exempt from the net quantity statement requirements of this regulation that specify how measurement of commodities should be expressed, provided:

(a) Unexposed or Unrecorded Media. - The net quantity of contents of unexposed or unrecorded image and audio media is expressed:

(1) For still film, tape, or other still image media, in terms of the usable or guaranteed number of available still image exposures. The length and width measurements of the individual exposures, expressed in millimeters or inches, are authorized as an optional statement. 


\section{Examples:}

36 exposures, $36 \mathrm{~mm} \times 24 \mathrm{~mm}$, or

12 exposures, $2^{1 / 4}$ in $\times 2^{1 / 4}$ in

(2) For bulk or movie film, in terms of length (in meters or feet) of film available for exposure.

(3) For all other image and/or audio media, in terms of length of time of electronic media available for recording, together with recording and/or playing speed or other machine settings as necessary. Supplemental information concerning the length of the media ${ }^{[s e e}$ Section 11.22. NOTE] may be provided.

Supplemental information may be provided on other than the principal display panel.

Section 11.22. NOTE: Size, length of media, and format details to ensure interchangeability and other characteristics of audio and imaging media are available in the applicable American National Standards.

(b) Exposed, Recorded, or Processed Media. - The net quantity of contents of exposed or processed film or prerecorded electronic media shall be expressed in terms of the length of time that is of entertainment value.

"Entertainment value" is defined as that portion of a film, tape, or other media that commences with the first frame of sound or picture, whichever comes first after the countdown sequence (if any), and ends with either: (a) the last frame of credits; (b) the last frame of the phrase "The End"; or (c) the end of sound, whichever is last.

(Amended 1990)

11.23. Tint Base Paint. - Tint base paint may be labeled on the principal display panel in terms of a liter, quart, or a gallon, including the addition of colorant selected by the purchaser, provided the system employed ensures that the purchaser always obtains a liter, quart, or a gallon; and further provided, in conjunction with the required quantity statement on the principal display panel, a statement indicating that the tint base paint is not to be sold without the addition of colorant is presented; and further provided the contents of the container, before the addition of colorant, is stated in fluid ounces elsewhere on the label.

Wherever the above conditions cannot be met, containers of tint base paint must be labeled with a statement of the actual net contents prior to the addition of colorant in full accord with all the requirements of this regulation.

(Added 1972) (Amended 1980 and 1993)

11.24. Motor Oil in Cans. - Motor oils when packed in cans bearing the principal display panel on the body of the container are exempt from the requirements of Section 3. Declaration of Identity: Consumer Package to the extent that the Society of Automotive Engineers (SAE) viscosity number is required to appear on the principal display panel, provided the SAE viscosity number appears on the can lid and is expressed in letters and numerals in type size of at least $6 \mathrm{~mm}$ or ${ }^{1 / 4} \mathrm{in}$.

(Amended 1974, 1980, and 1993)

11.25. Pillows, Cushions, Comforters, Mattress Pads, Sleeping Bags, and Similar Products. - Those products including pillows, cushions, comforters, mattress pads, and sleeping bags that bear a permanent label as designated by the International Association of Bedding and Furniture Law Officials (iabflo.org) or the Department of Consumer Affairs, Bureau of Household Goods and Services (BHGS) (bhgs.dca.ca.gov) shall be exempt from the requirements for location (Section 8.1.1. Location), size of letters or numbers (Sections 8.2.1. Minimum Height of Numbers and Letters and 8.2.2. Numbers and Letters: Proportion), free area (Section 8.1.4. Free Area), and the declarations of identity and responsibility (Sections 3.1. Declaration of Identity and 5. Declaration of Responsibility: Consumer and Non-Consumer Packages), provided declarations of identity, quantity, and responsibility are presented on a permanently attached label and satisfy the other requirements of this Regulation, and further provided the information on such permanently attached label be fully observable to the purchaser.

(Added 1973) (Amended 2019) 
11.26. Commodities' Variable Weights and Sizes. - Individual packaged commodities put up in variable weights and sizes for sale intact and intended to be weighed and marked with the correct quantity statement prior to or at the point of retail sale are exempt from the requirements of Section 6. Declaration of Quantity: Consumer Packages while moving in commerce and while held for sale prior to weighing and marking, provided the outside container bears a label declaration of the total net weight.

(Added 1973)

11.27. Packaged Commodities Sold by Count. [see Section 11.27. NOTE] - When a packaged consumer commodity is properly measured in terms of count only, or in terms of count and some other appropriate unit, and the individual units are fully visible to the purchaser, such packages shall be labeled in full accord with this Regulation, except that those containing six or less items need not include a statement of count.

(Added 1973)

Section 11.27. NOTE: When the net contents declaration of a package that may enter interstate commerce includes count, federal regulations under the Federal Fair Packaging and Labeling Act provide no exemption from declaring the count unless the count is one (1).

(Added 1990)

11.28. Textile Packages. - Packages of textiles that are required by Section 6.4.1. Combination Declaration to provide a combination declaration stating the quantity of each individual unit and the count shall be exempt from the requirements in this regulation for:

(a) Location (see Section 8.1.1. Location);

(b) Free area (see Section 8.1.4. Free Area); and

(c) Minimum height of numbers and letters (see Section 8.2.1. Minimum Height of Numbers and Letters). (Added 1971) (Amended 1989)

11.29. Spot Label. - The declaration of quantity of the contents of a package is exempt from Section 8.1.1. Location requiring the quantity declaration to appear in the bottom $30 \%$ of the principal display panel, as long as the declaration of quantity appears in the lower $30 \%$ of the spot label. In no case may the size of the spot label be used to determine the minimum type size; see Section 8.2. Calculation of Area of Principal Display Panel for Purposes of Type Size for this determination.

(Added 1990)

11.30. Header Strip. - The declaration of quantity of the contents of a package is exempt from Section 8.1.1. Location requiring the quantity declaration to appear in the bottom $30 \%$ of the principal display panel, as long as the declaration of quantity appears in the lower $30 \%$ of the header strip or header label. In no case may the size of the header strip be used to determine the minimum type size; see Section 8.2. Calculation of Area of Principal Display Panel for Purposes of Type Size for this determination.

(Added 1990)

11.31. Decorative Wallcovering Borders. - Decorative wallcovering borders when packaged and labeled for retail sale shall be exempt from the requirements of Sections 6.6.2. One Meter, 1 Square Meter, 1 Kilogram, 1 Liter, 1 Cubic Meter, or More; 6.8.2. One Foot, 1 Square Foot, 1 Pound, 1 Pint, 1 Gallon or More; and 6.9. Bi-dimensional Commodities provided the length and width of the border are presented in terms of the largest whole unit in full accord with the other requirements of the regulation.

(Added 1992) (Amended 1993)

11.32. SI Units, Exemptions - Consumer Commodities. - The requirements for statements of quantity in SI units (except for those in Section 10.10. Packaged Seed and Section 11.22. Camera Film, Video Recording Tape, Audio Recording Tape and Other Image and Audio Recording Media Intended for Retail Sale and Consumer Use) in Section 6. Declaration of Quantity: Consumer Packages shall not apply to: 
(a) foods packaged at the retail store level;

(b) random weight packages (see Sections 2.4. Random Package and 11.1. Random Packages);

(c) package labels printed before February 14, 1994;

(d) meat and poultry products subject to the Federal Meat or Poultry Products Inspection Acts;

(e) tobacco or tobacco products;

(f) any beverage subject to the Federal Alcohol Administration Act;

(g) any product subject to the Federal Insecticide, Fungicide, and Rodenticide Act;

(h) drugs and cosmetics subject to the Federal Food, Drug and Cosmetic Act;

(i) nutrition labeling information.

11.33. U.S. Customary Units, Exemptions - Consumer Commodities. - The requirements for statements of quantity in U.S. customary units shall not apply to packages that bear appropriate SI units. This exemption does not apply to foods, drugs, or cosmetics or to packages subject to regulation by the FTC, meat and poultry products subject to the Federal Meat or Poultry Products Inspection Acts, and tobacco or tobacco products. (see UPLR Appendix C. Reference Information for Packaged Commodities with Labeling Requirements Specified in Federal Laws and Regulations.)

(Added 1999)

11.34. Bacon - Bacon packages as sliced shingles in rectangular packages shall be exempt from the requirement in this regulation for location (see Section 8.1.1. Location) of the net quantity declaration. The statement of net quantity shall appear in a clear and conspicuous manner on the principal display panel. (see 9 CFR 317.2)

(Added 2021)

\section{Section 12. Variations to be Allowed}

\subsection{Packaging Variations. ${ }^{[s e e}$ Section 6.12. NOTE]}

12.1.1. Variations from Declared Net Quantity. - Variations from the declared net weight, measure, or count shall be permitted when caused by unavoidable deviations in weighing, measuring, or counting the contents of individual packages that occur in current good manufacturing practice, but such variations shall not be permitted to such extent that the average of the quantities in the packages of a particular commodity or a lot of the commodity that is kept, offered, or exposed for sale, or sold is below the quantity stated, and no unreasonable shortage in any package shall be permitted even though overages in other packages in the same shipment, delivery, or lot compensate for such shortage. Variations above the declared quantity shall not be unreasonably large.

12.1.2. Variations Resulting from Exposure. - Variations from the declared weight or measure shall be permitted when caused by ordinary and customary exposure to conditions that normally occur in current good distribution practice and that unavoidably result in change of weight or measure, but only after the commodity is introduced into intrastate commerce, provided the phrase "introduced into intrastate commerce" as used in this paragraph shall be construed to define the time and the place at which the first sale and delivery of a package is made within the state, the delivery being either:

(a) directly to the purchaser or to his/her agent; or

(b) to a common carrier for shipment to the purchaser, 
A. Uniform Packaging and Labeling Regulation

and this paragraph shall be construed as requiring that so long as a shipment, delivery, or lot of packages of a particular commodity remains in the possession or under the control of the packager or the person who introduces the package into intrastate commerce, exposure variations shall not be permitted.

12.2. Magnitude of Permitted Variations. ${ }^{[s e e}$ Section 6.12. NOTE] - The magnitude of package variations of this regulation permitted under Sections 12. Variations to be Allowed, 12.1. Package Variations, 12.1.1. Variations from Declared Net Quantity, and 12.1.2. Variations Resulting from Exposure shall be those expressly set forth in this regulation and variations such as those contained in the procedures and tables of NIST Handbook 133, "Checking the Net Contents of Packaged Goods."

(Amended 1976, 1980, 1984, and 1988)

\section{Section 13. Revocation of Conflicting Regulations}

All provisions of all orders and regulations heretofore issued on this same subject that are contrary to or inconsistent with the provisions of this regulation and specifically are hereby revoked.

\section{Section 14. Effective Date}

This regulation shall become effective on

Given under my hand and the seal of my office in the City of

on this

day of

Signed 


\section{UPLR Appendix A: SI/U.S. Customary Conversion Factors**}

\begin{tabular}{|c|c|c|c|c|c|c|c|}
\hline \multicolumn{8}{|c|}{ LENGTH } \\
\hline $1 \mathrm{mil}(0.001 \mathrm{in})$ & $=$ & 25.4 & $\mu \mathrm{m}^{*}$ & 1 micrometer & $=$ & 0.039370 & mil \\
\hline 1 inch & $=$ & 2.54 & $\mathrm{~cm}^{*}$ & 1 millimeter & $=$ & 0.0393701 & in \\
\hline 1 foot & $=$ & 30.48 & $\mathrm{~cm}^{*}$ & 1 centimeter & $=$ & 0.393701 & in \\
\hline 1 yard & $=$ & 0.9144 & $\mathrm{~m}^{*}$ & 1 meter & $=$ & 3.28084 & $\mathrm{ft}$ \\
\hline $1 \mathrm{rod}$ & $=$ & 5.0292 & $\mathrm{~m}^{*}$ & & & & \\
\hline \multicolumn{8}{|c|}{ AREA } \\
\hline 1 square inch & $=$ & 6.4516 & $\mathrm{~cm}^{2 *}$ & 1 square centimeter & $=$ & 0.155000 & in $^{2}$ \\
\hline 1 square foot & $=$ & 929.030 & $\mathrm{~cm}^{2}$ & 1 square decimeter & $=$ & 0.107639 & $\mathrm{ft}^{2}$ \\
\hline 1 square yard & $=$ & 0.836127 & $\mathrm{~m}^{2}$ & 1 square meter & $=$ & 10.7639 & $\mathrm{ft}^{2}$ \\
\hline \multicolumn{8}{|c|}{ VOLUME or CAPACITY } \\
\hline 1 cubic inch & $=$ & 16.3871 & $\mathrm{~cm}^{3}$ & 1 cubic centimeter & $=$ & 0.06102374 & in $^{3}$ \\
\hline \multirow{2}{*}{1 cubic foot } & \multirow{2}{*}{$=$} & \multirow{2}{*}{$\begin{array}{r}0.0283168 \\
28.3168\end{array}$} & \multirow{2}{*}{$\begin{array}{l}\mathrm{m}^{3} \\
\mathrm{~L}\end{array}$} & 1 cubic decimeter & $=$ & 0.0353147 & $\mathrm{ft}^{3}$ \\
\hline & & & & \multirow{2}{*}{1 cubic meter } & \multirow{2}{*}{$=$} & \multirow{2}{*}{$\begin{array}{l}35.3147 \\
1.30795\end{array}$} & \multirow{2}{*}{$\begin{array}{l}\mathrm{ft}^{3} \\
\mathrm{yd}^{3}\end{array}$} \\
\hline 1 cubic yard & $=$ & 0.764555 & $\mathrm{~m}^{3}$ & & & & \\
\hline 1 fluid ounce & $=$ & 29.5735 & $\mathrm{~mL}$ & 1 milliliter $\left(\mathrm{cm}^{3}\right)$ & $=$ & 0.033814 & fl oz \\
\hline 1 liquid pint & $=$ & $\begin{array}{r}473.177 \\
0.473177\end{array}$ & $\begin{array}{l}\mathrm{mL} \\
\mathrm{L}\end{array}$ & 1 liter & $=$ & $\begin{array}{r}1.05669 \\
0.264172\end{array}$ & $\begin{array}{l}\operatorname{liq} q t \\
\text { gal }\end{array}$ \\
\hline \multirow{2}{*}{1 liquid quart } & \multirow{2}{*}{$=$} & \multirow{2}{*}{$\begin{array}{r}946.353 \\
0.946353\end{array}$} & \multirow{2}{*}{$\begin{array}{l}\mathrm{mL} \\
\mathrm{L}\end{array}$} & 1 dry pint & $=$ & 550.6105 & $\mathrm{~mL}$ \\
\hline & & & & 1 dry quart & $=$ & 1.101221 & $\mathrm{~L}$ \\
\hline 1 gallon & $=$ & 3.78541 & $\mathrm{~L}$ & 1 peck & $=$ & 8.809768 & $\mathrm{~L}$ \\
\hline 1 bushel & $=$ & 35.2391 & $\mathrm{~L}$ & 1 gill & $=$ & 118.2941 & $\mathrm{~mL}$ \\
\hline \multicolumn{8}{|c|}{ MASS (weight) } \\
\hline 1 ounce & $=$ & 28.3495 & $\mathrm{~g}$ & \multirow{2}{*}{1 milligram } & \multirow{2}{*}{$=$} & \multirow{2}{*}{$\begin{array}{r}0.000035274 \\
0.0154324\end{array}$} & \multirow{2}{*}{$\begin{array}{l}\mathrm{oz} \\
\text { grain }\end{array}$} \\
\hline \multirow{2}{*}{1 pound } & \multirow{2}{*}{$=$} & \multirow{2}{*}{$\begin{array}{r}453.59237 \\
0.453592\end{array}$} & \multirow{2}{*}{$\begin{array}{l}\mathrm{g}^{*} \\
\mathrm{~kg}\end{array}$} & & & & \\
\hline & & & & 1 gram & $=$ & 0.035274 & $\mathrm{OZ}$ \\
\hline 1 grain & $=$ & 64.79891 & $\mathrm{mg}$ & 1 kilogram & $=$ & 2.20462 & $\mathrm{lb}$ \\
\hline \multicolumn{8}{|c|}{ TEMPERATURE } \\
\hline \multicolumn{4}{|c|}{$t_{{ }^{\circ} \mathrm{F}}=1.8 t^{\circ} \mathrm{C}+32^{*}$} & \multicolumn{4}{|c|}{$t^{\circ} \mathrm{C}=\frac{5}{9}\left(t_{\circ \mathrm{F}}-32\right)^{*}$} \\
\hline \multicolumn{8}{|c|}{$\begin{array}{l}\text { * Exactly } \\
\text { ** These conversion factors are given to six or more significant digits in the event such accuracy is } \\
\text { necessary. To convert to U.S. customary units, divide the factor rather than multiplying. } \\
\text { (Amended 1998) }\end{array}$} \\
\hline
\end{tabular}


IV. Uniform Regulations

Handbook $130-2022$

A. Uniform Packaging and Labeling Regulation

UPLR Appendix A. SI/U.S. Customary Conversion Factors

THIS PAGE INTENTIONALLY LEFT BLANK 


\section{UPLR Appendix B: Converting U.S. Customary Units to SI Units for Quantity Declarations on Packages}

\section{Conversion.}

To convert an U.S. customary quantity to an SI quantity, multiply the appropriate conversion factor in Table 1 in Appendix A by the U.S. customary unit and round according to the following rules.

\section{Rounding and Significant Digits.}

It is the packager's responsibility to round converted values appropriately and select the appropriate number of significant digits to use in quantity declaration. [These rounding rules are for converting quantity determinations on packages and do not apply to digital scales that automatically round indications to the nearest indicated value.] Conversions, the proper use of significant digits, and rounding must be based on the packer's knowledge of the accuracy of the original measurement that is being converted. For example, if a package is labeled $453.59 \mathrm{~g}(1 \mathrm{lb})$, the packer is implying that the package declaration is accurate within $\pm 0.005 \mathrm{~g}$ (or $\pm 5 \mathrm{mg}$ ). For liquid volume measure, a label declaration of $473 \mathrm{~mL}(16 \mathrm{fl} \mathrm{oz})$ implies that the package declaration is accurate to within $\pm 0.5 \mathrm{~mL}(0.01 \mathrm{fl} \mathrm{oz})$. The requirements of 6.13 . Rounding apply to all quantity declarations that are derived from converted values:

6.13. Rounding. - In all conversions for the purpose of showing an equivalent SI or U.S. customary quantity to a rounded U.S. customary or SI quantity, or in calculated values to be declared in the net quantity statement, the number of significant digits retained must be such that accuracy is neither sacrificed nor exaggerated. Conversions, the proper use of significant digits, and rounding must be based on the packer's knowledge of the accuracy of the original measurement that is being converted. In no case shall rounded net contents declarations overstate a quantity; the packer may round the converted values down to avoid overstating the net contents.

NOTE: When as a result of rounding SI or U.S. customary declarations calculated based on the conversion factors in Appendix A, the resulting declarations are not exact, the largest declaration, whether metric or U.S. customary, will be used for enforcement purposes to determine whether a package contains at least the declared amount of the product.

Do not round conversion factors or any other quantity used or determined in the calculation; only round the final quantity to the number of significant digits needed to maintain the accuracy of the original quantity. Use the rounding rules presented below in Table 1 as guidance to round the final result. In general, quantity declarations on consumer commodities should only be shown to two or three significant digits (for example, $453 \mathrm{~g}$ or $85 \mathrm{~g}$ ). Any final zeros to the right of the decimal point need not be expressed. The U.S. customary and SI declarations of quantity must be accurate and equivalent to each other. For example, a package bearing a net weight declaration of $2 \mathrm{lb}(32 \mathrm{oz}) \mathrm{must}$ also include an SI declaration of $907 \mathrm{~g}$. 
A. Uniform Packaging and Labeling Regulation

UPLR Appendix B. Converting U.S. Customary Units to SI Units

\begin{tabular}{||c|c|c||}
\hline \multicolumn{3}{|c||}{ Table 1. Rounding Rules } \\
\hline $\begin{array}{c}\text { When the First Digit } \\
\text { Dropped is: }\end{array}$ & The Last Digit Retained is: & Examples \\
\hline less than 5 & Unchanged & $\begin{array}{c}2.44 \text { to } 2.4 \\
2.429 \text { to } 2.4\end{array}$ \\
\hline $\begin{array}{c}\text { more than 5, or 5 } \\
\text { followed by at least 1 digit } \\
\text { other than 0 }\end{array}$ & Increased by 1 & $\begin{array}{c}2.46 \text { to } 2.5 \\
2.451 \text { to } 2.5\end{array}$ \\
\hline 5 followed by zeros & Unchanged if Even, or & 2.450 to 2.4 \\
& Increased by 1 \\
if Odd & 2.550 to 2.6 \\
\hline
\end{tabular}

(a) When the first digit discarded is less than 5, the last digit retained should not be changed. For example, if the quantity 984.3 is to be declared to three significant digits, the number 3 to the right of the decimal point must be discarded since it is less than 5 and the last digit to be retained (the number 4) will remain unchanged. The rounded number will read 984 . The same rationale applies to numbers declared to two significant digits (for example 68.4 and 7.34); again, the final digit is dropped and the last digit retained remains unchanged so that the "rounded-off" numbers become 68 and 7.3 respectively.

(b) When the first digit to be discarded is greater than 5 , or it is a 5 followed by at least one digit other than zero, the last digit to be retained should be increased by one unit.

\begin{tabular}{lll}
\multicolumn{2}{l}{ Examples: } \\
984.7 & becomes & 985 \\
984.51 & becomes & 985 \\
6.86 & becomes & 6.9 \\
6.88 & becomes & 6.9
\end{tabular}

(c) When the first digit to be discarded is exactly 5, followed only by zeros, the final digit to be retained should be rounded up if it is an odd number $(1,3,5,7$, or 9), but no adjustment should be made if it is an even number $(2,4,6$, or 8$)$.

$\begin{array}{lll}\text { Examples: } & \\ 984.50 & \text { becomes } & 984 \\ 985.50 & \text { becomes } & 986 \\ 68.50 & \text { becomes } & 68 \\ 7.450 & \text { becomes } & 7.4 \\ 7.550 & \text { becomes } & 7.6\end{array}$

*NOTE: See additional examples in Table 2.

\section{Additional Advice on Rounding and Significant Digits}

(a) These rules require the packer to use good judgment in making decisions on how to round and the number of significant digits to use in quantity declarations. Rounding should always be done in one step; for example, if $16.94647 \mathrm{~g}$ has to be rounded to three significant digits, it should be rounded to $16.9 \mathrm{~g}$, not 16.9465 , then to 16.946 , then to 16.95 which would then round to $17.0 \mathrm{~g}$ (see rounding rules above).

(b) Do not use rounded SI values to calculate quantities. For example, using 1 in $=25.4 \mathrm{~mm}$, rounded to $25 \mathrm{~mm}$, should not be multiplied by 2 to determine the SI equivalent for $2 \mathrm{in}$. The SI equivalent for 2 in is determined by multiplying 2 in $\times 25.4 \mathrm{~mm}=50.8 \mathrm{~mm}$, then rounding to $51 \mathrm{~mm}$. 
(c) If a dimension given as $8 \mathrm{ft}$ is valid to the nearest $1 / 10$ in, consider it to mean 96.0 in and treat it as having three significant digits. The rounded dimension would then be $2.44 \mathrm{~m}$ instead of $2.4 \mathrm{~m}$.

(d) Conversions using a multiple digit conversion factor usually give a product with more digits than the original quantity. The final product should contain no more significant digits than are contained in the number with the fewest significant digits used in the conversion. For example, the area of a sheet of paper is determined on a calculator by multiplying $1.25 \mathrm{~cm}$ (length) $\times 1.5 \mathrm{~cm}$ (width) $=1.875 \mathrm{~cm}^{2}$. The product given to four significant digits on the calculator cannot be any more accurate than two significant digits (the number of significant digits in $1.5 \mathrm{~cm}$ ), so the area should be declared as $1.9 \mathrm{~cm}^{2}$.

(e) Packagers of consumer commodities should be aware that when a converted value is rounded up, there may be a need to (1) increase the package contents and/or, (2) select a converted value that does not exaggerate the precision of the quantity or overstate the net contents. For example, under the rules above, a net weight declaration of $16 \mathrm{oz}$ ( $453.59237 \mathrm{~g}$ ) may be rounded up to $454 \mathrm{~g}$ for three significant digits. Inspections by weights and measures officials are typically conducted using devices with a resolution of $0.5 \mathrm{~g}$ or less. If the packer does not address this possibility, some lots of commodities may pass when the U.S. customary declaration is tested, but fail when the SI declaration is verified. 
A. Uniform Packaging and Labeling Regulation

UPLR Appendix B. Converting U.S. Customary Units to SI Units

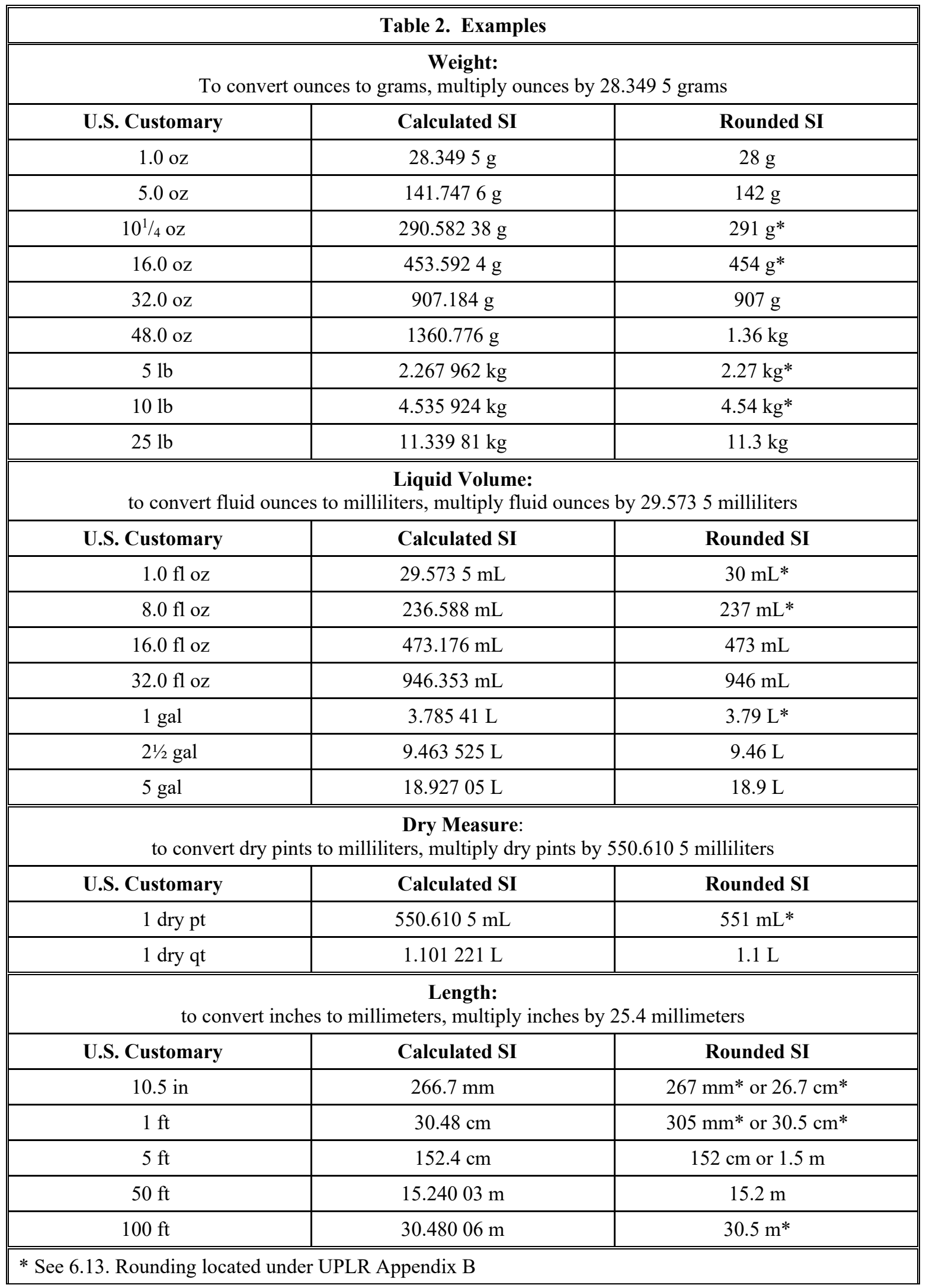




\section{Appendix C: Reference Information for Packaged Commodities with Labeling Requirements Specified in Federal Law and Regulation}

\begin{tabular}{|c|c|c|}
\hline \multicolumn{3}{|c|}{$\begin{array}{l}\text { Reference Information for Packaged Commodities } \\
\text { with Labeling Requirements Specified in the Federal Laws and Regulations }\end{array}$} \\
\hline Product Agency & $\begin{array}{c}\text { Code of } \\
\text { Federal Regulations } \\
\text { (CFR) }\end{array}$ & $\begin{array}{c}\text { Net Quantity of Contents Requirements, Guides, or } \\
\text { Other Information }\end{array}$ \\
\hline $\begin{array}{l}\text { Alcoholic Beverages, } \\
\text { Wine, and Beer } \\
\text { Treasury Department - Al- } \\
\text { cohol and Tobacco Tax } \\
\text { and Trade Bureau } \\
\text { www.ttb.gov }\end{array}$ & $\begin{array}{l}27 \text { CFR, Chapter I, } \\
\text { Subchapter A. "Alco- } \\
\text { hol" }\end{array}$ & $\begin{array}{l}\text { Refer to Part } 4 \text { "Labeling and Advertising of Wine" at } \\
\text { https://www.ttb.gov/wine/beverage-alcohol-manual } \\
\text { Refer Part } 5 \text { "Labeling and Advertising of Distilled } \\
\text { Spirits." See also: The Beverage Alcohol Manual } \\
\text { (BAM) A Practical Guide - "Basic Mandatory } \\
\text { Labeling Information for Distilled Spirits - Volume 2" } \\
\text { at www.ttb.gov/spirits/bam.shtml. } \\
\text { Refer to Part } 7 \text { "Labeling and Advertising of Malt } \\
\text { Beverages." See also: "The Beverage Alcohol Manual } \\
\text { (BAM) A Practical Guide" at } \\
\text { www.ttb.gov/beer/bam.shtml. }\end{array}$ \\
\hline $\begin{array}{l}\text { Animal Food } \\
\text { Food and Drug Admin- } \\
\text { istration (FDA) } \\
\text { www.fda.gov }\end{array}$ & $\begin{array}{l}21 \text { CFR 501, Chapter I, } \\
\text { Subchapter E - Animal } \\
\text { Drugs, Feeds and Re- } \\
\text { lated Products. "Ani- } \\
\text { mal Food Labeling. } \\
\text { Subpart F - Exemp- } \\
\text { tions, Animal Food La- } \\
\text { beling Requirements }\end{array}$ & $\begin{array}{l}\text { Refer to } \S 501.105 \text { - "Declaration of net quantity of } \\
\text { contents when exempt." }\end{array}$ \\
\hline $\begin{array}{l}\text { Catfish* (Siluriformes) } \\
\text { U.S. Department of Agri- } \\
\text { culture (USDA) - Food } \\
\text { Safety and Inspection Ser- } \\
\text { vice } \\
\text { www.fsis.usda.gov }\end{array}$ & $\begin{array}{l}9 \text { CFR 541, Chap- } \\
\text { ter III, Subchapter F, } \\
\text { "Marks, Marking and } \\
\text { Labeling of Products } \\
\text { and Containers" }\end{array}$ & $\begin{array}{l}\text { Refer to } \$ 541.7 \text { which incorporates the requirements } \\
\text { in Section } 9 \text { CFR } 317.2 \text { "Labels: definitions; required } \\
\text { features." } \\
\text { *Fish of the order Siluriformes include, but are not } \\
\text { limited to, "catfish" (fish of the family Ictaluridae) } \\
\text { and "basa", and "swai" (fish of the family } \\
\text { Pangasiidae). }\end{array}$ \\
\hline $\begin{array}{l}\text { Cosmetics } \\
\text { Food and Drug Admin- } \\
\text { istration (FDA) } \\
\text { www.fda.gov }\end{array}$ & $\begin{array}{l}21 \text { CFR 701, Chapter I } \\
\text { Subchapter G, "Cos- } \\
\text { metic Labeling" }\end{array}$ & $\begin{array}{l}\text { Refer to } \$ 701.13 \text { - "Declaration of net quantity of } \\
\text { contents." } \\
\text { See also: } \\
\text { www.fda.gov/Cosmetics/Labeling/default.htm }\end{array}$ \\
\hline
\end{tabular}


A. Uniform Packaging and Labeling Regulation

Appendix C. Reference Information for Packaged Commodities

\begin{tabular}{|c|c|c|}
\hline $\begin{array}{l}\text { Meat \& Poultry Products } \\
\text { U.S. Department of Agri- } \\
\text { culture (USDA) - Food } \\
\text { Safety and Inspection Ser- } \\
\text { vice } \\
\text { www.fsis.usda.gov }\end{array}$ & $\begin{array}{l}\text { Meat and Meat Products: } \\
9 \text { CFR 317, Chapter } \\
\text { III, Subchapter A, "La- } \\
\text { beling, Marking De- } \\
\text { vices and Containers" } \\
\text { Poultry: } \\
9 \text { CFR 442, Chap- } \\
\text { ter III, Subchapter E, } \\
\text { "Quantity of Contents } \\
\text { Labeling and Proce- } \\
\text { dures and Require- } \\
\text { ments for Accurate } \\
\text { Weights" }\end{array}$ & $\begin{array}{l}\text { Refer to } \S 317.2 \text { "Labels: definitions; required } \\
\text { features." }\end{array}$ \\
\hline $\begin{array}{l}\text { Over-the-Counter Medi- } \\
\text { cal Devices } \\
\text { Food and Drug Admin- } \\
\text { istration (FDA) } \\
\text { www.fda.gov }\end{array}$ & $\begin{array}{l}21 \text { CFR 801, Chapter I, } \\
\text { Subchapter H "Label- } \\
\text { ing Requirements for } \\
\text { Over-the-Counter } \\
\text { Medical Devices" }\end{array}$ & $\begin{array}{l}\text { Refer to } \S 801.62 \text { - "Declaration of net quantity of } \\
\text { contents." }\end{array}$ \\
\hline $\begin{array}{l}\text { Over-the-Counter Drugs } \\
\text { Food and Drug Admin- } \\
\text { istration (FDA) } \\
\text { www.fda.gov }\end{array}$ & $\begin{array}{l}21 \text { CFR 201, Chapter I, } \\
\text { Subchapter C Drugs, } \\
\text { "Labeling" }\end{array}$ & $\begin{array}{l}\text { Refer to } § 201.62 \text { "Declaration of Net Quantity of } \\
\text { Contents." }\end{array}$ \\
\hline $\begin{array}{l}\text { Pesticides } \\
\text { Environmental Protection } \\
\text { Agency (EPA) } \\
\text { www.epa.gov }\end{array}$ & $\begin{array}{l}40 \text { CFR 156, Chapter I, } \\
\text { Subchapter E, "Label- } \\
\text { ing Requirements for } \\
\text { Pesticides and De- } \\
\text { vices," Subpart A, } \\
\text { "General Provisions" }\end{array}$ & $\begin{array}{l}\text { Refer to } § \mathbf{1 5 6 . 1 0} \text { "Labeling requirements." } \\
\text { See also: "Pesticide Registration - Label Review Man- } \\
\text { ual" at } \\
\text { www.epa.gov/pesticide-registration/label-review- } \\
\text { manual. }\end{array}$ \\
\hline $\begin{array}{l}\text { Tobacco and Tobacco } \\
\text { Products } \\
\text { Food and Drug Admin- } \\
\text { istration (FDA) } \\
\text { www.fda.gov }\end{array}$ & $\begin{array}{l}\text { Section } 903 \text { of the Fed- } \\
\text { eral Food, Drug, and } \\
\text { Cosmetic Act -"Mis- } \\
\text { branded Tobacco } \\
\text { Products" }\end{array}$ & $\begin{array}{l}\text { Since } 2009 \text { FDA has regulated all tobacco products in- } \\
\text { cluding e-cigarettes, hookah tobacco, and cigars. The } \\
\text { exceptions to the UPLR Sections } 11.5 \text {. "Cuts, Plugs, } \\
\text { and Twists of Tobacco and Cigars" and Section } 11.7 \text {. } \\
\text { "Cigarettes and Small Cigars" remain in effect as they } \\
\text { were based on U.S. Treasury Department labeling re- } \\
\text { quirements for smokeless tobacco (chewing tobacco } \\
\text { and snuff) and recognize traditional methods of sale of } \\
\text { tobacco in cuts, plugs, and twists as well as cigars. }\end{array}$ \\
\hline
\end{tabular}

(Added 2018) 


\title{
B. Uniform Regulation for the Method of Sale of Commodities
}

\author{
as adopted by \\ The National Conference on Weights and Measures*
}

\section{Background}

The National Conference on Weights and Measures (NCWM) has long been concerned with the proper units of measurement to be used in the sale of all commodities. This approach has gradually broadened to concerns of standardized package sizes and general identity of particular commodities. Requirements for individual products were at one time made a part of the Weights and Measures Law or were embodied in separate individual Model Regulations. In 1971, this "Model State Method of Sale of Commodities Regulation" was established (renamed in 1983); amendments have been adopted by the Conference almost annually since that time.

Sections with "added 1971" dates refer to those sections that were originally incorporated in the Weights and Measures Law or in individual Model Regulations recommended by the NCWM. Subsequent dates reflect the actual amendment or addition dates.

The 1979 edition included, for the first time, requirements for items packaged in quantities of the International System of Units (SI), the modernized metric system, as well as continuing to present requirements for U.S. customary quantities. It should be stressed that nothing in this Regulation requires changing to the SI system of measurement. SI values are given for the guidance of those wishing to adopt new SI quantities of the commodities governed by this Regulation. SI means the International System of Units as established in 1960 by the General Conference on Weights and Measures and interpreted or modified for the United States by the Secretary of Commerce.

This Regulation assimilates all of the actions periodically taken by the Conference with respect to certain food items, non-food items, and general method of sale concepts. Its format is such that it will permit the addition of individual items at the end of appropriate sections as the need arises. Its adoption as a regulation by individual jurisdictions will eliminate the necessity for legislative consideration of changes in the method of sale of particular commodities. Such items will be able to be handled through the normal regulation-making process.

The Conference recognized that some states may only adopt the Method of Sale of Commodities Regulation but have the legal authority in their weights and measures law to also regulate and take enforcement action in the areas of fuels and related products. For this reason, the user will find fuels and related products within this regulation. A brief summary related to the development of regulations on these products can be found in the Background information of the Uniform Fuels and Automotive Lubricants Regulation. Efforts have been made when practical to align both regulations.

(Amended 2021)

\footnotetext{
* The National Conference on Weights and Measures (NCWM) is supported by the National Institute of Standards and Technology (NIST) in partial implementation of its statutory responsibility for "cooperation with the states in securing uniformity in weights and measures laws and methods of inspection."
} 
IV. Uniform Regulations

Handbook $130-2022$

B. Uniform Regulation for the Method of Sale of Commodities

\section{Status of Promulgation}

The table beginning on page 6 shows the status of adoption of the Uniform Regulation for the Method of Sale of Commodities. 


\section{B. Uniform Regulation for the Method of Sale of Commodities}

\section{Table of Contents}

Section Page

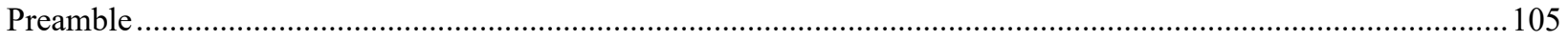

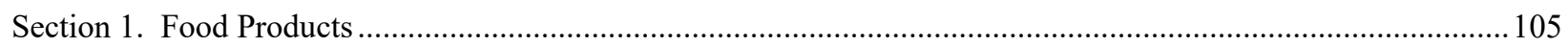

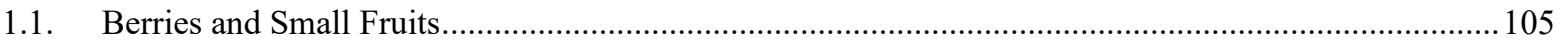

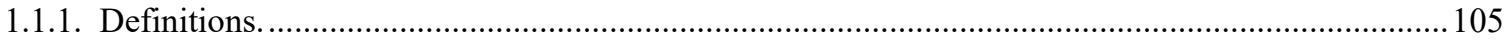

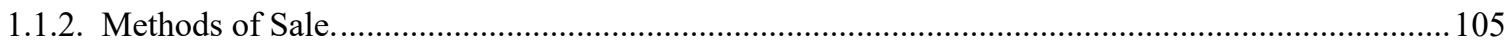

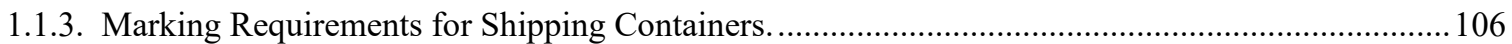

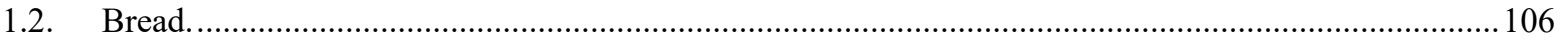

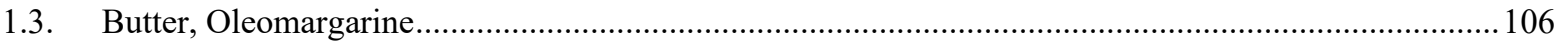

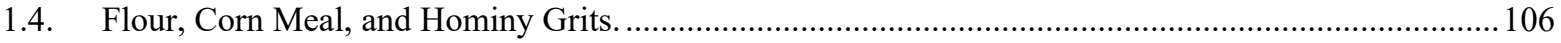

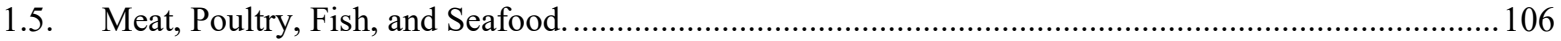

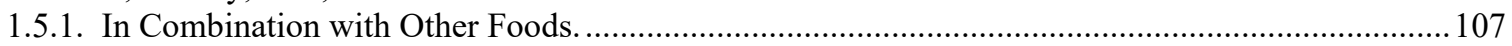

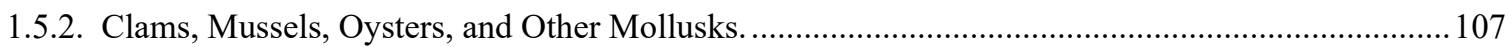

1.5.2.1. Whole Clams, Oysters, Mussels, or Other Mollusks in the Shell............................... 107

1.5.2.2. Whole Clams, Oysters, Mussels, or Other Mollusks on the Half Shell...................... 107

1.5.2.3. Fresh Oysters Removed from the Shell........................................................... 107

1.5.2.4. Processed Clams, Mussels, Oysters, or Other Mollusks on the Half Shell ................. 107

1.5.2.5. Canned (heat-processed) Mussels, Clams, Oysters, or Other Mollusks...................... 107

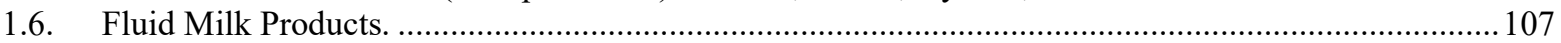

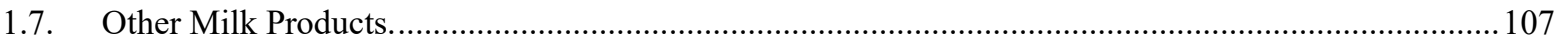

1.7.1. Factory Packaged Ice Cream and Similar Frozen Products..................................................... 107

1.7.2. Pelletized Ice Cream and Similar Pelletized Frozen Desserts. ................................................ 108

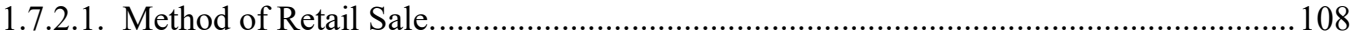

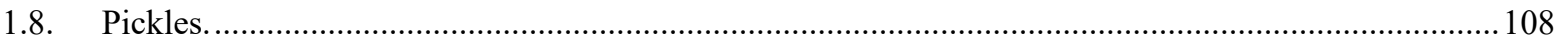

1.9. Advertising and Price Computing of Bulk Food Commodities. ........................................................ 108

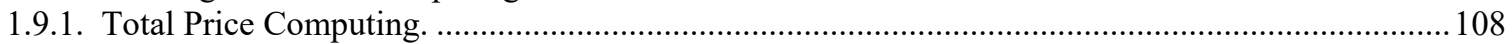

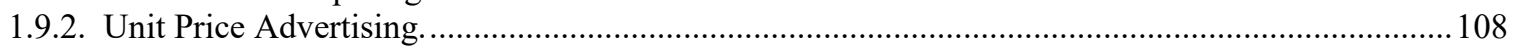

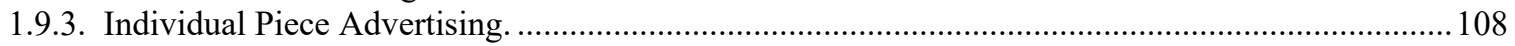

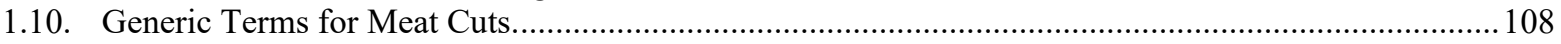

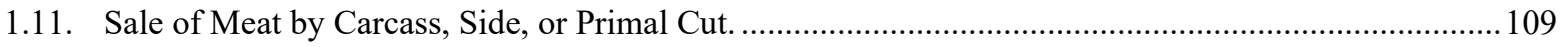

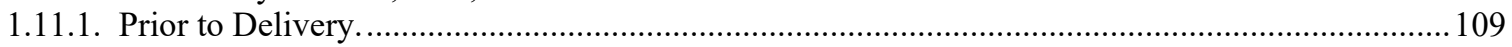

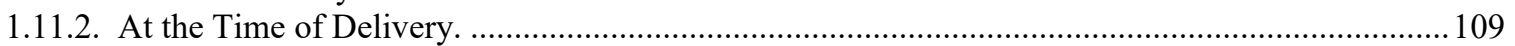

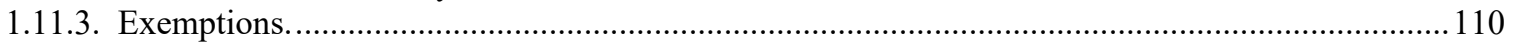

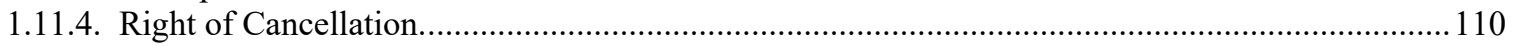

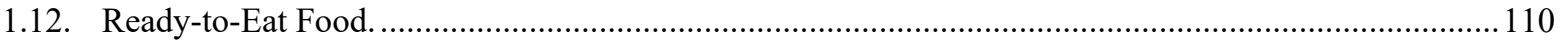

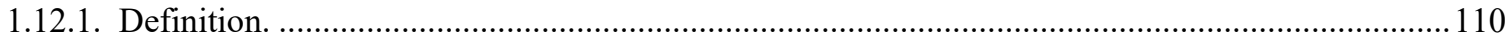

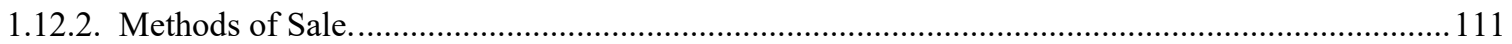

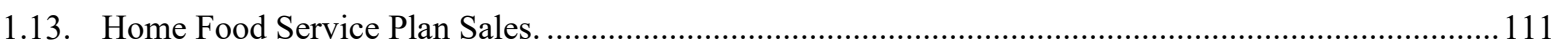

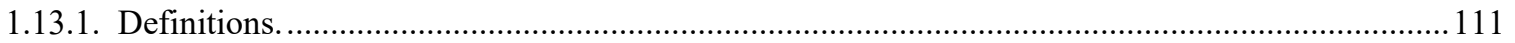

1.13.2. Contract and Disclosure Requirements. ....................................................................... 112

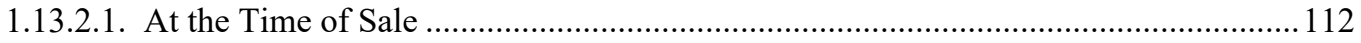

1.13.2.2. At the Time of Delivery. ...................................................................................... 113

1.13.3. Advertisement of Home Food Service Plans....................................................................... 113

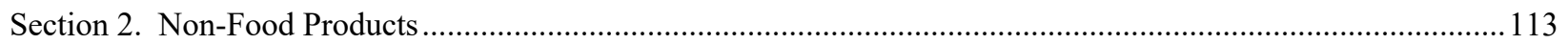

2.1. Advertising and Price Computing of Bulk Commodities. ............................................................ 113

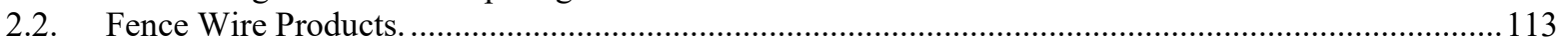


B. Uniform Regulation for the Method of Sale of Commodities

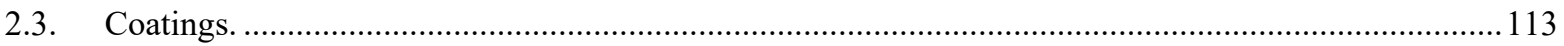

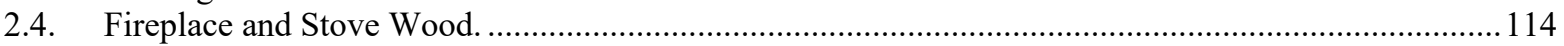

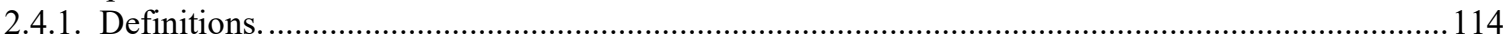

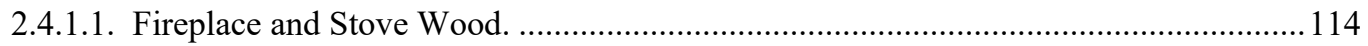

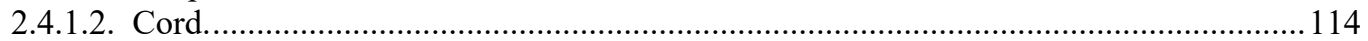

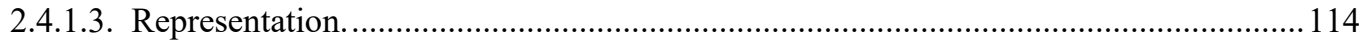

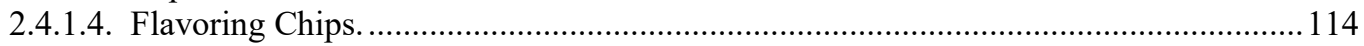

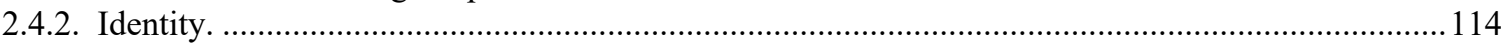

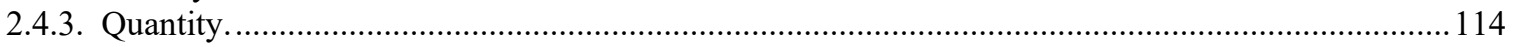

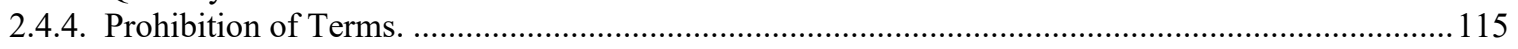

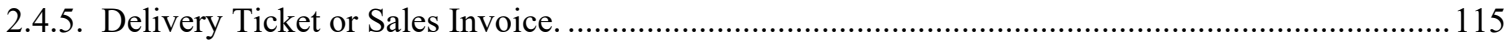

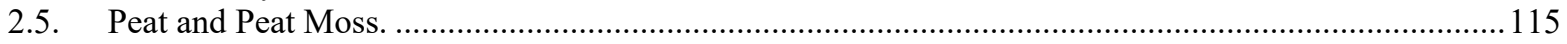

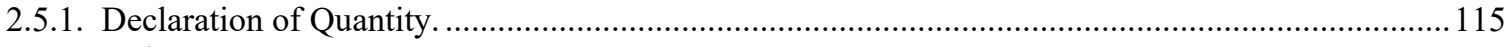

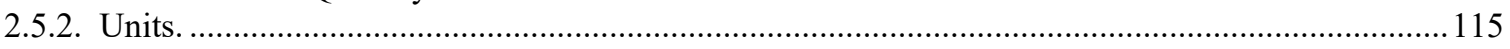

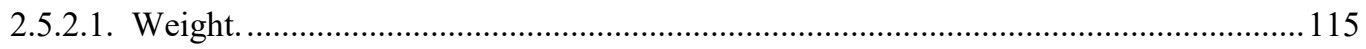

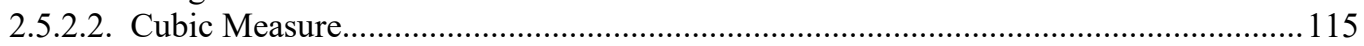

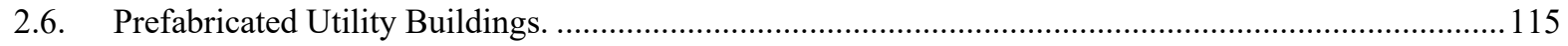

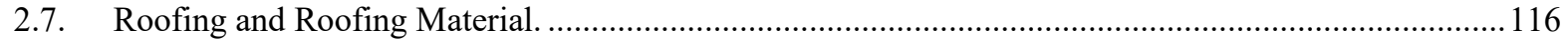

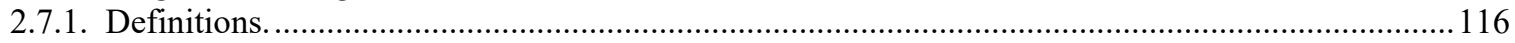

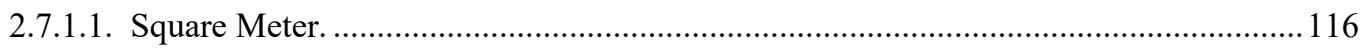

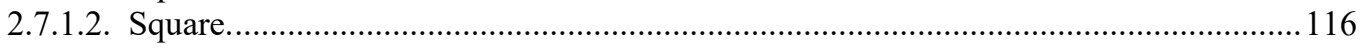

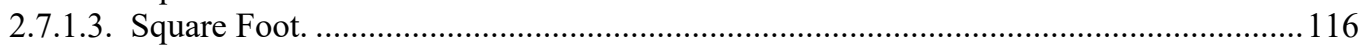

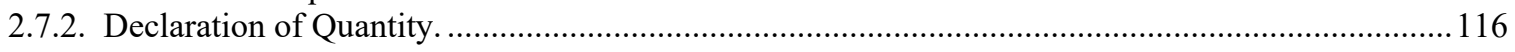

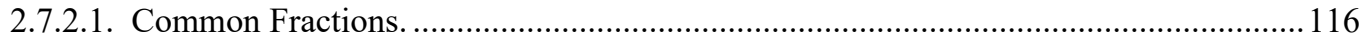

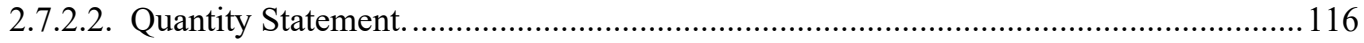

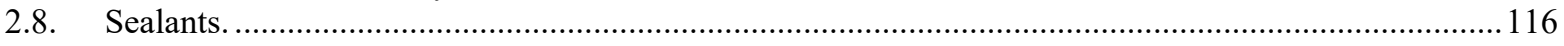

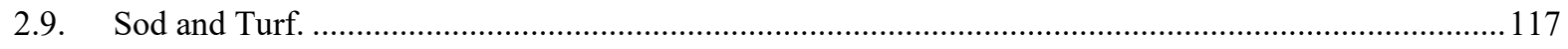

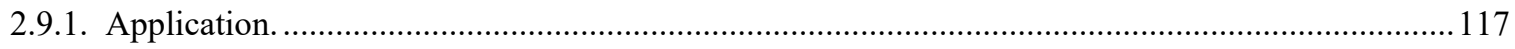

2.9.2. Definitions.

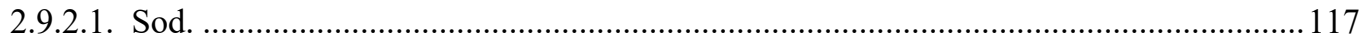

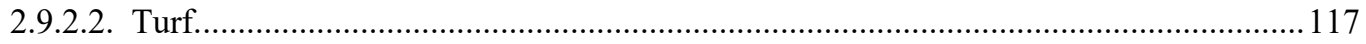

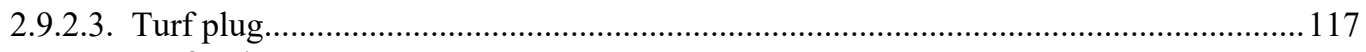

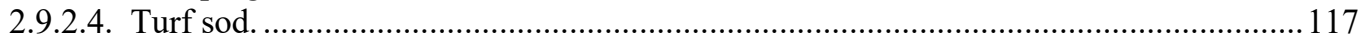

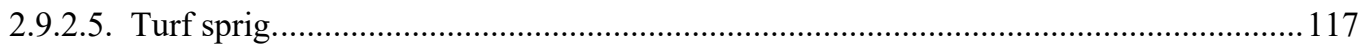

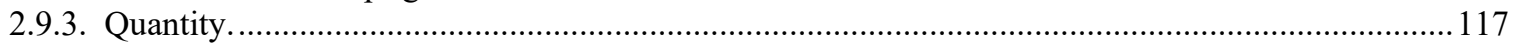

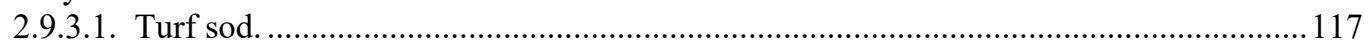

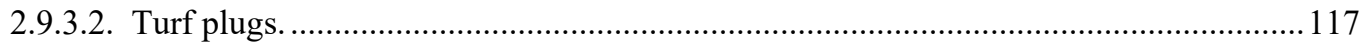

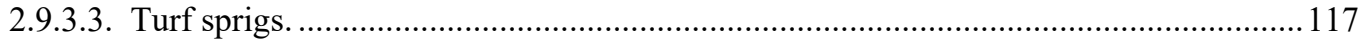

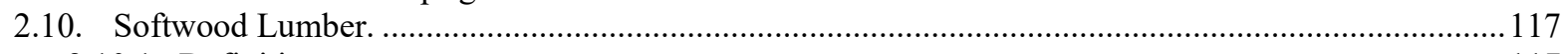

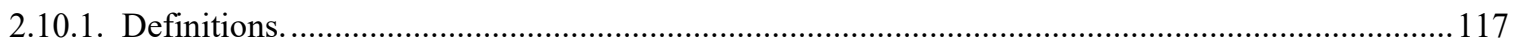

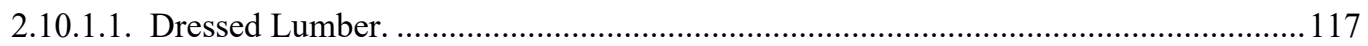

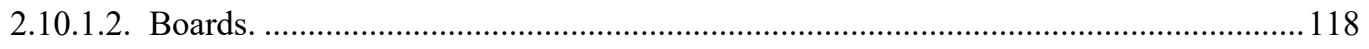

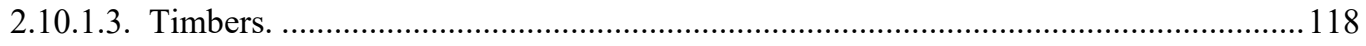

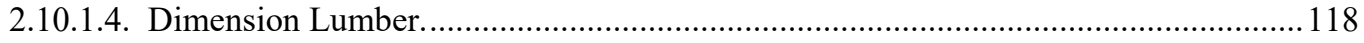

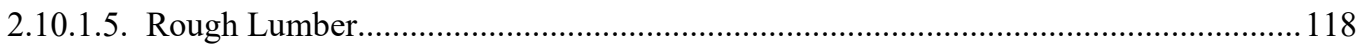

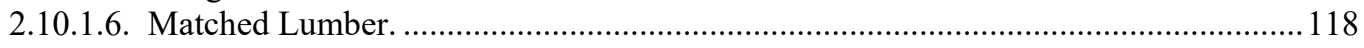

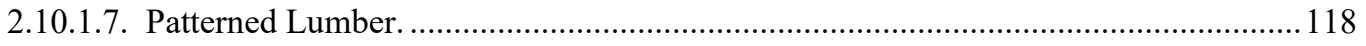

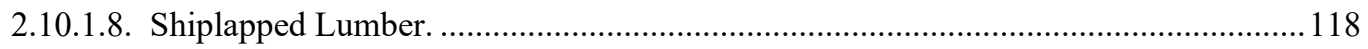

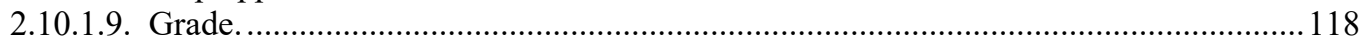

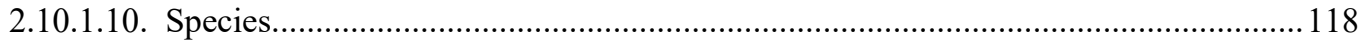

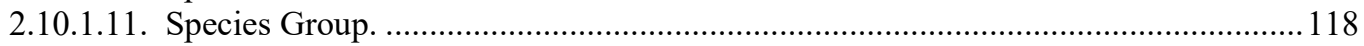

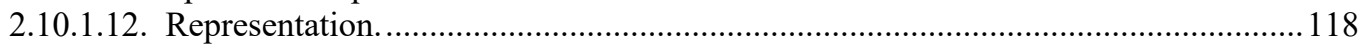

2.10.1.13. Minimum Dressed Sizes (width and thickness)....................................................... 118

2.10.2. Identity.

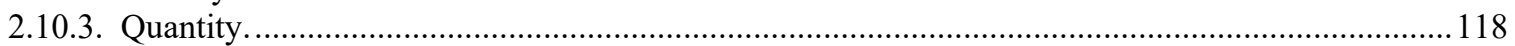

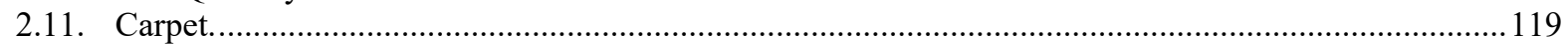




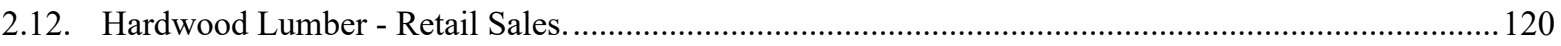

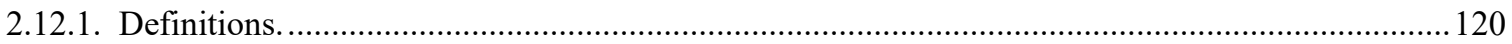

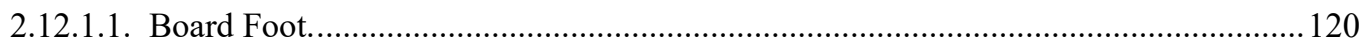

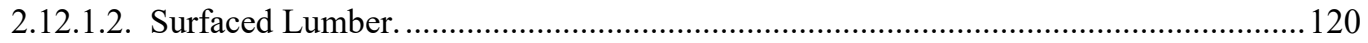

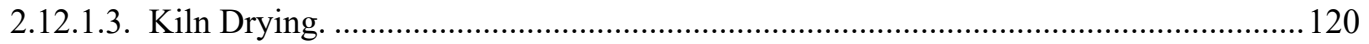

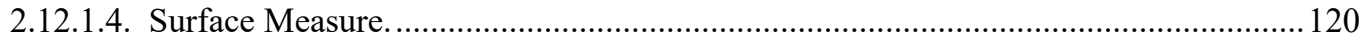

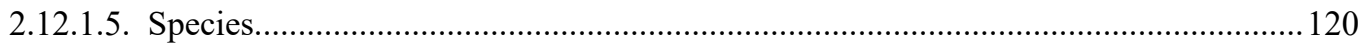

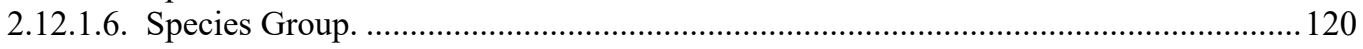

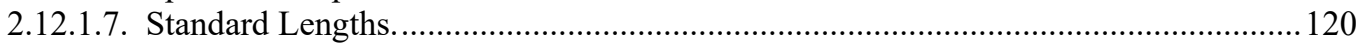

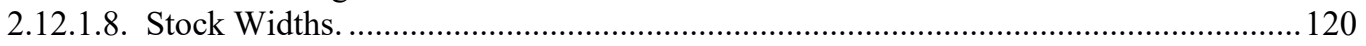

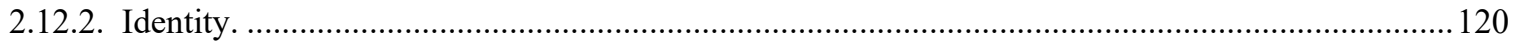

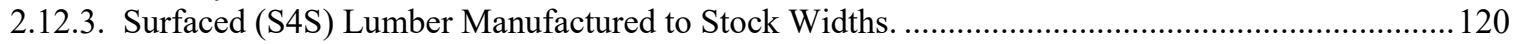

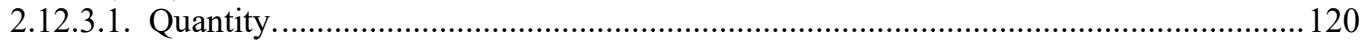

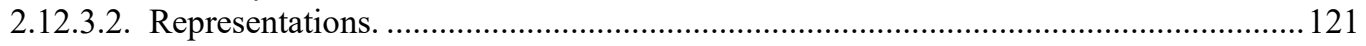

2.12.3.3. Minimum surfaced sizes for Kiln Dried Lumber (width and thickness).................... 121

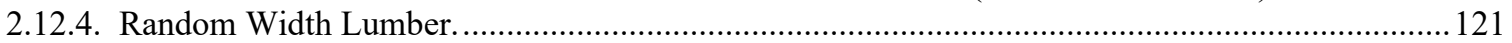

2.12.4.1. Sales of Random Width Hardwood Lumber. ........................................................... 121

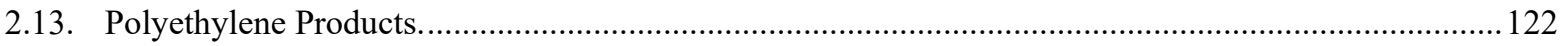

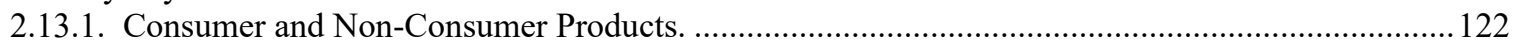

2.13.1.1. Sheeting and Film............................................................................................. 122

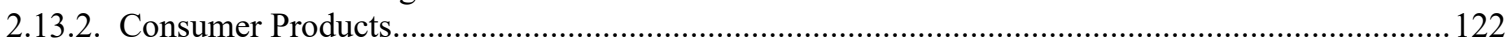

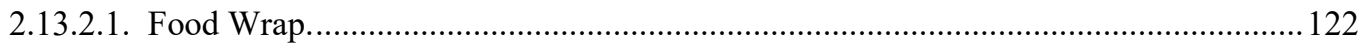

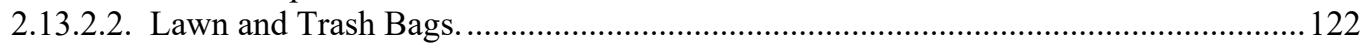

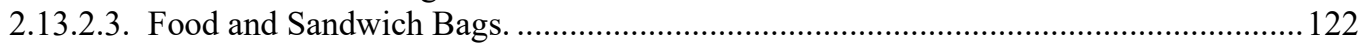

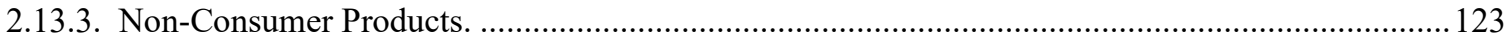

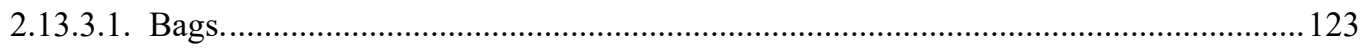

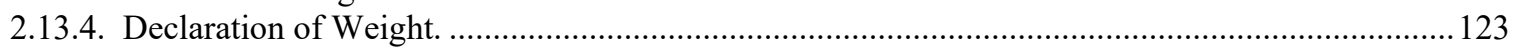

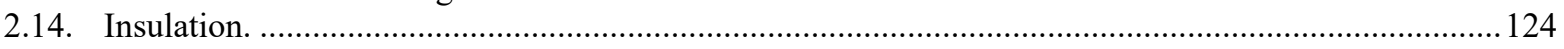

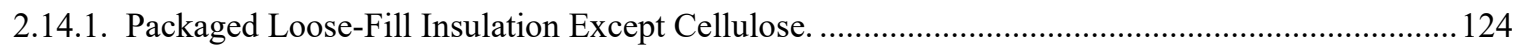

2.14.2. Packaged Loose-Fill Cellulose Insulation. ………................................................................. 124

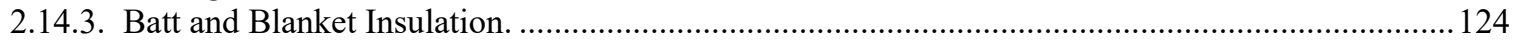

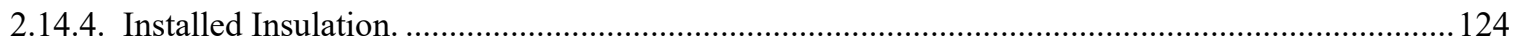

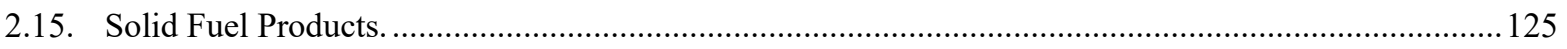

2.16. Compressed or Liquefied Gases in Refillable Cylinders. ................................................................ 125

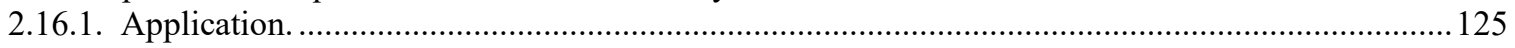

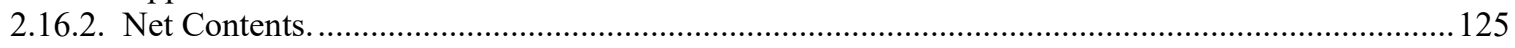

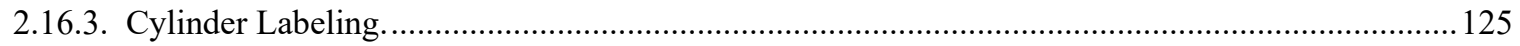

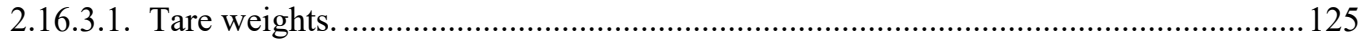

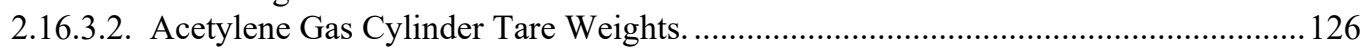

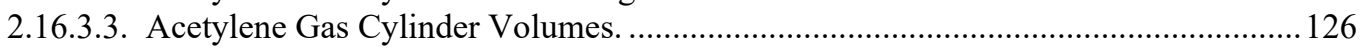

2.16.3.4. Compressed Gases such as Oxygen, Argon, Nitrogen, Helium, and Hydrogen..........126

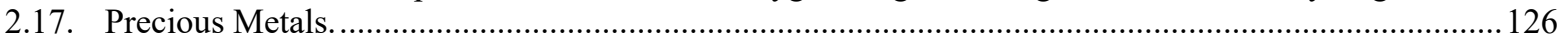

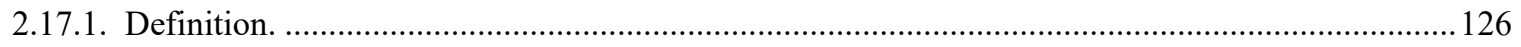

2.17.1.1. Precious Metals. ................................................................................................ 126

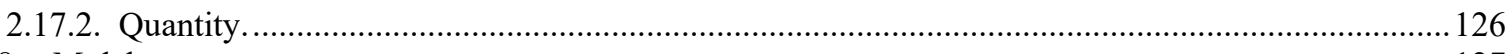

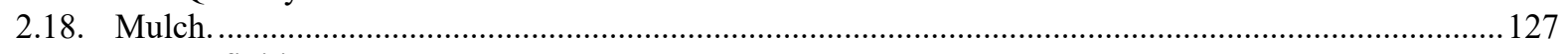

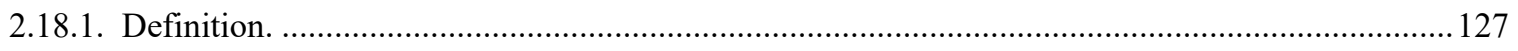

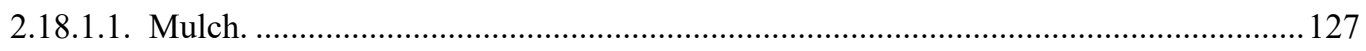

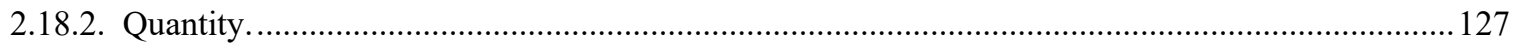

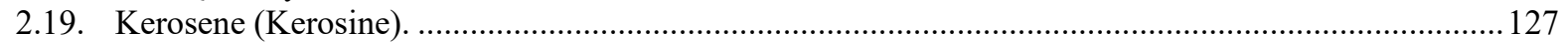

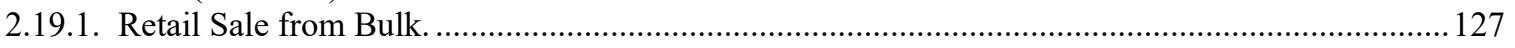

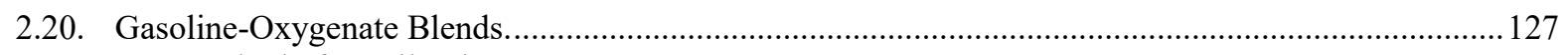

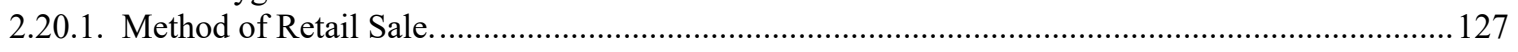

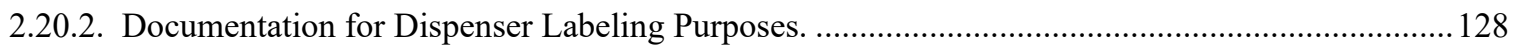

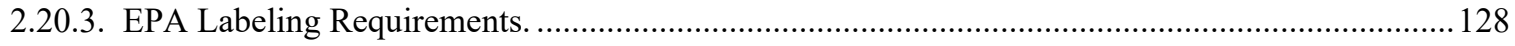

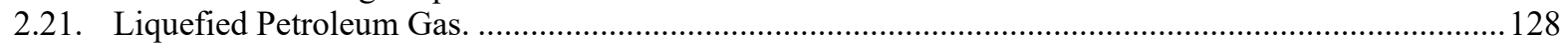




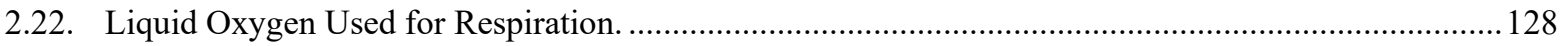

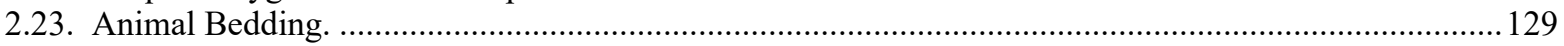

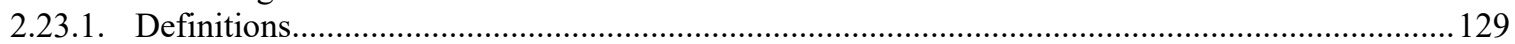

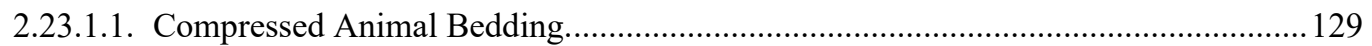

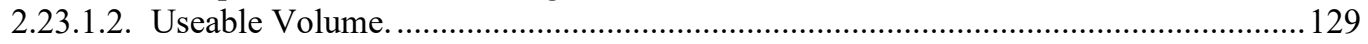

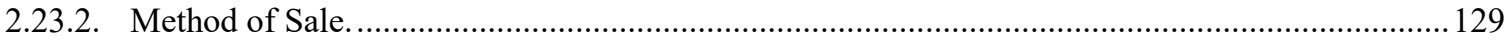

2.23.3. Exemption - Non-Consumer Packages Sold to Laboratory Animal Research Industry .................129

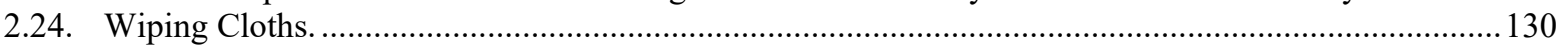

2.25. Baler Twine

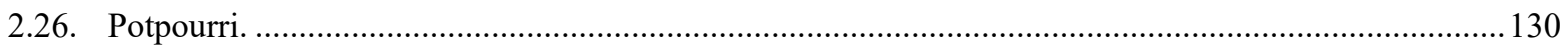

2.27. Retail Sales of Natural Gas Sold as a Vehicle Fuel. ..................................................................... 130

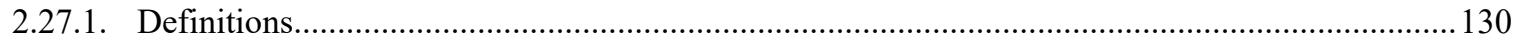

2.27.1.1. Compressed Natural Gas (CNG) ………………………................................... 130

2.27.1.2. Gasoline Gallon Equivalent (GGE) ..................................................................... 130

2.27.1.3. Diesel Gallon Equivalent (DGE)....................................................................... 130

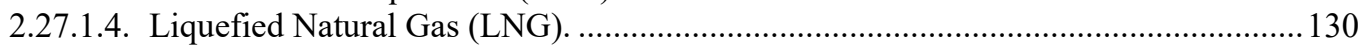

2.27.2. Method of Retail Sale and Dispenser Labeling...........................................................................130

2.27.2.1. Method of Retail Sale for Compressed Natural Gas. .................................................130

2.27.2.2. Dispenser Labeling Compressed Natural Gas............................................................. 130

2.27.2.3. Method of Retail Sale for Liquefied Natural Gas....................................................... 131

2.27.2.4. Dispenser Labeling of Retail Liquefied Natural Gas. ................................................ 131

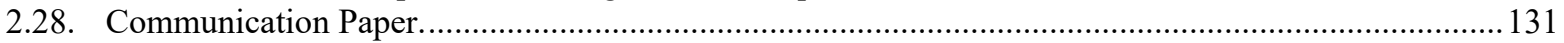

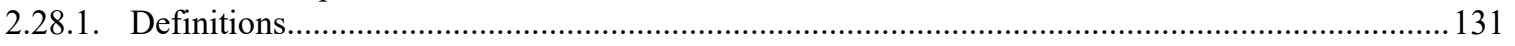

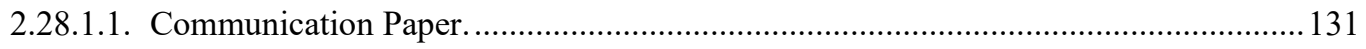

2.28.1.2. Basis Weight. ...................................................................................................... 131

2.28.2. Method of Retail Sale and Labeling....................................................................................... 131

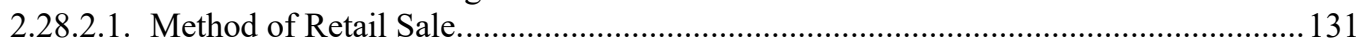

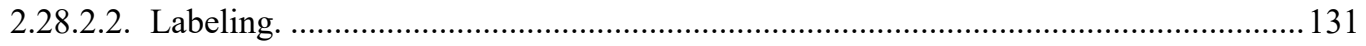

2.29. Sand, Rock, Gravel, Stone, Paving Stone, and Similar Materials, when Sold in Bulk........................ 131

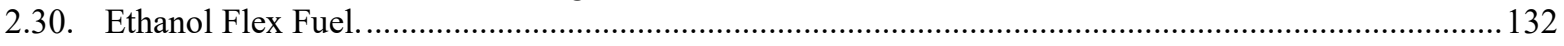

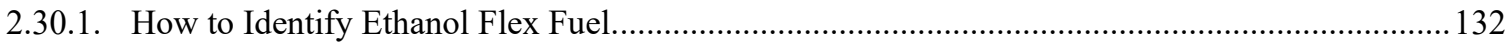

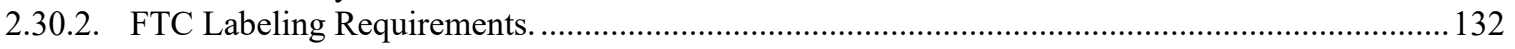

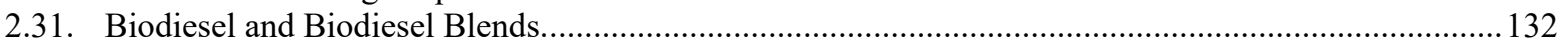

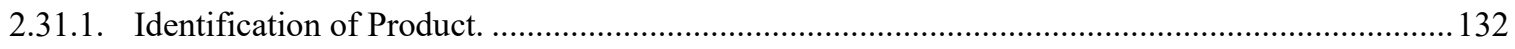

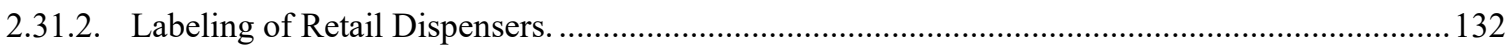

2.31.2.1. Labeling of Grade Required................................................................................... 132

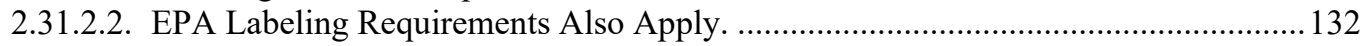

2.31.2.3. Automotive Fuel Rating..................................................................................... 132

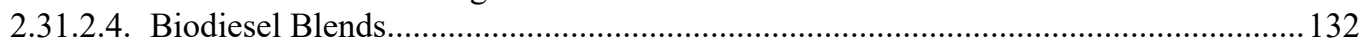

2.31.3. Documentation for Dispenser Labeling Purposes.................................................................. 132

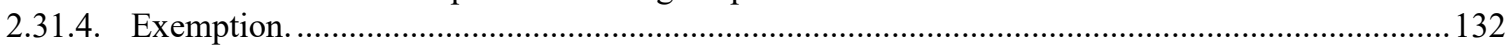

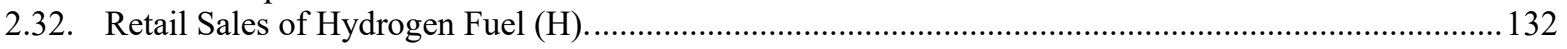

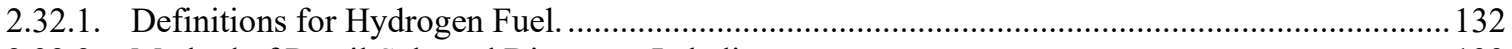

2.32.2. Method of Retail Sale and Dispenser Labeling ........................................................................133

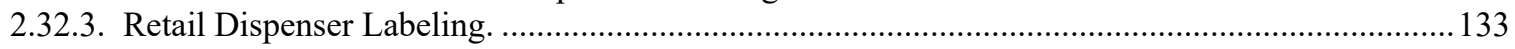

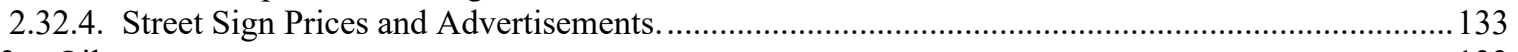

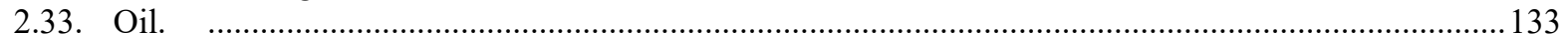

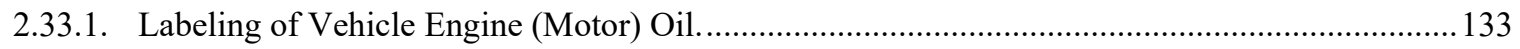

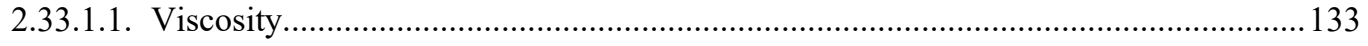

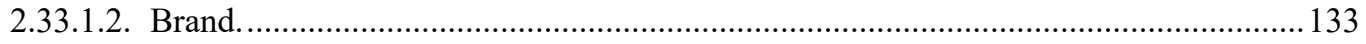

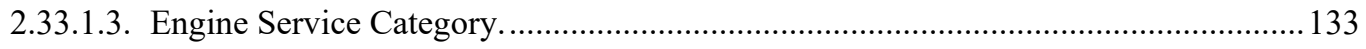

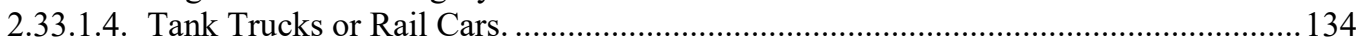

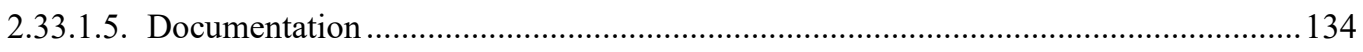

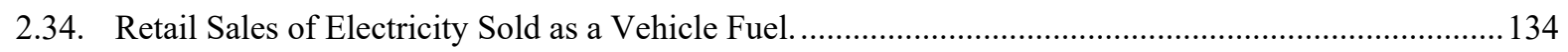

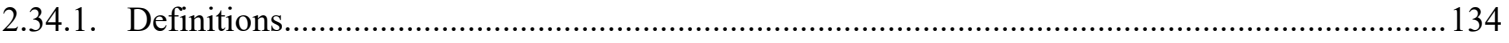

2.34.1.1. Electricity Sold as Vehicle Fuel. .......................................................................... 134 


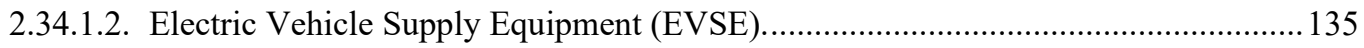

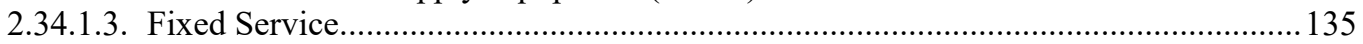

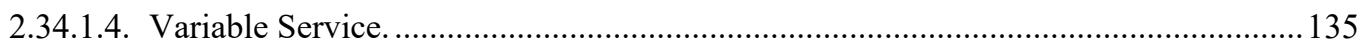

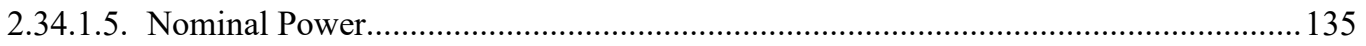

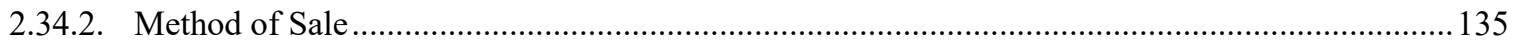

2.34.3. Retail Electric Vehicle Supply Equipment (EVSE) Labeling. ..................................................135

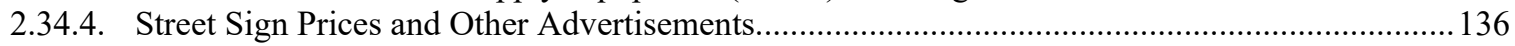

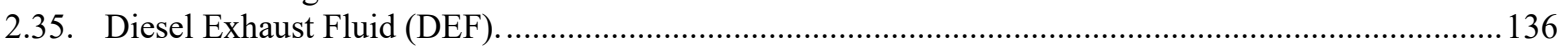

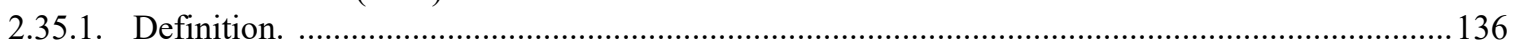

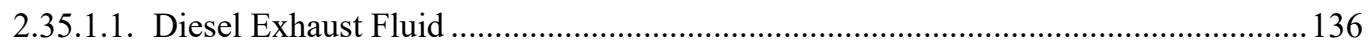

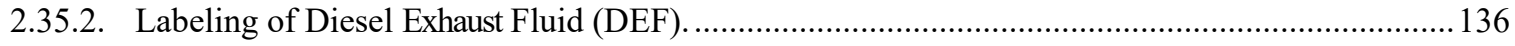

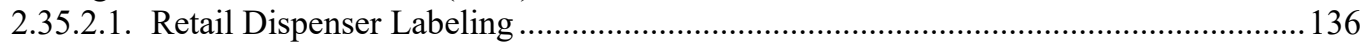

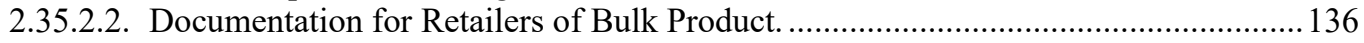

2.35.2.3. Labeling of Packaged Product................................................................................. 137

2.35.2.4. Documentation for Bulk Deliveries. ...................................................................... 137

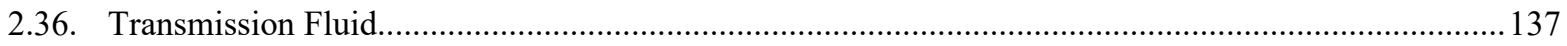

2.36.1. Products for Use in Lubricating Transmissions. .......................................................................137

2.36.1.1. Conformance...................................................................................................... 137

2.36.1.2. Transmission Fluid Additives. ................................................................................ 137

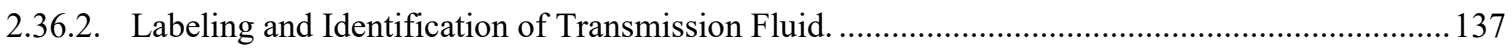

2.36.2.1. Container Labeling........................................................................................... 137

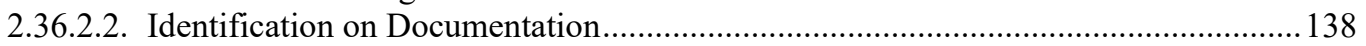

2.36.2.3. Identification on Service Provider Documentation. .................................................... 138

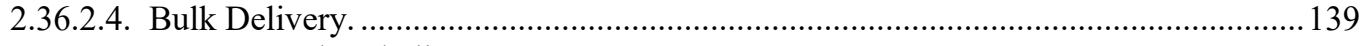

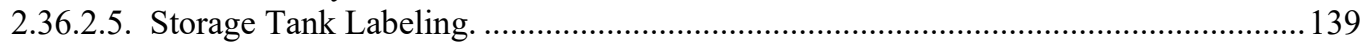

2.36.3. Documentation of Claims Made Upon Product Label................................................................... 139

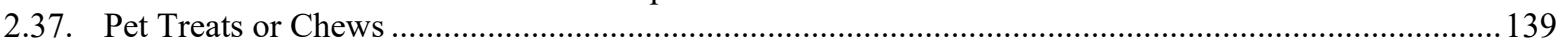

2.38. Non-Utility Transactions of Electrical Energy (Other than Vehicle Fueling Applications). ....................139

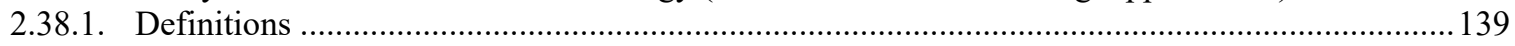

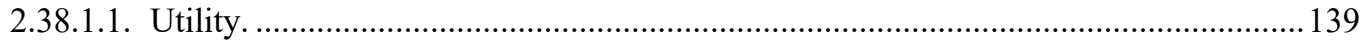

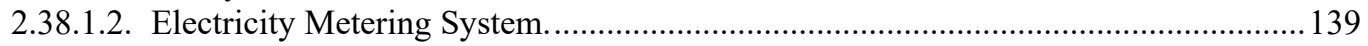

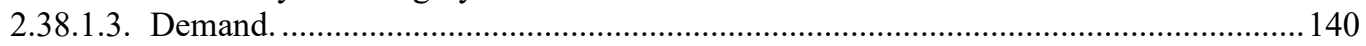

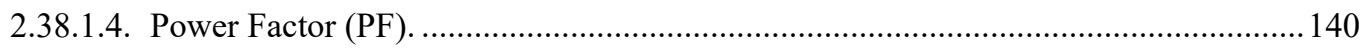

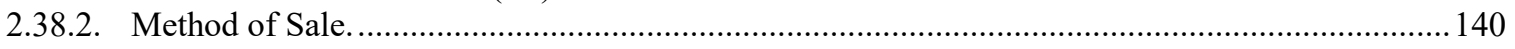

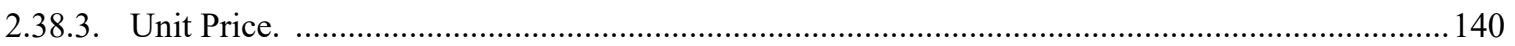

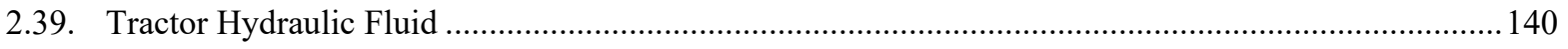

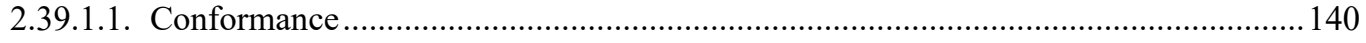

2.39.1.2. Tractor Hydraulic Fluid Additives ......................................................................... 140

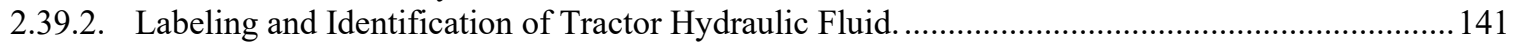

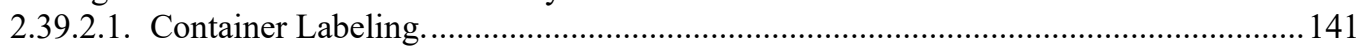

2.39.2.2. Identification on Documentation............................................................................ 141

2.39.2.3. Identification on Service Provider Documentation................................................... 142

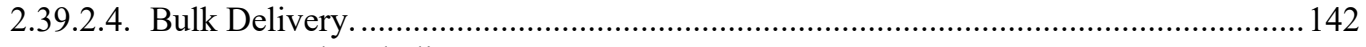

2.39.2.5. Storage Tank Labeling. ........................................................................................ 142

2.39.3. Documentation of Claims Made Upon Product Label. ...............................................................142

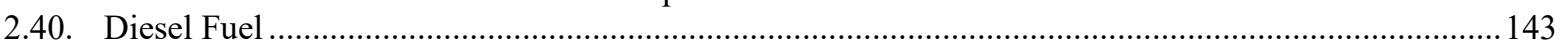

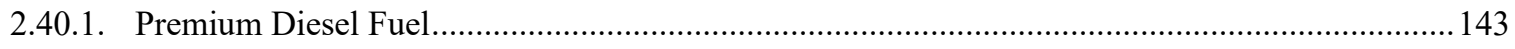

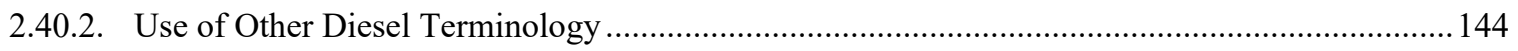

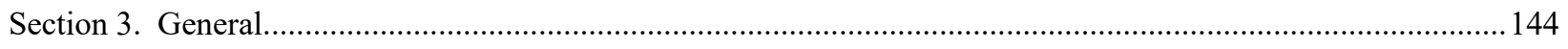

3.1. Presentation of Price .................................................................................................................. 144

3.2. Allowable Differences: Combination Quantity Declarations........................................................ 144

3.2.1. Beverageware: Pressed and Blown Tumblers and Stemware. ……............................................144

3.3. Labeling of Machines that Dispense Packaged Commodities.......................................................... 144

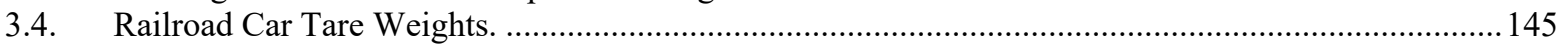


B. Uniform Regulation for the Method of Sale of Commodities

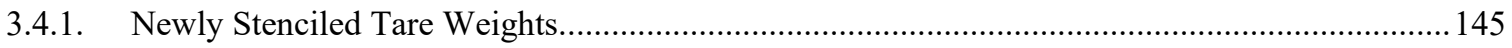

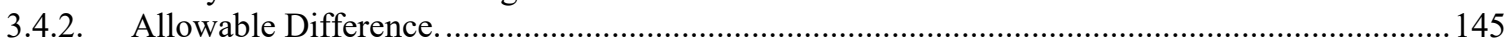

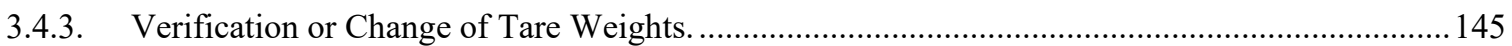

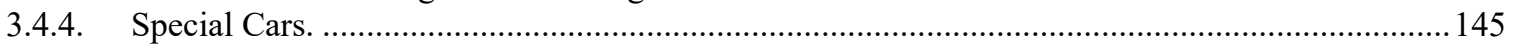

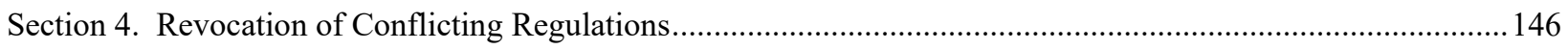

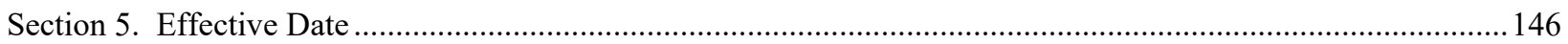




\section{B. Uniform Regulation for the Method of Sale of Commodities}

\section{Preamble}

The purpose of this regulation is to require accurate and adequate information about commodities so that purchasers can make price and quantity comparisons.

Packages and their labels should enable consumers to obtain accurate information as to the quantity of the contents and should facilitate value comparisons. Equally, sales of commodities from bulk should be according to methods and units readily recognized and understood by, both, buyer and seller.

(Added 1989) (Amended 2019)

Section 1. Food Products ${ }^{[\mathrm{see}}$ Section 1.1. NOTE 1]

Unless otherwise specified or specifically permitted, the sale of any food product, whether sold from bulk or in packaged form, shall be only according to a unit of measure or weight that meets all of the following criteria:

(1) Is recognized and defined by NIST as legal for use in commerce

(2) Has been published in the "Federal Register"; and

(3) The measurement values have metrological traceability (see Section 1.1. NOTE 2) to a national standard

NOTE: Sale of a product or commodity according to count, where appropriate to be fully informative to facilitate value comparison, is permissible as a method of sale.

(Added 2019)

\subsection{Berries and Small Fruits}

1.1.1. Definitions. - "Small fruits" includes, but is not limited to cherries, currants, and cherry tomatoes. "Berries" includes all fruit whose names end in the term "berry."

(Added 1991)

Section 1.1. NOTE 1: Packages subject to this Section and the Federal Fair Packaging and Labeling Act shall be labeled in units of the International System of Units (SI) and U.S. customary systems of measure effective February 14, 1994, [except for seed (see Section 10.10. Packaged Seed) and camera film and recording tape (see Section 11.22. Camera Film, Video Recording Tape, Audio Recording Tape, and Other Image and Audio Recording Media Intended for Retail Sale and Consumer Use), and as specified in the Uniform Packaging and Labeling Regulation under Section 11.32. SI Units, Exemptions - Consumer Commodities]. SI units may appear first.

(Added 1982) (Amended 1990 and 1993)

Section 1.1. NOTE 2: As defined in NIST Handbook 130, Uniform Weights and Measures Law, Metrological traceability means the property of a measurement result whereby the result can be related to a reference through a documented unbroken chain of calibrations, each contributing to the measurement uncertainty.

(Added 2019)

1.1.2. Methods of Sale. - Berries and small fruits shall be offered and exposed for sale and sold by weight [see Section 1.1.2. NOTE] or by volume. If sold by volume, they must:

(Amended 1991) 
B. Uniform Regulation for the Method of Sale of Commodities

(a) be in measure containers that are either open or else covered by uncolored transparent lids or other wrappings that do not obscure the contents, and

(b) have capacities per Section 1.1.2.(b)(1) or Section 1.1.2.(b)(2). When selling berries and small fruits by volume in measure containers, whether or not covered, the measure containers themselves shall not be packages for labeling purposes.

(1) SI Capacities - 250 milliliters, 500 milliliters, or 1 liter. (Added 1979) (Amended 1985)

(2) U.S. Customary Capacities - $1 / 2$ dry pint, 1 dry pint, or 1 dry quart.

Section 1.1.2. NOTE: When used in this regulation, the term "weight" means "mass." (See paragraphs K. "Mass" and "Weight" in Section I. Introduction of NIST Handbook 130 for an explanation of these terms.)

1.1.3. Marking Requirements for Shipping Containers. - If two or more measure containers are placed in a shipping package, the crate or package shall show the number of measure containers and the quantity of contents of each.

(Added 1971) (Amended 1979, 1985, 1989, and 1991)

1.2. Bread. - Bread kept, offered, or exposed for sale, whether or not packaged or sliced, shall be sold by weight. The wrappers of bread that is sold and expressly represented at the time of sale as "stale bread" shall not be considered packages for labeling purposes.

(Added 1971) (Amended 1979, 1980, 1985, 1987, 1991, and 1992)

1.3. Butter, Oleomargarine, Margarine, Butter-Like, and/or Margarine-Like Spreads. - Shall be offered and exposed for sale and sold by weight. "Butter-like and/or margarine-like spreads" are those products that meet the Federal Standard of Identity for butter or margarine and oleomargarine, except that they contain less than $80 \%$ fat and may contain other safe and suitable ingredients.

(Added 1971) (Amended 1979, 1985, 1986, and 1994)

1.4. Flour, Corn Meal, and Hominy Grits. - Wheat flour, whole wheat flour, graham flour, self-rising wheat flour, phosphated wheat flour, bromated flour, corn flour, corn meal, and hominy grits, whether enriched or not, shall be packaged, kept, offered, or exposed for sale and sold by weight.

(Amended 1994)

1.5. Meat, Poultry, Fish, and Seafood. [see Section 1.5. NOTE] - Shall be sold by weight, except that whole shellfish in the shell may be sold by weight, measure, and/or count. Shellfish are aquatic animals having a shell, such as mollusks (for example, scallops) or crustaceans (for example, lobster or shrimp).

(a) When meat, poultry, fish, or seafood is kept, offered or exposed for sale from bulk (e.g., direct service counters) by the portion or piece according to a pre-determined fixed weight, the product identity and net weight shall be displayed, as well as the unit price at which it is offered for sale. This information shall appear on a label or sign immediately adjacent to the meat, poultry, fish, or seafood and must be presented in an easy-to-read type style and color. The font size of the net weight and unit price declaration shall be equal to or greater than the font size used for the product identity.

(b) The unit price required under Sections 1.5.(a) shall be in terms of the unit price per kilogram or unit price per pound and not in common or decimal fractions of the permitted units. A supplemental declaration of a price per unit (i.e., price per ounce) is permitted.

(c) Similar or competing commodities kept, offered, or exposed for sale from bulk in any single display or facility 
(d) shall have unit prices posted or advertised in the same terms uniformly and consistently expressed (i.e., all in either prices per kilogram or prices per pound; not in differing units) to readily facilitate value comparison.

(Amended 1988 and 2016)

Section 1.4. NOTE: See Section 1.12. Ready-to-Eat Food for additional requirement.

1.5.1. In Combination with Other Foods. - When meat, poultry, fish, or seafood is combined with some other food element to form a distinctive food product, the quantity representation may be in terms of the total weight of the product or combination, and a quantity representation need not be made for each element provided a statement listing the ingredients in order of their predominance by weight must also appear on the label.

NOTE: Also see NCWM Policy, Interpretations, and Guidelines, Section 2.2.13. Declaration of Identity: Consumer Package (UPLR) and Section 1.5.1. In Combination with Other Foods (UMSCR).

(Amended 1989)

\subsubsection{Clams, Mussels, Oysters, and Other Mollusks.}

1.5.2.1. Whole Clams, Oysters, Mussels, or Other Mollusks in the Shell (fresh or frozen). - Shall be sold by weight (including the weight of the shell, but not including the liquid or ice packed with them), dry measure (e.g., bushel), and/or count. In addition, size designations may be provided.

1.5.2.2. Whole Clams, Oysters, Mussels, or Other Mollusks on the Half Shell (fresh, cooked, smoked, or frozen, with or without sauces or spices added). - Shall be sold by weight (excluding the weight of the shell) or by count. Size designations may also be provided.

(Added 1989)

1.5.2.3. Fresh Oysters Removed from the Shell. - Shall be sold by weight, drained weight, or by fluid volume. For oysters sold by weight or by volume, a maximum of $15 \%$ free liquid by weight is permitted.

(Amended 1991)

1.5.2.4. Processed Clams, Mussels, Oysters, or Other Mollusks on the Half Shell (fresh or frozen). Shall be sold by net weight excluding the weight of the shell. The term "processed" means removing the meat from the shell and chopping it or cutting it or commingling it with other solid foods.

(Amended 1989)

1.5.2.5. Canned (heat-processed) Mussels, Clams, Oysters, or Other Mollusks. - Shall be sold by net weight. A maximum of $41 \%$ free liquid by weight is permitted for canned oysters.

(Added 1986 and 1971) (Amended 1982, 1985, 1986, and 1989)

1.6. Fluid Milk Products. - All fluid milk products, including, but not limited to milk, lowfat milk, skim milk, cultured milks, and cream, shall be sold in terms of fluid volume.

(Amended 1995)

1.7. Other Milk Products. - Cottage cheese, cottage cheese products, and other milk products that are solid, semisolid, viscous, or a mixture of solid and liquid, as defined in the Pasteurized Milk Ordinance of the U.S. Public Health Service, as amended in 1965, shall be sold in terms of weight.

(Amended 1995)

1.7.1. Factory Packaged Ice Cream and Similar Frozen Products. - Ice cream, ice milk, frozen yogurt, and similar products shall be kept, offered, or exposed for sale or sold in terms of fluid volume.

(Amended 1995) 
B. Uniform Regulation for the Method of Sale of Commodities

1.7.2. Pelletized Ice Cream and Similar Pelletized Frozen Desserts. - A semi-solid food product manufactured at very low temperatures using a nitrogen process and consisting of small beads of varying sizes. Bits of inclusions (cookies, candy, etc.) that also vary in size and weight may be mixed with the pellets.

1.7.2.1. Method of Retail Sale. - Packaged pelletized ice cream or similar pelletized frozen desserts shall be kept, offered, or exposed for sale on the basis of net weight.

(Added 2010) (Amended 2011)

1.8. Pickles. - The declaration of net quantity of contents on pickles and pickle products, including relishes but excluding one or two whole pickles in a transparent wrapping, which may be declared by count, shall be expressed in terms of liquid measure. Sales of pickles from bulk may be by count.

(Added 1971)

\subsection{Advertising and Price Computing of Bulk Food Commodities.}

1.9.1. Total Price Computing. - The price of food commodities sold from bulk by weight shall be computed in terms of whole units of weight (i.e., price per kilogram, pound, gram, ounce, etc.) and not in common or decimal fractions.

(Amended 2016)

1.9.2. Unit Price Advertising. - The unit price of food commodities sold from bulk shall be advertised or displayed in terms of the price per whole units of weight units in kilograms or pounds only, not in common or decimal fractions of a kilogram or pound or in ounces. A supplemental declaration of a price per unit (i.e., price per ounce) is permitted in font size no larger than the whole unit price. This supplemental declaration may be expressed in common or decimal fractions or in ounces.

(Added 1976) (Amended 1985, 1987, 1991, and 2016)

1.9.3. Individual Piece Advertising. - The unit price and net weight of any food commodity offered or exposed for sale from bulk by the portion or piece, according to a pre-determined fixed weight, shall be advertised or displayed to include a declaration of the individual item price, a unit price in terms of kilogram or pound and net weight in terms of kilograms or pounds or decimal fractions, thereof. The font size of the net weight and the unit price declaration shall be equal to or greater than the font size used for the product identity.

(Added 2016)

NOTE: For specific requirements on Meat, Poultry, Fish and Seafood refer to Section 1.5. Meat, Poultry, Fish, and Seafood.

(Added 2016)

1.10. Generic Terms for Meat Cuts. - A declaration of identity for meat cuts shall be limited to generic terms, such as those listed in the Uniform Retail Meat Identity Standards.

The following abbreviations may be used: 
(Added 1976)

\begin{tabular}{||l|l||l|l||}
\hline \hline Abbreviation & \multicolumn{1}{|c|}{ Identity } & Abbreviation & \multicolumn{1}{||}{ Identity } \\
\hline \hline BAR B Q & Barbecue & POT-RST & Pot Roast \\
\hline BI & Bone In & RND & Round \\
\hline BNLS & Boneless & RST & Roast \\
\hline DBLE & Double & SHLDR & Shoulder \\
\hline LGE & Large & SQ & Square \\
\hline N.Y. (NY) & New York & STK & Steak \\
\hline PK & Pork & TRMD & Trimmed \\
\hline
\end{tabular}

1.11. Sale of Meat by Carcass, Side, or Primal Cut. - The seller of a carcass, side, quarter, or primal cut on a gross or hanging weight basis shall provide to the buyer a written statement giving the following information at the times indicated:

(Amended 1985)

\subsubsection{Prior to Delivery.}

(a) the name and address of the seller (firm);

(b) the date of the contract;

(c) the name and address of the buyer;

(c) the total net weight (hanging weight) of the carcass, side, or primal cut prior to cutting or processing;

(e) the USDA quality grade and yield grade of the meat to be supplied, if so represented;

(f) the price per pound for each species (not including any inducements) and the total price of the sale order;

(g) the estimated cutting loss on the order in terms of percentage and weight (e.g., $40 \%, 72.5 \mathrm{~kg}[160 \mathrm{lb}]$ );

(h) a list by name and estimated count of each cut to be derived from each primal source;

(i) additional costs, listed separately, for cutting, wrapping, freezing, and finance charges, if any; and

(j) that the buyer may keep the cutting loss.

(Added 1985)

\subsubsection{At the Time of Delivery.}

(a) the name and address of the buyer and seller;

(b) the date of delivery;

(c) the total net weight of the meat delivered;

(d) a list, by name and count, of each cut derived from each primal cut; and 
B. Uniform Regulation for the Method of Sale of Commodities

(e) a separate indication of the quantity of any meat or other commodity(s) received by the purchaser as an inducement in connection with the purchase of the carcass, side, or primal cut.

(Added 1985)

1.11.3. Exemptions. - This subsection shall not apply to the sale of any carcass, side, quarter, or primal cut of meat that individually or collectively has a gross or hanging weight of $22.6 \mathrm{~kg}(50 \mathrm{lb})$ or less.

(Added 1985)

1.11.4. Right of Cancellation. - The buyer shall have the right to cancel any carcass, side, quarter, or primal cut meat contract until midnight of the third business day after the day on which the buyer executed the contract or after the day on which the seller provided the buyer with a fully executed copy of the contract, whichever is later. (Added 1985 and 1977) (Amended 1980 and 1985)

\subsection{Ready-to-Eat Food.}

1.12.1. Definition. - Restaurant style food offered or exposed for sale, whether in restaurants, supermarkets, or similar food service establishments that is ready for immediate human consumption, though not necessarily on the premises where sold, and which does not require any cooking or heating preparation by the customer. Readyto-eat food does not include sliced luncheon products, such as meat, poultry, or cheese when sold separately.

Some examples of ready-to-eat food items: (This list is not intended to be all inclusive.)

- servings of pasta, potato, or coleslaw;

- servings of salads, vegetables, or grains such as rice;

- pizzas, whole or sliced;

- meat/vegetable pockets/pies;

- tacos, fajitas, enchiladas, tostadas;

- cooked, whole chickens or turkeys;

- buckets, tubs, or individual pieces of cooked chicken or fish;

- cooked ribs by the slab or piece;

- stuffed clams, oysters, shrimp, and fish;

- cooked shrimp or crab cakes;

- $\quad$ slices of cake, pie, or quiche;

- donuts, bagels, or rolls for individual sale;

- cookies or brownies for individual sale;

- sandwiches, eggs, or spring rolls;

- $\quad$ servings of prepared chili or soup;

- $\quad$ stuffed peppers, tomatoes, and cabbage;

- knishes; and

- pickles.

NOTE: The sale of an individual piece of fresh fruit (like an apple, banana, or orange) is allowed by count. (Added 2004) (Amended 2017) 
1.12.2. Methods of Sale. - Ready-to-eat food sold from retail cases displaying product in bulk or in servings packed or prepared on the premises may be sold by weight, measure, or count (i.e., by piece, portion, or serving). If pre-packaged, the product shall have the appropriate statement of quantity set forth in the current edition of NIST Handbook 130, Uniform Packaging and Labeling Regulation (UPLR).

(Amended 1993) (Amended 2017)

\subsection{Home Food Service Plan Sales.}

\subsubsection{Definitions.}

As used in this section, the following words and phrases shall have the following meanings:

(a) Home Food Service Plan. - The offering for sale to a consumer, in the consumer's home, any food item, or food item in combination with any nonfood item and/or services, whether or not a membership fee or similar charge is involved.

(b) Seller. - Any person, partnership, corporation, or association, however organized, engaged in the sale of a home food service plan.

(c) Buyer. - Both the actual and prospective purchaser, but does not include persons purchasing for resale.

(d) Contract. - All of the collective written agreements subscribed by a buyer at the time of sale relating to the purchase of a home food service plan, except promissory notes or other financing agreements.

(e) Food Item. - Each edible product sold as part of a home food service plan, including, but not limited to, each constituent part or kind of meat cut from a primal source, each kind of whole poultry or poultry part, seafood products, and other like products.

(f) Nonfood Item. - Each inedible product sold as part of a home food service plan, including, but not limited to, paper products, health and beauty products, detergents, cleaners and disinfectants, rolls of wrapping, and like products. The term does not include food items and durable consumer goods such as appliances.

(g) Unit Price. - The price of a food or nonfood item sold as part of a home food service plan, computed to the nearest tenth of 1 cent when less than 1 dollar, and to the nearest cent when 1 dollar or more. The unit price, exclusive of any service charge(s), shall be expressed in terms of the price per unit of weight, measure, or count set forth in the "Uniform Unit Pricing Regulation" in the current edition of NIST Handbook 130.

(h) Service Charge. - The total price for any additional features, services, and processing associated with the purchase of a home food service plan, whether stated in terms of membership fees or otherwise.

(i) Primal Source. - Refers to the following cuts:

(1) for beef, the primal sources are the round, flank, loin, rib, plate, brisket, chuck, and shank;

(2) for veal and lamb or mutton, the primal sources are the leg, flank, loin, rack (rib), and shoulder; and

(3) for pork, the primal sources are the belly, loin, ham, spareribs, shoulder, and jowl. 


\subsubsection{Contract and Disclosure Requirements.}

\subsubsection{At the Time of Sale.}

(a) At the time of sale, the Seller shall provide the Buyer with a single document, referred to in this subsection as the "written agreement," which shall clearly and conspicuously disclose the following:

(1) the name, address, and telephone number of the Seller and the name and address of the Buyer;

(2) the date of the contract;

(3) the price of the food and nonfood items of the home food service plan;

(4) the service charge or the price of any service charges associated with the home food service plan;

(5) the total price of the home food service plan, including the price of the food and nonfood items, and the price of any service charge; and

(6) a statement that the Buyer shall have the right to cancel the home food service plan contract until midnight of the third business day after the date on which the Buyer executed the contract or after the day on which the Seller provided the Buyer with a fully executed copy of the contract, whichever is later, by giving written notice of cancellation to the Seller. Compliance with requirements of federal statutes, rules, or regulations governing form of notice of right of cancellation shall be deemed satisfactory notice of the requirements of this regulation.

(b) In addition to the above disclosures required in the written agreement, the following disclosures are required to be given to the Buyer at the time of sale:

(1) A written list of all food and nonfood items to be sold, which shall include:

i. the identity of each unit and, where applicable, the USDA quality grade of the item, if so graded; the primal source; and the brand or trade name;

ii. the quantity of each item sold;

iii. the estimated serving size by net weight of each piece of meat, poultry, and seafood item offered for sale under the home food service plan, provided, however, that such estimates shall not differ from the actual weight at the time of delivery by more than $5 \%$ and the dollar value of the meat, poultry, and seafood items delivered is equal to or greater than that represented to the Buyer; and

iv. the net weight, measure, or count of all other food and nonfood items offered for sale.

(2) A current unit price list stating in dollars and cents the price per kilogram or pound or other appropriate unit of measure, and the total sale price of each item to be delivered. This price list shall clearly and conspicuously make reference to the fact of whether there are additional costs disclosed in the written agreement relating to any "service charges" associated with the purchase of the home food service plan.

(3) If a membership is sold, a written statement of all terms, conditions, benefits, and privileges applicable to the membership.

(4) If a service charge is included, a written statement specifically identifying the service(s) provided and the price(s) charged for them. 


\subsubsection{At the Time of Delivery.}

(a) At the time of delivery, the Seller shall provide a receipt, for signature by the Buyer, disclosing the following information:

(1) the identity of the item and the net quantity of the contents in terms of either weight, measure, or count, as required by applicable law. The net weight of each food item delivered shall be within the limit specified in Section 1.13.2.1.b(i)(iii) Contract and Disclosure Requirements; and

(2) the unit price and total sales price of each food and nonfood item. The unit price shall be the same as that specified on the unit price list given to the Buyer at the time of sale.

1.13.3. Advertisement of Home Food Service Plans. - Any advertisement of a home food service plan which discloses item pricing information in accordance with the provisions of this section shall set forth, in a clear and conspicuous manner, whether there are any service charges or other additional costs associated with the purchase of the home food service plan.

(Added 1992)

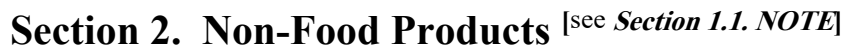

Unless otherwise specified or specifically permitted, the sale of any non-food product, whether sold from bulk or in packaged form, shall be only according to a unit of measure or weight that meets all of the following criteria:

(1) Is recognized and defined by NIST as legal for use in commerce

(2) Has been published in the "Federal Register"; and

(3) The measurement values have metrological traceability (see Section 1.1. NOTE) to a national standard.

NOTE: Sale of a product or commodity according to count, where appropriate to be fully informative to facilitate value comparison, is permissible as a method of sale.

(Added 2019)

2.1. Advertising and Price Computing of Bulk Commodities. - The price of bulk commodities or commodities not in package form and sold by weight shall be advertised, displayed, and computed in terms of whole units of weight (i.e., grams, kilograms, pounds, ounces, etc.), and not in common or decimal fractions.

(Added 1989)

2.2. Fence Wire Products. - Rolls of fence wire products shall be sold by:

(a) Gauge of wire.

(b) Height in terms of inches or centimeters, if applicable.

(c) Length in terms of rods, meters, or feet. (Added 1979)

2.3. Coatings. - Asphalt paints, coatings, and plastics shall be sold in terms of liquid measure. (Added 1971) 
B. Uniform Regulation for the Method of Sale of Commodities

2.4. Fireplace and Stove Wood. - For the purpose of this regulation, this section shall apply to the sale of all wood, natural and processed, for use as fuel or flavoring.

(Amended 1999)

\subsubsection{Definitions.}

2.4.1.1. Fireplace and Stove Wood. - Any kindling, logs, boards, timbers, or other wood, natural or processed, split or not split, advertised, offered for sale, or sold for use as fuel.

(Amended 1991)

2.4.1.2. Cord. - The amount of wood that is contained in a space of $128 \mathrm{ft}^{3}$ when the wood is ranked and well stowed. For the purpose of this regulation, "ranked and well stowed" shall be construed to mean that pieces of wood are placed in a line or row, with individual pieces touching and parallel to each other, and stacked in a compact manner.

2.4.1.3. Representation. - This shall be construed to mean any advertisement, offering, invoice, or the like that pertains to the sale of fireplace or stove wood.

2.4.1.4. Flavoring Chips. - Any kindling, logs, boards, timbers, or other natural or processed, split or unsplit wood that is advertised, offered for sale, or sold for flavoring smoked or barbequed foods.

(Added 1999)

2.4.2. Identity. - A representation may include a declaration of identity that indicates the species group (for example, $50 \%$ hickory, $50 \%$ miscellaneous softwood). Such a representation shall indicate, within $10 \%$ accuracy, the percentages of each group.

2.4.3. Quantity. - Fireplace and stove wood shall be advertised, offered for sale, and sold only by measure, using the term "cord" and fractional parts of a cord or the cubic meter, except that:

(a) Packaged natural wood. - Natural wood offered for sale in packaged form in quantities less than $0.45 \mathrm{~m}^{3}\left(1 / 8\right.$ cord or $\left.16 \mathrm{ft}^{3}\right)$ shall display the quantity in terms of:

(1) liters, to include fractions of a liter, and may also include a declaration of quantity in terms of cubic foot or feet to include fractions of a cubic foot.

(Amended 2010 and 2016)

NOTE: Implementation for the requirement for use of the liter in (1) packages may continue to show the cubic decimeter $\left(\mathrm{dm}^{3}\right)$ instead of liters $(L)$ for four years after the effective date of this regulation to allow for the use of current packages inventories.

(Added 2016) (Amended 2019)

(b) Artificial compressed or processed logs. - A single fireplace log shall be sold by weight, and packages of such individual logs shall be sold by weight plus count.

(c) Stove wood pellets or chips. - Pellets or chips not greater than $15 \mathrm{~cm}$ (6 in) in any dimension shall be sold by weight. This requirement does not apply to flavoring chips.

(Amended 1976 and 1991)

(d) Flavoring chips. - Flavoring chips offered for sale in packaged form in quantities less than $0.45 \mathrm{~m}^{3}$ $\left(1 / 8\right.$ cord or $\left.16 \mathrm{ft}^{3}\right)$ shall display the quantity in terms of: 
(1) liters, to include fractions of a liter, and may also include a declaration of quantity in terms of cubic foot or feet to include fractions of a cubic foot.

(Added 1998) (Amended 2010 and 2016)

NOTE: In determining the appropriate Method of Sale, a clear distinction must be made as to whether the wood is being sold primarily as fuel (some wood is sold as fuel but flavoring is a byproduct) or strictly as a wood flavoring.

(Added 2010)

(Amended 1976, 1991, 1998, 2010, and 2016)

2.4.4. Prohibition of Terms. - The terms "face cord," "rack," "pile," "truckload," or terms of similar import shall not be used when advertising, offering for sale, or selling wood for use as fuel.

2.4.5. Delivery Ticket or Sales Invoice. - A delivery ticket or sales invoice shall be presented by the seller to the purchaser whenever any non-packaged fireplace or stove wood is sold. The delivery ticket or sales invoice shall contain at least the following information:

(a) the name and address of the vendor;

(b) the name and address of the purchaser;

(c) the date delivered;

(d) the quantity delivered and the quantity upon which the price is based, if this differs from the delivered quantity;

(e) the price of the amount delivered; and

(f) the identity, in the most descriptive terms commercially practicable, including any quality representation made in connection with the sale.

(Added 1975)

2.5. Peat and Peat Moss. - Applies only with respect to organic matter of geological origin, excluding coal and lignite, originating principally from dead vegetative remains through the agency of water in the absence of air and occurring in a bog, swampland, or marsh, and containing an ash content not exceeding $25 \%$ on a dry weight basis [dried in an oven at $105^{\circ} \mathrm{C}\left(221^{\circ} \mathrm{F}\right)$ until no further weight loss can be determined].

2.5.1. Declaration of Quantity. - The declaration of quantity of peat and peat moss shall be expressed in terms of weight units or in cubic measure units.

\subsubsection{Units.}

2.5.2.1. Weight. - Peat and peat moss sold in terms of weight shall be offered and exposed for sale only in kilograms and/or pounds.

2.5.2.2. Cubic Measure. - Peat and peat moss sold in terms of cubic measure shall be offered and exposed for sale only in liters and/or cubic feet. If the commodity is labeled in terms of compressed cubic measurement, the quantity declaration shall represent the quantity in the compressed state.

(Added 1971) (Amended 1975, 1979, 1983, and 1997)

2.6. Prefabricated Utility Buildings. - Shall be offered for retail sale on the basis of usable inside space as follows:

(a) length, measured from inside surface of wall panels at the base; 
B. Uniform Regulation for the Method of Sale of Commodities

(b) width, measured from inside surface of wall panels at the base;

(c) height, measured from the base to the top of the shortest wall panel.

Inside dimensions in SI units shall be declared to the nearest 0.01 meter; inside dimensions in U.S. customary units shall be declared to the nearest inch.

If total usable inside space is declared in a supplemental declaration, it shall be to the nearest cubic decimeter or cubic foot.

(Added 1975)

2.7. Roofing and Roofing Material. - Shall be sold by the square meter only if sold in SI units, by the square, or by the square foot only if sold in U.S. customary units.

(Amended 1979)

\subsubsection{Definitions.}

2.7.1.1. Square Meter. - The quantity of roofing or roofing material that, when applied according to the directions or instructions of the manufacturer, will cover one square meter exclusive of side laps or side joints.

(Added 1979)

2.7.1.2. Square. - The quantity of roofing or roofing material that, when applied according to directions or instructions of the manufacturer, will cover an area of $100 \mathrm{ft}^{2}$ exclusive of side laps or side joints, provided, in the case of roofing or roofing material of corrugated design, the side lap or side joint shall be one full corrugation.

2.7.1.3. Square Foot. - The quantity of roofing or roofing material that, when applied according to the directions or instructions of the manufacturer, will cover $1 \mathrm{ft}^{2}\left(144 \mathrm{in}^{2}\right)$ exclusive of side laps or side joints.

2.7.2. Declaration of Quantity. - When the declaration of quantity on a package of roofing or roofing material contains the term "square," it shall include, plainly and conspicuously, a numerical definition of the term "square."

\section{Example: \\ "One square covers $100 \mathrm{ft}^{2}$ of roof area."}

2.7.2.1. Common Fractions. - The use of the common fraction one-third $(1 / 3)$ is specifically authorized in the quantity statement of a package of roofing or roofing material when, and only when, used as the common fraction of the "square."

2.7.2.2. Quantity Statement. - The primary declaration if in U.S. customary units shall only be in terms of squares or square feet, and if in metric units shall only be in terms of square meters. There is no prohibition against the use of supplementary quantity declarations, such as shingle dimensions, but in no case shall the weight of the material be stated or implied. However, the use of numerical descriptions for rolls of felt roofing material may continue to be used.

(Added 1971) (Amended 1979)

2.8. Sealants. - Caulking compounds, glazing compounds, and putty shall be sold in terms of liquid measure, except that rope caulk shall be sold by weight.

(Added 1971) (Amended 1981) 


\subsection{Sod and Turf.}

2.9.1. Application. - For the purpose of this regulation, this section shall apply to all sod, including turf sod, turf plugs, and turf sprigs.

\subsubsection{Definitions.}

2.9.2.1. Sod. - Shall mean "turf sod," "turf plugs," or "turf sprigs" of a single kind or variety or a mixture of kinds and varieties.

2.9.2.2. Turf. - The live population of one or more kinds of grasses, legumes, or other plant species used for lawns, recreational use, soil erosion control, or other such purposes.

2.9.2.3. Turf plug. - A small section cut from live turf of those kinds of turf normally vegetatively propagated (such as zoysia grass) that when severed contain sufficient plant material to remain intact.

2.9.2.4. Turf sod. - A strip or section of live turf that when severed contains sufficient plant material to remain intact.

2.9.2.5. Turf sprig. - A live plant, stolon, crown, or section cut from stolonifera plants used as turf.

2.9.3. Quantity. - Sod shall be advertised, offered for sale, and sold by measure or by a combination of count and measure as prescribed by this subsection.

2.9.3.1. Turf sod. - Turf sod shall be advertised for sale and sold in terms of the square meter, square foot, or square yard, as appropriate.

(Amended 1979)

2.9.3.2. Turf plugs. - Turf plugs shall be advertised for sale and sold in terms of count, combined with a statement of the plug diameter.

2.9.3.3. Turf sprigs. - Turf sprigs shall be advertised for sale and sold in terms of the liter or bushel.

(Added 1976) (Amended 1979)

2.10. Softwood Lumber. - Applies to softwood boards, timbers, and dimension lumber that have been surfaced; to other products set forth in the latest version of the U.S. Department of Commerce, Voluntary Product Standard PS 20-20, "American Softwood Lumber Standard," Tables 1 through 4; but shall not apply to rough lumber or lumber (other than products in the tables) remanufactured or joined so as to have changed the form or identity, such as individually assembled or packaged millwork items. "Nominal sizes" are customary dimensions to describe approximate, rather than actual, sizes of lumber. "Nominal sizes" were originally derived from the dimensions of rough lumber before surfacing and are always greater than the actual or minimum dressed dimensions; thus, a dry " $2 \times 4$ " is surfaced to the actual dimensions of $1 \frac{1}{2} 2$ in $\times 3 \frac{1}{2}$ in $(38 \mathrm{~mm} \times 89 \mathrm{~mm})$. The requirements in Section 2.10.1. Definitions refer to actual sizes of lumber. Examples of nominal sizes and minimum dressed sizes for board and dimension lumber are shown in Table 1. Softwood Lumber Sizes. A complete listing of nominal size categories is available in the latest version of PS 20-20, "American Softwood Standard" in Tables 1 through 4.

(Amended 2016)

\subsubsection{Definitions.}

2.10.1.1. Dressed Lumber. - Lumber that has been surfaced by a machine (to attain smoothness of surface and uniformity of size) on one side (S1S), on two sides (S2S), one edge (S1E), two edges (S2E), or a combination of sides and edges (S1S1E, S1S2E, S2S1E, S4S).

(Amended 2016) 
2.10.1.2. Boards. - Lumber $38 \mathrm{~mm}\left(1^{1 / 2} / 2\right.$ in $)$ or less in actual thickness and $38 \mathrm{~mm}\left(1 \frac{1}{2}\right.$ in) or more in actual width. Lumber less than $140 \mathrm{~mm}\left(5^{1 / 2} / 2\right.$ in) in actual width may be classified as strips.

(Amended 2016)

2.10.1.3. Timbers. - Lumber $114 \mathrm{~mm}\left(4^{1} / 2\right.$ in) or more in smallest dimension. Timbers may be designated as beams, stringers, posts, caps, sills, girders, or purlins.

2.10.1.4. Dimension Lumber. - Lumber from $38 \mathrm{~mm}\left(1 \frac{1}{2}\right.$ in) to, but not including, $114 \mathrm{~mm}\left(4^{1 / 2}\right.$ in) in actual thickness, and $38 \mathrm{~mm}\left(1 \frac{1}{2}\right.$ in) or more in actual width. Dimension lumber may be designated as framing, joists, planks, rafters, or studs.

2.10.1.5. Rough Lumber. - Lumber that has not been dressed, but that has been sawed, edged, and trimmed at least to the extent of showing saw marks, or other primary manufacturing marks in the wood, on the four longitudinal surfaces of each piece for its overall length.

(Amended 2016)

2.10.1.6. Matched Lumber. - Lumber that has been worked with a tongue on one edge of each piece and a groove on the opposite edge to provide a close tongue and groove joint by fitting two pieces together; when end-matched, the tongue and groove are worked in the ends also.

2.10.1.7. Patterned Lumber. - Lumber that is shaped to a pattern or a molded form, in addition to being dressed, matched, or shiplapped, or any combination of these workings.

2.10.1.8. Shiplapped Lumber. - Lumber that has been worked or rabbeted on both edges of each piece to provide a closelapped joint by fitting two pieces together.

2.10.1.9. Grade. - The commercial designation assigned to lumber meeting specifications established by a nationally recognized grade rule writing organization.

2.10.1.10. Species. - The commercial name assigned to a species of trees.

2.10.1.11. Species Group. - The commercial name assigned to two or more individual species having similar characteristics.

2.10.1.12. Representation. - A "representation" shall be construed to mean any advertisement, offering, invoice, or the like that pertains to the sale of lumber.

2.10.1.13. Minimum Dressed Sizes (width and thickness). - The standardized width and thickness at which lumber is dressed when manufactured in accordance with the latest edition of U.S. Department of Commerce Voluntary Product Standard PS 20-20, "American Softwood Lumber Standard," and regional grading rules conforming to the latest version of PS 20-20. (See Table 1. Softwood Lumber Sizes containing examples of some minimum dressed sizes.)

(Amended 2016)

2.10.2. Identity. - Representations shall include a declaration of identity that specifies the grade or grades, species or species group, and whether the lumber is unseasoned (green) or dry.

2.10.3. Quantity. - Representations shall be in terms of:

(a) the number of pieces;

(b) the minimum dressed width and thickness or actual width and thickness, except that the use of nominal dimensions shall be allowed as long as: 
(1) the term "nominal" or "nom" is also used; and

(2) the actual or minimum dressed sizes are prominently displayed to the customer either by means of a table or label.

(c) either the length of individual pieces or the lineal footage.

(Amended 2016)

Table 1. Softwood Lumber Sizes

Examples of the minimum dressed sizes at the time of manufacture for both unseasoned (green) and dry lumber in the latest version of the U.S. Department of Commerce, Voluntary Product Standard PS 20-20.

\begin{tabular}{|c|c|c|c|c|}
\hline \multirow{3}{*}{$\begin{array}{c}\begin{array}{c}\text { Product Classification } \\
\text { (Nominal Size) }\end{array} \\
\text { Inches }\end{array}$} & \multicolumn{4}{|c|}{ Minimum Dressed Sizes** } \\
\hline & \multicolumn{2}{|c|}{ Unseasoned } & \multicolumn{2}{|c|}{ Dry } \\
\hline & Inches & Millimeters & Inches & Millimeters \\
\hline \multicolumn{5}{|c|}{ Surfaced Lumber* } \\
\hline $2 \times 2$ & $19 / 16 \times 19 / 16$ & $40 \times 40$ & $1 \frac{1 / 2}{2} 1^{1 / 2}$ & $38 \times 38$ \\
\hline $2 \times 2^{1 / 2}$ & $19 / 16 \times 21 / 16$ & $40 \times 52$ & $1 \frac{1}{2} \times 2$ & $38 \times 51$ \\
\hline $2 \times 3$ & $19 / 16 \times 29 / 16$ & $40 \times 65$ & $1 \frac{1}{2} \times 2^{1 / 2}$ & $38 \times 64$ \\
\hline $2 \times 4$ & $19 / 16 \times 3 \% / 16$ & $40 \times 90$ & $1^{1 / 2} \times 3^{1 / 2}$ & $38 \times 89$ \\
\hline $2 \times 6$ & $19 / 16 \times 5 \% / 8$ & $40 \times 143$ & $1^{1 / 2} \times 5^{1 / 2}$ & $38 \times 140$ \\
\hline $2 \times 8$ & $19 / 16 \times 71 / 2$ & $40 \times 190$ & $1 \frac{1}{2} \times 7^{1 / 4}$ & $38 \times 184$ \\
\hline $2 \times 10$ & $19 / 16 \times 9^{1 / 2}$ & $40 \times 241$ & $11 / 2 \times 9^{1 / 4}$ & $38 \times 235$ \\
\hline $2 \times 12$ & $19 / 16 \times 11^{1 / 2}$ & $40 \times 292$ & $1^{1 / 2} \times 11^{1 / 4}$ & $38 \times 286$ \\
\hline \multicolumn{5}{|c|}{ Board Lumber } \\
\hline $1 \times 2$ & $25 / 32 \times 19 / 16$ & $20 \times 40$ & $3 / 4 \times 1 / 2$ & $19 \times 38$ \\
\hline $1 \times 3$ & $25 / 32 \times 29 / 16$ & $20 \times 65$ & $3 / 4 \times 21 / 2$ & $19 \times 64$ \\
\hline $1 \times 4$ & $25 / 32 \times 39 / 16$ & $20 \times 90$ & $3 / 4 \times 3^{1 / 2}$ & $19 \times 89$ \\
\hline $1 \times 6$ & $25 / 32 \times 55 / 8$ & $20 \times 143$ & $3 / 4 \times 5^{1 / 2}$ & $19 \times 140$ \\
\hline $1 \times 8$ & $25 / 32 \times 7^{1 / 2}$ & $20 \times 190$ & $3 / 4 \times 71 / 4$ & $19 \times 184$ \\
\hline $1 \times 10$ & $25 / 32 \times 9^{1 / 2}$ & $20 \times 241$ & $3 / 4 \times 91 / 4$ & $19 \times 235$ \\
\hline $1 \times 12$ & $25 / 32 \times 11^{1 / 2}$ & $20 \times 292$ & $3 / 4 \times 11^{1 / 4}$ & $19 \times 286$ \\
\hline \multicolumn{5}{|c|}{$\begin{array}{l}\text { *The dry thicknesses of nominal } 3 \text { in and } 4 \text { in lumber are } 2^{1 / 2} \text { in }(64 \mathrm{~mm}) \text { and } 3^{1 / 2} \text { in }(89 \mathrm{~mm}) \text {; unseasoned thick- } \\
\text { nesses are } 2 \% 16 \text { in }(65 \mathrm{~mm}) \text { and } 39 / 16(90 \mathrm{~mm}) \text {. Widths for these thicknesses are the same as shown above. }\end{array}$} \\
\hline \multicolumn{5}{|c|}{$\begin{array}{l}\text { **PS } 20-20 \text { defines dry lumber as being } 19 \% \text { or less in moisture content and unseasoned lumber as being over } \\
19 \% \text { moisture content. The size of lumber changes approximately } 1 \% \text { for each } 4 \% \text { change in moisture content. } \\
\text { Lumber stabilizes at approximately } 15 \% \text { moisture content under normal use conditions. } \\
\text { (Added } 1971 \text { ) (Amended 2016) }\end{array}$} \\
\hline
\end{tabular}

(Added 1971) (Amended 1990, 1993, and 2016)

2.11. Carpet. - Anyone who sells carpet shall provide the purchaser with written statements at the time of sale giving the following information:

(a) The name and address of the manufacturer. 
B. Uniform Regulation for the Method of Sale of Commodities

(b) The style name and roll number of the carpet.

(c) The generic name of the fiber and the type of backing material.

(d) The amount delivered (exact size shipped).

(e) The price per square meter if sold in SI units, or the price per square foot if sold in U.S. customary units, and the total price.

(Added 1977) (Amended 1979 and 1999)

2.12. Hardwood Lumber - Retail Sales. - The requirements of this section apply to retail sales of hardwood lumber, but not too hardwood flooring, molding, or other pre-formed products.

\subsubsection{Definitions.}

2.12.1.1. Board Foot. - The U.S. customary unit of volume measurement for hardwood lumber. A board foot is the volume of a board $1 \mathrm{ft}$ long, $1 \mathrm{ft}$ wide, and 1 in thick or its equivalent (144 $\mathrm{in}^{3}$ of wood).

2.12.1.2. Surfaced Lumber. - Lumber that has been surfaced for the purpose of attaining smoothness of surface and uniformity of size.

2.12.1.3. Kiln Drying. - A specialized process used to minimize dimensional changes in service. Hardwood lumber used for most products must have moisture removed by placing it in a drying kiln with controlled humidity and heat for a period of time determined by the initial and the final moisture content, the species, and the thickness.

2.12.1.4. Surface Measure. - A rounded area measurement for hardwood lumber. The surface measure shall be determined by multiplying the full width of the piece in inches and fractions by the standard length (see Section 2.12.1.7. Standard Lengths) in feet, dividing by 12, and rounding up or down to the nearest whole square foot. (Fractions less than or equal to one-half square foot are rounded down and those greater than one-half square foot are rounded up.)

2.12.1.5. Species. - The commercial name assigned to a species of trees.

2.12.1.6. Species Group. - The commercial name assigned to two or more individual species having similar characteristics.

2.12.1.7. Standard Lengths. $-4,5,6,7,8,9,10,11,12,13,14,15$, or 16 feet. Fractional lengths are rounded down to the next lower standard length (for example, if a board is $6 \mathrm{ft} 8 \mathrm{in} \mathrm{long}$, its length is rounded down to $6 \mathrm{ft}$ ).

2.12.1.8. Stock Widths. - Special items manufactured to predetermined widths, normally for retail sale.

2.12.2. Identity. - Representations shall include a declaration of identity that specifies the species or species group.

\subsubsection{Surfaced (S4S) Lumber Manufactured to Stock Widths.}

2.12.3.1. Quantity. - Representations shall be in terms of one of the following:

(a) by linear measure when surfaced width and thickness are stated; or

(b) by count when length and surfaced width and thickness are stated; or

(c) by surface measure (square feet) when a thickness is stated. 
2.12.3.2. Representations. - The use of nominal dimensions shall be allowed if the table of Minimum Surfaced Sizes for Kiln Dried Hardwood Lumber or the actual dimensions are prominently displayed to the customer, and the term "nominal" or "nom" is used in conjunction with any representation of nominal dimensions.

2.12.3.3. Minimum surfaced sizes for Kiln Dried Lumber (width and thickness). - Table 2. Minimum Surfaced Sizes for Kiln Dried Hardwood Lumber shows the minimum sizes for the stock widths listed. This table includes dimensions for thicknesses of 1 in and 2 in thick stock lumber. Hardwood lumber is also manufactured in thicknesses of $1 \frac{1 / 4}{4}$ in ( 1 in surfaced) and $1 \frac{1}{2}$ in (13/16 in surfaced). For other thicknesses, use the nominal and minimum widths from the table. For example: a board with the nominal dimensions of $1 \frac{1}{4}$ in $\times 4$ in would have minimum thickness of 1 in and minimum width of $3 \frac{1}{2}$ in.

Table 2. Minimum Surfaced Sizes for Kiln Dried Hardwood Lumber

\begin{tabular}{|c|c|c|}
\hline SI Units for Thickness and Width & \multicolumn{2}{|c|}{ Thickness and Width in Inches } \\
\hline Minimum Sizes in Millimeters & Nominal Sizes & Minimum Sizes \\
\hline $38 \times 89$ & $2 \times 4$ & $1 \frac{1}{2} \times 3^{1 / 2}$ \\
\hline $38 \times 140$ & $2 \times 6$ & $1 \frac{1 / 2}{} \times 5^{1 / 2}$ \\
\hline $38 \times 184$ & $2 \times 8$ & $1 \frac{1}{2} \times 7^{1 / 4}$ \\
\hline $38 \times 235$ & $2 \times 10$ & $1 \frac{1}{2} \times 9^{1 / 4}$ \\
\hline $38 \times 286$ & $2 \times 12$ & $1 \frac{1 / 2}{2} \times 11^{1 / 4}$ \\
\hline $19 \times 19$ & $1 \times 1$ & $3 / 4 \times 3 / 4$ \\
\hline $19 \times 38$ & $1 \times 2$ & $3 / 4 \times 1 \frac{1}{2}$ \\
\hline $19 \times 63$ & $1 \times 3$ & $3 / 4 \times 21 / 2$ \\
\hline $19 \times 89$ & $1 \times 4$ & $3 / 4 \times 31 / 2$ \\
\hline $19 \times 140$ & $1 \times 6$ & $3 / 4 \times 51 / 2$ \\
\hline $19 \times 184$ & $1 \times 8$ & $3 / 4 \times 71 / 4$ \\
\hline $19 \times 235$ & $1 \times 10$ & $3 / 4 \times 9^{1 / 4}$ \\
\hline $19 \times 286$ & $1 \times 12$ & $3 / 4 \times 11^{1 / 4}$ \\
\hline \multicolumn{3}{|c|}{$\begin{array}{l}\text { The dry thickness of nominal } 1 \frac{1 / 2}{2} \text { in lumber is } 13 / 16 \text { in. The dry thickness of nominal } 1 \frac{1}{4} \text { in lumber is } 1 \mathrm{in} \text {. Sizes } \\
\text { are shown in inches and millimeters. Minimum sizes in millimeters are calculated by multiplying the size in inches } \\
\text { by } 25.4 \text { and rounding to the nearest millimeter. The rule for rounding is: round up for numbers greater than } 0.50 \mathrm{~mm} \\
\text { and round down for numbers less than or equal to } 0.50 \mathrm{~mm} \text {. In case of a dispute on size measurements, the inch } \\
\text { measurement takes precedence. Nominal and minimum widths for these thicknesses are shown above. The SI } \\
\text { equivalents for } 1 \text { in and } 13 / 16 \text { in lumber are } 25.4 \mathrm{~mm} \text { and } 30.1 \mathrm{~mm} \text {, respectively. }\end{array}$} \\
\hline
\end{tabular}

\subsubsection{Random Width Lumber.}

2.12.4.1. Sales of Random Width Hardwood Lumber. - Sales of random width hardware lumber measured after kiln drying shall be quoted, invoiced, and delivered on the basis of net board footage with no addition of footage for kiln drying shrinkage or surfacing. Sales of hardwood lumber measured and sold prior to kiln drying or surfacing shall be quoted, invoiced, and delivered on the basis of net board footage before kiln drying or surfacing. If the lumber is to be kiln dried or surfaced at the request of the purchaser, the kiln drying or surfacing charge shall be clearly shown and identified on the quotation and invoice.

(Amended 1993) 
B. Uniform Regulation for the Method of Sale of Commodities

\subsection{Polyethylene Products.}

2.13.1. Consumer and Non-Consumer Products. - Offered and exposed for sale shall be sold in the terms given in Section 2.13.1.1. Sheeting and Film.

2.13.1.1. Sheeting and Film. - Consumer products shall include quantity statements in both SI and U.S. customary units.

\section{Consumer products:}

(a) length and width (in SI and U.S. customary units)

(b) area (in square meters and square feet)

(c) thickness (in micrometers and mils*

(d) weight (in SI and U.S. customary units)

\section{Non-Consumer Products:}

(a) length and width (in SI or U.S. customary units)

(b) area (in square meters or square feet)

(c) thickness (in micrometers or mils*

(d) weight (in SI or U.S. customary units) (Added 1982) (Amended 1979, 1993, and 1998)

$(* 1 \mathrm{mil}=0.001$ in $=25.4$ micrometers $(\mu \mathrm{m}) .1$ micrometer $=0.00003937$ in. $)$ (Amended 1993)

2.13.2. Consumer Products. - At retail shall be sold in the terms given in Section 2.13.2.1. Food Wrap, Section 2.13.2.2. Lawn and Trash Bags, and Section 2.13.2.3. Food and Sandwich Bags.

\subsubsection{Food Wrap.}

(a) length and width

(b) area in square meters and square feet (Amended 1979)

\subsubsection{Lawn and Trash Bags.}
(a) count
(b) dimensions
(c) thickness in micrometers and mils (Amended 1993)

(d) capacity [see Section 2.13.2. NOTE]

2.13.2.3. Food and Sandwich Bags. - The capacity statement does not apply to fold-over sandwich bags. 

(a) count
(b) dimensions
(c) capacity [see Section 2.13.2. NOTE]

Section 2.13.2. NOTE: See Section 10.8.2. Capacity of the Uniform Packaging and Labeling Regulation.

2.13.3. Non-Consumer Products. - Shall be offered and exposed for sale in the terms given in Section 2.13.3.1. Bags. (Package shall be labeled in SI or U.S. customary units and may include both units.) (Amended 1998)

\subsubsection{Bags.}
(a) count
(b) dimensions
(c) thickness in micrometers or mils
(d) weight
(e) capacity [see Section 2.13.2. NoTE ]

2.13.4. Declaration of Weight. - The labeled statement of weight for polyethylene sheeting and film products under Sections 2.13.1.1. Sheeting and Film, and 2.13.3.1. Bags, shall be equal to or greater than the weight calculated by using the formula below.

(a) For values, less than $453.6 \mathrm{~kg}(1000 \mathrm{lb})$, the final value shall be calculated to at least four digits and declared to three digits, truncating the final digits as calculated (e.g., a calculated value of $943.1 \mathrm{~g}$ $(2.079 \mathrm{lb})$ is truncated to $943 \mathrm{~g}(2.07 \mathrm{lb})$, a calculated value of $14.92 \mathrm{~kg}(32.89 \mathrm{lb})$ is truncated to $14.9 \mathrm{~kg}$ (32.8 lb), a calculated value of $124.4 \mathrm{~kg}(274.2 \mathrm{lb})$ is truncated to $124 \mathrm{~kg}(274 \mathrm{lb})$.

(Added 2018)

(b) For values of $453.6 \mathrm{~kg}(1000 \mathrm{lb})$ or more, the final value shall be calculated to at least five digits and declared to four digits, truncating the final digits as calculated (e.g., a calculated value of $570.44 \mathrm{~kg}$ $(1257.6 \mathrm{lb})$ is truncated to $570.4 \mathrm{~kg}(1257 \mathrm{lb})$.

(Added 2018)

\section{For SI dimensions:}

$$
\begin{aligned}
& \mathrm{M}=\mathrm{T} \times \mathrm{A} \times \mathrm{D} / 1000, \text { where: } \\
& \mathrm{M}= \text { net mass in kilograms } \\
& \mathrm{T}= \text { nominal thickness in centimeters } \\
& \mathrm{A}= \text { nominal length in centimeters times the nominal width }{ }^{[\mathrm{see} \text { Section } 2.13 .4 . \text { NOTE] }} \text { in centimeters } \\
& \mathrm{D}= \text { minimum density in grams per cubic centimeter as defined by the latest version of ASTM } \\
& \text { Standard D1505, "Standard Test Method for Density of Plastics by the Density-Gradient } \\
& \text { Technique" and the latest version of ASTM Standard D883, "Standards Terminology Relating to } \\
& \text { Plastics." }
\end{aligned}
$$

For the purpose of this regulation, the minimum density (D) for linear low density polyethylene plastics (LLDPE) shall be $0.92 \mathrm{~g} / \mathrm{cm}^{3}$ (when D is not known).

For the purpose of this regulation, the minimum density (D) for linear medium density polyethylene plastics (LMDPE) shall be $0.93 \mathrm{~g} / \mathrm{cm}^{3}$ (when D is not known). 
B. Uniform Regulation for the Method of Sale of Commodities

For the purpose of this regulation, the minimum density (D) for high density polyethylene plastics (HDPE) shall be $0.94 \mathrm{~g} / \mathrm{cm}^{3}$ (when $\mathrm{D}$ is not known).

\section{For U.S. customary dimensions:}

$$
\begin{aligned}
& \mathrm{W}=\mathrm{T} \times \mathrm{A} \times 0.03613 \times \mathrm{D}, \text { where: } \\
& \mathrm{W}= \text { net weight in pounds } \\
& \mathrm{T}= \text { nominal thickness in inches; } \\
& \mathrm{A}= \text { nominal length in inches times nominal width [see Section } 2.13 .4 \text { NOTE ] in inches } \\
& \mathrm{D}= \text { minimum density in grams per cubic centimeter as defined by the latest version of ASTM } \\
& \text { Standard D1505, "Standard Test Method for Density of Plastics by the Density-Gradient } \\
& \text { Technique" and the latest version of ASTM Standard D883, "Standards Terminology Relating to } \\
& \text { Plastics." } \\
& 0.03613 \text { is a factor for converting } \mathrm{g} / \mathrm{cm}^{3} \text { to } \mathrm{lb} / \mathrm{in}^{3}
\end{aligned}
$$

For the purpose of this regulation, the minimum density (D) for linear low-density polyethylene plastics (LLDPE) shall be $0.92 \mathrm{~g} / \mathrm{cm}^{3}$ (when D is not known).

For the purpose of this regulation, the minimum density (D) for linear medium density polyethylene plastics (LMDPE) shall be $0.93 \mathrm{~g} / \mathrm{cm}^{3}$ (when D is not known).

For the purpose of this regulation, the minimum density (D) for high-density polyethylene plastics (HDPE) shall be $0.94 \mathrm{~g} / \mathrm{cm}^{3}$ (when $\mathrm{D}$ is not known).

(Added 1977) (Amended 1980, 1982, 1987, 1989, 1990, 1993, 2012, and 2018)

Section 2.13.4. NOTE: The nominal width for bags in this calculation is twice the labeled width.

\subsection{Insulation.}

2.14.1. Packaged Loose-Fill Insulation Except Cellulose. - The label shall declare:

(a) the type of insulation and the net weight with no qualifying statement; and

(b) the minimum thickness, maximum net coverage area, and minimum weight per square foot at $\mathrm{R}$ values of 11,19 , and 22. This information shall also be supplied for any additional $\mathrm{R}$ values listed.

(Amended 1990)

2.14.2. Packaged Loose-Fill Cellulose Insulation. - The label shall declare:

(a) the type of insulation and the net weight with no qualifying statement; and

(b) the minimum thickness, maximum net coverage area, number of bags per $1000 \mathrm{ft}^{2}$, and minimum weight per square foot at $\mathrm{R}$ values of $13,19,24,32$, and 40 . This information shall also be supplied for any additional $\mathrm{R}$ values listed.

(Amended 1990)

2.14.3. Batt and Blanket Insulation. - The principal display panel of packaged batt or blanket insulation shall declare the square feet of insulation in the package and the length and width of the batt or blanket. In addition, $R$ value and thickness shall be declared on the package.

2.14.4. Installed Insulation. - Installed insulation must be accompanied by a contract or receipt. For all insulation except loose-fill and aluminum foil, the receipt must show the coverage area, thickness, and $\mathrm{R}$ value of 
the insulation installed. For loose-fill, the receipt must show the coverage area, thickness, and $\mathrm{R}$ value of the insulation, plus the number of bags used. For aluminum foil, the receipt must show the number and thickness of the air spaces, the direction of heat flow, and $\mathrm{R}$ value. The receipt must be dated and signed by the installer.

Example: This is to certify that the insulation has been installed in conformance with the requirements indicated by the manufacturer to provide a value of $\mathrm{R} 19$ using 31.5 bags of insulation to cover $1500 \mathrm{ft}^{2}$ area. Signed and dated.

(Added 1979) (Amended 1983)

2.15. Solid Fuel Products. - Anthracite, semi anthracite, bituminous, semi-bituminous or lignite coal, and any other natural, manufactured, or patented fuel, not in liquid or gaseous form, except fireplace and stove wood, shall be offered, exposed for sale, or sold by net weight when in package form.

(Added 1979)

\subsection{Compressed or Liquefied Gases in Refillable Cylinders.}

2.16.1. Application. - This section does not apply to disposable cylinders of compressed or liquefied gases.

2.16.2. Net Contents. - The net contents shall be expressed in terms of cubic meters or cubic feet, kilograms, or pounds and ounces. See Section 2.21. Liquefied Petroleum Gas for permitted expressions of net contents for liquefied petroleum gas. A standard cubic foot of gas is defined as a cubic foot at a temperature of $21^{\circ} \mathrm{C}\left(70{ }^{\circ} \mathrm{F}\right)$ and a pressure of 101.35 kilopascals (14.696 psia), except for liquefied petroleum gas as stated in Section 2.21 . Liquified Petroleum Gas.

2.16.3. Cylinder Labeling. - Whenever cylinders are used for the sale of compressed or liquefied gases by weight, or are filled by weight and converted to volume, the following shall apply:

\subsubsection{Tare weights.}

(a) Stamped or Stenciled Tare Weight. - For safety purposes, the tare weight shall be legibly and permanently stamped or stenciled on the cylinder. All tare weight values shall be preceded by the letters "TW" or the words "tare weight." The tare weight shall include the weight of the cylinder (including paint), valve, and other permanent attachments. The weight of a protective cap shall not be included in tare or gross weights. The 49 CFR 178.35 "General Requirements for Specification Cylinders" requires the maker of cylinders to retain test reports verifying the cylinder tare weight accuracy to a tolerance of $1 \%$.

(b) Tare Weight for Purposes of Determining the Net Contents. - The tare weight used in the determination of the final net contents may be either:

(1) the stamped or stenciled tare weight; or

(2) the actual tare determined at the time of filling the cylinder. If the actual tare is determined at the time of filling the cylinder, it must be legibly marked on the cylinder or on a tag attached to the cylinder at the time of filling.

(c) Allowable difference. - If the stamped or stenciled tare is used to determine the net contents of the cylinder, the allowable difference between the actual tare weight and the stamped (or stenciled) tare weight, or the tare weight on a tag attached to the cylinder for a new or used cylinder, shall be:

(1) $1 / 2 \%$ for tare weights of $9 \mathrm{~kg}(20 \mathrm{lb})$ or less; or

(2) $1 / 4 \%$ for tare weights of more than $9 \mathrm{~kg}(20 \mathrm{lb})$. 
B. Uniform Regulation for the Method of Sale of Commodities

(d) Average requirement. - When used to determine the net contents of cylinders, the stamped or stenciled tare weights of cylinders at a single place of business found to be in error predominantly in a direction favorable to the seller and near the allowable difference limit shall be considered to be not in conformance with these requirements.

2.16.3.2. Acetylene Gas Cylinder Tare Weights. - Acetone in the cylinder shall be included as part of the tare weight.

2.16.3.3. Acetylene Gas Cylinder Volumes. - The volumes of acetylene shall be determined from the product weight using approved tables such as those published in NIST Handbook 133 or those developed using $70 \mathrm{~F}(21 \mathrm{C})$ and $14.7 \mathrm{ft}^{3}(101.35 \mathrm{kPa})$ per pound at 1 atmosphere as conversion factors.

2.16.3.4. Compressed Gases such as Oxygen, Argon, Nitrogen, Helium, and Hydrogen. - The volumes of compressed gases such as oxygen, argon, nitrogen, helium, or hydrogen shall be determined using NIST Standard Reference Database 23 "Reference Fluid Thermodynamic and Transport Properties Database" (REFPROP) (www.nist.gov/srd/REFPROP) and supplemented by additional procedures and tables in NIST Handbook 133.

(Added 1981) (Amended 1990)

\subsection{Precious Metals.}

\subsubsection{Definition.}

2.17.1.1. Precious Metals. - Gold, silver, palladium, platinum, or any item composed partly or completely of these metals or their alloys and in which the market value of the metal in the item is principally the gold, silver, palladium, or platinum component.

(Amended 2017)

2.17.2. Quantity. - The unit of measure and the method of sale of precious metals, if the price is based in part or wholly on a weight determination, shall be either troy weight or SI units. To facilitate price comparison and provide information allowing consumers to make an informed decision a chart must be prominently displayed and present in proximity to the purchasing scale being used for the transaction. This chart requirement is not intended to apply to pure precious metal bullion traded or commodity markets such as stock exchanges and the like rather it is only intended to apply to precious metals purchased by weight by businesses from the general public through non-retail transactions. The chart must be clearly visible to the seller and contain at a minimum the following information.

(a) A table of weights indicating grams and troy ounces.

(b) The percentages as noted in Table 3. Percentage of Precious Metals Contained in Common Mixtures found in the marketplace.

(c) If buying precious metals based on weight, the chart shall also state the price per unit weight on which the buying price is based.

(d) If buying precious metals based on weight in the following formula:

(Item Weight $\times$ Percentage in Decimal Form of Precious Metal Contained in the Item $) \times$ $($ Price per Weight Being Paid $)=$ Potential Monetary Offer.

NOTE: The item weight and price per unit weight must be in the same units.

(e) When the measurement of method of sale is expressed in SI units of mass, a conversion chart to troy units must also be present on the chart. 


\begin{tabular}{||c|c|c|}
\hline \multicolumn{3}{|c|}{ Table 3. Percentage of Precious Metal Contained in Common Mixtures } \\
\hline \multirow{3}{*}{ Gold } & 10 karat & $41.7 \%$ \\
\cline { 2 - 3 } & 14 karat & $58.3 \%$ \\
\cline { 2 - 3 } & 18 karat & $75.0 \%$ \\
\cline { 2 - 3 } & 24 karat & $100 \%$ \\
\hline Silver & Sterling & $92.5 \%$ \\
\hline \multirow{2}{*}{ Platinum } & 900 Platinum & $90 \%$ \\
\hline Palladium & 950 Platinum & $95 \%$ \\
\hline
\end{tabular}

(Added 1982) (Amended 2017)

\subsection{Mulch.}

\subsubsection{Definition.}

2.18.1.1. Mulch. - Any product or material except peat or peat moss (see Section 2.5. Peat and Peat Moss) that is advertised, offered for sale, or sold for primary use as a horticultural, aboveground dressing, for decoration, moisture control, weed control, erosion control, temperature control, or other similar purposes.

(Added 1987)

2.18.2. Quantity. - All mulch shall be sold, offered, or exposed for sale in terms of volume measure in SI units in terms of the cubic meter or liter or in U.S. customary units in terms of the cubic yard or cubic foot.

(Added 1983) (Amended 1987)

2.19. Kerosene (Kerosine). - All kerosene kept, offered, exposed for sale, or sold shall be identified as such and will include, with the word kerosene, an indication of its compliance with the latest version of the standard specification ASTM Standard D3699, "Standard Specification for Kerosine."

Example:

$1 \mathrm{~K}$ Kerosene; Kerosene - 2K.

(Added 1983)

2.19.1. Retail Sale from Bulk. - All kerosene kept, offered, or exposed for sale and sold from bulk at retail shall be in terms of the gallon or liter.

(Added 2012)

\subsection{Gasoline-Oxygenate Blends.}

2.20.1. Method of Retail Sale. - Type of Oxygenate must be Disclosed. - All automotive gasoline or automotive gasoline-oxygenate blends kept, offered, or exposed for sale, or sold at retail containing at least 1.5 mass percent oxygen shall be identified as "with" or "containing" (or similar wording) the predominant oxygenate in the engine fuel. For example, the label may read "contains ethanol" or "with MTBE." The oxygenate contributing the largest mass percent oxygen to the blend shall be considered the predominant oxygenate. Where mixtures of only ethers are present, the retailer may post the predominant oxygenate followed by the phrase "or other ethers" or alternatively post the phrase "contains MTBE or other ethers." In addition, gasoline-methanol blend fuels containing more than 0.15 mass percent oxygen from methanol shall be identified as "with" or "containing" methanol. This information shall be posted on the upper $50 \%$ of the dispenser front panel in a position clear and conspicuous from the driver's position in a type at least $12.7 \mathrm{~mm} \mathrm{(1/2}$ in) in height, $1.5 \mathrm{~mm}(1 / 16$ in) stroke (width of type).

(Amended 1996) 
B. Uniform Regulation for the Method of Sale of Commodities

2.20.2. Documentation for Dispenser Labeling Purposes. - The retailer shall be provided, at the time of delivery of the fuel, on product transfer documents such as an invoice, bill of lading, shipping paper, or other documentation:

(a) Information that complies with 40 CFR 80.1503 when the fuel contains ethanol.

(b) For fuels that do not contain ethanol, information that complies with 40 CFR 80.1503 and a declaration of the predominant oxygenate or combination of oxygenates present in concentrations sufficient to yield an oxygen content of at least 1.5 mass percent in the fuel. Where mixtures of only ethers are present, the fuel supplier may identify either the predominant oxygenate in the fuel (i.e., the oxygenate contributing the largest mass percent oxygen) or alternatively, use the phrase "contains MTBE or other ethers."

(c) Gasoline containing more than 0.15 mass percent oxygen from methanol shall be identified as "with" or "containing" methanol.

(Added 1984) (Amended 1985, 1986, 1991, 1996, and 2014)

2.20.3. EPA Labeling Requirements. - Retailers and wholesale purchaser-consumers of gasoline shall comply with the EPA pump labeling requirements for gasoline containing greater than 10 volume percent $(\mathrm{v} \%)$ up to 15 volume percent (v\%) ethanol (E15) under 40 CFR 80.1501. (For additional information, refer to Section 2.30.2. FTC Labeling Requirements.)

(Added 2018)

2.21. Liquefied Petroleum Gas. - All liquefied petroleum gas, including, but not limited to propane, butane, and mixtures thereof, shall be kept, offered, exposed for sale, or sold by the pound, metered cubic foot [see Section 2.21 NOTE] of vapor (defined as $1 \mathrm{ft}^{3}$ at $60 \mathrm{~F}$ [15.6 C]), or the gallon (defined as $231 \mathrm{in}^{3}$ at $60 \mathrm{~F}$ [15.6 C]). All metered sales by the gallon, except those using meters with a maximum rated capacity of $20 \mathrm{gal} / \mathrm{min}$ or less, shall be accomplished by use of a meter and device that automatically compensates for temperature.

(Added 1986)

Section 2.21. NOTE: Sources: American National Standards Institute, Inc., "American National Standard for Gas Displacement Meters (500 Cubic Feet per Hour Capacity and Under), " First edition, 1974, and NIST Handbook 44, "Specifications, Tolerances, and Other Technical Requirements for Weighing and Measuring Devices."

\subsection{Liquid Oxygen Used for Respiration.}

(a) If sold by weight, liquid oxygen must be weighed on an appropriate, sealed commercial scale. A pressure or other type of gauge may not be used to determine weight.

(b) A delivery ticket or sales invoice shall be provided and shall contain at least the following information:

(1) date delivered;

(2) name and address of vendor;

(3) name and address of the purchaser;

(4) if sold by weight:

i. weight of cylinder before filling;

ii. weight of cylinder after filling; and

iii. the net weight of liquid oxygen delivered; 
(5) if sold by measure:

i. measurement and any computation used to arrive at the net quantity of liquid oxygen delivered;

(6) the unit price;

(7) the total computed price; and

(8) weigher's or measurer's signature.

(Added 1989)

\subsection{Animal Bedding.}

(Amended 2016)

\subsubsection{Definitions.}

2.23.1.1. Compressed Animal Bedding. - Means the volume of the bedding was reduced under pressure during the packaging process.

(Added 2016)

2.23.1.2. Useable Volume. - The volume of the product that can be recovered from a package by the consumer after it is unwrapped and, if necessary, uncompressed.

(Added 2016)

\subsubsection{Method of Sale.}

(a) Packaged animal bedding of all kinds, except for baled straw, shall be advertised, labeled, offered for sale and sold by volume in either a compressed or an uncompressed package. A package of compressed animal bedding shall be advertised, labeled, offered, and exposed for sale and sold on the basis of the "Useable Volume." If unit pricing is provided for use by retail customers to make a value comparison, it shall be in terms of the price per liter.

(b) A quantity declaration shall be in terms of the largest whole unit of the milliliter, liter, or cubic meter. A declaration may also include the quantity in terms of largest whole unit of the cubic inch, cubic foot, or cubic yard only. The terms "Useable Volume" must appear in the quantity declaration on a package of compressed animal bedding.

\section{Examples for Uncompressed Animal Bedding: \\ Volume 41 Liters (1.4 Cubic Feet) \\ Volume 125 Liters \\ Examples for Compressed Animal Bedding: Useable Volume 1.4 Cubic Feet (41 Liters) \\ Useable Volume 27.9 Liters (1700 Cubic Inches) \\ Useable Volume 113 L (4 Cubic Feet) \\ Useable Volume $226 \mathrm{~L}$}

(c) The display of a net or gross weight, pre-compression volume, compressed volume, or supplementary dry measure quantities (e.g., dry pint, dry quart, or bushel) anywhere on the package is prohibited.

(Added 2016) (Amended 2017)

2.23.3. Exemption - Non-Consumer Packages Sold to Laboratory Animal Research Industry. - Packaged animal bedding consisting of granular corncobs and other dry (8\% or less moisture), pelleted, and/or noncompressible bedding materials that are sold to commercial (non-retail) end users in the laboratory animal 
B. Uniform Regulation for the Method of Sale of Commodities

research industry (government, medical, university, preclinical, pharmaceutical, research, biotech, and research institutions) may be sold on the basis of weight.

(Added 2010)

2.24. Wiping Cloths. - Wiping cloths shall be sold by net weight or by count plus size of wiping cloths. When sold by count plus size, and the wiping cloths are of assorted sizes, the term "irregular dimensions" and the minimum size of such cloths must be declared. The gross weight may not be printed on any package, either consumer or nonconsumer.

(Added 1991)

2.25. Baler Twine. - Baler twine shall be sold on the basis of length in meters or feet, and net mass or weight by kilograms or pounds.

(Added 1992)

2.26. Potpourri. - Potpourri shall be sold as follows:

(a) Potpourri packaged in advance of sale shall be sold by weight, except when sold in a decorative container or sachet, which may be sold by count.

(b) Potpourri sold from bulk shall be sold by weight or by dry volume.

(Added 1992)

\subsection{Retail Sales of Natural Gas Sold as a Vehicle Fuel.}

\subsubsection{Definitions.}

2.27.1.1. Compressed Natural Gas (CNG). - A gaseous fuel composed primarily of methane that is suitable for compression and dispensing into a fuel storage container(s) for use as an engine fuel.

(Amended 2016)

2.27.1.2. Gasoline Gallon Equivalent (GGE). - Gasoline gallon equivalent (GGE) means $2.567 \mathrm{~kg}$ $(5.660 \mathrm{lb})$ of compressed natural gas.

(Amended 2016)

2.27.1.3. Diesel Gallon Equivalent (DGE). - Diesel gallon equivalent means $6.384 \mathrm{lb}$ of compressed natural gas or $6.059 \mathrm{lb}$ of liquefied natural gas.

(Added 2016)

2.27.1.4. Liquefied Natural Gas (LNG). - Natural gas, which is predominantly methane, that has been liquefied at $-162^{\circ} \mathrm{C}\left(-260^{\circ} \mathrm{F}\right)$ at $14.696 \mathrm{psia}$ and stored in insulated cryogenic fuel storage tanks for use as an engine fuel.

(Added 2016)

\subsubsection{Method of Retail Sale and Dispenser Labeling.}

2.27.2.1. Method of Retail Sale for Compressed Natural Gas. - All compressed natural gas kept, offered, or exposed for sale and sold at retail as a vehicle fuel shall be measured in terms of mass, and indicted in the gasoline gallon equivalent (GGE), diesel gallon equivalent (DGE) units, or mass.

(Amended 2016)

2.27.2.2. Dispenser Labeling Compressed Natural Gas. - All retail compressed natural gas dispensers shall be labeled with the equivalent conversion factor in terms of pounds (lb). The label shall be permanently and conspicuously displayed on the face of the dispenser and shall have the statement "1 Gasoline Gallon 
Equivalent (GGE) means 5.660 lb of Compressed Natural Gas" or "1 Diesel Gallon Equivalent (DGE) means $6.384 \mathrm{lb}$ of Compressed Natural Gas" consistent with the method of sale used.

(Amended 2016)

2.27.2.3. Method of Retail Sale for Liquefied Natural Gas. - All liquefied natural gas kept, offered, or exposed for sale and sold at retail as a vehicle fuel shall be measured in mass and indicated in diesel gallon equivalent (DGE) units or mass.

(Added 2016)

2.27.2.4. Dispenser Labeling of Retail Liquefied Natural Gas. - All retail liquefied natural gas dispensers shall be labeled with the equivalent conversion factor in terms of pounds (lb). The label shall be permanently and conspicuously displayed on the face of the dispenser and shall have the statement " 1 Diesel Gallon Equivalent (DGE) means 6.059 lb of Liquefied Natural Gas."

(Added 2016)

\subsection{Communication Paper.}

\subsubsection{Definitions.}

2.28.1.1. Communication Paper. - Packaged bond, mimeo, spirit duplicator, xerographic, and other papers, including cut-sized office paper and computer paper.

2.28.1.2. Basis Weight. - As used in this regulation for labeling means the grade, category, or identity of the paper determined according to the latest version of ASTM D646, "Standard Test Method for Mass Per Unit Area of Paper and Paperboard of Aramid Papers (Basis Weight)." Basis weight is used as a standard of identity and is not considered a net weight declaration.

\subsubsection{Method of Retail Sale and Labeling.}

2.28.2.1. Method of Retail Sale. - All packaged communication paper kept, offered, or exposed for sale and sold at retail shall be sold in terms of sheet length and width and count.

2.28.2.2. Labeling. - Communication paper in package form shall bear a label that includes:

(a) a declaration of quantity, in terms of sheet length and width and count, in the lower $30 \%$ of the principal display panel.

(b) a declaration of identity including the basis weight, and may include such other information as grain direction, color, brightness, printed lines, and hole punch information. Due to the variation in basis weight in manufacturing and analysis, the basis weight declared on the label shall correspond to the basis weight declared by the original manufacturer.

(Added 1994)

2.29. Sand, Rock, Gravel, Stone, Paving Stone, and Similar Materials, when Sold in Bulk. - All sand, rock, gravel, stone, paving stone, and similar materials kept, offered, or exposed for sale in bulk must be sold as follows:

(a) Top soil, fill dirt, aggregate or chipped rock, sand (including concrete and mortar sand), decomposed granite, landscape type rock, and cinders must be sold by the cubic meter or cubic yard or by weight.

(b) Flagstone must be sold by weight.

(c) Dimensional cut stone must be sold by the square meter, square foot, or weight. 
B. Uniform Regulation for the Method of Sale of Commodities

(d) This requirement does not apply to single stones with engraving such as gravestones, natural or manmade artwork, landscape boulders, and pre-cast uniform size blocks.

(Added 2000)

\subsection{Ethanol Flex Fuel.}

2.30.1. How to Identify Ethanol Flex Fuel. - Ethanol flex fuel shall be identified as "Ethanol Flex Fuel or EXX Flex Fuel."

2.30.2. FTC Labeling Requirements. - Ethanol flex fuel shall be identified and labeled in accordance with the Federal Trade Commission (FTC) Automotive Fuel Ratings, Certification and Posting Rule, 16 CFR 306, as amended. (For additional information, see Section 2.20.3. EPA Labeling Requirements.)

(Added 2007) (Amended 2014 and 2018)

\subsection{Biodiesel and Biodiesel Blends.}

2.31.1. Identification of Product. - Biodiesel shall be identified by the term "Biodiesel" with the designation "B100." Biodiesel Blends shall be identified by the term "Biodiesel Blend."

\subsubsection{Labeling of Retail Dispensers.}

2.31.2.1. Labeling of Grade Required. - Biodiesel shall be identified by the grades S15 or S500. biodiesel blends shall be identified by the grades No. 1-D, No. 2-D, or No. 4-D.

2.31.2.2. EPA Labeling Requirements Also Apply. - Retailers and wholesale purchaser-consumers of biodiesel blends shall comply with EPA pump labeling requirements for sulfur under 40 CFR 80.570.

2.31.2.3. Automotive Fuel Rating. - Biodiesel and biodiesel blends shall be labeled with its automotive fuel rating in accordance with 16 CFR 306.

2.31.2.4. Biodiesel Blends. - When biodiesel blends greater than $20 \%$ by volume are offered by sale, each side of the dispenser where fuel can be delivered shall have a label conspicuously placed that states "Consult Vehicle Manufacturer Fuel Recommendations." The lettering of this legend shall not be less than $6 \mathrm{~mm}$ $(1 / 4$ in) in height by $0.8 \mathrm{~mm}(1 / 32$ in) stroke; block style letters and the color shall be in definite contrast to the background color to which it is applied.

2.31.3. Documentation for Dispenser Labeling Purposes. - The retailer shall be provided, at the time of delivery of the fuel, a declaration of the volume percent biodiesel on an invoice, bill of lading, shipping paper, or other document. This documentation is for dispenser labeling purposes only; it is the responsibility of any potential blender to determine the amount of biodiesel in the diesel fuel prior to blending.

2.31.4. Exemption. - Biodiesel blends that contain less than or equal to $5 \%$ biodiesel by volume are exempt from the requirements of Sections 2.31.1. Identification of Product, 2.31.2. Labeling of Retail Dispensers, and 2.31.3. Documentation for Dispenser Labeling Purposes when it is sold as diesel fuel.

(Added 2008)

\subsection{Retail Sales of Hydrogen Fuel (H).}

2.32.1. Definitions for Hydrogen Fuel. - A fuel composed of molecular hydrogen intended for consumption in a surface vehicle or electricity production device with an internal combustion engine or fuel cell.

(Amended 2012) 
2.32.2. Method of Retail Sale and Dispenser Labeling. - All hydrogen fuel kept, offered, or exposed for sale and sold at retail shall be in mass units in terms of the kilogram. The symbol for hydrogen vehicle fuel shall be the capital letter " $H$ " (the word Hydrogen may also be used).

\subsubsection{Retail Dispenser Labeling.}

(a) A computing dispenser must display the unit price in whole cents on the basis of price per kilogram.

(b) The service pressure(s) of the dispenser must be conspicuously shown on the user interface in bar or the SI unit of pascal $(\mathrm{Pa})$ (e.g., $\mathrm{MPa})$.

(c) The product identity must be shown in a conspicuous location on the dispenser.

(d) National Fire Protection Association (NFPA) labeling requirements also apply.

(e) Hydrogen shall be labeled in accordance with 16 CFR 309 - FTC Labeling Alternative Fuels.

\subsubsection{Street Sign Prices and Advertisements.}

(a) The unit price must be in terms of price per kilogram in whole cents (e.g., $\$ 3.49$ per $\mathrm{kg}$, not $\$ 3.499$ per kg).

(b) The sign or advertisement must include the service pressure (expressed in megapascals) at which the dispenser(s) delivers hydrogen fuel (e.g., H35 or H70).

(Added 2010)

2.33. Oil.

2.33.1. Labeling of Vehicle Engine (Motor) Oil. - Vehicle engine (motor) oil shall be labeled.

2.33.1.1. Viscosity. - The label on any vehicle engine (motor) oil container, receptacle, dispenser, or storage tank, and any invoice or receipt from service on an engine that includes the installation of vehicle engine (motor) oil dispensed from a receptacle, dispenser, or storage tank, shall contain the viscosity grade classification preceded by the letters "SAE" in accordance with SAE International's latest version of SAE J300, "Engine Oil Viscosity Classification."

NOTE: If an invoice or receipt from service on an engine has limited room for identifying the viscosity, brand, and service category, then abbreviated versions of each may be used on the invoice or receipt and the letters "SAE" may be omitted from the viscosity classification.

(Note added 2014)

(Amended 2014)

2.33.1.2. Brand. - The label on any vehicle engine (motor) oil container and the invoice or receipt from service on an engine that includes the installation of bulk vehicle engine (motor) oil dispensed from a receptacle, dispenser, or storage tank shall contain the name, brand, trademark, or trade name of the vehicle engine (motor) oil.

(Amended 2014)

2.33.1.3. Engine Service Category. - The label on any vehicle engine (motor) oil container, receptacle, dispenser, or storage tank and the invoice or receipt from service on an engine that includes the installation of bulk vehicle engine (motor) oil dispensed from a receptacle, dispenser, or storage tank shall contain the engine service category, or categories, displayed in letters not less than $3.18 \mathrm{~mm}(1 / 8 \mathrm{in})$ in height, as defined by the latest version of SAE J183, "Engine Oil Performance and Engine Service Classification (Other than "Energy Conserving")," API Publication 1509, "Engine Oil Licensing and Certification System," European 
Automobile Manufacturers Association (ACEA), "European Oil Sequences," or other Vehicle or Engine Manufacturer standards as approved in Section 2.33.1.3.1. Vehicle or Engine Manufacturer Standard.

(Amended 2014)

2.33.1.3.1. Vehicle or Engine Manufacturer Standard. - The label on any vehicle engine (motor) oil container, receptacle, dispenser, or storage tank and the invoice or receipt from service on an engine that includes the installation of vehicle engine (motor) oil dispensed from a receptacle, dispenser, or storage tank shall identify the specific vehicle or engine manufacturer standard, or standards, met in letters not less than $3.18 \mathrm{~mm}(1 / 8 \mathrm{in})$ in height. If the vehicle (motor) oil only meets a vehicle or engine manufacturer standard, the label must clearly identify that the oil is only intended for use where specifically recommended by the vehicle or engine manufacturer.

(Added 2014)

2.33.1.3.2. Inactive or Obsolete Service Categories. - Whenever any vehicle engine (motor) oil in a container, receptable, dispenser, storage tank, or in bulk does not meet an active API service category as defined by the latest version of SAE J183, "Engine Oil Performance and Engine Service Classification (Other than "Energy Conserving")," API Publication 1509, "Engine Oil Licensing and Certification System," European Automobile Manufacturers Association (ACEA), "European Oil Sequences," or other Vehicle or Engine Manufacturer Standards as approved in Section 2.33.1.3.1., Vehicle Or Engine Manufacturer Standard the front or forward facing-label of such vehicle engine (motor) oil container, receptacle, dispenser, or storage tank and the invoice or receipt from service on an engine that includes the installation of bulk vehicle engine (motor) oil dispensed from a receptacle, dispenser, or storage tank shall bear the plainly visible, cautionary statement set forth in the latest version of SAE J183, Appendix A. Whenever any vehicle engine (motor) oil is declared obsolete by a vehicle or engine manufacturer, the front or forward-facing label of such vehicle engine (motor) oil container, receptacle, dispenser, or storage tank and the invoice or receipt from service on an engine that includes the installation of bulk vehicle engine (motor) oil dispensed from a receptacle, dispenser, or storage tank shall bear the plainly visible, cautionary statement required by the vehicle or engine manufacturer.

(Amended 2014 and 2021)

2.33.1.4. Tank Trucks or Rail Cars. - Tank trucks, rail cars, and other types of delivery trucks that are used to deliver bulk vehicle engine (motor) oil are not required to display the SAE viscosity grade and service category or categories on such tank trucks, rail cars, and other types of delivery trucks. In lieu of such display requirements, the documentation defined in Section 2.33.1.5. Documentation shall be readily available for inspection.

(Amended 2013, 2014, and 2021)

2.33.1.5. Documentation. - When the engine (motor) oil is sold in bulk, an invoice, bill of lading, shipping paper, or other documentation must accompany each delivery. This document must identify the quantity of bulk engine (motor) oil delivered as defined in Sections 2.33.1.1. Viscosity, grade as defined by SAE J300, "Engine Oil Viscosity Classification," 2.33.1.2. Brand; 2.33.1.3. Engine Service Category; the name and address of the seller and buyer; and the date and time of the sale. For inactive or obsolete service categories, the documentation shall also bear the plainly visible cautionary statement as required in Section 2.33.1.3.2. Inactive or Obsolete Service Categories. Documentation must be retained at the retail establishment for a period of not less than one year.

(Added 2013) (Amended 2014 and 2021)

(Added 2012) (Amended 2013 and 2014 and 2021)

\subsection{Retail Sales of Electricity Sold as a Vehicle Fuel.}

\subsubsection{Definitions.}

2.34.1.1. Electricity Sold as Vehicle Fuel. - Electrical energy transferred to and/or stored onboard an electric vehicle primarily for the purpose of propulsion. 
2.34.1.2. Electric Vehicle Supply Equipment (EVSE). - The conductors, including the ungrounded, grounded, and equipment grounding conductors; the electric vehicle connectors; attachment plugs; and all other fittings, devices, power outlets, or apparatuses installed specifically for the purpose of measuring, delivering, and computing the price of electrical energy delivered to the electric vehicle.

2.34.1.3. Fixed Service. - Service that continuously provides the nominal power that is possible with the equipment as it is installed.

2.34.1.4. Variable Service. - Service that may be controlled resulting in periods of reduced, and/or interrupted transfer of electrical energy.

2.34.1.5. Nominal Power. - Refers to the "intended" or "named" or "stated" as opposed to "actual" rate of transfer of electrical energy (i.e., power).

2.34.2. Method of Sale. - All electrical energy kept, offered, or exposed for sale and sold at retail as a vehicle fuel shall be in units in terms of the megajoule (MJ) or kilowatt-hour ( $\mathrm{kWh}$ ). In addition to the fee assessed for the quantity of electrical energy sold, fees may be assessed for other services; such fees may be based on time measurement and/or a fixed fee.

\subsubsection{Retail Electric Vehicle Supply Equipment (EVSE) Labeling.}

(a) A computing EVSE shall display the unit price in whole cents (e.g., \$0.12) or tenths of one cent (e.g., \$0.119) on the basis of price per megajoule (MJ) or kilowatt-hour (kWh). In cases where the electrical energy is unlimited or free of charge, this fact shall be clearly indicated in place of the unit price.

(b) For fixed service applications, the following information shall be conspicuously displayed or posted on the face of the device:

(1) the level of EV service expressed as the nominal power transfer (i.e., nominal rate of electrical energy transfer), and

(2) the type of electrical energy transfer (e.g., AC, DC, wireless).

(c) For variable service applications, the following information shall be conspicuously displayed or posted on the face of the device:

(1) the type of delivery (i.e., variable);

(2) the minimum and maximum power transfer that can occur during a transaction, including whether service can be reduced to zero;

(3) the condition under which variations in electrical energy transfer will occur; and

(4) the type of electrical energy transfer (e.g., AC, DC, wireless).

(d) Where fees will be assessed for other services in direct connection with the fueling of the vehicle, such as fees based on time measurement and/or a fixed fee, the additional fees shall be displayed.

(e) The EVSE shall be labeled in accordance with 16 CFR 309 - FTC Labeling Requirements for Alternative Fuels and Alternative Fueled Vehicles.

(f) The EVSE shall be listed and labeled in accordance with the National Electric Code ${ }^{\circledR}$ (NEC) NFPA 70, Article 625 Electric Vehicle Charging Systems (www.nfpa.org). 
B. Uniform Regulation for the Method of Sale of Commodities

2.34.4. Street Sign Prices and Other Advertisements. - Where electrical energy unit price information is presented on street signs or in advertising other than on EVSE:

(a) The electrical energy unit price shall be in terms of price per megajoule (MJ) or kilowatt-hour $(\mathrm{kWh})$ in whole cents (e.g., \$0.12) or tenths of one cent (e.g., \$0.119). In cases where the electrical energy is unlimited or free of charge, this fact shall be clearly indicated in place of the unit price.

(b) In cases where more than one electrical energy unit price may apply over the duration of a single transaction to sales to the general public, the terms and conditions that will determine each unit price and when each unit price will apply shall be clearly displayed.

(c) For fixed service applications, the following information shall be conspicuously displayed or posted:

(1) the level of EV service expressed as the nominal power transfer (i.e., nominal rate of electrical energy transfer), and

(2) the type of electrical energy transfer (e.g., AC, DC, wireless).

(d) For variable service applications, the following information shall be conspicuously displayed or posted:

(1) the type of delivery (i.e., variable);

(2) the minimum and maximum power transfer that can occur during a transaction, including whether service can be reduced to zero;

(3) the conditions under which variations in electrical energy transfer will occur; and

(4) the type of electrical energy transfer (e.g., AC, DC, wireless).

Where fees will be assessed for other services in direct connection with the fueling of the vehicle, such as fees based on time measurement and/or a fixed fee, the additional fees shall be included on all street signs or other advertising.

(Added 2013)

\subsection{Diesel Exhaust Fluid (DEF).}

\subsubsection{Definition.}

2.35.1.1. Diesel Exhaust Fluid (DEF). - A preparation of aqueous urea [(NH2)2CO], containing $32.5 \%$ by mass of technically-pure urea in high-purity water with quality characteristics defined by the latest version of ISO 22241, "Diesel engines - NOx reduction agent AUS 32."

2.35.2. Labeling of Diesel Exhaust Fluid (DEF). - DEF shall be labeled.

2.35.2.1. Retail Dispenser Labeling. - A label shall be clearly and conspicuously placed on the front panel of the Diesel Exhaust Fluid dispenser stating "for operation of selective catalytic reduction (SCR) converters in motor vehicles with diesel engines."

2.35.2.2. Documentation for Retailers of Bulk Product. - A DEF supplier shall provide, at the time of delivery of the bulk shipment of DEF, identification of the fluid's origin including the name of the fluid manufacturer, the brand name, trade name, or trademark, and a statement identifying the fluid as DEF conforming to specifications given in the latest version of ISO 22241, "Diesel engines - NOx reduction agent AUS 32." This information shall be provided by the supplier on an invoice, bill of lading, shipping paper, or other document. 
2.35.2.3. Labeling of Packaged Product. - Any diesel exhaust fluid retail package shall bear a label that includes the name of the fluid manufacturer, the brand name, trade name, or trademark, a statement identifying the fluid as DEF conforming to specifications given in the latest version of ISO 22241 "Diesel engines - NOx reduction agent AUS 32," and the statement, "It is recommended to store DEF between $-5{ }^{\circ} \mathrm{C}$ to $30^{\circ} \mathrm{C}\left(23^{\circ} \mathrm{F}\right.$ to $\left.86^{\circ} \mathrm{F}\right) . "$

2.35.2.4. Documentation for Bulk Deliveries. - A carrier that transports or accepts for transportation any bulk shipment by tank truck, freight container, cargo tank, railcar, or any other vehicle used to transport or deliver bulk quantities of DEF shall, at the time of delivery of the DEF, provide identification of the fluid's origin including the name of the fluid manufacturer, the brand name, trade name, or trademark, and a statement identifying the fluid as DEF conforming to specifications given in the latest version of ISO 22241, "Diesel engines - NOx reduction agent AUS 32." This information shall be provided to the recipient on an invoice, bill of lading, shipping paper, or other document.

(Added 2014)

\subsection{Transmission Fluid.}

2.36.1. Products for Use in Lubricating Transmissions. - Transmission fluids shall meet the original equipment manufacturer's requirements for those transmissions or have demonstrated performance claims to be suitable for use in those transmissions. Where a fluid can be licensed against an original equipment manufacturer's specification, evidence of current licensing by the marketer is acceptable documentation of performance against the specification. In the absence of a license from the original equipment manufacturer, adherence to the original equipment manufacturer's recommended requirements shall be assessed after testing per relevant methods available to the lubricants industry and the state regulatory agency. Suitability for use claims shall be based upon appropriate field, bench, and/or transmission rig testing. Any manufacturer of a transmission fluid making suitable-for-use claims shall provide, upon request by a duly authorized representative of the Director, credible documentation of such claims. If the product performance claims published by a blender and/or marketer are based on the claim(s) of one or more additive suppliers, documentation of the claims may be requested in confidence by a duly authorized representative of the Director. Supporting data may be supplied directly to the Director's office by the additive supplier(s).

(Added 2017)

2.36.1.1. Conformance. - Conformance of a fluid per Section 2.36.1. Products for Use in Lubricating Transmissions does not absolve the obligations of a fluid licensee with respect to the licensing original equipment manufacturer or the original equipment manufacturer's licensing agent(s), where relevant.

(Added 2017)

2.36.1.2. Transmission Fluid Additives. - Any material offered for sale or sold as an additive to transmission fluids shall be compatible with the transmission fluid to which it is added, and shall meet all performance claims as stated on the label or published on any website referenced by the label. Any manufacturer of any such product sold in this state shall provide, upon request by a duly authorized representative of the Director, documentation of any claims made on their product label or published on any website referenced by the label.

(Added 2017)

2.36.2. Labeling and Identification of Transmission Fluid. - Transmission fluid shall be labeled or identified as described below.

(Added 2017)

2.36.2.1. Container Labeling. - The label on a container of transmission fluid shall not contain any information that is false or misleading. Containers include bottles, cans, multi-quart or liter containers, pails, kegs, drums, and intermediate bulk containers (IBCs). In addition, each container of transmission fluid shall be labeled with the following: 
(a) the brand name;

(b) the name and place of business of the manufacturer, packer, seller, or distributor;

(c) the words "Transmission Fluid," which may be incorporated into a more specific description of transmission type such as "Automatic Transmission Fluid" or "Continuously Variable Transmission Fluid";

(d) the primary performance claim or claims met by the fluid and reference to where any supplemental claims may be viewed (for example, website reference). Performance claims include but are not limited to those set by original equipment manufacturers and standards setting organizations such as SAE and JASO and are acknowledged by reference; and

(e) an accurate statement of the quantity of the contents in terms of liquid measure.

(Added 2017)

2.36.2.2. Identification on Documentation. - Transmission fluid sold in bulk shall be identified on the manufacturer, packer, seller, or distributor invoice, bill of lading, shipping paper, or other documentation with the information listed below:

(a) the brand name;

(b) the name and place of business of the manufacturer, packer, seller, or distributor;

(c) the words "Transmission Fluid," which may be incorporated into a more specific description of transmission type such as "Automatic Transmission Fluid" or "Continuously Variable Transmission Fluid";

(d) the primary performance claim or claims met by the fluid or reference to where these claims may be viewed (for example, website reference). Performance claims include but are not limited to those set by original equipment manufacturers and standards setting organizations such as SAE and JASO and are acknowledged by reference; and

(e) an accurate statement of the quantity of the contents in terms of liquid measure.

(Added 2017)

2.36.2.3. Identification on Service Provider Documentation. - Transmission fluid installed from a bulk tank at time of transmission service shall be identified on the customer invoice with the information listed below:

(a) the brand name;

(b) the name and place of business of the service provider;

(c) the words "Transmission Fluid," which may be incorporated into a more specific description of transmission type such as "Automatic Transmission Fluid" or "Continuously Variable Transmission Fluid";

(d) the primary performance claim or claims met by the fluid or reference to where these claims may be viewed (for example, website reference). Performance claims include but are not limited to those set by original equipment manufacturers and standards setting organizations such as SAE and JASO and are acknowledged by reference; and 
(e) an accurate statement of the quantity of the contents in terms of liquid measure. (Added 2017)

2.36.2.4. Bulk Delivery. - When the transmission fluid is sold in bulk, an invoice, bill of lading, shipping paper, or other documentation must accompany each delivery. This document must identify the fluid as defined in Section 2.36.2.2. Identification on Documentation.

(Added 2017)

2.36.2.5. Storage Tank Labeling. - Each storage tank of transmission fluid shall be labeled with the following:

(a) the brand name;

(b) the primary performance claim or claims met by the fluid or reference to where these claims may be viewed (for example, website reference). Performance claims include but are not limited to those set by original equipment manufacturers and standards-setting organizations such as SAE and JASO and are acknowledged by reference.

(Added 2017)

2.36.3. Documentation of Claims Made Upon Product Label. - Any manufacturer, packer, or distributor of any product subject to this article and sold in this state shall provide, upon request of duly authorized representatives of the Director, credible documentation of any claim made upon their product label, including claims made on any website referenced by said label. If the product performance claims published by a blender and/or marketer are based on the claim(s) of one or more additive suppliers, documentation of the claims may be requested in confidence by a duly authorized representative of the Director. Supporting data may be supplied directly to the Director's office by the additive supplier(s).

(Added 2017)

(Added 2017)

2.37. Pet Treats or Chews. - Digestive chews, rawhides, bones, biscuits, antlers or similar type products shall be sold by weight.

(Effective July 18, 2019. Enforceable January 1, 2022)

(Added 2018) (Amended 2019)

2.38. Non-Utility Transactions of Electrical Energy (Other than Vehicle Fueling Applications). - This applies to non-utility sales of electricity; that is, transactions of electrical energy by other than a utility where the transaction is based in whole or in part on measured quantities of energy delivered.

This section does not apply to:

(a) Electrical energy sold in vehicle fueling applications as defined in Section 2.34. Retail Sales of Electricity Sold as a Vehicle Fuel.

(b) Transactions not subject to weights and measures authority.

\subsubsection{Definitions}

2.38.1.1. Utility. - In this regulation, an entity not subject to weights and measures authority as defined by law or regulation, such as a public utility or municipality or electric cooperative.

2.38.1.2. Electricity Metering System. - An electricity metering system comprises of components functioning together to measure and register active energy, apparent energy and/or power factor. An electricity metering system may measure alternating current (AC) or direct current (DC) energy. 
2.38.1.3. Demand. - The average rate at which a particular integrated quantity is being supplied to the load. Generally, it is indicated, recorded, or computed as the average obtained over a specified time interval. Demand is expressed in kilowatts $(\mathrm{kW})$, kilovolt-amperes (kVA), kilovars (kvar), or other suitable units.

2.38.1.4. Power Factor (PF). - The ratio of the "active power" to "apparent power", in an AC circuit. It describes the efficient use of available power.

2.38.2. Method of Sale. - All electrical energy offered for sale and sold based on the electrical energy transfer through the electric meter shall be in units specified below.
(a) Active Energy:
megajoules (MJ) or kilowatt-hours (kWh)
(b) Apparent Energy:
kilovolt-ampere hours (kVAh)
(c) Demand:
kilowatts $(\mathrm{kW})$ or kilovolt-amperes $(\mathrm{kVA})$

In addition to the fees assessed for the quantity of electrical energy sold, where permitted, fees may also be assessed for other services, such as taxes and/or fixed fees.

(a) a "power factor (PF)" and

(b) other services related to the sale of electrical energy, such as taxes and/or fixed fees.

2.38.3. Unit Price. - The electrical energy unit price shall be in terms of price per unit of measure and in U.S. currency.

(Added 2019)

\subsection{Tractor Hydraulic Fluid.}

2.39.1. Products for Use in Lubricating Tractors. - Tractor hydraulic fluids shall meet at least one current and/or verifiable original equipment manufacturer's specifications for respective tractors. A specification is deemed verifiable if all necessary bench and laboratory tests are available to verify the fluid's ability to pass those requirements set out by the original equipment manufacturer. A list of current and verifiable original equipment manufacturer's specifications is located on the NCWM website (www.ncwm.com). Where a fluid can be licensed against an original equipment manufacturer's specification, evidence of current licensing by the marketer is acceptable documentation of performance against the specification. In the absence of a license from the original equipment manufacturer, adherence to the original equipment manufacturer's specifications shall be assessed after testing per relevant methods available to the lubricants industry and the regulatory agency. Suitability for use claims shall be based upon appropriate field, bench, and/or rig testing. Any manufacturer of a tractor hydraulic fluid making suitable for use claims shall provide, upon request by a duly authorized representative of the Director, credible documentation of such claims. If the product performance claims published by a blender and/or marketer are based on the claim(s) of one or more additive suppliers, documentation of the claims shall be provided upon request to a duly authorized representative of the Director. Supporting data shall, upon request, be supplied directly to the Director's office by the additive supplier(s).

(Amended 2021)

2.39.1.1. Conformance. - Conformance of a fluid per Section 2.39.1. Products for Use in Lubricating Tractors does not absolve the obligations of a fluid licensee with respect to the licensing original equipment manufacturer or the original equipment manufacturer's licensing agent(s), where relevant.

2.39.1.2. Tractor Hydraulic Fluid Additives. - Any material offered for sale or sold as an additive to tractor hydraulic fluids shall be compatible with the tractor hydraulic fluid to which it is added and shall meet all performance claims as stated on the label or published on any website referenced by the label. Any manufacturer of any such product sold shall provide, upon request by a duly authorized representative of the 
Director, documentation of any claims made on their product label or published on any website referenced by the label.

2.39.2. Labeling and Identification of Tractor Hydraulic Fluid. - Tractor hydraulic fluids shall be labeled or identified as described below.

2.39.2.1. Container Labeling. - The label on a container of tractor hydraulic fluid shall not contain any information that is false or misleading. Containers include bottles, cans, multi-quart or liter containers, pails, kegs, drums, and intermediate bulk containers (IBCs). In addition, each container of tractor hydraulic fluid shall be labeled with the following:

(a) the brand name;

(b) the name and place of business of the manufacturer, packer, seller, or distributor;

(c) the words "Tractor Hydraulic Fluid," which may include words such as "Hydraulic Fluid for Agricultural Applications" or "Universal Tractor Transmission Oil";

(d) the primary claim or claims met by the fluid and reference to where any supplemental claims may be viewed (e.g., website reference). Performance claims are those set by original equipment manufacturers;

(e) any obsolete equipment manufacturer specifications shall be clearly identified as "obsolete" and accompanied by the following cautionary statement on the principal display panel in accordance with the Uniform Packaging and Labeling Regulation, Section 8. Prominence and Placement: Consumer Packages and Section 9. Prominence and Placement: Non-Consumer Packages.

Caution: Some of the specifications are no longer deemed active by the original equipment manufacturer. Significant harm to the transmission, hydraulic system, seals, final drive or axles is possible when using this product in applications in which it is not intended.

The above cautionary statement is not required if the fluid claims to meet current original equipment manufacturer's specifications and refers to thereby preceding specifications; and

(f) an accurate statement of the quantity of the contents in terms of liquid measure.

(Amended 2021)

2.39.2.2. Identification on Documentation. - Tractor hydraulic fluid sold in bulk shall be identified on the manufacturer, packer, seller, or distributor invoice, bill of lading, shipping paper, or other documentation with the information listed below:

(a) the brand name;

(b) the name and place of business of the manufacturer, packer, seller, or distributor;

(c) the words "Tractor Hydraulic Fluid," which may include words such as "Hydraulic Fluid for Agricultural Applications" or "Universal Tractor Transmission Oil";

(d) the primary claim or claims met by the fluid and reference to where any supplemental claims may be viewed (e.g., website reference). Performance claims are those set by original equipment manufacturers;

(e) any obsolete equipment manufacturer specifications shall be clearly identified as "obsolete" and accompanied by the following cautionary statement on the documentation in a clear and conspicuous manner. 
B. Uniform Regulation for the Method of Sale of Commodities

Caution: Some of the specifications are no longer deemed active by the original equipment manufacturer. Significant harm to the transmission, hydraulic system, seals, final drive or axles is possible when using in applications in which it is not intended.

The above cautionary statement is not required if the fluid claims to meet current original equipment manufacturer's specifications and refers to thereby preceding specifications; and

(f) an accurate statement of the quantity of the contents in terms of liquid measure.

(Amended 2021)

2.39.2.3. Identification on Service Provider Documentation. - Tractor hydraulic fluid installed from a bulk tank at time of service shall be identified on the customer invoice with the information listed below:

(a) the brand name;

(b) the name and place of business of the service provider;

(c) the words "Tractor Hydraulic Fluid," which may include words such as "Hydraulic Fluid for Agricultural Applications" or "Universal Tractor Transmission Oil";

(d) the primary claim or claims met by the fluid and reference to where any supplemental claims may be viewed (e.g., website reference). Performance claims are those set by original equipment manufacturers;

(e) any obsolete equipment manufacturer specifications shall be clearly identified as "obsolete" and accompanied by the following cautionary statement on the customer invoice in a clear and conspicuous manner.

Caution: Some of the specifications are no longer deemed active by the original equipment manufacturer. Significant harm to the transmission, hydraulic system, seals, final drive or axles is possible when using in applications in which it is not intended.

The above cautionary statement is not required if the fluid claims to meet current original equipment manufacturer's specifications and refers to thereby preceding specifications; and

(f) an accurate statement of the quantity of the contents in terms of liquid measure.

(Amended 2021)

2.39.2.4. Bulk Delivery. - When the tractor hydraulic fluid is sold in bulk, an invoice, bill of lading, shipping paper, or other documentation must accompany each delivery. This document must identify the fluid as defined in Section 2.39.2.2. Identification on Documentation.

2.39.2.5. Storage Tank Labeling. - Each storage tank of tractor hydraulic fluid shall be labeled with the following:

(a) the brand name; and

(b) the primary performance claim or claims met by the fluid or reference to where these claims may be viewed (for example, website reference). Performance claims are those set by original equipment manufacturers

(Amended 2021)

2.39.3. Documentation of Claims Made Upon Product Label. - Any manufacturer, packer, or distributor of any product subject to this article and sold shall provide, upon request of duly authorized representatives of the 
Director, credible documentation of any claim made upon their product label, including claims made on any website referenced by said label. If the product performance claims published by a blender and/or marketer are based on the claim(s) of one or more additive suppliers, documentation of the claims shall be provided upon request to a duly authorized representative of the Director. Supporting data shall, upon request, be supplied directly to the Director's office by the additive supplier(s).

(Added 2019) (Amended 2021)

2.40. Diesel Fuel. - Shall meet the following requirements, based on the biodiesel concentration of the fuel:

(a) Diesel fuel that contains less than or equal to $5 \%$ by volume biodiesel shall meet the latest version of ASTM D975, "Standard Specifications for Diesel Fuels" and shall be sold as diesel fuel.

(b) Diesel fuel that contains greater than or equal to $6 \%$ by volume biodiesel and that contains less than or equal to $20 \%$ by volume shall meet the latest version of ASTM D7467, "Standard Specifications for Diesel Fuel Oil, Biodiesel Blend (B6 to B20).”

(c) Only fuel additive registered with the U.S. EPA may be used to additize diesel fuel, and the final product shall meet the latest version of ASTM D975 and/or ASTM D7467.

2.40.1. Premium Diesel Fuel. - All diesel fuels identified on retail dispensers as premium, super, supreme, or premier must conform to the following minimum requirements.

(a) Cetane Number. - A minimum cetane number of 47.0 as determined by the latest version of ASTM D613, "Standard Test Method for Cetane Number of Diesel Fuel Oil."

NOTE: ASTM D613, "Standard Test Method for Cetane Number of Diesel Fuel Oil" is the referee method; however, the following methods can be used to determine cetane number: the latest version of ASTM D6890, "Standard Test Method for Determination of Ignition Delay and Derived Cetane Number" (DCN) of Diesel Fuel Oils by Combustion in a Constant Volume Chamber"; and ASTM D7668, "Standard Test Method for Determination of Derived Cetane Number (DCN) of Diesel Fuel Oils-Ignition Delay and Combustion Delay Using a Constant Volume Combustion Chamber Method."

(b) Low Temperature Operability. - A cold flow performance measurement which meets the latest version of ASTM D975, "Standard Specification for Diesel Fuel," tenth percentile minimum ambient air temperature charts and maps by the latest version of either ASTM D2500, "Standard Test Method for Cloud Point of Petroleum Products and Liquid Fuels" or ASTM Standard D4539, "Standard Test Method for Filterability of Diesel Fuels by Low-Temperature Flow Test (LTFT)." The latest version of ASTM D6371, "Standard Test Method for Cold Filter Plugging Point of Diesel and Heating Fuels" may be used when the test results are a maximum of $6{ }^{\circ} \mathrm{C}$ below the Cloud Point. Low temperature operability is only applicable October 1 to March 31 of each year.

(c) Lubricity. - A maximum wear scar diameter of 460 micrometers as determined by the latest version ASTM D6079, "Standard Test Method for Evaluating Lubricity of Diesel Fuels by the High-Frequency Reciprocating Rig (HFRR)."

NOTE: The latest version of ASTM D6079, "Standard Test Method for Evaluating Lubricity of Diesel Fuels by the High-Frequency Reciprocating Rig (HFRR)" is the referee method; however, the latest version of ASTM D7688, "Standard Test Method for Evaluating Lubricity of Diesel Fuels by the HighFrequency Reciprocating Rig (HFRR) by Visual Observation” can be used.

(d) Corrosion. - A minimum rating of $\mathrm{B}+$ as determined by the most recent version of NACE TM0172, "Determining Corrosive Properties of Cargoes in Petroleum Product Pipelines." 
B. Uniform Regulation for the Method of Sale of Commodities

NOTE: The latest recent version of NACE TM0172 "Determining Corrosive Properties of Cargoes in Petroleum Product Pipelines" is the referee method. The latest version of ASTM D7548 "Standard Test Method for Determination of Accelerated Iron Corrosion in Petroleum Products" can be used.

(e) Filter Blocking Tendency (FBT) - A maximum of 2.2 by the latest version of ASTM D2068, "Standard Test Method for Determining Filter Blocking Tendency", following procedure B.

(f) Injector Deposit Control. - Maximum power loss in keep-clean mode of $2 \%$ by the latest version of Coordinating European Council, CEC F-98-08, "Direct Injection, Common Rail Diesel Engine Nozzle Coking Test."

2.40.2. Use of Other Diesel Terminology. - For any terms other than premium, super, supreme, or premier included in the diesel fuel product or grade name and/or advertisements and claims displayed on dispensers, pump toppers, pole signs and bollard signs which imply improved performance, the product must have a clearly-defined fuel property with a substantiated functional benefit. Such property must be measurable utilizing industry accepted test methodologies developed by recognized standards organizations such as ASTM, SAE, and CEC to allow verification of the improved performance.

(Added 2021)

\section{Section 3. General}

3.1. Presentation of Price. - Whenever an advertised, posted, or labeled price per unit of weight, measure, or count for any commodity includes a fraction of a cent, all elements of the fraction shall be prominently displayed, and the numerals expressing the fraction shall be immediately adjacent to, of the same general design and style as, and at least one half the height and width of, the numerals representing the whole cent.

(Added 1976)

3.2. Allowable Differences: Combination Quantity Declarations. - Whenever the method of sale for a bulk or packaged commodity requires the use of a statement that includes count in addition to weight, measure, or size, the following shall apply to the particular commodity:

3.2.1. Beverageware: Pressed and Blown Tumblers and Stemware. - The allowable difference between actual and declared capacity shall be:

(a) SI Units:

(1) plus or minus $10 \mathrm{~mL}$ for items of $200 \mathrm{~mL}$ capacity or less; and

(2) plus or minus $5 \%$ of the stated capacity for items over $200 \mathrm{~mL}$ capacity.

(Added 1973) (Amended 1974, 1979, and 1980)

(b) U.S. Customary Units:

(1) plus or minus $1 / 4 \mathrm{fl} \mathrm{oz}$ for items of $5 \mathrm{fl} \mathrm{oz}$ capacity or less; and

(2) plus or minus $5 \%$ of the stated capacity for items over $5 \mathrm{fl} \mathrm{oz} \mathrm{capacity.}$

3.3. Labeling of Machines that Dispense Packaged Commodities. - All vending machines dispensing packaged commodities shall indicate:

(a) product identity;

(b) net quantity; and 
(c) the party responsible for the vending machine.

Examples:

"For service or refunds contact: XYZ Cola Company Rockville, MD 20800"

"Telephone: (301) 555-1000," or "See attendant inside for refunds."

(Amended 1995)

(d) the requirements for product identity and net quantity can be met either by display of the package or by information posted on the outside of the machine.

(Added 1972)

3.4. Railroad Car Tare Weights. - Whenever stenciled tare weights on freight cars are employed in the sale of commodities or the assessment of freight charges, the following conditions and requirements shall apply:

3.4.1. Newly Stenciled Tare Weights. - All newly stenciled or re-stenciled tare weights shall be accurately represented to the nearest $50 \mathrm{~kg}$ for metric units and to the nearest $100 \mathrm{lb}$ for U.S. customary units, and the representation shall include the date of weighing.

(Amended 1979)

3.4.2. Allowable Difference. - The allowable difference between actual tare weight and stenciled tare weight on freight cars in use shall be per Section 3.4.2.(a) SI allowable difference or Section 3.4.2.(b) U.S. customary allowable difference.

\section{(a) SI allowable difference:}

(1) plus or minus $150 \mathrm{~kg}$ for cars $25000 \mathrm{~kg}$ or less;

(2) plus or minus $200 \mathrm{~kg}$ for cars over $25000 \mathrm{~kg}$ to and including $30000 \mathrm{~kg}$; and

(3) plus or minus $250 \mathrm{~kg}$ for cars over $30000 \mathrm{~kg}$. (Added 1979)

(b) U.S. customary allowable difference:

(1) plus or minus $300 \mathrm{lb}$ for cars $50000 \mathrm{lb}$ or less;

(2) plus or minus $400 \mathrm{lb}$ for cars over $50000 \mathrm{lb}$ to and including $60000 \mathrm{lb}$; and

(3) plus or minus $500 \mathrm{lb}$ for cars over $60000 \mathrm{lb}$.

3.4.3. Verification or Change of Tare Weights. - Tare weight determinations for verification or change of stenciled weights shall only be made on properly prepared and adequately cleaned freight cars.

3.4.4. Special Cars. - Tank cars, covered hopper cars, flat cars equipped with multi-deck racks or special superstructure, mechanical refrigerator cars, and house type cars equipped with special lading protective devices must be reweighed and re-stenciled only by owners or their authorized representatives:

(a) when car bears no lightweight (empty weight) stenciling; and

(b) when repairs or alterations result in a change of weight in excess of the permissible lightweight tolerance. (Added 1974) (Renumbered 1985)

(Added 1973) (Amended 1974, 1979, and 1985) 
B. Uniform Regulation for the Method of Sale of Commodities

\section{Section 4. Revocation of Conflicting Regulations}

All provisions of all orders and regulations heretofore issued on this same subject that are contrary to or inconsistent with the provisions of this regulation, and specifically , are hereby revoked.

(Added 1971)

\section{Section 5. Effective Date}

This regulation shall become effective on

Given under my hand and the seal of my office in the City of on this day of Signed

(Added 1971) (Amended 1973) 


\title{
C. Uniform Unit Pricing Regulation
}

\author{
as adopted by \\ The National Conference on Weights and Measures*
}

\section{Background}

The Uniform Unit Pricing Regulation (UPR) (renamed in 1983) provides a national approach to the subject for those jurisdictions choosing to adopt such a regulation. The traditional approach of the Conference in drafting Uniform Regulations has been to design specific implementing Regulations for the enforcement of the broader requirements of the Uniform Weights and Measures Law. Given the authority of Sections 12.(c) and (d), and the mandate of Section 16. of this Law, as well as the trend in unit pricing, both voluntary and mandatory, the UPR is considered appropriate. Unit pricing has been a concern of the weights and measures official and has been required for random weight packages for a long time.

In 1993, the NCWM was contacted by several weights and measures jurisdictions and retail trade associations who requested that the UPR be updated to add new commodity groups and pricing requirements. The comments indicated that many commodity groups for non-food products were not included in the table and that some of the required units may not be appropriate for many of the new products being sold in stores. Another concern was that the UPR specified pricing only on the basis of price per pound on most products sold by weight. This has resulted in some jurisdictions not enforcing the requirements on stores that voluntarily unit price on the basis of price per ounce instead of price per pound. The NCWM agreed that the UPR should be revised to encourage wider adoption and use of the uniform regulation and that provisions for unit pricing in metric units should be included.

At the 1997 Annual Meeting, the NCWM adopted revisions to the regulation to permit retail stores that voluntarily provide unit pricing to present prices using various units of measure.

The NCWM eliminated the table of product groupings because it is difficult to keep it current and inclusive, so some newer products were not included under the uniform requirements. The table was replaced with requirements that specify that the unit price is to be based on price per ounce or pound, or price per 100 grams or kilogram, if the packaged commodity is labeled by weight. For example, the proposed revisions would require the unit price for soft drinks sold in various package sizes (e.g., $12 \mathrm{fl} \mathrm{oz} \mathrm{cans} \mathrm{through} 2 \mathrm{~L}$ bottles) to be uniformly and consistently displayed in terms of either price per fluid ounce, price per quart, or price per liter. The NCWM also increased the price of commodities exempted from unit pricing from 10 cents to 50 cents. The NCWM believed these revisions would ensure that unit pricing information facilitates value comparison between different package sizes and/or brands offered for sale in a store.

The NCWM also considered several comments on this item from members of the U.S. Metric Association (USMA). Most of these comments suggested that the UPR be amended to require unit pricing in metric units and permit U.S. customary unit pricing to be provided voluntarily. When it developed the proposed revisions, the NCWM included guidelines for both U.S. customary and metric unit pricing and believes this is the correct approach to implementing metric revisions in the regulation. The NCWM would like to make it clear that the UPR applies only when stores voluntarily provide unit pricing information. Its purpose is to provide a standard that retailers must follow to ensure that consumers will have pricing information that helps them make value comparisons. The decision to provide unit

${ }^{*}$ The National Conference on Weights and Measures (NCWM) is supported by the National Institute of Standards and Technology (NIST) in partial implementation of its statutory responsibility for "cooperation with the states in securing uniformity in weights and measures laws and methods of inspection." 
price information in metric or U.S. customary units rests with retailers who will respond to consumer preference. The NCWM believes that consumer preference will be the deciding factor as to when and how quickly metric unit pricing is used in the marketplace. Therefore, the NCWM does not support amendments to include mandatory provisions in the UPR as these provisions would take the decision to go to metric unit pricing out of the hands of consumers and retailers. Finally, the NCWM does not want to include any requirement that may discourage retailers from voluntarily providing unit price information.

(Amended 1997)

In December 2014, NIST published a unit pricing best practice guide, NIST SP 1181, "Unit Pricing Guide, A Best Practice Approach to Unit Pricing," which can be found at nvlpubs.nist.gov/nistpubs/SpecialPublications/NIST.SP.1181.pdf. The guide was developed to provide retailers with information about the best practice requirements for the unit pricing of pre-packaged commodities, which will improve the accuracy, usability, and uniformity of unit pricing information offered in retail stores. The guide is not intended to conflict with the UPR. Mandatory regulations should be consulted to ensure those requirements are met before the recommended best practice requirements in this guide are implemented.

*The National Conference on Weights and Measures (NCWM) is supported by the National Institute of Standards and Technology (NIST) in partial implementation of its statutory responsibility for "cooperation with the states in securing uniformity in weights and measures laws and methods of inspection."

\section{Status of Promulgation}

The table beginning on page 6 shows the status of adoption of the Uniform Unit Pricing Regulation. 


\section{Uniform Unit Pricing Regulation}

\section{Table of Contents}

Section

Section 1. Application 151

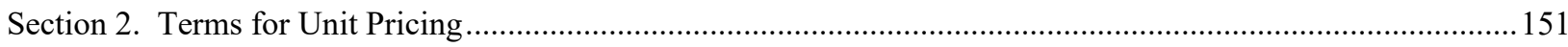

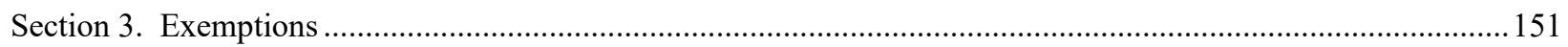

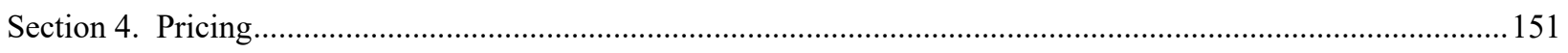

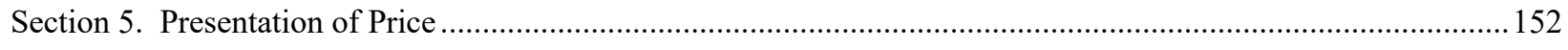

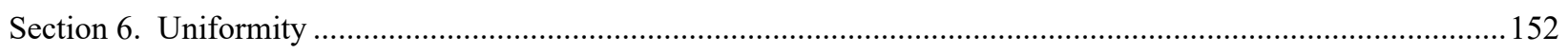

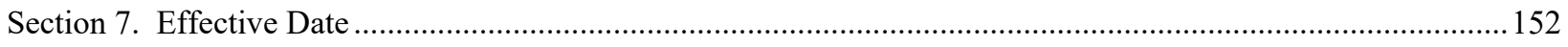


C. Uniform Unit Pricing Regulation 


\section{Uniform Unit Pricing Regulation}

\section{Section 1. Application}

Except for random and uniform weight packages that clearly state the unit price in accordance with existing regulations, any retail establishment providing unit price information for packaged commodities shall provide the unit price information in the manner prescribed herein.

\section{Section 2. Terms for Unit Pricing}

The declaration of the unit price of a particular commodity in all package sizes offered for sale in a retail establishment shall be uniformly and consistently expressed in terms of:

(a) Price per kilogram or $100 \mathrm{~g}$, or price per pound or ounce, if the net quantity of contents of the commodity is in terms of weight.

(b) Price per liter or $100 \mathrm{~mL}$, or price per dry quart or dry pint, if the net quantity of contents of the commodity is in terms of dry measure or volume.

(c) Price per liter or $100 \mathrm{~mL}$, or price per gallon, quart, pint, or fluid ounce, if the net quantity of contents of the commodity is in terms of liquid volume.

(d) Price per individual unit or multiple units if the net quantity of contents of the commodity is in terms of count.

(e) Price per square meter, square decimeter, or square centimeter, or price per square yard, square foot, or square inch, if the net quantity of contents of the commodity is in terms of area.

\section{Section 3. Exemptions}

(a) Small Packages. - Commodities shall be exempt from these provisions when packaged in quantities of less than $28 \mathrm{~g}(1 \mathrm{oz})$ or $29 \mathrm{~mL}(1 \mathrm{fl} \mathrm{oz})$ or when the total retail price is 50 cents or less.

(b) Single Items. - Commodities shall be exempt from these provisions when only one brand in only one size is offered for sale in a particular retail establishment.

(c) Infant Formula. - For "infant formula," unit price information may be based on the reconstituted volume. "Infant formula" means a food that is represented for special dietary use solely as a food for infants by reason of its simulation of human milk or suitability as a complete or partial substitute for human milk.

(d) Variety and Combination Packages. - Variety and Combination Packages as defined in Section 2.9 and Section 2.10 in the Uniform Packaging and Labeling Regulation [see Section 3. NOTE ] shall be exempt from these provisions.

Section 3. NOTE: See "Uniform Packaging and Labeling Regulation."

\section{Section 4. Pricing}

(a) The unit price shall be to the nearest cent when a dollar or more. 
(b) If the unit price is under a dollar, it shall be listed:

(1) to the tenth of a cent; or

(2) to the whole cent.

The retail establishment shall have the option of using (b)(1) or (b)(2), but shall not implement both methods.

The retail establishment shall accurately and consistently use the same method of rounding up or down to compute the price to the whole cent.

\section{Section 5. Presentation of Price}

(a) In any retail establishment in which the unit price information is provided in accordance with the provisions of this regulation, that information may be displayed by means of a sign that offers the unit price for one or more brands and/or sizes of a given commodity, by means of a sticker, stamp, sign, label, or tag affixed to the shelf upon which the commodity is displayed, or by means of a sticker, stamp, sign, label, or tag affixed to the consumer commodity.

(b) Where a sign providing unit price information for one or more sizes or brands of a given commodity is used, that sign shall be displayed clearly and in a non-deceptive manner in a central location as close as practical to all items to which the sign refers.

(c) If a single sign or tag includes the unit price information for more than one brand or size of a given commodity, the following information shall be provided:

(1) the identity and the brand name of the commodity;

(2) the quantity of the packaged commodity, if more than one package size per brand is displayed;

(3) the total retail sales price; and

(4) the price per appropriate unit, in accordance with Section 2. Terms for Unit Pricing.

\section{Section 6. Uniformity}

(a) If different brands or package sizes of the same consumer commodity are expressed in more than one unit of measure (e.g., soft drinks are offered for sale in $2 \mathrm{~L}$ bottles and $12 \mathrm{fl} \mathrm{oz}$ cans), the retail establishment shall unit price the items consistently.

(b) When metric units appear on the consumer commodity in addition to other units of measure, the retail establishment may include both units of measure on any stamps, tags, labels, signs, or lists.

\section{Section 7. Effective Date}

This regulation shall become effective on , 20

Given under my hand and the seal of my office in the City of on this day of , 20

Signed

(Amended 1997) 


\title{
D. Uniform Regulation for the Voluntary Registration of Servicepersons and Service Agencies for Commercial Weighing and Measuring Devices
}

\author{
as adopted by \\ The National Conference on Weights and Measures*
}

\section{Background}

The Uniform Regulation covering the registration of servicepersons and service agencies was developed and adopted by the National Conference on Weights and Measures (NCWM) in 1966, retitled in 1983, and substantially revised in 1984. It is designed to promote uniformity among those jurisdictions that provide for or are contemplating the establishment of some type of control over the servicing of commercial weighing and measuring devices. It offers to a serviceperson or to a service agency the opportunity to register and carries with it the privilege of restoring devices to service and of placing new or used devices in service.

Two unique features of the registration plan are its voluntary nature and the provision for reciprocity. Registration is not required; however, the privileges gained make it attractive. Also, in order to provide maximum effectiveness of the program and to reduce legal obstacles to a minimum to service across state lines, provision is made for reciprocity in certification of standards and testing equipment among states.

\section{Status of Promulgation}

The table beginning on page 6 shows the status of adoption of the Uniform Regulation for the Voluntary Registration of Servicepersons and Service Agencies for Commercial Weighing and Measuring Devices.

* The National Conference on Weights and Measures (NCWM) is supported by the National Institute of Standards and Technology (NIST) in partial implementation of its statutory responsibility for "cooperation with the states in securing uniformity in weights and measures laws and methods of inspection." 
IV. Uniform Regulations

Handbook 130 - 2022

D. Uniform Regulation for the Voluntary Registration

THIS PAGE INTENTIONALLY LEFT BLANK 


\section{Uniform Regulation for the Voluntary Registration of Servicepersons and Service Agencies for Commercial Weighing and Measuring Devices}

\section{Table of Contents}

$\begin{array}{ll}\text { Section } & \text { Page }\end{array}$

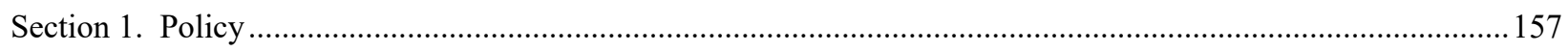

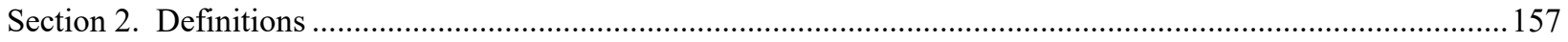

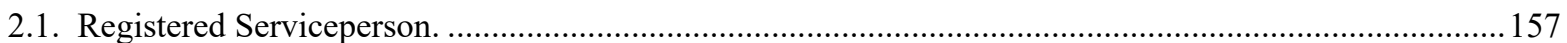

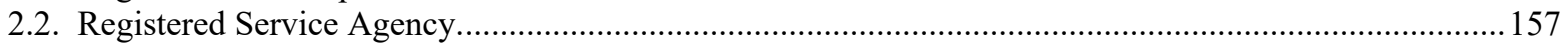

2.3. Commercial and Law Enforcement Weighing and Measuring Devices.................................................. 157

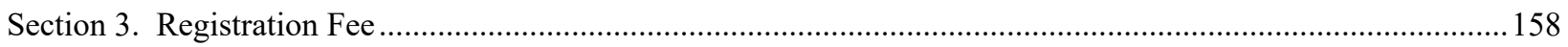

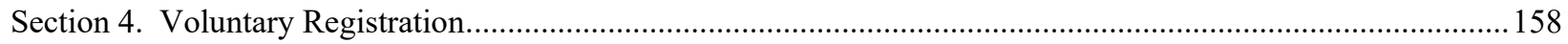

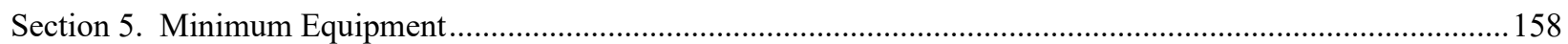

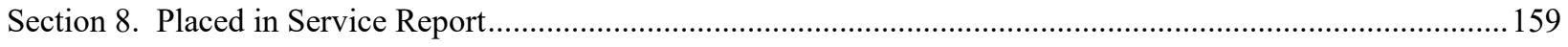

Section 9. Examination and Calibration or Certification of Standards and Testing Equipment ..............................159

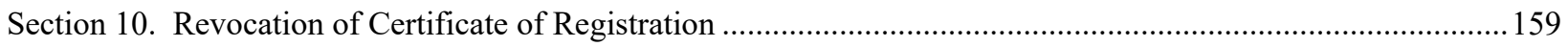

Section 11. Publication of Lists of Registered Servicepersons and Registered Service Agencies ..........................159

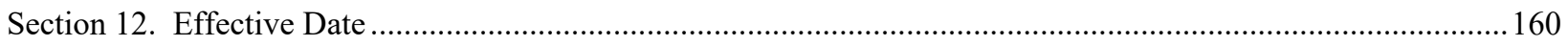


IV. Uniform Regulations

Handbook 130 - 2022

D. Uniform Regulation for the Voluntary Registration

THIS PAGE INTENTIONALLY LEFT BLANK 


\section{Uniform Regulation for the Voluntary Registration of Servicepersons and Service Agencies for Commercial Weighing and Measuring Devices}

\section{Section 1. Policy}

For the benefit of the users, manufacturers, and distributors of commercial weighing and measuring devices, it shall be the policy of the Director of Weights and Measures, hereinafter referred to as "Director," to accept registration of (a) an individual and (b) an agency providing acceptable evidence that he, she, or it is fully qualified by training or experience to install, service, repair, or recondition a commercial weighing or measuring device; has a thorough working knowledge of all appropriate weights and measures laws, orders, rules, and regulations; and has possession of, or has available for use, and will use suitable and calibrated weights and measures field standards and testing equipment appropriate in design and adequate in amount. (An employee of the government shall not be eligible for registration.)

The Director will check the qualifications of each applicant. It will be necessary for an applicant to have available sufficient field standards and equipment (see Section 5, Minimum Equipment).

It shall also be the policy of the Department to issue a "Certificate of Registration" to qualified applicants whose applications for registration are approved. This Certificate grants authority to remove rejection seals and tags placed on Commercial and Law Enforcement Weighing and Measuring Devices by authorized weights and measures officials, to place in service repaired devices that were rejected, and to place in service devices that have been newly installed.

The Director is NOT guaranteeing the work or fair dealing of a Registered Serviceperson or Service Agency. The Director will, however, remove from the registration list any Registered Serviceperson or Service Agency that performs unsatisfactory work or takes unfair advantage of a device owner.

Registration with the Director shall be on a voluntary basis. The Director shall reserve the right to limit or reject the application of any Serviceperson or Service Agency and to revoke his, her, or its permit to remove rejection seals or tags for good cause.

This policy shall in no way preclude or limit the right and privilege of any individual or agency not registered with the Director to install, service, repair, or recondition a commercial weighing or measuring device (see Section 7 , Privileges and Responsibilities of a Voluntary Registrant).

(Added 1966) (Amended 1984 and 2005)

\section{Section 2. Definitions}

2.1. Registered Serviceperson. - Any individual who for hire, award, commission, or any other payment of any kind, installs, services, repairs, or reconditions a commercial weighing or measuring device, and who voluntarily registers with the Director of Weights and Measures.

(Added 1966)

2.2. Registered Service Agency. - Any agency, firm, company, or corporation that for hire, award, commission, or any other payment of any kind installs, services, repairs, or reconditions a commercial weighing or measuring device, and that voluntarily registers with the Director of Weights and Measures. Under agency registration, identification of individual servicepersons shall be required.

(Added 1966) (Amended 1984)

2.3. Commercial and Law Enforcement Weighing and Measuring Devices. - Any weight or measure or weighing or measuring device commercially used or employed in establishing the size, quantity, extent, area, or 
measurement of quantities, things, produce, or articles for distribution or consumption, purchased, offered, or submitted for sale, hire, or award, or in computing any basic charge or payment for services rendered on the basis of weight or measure. It shall also include any accessory attached to or used in connection with a commercial weighing or measuring device when such accessory is so designed or installed that its operation affects the accuracy of the device. It also includes weighing and measuring equipment in official use for the enforcement of law or for the collection of statistical information by government agencies.

(Added 1966) (Amended 1984)

\section{Section 3. Registration Fee}

There shall be charged by the Director an annual fee of $\$$ per Registered Serviceperson and per Registered Service Agency to cover costs at the time application for registration is made, and annually, thereafter.

(Added 1966) (Amended 1984)

\section{Section 4. Voluntary Registration}

An individual or agency qualified by training or experience may apply for registration to service weighing devices or measuring devices on an application form supplied by the Director. Said form, duly signed and witnessed, shall include certification by the applicant that the individual or agency is fully qualified to install, service, repair, or recondition whatever devices for the service of which competence is being registered; has in possession or available for use, and will use, all necessary testing equipment and standards; and has full knowledge of all appropriate weights and measures laws, orders, rules, and regulations. An applicant also shall submit appropriate evidence or references as to qualifications. Application for registration shall be voluntary, but the Director is authorized to reject or limit any application.

(Added 1966) (Amended 1984)

\section{Section 5. Minimum Equipment}

Applicants must have available sufficient standards and equipment to adequately test devices as set forth in the Notes section of each applicable code in NIST Handbook 44, "Specifications, Tolerances, and Other Technical Requirements for Weighing and Measuring Devices." This equipment will meet the specifications of NIST 105-series standards (or other suitable and designated standards). This section shall not preclude the use of additional field standards and/or equipment, as approved by the Director, for uniform evaluation of device performance (see Section 9, Examination and Calibration or Certification of Standards and Testing Equipment).

(Added 1984) (Amended 2005)

\section{Section 6. Certificate of Registration}

The Director will review and check the qualifications of each applicant. The Director shall issue to the applicant a "Certificate of Registration," including an assigned registration number if it is determined that the applicant is qualified. The "Certificate of Registration" will expire 1 year from the date of issuance.

(Added 1966) (Amended 1984)

\section{Section 7. Privileges and Responsibilities of a Voluntary Registrant}

A bearer of a Certificate of Registration shall have the authority to remove an official rejection tag or mark placed on a weighing or measuring device by the authority of the Director; place in service, until such time as an official examination can be made, a weighing or measuring device that has been officially rejected; and place in service, until 
such time as an official examination can be made, a new or used weighing or measuring device. The registered serviceperson or service agency is responsible for installing, repairing, and adjusting devices such that the devices are adjusted as closely as practicable to zero error.

(Added 1966) (Amended 1984)

\section{Section 8. Placed in Service Report}

The Director shall furnish each registered serviceperson and registered service agency with a supply of report forms to be known as "Placed in Service Reports." Such a form shall be executed in triplicate, shall include the assigned registration number, and shall be signed by a registered serviceperson or by a serviceperson representing a registered agency for each rejected device restored to service and for each newly installed device placed in service. Within 24 hours after a device is restored to service or placed in service, the original of the properly executed Placed in Service Report, together with any official rejection tag removed from the device, shall be forwarded to the Director at___ (address). The duplicate copy of the report shall be handed to the owner or operator of the device, and the triplicate copy of the report shall be retained by the Registered Serviceperson or Registered Service Agency.

(Added 1966) (Amended 2005)

\section{Section 9. Examination and Calibration or Certification of Standards and Testing Equip- ment}

All field standards that are used for servicing and testing weights and measures devices for which competence is registered shall be submitted to the Director for initial and subsequent verification and calibration at intervals determined by the Director. A registered serviceperson or registered service agency shall not use in servicing commercial weighing or measuring devices any field standards or testing equipment that have not been calibrated or verified by the Director. In lieu of submission of physical standards, the Director may accept calibration and/or verification reports from any laboratory that is formally accredited or recognized. The Director shall maintain a list of organizations from which the state will accept calibration reports. The state shall retain the right to periodically monitor calibration results and/or to verify field standard compliance to specifications and tolerances when field standards are initially placed into service or at any intermediate point between calibrations.

(Added 1966) (Amended 1984, 1999, and 2005)

\section{Section 10. Revocation of Certificate of Registration}

The Director is authorized to suspend or revoke a Certificate of Registration for good cause which shall include, but not be limited to: taking of unfair advantage of an owner of a device; failure to have test equipment or standards certified; failure to use adequate testing equipment; or failure to adjust commercial or law enforcement devices to comply with Handbook 44 subsequent to service or repair.

(Added 1966) (Amended 1984)

\section{Section 11. Publication of Lists of Registered Servicepersons and Registered Service Agencies}

The Director shall publish, from time to time as deemed appropriate, and may supply upon request, lists of Registered Servicepersons and Registered Service Agencies.

(Added 1966) 
IV. Uniform Regulations

Handbook 130 - 2022

D. Uniform Regulation for the Voluntary Registration

\section{Section 12. Effective Date}

This regulation shall become effective on

(Added 1966) 


\title{
E. Uniform Regulation for National Type Evaluation
}

\author{
as adopted by \\ The National Conference on Weights and Measures*
}

\section{Background}

The Uniform Regulation for National Type Evaluation was adopted by the NCWM at the $68^{\text {th }}$ Annual Meeting in 1983 and is a necessary adjunct to recognize and enable participation in the National Type Evaluation Program administered by the National Conference on Weights and Measures (NCWM). The Regulation specifically authorizes: type evaluation; recognition of a NCWM "Certificate of Conformance" of type; the State Measurement Laboratory to operate as a Participating Laboratory, if authorized by the National Institute of Standards and Technology (NIST) under its program of recognition of State Measurement Laboratories; and, the state to charge fees to those persons who seek type evaluation of weighing and measuring devices.

(Amended 2000)

At the $81^{\text {st }}$ Annual Meeting in 1996, the NCWM adopted major revisions to the Uniform Regulation for National Type Evaluation. These revisions were made to clarify the requirements and incorporate the policies and guidelines adopted by the Executive Committee as published in NCWM Publication 14, "Technical Policy, Checklists, and Test Procedures."

(Amended 1997)

\section{Intent}

It is the intent of this regulation to have all states use the National Type Evaluation, as approved by the NCWM, as their examining procedure. If a state does not wish to establish a Participating Laboratory, Section 2.4. Participating Laboratory and Section 4. Participating Laboratory may be deleted.

\section{Status of Promulgation}

The table beginning on page 6 shows the status of adoption of the Uniform Regulation for National Type Evaluation.

*The National Conference on Weights and Measures (NCWM) is supported by the National Institute of Standards and Technology (NIST) in partial implementation of its statutory responsibility for "cooperation with the states in securing uniformity in weights and measures laws and methods of inspection." 
IV. Uniform Regulations

Handbook $130-2022$

E. Uniform Regulation for National Type Evaluation

THIS PAGE INTENTIONALLY LEFT BLANK 


\section{E. Uniform Regulation for National Type Evaluation}

\section{Table of Contents}

Section

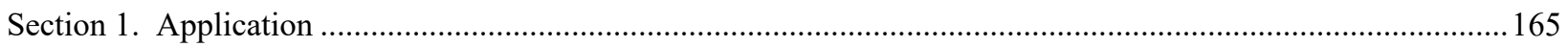

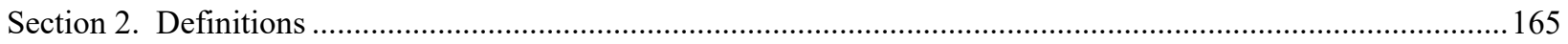

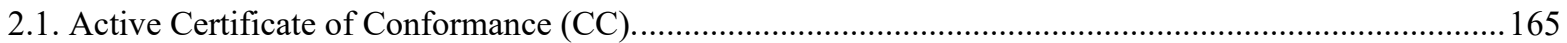

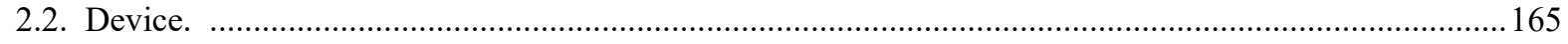

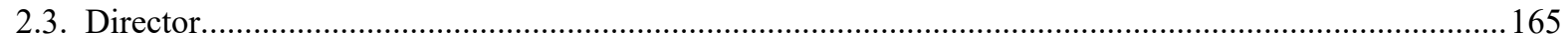

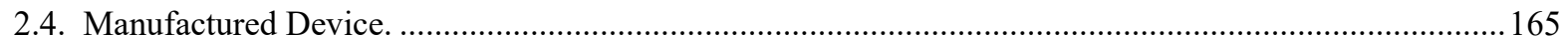

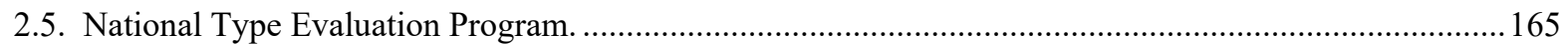

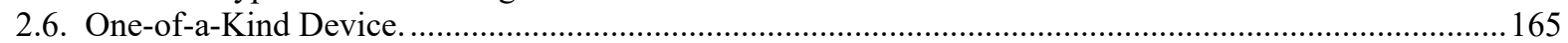

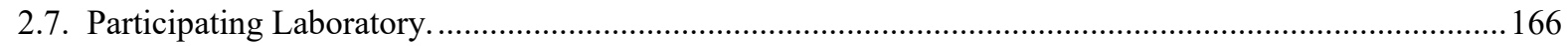

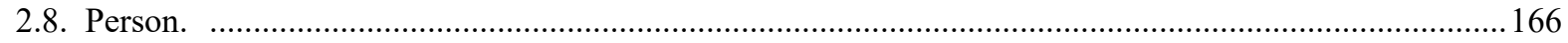

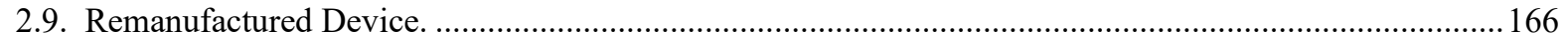

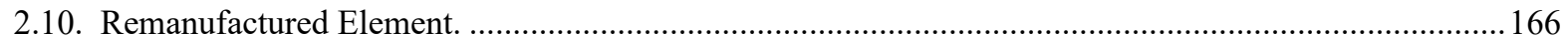

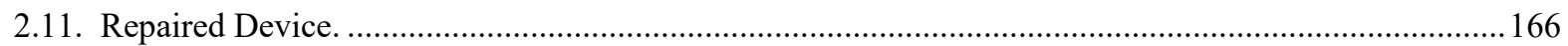

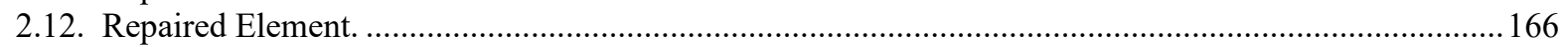

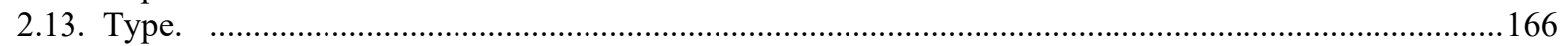

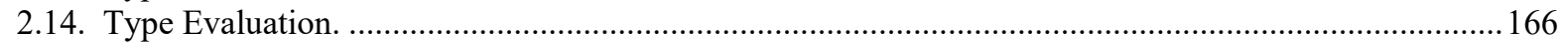

2.15. Commercial and Law Enforcement Equipment...................................................................... 166

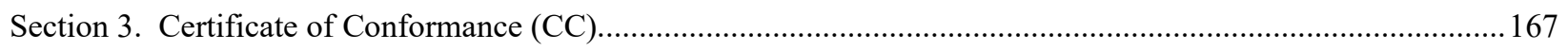

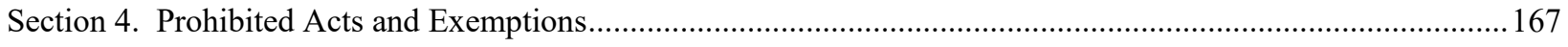

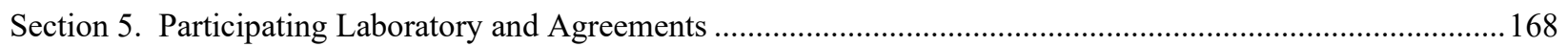

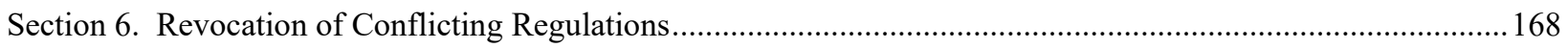

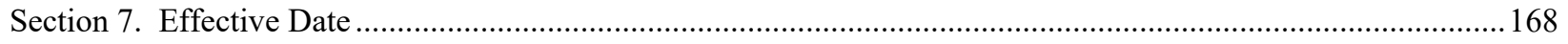


IV. Uniform Regulations

Handbook 130 - 2022

E. Uniform Regulation for National Type Evaluation

THIS PAGE INTENTIONALLY LEFT BLANK 


\section{E. Uniform Regulation for National Type Evaluation}

\section{Section 1. Application}

This regulation shall apply to [see Section 1. NOTE] any type of device and/or equipment covered in National Institute of Standards and Technology (NIST) Handbook 44 for which evaluation procedures have been published in the National Conference on Weights and Measures (NCWM), Publication 14, "National Type Evaluation Program, Technical Policy, Checklists, and Test Procedures."

Section 1. NOTE: This section can be amended to include a list of devices or device types to which NTEP evaluation criteria does not apply. Additionally, a state can amend this section to allow it to conduct a type evaluation and issue a "Certificate of Approval." This approach should be limited to occasions where formal NTEP Type Evaluation criteria does not apply and to new technologies or device applications where the development of criteria is deemed necessary by the Director.

\section{Section 2. Definitions}

2.1. Active Certificate of Conformance (CC). - A document issued based on testing by a Participating Laboratory, which the certificate holder maintains in active status under the National Type Evaluation Program (NTEP). The document constitutes evidence of conformance of a type with the requirements of this document, NIST Handbook 44, "Specifications, Tolerances, and Other Technical Requirements for Weighing and Measuring Devices," and the test procedures contained in NCWM Publication 14. By maintaining the Certificate in active status, the Certificate holder declares the intent to continue to manufacture or remanufacture the device consistent with the type and in conformance with the applicable requirements. A device is traceable to an active CC if: (a) it is of the same type identified on the Certificate, and (b) it was manufactured during the period that the Certificate was maintained in active status. For manufacturers of grain moisture meters, maintenance of active status also involves annual participation in the NTEP Laboratory On-going Calibration Program, OCP (Phase II).

(Amended 2000, 2001, and 2004)

2.2. Device. - A piece of commercial or law enforcement equipment as defined in Section 2.15. Commercial and Law Enforcement Equipment. A device may be a single unit or a combination of separate and compatible main elements. A device shall include, at a minimum, those main elements that: (a) perform the measurement, and (b) process the measurement signals up to the first indicated or recorded value of the final quantity upon which the transaction is based.

(Amended 2004)

2.3. Director. - Means the of the Department of

2.4. Manufactured Device. - Any commercial weighing or measuring device shipped as new from the original equipment manufacturer.

(Added 2001)

2.5. National Type Evaluation Program. - A program of cooperation between the NCWM, NIST, other federal agencies, the states, and the private sector for determining, on a uniform basis, conformance of a type with the relevant provisions of NIST Handbook 44, "Specifications, Tolerances, and Other Technical Requirements for Weighing and Measuring Devices," and NCWM, Publication 14, "National Type Evaluation Program, Technical Policy, Checklists, and Test Procedures."

(Amended 2000)

2.6. One-of-a-Kind Device. - A (non-NTEP) device designed to meet unique demands for a specific installation and of a specific design which is not commercially available elsewhere (one such device per manufacturer). If a 
E. Uniform Regulation for National Type Evaluation

device manufactured for sale by a company has been categorized and tested as a "one-of-a-kind" device and the manufacturer then decides to manufacture an additional device or devices of that same type, the device will no longer be considered a "one-of-a-kind." This also applies to a device that has been determined to be a "one-of-a-kind" device by a weights and measures jurisdiction in one state and the manufacturer decides to manufacture and install another device of that same type in another state. In this case, the manufacturer of the device must request an NTEP evaluation on the device through the normal application process unless NTEP has already deemed that such evaluation will not be conducted.

(Amended 1998)

2.7. Participating Laboratory. - Any State Measurement Laboratory or State Weights and Measures Agency or other laboratory that has been authorized to conduct a type evaluation under the NTEP.

(Amended 2001)

2.8. Person. - The term "person" means both singular and plural, as the case demands, and includes individuals, partnerships, corporations, companies, societies, and associations.

2.9. Remanufactured Device. - A device that is disassembled, checked for wear, parts replaced or fixed, reassembled, and made to operate like a new device of the same type.

(Amended 2001)

2.10. Remanufactured Element. - An element that is disassembled, checked for wear, parts replaced or fixed, reassembled, and made to operate like a new element of the same type.

(Added 2001)

2.11. Repaired Device. - A device on which work is performed that brings the device back into proper operating condition.

(Amended 2001)

2.12. Repaired Element. - An element on which work is performed that brings the element back into proper operating condition.

(Added 2001)

2.13. Type. - A model or models of a particular device, measurement system, instrument, or element that positively identifies the design. A specific type may vary in its measurement ranges, size, performance, and operating characteristics as specified in the CC.

2.14. Type Evaluation. - The testing, examination, and/or evaluation of a type by a Participating Laboratory under the NTEP.

\subsection{Commercial and Law Enforcement Equipment.}

(a) Weighing and measuring equipment commercially used or employed in establishing the size, quantity, extent, area, or measurement of quantities, things, produce, or articles for distribution or consumption, purchased, offered, or submitted for sale, hire, or award, or in computing any basic charge or payment for services rendered on the basis of weight or measure.

(b) Any accessory attached to or used in connection with a commercial weighing or measuring device when such accessory is so designed that its operation affects the accuracy of the device.

(c) Weighing and measuring equipment in official use for the enforcement of law or for the collection of statistical information by government agencies. [see Section 2.15. NOTE]

Section 2.15. NOTE: The section is identical to G-A.1. Commercial and Law Enforcement Equipment, Section 1.10. General Code, NIST Handbook 44 for definition of "commercial" and "law enforcement equipment." 


\section{Section 3. Certificate of Conformance (CC)}

The Director shall require a device to be traceable to an active Certificate of Conformance (CC) prior to its installation or use for commercial or law enforcement purposes. If the device consists of separate and compatible main elements, each main element shall be traceable to a CC. A device is traceable to a $\mathrm{CC}$ if:

(a) it is of the same type identified on the Certificate; and

(b) it was manufactured during the period that the Certificate was maintained in active status.

(Amended 2001 and 2004)

\section{Section 4. Prohibited Acts and Exemptions}

(a) Except for a device exempted by this section, no person shall sell a device unless it is traceable to an active $\mathrm{CC}$.

(Amended 2001)

(b) Except for a device exempted by this section, no person shall use a device unless it is traceable to an active $\mathrm{CC}$.

(Amended 2001)

(c) A device in service in this State prior to , (date) that meets the specifications, tolerances, and other technical requirements of NIST Handbook 44 shall not be required to be traceable to an active CC.

(Amended 2001)

(d) A device in service in this State prior to which the department has issued a removal order after , (date) removed from service by the owner or on later date shall be modified to meet all specifications, tolerances, and other technical requirements of NIST Handbook 44 effective on the date of the return to service. Such a device shall not be required to be traceable to an active CC.

(Amended 2001)

(e) A device in service in this State prior to (date) which is repaired after such date shall meet the specifications, tolerances, and other technical requirements of NIST Handbook 44 and shall not be required to be traceable to an active CC.

(Amended 2001)

(f) A device in service in this State prior to (date) that is still in use may be installed at another location in this state provided the device meets requirements in effect as of the date of installation in the new location; however, the device shall not be required to be traceable to an active CC.

(Amended 2001)

(g) A device in service in another State prior to (date) may be installed in this State; however, the device shall meet the specifications, tolerances, and technical requirements for weighing and measuring devices in NIST Handbook 44 and be traceable to an active CC.

(Amended 2001)

(h) One-of-a-kind Device. - The Director may accept the design of a one-of-a-kind device without an NTEP evaluation pending inspection and performance testing to satisfy that the device complies with NIST Handbook 44 and is capable of performing within the Handbook 44 requirements for a reasonable period of time under normal conditions of use. Indicators and load cells in all "one-of-a-kind" scale installations must 
E. Uniform Regulation for National Type Evaluation

have an active NTEP CC as evidence that the system meets the influence factor requirements of NIST Handbook 44.

(Amended 1998 and 2001)

(i) Repaired Device. - If a person makes changes to a device to the extent that the metrological characteristics are changed, that specific device is no longer traceable to the active CC.

(Amended 2001)

(j) Remanufactured Device. - If a person repairs or remanufactures a device, they are obligated to repair or remanufacture it consistent with the manufacturer's original design; otherwise, that specific device is no longer traceable to an active CC.

(Amended 2001)

(k) Copy of a Device. - The manufacturer who copies the design of a device that is traceable to an active CC, but which is made by another company, must obtain a separate $\mathrm{CC}$ for the device. The $\mathrm{CC}$ for the original device shall not apply to the copy.

(1) Device Components. - If a person buys a load cell(s) and an indicating element that are traceable to CCs and then manufactures a device from the parts, that person shall obtain an active $\mathrm{CC}$ for the device.

(Amended 2001)

\section{Section 5. Participating Laboratory and Agreements}

The Director is authorized to:

(a) Operate a Participating Laboratory as part of the NTEP. In this regard, the Director is authorized to charge and collect fees for type evaluation services.

(b) Cooperate with and enter into agreements with any person in order to carry out the purposes of the act.

\section{Section 6. Revocation of Conflicting Regulations}

All provisions of all orders and regulations before issued on this same subject that are contrary to or inconsistent with the provisions of this regulation, are hereby revoked.

(Amended 2001)

\section{Section 7. Effective Date}

This regulation shall become effective on

(Amended 2001) 


\title{
F. Uniform Fuels and Automotive Lubricants Regulation
}

\author{
as adopted by \\ The National Conference on Weights and Measures*
}

\section{Background}

In 1984, the National Conference on Weights and Measures (NCWM) adopted a Section 2.20. in the Uniform Regulation for the Method of Sale of Commodities requiring that motor fuels containing alcohol be labeled to disclose to the retail purchaser that the fuel contains alcohol. The delegates deemed this action necessary since motor vehicle manufacturers were qualifying their warranties with respect to some gasoline-alcohol blends, motor fuel users were complaining to weights and measures officials about fuel quality and vehicle performance, and ASTM International (ASTM) had not yet finalized quality standards for oxygenated (which includes alcohol-containing) fuels. While a few officials argued weights and measures officials should not cross the line from quantity assurance programs to programs regulating quality, the delegates were persuaded that the issue needed immediate attention.

A Motor Fuels Task Force was appointed in 1984 to develop mechanisms for achieving uniformity in the evaluation and regulation of motor fuels. The Task Force developed the Uniform Motor Fuel Inspection Law (see the Uniform Fuels and Automotive Lubricants Inspection Law section of this handbook) and the Uniform Fuel and Automotive Lubricants Regulation to accompany the law. The Uniform Law required registration and certification of motor fuel as meeting ASTM standards. The regulation defined the ASTM standards to be applied to motor fuel.

In 1992, the NCWM established the Petroleum Subcommittee under the Laws and Regulations Committee. The subcommittee recommended major revisions to the Regulation that was adopted at the $80^{\text {th }}$ NCWM in 1995 . The scope of the regulation was expanded to include all engine fuels, petroleum products, and automotive lubricants; its title was changed accordingly; and the fuel specifications and method of sale sections were revised to address the additional products. Other changes included expansion of the definitions section and addition of sections on retail storage tanks, condemned product, registration of engine fuels designed for special use, and test methods and reproducibility limits.

In 2007, the Petroleum Subcommittee (now referred to as the Fuels and Lubricants Subcommittee) undertook a review of this regulation to update it by eliminating reference to "petroleum products" and to reflect the addition of new engine fuels to the marketplace. The regulation continues to be updated to incorporate new regulatory requirements and other key changes.

(Amended 2018)

Even after the inclusion of the Uniform Regulation for Motor Fuel and Automotive Lubricants into NIST Handbook 130, the Conference recognized that more states adopt the Uniform Regulation for the Method of Sale of Commodities than adopt the Uniform Fuel and Automotive Lubricants Regulation. To promote uniformity in state regulations a number of these regulations continue to be included in both regulations.

(Amended 2018 and 2021)

${ }^{*}$ The National Conference on Weights and Measures (NCWM) is supported by the National Institute of Standards and Technology (NIST) in partial implementation of its statutory responsibility for "cooperation with the states in securing uniformity in weights and measures laws and methods of inspection." 
F. Uniform Fuels and Automotive Lubricants Regulation

\section{Status of Promulgation}

The Uniform Regulation for Engine Fuels and Automotive Lubricants was adopted by the NCWM in 1995. The status of state actions with respect to this Regulation is shown in the table beginning on page 6 .

(Amended 2008) 


\section{F. Uniform Fuels and Automotive Lubricants Regulation}

\section{Table of Contents}

Section $\quad$ Page

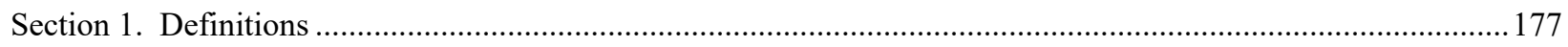

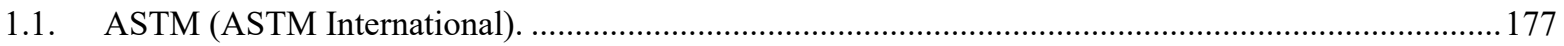

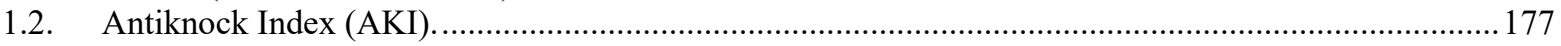

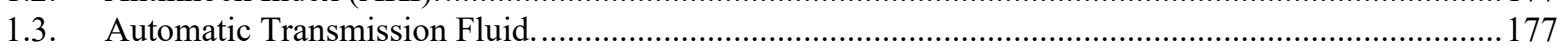

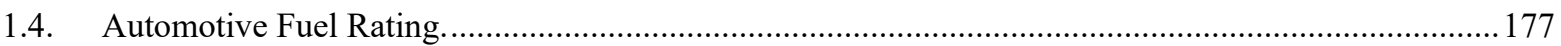

1.5. Automotive Gasoline, Automotive Gasoline-Oxygenate Blend. ...................................................... 177

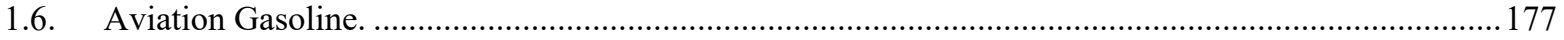

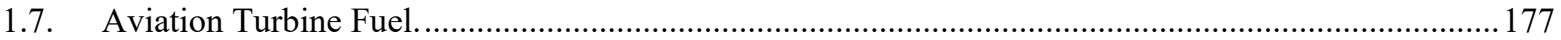

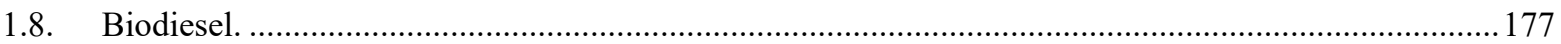

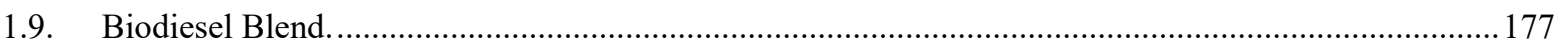

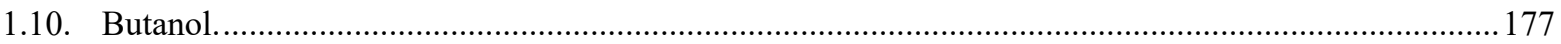

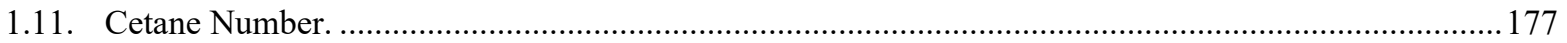

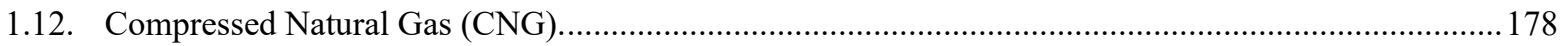

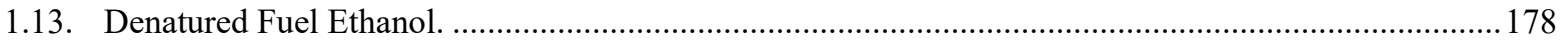

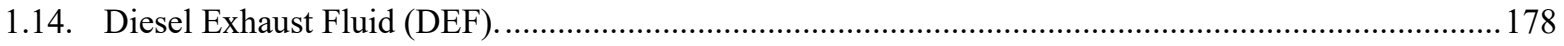

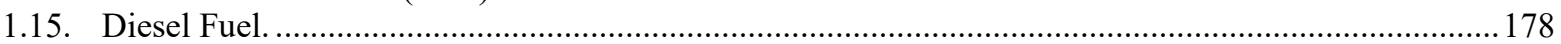

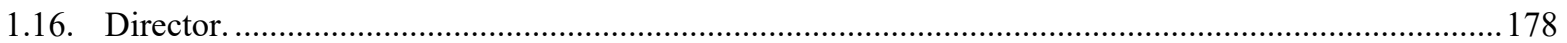

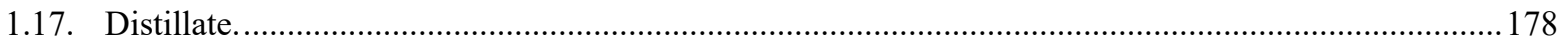

1.18. EPA. . .

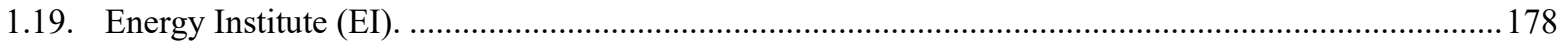

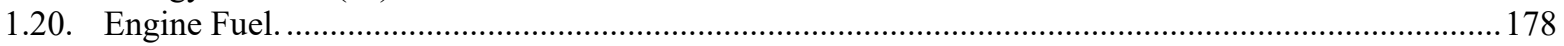

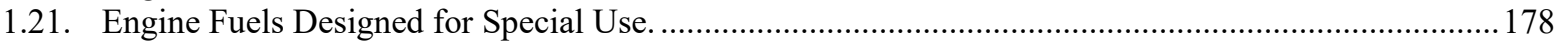

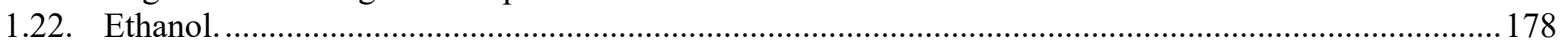

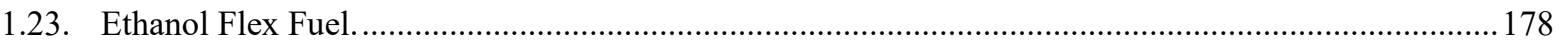

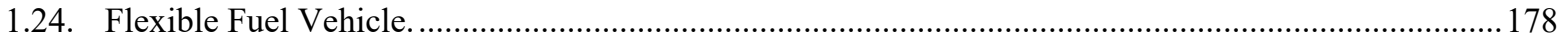

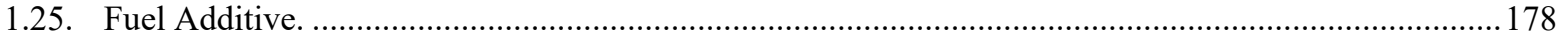

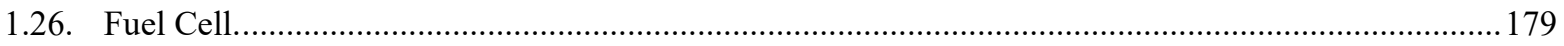

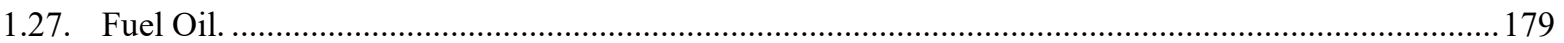

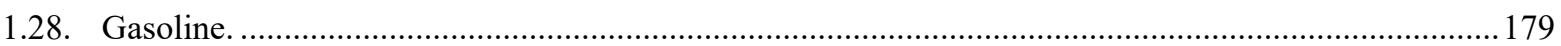

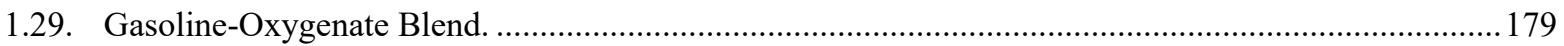

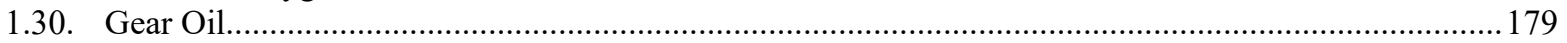

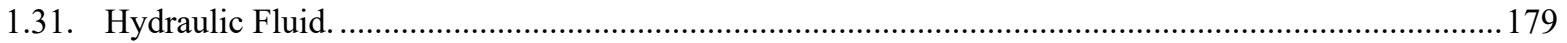

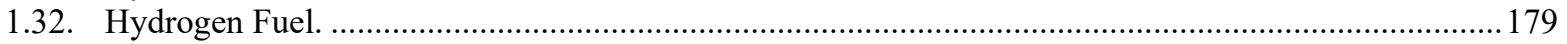

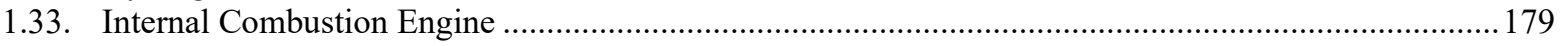

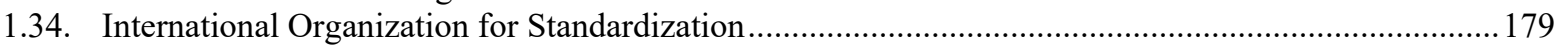

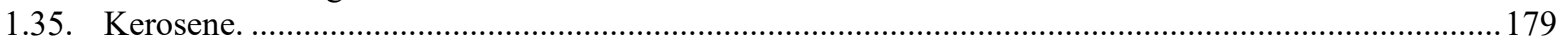

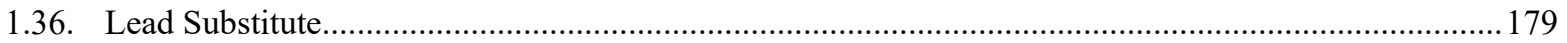

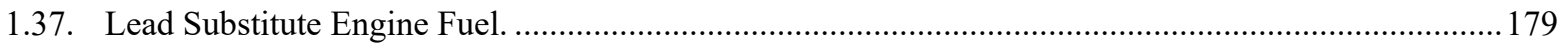

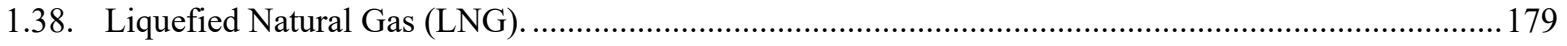

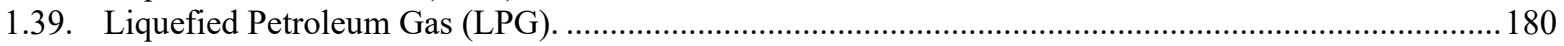

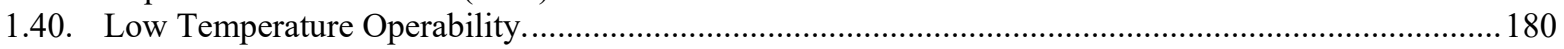

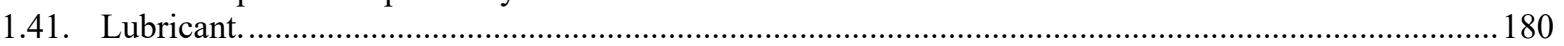

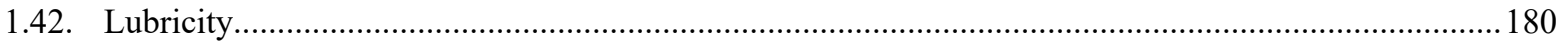

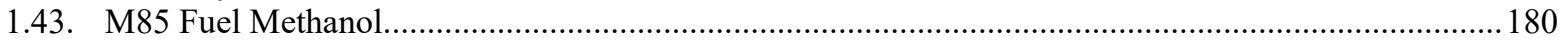

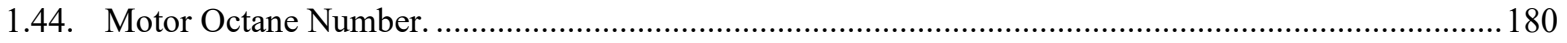

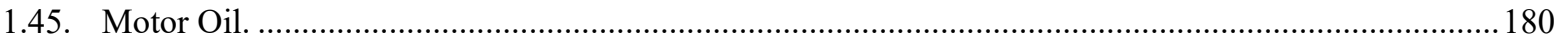

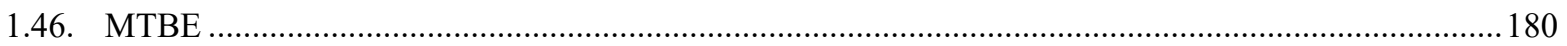




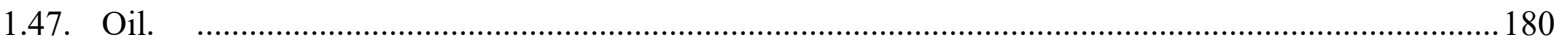

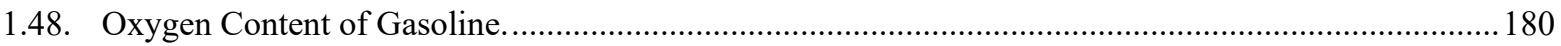

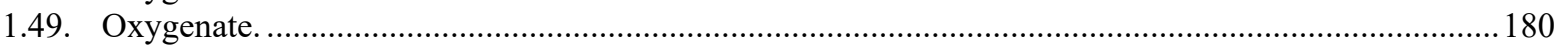

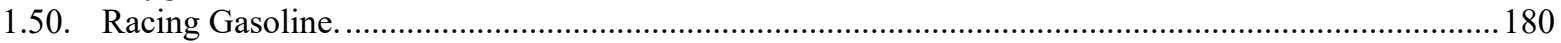

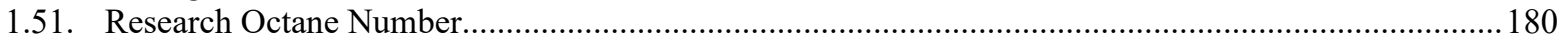

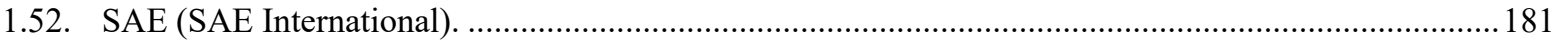

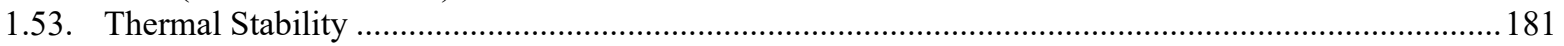

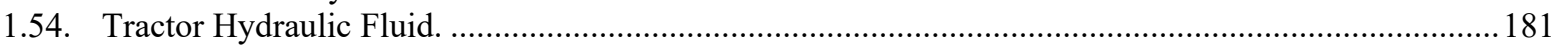

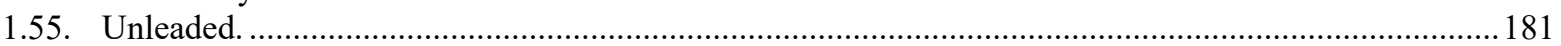

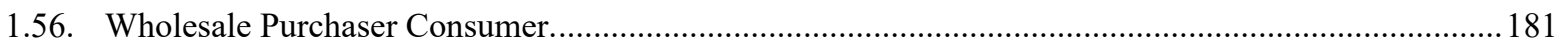

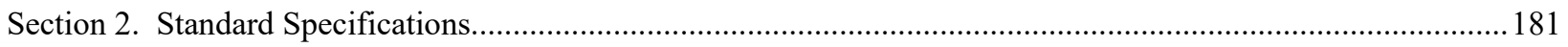

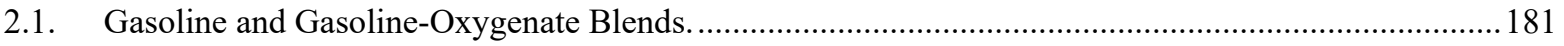

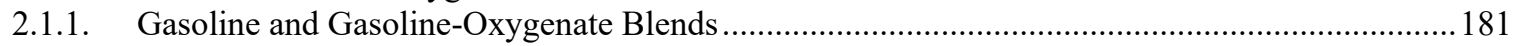

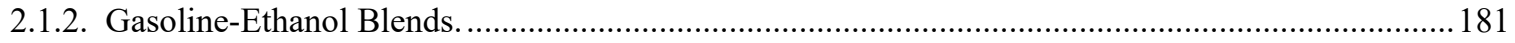

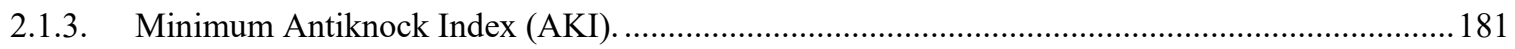

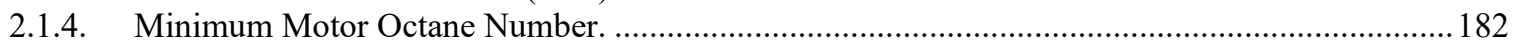

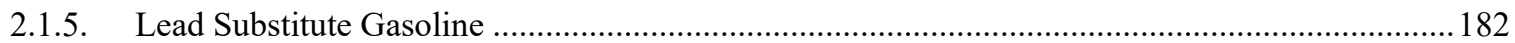

2.1.5.1. Documentation of Exhaust Valve Seat Protection. ................................................. 182

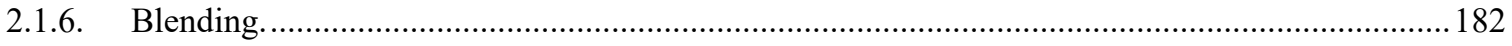

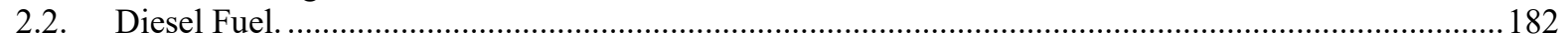

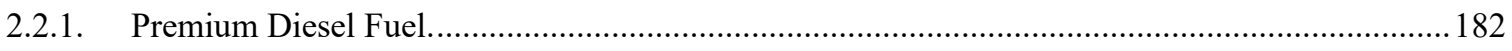

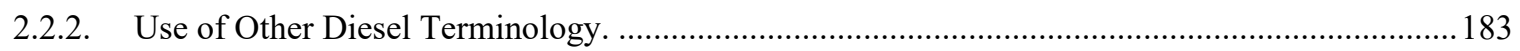

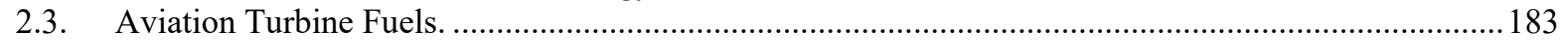

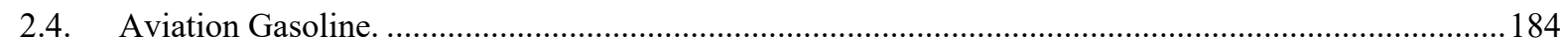

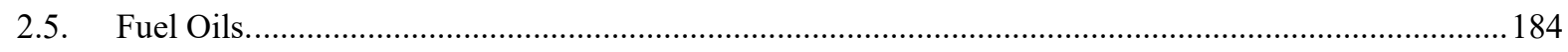

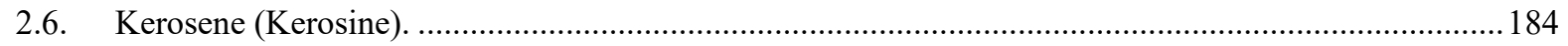

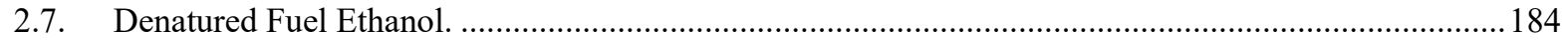

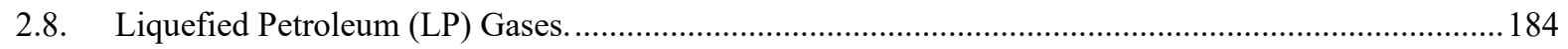

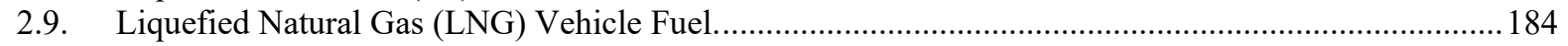

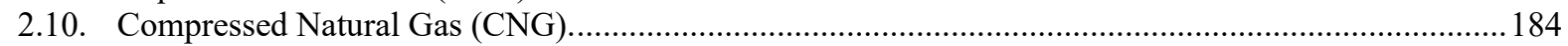

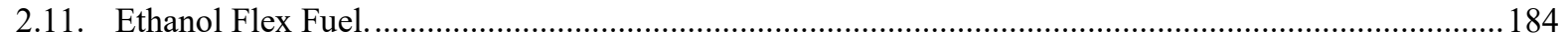

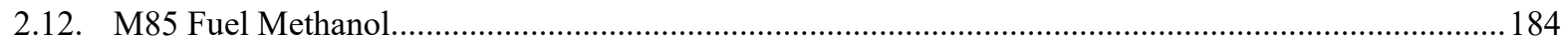

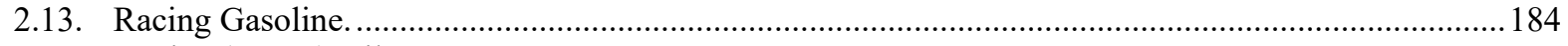

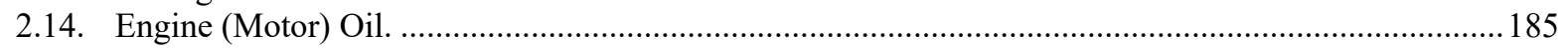

2.15. Products for Use in Lubricating Manual Transmissions, Gears, or Axles. ......................................... 185

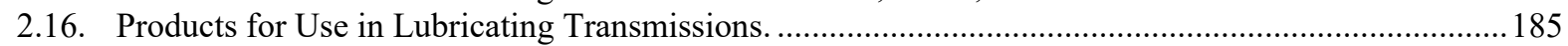

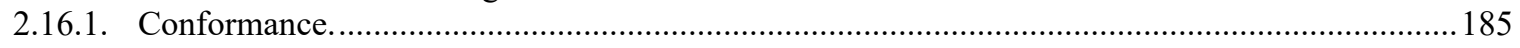

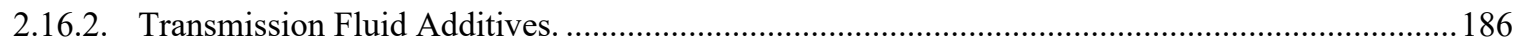

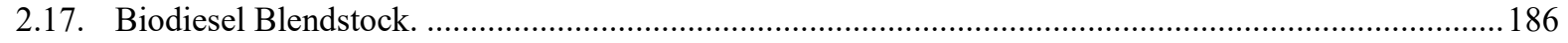

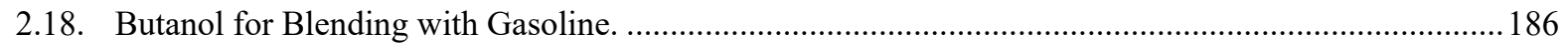

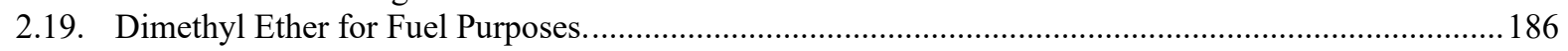

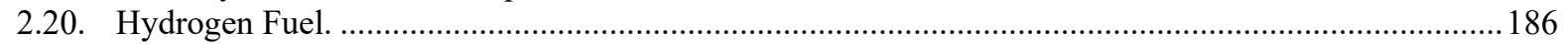

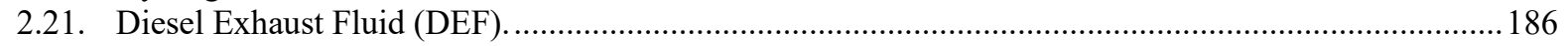

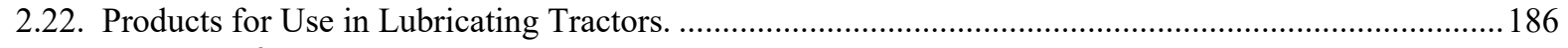

2.22.1. Conformance................................................................................................................ 186

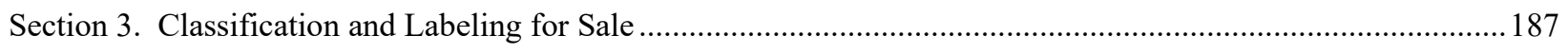

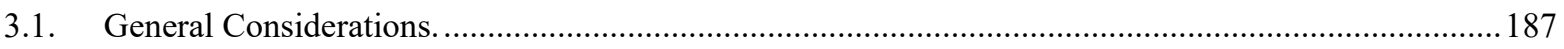

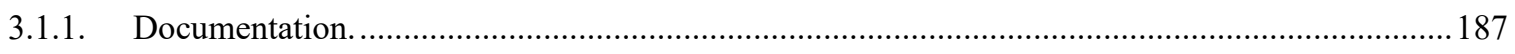

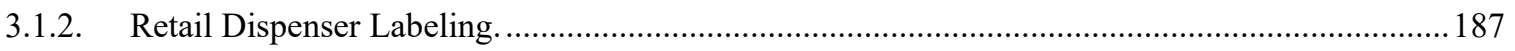

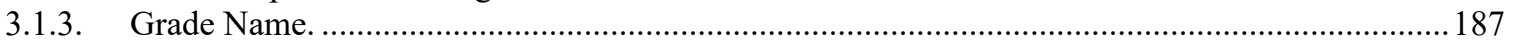

3.1.4. Nozzle Requirements for Automotive Gasoline, Gasoline-Oxygenate Blends, ........................... 187

3.2. Automotive Gasoline and Automotive Gasoline-Oxygenate Blends (Including Racing Gasoline)........187 


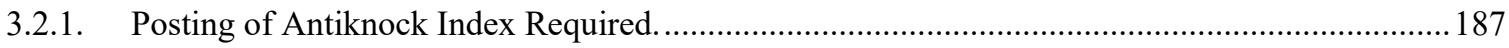

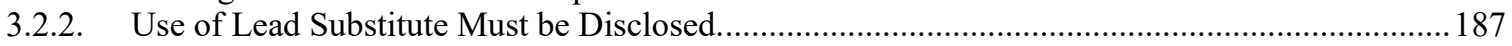

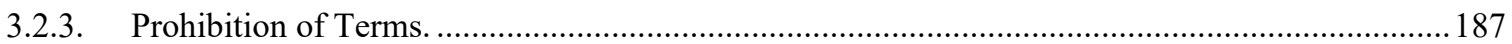

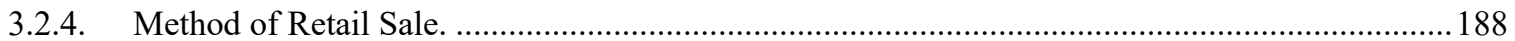

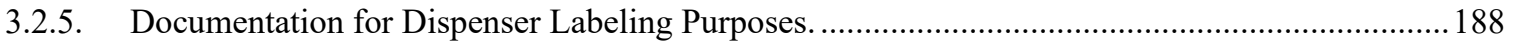

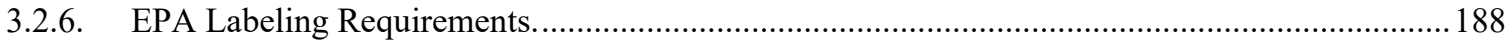

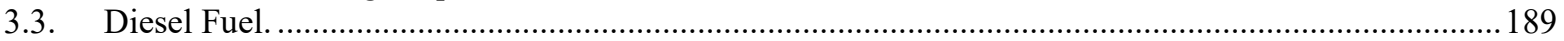

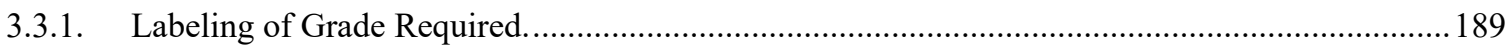

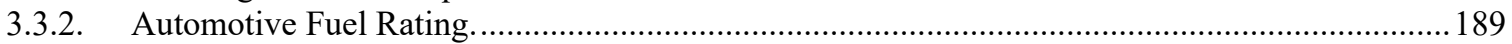

3.3.3. Delivery Documentation for Premium Diesel.......................................................................... 189

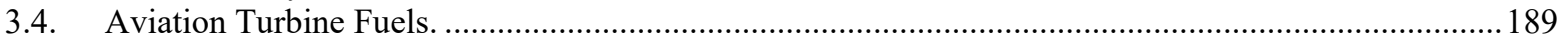

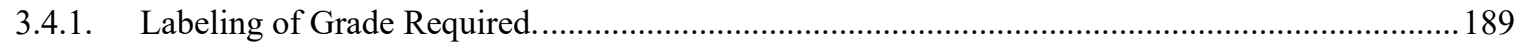

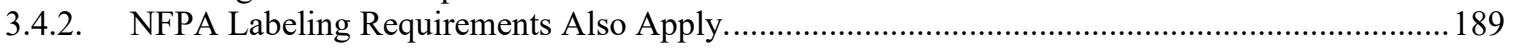

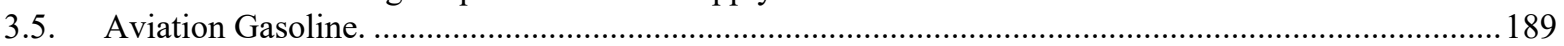

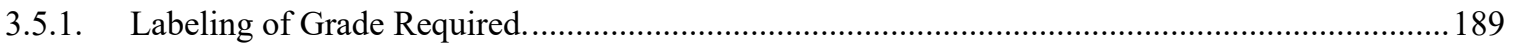

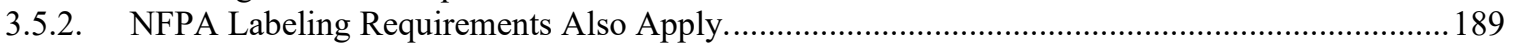

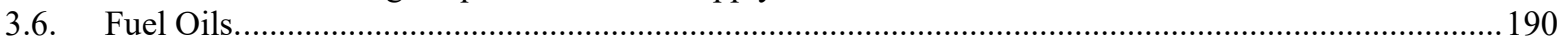

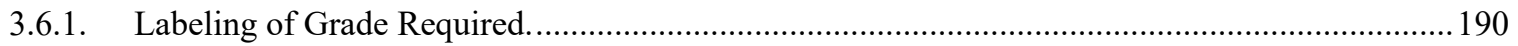

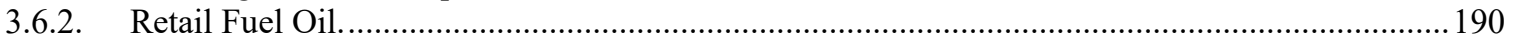

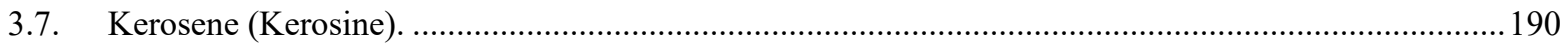

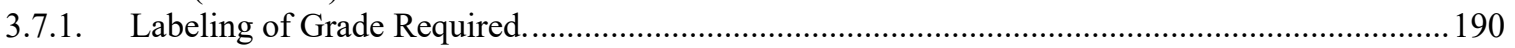

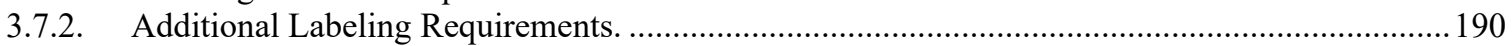

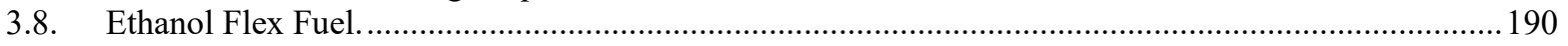

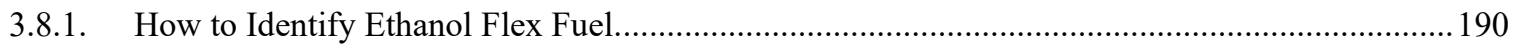

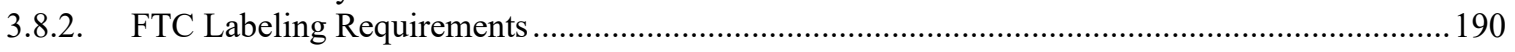

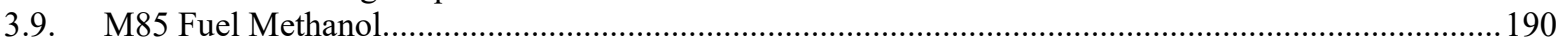

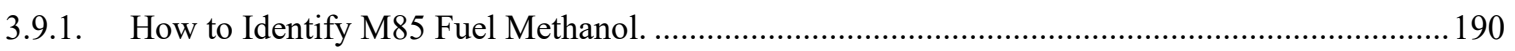

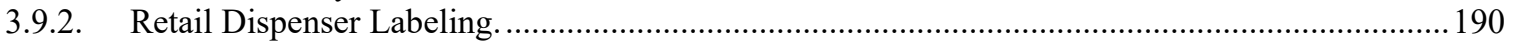

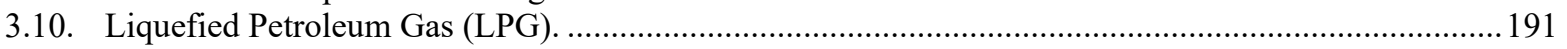

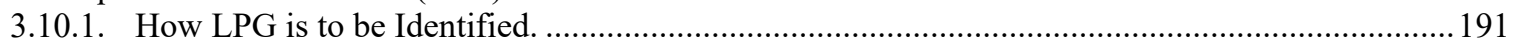

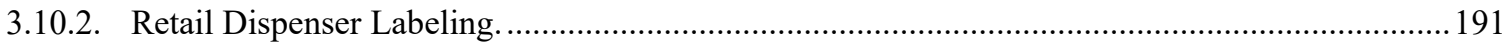

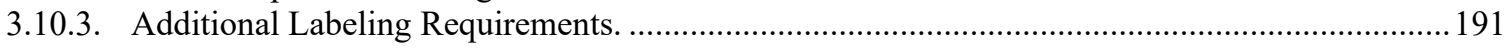

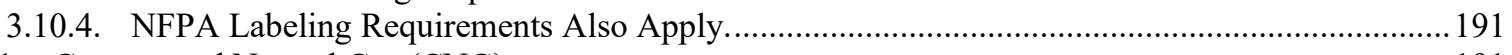

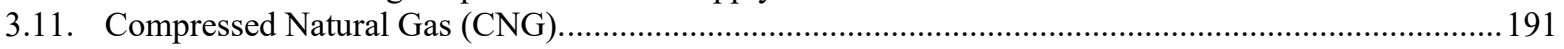

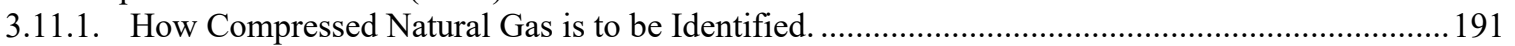

3.11.2. Retail Sales of Compressed Natural Gas Sold as a Vehicle Fuel...............................................191

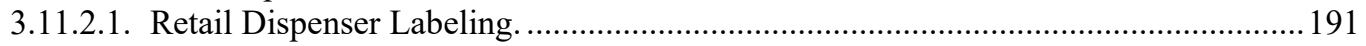

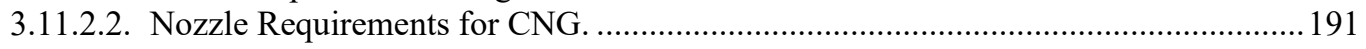

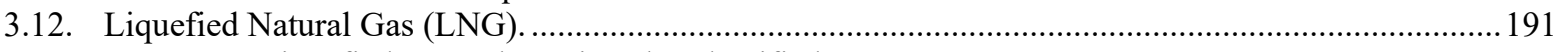

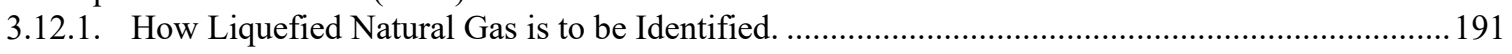

3.12.2. Labeling of Retail Dispensers of Liquefied Natural Gas Sold as a Vehicle Fuel........................... 191

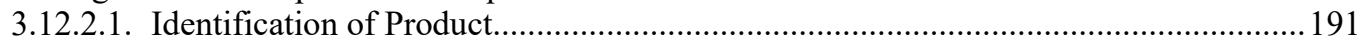

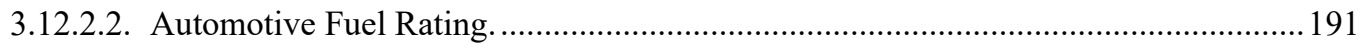

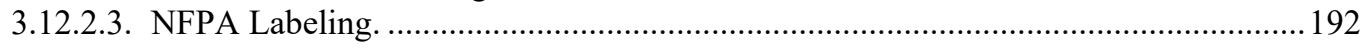

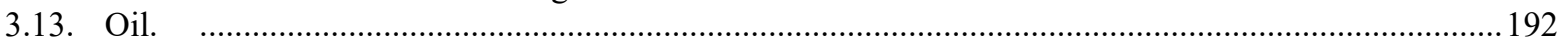

3.13.1. Labeling of Vehicle Engine (Motor) Oil Required. ............................................................... 192

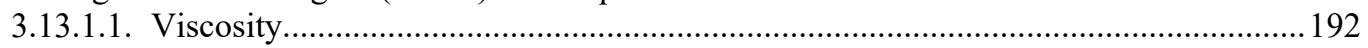

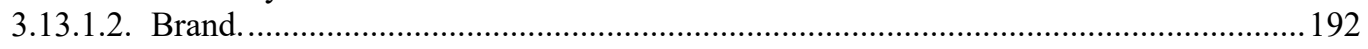

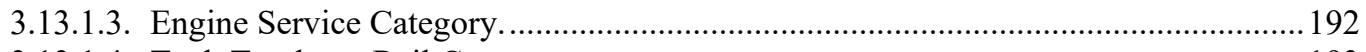

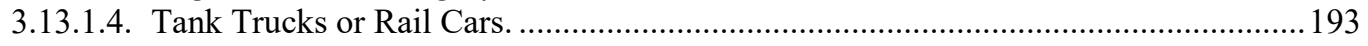

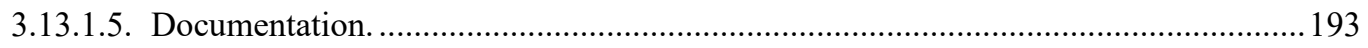

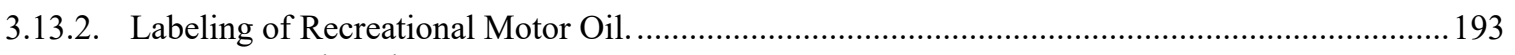

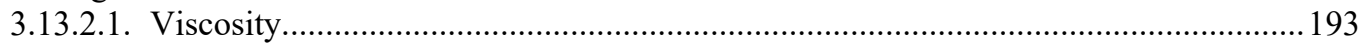

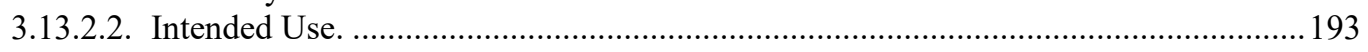

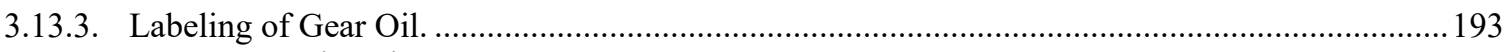

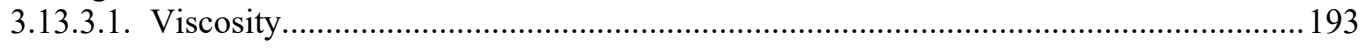




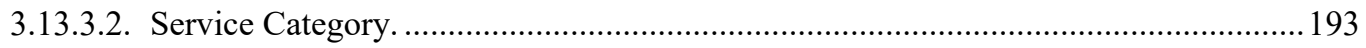

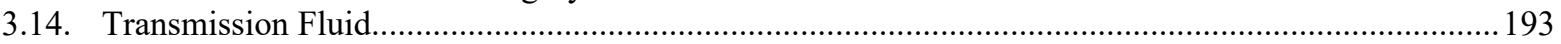

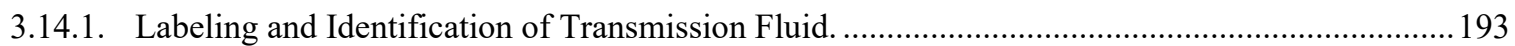

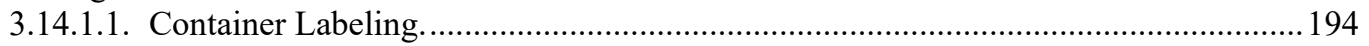

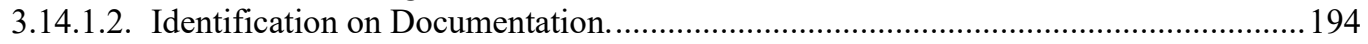

3.14.1.3. Identification on Service Provider Documentation .................................................... 194

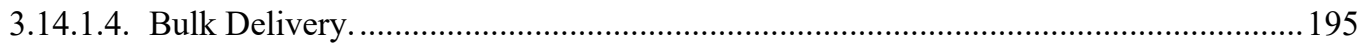

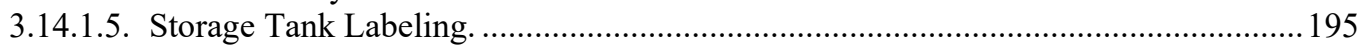

3.14.1.6. Documentation of Claims Made Upon Product Label. ............................................... 195

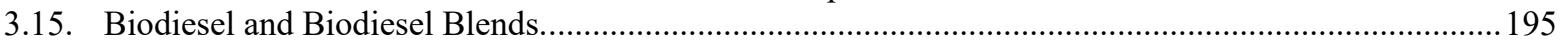

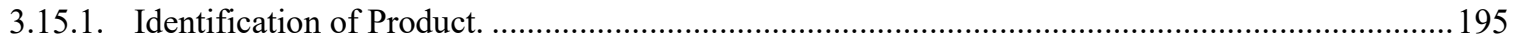

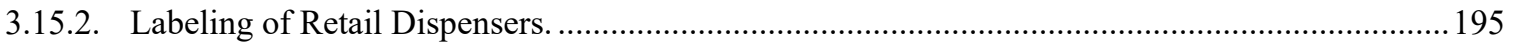

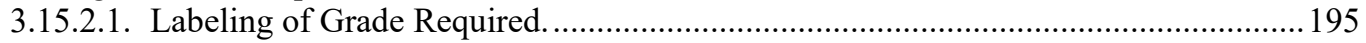

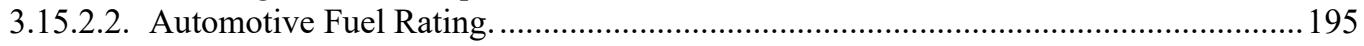

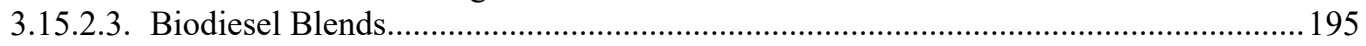

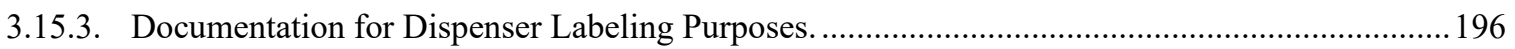

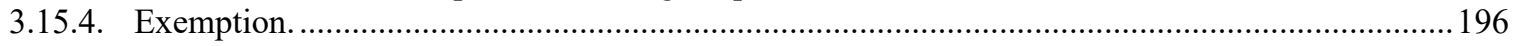

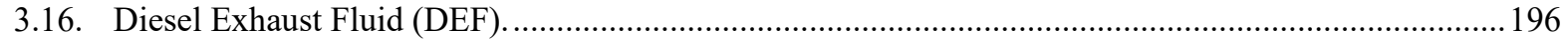

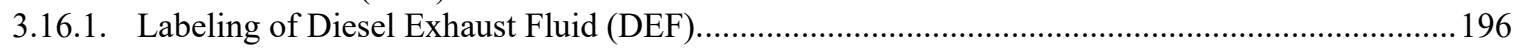

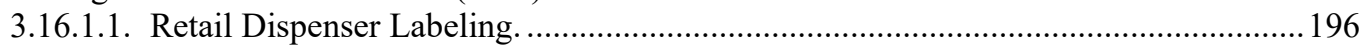

3.16.1.2. Documentation for Retailers of Bulk Product........................................................... 196

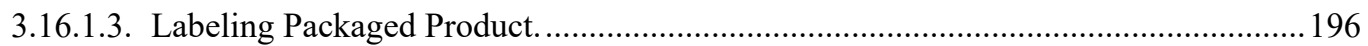

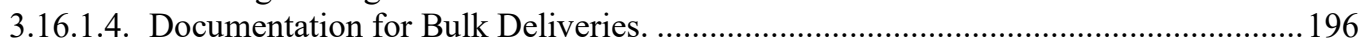

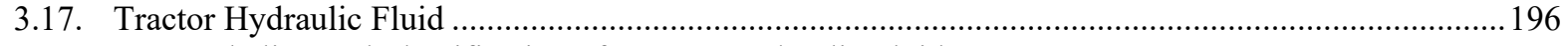

3.17.1. Labeling and Identification of Tractor Hydraulic Fluid .............................................................196

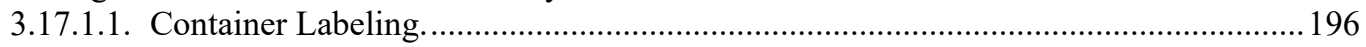

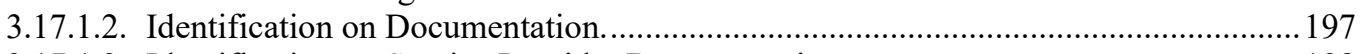

3.17.1.3. Identification on Service Provider Documentation. .................................................. 198

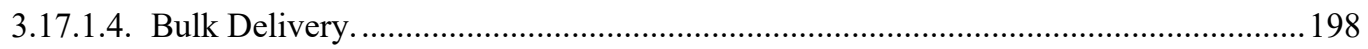

3.17.1.5. Storage Tank Labeling. .................................................................................. 198

3.17.1.6. Documentation of Claims Made Upon Product Label. ................................................. 198

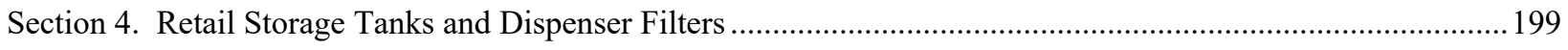

4.1. Water in Gasoline-Alcohol Blends, Biodiesel Blends, Ethanol Flex Fuel, Aviation Gasoline, and

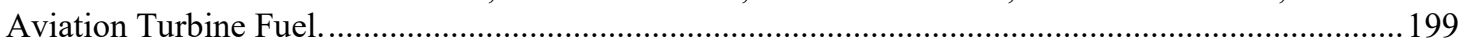

4.2. Water in Gasoline, Diesel, Gasoline-Ether, and Other Fuels........................................................... 199

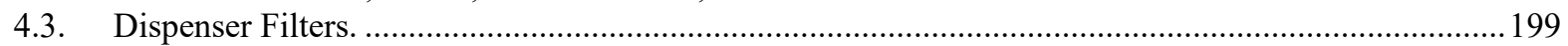

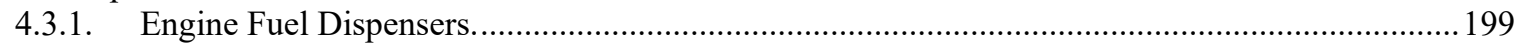

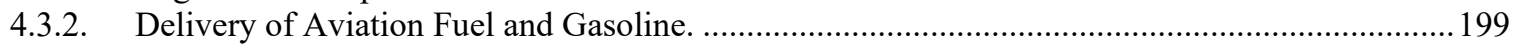

4.4. Product Storage Identification. .................................................................................................. 199

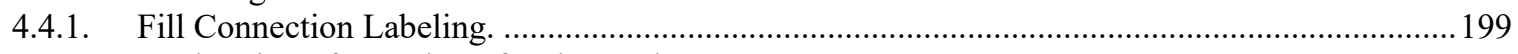

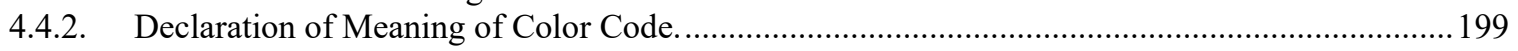

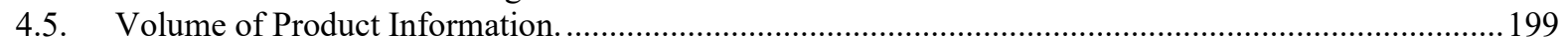

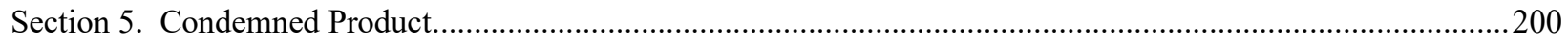

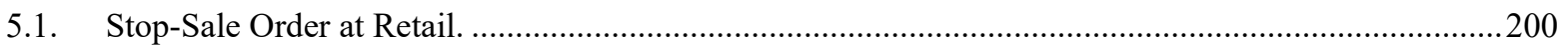

5.2. Stop-Sale Order at Terminal or Bulk Plant Facility............................................................................2200

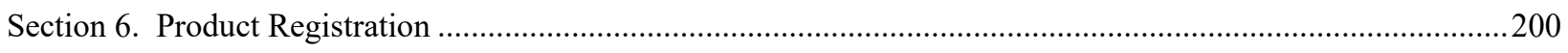

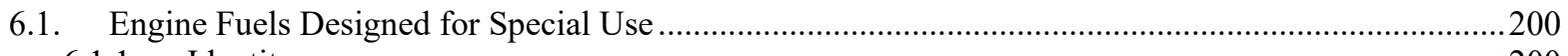

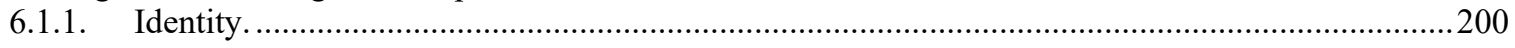

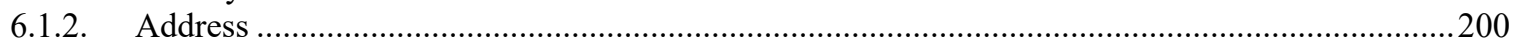

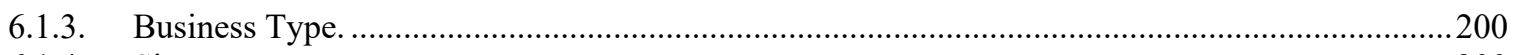

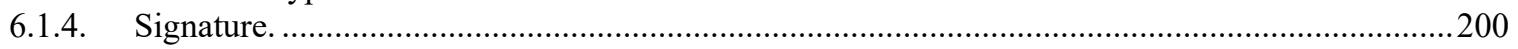




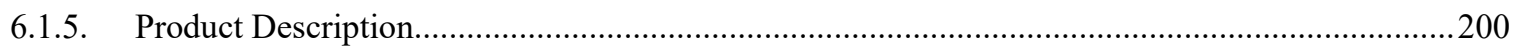

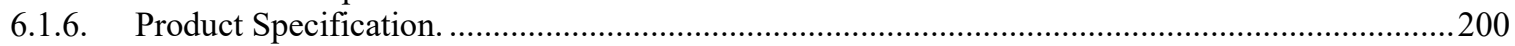

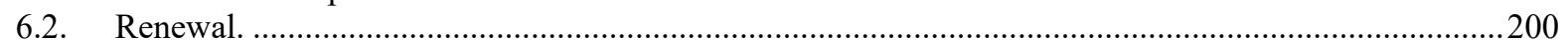

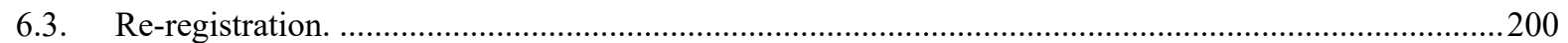

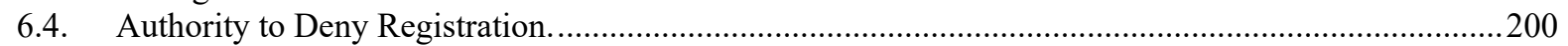

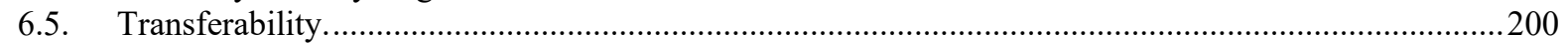

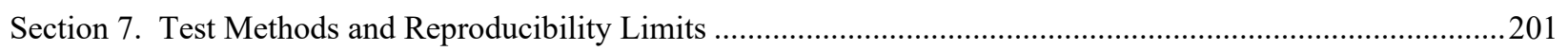

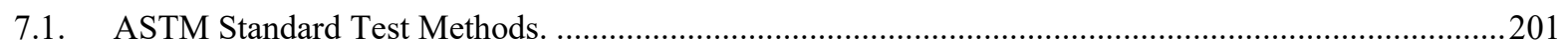

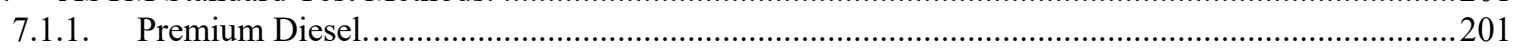

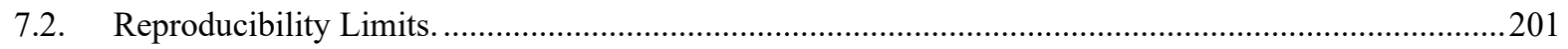

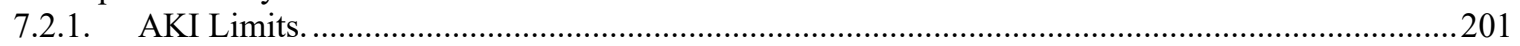

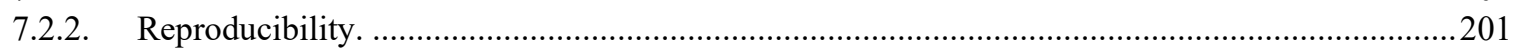

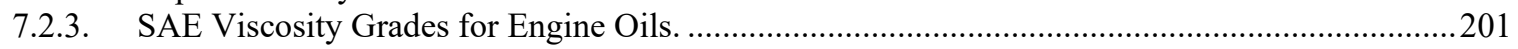

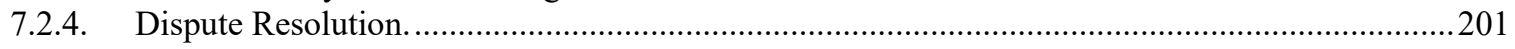

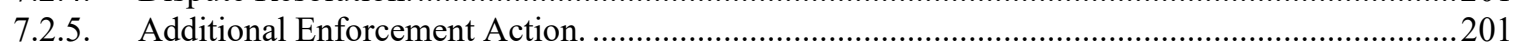


F. Uniform Fuels and Automotive Lubricants Regulation

THIS PAGE INTENTIONALLY LEFT BLANK 


\section{F. Uniform Fuels and Automotive Lubricants Regulation}

\section{Section 1. Definitions}

1.1. ASTM (ASTM International). (www.astm.org) - The international voluntary consensus standards organization formed for the development of standards on characteristics and performance of materials, products, systems, and services, and the promotion of related knowledge.

1.2. Antiknock Index (AKI). - The arithmetic average of the Research Octane Number (RON) and Motor Octane Number $(\mathrm{MON}): \mathrm{AKI}=(\mathrm{RON}+\mathrm{MON}) / 2$. This value is called by a variety of names, in addition to antiknock index, including: octane rating, posted octane, $(\mathrm{R}+\mathrm{M}) / 2$ octane.

1.3. Automatic Transmission Fluid. - A product intended for use in a passenger vehicle, other than a bus, as either lubricant, coolant, or liquid medium in any type of fluid automatic transmission that contains a torque converter. For the purposes of this regulation, fluids intended for use in continuously variable transmissions are not considered "Automatic Transmission Fluid."

(Added 2004)

1.4. Automotive Fuel Rating. - The automotive fuel rating required under the amended Automotive Fuel Ratings, Certification and Posting Rule (or as amended, the Fuel Rating Rule), 16 CFR 306. Under this Rule, sellers of liquid automotive fuels, including alternative fuels, must determine, certify, and post an appropriate automotive fuel rating. The automotive fuel rating for gasoline and gasoline-oxygenate blends is the antiknock index (octane rating). The automotive fuel rating for alternative liquid automotive fuels consists of the common name of the fuel, along with a disclosure of the amount, expressed as a minimum volume percent of the principal component of the fuel. For alternative liquid automotive fuels, a disclosure of other components, expressed as a minimum volume percent, may be included, if desired.

(Amended 2018)

1.5. Automotive Gasoline, Automotive Gasoline-Oxygenate Blend. - A type of fuel suitable for use in spark ignition automobile engines containing small amounts of fuel additives and also commonly used in marine and nonautomotive applications.

(Amended 2018)

1.6. Aviation Gasoline. - A type of gasoline suitable for use as a fuel in an aviation spark-ignition internal combustion engine.

1.7. Aviation Turbine Fuel. - A refined middle distillate suitable for use as a fuel in an aviation gas turbine internal combustion engine.

1.8. Biodiesel. - A fuel comprised of at least $99 \%$ by volume mono-alkyl esters of long chain fatty acids derived from vegetable oils or animal fats, designated B100 or B99.

(Amended 2018)

1.9. Biodiesel Blend. - A fuel comprised of a blend of biodiesel with hydrocarbon diesel fuel.

(Amended 2018)

1.10. Butanol. - Butyl alcohol, the chemical compound $\mathrm{C}_{4} \mathrm{H}_{9} \mathrm{OH}$, a colorless substance existing in four isomeric forms.

(Added 2018)

1.11. Cetane Number. - A numerical measure of the ignition performance of a diesel fuel obtained by comparing it to reference fuels in a standardized engine test. 
F. Uniform Fuels and Automotive Lubricants Regulation

1.12. Compressed Natural Gas (CNG). - Natural gas which has been compressed and dispensed into fuel storage containers and is suitable for use as an engine fuel.

1.13. Denatured Fuel Ethanol. - An ethanol blend component for use in gasoline-ethanol blends and ethanol flex fuel. The ethanol is rendered unfit for beverage use by the addition of denaturants under formulas approved by the Alcohol and Tobacco Tax and Trade Bureau (TTB) (www.ttb.gov), by the latest version of ASTM D4806, "Standard Specification for Denatured Fuel Ethanol for Blending with Gasolines for Use as Automotive Spark Ignition Engine Fuel" describes the acceptable denaturants for denatured fuel ethanol to be blended into spark ignition engine fuels.

(Amended 2014)

1.14. Diesel Exhaust Fluid (DEF). - A preparation of aqueous urea [(NH2)2CO], containing $32.5 \%$ by mass of technically-pure urea in high-purity water with quality characteristics defined by the latest version of ISO 22241 , "Diesel engines - NOx reduction agent AUS 32."

(Added 2014)

1.15. Diesel Fuel. - A refined hydrocarbon suitable for use as a fuel in a compression-ignition (diesel) internal combustion engine that may contain a combination of biodiesel, renewable diesel, and fuel additives.

(Amended 2018)

1.16. Director. - The Director, Commissioner, or other authority having jurisdiction over a department and/or their designated agent(s).

(Added 2018)

1.17. Distillate. - Any product obtained by condensing the vapors given off by boiling petroleum or its products.

1.18. EPA. (www.epa.gov) - The United States Environmental Protection Agency.

1.19. Energy Institute (EI). (knowledge.energyinst.org) - A professional organization for the energy industry, developing standards, and other technical documents.

(Added 2018)

1.20. Engine Fuel. - Any liquid or gaseous matter used for the generation of power in an internal combustion engine.

1.21. Engine Fuels Designed for Special Use. - Engine fuels designated by the Director as requiring registration. These fuels normally do not have ASTM or other national consensus standards applying to their quality or usability; common special fuels are racing fuels and those intended for agricultural and other off-road applications.

1.22. Ethanol. - Also known as "ethyl alcohol." Ethanol is provided in gasoline-ethanol blends by blending denatured fuel ethanol. (See Section 1.13. Denatured Fuel Ethanol.)

(Amended 2014)

1.23. Ethanol Flex Fuel. - Blends of ethanol and hydrocarbons restricted for use as fuel in ground vehicles equipped with flexible-fuel spark-ignition engines.

(Amended 2014)

1.24. Flexible Fuel Vehicle. - A vehicle designed to operate on either unleaded gasoline or ethanol flex fuel or mixtures of both. Flexible fuel vehicles may also be designated to run on M85 Fuel Methanol.

(Added 2018)

1.25. Fuel Additive. - A material added to a fuel in small amounts to impart or enhance desirable properties or to suppress undesirable properties.

(Added 2018) 
1.26. Fuel Cell. - An electrochemical energy conversion device in which fuel and an oxidant react to generate electricity without consumption, physically or chemically, of its electrodes or electrolytes.

(Added 2012)

1.27. Fuel Oil. - Refined oil middle distillates, heavy distillates, or residues of refining, or blends of these, suitable for use as a fuel for heating or power generation.

(Amended 2018)

1.28. Gasoline. - A volatile mixture of liquid hydrocarbons containing small amounts of additives suitable for use as a fuel in a spark-ignition internal combustion engine.

(Amended 2018)

1.29. Gasoline-Oxygenate Blend. - A fuel consisting primarily of gasoline along with a substantial amount (more than $1 \%$ by volume oxygenate, or more than $0.3 \%$ by volume methanol not to exceed the total oxygen content permitted by applicable laws and regulations. Examples of oxygenates used in gasoline-alcohol blends are ethanol and butanol.

(Amended 2018)

1.30. Gear Oil. - An oil used to lubricate gears, axles, or some manual transmissions.

(Added 2004)

1.31. Hydraulic Fluid. - A product intended for use in multiple applications with a dedicated hydraulic system and sump. Such fluids cannot be used in tractors. A person shall not represent a hydraulic fluid in any manner that may deceive or tend to deceive the purchaser as to suitability for the use of the product as a Tractor Hydraulic Fluid. (see Tractor Hydraulic Fluid for reference.)

(Added 2019) (Amended 2021)

1.32. Hydrogen Fuel. - A fuel composed of molecular hydrogen intended for consumption in a surface vehicle or electricity production device with an internal combustion engine or fuel cell.

(Added 2012)

1.33. Internal Combustion Engine. - A device used to generate power by converting chemical energy bound in the fuel via spark-ignition or compression ignition combustion into mechanical work to power a vehicle or other device.

(Added 2012)

1.34. International Organization for Standardization (ISO) (www.iso.org). - An independent international organization with a membership of national standards and bodies.

(Added 2018)

1.35. Kerosene. - (or "Kerosine") A refined middle distillate suitable for use as a fuel for heating or illuminating. (Amended 2018)

1.36. Lead Substitute. - An EPA-registered gasoline additive suitable, when added in small amounts to fuel, to reduce or prevent exhaust valve recession (or seat wear) in automotive spark-ignition internal combustion engines designed to operate on leaded fuel.

1.37. Lead Substitute Engine Fuel. - For labeling purposes, a gasoline or gasoline-oxygenate blend that contains a "lead substitute".

1.38. Liquefied Natural Gas (LNG). - Natural gas that has been liquefied at $-162{ }^{\circ} \mathrm{C}\left(-260^{\circ} \mathrm{F}\right)$ and stored in insulated cryogenic tanks for use as an engine fuel.

(Amended 2016) 
F. Uniform Fuels and Automotive Lubricants Regulation

1.39. Liquefied Petroleum Gas (LPG). - A mixture of normally gaseous hydrocarbons, predominantly propane, or butane, or both, that has been liquefied by compression or cooling, or both to facilitate storage, transport, and handling.

1.40. Low Temperature Operability. - A condition which allows the uninterrupted operation of a diesel engine through the continuous flow of fuel throughout its fuel delivery system at low temperatures. Fuels with adequate low temperature operability characteristics have the ability to avoid wax precipitation and clogging in fuel filters.

(Added 1998) (Amended 1999)

1.41. Lubricant. - Oil. (See 1.47. Oil below.).

(Added 2008)

1.42. Lubricity. - A qualitative term describing the ability of a fluid to affect friction between, and wear to, surfaces in relative motion under load.

(Added 2003)

1.43. M85 Fuel Methanol. - A blend of methanol and hydrocarbons of which the methanol portion is nominally 70 to 85 volume percent.

1.44. Motor Octane Number. - A numerical indication of a spark-ignition engine fuel's resistance to knock obtained by comparison with reference fuels in a standardized ASTM D2700, "Standard Test Method for Motor Octane Number of Spark-Ignition Engine Fuel.

1.45. Motor Oil. - An oil that reduces friction and wear between the moving parts within a reciprocating internal combustion engine and also serves as a coolant. For the purposes of this regulation, "vehicle motor oil" refers to motor oil which is intended for use in light- to heavy-duty vehicles including cars, sport utility vehicles, vans, trucks, buses, and off-road farming and construction equipment. For the purposes of this regulation, "recreational motor oil" refers to motor oil which is intended for use in four-stroke cycle engines used in motorcycles, ATVs, and lawn and garden equipment. For the purposes of this regulation, motor oil also means engine oil.

(Added 2004)

1.46. MTBE. - Methyl tertiary-butyl ether, the chemical compound $\left(\mathrm{CH}_{3}\right)_{3} \mathrm{COCH}_{3}\left[\mathrm{C}_{5} \mathrm{H}_{12} \mathrm{O}\right]$.

(Added 2008) (Amended 2018)

1.47. Oil. - A motor oil, engine oil, and/or gear oil.

(Added 2004)

1.48. Oxygen Content of Gasoline. - The percentage of oxygen contained in a gasoline.

(Amended 2018)

1.49. Oxygenate. - An oxygen-containing, ashless, organic compound, such as an alcohol or ether, which can be used as a fuel or fuel supplement.

1.50. Racing Gasoline. - A specialty fuel typically used in non-road racing vehicles that is generally of lower volatility, has a narrower boiling range and a higher octane rating than gasolines made for use in conventional passenger vehicles.

(Added 2018)

1.51. Research Octane Number. - A numerical indication of a spark-ignition engine fuel's resistance to knock obtained by comparison with reference fuels in a standardized in the latest version of ASTM D2699, "Standard Test Method for Research Octane Number of Spark-Ignition Engine Fuel.”

(Amended 2018) 
1.52. SAE (SAE International). (www.sae.org) - A technical organization for engineers, scientists, technicians, and others who cooperate closely in the engineering, design, manufacture, use, and maintainability of self-propelled vehicles.

1.53. Thermal Stability. - The ability of a fuel to resist the thermal stress which is experienced by the fuel when exposed to high temperatures in a fuel delivery system. Such stress can lead to formation of insoluble gums or organic particulates. Insolubles (e.g., gums or organic particulates) can clog fuel filters and contribute to injector deposits.

(Added 1998) (Amended 1999 and 2018)

1.54. Tractor Hydraulic Fluid. - A product intended for use in tractors with a common sump for the transmission, final drives, wet brakes, axles, and hydraulic system.

(Added 2019)

1.55. Unleaded. - When used in conjunction with "engine fuel" or "gasoline" means any gasoline or gasolineoxygenate blend to which no lead or phosphorus compounds have been intentionally added and which contains not more than $0.013 \mathrm{~g}$ of lead per liter $(0.05 \mathrm{~g}$ lead per U.S. gallon) and not more than $0.0013 \mathrm{~g}$ of phosphorus per liter (0.005 g phosphorus per U.S. gallon).

1.56. Wholesale Purchaser Consumer. - Any person who is an ultimate consumer of gasoline, fuel methanol, ethanol flex fuel, diesel fuel, biodiesel, biodiesel blends, fuel oil, kerosene, aviation turbine fuels, natural gas, compressed natural gas, or liquefied petroleum gas and who purchases or obtains the product from a supplier and receives delivery of that product into a storage tank.

(Added 1998) (Amended 1999 and 2014)

\section{Section 2. Standard Specifications}

\subsection{Gasoline and Gasoline-Oxygenate Blends.}

2.1.1. Gasoline and Gasoline-Oxygenate Blends (as defined in this regulation). - Shall meet the latest version of ASTM D4814, "Standard Specification for Automotive Spark-Ignition Engine Fuel" except for the permissible offsets for ethanol blends as provided in Section 2.1.2. Gasoline-Ethanol Blends.

(a) The maximum concentration of oxygenates contained in gasoline-oxygenate blends shall not exceed those permitted by the EPA under Section 211 of the Clean Air Act and applicable waivers.

(Added 2009) (Amended 2018)

2.1.2. Gasoline-Ethanol Blends. - When gasoline is blended with denatured fuel ethanol, the denatured fuel ethanol shall meet the latest version of ASTM D4806, "Standard Specification for Denatured Fuel Ethanol for Blending with Gasolines for Use as Automotive Spark-Ignition Engine Fuel," and the blend shall meet the latest version of ASTM D4814, "Standard Specification for Automotive Spark-Ignition Engine Fuel," with the following permissible exceptions:

(a) The maximum vapor pressure shall not exceed the latest version of ASTM D4814, "Standard Specification for Automotive Spark-Ignition Engine Fuel," limits by more than 1.0 psi for blends from June 1 through September 15 as allowed by EPA per 40 CFR 80.27(d).

(Amended 2016, 2018, and 2019)

NOTE: The values shown above appear only in U.S. customary units to ensure that the values are identical to those in ASTM standards and the Environmental Protection Agency regulation.

(Added 2009) (Amended 2012 and 2016)

2.1.3. Minimum Antiknock Index (AKI). - The AKI shall not be less than the AKI posted on the product dispenser or as certified on the invoice, bill of lading, shipping paper, or other documentation; 
F. Uniform Fuels and Automotive Lubricants Regulation

2.1.4. Minimum Motor Octane Number. - The minimum motor octane number shall not be less than 82 for gasoline with an AKI of 87 or greater;

2.1.5. Lead Substitute Gasoline. - Gasoline and gasoline-oxygenate blends sold as "lead substitute" gasoline shall contain a lead substitute which provides protection against exhaust valve seat recession equivalent to at least $0.026 \mathrm{~g}$ of lead per liter ( $0.10 \mathrm{~g}$ per U.S. gallon).

2.1.5.1. Documentation of Exhaust Valve Seat Protection. - Upon the request of the Director, the lead substitute additive manufacturer shall provide documentation to the Director that demonstrates that the treatment level recommended by the additive manufacturer provides protection against exhaust valve seat recession equivalent to or better than $0.026 \mathrm{~g} / \mathrm{L}(0.1 \mathrm{~g} / \mathrm{gal})$ lead. The Director may review the documentation and approve the lead substitute additive before such additive is blended into gasoline. This documentation shall consist of:

(a) test results as published in the Federal Register by the EPA Administrator as required in Section 211(f)(2) of the Clean Air Act; or

(b) until such time as the EPA Administrator develops and publishes a test procedure to determine the additive's effectiveness in reducing valve seat wear, test results and description of the test procedures used in comparing the effectiveness of $0.026 \mathrm{~g}$ per liter lead and the recommended treatment level of the lead substitute additive shall be provided.

2.1.6. Blending. - Leaded, lead substitute, and unleaded gasoline-oxygenate blends shall be blended according to the EPA "substantially similar" rule or an EPA waiver for unleaded fuel.

(Amended 2009)

2.2. Diesel Fuel. - Shall meet the following requirements, based on the biodiesel concentration of the fuel:

(a) Diesel fuel that contains less than or equal to $5 \%$ by volume biodiesel shall meet the latest version of ASTM D975, "Standard Specifications for Diesel Fuels" and shall be sold as diesel fuel.

(b) Diesel fuel that contains greater than or equal to $6 \%$ by volume biodiesel and that contains less than or equal to $20 \%$ by volume shall meet the latest version of ASTM D7467, "Standard Specifications for Diesel Fuel Oil, Biodiesel Blend (B6 to B20).”

(c) Only fuel additive registered with the U.S. EPA may be used to additize diesel fuel, and the final product shall meet the latest version of ASTM D975 and/or ASTM D7467.

(Amended 2003 and 2018)

2.2.1. Premium Diesel Fuel. - All diesel fuels identified on retail dispensers as premium, super, supreme, or premier must conform to the following minimum requirements:

(a) Cetane Number. - A minimum cetane number of 47.0 as determined by the latest version of ASTM D613, "Standard Test Method for Cetane Number of Diesel Fuel Oil."

NOTE: ASTM D613, "Standard Test Method for Cetane Number of Diesel Fuel Oil" is the referee method; however, the following methods can be used to determine cetane number: the latest version of ASTM D6890, "Standard Test Method for Determination of Ignition Delay and Derived Cetane Number" (DCN) of Diesel Fuel Oils by Combustion in a Constant Volume Chamber"; and ASTM D7668, "Standard Test Method for Determination of Derived Cetane Number (DCN) of Diesel Fuel Oils-Ignition Delay and Combustion Delay Using a Constant Volume Combustion Chamber Method." (Note added 2019)

(b) Low Temperature Operability. - A cold flow performance measurement which meets the latest version of ASTM D975, "Standard Specification for Diesel Fuel," tenth percentile minimum ambient air 
temperature charts and maps by the latest version of either ASTM D2500, "Standard Test Method for Cloud Point of Petroleum Products and Liquid Fuels" or ASTM D4539, "Standard Test Method for Filterability of Diesel Fuels by Low Temperature Flow Test, (LTFT)." The latest version of ASTM D6371, "Standard Test Method for Cold Filter Plugging Point of Diesel and Heating Fuels" may be used when the test results are a maximum of $6{ }^{\circ} \mathrm{C}$ below the Cloud Point. Low temperature operability is only applicable October 1 to March 31 of each year.

(c) Lubricity. - A maximum wear scar diameter of 460 micrometers as determined by the latest version ASTM D6079, "Standard Test Method for Evaluating Lubricity of Diesel Fuels by the High-Frequency Reciprocating Rig (HFRR)."

NOTE: The latest version of ASTM D6079, "Standard Test Method for Evaluating Lubricity of Diesel Fuels by the High-Frequency Reciprocating Rig (HFRR)" is the referee method; however, the latest version of ASTM D7688, "Standard Test Method for Evaluating Lubricity of Diesel Fuels by the HighFrequency Reciprocating Rig (HFRR) by Visual Observation" can be used.

(Note added 2019)

(d) Corrosion. - A minimum rating of $\mathrm{B}+$ as determined by the latest version of NACE TM0172, "Determining Corrosive Properties of Cargoes in Petroleum Product Pipelines."

NOTE: The latest version of NACE TM0172 "Determining Corrosive Properties of Cargoes in Petroleum Product Pipelines" is the referee method. The latest version of ASTM D7548 "Standard Test Method for Determination of Accelerated Iron Corrosion in Petroleum Products" can be used.

(Added 2019)

(e) Filter Blocking Tendency (FBT). - A maximum of 2.2 by the latest version of ASTM D2068, "Standard Test Method for Determining Filter Blocking Tendency", following procedure B.

(Added 2019)

(f) Injector Deposit Control. - Maximum power loss in keep-clean mode of $2 \%$ by the latest version of Coordinating European Council, CEC F-98-08, "Direct Injection, Common Rail Diesel Engine Nozzle Coking Test."

(Added 2019)

2.2.2. Use of Other Diesel Terminology. - For any terms other than premium, super, supreme, or premier included in the diesel fuel product or grade name and/or advertisements and claims displayed on dispensers, pump toppers, pole signs and bollard signs which imply improved performance, the product must have a clearly-defined fuel property with a substantiated functional benefit. Such property must be measurable utilizing industry accepted test methodologies developed by recognized standards organizations such as ASTM, SAE, and CEC to allow verification of the improved performance.

(Added 2019)

(Amended 2003 and 2019)

2.3. Aviation Turbine Fuels. - Shall meet the latest version of the following standards as appropriate:

(a) ASTM D1655, "Standard Specification for Aviation Turbine Fuels."

(b) ASTM D6615, "Standard Specification for Jet B Wide-Cut Aviation Turbine Fuel."

(c) ASTM D7223, "Standard Specification for Aviation Certification Turbine Fuel."

(d) ASTM D7566, "Standard Specification for Aviation Turbine Fuel Containing Synthesized Hydrocarbons." (Amended 2018) 
F. Uniform Fuels and Automotive Lubricants Regulation

2.4. Aviation Gasoline. - Shall meet the latest version of one of the following as appropriate:

(a) ASTM D910, "Standard Specification Leaded for Aviation Gasolines."

(b) ASTM D6227, "Standard Specification for Unleaded Aviation Gasoline Containing a Non-hydrocarbon Component."

(c) ASTM 7547, "Standard Specification for Hydrocarbon Unleaded Aviation Gasoline."

(Amended 2008 and 2018)

2.5. Fuel Oils. - Shall meet the latest version of ASTM D396, "Standard Specification for Fuel Oils."

2.6. Kerosene (Kerosine). - Shall meet the latest version of ASTM D3699, "Standard Specification for Kerosine."

2.7. Denatured Fuel Ethanol. - Intended for blending with gasoline shall meet the latest version of ASTM D4806, "Standard Specification for Denatured Fuel Ethanol for Blending with Gasolines for Use as Automotive SparkIgnition Engine Fuel."

(Amended 2014)

2.8. Liquefied Petroleum (LP) Gases. - Shall meet the latest version ASTM D1835, "Standard Specification for Liquefied Petroleum (LP) Gases.”

NOTE: Also reference Gas Processors Association 2140, Liquefied Petroleum Gas Specification and Test Methods.

2.9. Liquefied Natural Gas (LNG) Vehicle Fuel. - Shall meet the latest version of SAE J2699, "Liquefied Natural Gas (LNG) Vehicle Fuel."

(Added 2018)

2.10. Compressed Natural Gas (CNG). - Shall meet the latest version of SAE J1616, "Recommended Practice for Compressed Natural Gas Vehicle Fuel."

2.11. Ethanol Flex Fuel. -Ethanol flex fuel is covered by one of two ASTM standards based on the ethanol concentration of blend:

(a) Ethanol flex fuel containing 51 to 83 volume percent ethanol shall meet the latest version of ASTM D5798, "Standard Specification for Ethanol Fuel Blends for Flexible Fuel Automotive Spark-Ignition Engines"; and

(b) Ethanol flex fuel containing 16 to 50 volume percent ethanol shall be blended, stored, delivered and offered for consumption in accordance with the latest version of ASTM D7794, "Standard Practice for Blending Mid-Level Ethanol Fuel Blends for Flexible Fuel Vehicles with Automotive Spark-Ignition Engines."

(Amended 2018)

(Added 1997) (Amended 2014 and 2018)

2.12. M85 Fuel Methanol. - Shall meet the latest version of ASTM D5797, "Standard Specification for Methanol Fuel Blends (M51-M85) for Methanol-Capable Automotive Spark Ignition Engines."

(Added 1997)

2.13. Racing Gasoline. - Shall meet the following requirements:

(a) the Minimum Antiknock Index (AKI) shall not be less than the AKI posted on the product dispenser or as certified on the invoice, bill of lading, shipping paper, or other documentation. 
(b) the product specification limits shall be those as declared by the manufacturer's product specifications. Upon the request of the Director, each supplier of racing gasoline shall provide a copy of the manufacturer's product specifications.

(Added 2018)

2.14. Engine (Motor) Oil. - Shall not be sold or distributed for use unless the product conforms to the following specifications:

(a) performance claims made regarding active performance categories, as listed on the label shall be evaluated against the latest version of SAE J183, "Engine Oil Performance and Engine Service Classification," API 1509 "Engine Oil Licensing and Certification System," European Automobile Manufacturers' Association (ACEA), "European Oil Sequences," or other "Vehicle or Engine Manufacturer Standards" as applicable;

(b) performance claims made regarding any obsolete performance categories, as listed on the label, shall be determined to meet the requirements of Section 3.13.1.3.2. "Inactive or Obsolete Service Categories" by displaying the appropriate cautionary labeling; and

(c) the product shall meet its labeled viscosity grade specification as specified in the latest version of SAE J300, "Engine Oil Viscosity Classification."

(Added 2004) (Amended 2014 and 2021)

2.15. Products for Use in Lubricating Manual Transmissions, Gears, or Axles. - Shall not be sold or distributed for use in lubricating manual transmissions, gears, or axles unless the product conforms to the following specifications:

(a) it is labeled with one or more of the service designations found in the latest version of the SAE Information Report on axle and manual transmission lubricants, SAE J308, and API Publication 1560, and meets all applicable requirements of those designations;

(b) the product shall meet its labeled viscosity grade classification as specified in the latest version of SAE J306; and

(c) the product shall be free from water and suspended matter when tested by means of centrifuge, in accordance with the latest version of ASTM D2273, "Standard Test Method for Trace Sediment in Lubricating Oils."

(Added 2004)

2.16. Products for Use in Lubricating Transmissions. - Transmission fluids shall meet the original equipment manufacturer's requirements for those transmissions or have demonstrated performance claims to be suitable for use in those transmissions. Where a fluid can be licensed against an original equipment manufacturer's specification, evidence of current licensing by the marketer is acceptable documentation of performance against the specification. In the absence of a license from the original equipment manufacturer, adherence to the original equipment manufacturer's recommended requirements shall be assessed after testing per relevant methods available to the lubricants industry and the state regulatory agency. Suitability for use claims shall be based upon appropriate field, bench, and/or transmission rig testing. Any manufacturer of a transmission fluid making suitable-for-use claims shall provide, upon request by a duly authorized representative of the Director, credible documentation of such claims. If the product performance claims published by a blender and/or marketer are based on the claim(s) of one or more additive suppliers, documentation of the claims may be requested in confidence by a duly authorized representative of the Director. Supporting data may be supplied directly to the Director's office by the additive supplier(s).

(Added 2004) (Amended 2017)

2.16.1. Conformance. - Conformance of a fluid per Section 2.14. Products for Use in Lubricating Transmissions does not absolve the obligations of a fluid licensee with respect to the licensing original equipment manufacturer or the original equipment manufacturer's licensing agent(s), where relevant.

(Added 2017) 
F. Uniform Fuels and Automotive Lubricants Regulation

2.16.2. Transmission Fluid Additives. - Any material offered for sale or sold as an additive to transmission fluids shall be compatible with the transmission fluid to which it is added and shall meet all performance claims as stated on the label or published on any website referenced by the label. Any manufacturer of any such product sold in this state shall provide, upon request by a duly authorized representative of the Director, documentation of any claims made on their product label or published on any website referenced by the label.

(Added 2017)

2.17. Biodiesel Blendstock. - Biodiesel intended for blending with diesel fuel shall meet the latest version of ASTM D6751, "Standard Specification for Biodiesel Fuel Blend Stock (B100) for Middle Distillate Fuels." Any blend stock less than $99 \%$ by volume biodiesel (no more than $1 \%$ by volume diesel fuel). Any blend stock less than $99 \%$ by volume shall not be used as a commercial blend stock for biodiesel blends without the permission of the Director.

(Added 2004) (Amended 2018)

2.18. Butanol for Blending with Gasoline. - Shall meet the latest version of ASTM D7862, "Standard Specifications for Butanol for Blending with Gasoline for Use as Automotive Spark-Ignition Engine Fuel."

(Added 2018)

2.19. Dimethyl Ether for Fuel Purposes. - Shall meet the latest version of ASTM D7901, "Standard Specifications for Dimethyl Ether for Fuel Purposes."

(Added 2018)

2.20. Hydrogen Fuel. - Shall meet the latest version of SAE J2719, "Hydrogen Fuel Quality for Fuel Cell Vehicles." (Added 2012)

2.21. Diesel Exhaust Fluid (DEF). - Shall meet the latest version of the ISO 22241, "Diesel engines - NOx reduction agent AUS 32."

(Added 2014)

2.22. Products for Use in Lubricating Tractors. - Tractor hydraulic fluids shall meet at least one current and/or verifiable original equipment manufacturer's specifications for respective tractors. A specification is deemed verifiable if all necessary bench and laboratory tests are available to verify the fluid's ability to pass those requirements set out by the original equipment manufacturer. A list of current and verifiable original equipment manufacturer's specifications is located on the NCWM website (www.ncwm.com). Where a fluid can be licensed against an original equipment manufacturer's specification, evidence of current licensing by the marketer is acceptable documentation of performance against the specification. In the absence of a license from the original equipment manufacturer, adherence to the original equipment manufacturer's specifications shall be assessed after testing per relevant methods available to the lubricants industry and the regulatory agency. Suitability for use claims shall be based upon appropriate field, bench, and/or rig testing. Any manufacturer of a tractor hydraulic fluid making suitable for use claims shall provide, upon request by a duly authorized representative of the Director, credible documentation of such claims. If the product performance claims published by a blender and/or marketer are based on the claim(s) of one or more additive suppliers, documentation of the claims shall be provided upon request to a duly authorized representative of the Director. Supporting data shall, upon request, be supplied directly to the Director's office by the additive supplier(s).

(Amended 2021)

2.22.1. Conformance. - Conformance of a fluid per Section 2.22. Products for Use in Lubricating Tractors does not absolve the obligations of a fluid licensee with respect to the licensing original equipment manufacturer or the original equipment manufacturer's licensing agent(s), where relevant.

2.22.2. Tractor Hydraulic Fluid Additives. - Any material offered for sale or sold as an additive to tractor hydraulic fluids shall be compatible with the tractor hydraulic fluid to which it is added and shall meet all performance claims as stated on the label or published on any website referenced by the label. Any manufacturer of any 
such product sold shall provide, upon request by a duly authorized representative of the Director, documentation of any claims made on their product label or published on any website referenced by the label.

(Added 2019) (Amended 2021)

\section{Section 3. Classification and Labeling for Sale}

\subsection{General Considerations.}

3.1.1. Documentation. - When products regulated by this rule are sold, an invoice, bill of lading, shipping paper, or other documentation must accompany each delivery other than a retail sale. This document must identify the quantity, the name of the product, the particular grade of the product, the applicable automotive fuel rating, and oxygenate type and content (if applicable), the name and address of the seller and buyer, and the date and time of the sale. Documentation must be retained at the retail establishment for a period not less than one year.

(Amended 2008)

3.1.2. Retail Dispenser Labeling. - All retail dispensing devices must identify conspicuously the type of product (exception: gasoline and gasoline-oxygenate blends), the particular grade of the product (exception: No. 2 Diesel), and the applicable automotive fuel rating.

(Amended 2018)

3.1.3. Grade Name. - The sale of any product under any grade name that indicates to the purchaser that it is of a certain automotive fuel rating or ASTM grade shall not be permitted unless the automotive fuel rating or grade indicated in the grade name is consistent with the value and meets the requirements of Section 2, Standard Specifications.

3.1.4. Nozzle Requirements for Automotive Gasoline, Gasoline-Oxygenate Blends, and Diesel Fuel Dispensers. - Each retail dispensing device from which fuel products are sold shall be equipped with a nozzle spout having a diameter that conforms with the latest version of SAE J285, "Dispenser Nozzle Spouts for Liquid Fuel Intended for Use with Spark-Ignition and Compression Ignition Engines."

(Added 2018)

(Amended 2018)

\subsection{Automotive Gasoline and Automotive Gasoline-Oxygenate Blends (Including Racing Gasoline).}

3.2.1. Posting of Antiknock Index Required. - Automotive gasoline and automotive gasoline-oxygenate blends shall post the minimum antiknock index in accordance with applicable regulations, 16 CFR 306 issued pursuant to the "Petroleum Marketing Practices Act," as amended.

(Amended 2018)

3.2.2. Use of Lead Substitute Must be Disclosed. - Each dispensing device from which gasoline or gasolineoxygenate blends containing a lead substitute is dispensed shall display the following legend: "Contains Lead Substitute." The lettering of this legend shall not be less than $12.7 \mathrm{~mm}(1 / 2 \mathrm{in})$ in height and the color of the lettering shall be in definite contrast to the background color to which it is applied.

3.2.3. Prohibition of Terms. - It is prohibited to use specific terms to describe a grade of gasoline or gasolineoxygenate blend unless it meets the minimum antiknock index requirement shown in Table 1. Minimum Antiknock Index Requirements. 


\begin{tabular}{||c|c|c||}
\hline \multicolumn{2}{|c|}{ Table 1. Minimum Antiknock Index Requirements } \\
\hline \multirow{2}{*}{ Term } & \multicolumn{2}{|c||}{ Minimum Antiknock Index } \\
\cline { 2 - 3 } & $\begin{array}{c}\text { ASTM D4814 Altitude Reduc- } \\
\text { tion Areas IV and V }\end{array}$ & All Other ASTM D4814 Areas \\
\hline Premium, Super, Supreme, High Test & 90 & 91 \\
\hline Midgrade, Plus & 87 & 89 \\
\hline Regular, Unleaded (alone) & 85 & 87 \\
\hline Economy & -- & 86 \\
\hline
\end{tabular}

(Table 1. Amended 1997 and 2018)

3.2.4. Method of Retail Sale. - Type of Oxygenate must be disclosed. All automotive gasoline or automotive gasoline-oxygenate blends, or racing gasoline kept, offered, or exposed for sale, or sold at retail containing more than one volume percent oxygenate shall be identified as "with" or "containing" (or similar wording) the predominant oxygenate in the engine fuel. For example, the label may read "contains ethanol" or "with methyl tertiary-butyl ether (MTBE)." The oxygenate contributing the largest mass percent oxygen to the blend shall be considered the predominant oxygenate. Where mixtures of only ethers are present, the retailer may post the predominant oxygenate followed by the phrase "or other ethers" or alternatively post the phrase "contains MTBE or other ethers." In addition, gasoline-methanol blends containing more than $0.3 \%$ by volume methanol shall be identified as "with" or "containing" methanol. This information shall be posted on the upper $50 \%$ of the dispenser front panel in a position clear and conspicuous from the driver's position in a type at least $12.7 \mathrm{~mm}(1 / 2 \mathrm{in})$ in height, $1.5 \mathrm{~mm}(1 / 16$ in) stroke (width of type).

(Amended 1996 and 2018)

3.2.5. Documentation for Dispenser Labeling Purposes. - For automotive gasoline, automotive gasolineoxygenate blends or racing gasoline, the retailer shall be provided, at the time of delivery of the fuel, on product transfer documents such as an invoice, bill of lading, shipping paper, or other documentation:

(a) Information that complies with 40 CFR 80.1503 when the fuel contains ethanol. (Added 2014)

(b) For fuels that do not contain ethanol, information that complies with 40 CFR 80.1503 and a declaration of the predominant oxygenate or combination of oxygenates present in concentrations sufficient to yield an oxygenate content of at least $1.0 \%$ by volume in the fuel. Where mixtures of only ethers are present, the fuel supplier may identify either the predominant oxygenate in the fuel (i.e., the oxygenate contributing the largest mass percent oxygen) or alternatively, use the phrase "contains MTBE or other ethers."

(Added 2014)

(c) Gasoline containing more than $0.3 \%$ by volume methanol shall be identified as "with" or "containing" methanol.

(Added 2014) (Amended 2018)

(Amended 1996, 2014, and 2018)

3.2.6. EPA Labeling Requirements. - Retailers and wholesale purchaser-consumers of gasoline shall comply with the EPA pump labeling requirements for gasoline containing greater than 10 volume percent $(\mathrm{v} \%)$ up to 15 volume percent (v\%) ethanol (E15) under 40 CFR 80.1501. (For additional information, refer to Section 3.8.2. FTC Labeling Requirements.)

(Added 2012) (Amended 2018)

(Amended 2018) 


\subsection{Diesel Fuel.}

3.3.1. Labeling of Grade Required. - Diesel Fuel other than No 2-D shall be identified by grade.

(Amended 2018)

3.3.2. Automotive Fuel Rating. - Diesel fuel containing $6 \%$ to $20 \%$ by volume biodiesel shall be labeled with its automotive fuel rating in accordance with the FTC "Automotive Fuel Ratings, Certification and Posting Rule," 16 CFR 306.

(Added 2018)

3.3.3. Delivery Documentation for Premium Diesel. - Before or at the time of delivery of premium diesel fuel, the retailer or the wholesale purchaser-consumer shall be provided on an invoice, bill of lading, shipping paper, or other documentation a declaration of all performance properties that qualifies the fuel as premium diesel fuel as required in Section 2.2.1. Premium Diesel Fuel.

(Added 1998) (Amended 1999)

(Amended 1998, 1999, 2008, 2012, and 2018)

\subsection{Aviation Turbine Fuels.}

3.4.1. Labeling of Grade Required. - Aviation turbine fuels shall be identified by the grade terms contained in applicable ASTM Standard Specifications. (See EI 1542 for additional details.)

(Amended 2018)

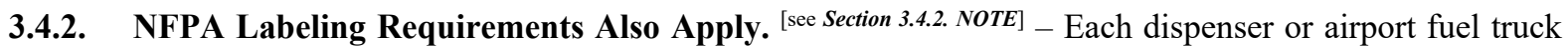
dispensing aviation turbine fuels shall be labeled in accordance with the latest version of National Fire Protection Association (NFPA 407), "Standard for Aircraft Fuel Servicing."

Section 3.4.2. NOTE: For example, NFPA 407, 2017 edition: Section 6.1.11.3. Signage. Each aircraft fuel servicing vehicle or cart shall have signage viewable from all sides of the vehicle. Signs shall have letters at least $75 \mathrm{~mm}(3 \mathrm{in})$ high. Signs shall be of a color contrasting sharply with the background for visibility. The words "FLAMMABLE," "NO SMOKING," and the name of the product carried, such as JET A, JET B, GASOLINE, or AVGAS shall appear on each sign. (NOTE: Refer to the latest version of NFPA 407.)

(Amended 2018)

\subsection{Aviation Gasoline.}

3.5.1. Labeling of Grade Required. - Aviation gasoline shall be identified by the grade terms contained in the latest version of ASTM Standard Specifications. (See EI 1542, "Identification Markings for Dedicated Aviation Fuel Manufacturing and Distribution Facilities, Airport Storage and Mobile Fueling Equipment" for additional detail.)

(Amended 2008 and 2018)

3.5.2. NFPA Labeling Requirements Also Apply. [see Section 3.4.2. NOTE] - Each dispenser or airport fuel truck dispensing aviation gasoline shall be labeled in accordance with the most recent edition of National Fire Protection Association (NFPA) 407, "Standard for Aircraft Fuel Servicing."

(Amended 2018) 
F. Uniform Fuels and Automotive Lubricants Regulation

\subsection{Fuel Oils.}

3.6.1. Labeling of Grade Required. - Fuel Oil shall be identified by the grades contained in the latest version of ASTM D396, "Standard Specification for Fuel Oils."

(Amended 2018)

3.6.2. Retail Fuel Oil. - Dispensers shall display the following legend:

"Warning - Not Suitable for Use in Unvented Heaters Requiring No. 1-K Kerosene."

The lettering of this legend shall not be less than $12.7 \mathrm{~mm}(1 / 2$ in) in height by $1.5 \mathrm{~mm}(1 / 16 \mathrm{in})$ strokes (width of type), block style letters, and the color of lettering shall be in definite contrast to the background color to which it is applied.

(Added 2018)

(Amended 2008 and 2018)

\subsection{Kerosene (Kerosine).}

3.7.1. Labeling of Grade Required. - Kerosene shall be identified by the grades No. 1-K or No. 2-K.

3.7.2. Additional Labeling Requirements. - Each retail dispenser of kerosene shall be labeled as 1-K Kerosene or 2-K. In addition, No. 2-K dispensers shall display the following legend:

"Warning - Not Suitable for Use in Unvented Heaters Requiring No. 1-K"

The lettering of this legend shall not be less than $12.7 \mathrm{~mm}(1 / 2$ in) in height by $1.5 \mathrm{~mm}(1 / 16$ in) stroke; block style letters and the color of lettering shall be in definite contrast to the background color to which it is applied.

\subsection{Ethanol Flex Fuel.}

3.8.1. How to Identify Ethanol Flex Fuel. - Ethanol flex fuel shall be identified as Ethanol Flex Fuel or EXX Flex Fuel.

3.8.2. FTC Labeling Requirements. - Ethanol flex fuel shall be identified and labeled in accordance with the Federal Trade Commission, Automotive Fuel Ratings, Certification and Posting, 16 CFR 306, as amended. (For additional information, see to Section 3.2.6. EPA Labeling Requirements.)

(Amended 2007, 2008, 2014, and 2018)

\subsection{M85 Fuel Methanol.}

3.9.1. How to Identify M85 Fuel Methanol. - Fuel methanol shall be identified as M85.

\section{Example:}

M85

\subsubsection{Retail Dispenser Labeling.}

(a) Fuel methanol shall be labeled with its automotive fuel rating in accordance with 16 CFR 306.

Example:

M85 Methanol 
(b) A label shall be posted which states "For Use in Vehicles Capable of Using M85 Only." This information shall be clearly and conspicuously posted on the upper $50 \%$ of the dispenser front panel in a type of at least $12.7 \mathrm{~mm}(1 / 2 \mathrm{in})$ in height, $1.5 \mathrm{~mm}(1 / 16 \mathrm{in})$ stroke (width of type).

(Amended 2008)

\subsection{Liquefied Petroleum Gas (LPG).}

3.10.1. How LPG is to be Identified. - Liquefied petroleum gases shall be identified by grades Commercial Propane, Commercial Butane, Commercial PB Mixtures or Special-Duty Propane (HD5).

3.10.2. Retail Dispenser Labeling. - Each retail dispenser of LPGs shall be labeled as "Commercial Propane," "Commercial Butane," "Commercial PB Mixtures,” or "Special-Duty Propane (HD5).”

3.10.3. Additional Labeling Requirements. - LPG shall be labeled with its automotive fuel rating in accordance with 16 CFR 306.

3.10.4. NFPA Labeling Requirements Also Apply. (Refer to the most recent edition of NFPA 58, "Liquified Petroleum Gas Code")

\subsection{Compressed Natural Gas (CNG).}

3.11.1. How Compressed Natural Gas is to be Identified. - For the purposes of this regulation, compressed natural gas shall be identified by the term "Compressed Natural Gas" or "CNG."

\subsubsection{Retail Sales of Compressed Natural Gas Sold as a Vehicle Fuel.}

\subsubsection{Retail Dispenser Labeling.}

3.11.2.1.1. Identification of Product. - Each retail dispenser of CNG shall be labeled as "Compressed Natural Gas."

3.11.2.1.2. Non-Liquid Alternative Vehicle Fuel Rating. - CNG shall be labeled with its non-liquid alternative vehicle fuel rating in accordance with 16 CFR 309.

(Added 2018)

3.11.2.1.3. NFPA Labeling. - NFPA Labeling requirements also apply. (refer to NFPA 52, "Vehicular Natural Gas Fuel Systems Code")

3.11.2.2. Nozzle Requirements for CNG. - CNG fueling nozzles shall comply with ANSI/AGA/CGA NGV 1.

\subsection{Liquefied Natural Gas (LNG).}

3.12.1. How Liquefied Natural Gas is to be Identified. - For the purposes of this regulation, liquefied natural gas shall be identified by the term "Liquefied Natural Gas" or "LNG."

\subsubsection{Labeling of Retail Dispensers of Liquefied Natural Gas Sold as a Vehicle Fuel.}

3.12.2.1. Identification of Product. - Each retail dispenser of LNG shall be labeled as "Liquefied Natural Gas."

3.12.2.2. Automotive Fuel Rating. - LNG automotive fuel shall be labeled with its automotive fuel rating in accordance with 16 CFR 306. 
3.12.2.3. NFPA Labeling. - NFPA Labeling requirements also apply. (Refer to NFPA 57, "Liquefied Natural Gas (LNG) Vehicular Fuel Systems Code")

\subsection{Oil.}

\subsubsection{Labeling of Vehicle Engine (Motor) Oil Required.}

3.13.1.1. Viscosity. - The label on any vehicle engine (motor) oil container, receptacle, dispenser, or storage tank and the invoice or receipt from service on an engine that includes the installation of bulk vehicle engine (motor) oil dispensed from a receptacle, dispenser, or storage tank shall contain the viscosity grade classification preceded by the letters "SAE" in accordance with the SAE International's latest version of SAE J300, "Engine Oil Viscosity Classification."

(Amended 2012 and 2014)

3.13.1.2. Brand. - The label on any vehicle engine (motor) oil container and the invoice or receipt from service on an engine that includes the installation of bulk vehicle engine (motor) oil dispensed from a receptacle, dispenser, or storage tank shall contain the name, brand, trademark, or trade name of the vehicle engine (motor) oil.

(Added 2012 and 2014)

3.13.1.3. Engine Service Category. - The label on any vehicle engine (motor) oil container, receptacle, dispenser or storage tank and the invoice or receipt from service on an engine that includes the installation of bulk vehicle engine (motor) oil dispensed from a receptacle, dispenser, or storage tank shall contain the engine service category, or categories, displayed in letters not less than $3.18 \mathrm{~mm}(1 / 8$ in) in height, as defined by the latest version of SAE J183, "Engine Oil Performance and Engine Service Classification (Other than "Energy Conserving")" API Publication 1509, "Engine Oil Licensing and Certification System," European Automobile Manufacturers Association (ACEA), "European Oil Sequences," or other "Vehicle or Engine Manufacturer Standards" as provided in Section 3.13.1.3.1.

(Amended 2012 and 2014)

3.13.1.3.1. Vehicle or Engine Manufacturer Standard. - The label on any vehicle engine (motor) oil container, receptacle, dispenser, or storage tank and the invoice or receipt from service on an engine that includes the installation of vehicle engine (motor) oil dispensed from a receptacle, dispenser, or storage tank shall identify the specific vehicle or engine manufacturer standard, or standards, met in

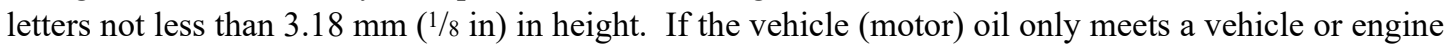
manufacturer standard, the label must clearly identify that the oil is only intended for use where specifically recommended by the vehicle or engine manufacturer.

(Added 2014)

3.13.1.3.2. Inactive or Obsolete Service Categories. - Whenever any vehicle engine (motor) oil in a container receptacle, dispenser, storage tank or in bulk does not meet an active API service category as defined by the latest version of SAE J183, "Engine Oil Performance and Engine Service Classification (Other than "Energy Conserving"),," API Publication 1509, "Engine Oil Licensing and Certification System," European Automobile Manufacturers Association (ACEA), "European Oil Sequences," or other Vehicle or Engine Manufacturer Standards as approved in Section 2.33.1.3.1., Vehicle or Engine Manufacturer Standard the front or forward-facing label of such vehicle engine (motor) oil container, receptacle, dispenser, or storage tank and the invoice or receipt from service on an engine that includes the installation of bulk vehicle engine (motor) oil dispensed from a receptacle, dispenser or storage tank shall bear the plainly visible cautionary statement set forth in the latest version of SAE J183, Appendix A. Whenever any vehicle engine (motor) oil is declared obsolete by a vehicle or engine manufacturer, the front of forward-facing label of such vehicle engine (motor) oil container, receptacle, dispenser or 
storage tank and the invoice or receipt from service on an engine that includes the installation of bulk vehicle engine (motor) oil dispensed from a receptacle, dispenser, or storage tank shall bear the plainly visible cautionary statement required by the vehicle or engine manufacturer.

(Added 2012) (Amended 2014 and 2021)

3.13.1.4. Tank Trucks or Rail Cars. - Tank trucks, rail cars, and types of delivery trucks that are used to deliver bulk vehicle engine (motor) oil are not required to display the SAE viscosity grade and service category or categories on such tank trucks, rail cars, and other types of delivery trucks. In lieu of such display requirements the documentation defined in Section 3.13.1.5. Documentation shall be readily available for inspection.

(Added 2012) (Amend 2013, 2014 and 2021)

3.13.1.5. Documentation. - When the engine (motor) oil is sold in bulk, an invoice, bill of lading, shipping paper, or other documentation must accompany each delivery. This document must identify the quantity of bulk engine (motor) oil delivered as defined in Sections 3.13.1.1. Viscosity, grade as defined by the latest version of SAE J300, "Engine Oil Viscosity Classification;" 3.13.1.2. Brand; 3.13.1.3. Engine Service Category; the name and address of the seller and buyer; and the date and time of the sale. For inactive or obsolete service categories, the documentation shall also bear a plainly visible cautionary statement as required in Section 3.13.1.3.2. Inactive or Obsolete Service Categories. Documentation must be retained at the retail establishment for a period of not less than one year.

(Added 2013) (Amended 2014 and 2021)

(Amended 2012, 2013, 2014, and 2021)

\subsubsection{Labeling of Recreational Motor Oil.}

3.13.2.1. Viscosity. - The label on each container of recreational motor oil shall contain the viscosity grade classification preceded by the letters "SAE" in accordance with the SAE International's latest version of SAE J300, "Engine Oil Viscosity Classification."

3.13.2.2. Intended Use. - The label on each container of recreational motor oil shall contain a statement of its intended use in accordance with the latest version of SAE J300, "Engine Oil Viscosity Classification."

\subsubsection{Labeling of Gear Oil.}

3.13.3.1. Viscosity. - The label on each container of gear oil shall contain the viscosity grade classification preceded by the letters "SAE" in accordance with the SAE International's latest version of SAE J306, "Automotive Gear Lubricant Viscosity Classification” or SAE J300, "Engine Oil Viscosity Classification."

3.13.3.1.1. Exception. - Some automotive equipment manufacturers may not specify an SAE viscosity grade requirement for some applications. Gear oils intended to be used only in such applications are not required to contain an SAE viscosity grade on their labels.

3.13.3.2. Service Category. - The label on each container of gear oil shall contain the service category, or categories, in letters not less than $3.18 \mathrm{~mm}(1 / 8$ in) in height, as defined by the latest version of SAE J308, "Axle and Manual Transmission Lubricants."

(Added 2004)

\subsection{Transmission Fluid.}

3.14.1. Labeling and Identification of Transmission Fluid. - Transmission fluid shall be labeled or identified as described below.

(Added 2017) 
3.14.1.1. Container Labeling. - The label on a container of transmission fluid shall not contain any information that is false or misleading. Containers include bottles, cans, multi-quart or liter containers, pails, kegs, drums, and intermediate bulk containers (IBCs). In addition, each container of transmission fluid shall be labeled with the following:

(a) the brand name;

(b) the name and place of business of the manufacturer, packer, seller, or distributor;

(c) the words "Transmission Fluid," which may be incorporated into a more specific description of transmission type such as "Automatic Transmission Fluid" or "Continuously Variable Transmission Fluid";

(d) the primary performance claim or claims met by the fluid and reference to where any supplemental claims may be viewed (e.g., website reference). Performance claims include but are not limited to those set by original equipment manufacturers and standards setting organizations such as SAE and JASO and are acknowledged by reference; and

(e) an accurate statement of the quantity of the contents in terms of liquid measure.

(Amended 2017)

3.14.1.2. Identification on Documentation. - Transmission fluid sold in bulk shall be identified on the manufacturer, packer, seller or distributor invoice, bill of lading, shipping paper, or other documentation with the information listed below:

(a) the brand name;

(b) the name and place of business of the manufacturer, packer, seller, or distributor;

(c) the words "Transmission Fluid" which may be incorporated into a more specific description of transmission type such as "Automatic Transmission Fluid" or "Continuously Variable Transmission Fluid";

(d) the primary performance claim or claims met by the fluid or reference to where these claims may be viewed (e.g., website reference). Performance claims include but are not limited to those set by original equipment manufacturers and standards-setting organizations such as SAE and JASO and are acknowledged by reference; and

(e) an accurate statement of the quantity of the contents in terms of liquid measure.

(Added 2017)

3.14.1.3. Identification on Service Provider Documentation. - Transmission fluid installed from a bulk tank at time of transmission service shall be identified on the customer invoice with the information listed below:

(a) the brand name;

(b) the name and place of business of the service provider;

(c) the words "Transmission Fluid" which may be incorporated into a more specific description of transmission type such as "Automatic Transmission Fluid" or "Continuously Variable Transmission Fluid";

(d) the primary performance claim or claims met by the fluid or reference to where these claims may be viewed (e.g., website reference). Performance claims include but are not limited to those set by 
original equipment manufacturers and standards-setting organizations such as SAE and JASO and are acknowledged by reference; and

(e) an accurate statement of the quantity of the contents in terms of liquid measure. (Added 2017)

3.14.1.4. Bulk Delivery. - When the transmission fluid is sold in bulk, an invoice, bill of lading, shipping paper, or other documentation must accompany each delivery. This document must identify the fluid as defined in Section 3.14.2. Container Labeling.

(Added 2017)

3.14.1.5. Storage Tank Labeling. - Each storage tank of transmission fluid shall be labeled with the following:

(a) the brand name;

(b) the primary performance claim or claims met by the fluid or reference to where these claims may be viewed (e.g., website reference). Performance claims include but are not limited to those set by original equipment manufacturers and standards-setting organizations such as SAE and JASO and are acknowledged by reference.

(Added 2017)

3.14.1.6. Documentation of Claims Made Upon Product Label. - Any manufacturer, packer, or distributor of any product subject to this article and sold in this state shall provide, upon request of duly authorized representatives of the Director, credible documentation of any claim made upon their product label, including claims made on any website referenced by said label. If the product performance claims published by a blender and/or marketer are based on the claim(s) of one or more additive suppliers, documentation of the claims may be requested in confidence by a duly authorized representative of the Director. Supporting data may be supplied directly to the Director's office by the additive supplier(s).

(Added 2004) (Amended 2017)

\subsection{Biodiesel and Biodiesel Blends.}

3.15.1. Identification of Product. - Biodiesel Blendstock shall be identified by the term "biodiesel" with the designation "B100" or "B99."

(Amended 2018)

\subsubsection{Labeling of Retail Dispensers.}

3.15.2.1. Labeling of Grade Required. - Biodiesel shall be identified by the grades No. 1-B S15 or No. 1-B S500, or No. 2-B S500.

(Amended 2018)

3.15.2.2. Automotive Fuel Rating. - Biodiesel and biodiesel blends shall be labeled with its automotive fuel rating in accordance with the FTC Automotive Fuel Ratings, Certification and Posting Rule, 16 CFR 306.

(Amended 2018)

3.15.2.3. Biodiesel Blends. - When biodiesel blends greater than $20 \%$ by volume are offered by sale, each side of the dispenser where fuel can be delivered shall have a label conspicuously placed that states "Consult Vehicle Manufacturer Fuel Recommendations." 
F. Uniform Fuels and Automotive Lubricants Regulation

The lettering of this legend shall not be less than $6 \mathrm{~mm}(1 / 4$ in) in height by $0.8 \mathrm{~mm}(1 / 32$ in) stroke; block style letters and the color shall be in definite contrast to the background color to which it is applied.

3.15.3. Documentation for Dispenser Labeling Purposes. - The retailer shall be provided, at the time of delivery of the fuel, a declaration of the volume percent biodiesel on an invoice, bill of lading, shipping paper, or other document. This documentation is for dispenser labeling purposes only; it is the responsibility of any potential blender to determine the amount of biodiesel in the diesel fuel prior to blending.

3.15.4. Exemption. - Biodiesel blends that contain less than or equal to $5 \%$ biodiesel by volume are exempted from the requirements of Sections 3.15.1. Identification of Product, 3.15.2. Labeling of Retail Dispensers, and 3.15.3. Documentation for Dispenser Labeling Purposes when it is sold as "diesel fuel" as required in Section 3.3. Diesel Fuel.

(Added 2005) (Amended 2008 and 2018)

\subsection{Diesel Exhaust Fluid (DEF).}

3.16.1. Labeling of Diesel Exhaust Fluid (DEF). - DEF shall be labeled.

3.16.1.1. Retail Dispenser Labeling. - A label shall be clearly and conspicuously placed on the front panel of the DEF dispenser stating "for operation of selective catalytic reduction (SCR) converters in motor vehicles with diesel engines."

3.16.1.2. Documentation for Retailers of Bulk Product. - A DEF supplier shall provide, at the time of delivery of the bulk shipment of DEF, identification of the fluid's origin including the name of the fluid manufacturer, the brand name, trade name, or trademark, and a statement identifying the fluid as DEF conforming to specifications given in the latest version of ISO 22241, "Diesel engines - NOx reduction agent AUS 32." This information shall be provided by the supplier on an invoice, bill of lading, shipping paper, or other document.

3.16.1.3. Labeling Packaged Product. - Any DEF retail package shall bear a label that includes the name of the fluid manufacturer, the brand name, trade name, or trademark, a statement identifying the fluid as DEF conforming to specifications given in the latest version of ISO 22241, "Diesel engines - NOx reduction agent AUX 32." And the statement, "It is recommended to store DEF between $-5{ }^{\circ} \mathrm{C}$ to $30^{\circ} \mathrm{C}\left(23^{\circ} \mathrm{F}\right.$ to $\left.86^{\circ} \mathrm{F}\right)$."

3.16.1.4. Documentation for Bulk Deliveries. - A carrier that transports or accepts for transportation any bulk shipment by tank truck, freight container, cargo tank, railcar, or any other vehicle used to transport or deliver bulk quantities of DEF shall, at the time of delivery of the DEF, provide identification of the fluid's origin including the name of the fluid manufacturer, the brand name, trade name, or trademark, and a statement identifying the fluid as DEF conforming to specifications given in the latest version of ISO 22241, "Diesel engines - NOx reduction agent AUS 32." This information shall be provided to the recipient on an invoice, bill of lading, shipping paper, or other document.

(Added 2014)

\subsection{Tractor Hydraulic Fluid}

3.17.1. Labeling and Identification of Tractor Hydraulic Fluid. - Tractor hydraulic fluid shall be labeled or identified as described below

3.17.1.1. Container Labeling. - The label on a container of tractor hydraulic fluid shall not contain any information that is false or misleading. Containers include bottles, cans, multi-quart or liter containers, pails, kegs, drums, and intermediate bulk containers (IBCs). In addition, each container of tractor hydraulic fluid shall be labeled with the following:

(a) the brand name; 
(b) the name and place of business of the manufacturer, packer, seller, or distributor;

(c) the words "Tractor Hydraulic Fluid," which may include words such as "Hydraulic Fluid for Agricultural Applications" or "Universal Tractor Transmission Oil";

(d) the primary performance claim or claims met by the fluid and reference to where any supplemental claims may be viewed (e.g., website reference). Performance claims are those set by original equipment manufacturers;

(e) any obsolete equipment manufacturer specifications shall be clearly identified as "obsolete" and accompanied by the following cautionary statement on the principal display panel in accordance with the Uniform Packaging and Labeling Regulation, Section 8, Prominence and Placement: Consumer Packages and Section 9. Prominence and Placement: Non-Consumer Packages.

Caution: Some specifications are no longer deemed active by the original equipment manufacturer. Significant harm to the transmission, hydraulic system, seals, final drive or axles is possible when using in applications in which it was not intended.

The above cautionary statement is not required if the fluid claims to meet current original equipment manufacturer's specifications and refers to thereby preceding specifications; and

(f) an accurate statement of the quantity of the contents in terms of liquid measure.

(Amended 2021)

3.17.1.2. Identification on Documentation. - Tractor hydraulic fluid sold in bulk shall be identified on the manufacturer, packer, seller or distributor invoice, bill of lading, shipping paper, or other documentation with the information listed below:

(a) the brand name;

(b) the name and place of business of the manufacturer, packer, seller, or distributor;

(c) the words "Tractor Hydraulic Fluid," which may include words such as "Hydraulic Fluid for Agricultural Applications" or "Universal Tractor Transmission Oil";

(d) the primary performance claim or claims met by the fluid and reference to where any supplemental claims may be viewed (e.g., website reference). Performance claims include but are not limited to those set by original equipment manufacturers;

(e) any obsolete equipment manufacturer standard shall be clearly identified as "obsolete" and accompanied by the following cautionary statement on the principal display panel in accordance with the Uniform Packaging and Labeling Regulation, Section 8. Prominence and Placement: Consumer Packages and Section 9. Prominence and Placement: Non-Consumer Packages.

Caution: Some of the specifications are no longer deemed active by the original equipment manufacturer. Significant harm to the transmission, hydraulic system, seals, final drive or axles is possible when using in applications in which it is not intended.

The above cautionary statement is not required if the fluid claims to meet current original equipment manufacturer's specifications and refers to thereby preceding specifications; and

(f) an accurate statement of the quantity of the contents in terms of liquid measure.

(Amended 2021) 
3.17.1.3. Identification on Service Provider Documentation. - Tractor hydraulic fluid installed from a bulk tank at time of service shall be identified on the customer invoice with the information listed below:

(a) the brand name;

(b) the name and place of business of the service provider;

(c) the words "Tractor Hydraulic Fluid," which may include words such as "Hydraulic Fluid for Agricultural Applications" or "Universal Tractor Transmission Oil";

(d) the primary claim or claims met by the fluid and reference to where any supplemental claims may be viewed (e.g., website reference). Performance claims are those set by original equipment manufacturers;

(e) any obsolete equipment manufacturer specifications shall be clearly identified as "obsolete" and accompanied by the following cautionary statement on the customer invoice in a clear and conspicuous manner.

Caution: Some of the specifications are no longer deemed active by the original equipment manufacturer. Significant harm to the transmission, hydraulic system, seals, final drive or axles is possible when using in applications in which it is not intended.

The above cautionary statement is not required if the fluid claims to meet current original equipment manufacturer's specifications and refers to thereby preceding specifications; and

(f) an accurate statement of the quantity of the contents in terms of liquid measure.

(Amended 2021)

3.17.1.4. Bulk Delivery. - When the tractor hydraulic fluid is sold in bulk, an invoice, bill of lading, shipping paper, or other documentation must accompany each delivery. This document must identify the fluid as defined in Section 3.17.1.1. Container Labeling.

3.17.1.5. Storage Tank Labeling. - Each storage tank of tractor hydraulic fluid shall be labeled with the following:

(a) the brand name; and

(b) the primary performance claim or claims met by the fluid and reference to where any supplemental claims may be viewed (e.g., website reference). Performance claims are those set by original equipment manufacturers;

(Amended 2021)

3.17.1.6. Documentation of Claims Made Upon Product Label. - Any manufacturer, packer, or distributor of any product subject to this article and sold shall provide, upon request of duly authorized representatives of the Director, credible documentation of any claim made upon their product label, including claims made on any website referenced by said label. If the product performance claims published by blender and/or marketer are based on the claim(s) of one or more additive suppliers, documentation of the claims shall be provided upon request to a duly authorized representative of the Director. Supporting data shall, upon request, be supplied directly to the Director's office by the additive supplier(s).

(Added 2019) 


\section{Section 4. Retail Storage Tanks and Dispenser Filters}

\subsection{Water in Gasoline-Alcohol Blends, Biodiesel Blends, Ethanol Flex Fuel, Aviation Gasoline, and Aviation} Turbine Fuel. - No water phase greater than $6 \mathrm{~mm}(1 / 4$ in) as determined by an appropriate detection paste or other acceptable means, is allowed to accumulate in any tank utilized in the storage of gasoline-alcohol blend, biodiesel, biodiesel blends, ethanol flex fuel, aviation gasoline, and aviation turbine fuel.

(Amended 2008, 2012, and 2014)

4.2. Water in Gasoline, Diesel, Gasoline-Ether, and Other Fuels. - Water shall not exceed $25 \mathrm{~mm}(1 \mathrm{in})$ in depth when measured with water indicating paste or other acceptable means in any tank utilized in the storage of diesel, gasoline, gasoline-ether blends, and kerosene sold at retail except as required in Section 4.1. Water in GasolineAlcohol Blends, Biodiesel Blends, Ethanol Flex Fuel, Aviation Gasoline, and Aviation Turbine Fuel.

(Amended 2008, 2012, and 2014)

\subsection{Dispenser Filters.}

\subsubsection{Engine Fuel Dispensers.}

(a) All gasoline, gasoline-alcohol blends, gasoline-ether blends, ethanol flex fuel, and M85 methanol dispensers shall have a 10 micron or smaller nominal pore-sized filter.

(b) All biodiesel, biodiesel blends, diesel, and kerosene dispensers shall have a 30 micron or smaller nominal pore-sized filter.

(Amended 2014)

\subsubsection{Delivery of Aviation Fuel and Gasoline.}

(a) Fuel delivery of aviation turbine fuel into aircraft shall be filtered through a fuel filter/separator conforming to EI 1581, "Specification and Laboratory Qualification Procedures for Aviation Jet Fuel Filter/Water Separators."

(b) Fuel delivery of aviation gasoline into aircraft shall be filtered through a fuel filter/separator conforming to EI 1581, "Specification and Laboratory Qualification Procedures for Aviation Jet Fuel Filter/Water Separators."

(Amended 2018)

(Added 2008) (Amended 2014 and 2018)

\subsection{Product Storage Identification.}

4.4.1. Fill Connection Labeling. - The fill connection for any fuel product storage tank or vessel supplying engine-fuel devices shall be permanently, plainly, and visibly marked as to the product contained.

(Amended 2008)

4.4.2. Declaration of Meaning of Color Code. - When the fill connection device is marked by means of a color code, the color code shall be conspicuously displayed at the place of business and the API color codes as specified and published in "API Recommended Practice 1637, Using the API Color-Symbol System to Identify Equipment, Vehicles, and Transfer Points for Petroleum Fuels and Related Products at Dispensing and Storage Facilities and Distribution Terminals" shall be used.

(Amended 2018)

4.5. Volume of Product Information. - Each retail location shall maintain on file a calibration chart or other means of determining the volume of each regulated product in each storage tank and the total capacity of such storage tank(s). This information shall be supplied immediately to the Director. 


\section{Section 5. Condemned Product}

5.1. Stop-Sale Order at Retail. - A stop-sale order may be issued to retail establishment dealers for fuels failing to meet specifications or when a condition exists that causes product degradation. A release from a stop-sale order will be awarded only after final disposition has been agreed upon by the Director. Confirmation of disposition shall be submitted in writing on form(s) provided by the Director and contain an explanation for the fuel's failure to meet specifications. Upon discovery of fuels failing to meet specifications, meter readings and physical inventory shall be taken and reported in confirmation for disposition. Specific variations or exemptions may be made for fuels designed for special equipment or services and for which it can be demonstrated that the distribution will be restricted to those uses.

5.2. Stop-Sale Order at Terminal or Bulk Plant Facility. - A stop-sale order may be issued when products maintained at terminals or bulk plant facilities fail to meet specifications or when a condition exists that may cause product degradation. The terminal or bulk storage plant shall immediately notify all customers that received those product(s) and make any arrangements necessary to replace or adjust to specifications those product(s). A release from a stop-sale order will be awarded only after final disposition has been agreed upon by the Director. Confirmation of disposition of products shall be made available in writing to the Director. Specific variations or exemptions may be made for fuels used for blending purposes or designed for special equipment or services and for which it can be demonstrated that the distribution will be restricted to those uses.

\section{Section 6. Product Registration}

6.1. Engine Fuels Designed for Special Use. - All engine fuels designed for special use that do not meet ASTM specifications or standards addressed in Section 2. Standard Specifications shall be registered with the Director on forms prescribed by the Director 30 days prior to when the registrant wishes to engage in sales. The registration form shall include all of the following information:

6.1.1. Identity. - Business name and address(es).

6.1.2. Address. - Mailing address, if different than business address.

6.1.3. Business Type. - Type of ownership of the distributor or retail dealer, such as an individual, partnership, association, trust, corporation, or any other legal entity or combination thereof.

6.1.4. Signature. - An authorized signature, title, and date for each registration.

6.1.5. Product Description. - Product brand name and product description.

6.1.6. Product Specification. - A product specification sheet shall be attached.

6.2. Renewal. - Registration is subject to annual renewal.

6.3. Re-registration. - Re-registration is required 30 days prior to any changes in Section 6.1. Engine Fuels Designed for Special Use.

6.4. Authority to Deny Registration. - The Director may decline to register any product that actually or by implication would deceive or tend to deceive a purchaser as to the identity or the quality of the engine fuel.

6.5. Transferability. - The registration is not transferable. 


\section{Section 7. Test Methods and Reproducibility Limits}

7.1. ASTM Standard Test Methods. - ASTM Standard Test Methods referenced for use within the applicable Standard Specification shall be used to determine the specification values for enforcement purposes.

7.1.1. Premium Diesel. - The following test methods shall be used to determine compliance with the premium diesel parameters:

(a) Cetane Number. - The latest version of ASTM D613, "Standard Test Method for Cetane Number of Diesel Fuel Oil";

(b) Low Temperature Operability. - The latest version of ASTM D4539, "Standard Test Method for Filterability of Diesel Fuels by Low-Temperature Flow Test (LTFT)" or ASTM D2500, "Standard Test Method for Cloud Point of Petroleum Products" (according to marketing claim);

(c) Thermal Stability. - The latest version of ASTM D6468, "Standard Test Method for High Temperature Stability of Middle Distillate Fuels" $\left(180 \mathrm{~min}, 150^{\circ} \mathrm{C}\right)$; and

(d) Lubricity. - The latest version of ASTM D6079, "Standard Test Method for Evaluating Lubricity of Diesel Fuels by the High Frequency Reciprocating Rig (HFRR)."

(Amended 2003)

\subsection{Reproducibility Limits.}

7.2.1. AKI Limits. - When determining the antiknock index (AKI) acceptance or rejection of a gasoline sample, the AKI reproducibility limits as outlined in the latest version of ASTM D4814, "Standard Specification for Automotive Spark-Ignition Engine Fuel," Appendix X1 shall be acknowledged for enforcement purposes.

7.2.2. Reproducibility. - The reproducibility limits of the standard test method used for each test performed shall be acknowledged for enforcement purposes, except as indicated in Section 2.2.1. Premium Diesel Fuel and Section 7.2.1. AKI Limits. No allowance shall be made for the precision of the test methods for aviation gasoline or aviation turbine fuels.

(Amended 2008)

7.2.3. SAE Viscosity Grades for Engine Oils. - With the exception of the low-temperature cranking viscosity, all values required to define SAE Viscosity Grades, as defined in the latest version of SAE J300, "Engine Oil Viscosity Classification", are critical specifications as defined by the latest version of ASTM D3244, "Standard Practice for Utilization of Test Data to Determine Conformance with Specifications".

(Added 2008) (Amended 2021)

7.2.4. Dispute Resolution. - In the event of a dispute over a reported test value, the guidelines presented in the latest version of ASTM D3244, "Standard Practice for Utilization of Test Data to Determine Conformance with Specifications," shall be used to determine the acceptance or rejection of the sample.

7.2.5. Additional Enforcement Action. - The Director may initiate enforcement action in the event that, based upon a statistically significant number of samples, the average test result for products sampled from the same source location is greater than the legal maximum or less than the legal minimum limits (specification value), posted values, certified values, or registered values.

(Added 2008) (Amended 2018) 
F. Uniform Fuels and Automotive Lubricants Regulation

THIS PAGE INTENTIONALLY LEFT BLANK 


\title{
V. Examination Procedure for Price Verification
}

\author{
as adopted by \\ The National Conference on Weights and Measures*
}

\section{A. Background}

The NCWM established the Price Verification Working Group in 1993 to respond to public concern about price accuracy in retail stores. More than 500 retailers, consumer representatives, and state and local weights and measures officials participated in the development of the procedure. It was adopted by the NCWM at the $80^{\text {th }}$ Annual Meeting in 1995.

The procedure applies to all retail stores, including food, hardware, general merchandise, drug, automotive supply, convenience, and club or other stores. Model inspection reports are included to promote the collection of uniform data. The model reports and uniform procedures will serve as the foundation for the collection and summarization of price accuracy data on a national basis. This information may be used to provide reliable information on price accuracy with a national perspective. The procedure provides administrators with the tools, guidance, and background information, as well as uniform test procedures and enforcement practices, to enhance the economic well-being of consumers and retail businesses in their jurisdiction. By implementing this program in cooperation with industry, officials will help to restore and maintain consumer confidence in retail pricing practices and technologies, such as scanners, and provide economic benefits for consumers and the business community.

\section{B. Status of Promulgation}

The Examination Procedure for Price Verification was recommended for adoption by the Conference in 1995 . The table beginning on page 6 shows the status of adoption of the procedure.

*The National Conference on Weights and Measures (NCWM) is supported by the National Institute of Standards and Technology (NIST) in partial implementation of its statutory responsibility for "cooperation with the states in securing uniformity in weights and measures laws and methods of inspection." 


\section{THIS PAGE INTENTIONALLY LEFT BLANK}




\section{Examination Procedure for Price Verification}

\section{Table of Contents}

Section $\quad$ Page

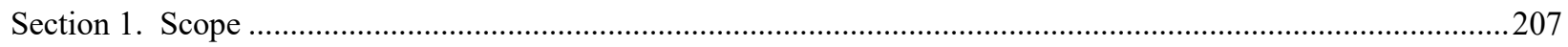

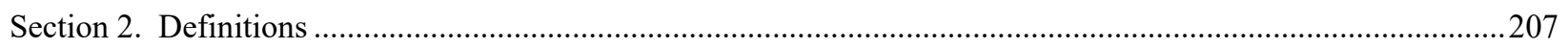

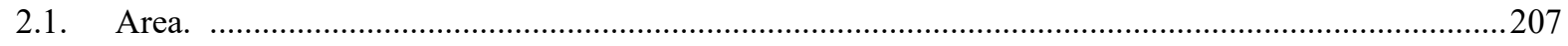

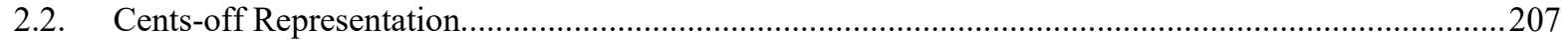

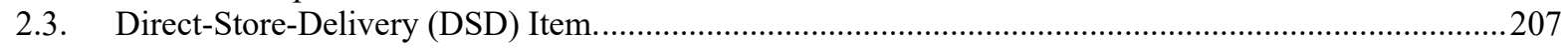

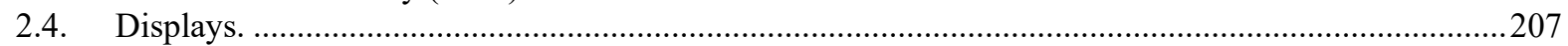

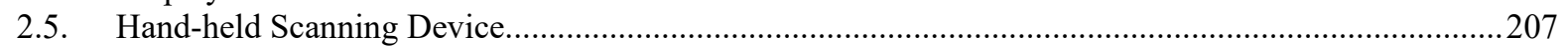

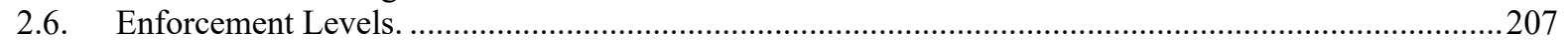

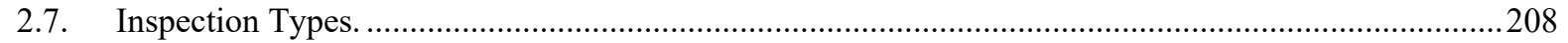

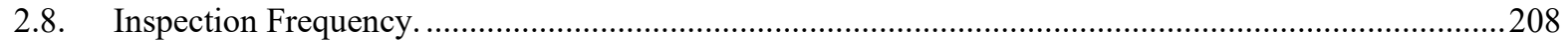

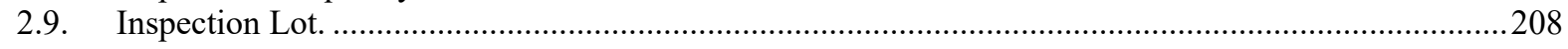

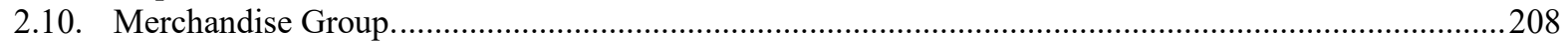

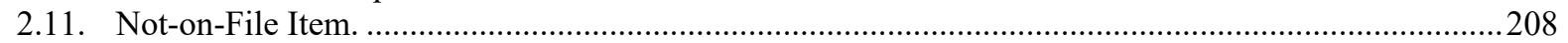

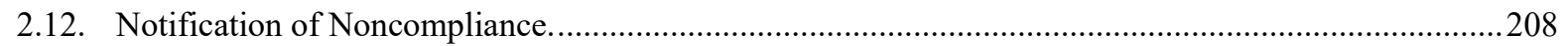

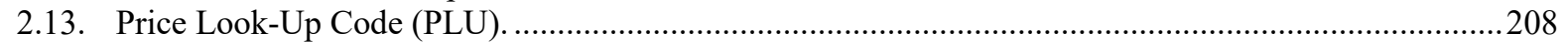

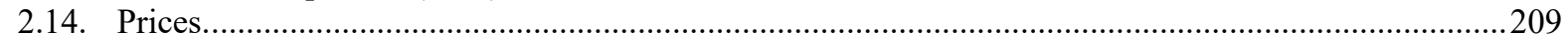

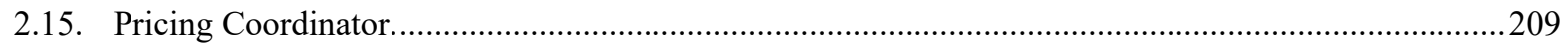

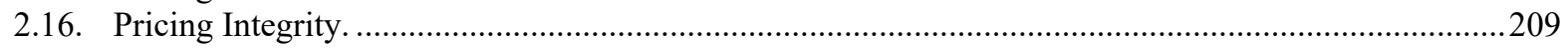

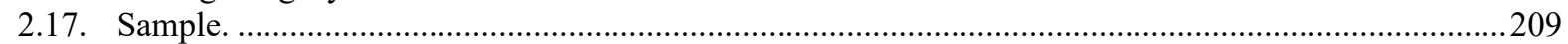

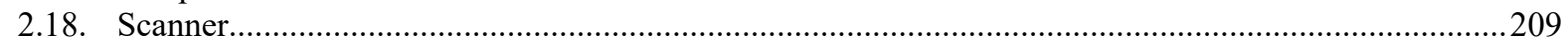

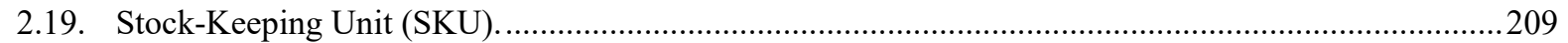

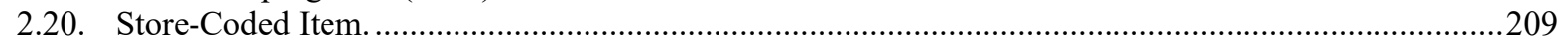

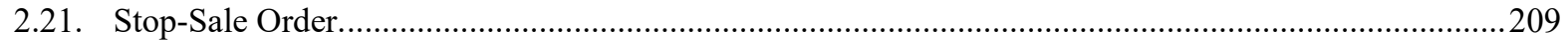

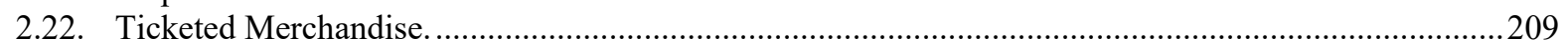

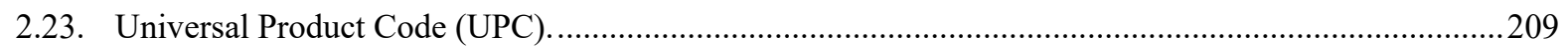

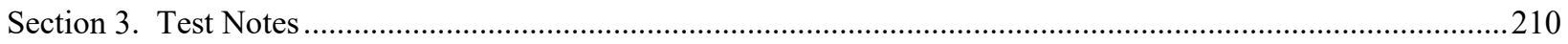

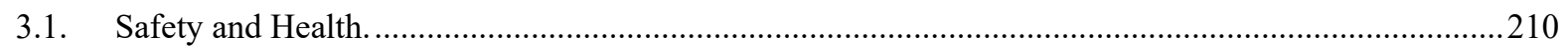

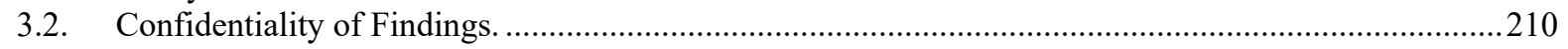

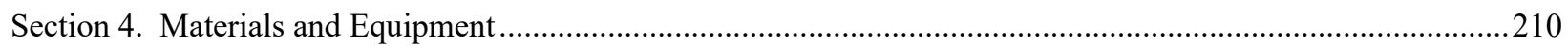

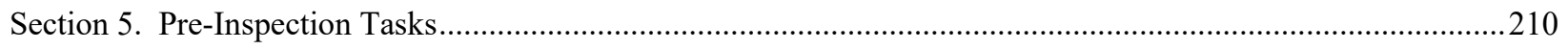

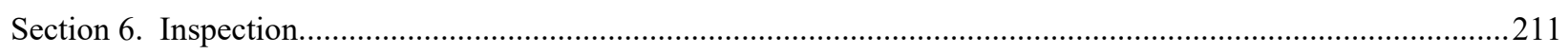

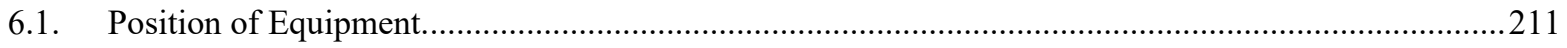

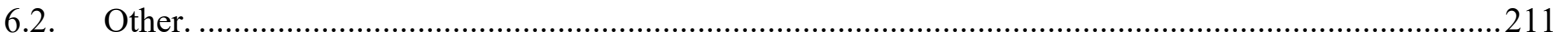

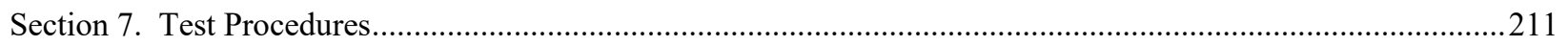

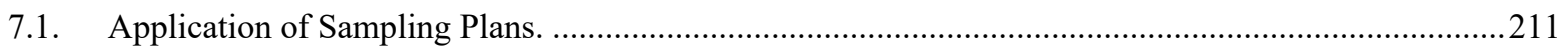

7.2. Table 1. Samples, Sample Collection, and Accuracy Requirements..................................................211

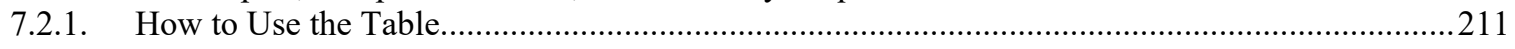

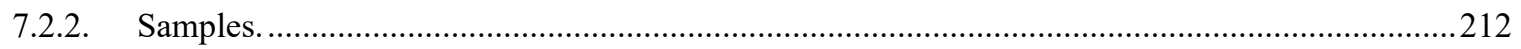


7.3. Sample Collection Procedures (for use with either manual or automated inspection procedures). .......212 7.3.1. Randomized Sample Collection........................................................................................2 214 7.3.1.1. Example 1. Illustrations of the Randomized Sampling Procedure...........................214

7.3.2. Stratified Sample Collection. ..............................................................................................218 7.3.2.1. Example 2. Two-Stage Manual Inspection using the Stratified Sampling Procedure..... 219

7.4. Procedures for Test Purchases, Investigation of Consumer Complaints, and for Verification of Manually

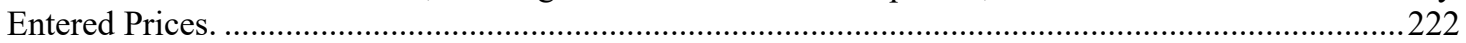

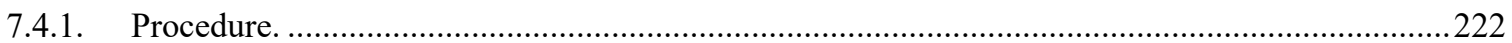

7.4.2. Alternative Procedure - Consumer Complaints..................................................................2223

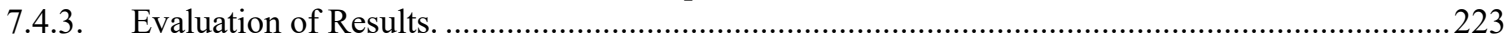

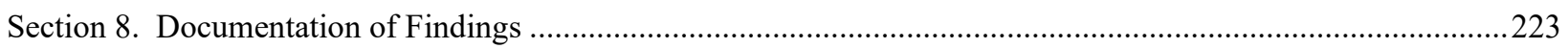

Section 9. Evaluation of Inspection Results .......................................................................................22

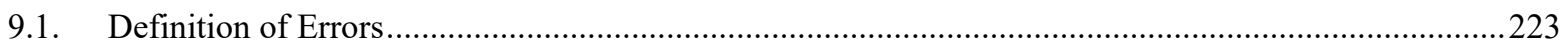

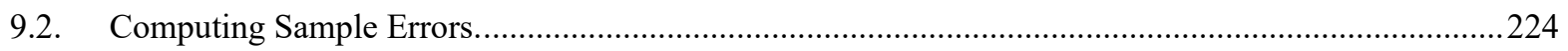

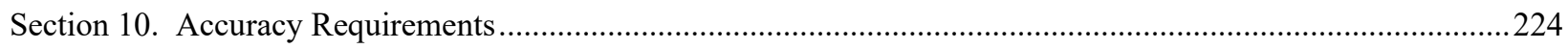

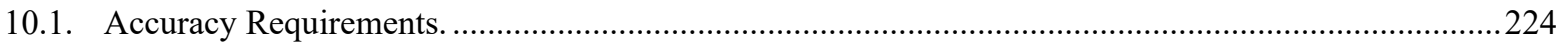

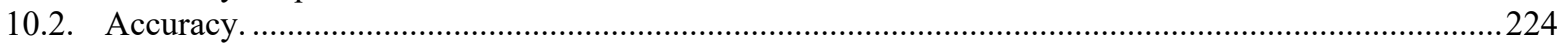

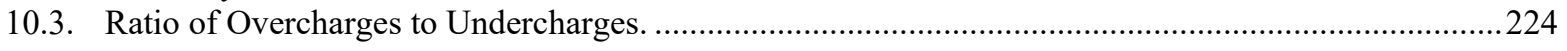

Section 11. Enforcement Procedures .....................................................................................................225

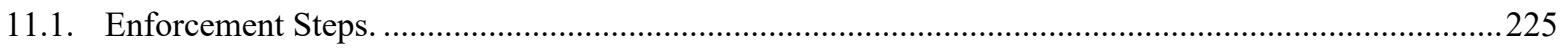

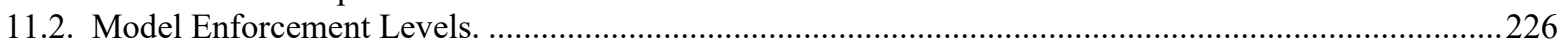

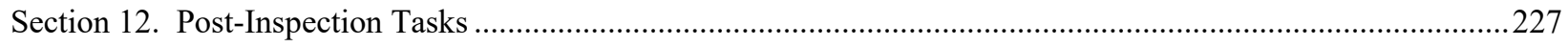

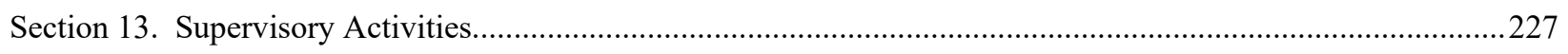

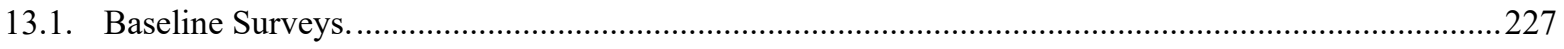

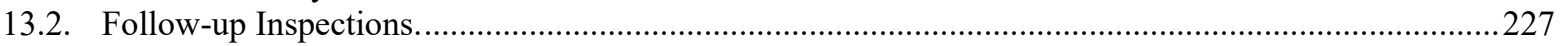

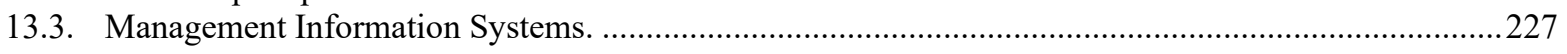

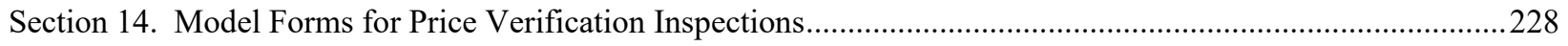




\section{Examination Procedure for Price Verification}

\section{Section 1. Scope}

These procedures may be used to conduct price verification inspections in any type of store, including those that use Universal Product Code (UPC) scanners and price-look-up codes at the check-out counter as a means for pricing. Procedures are included for test purchases and verifying manual entries. The purpose of the procedure is to ensure that consumers are charged the correct price for the items they purchase. The "randomized" and "stratified" sampling procedures are intended for use in routine inspections to determine how well a store is maintaining price accuracy. Nothing in this procedure should be construed or interpreted to redefine any state or local law or limit any jurisdiction from enforcing any law, regulation, or procedures that relates to the accuracy of advertisements of retail prices, or any other legal requirement.

\section{Section 2. Definitions}

2.1. Area. - "Entire store," a "department," "grouping of shelves or displays," or other "section" of a store as defined by the inspector from which samples are selected for verification. "Non-public" areas of a store are not included (e.g., the area in a pharmacy where controlled drugs are kept or product store rooms).

2.2. Cents-off Representation. - Any printed matter consisting of the words "cents off" or words of similar import placed upon any item or on a label affixed or adjacent to an item, stating or representing by implication that it is offered for sale at a lower price than the ordinary and customary retail selling price (e.g., $15 \%$ off, bonus offers, 2 for 1, or 1-cent sales, etc.).

2.3. Direct-Store-Delivery (DSD) Item. - An item delivered to a store, and usually priced, by route salespeople (e.g., milk, beer, soft drinks, bread, and snack foods).

\subsection{Displays.}

(a) Aisle Stacks or End-of-Aisle Displays. - Displays located in freestanding units or attached at the end of or adjacent to a tier of shelves.

(b) Tie-in Displays. - Displays of related products at secondary locations in a store (e.g., barbecue sauce on shelves in an aisle that may also be simultaneously displayed in the meat department of a food store).

(c) Multiple Displays. - Displays of the same product at several locations in a store.

2.5. Hand-held Scanning Device. - A portable device that scans UPC codes and also allows for the comparison of the price displayed on a shelf, item, or otherwise advertised to the price for the item in the point-of-sale database.

NOTE: These devices either retain a "batch" file of entered prices and identities for later comparison to the database or operate "on-line" via FM radio to the database. When used for price verification, they shall only be used with the active point-of-sale database. If you use a hand-held scanner, verify all price discrepancies by scanning the item at a check-out register and request a printed receipt to document the price that consumers would be charged.

\subsection{Enforcement Levels.}

NOTE: These recommendations are not intended to modify the enforcement policy of any jurisdiction unless they are adopted by the jurisdiction.

(a) Lower levels of enforcement actions. - Includes increased inspection frequency, stop-sale or correction orders, warning letters, and other notifications of noncompliance. 
(b) Higher levels of enforcement actions. - Includes issuance of citations, administrative hearings, civil penalties, or prosecution under criminal statutes.

\subsection{Inspection Types.}

(a) Automated Inspection. - Inspections that are conducted using a hand-held scanning device.

(b) Manual Inspection. - Removing items from displays and taking them to a check-out terminal to verify the price (e.g., select the items and either (1) take them to a check-out terminal for scanning or (2) record the product identity, UPC number, and shelf price for each package on an inspection report) and then manually entering the UPC numbers in the register. The manual entries may be made by the official or by a store employee.

\subsection{Inspection Frequency.}

These recommendations do not modify the inspection policy of any jurisdiction unless adopted by the jurisdiction.

Inspection Control. - After a program has been in place for a period of time and a database is established, procedures can be developed to randomly select stores for inspection, or to focus inspections on stores with low levels of compliance.

(a) Normal Inspection Frequency. - An inspection made at the customary time interval used by an enforcement agency. Inspections may be conducted during normal business hours. Stores under this normal frequency should be inspected semi-annually or annually.

(b) Increased Inspection Frequency. - An inspection made more often than with the customary time interval, usually as a follow-up on prior violations. Inspections may be conducted during the normal business hours. Stores under this increased frequency should be inspected on a quarterly, bi-monthly, or more frequent basis.

(c) Term of Increased Inspection Frequency. - A store placed on an increased inspection frequency shall remain at that frequency until there are two consecutive inspections with an accuracy of $98 \%$ or higher.

(d) Special Inspection. - An inspection that is conducted as a follow-up to a prior inspection or to investigate a complaint.

2.9. Inspection Lot. - A group of items available for testing in an "area" or "areas." (See 2.1. "Area.")

2.10. Merchandise Group. - A group of products identified under a common heading for inspection purposes only (e.g., "advertised sale" items, "end-of-aisle" items, "direct delivery" items, "cents-off" items, or all the items in the "men's" department in a department store).

2.11. Not-on-File Item. - Items not found in the point-of-sale database. When found, another item is selected at random (e.g., an item on either side of the one that was not on file) to replace the item in the sample. A "not-on-file" item is not an error unless you determine that the price "charged" for the item is incorrect by conducting a test purchase or by asking the check-out clerk to determine the price by using the store's written or stated policy or procedures. If the price is found to be inconsistent, the error is included in the total.

2.12. Notification of Noncompliance. - Any written notice given to a store describing the violations of the law that were found.

2.13. Price Look-Up Code (PLU). - A pricing system where numbers are assigned to items or commodities, and the price is stored in a database for recall when the numbers are manually entered. PLU codes are used with scales, cash registers, and point-of-sale systems. 
2.14. Prices. - These definitions do not amend or effect the provisions of any law, regulation, or other test procedure.

(a) Misrepresented Price. - The price charged differs from the price at which the item is offered, exposed, or advertised for sale, or that the price is different from the price on the item, shelf label, or sign.

(b) Price Charged. - The price charged for an item and either displayed on the automated device or on the receipt issued by the device, whether the item is scanned or actually purchased, the device is computing or recording while in a training or inspection mode, or by using the hand-held device tied to the point-of-sale database.

(c) Overcharge. - The price charged for an item is more than the lowest advertised, quoted, posted, or marked price.

(d) Undercharge. - The price charged for an item is less than the lowest advertised, quoted, posted, or marked price.

(e) Intentional Undercharge. - Undercharges are not counted as errors if the store provides, at the time of inspection, information that confirms that the price error was intentional (e.g., an undercharge that occurs when a store lowers a price in a database before it changes shelf tags or signs in anticipation of selling the item at a lower price, or when a store increases the price or advertised price of an item, and then increases the price in the database, or when a discounted price is rounded to a lower value).

2.15. Pricing Coordinator. - The individual designated by the store to control and maintain "pricing integrity" in the store, although the title will differ among retailers.

2.16. Pricing Integrity. - Ensuring that the computer price file and/or the price charged to consumers at a cash register is the same price that is marked on the product, in an advertisement, and/or the shelf tag.

2.17. Sample. - The number of items selected for testing from the inspection lot.

2.18. Scanner. - An electronic system that employs a laser bar code reader to retrieve product identity, price, and other information stored in computer memory.

2.19. Stock-Keeping Unit (SKU). - A system of product identity and pricing similar to PLUs.

2.20. Store-Coded Item. - The application of UPC codes to items in the store. Scales in the meat, deli, and other departments generate UPC labels that include identity and price information that can be read by point-of-sale scanners.

2.21. Stop-Sale Order. - An official document placing a package or an amount of any commodity off-sale, that is offered or exposed for sale in violation of the law.

2.22. Ticketed Merchandise. - Items from which the price must be read from a ticket (or price sticker) and manually keyed into a register.

2.23. Universal Product Code (UPC). - A unique symbol that consists of a machine-readable code and humanreadable numbers. UPCs are printed on package labels or are applied with tags or labels. UPC codes may be printed for random weight packages by price computing scales. UPC symbols must meet the standards established by the GS1 US (formerly the Uniform Code Council [UCC]) in order for them to "scan" accurately. The size and clarity of the print and clear area surrounding the symbol are just a few of the factors that affect accuracy. The GS1 US issues codes and answers technical questions. For more information, contact GS1 US Corporate Headquarters at Princeton South Corporate Center, 300 Charles Ewing Boulevard, Ewing, NJ 08648, telephone: (937) 435-3870 or at www.gs1us.org. 


\section{Section 3. Test Notes}

3.1. Safety and Health. - Practice safe work habits to avoid personal injuries or property damage. Be aware of and follow all safety or sanitation rules at the inspection site. Handle perishable, dairy, or frozen products properly to avoid damage (e.g., avoid defrosting frozen foods or allowing dairy products to warm to room temperature that may result in spoilage).

3.2. Confidentiality of Findings. - Inspection findings should be discussed only with an authorized store representative and released only in accordance with applicable public records laws.

\section{Section 4. Materials and Equipment}

The following materials and equipment are recommended for use in conducting the inspections in this procedure:

Inspection report:

- Copy of laws or regulations

- Hand-held counter or Price Verification Tally Sheets

- $1 \mathrm{lb}($ or $1 \mathrm{~kg})$ test standard

- Merchandise cart (if required and available)

Other equipment and materials provided by the store when available:

- Current newspaper advertisement or store sales brochures

- Hand-held scanning device(s) - Stores are not required to have this equipment or to make it available for your use. However, many stores use this equipment to maintain price integrity and may make it available for your use on request.

\section{Section 5. Pre-Inspection Tasks}

Prior to conducting an inspection, it is recommended that you contact the store management, identify yourself, and explain the purpose of your visit. Determine if there are any health, sanitation, or safety rules. If requested, provide information on the law or the inspection procedure.

NOTE: When verifying manual price entries or conducting test purchases, store management is typically not notified of the test until the items have been totaled and the transaction completed.

(a) Notify store representatives that they are invited to participate in the inspection.

(b) If the store makes a hand-held scanning device available for use, request instructions on how to operate it properly. It is acceptable for the "pricing coordinator" to operate the scanning device and participate in the inspection.

(c) If you use the manual inspection procedure, advise the store representative that you will return the merchandise to its display location unless the store representative wants to restock the items, which is acceptable. Determine which check-out location to use. Arrange to have the register set so that the items you verify are not included in sales records.

(d) Conduct inspections in a manner that does not disrupt normal business activities. 


\section{Section 6. Inspection}

Perform the following inspections:

6.1. Position of Equipment. - Determine if customer indications on point-of-sale systems meet NIST Handbook 44, General Code, User Requirement, 3.3. Position of Equipment. A device equipped with a primary indicating element and used in direct sales shall be so positioned that its indications may be accurately read and the weighing and measuring operation may be observed from some "reasonable" customer position.

NIST Handbook 44 defines "point-of-sale system" as an assembly of elements including a weighing element, indicating element, and a recording element (and may be equipped with a scanner) used to complete a direct sale transaction.

NOTE: The importance of consumer access to the cash register display of product information and price cannot be overstated. If consumers cannot verify prices as the items are being scanned, they must wait until the transaction is completed (i.e., they must pay by cash, check, or credit card) before they receive the receipt and can confirm the prices charged for the items.

\subsection{Other.}

(a) If you use a cash register, verify the accuracy and legibility of information provided on register's receipts.

(b) Conduct inspections to enforce local requirements if your jurisdiction has specific laws or regulations relating to price marking, shelf labels, or unit pricing.

\section{Section 7. Test Procedures}

These procedures shall be used to conduct inspections in any type of store, whether the store uses scanners or automated price look-up registers, or where a clerk manually enters the prices.

\subsection{Application of Sampling Plans.}

(a) For normal or increased frequency inspections, follow the procedures referred to in Columns 1, 2, and 3 in Table 1. Samples, Sample Collection, and Accuracy Requirements.

(b) For special inspections, use the test procedures in Section 7.2. Table 1. Samples, Sample Collection, and Accuracy Requirements or 7.4. Procedure for Test Purchases and for Verifying Manually Entered Prices.

\subsection{Table 1. Samples, Sample Collection, and Accuracy Requirements.}

\subsubsection{How to Use the Table:}

(a) Look in Column 1 for the type of store you are inspecting; select the appropriate sample size from Column 2; then refer to Column 3 for the type of sample collection plan to use.

(b) Follow the single-stage or two-stage sampling plans to conduct the inspection and collect the samples using either the "randomized" or "stratified" sample collection procedures described in Section 7.3. Sample Collection Procedures or the procedure in Section 7.4. Procedure for Test Purchases and for Verifying Manually Entered Prices.

(c) Apply the accuracy requirements for the appropriate sample size in Column 4. 
7.2.2. Samples. - Refer to Column 2 in Table 1. Samples, Sample Collection, and Accuracy Requirements to determine how many items to select for the store type and whether to use the single-stage or two-stage sampling plan. You may use either:

(a) Single-Stage Sample. - A single-stage sample is typically used for, but is not limited to, stores where a hand-held scanner device is available for the inspection; or

(b) Two-Stage Sample. - A two-stage sample saves time. If the sample (usually one-half the total sample size) taken in the first-stage meets the accuracy requirements specified in Column 4 in Table 1. Samples, Sample Collection, and Accuracy Requirements, the inspection is complete. However, if the errors in the first-stage sample fall within the limits set in Column 4, the second-stage of the sample is taken.

7.3. Sample Collection Procedures (for use with either manual or automated inspection procedures). - These sample collection procedures may be used to conduct either manual or automated inspections with a single-stage or two-stage sample. That is, you can either use a hand-held scanning device to verify the price of an item (automated), or you can remove the items from display and take them to a check-out location to verify the price of the item (manual) regardless of which sample collection procedure is used. No sample collection procedure is ideal for all retail store arrangements. You can modify the procedure to fit each store, but you should adhere to the sample size and sample collection procedures described in Table 1. Samples, Sample Collection, and Accuracy Requirements. When using any of the procedures, test the store as a whole unit by taking samples from all parts of the store, or divide the store into "areas" and select samples from several "areas" (e.g., at least 10 areas, or one-third or one-half of the "areas"). 


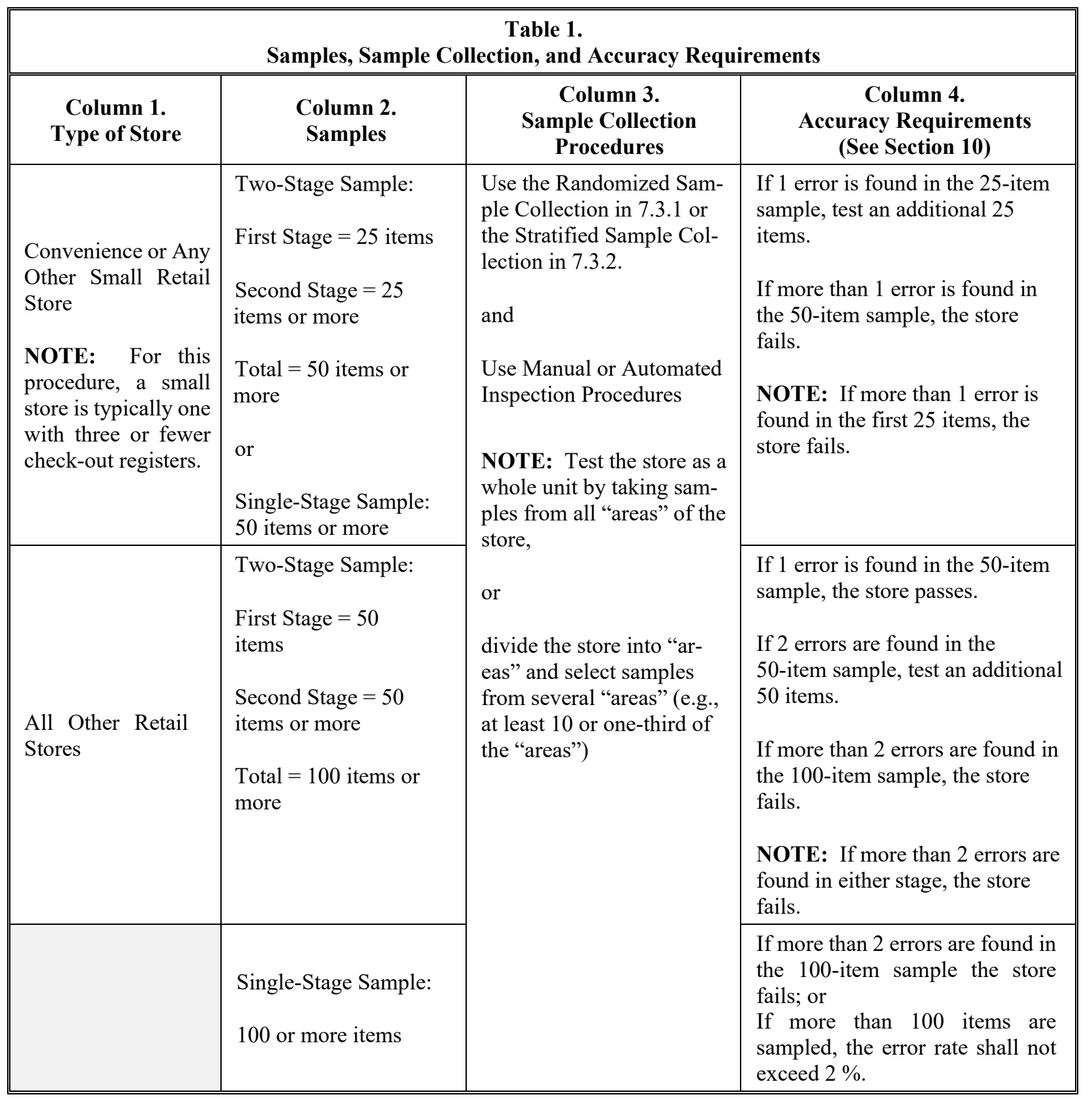

NOTE 1: These sampling procedures allow flexibility in sample collection for use in any type or size of store. You can take several different approaches and select a number of "areas" to sample using the sample sizes in Table 1. For example, to perform a 100-item inspection in a department store with 20 "areas," you can either verify 5 items in an "area," 10 items in each of 10 "areas," or 20 items from each of 5 "areas."

NOTE 2: The sample sizes used for routine inspections in this procedure should not be used to estimate the overall accuracy of prices in a store.

NOTE 3: In some stores, price reductions are not programmed into the point-of-sale system. Instead, discounts are manually entered by a sales clerk; however, the sales clerks should have a means of identifying a sale item. When conducting normal inspections, verify the price of the sale items by allowing the sales clerk to determine the price of the item using the store's customary procedures. This will ensure that the customer receives the correct price regardless of the location where the check-out occurs. 
7.3.1. Randomized Sample Collection. - In "randomized" sample collection, all items in an "area" have an equal chance of being included in the sample. This test procedure has several benefits, including: (1) having more effective coverage and being simpler to conduct because you select items by count following a systematic pattern throughout the store, and (2) ensuring that a wider range of items are verified, which increases scrutiny; therefore, there is greater confidence in the results. With most samples, several items will be verified in each "area" of the store. Since store sizes differ, this number will vary, but samples should be taken from a wide variety of items (and merchandise groups) from locations throughout the store or "area."

The steps of the randomized sampling collection procedure are as follows:

(a) Count the number of "areas" in the store which have products to be verified:

(1) Stand-alone counters and displays or whole departments (e.g., bakery or seafood, or "men's clothing" or "sporting goods" department, etc.) are considered and counted as individual "areas" to be sampled.

(2) End of aisle displays may be considered as a single, distinct "area" and either verified separately or included as part of one side of an aisle.

(b) The sample size (e.g., 100 items) is divided by the number of "areas" to determine the number of items to be sampled from each "area." Depending on the number of areas in the store, you may calculate a fractional number of items per area. In this case, round off the sample size and select one or two additional items from an "area" to complete the full sample size of 100 items.

\subsubsection{Example 1. Illustrations of the Randomized Sampling Procedure.}

(a) Figure 1 illustrates how the randomized sampling procedures are used in a food store. This example is based on a 100-item sample. To simplify the selection process, simply divide the store into 4 major "areas" and select samples as follows:

\section{Examples:}

- Select 5 items from all of the shelves and displays in the produce section which are grouped as a single "area,"

- Select 85 items by choosing 5 items from either side of several of the 13 aisles (e.g., there are 26 rows of shelves from which samples may be selected. To select 85 items, select 5 items from 17 of the 26 rows of shelves).

- Select 5 items from the counters along the back of the store, and

- Select 5 items from the deli-bakery and the cash register areas which are grouped as a single "area."

(b) Figures 2 and 3 illustrate how the randomized sampling procedures may be used in any store. The examples are based on a 100-item sample for stores that have a total of 30 "areas" to sample. The procedure allows the flexibility needed to adjust the sample to fit the store layout. To simplify the selection process, the stand-alone displays may be grouped together as an "area" to be sampled.

The following breakdown of "areas" is illustrated in Figure 2; the same approach is used in Figure 3. Figure 4 illustrates an example of sampling 100 items by selecting 20 items from 5 different areas in a department store. 
1 - All shelves and displays in the produce section are grouped as a single "area."

28 - The 13 aisles (26 rows of shelves), the counters along the back of the store, and the cash register areas are counted as "areas."

1 - The "end-of-aisle" displays at the front and back of the store are grouped as a single "area."

\section{0 - Total "areas"}

(1) To select samples from the entire store, divide 100 by 30 to calculate how many "samples" to take from each "area." In this example, $100 \div 30=3.3$ items per area. Rounding down to 3 items, take a total of 90 samples from the different "areas," then select an additional one (1) item from each of 10 "areas" to obtain a sample of 100 items.

(2) If you round up to 4 items per area, you take a total of 120 samples, or

(3) You may select 10 items from 10 "areas."

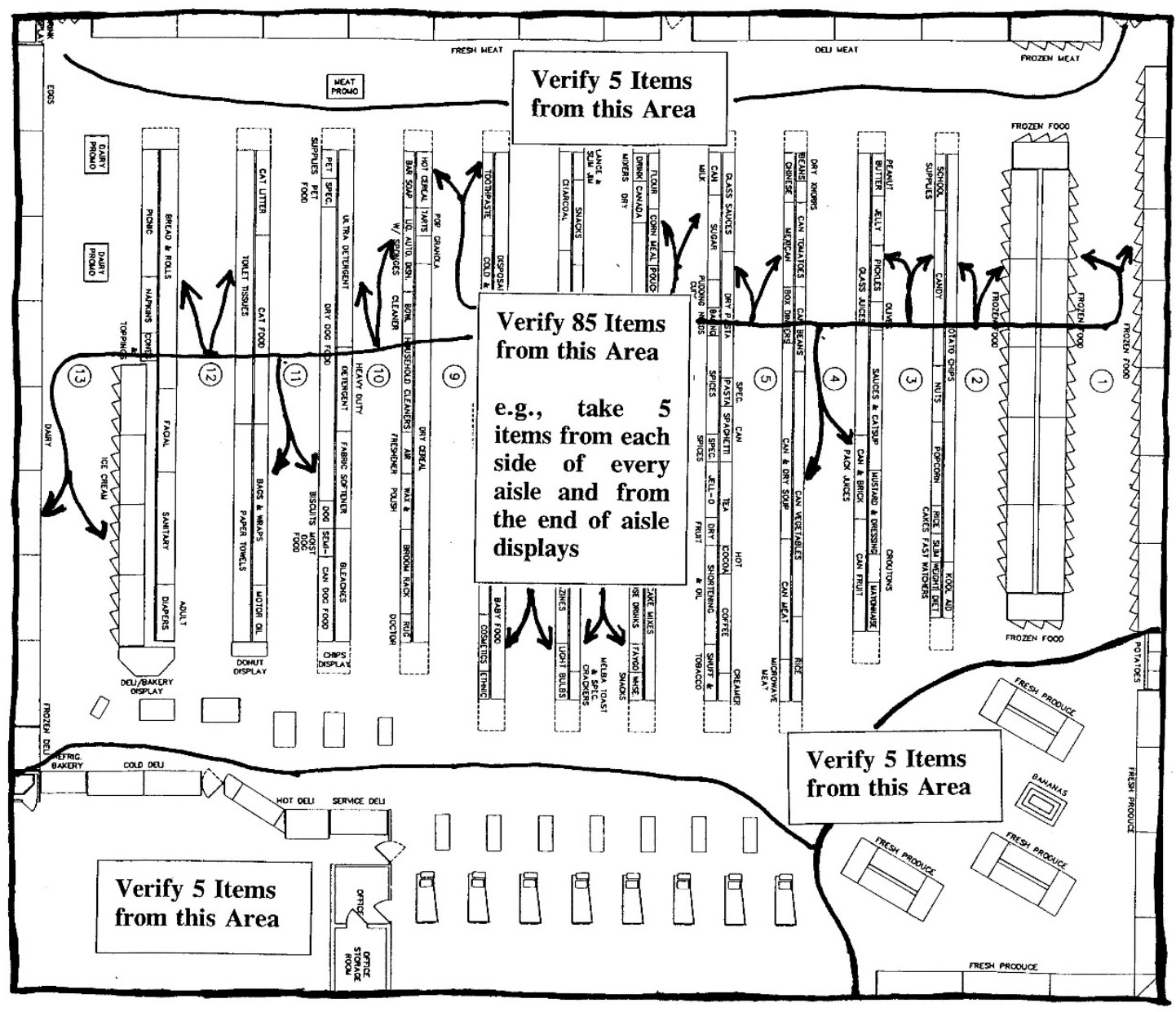

Figure 1. Illustration of the Randomized Sampling Procedure 


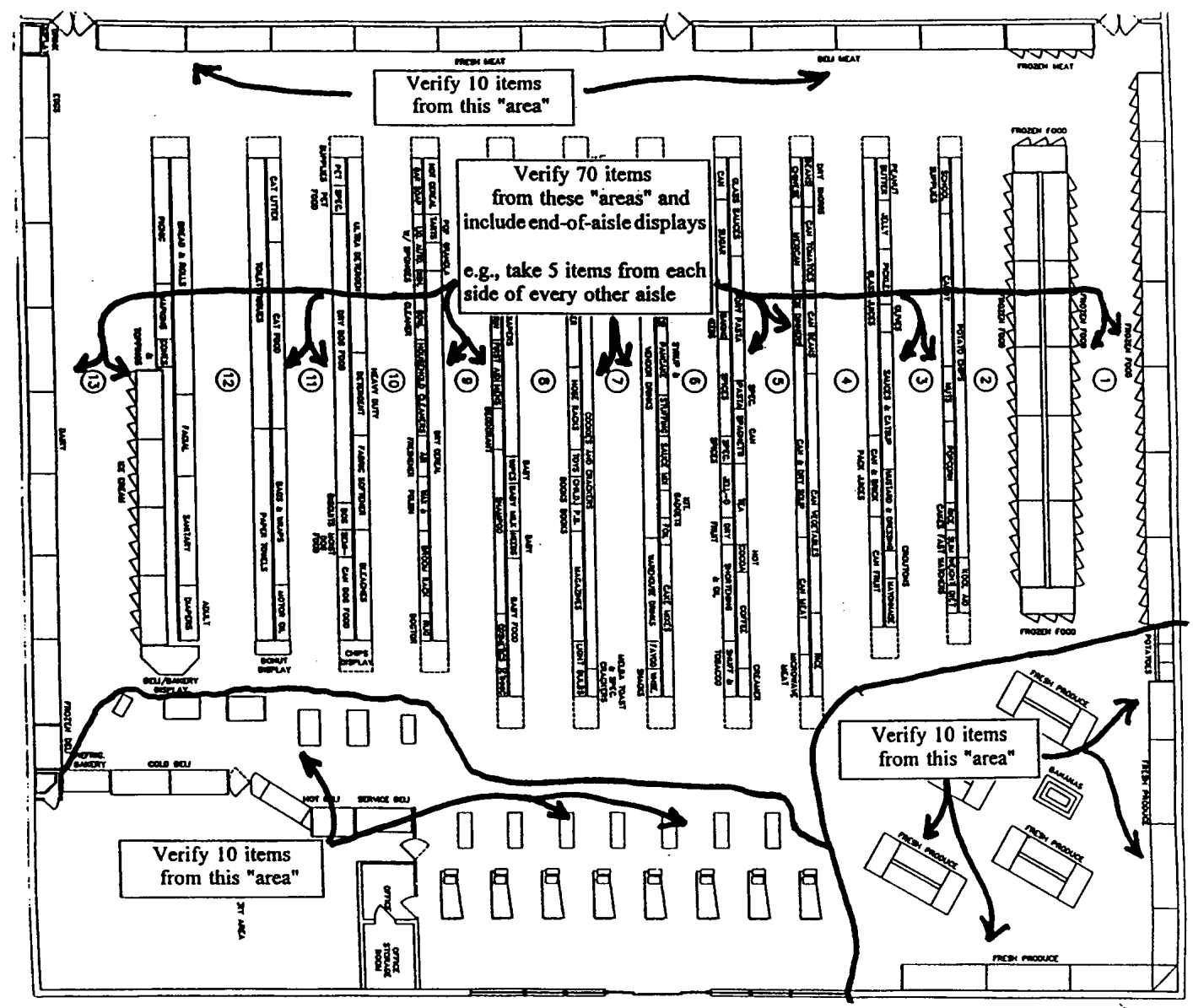

Figure 2. Illustration of the Randomized Sampling Procedure

(c) Start in any "area" in the store at any shelf, rack, or display (top, bottom, front, back; anywhere on a circular rack or display). Begin with the first, second, or third item and count either 5, 10, or 15 items along the shelf (varying the number of items counted depending on how many items are available on the shelf) or along the aisle. Select the $5^{\text {th }}, 10^{\text {th }}$, or $15^{\text {th }}$ item as appropriate (See Figures 5, 6, and 7). Only select one item from each brand or product (if they are the same price) from a display that has two or more items of the same product size and price displayed side by side. You can change the number of items you count off as often as necessary during the inspection.

(d) Either verify the price with a hand-held scanning device or take the item (along with the other items you select) to the check-out location to verify the price, keeping count of the items using a hand counter or tally sheet. If the price of an item is incorrect, record the item's name, description, and price along with other information (e.g., whether the product is on sale, aisle location so you can easily find the items again to verify the error, etc.).

(e) From the first item sampled, move down (or up) one shelf to the item most directly below (or above) and count 5,10 , or 15 items in the same direction and sample the $5^{\text {th }}, 10^{\text {th }}$, or $15^{\text {th }}$ items, as appropriate. After the number of items to be verified in each "area" have been selected, go to the next "area" and start on the next shelf (either down or up) from where the previous sample was selected, count 5, 10, or 15 items and select the appropriate item using the count system until the required number of samples is selected. If you have sampled an item on the bottom (or top) shelf and have more items to test in the "area," simply go up (or down) one shelf. This will create a "zigzag" trail up and down the display. 
NOTE: Randomness can be increased by starting on different shelves or at the midpoint or rear of an aisle during an inspection, or by starting at different locations in a store on subsequent inspections. Always start at a different location on subsequent inspections of a store. To maintain "randomness," do not search for obvious pricing errors. If you see pricing errors, have them corrected. The sample should not include more than one of the same item from the same display. If an item is out of stock, select the next item.

(f) This procedure is repeated for all "areas" until you complete the sample. (See following Notes)

NOTE 1: Include at least 5 to 10 Price Look Up (PLU) and store-coded items in the samples. In food stores, these items do not usually have to be removed from the produce, bulk foods section, or deli display for use in this procedure. You can use a hand-held scanner or record the identity and item price designated at the product sales display of the items from the different department (produce, bakery, deli), if available, for price comparison through either the PLU programmed in the department's scale or at the point-of-sale system. Have the PLU entered in the scale (See NOTE 2) or point-of-sale system (or have "store-coded" items scanned) and record the price, comparing it with the displayed sale price. Record any errors (See NOTE 3). When checking "store-coded" items from the meat or other departments, remember a "UPC symbol" on a random weight label is read by a scanner to obtain the total price and identity. The price is not stored in the point-of-sale database, but in the memory of the prepackaging scale.

NOTE 2: Some scales or point-of-sale systems do not display or record the unit price associated with the PLU unless a weight is on the scale. For this type of device, a one-pound standard (or $1 \mathrm{~kg}$ ) is placed on the scale load-receiving element. Some systems automatically deduct tare, so check to make sure that this does not affect the price indication.

NOTE 3: When you manually enter PLU codes and find errors, reenter the PLU number to ensure that the error was not caused by a keying mistake and that the item was identified accurately. 


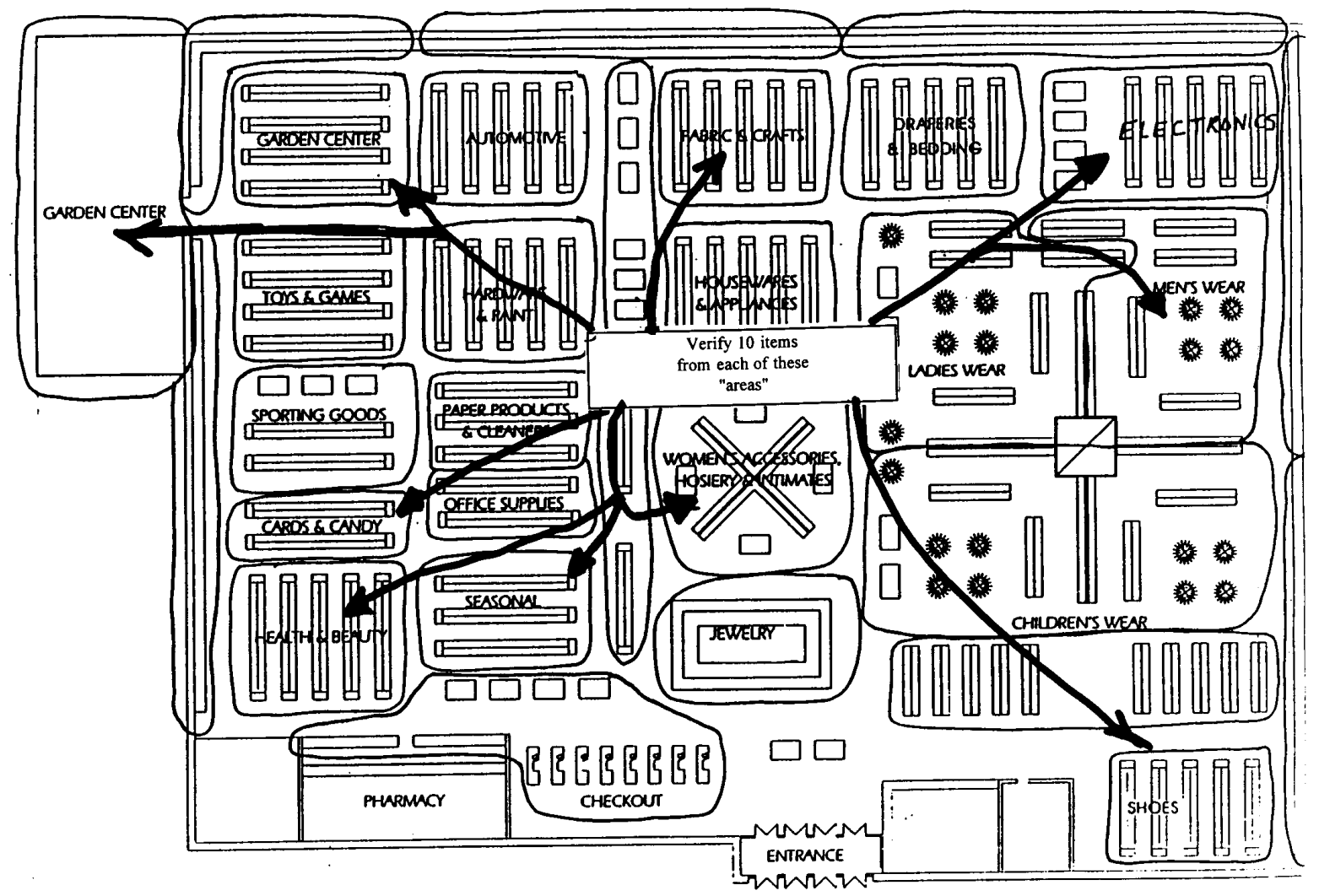

Figure 3. Illustration of the Randomized Sampling Procedure

7.3.2. Stratified Sample Collection. - Stratified sample collection (i.e., selecting samples from specific merchandise groups) of items on sale, specials, seasonal items, or items on end-of-aisle displays) is typically used (e.g., if a store has failed an inspection based on the randomized sample collection procedures) to focus on specific merchandise groups that appear to have more errors than others (e.g., you find that many of the errors found in the randomized sample were in "advertised specials" or with "discontinued items"). You can also combine sample collection procedures by using a "randomized/stratified" approach. The "stratified" approach may be used the first time you inspect a store, in stores that have just implemented scanning, in stores that have high error rates on particular groups of items in past inspections, or in responding to consumer complaints involving a particular group of items.

For stratified sample collection, items are randomly selected from different "merchandise groups" in a store. They are tested in the first stage of the two-stage manual sampling plan to determine if (1) any group has more errors than any other and (2) the sample taken in the first stage meets accuracy requirements. This method should be modified depending on the marketing practices of the store in which it is used (e.g., if you are in a department store, there may be fewer groups to sample from, or the list provided below may not include the types of groups typically encountered in a hardware superstore). The next example shows how to conduct a stratified sample and how it is used, but it should not be the sole basis for sample collection because a specific list of items does not look at the store as a whole. Focusing on specific merchandise groups takes time, but this may be necessary when investigating a complaint or following up on a prior noncompliance. Select only one item from each brand or product from a display that has two or more items of the same product, size, and price displayed side by side if they are the same price. 


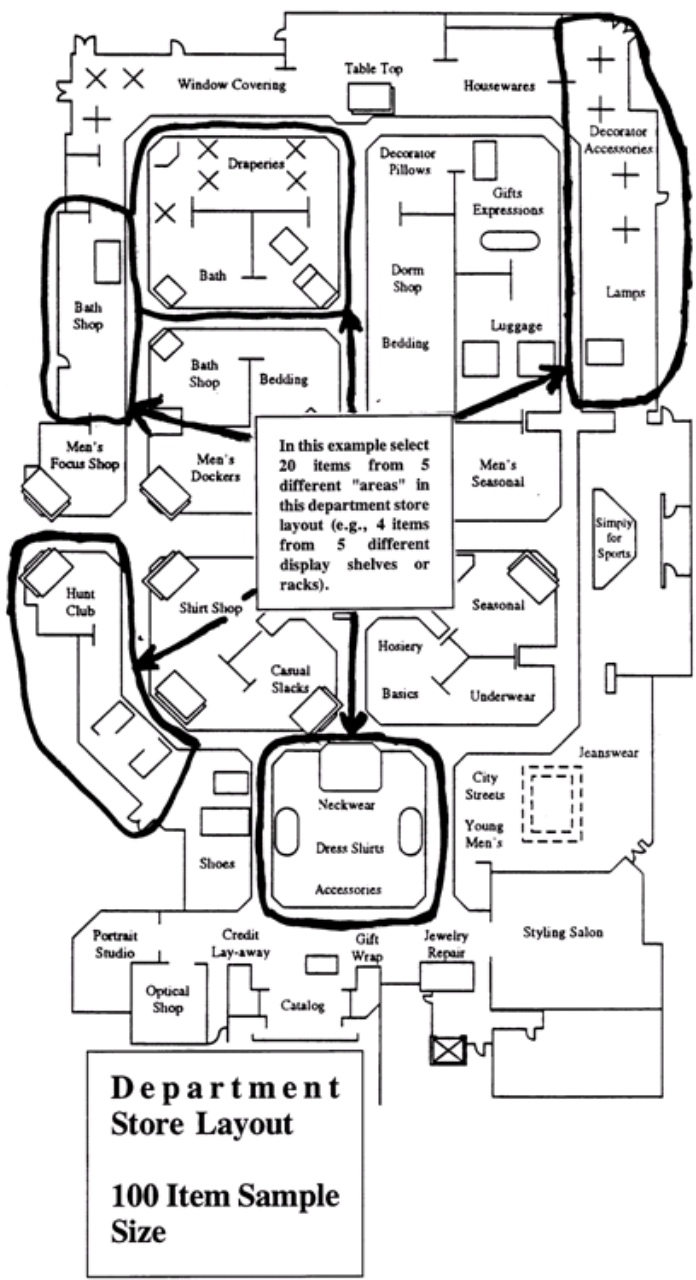

Figure 4. Stratified Sample Collection

\section{RANDOMIZED SAMPLE COLLECTION}

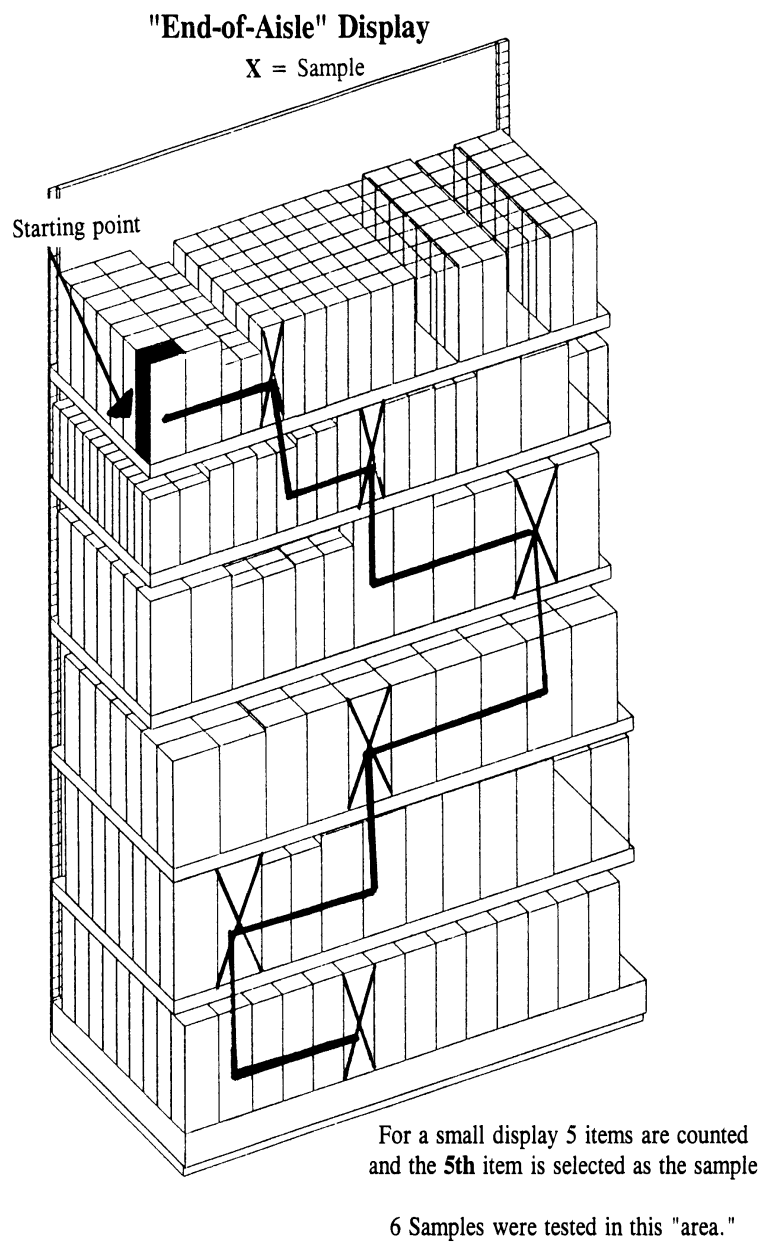

Figure 5. Randomized Sample Collection

Sample Size. - In this example, a large food store is inspected using a two-stage sampling plan ( 50 items/100 total items). The inspection begins with an initial sample of 50 items (see Column 1. Type of Store for All Other Retail Stores and Column 2. Sample Sizes in Table 1).

Stratified Sample Collection. - Select 50 items from the merchandise groups listed below (provided as examples only; stores may have other groups that should be included). This procedure allows you to focus on specific merchandise groups to determine if errors are indeed occurring in groups where they are thought to occur most frequently (e.g., sale and direct delivery items).

\subsubsection{Example 2. Two-Stage Manual Inspection using the Stratified Sampling Procedure.}

If there is an insufficient number of items in any merchandise group, or if the group of items is not available, increase the number of "randomized" items selected from the overall inspection lot to obtain a total of 50 items. As marketing practices evolve, these groups may change as well. You may substitute "other" or new merchandise groups for any of those listed below (e.g., you may have identified errors in the "health and beauty aids" section or on "manager specials" during a previous inspection, so samples from these groups may be substituted for any of the groups listed below). Model "Price Verification Tally Sheets" in Section 14. Model Forms for Price Verification Inspections are provided for your use with the test procedures to keep track of the number of items selected. 
First-Stage: 50 items. - Use the "randomized" sample collection procedures described in 7.3.1. Randomized Sample Collection to select the following items. These sample collection procedures simplify the inspection process and ensure that samples are collected as randomly as possible.

\section{Examples:}

- Twenty-five "Regular Priced" items. Select one or two items at random from different shelves in each "area" or limit your sampling to shelves in one-half the "areas" in the store, and

- Twenty-five Items. Select a total of 25 items. Include several items from any of the following merchandise groups:

- "Direct-Store-Delivery (DSD)" items. If the store allows vendors to price DSD items, include those items in the sample.

- "End-of-Aisle" or "Tie-In-Display" items. This group can include both regular and sale-priced items.

- "Advertised Sale" items. Use the store's sales brochure or newspaper advertisements to identify sale items.

- "Special" items. This includes any item with a reduced price (e.g., items on "special" including "cents-off" or "percentage-off" items, 2-for-the-price-of-1 specials, manager and in-store specials, or discontinued items). Items typically discounted on a percentage basis include a manufacturer's product line, greeting cards, magazines, or books.

- "PLU" items. This includes both regular and sale priced items offered in the produce, bakery, or bulk food departments and over scales at the direct sale counters. For direct service departments (e.g., produce, deli, specialty meats, etc.), select products at random (include some sale or special prices) and enter the code in the scale ${ }^{\text {[see Section 7.3.2.1. NOTE 1] }}$ to verify that the coded price matches the advertised price. [see Section 7.3.2.1. NOTE 2]

- "Store-coded" items. This includes items offered in the produce, bakery, or meat departments that have labels with the UPC symbol generated by scales and printers in the store. For store-coded items, scan the item and determine if the total price and identity on the label are accurately read by the point-of-sale system. When checking "store-coded" items from the meat or other departments, remember that a "UPC symbol" on a random weight label is read by a scanner to obtain the total price and identity. The price is not stored in the point-of-sale database.

- "Other" items. This category is included to provide flexibility in selecting a sample so that "seasonal" items, or products unique to the store or local market, can be included. Both regular and sale-priced items can be included in this category.

NOTE 1: Some scales or point-of-sale systems do not display or record the unit price associated with the PLU unless weight is on the scale. For these devices, a $1 \mathrm{lb}$ (or $1 \mathrm{~kg}$ ) standard is placed on the scale loadreceiving element. Some systems automatically deduct tare, so make sure this does not affect the price indication.

NOTE 2: When a not-on-file item is found, another item is selected at random to replace it in the sample. A "not-on-file" item is not an error unless you determine (e.g., by conducting a test purchase or by asking the check-out clerk to determine the price of the item using the store's customary procedures) that the price "charged" for the item is incorrect. If the price determined is not correct, the error is included in the total. 


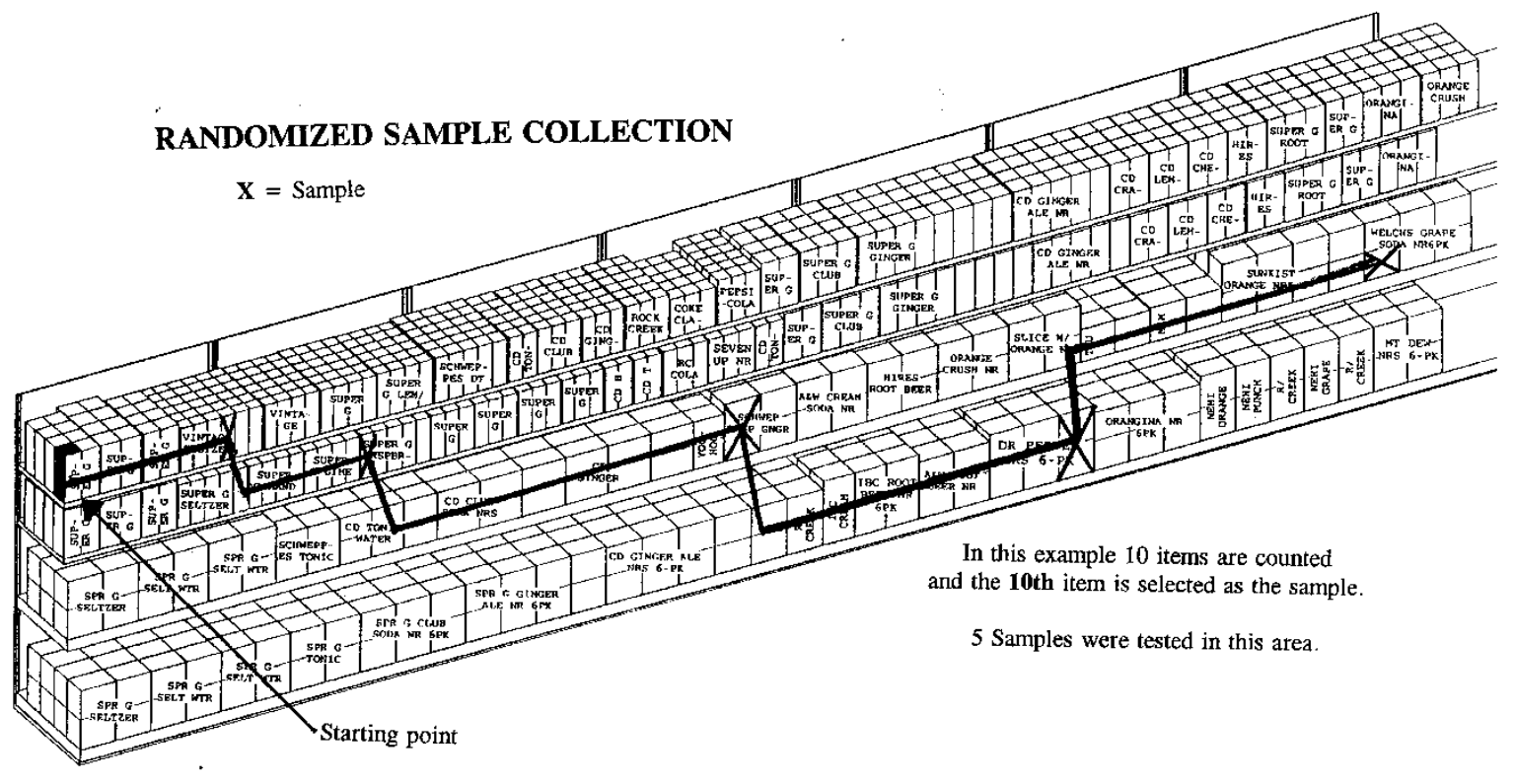

Figure 6. Randomized Sample Collection

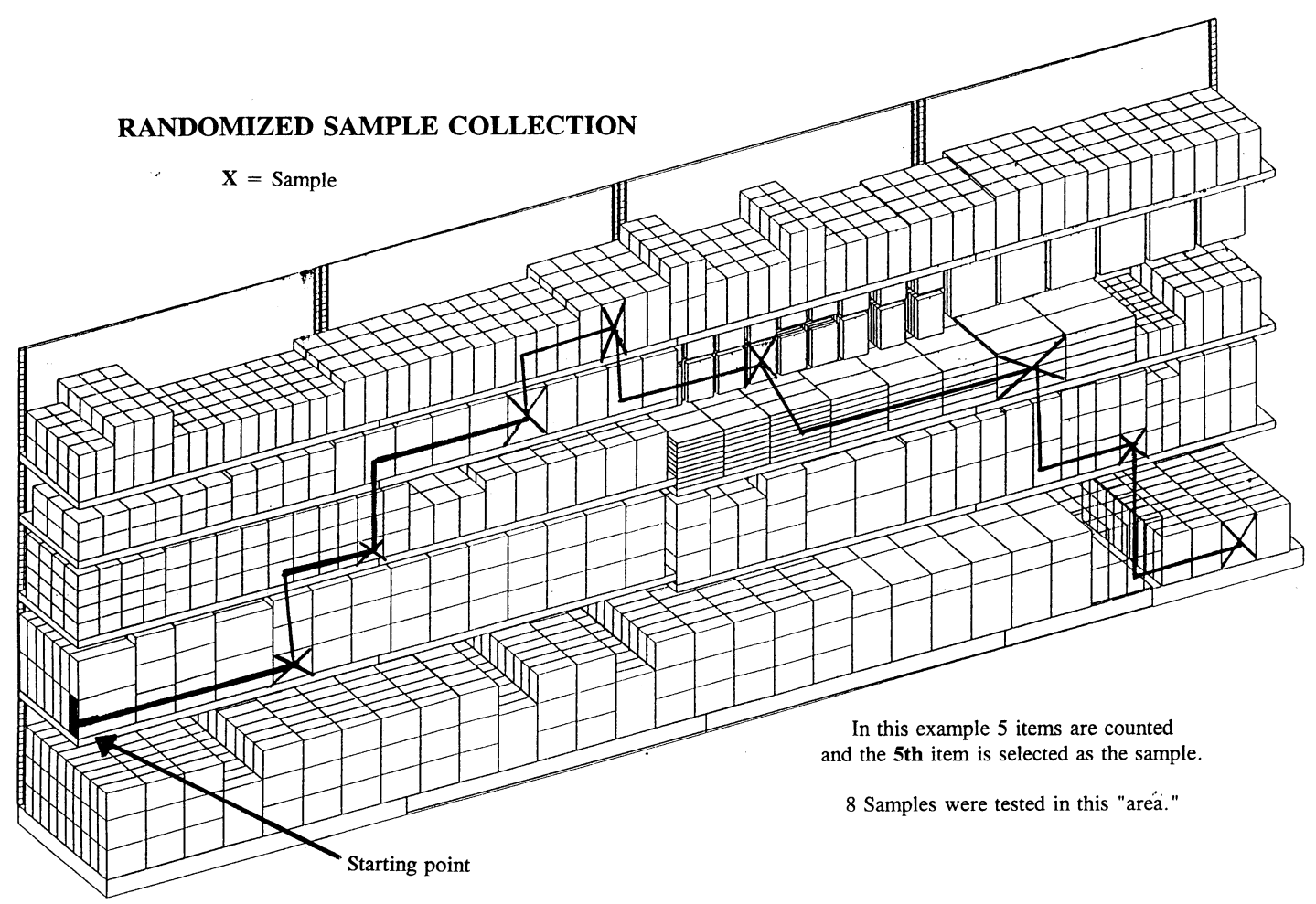

Figure 7. Randomized Sample Collection

Identify the item on an inspection report (e.g., record a brief description, item number, shelf, or advertised price and aisle location. The aisle location makes it easy to find the product if errors are found and to reshelve the items). As items are selected, use the "Price Verification Tally Sheet," or other means, to keep track of the number of items collected. (see Section 14. Model Forms for Price Verification Inspections. The "Model Price Verification Reports" in this proposal were developed with the assumption that it is only necessary to record information of items found with price errors, not all items verified. This reduces paperwork and saves time.) Either use a hand-held scanning device or take the items to a cash register, verify 
the prices by scanning the items or entering a PLU code into the register and printing a receipt. The prices "charged" at the register are then compared to the advertised price of each item. For large or perishable items, record the identity, UPC Code, location, and price and manually enter the UPC number into the register to verify the price. However, this method is subject to recording and key entry errors.

\title{
Evaluation of Results on First-Stage.
}

See Section 9. Evaluation and Inspection Results for guidance on which errors are considered violations: One error in a 50-item sample is permitted. If not more than one error is found and verified, the store passes; if 3 items are found in error in the first 50 items, the store fails and the inspection is complete.

If two errors are found, collect 50 more items using the randomized sampling procedures and verify a total of 100 items. If errors were found in any specific merchandise group (or groups) of items (e.g., direct-storedelivery items, PLU codes, or specials), the additional 50 items should include items from those merchandise groups.

\begin{abstract}
Accuracy.
Refer to Column 4 in Table 1. Samples, Sample Collection, and Accuracy Requirements. The required accuracy is $98 \%$ on the 100 -item sample (that is, at most two errors are permitted on a 100-item sample). If more than two errors are found and verified, the store does not meet the accuracy requirement.
\end{abstract}

NOTE: The "randomized" and "stratified" sample collection procedures in this section are intended for use in routine inspections to determine how a store is maintaining price accuracy on all of the items it offers for sale. If you use these sampling procedures in routine inspections and uncover a significant number of errors in a particular merchandise group (e.g., a significant number of the pricing errors are found with "advertised sale item" items), a randomized sample can be collected entirely within this specific merchandise group. For example, if the error rate for "advertised specials" is higher than the rate for regular priced items, a more focused inquiry to determine if there is a significant error rate in this merchandise group may be justified. If several "advertised specials" have been the subject of consumer complaints, or if they are repeatedly found to be in error during routine inspections, then a randomized sample can be limited to the "advertised specials" merchandise group. In this case, a randomized sample (e.g., a 50/100 item two-stage approach) is taken from all of the "advertised sale items" offered for sale in the store or in a specific "area." The results of this sample are applicable only to the "advertised specials" group and not to all items in the store.

\subsection{Procedures for Test Purchases, Investigation of Consumer Complaints, and for Verification of Manually Entered Prices.}

7.4.1. Procedure. - This procedure may be used to (1) investigate consumer complaints, (2) determine if a store has corrected a pricing error after being notified that an error occurred, or (3) determine if manually keyedin prices or PLU codes are accurate.

NOTE: When verifying manual price entries, store management is typically not notified of the test until the items have been totaled and the transaction completed.

(a) Do not alert the clerk to the fact that the test purchase procedure is being conducted. Do not ask questions concerning any errors that you observe or offer any information if asked the price of an item, in cases where the item price is illegible, or where the item is not on file.

(b) Use the "randomized" sampling procedures to select a sample of 10 to 50 items that includes regular and sale priced items, PLU items, and advertised specials from various "areas." It is acceptable to purchase only one or just a few items if you are investigating a complaint on a specific item. Record the name and identity of the product, as well as the labeled or advertised price, for each item. 
(c) Proceed through a check-out as if you were a customer and pay for the purchase. Obtain the original sales receipt, and compare the price charged with the labeled or advertised price for each item. Record the time of day, lane number, and the identity of the checker. Before leaving the store, determine if any errors have occurred. Identify yourself and inform the store management that a test purchase was conducted, and report the results. (In many instances, the store will credit back all of the items and refund the test purchase money.) Record the information on the test report form and determine the cause of the error (e.g., operator error, mislabeling, or incorrect price sign).

7.4.2. Alternative Procedure - Consumer Complaints. - Complaints can be investigated by using any of the test procedures described above or by verifying only the price of the item or items subject to the complaint. If the complaint is valid, you can limit your inspection to the items described in the complaint or you may conduct a complete inspection.

7.4.3. Evaluation of Results. - The errors for items verified using these procedures should be evaluated according to Section 9. Evaluation of Inspection Results and Section 10. Accuracy Requirements.

\section{Section 8. Documentation of Findings}

Several examples of Model Price Verification Reports are contained in pages 229 to 234. These forms were developed so that you only have to record the items found with price errors.

(a) Record errors and provide information on the cause, if determined. Indicate if the errors are considered to be violations, if stop-sale orders were issued, or if the violation was corrected.

(b) Notices of violations or other significant comments (e.g., warnings or violations ordered corrected) should always be included on the test form.

(c) Cash register receipts on verified items should be retained and attached to the inspection report as evidence.

(d) Printed advertisements and sales flyers should be retained and attached to the inspection report when errors are found in these categories.

\section{Section 9. Evaluation of Inspection Results}

9.1. Definition of Errors. - An error found to result from any of the following causes should not be considered a violation for enforcement purposes:

(a) An intentional undercharge if documentation or confirmation of the date and time of the price change is provided at the time of the inspection.

(b) An error caused by a mistake made in any kind of advertisement (e.g., newspaper, printed brochure, or radio or television advertisement) if the store has placed a notice adjacent to the item indicating that a mistake occurred in the advertisement.

(c) An error obviously caused by a price label that is missing or that has fallen off the shelf, or the item or the price label or sign has obviously been relocated by an unauthorized person.

(d) A "not-on-file" item is not an error unless you determine that the price "charged" for the item is incorrect (e.g., by conducting a test purchase or by asking the check-out clerk to determine the price of the item using the store's documented or customary procedures. If the price determined is incorrect, it is considered an error.)

NOTE: It is recommended that you work with the store representative to identify the cause of any error and note the problem/cause on the report. This may not change your findings, but will help to identify problems related to staff 
errors, failure to follow through on established store pricing procedures, data entry errors, or failure of management to provide correct written data, etc. The supporting information will help with enforcement decisions as well as inhouse monitoring of product pricing.

9.2. Computing Sample Errors. - The following formulas are used to determine sample error and the overcharge to undercharge ratio:

(a) Adjust the total sample by subtracting any items or errors specified in Section 9.1. Definition of Errors.

(b) To compute the sample error, divide the number of errors by the total sample size to obtain the error in percent.

For example: a sample of 100 items is verified; 3 overcharges and 1 undercharge are found for a total of 4 errors:

$4 \div 100=4 \%$ sample error

(c) To compute the ratio of overcharges to undercharges (used on large samples and in follow-up activities), total the overcharges/undercharges and compare the numbers:

3 overcharges $/ 1$ undercharge $=$ a 3 to 1 ratio.

\section{Section 10. Accuracy Requirements}

10.1. Accuracy Requirements. - Accuracy information, based on a percentage of errors found in a sample and the ratio of overcharges to undercharges, constitutes useful criteria for evaluating the "pricing integrity" of the store. Both overcharges and undercharges should be considered as errors in taking lower level enforcement actions since (1) either type of error misrepresents the price of the item; and (2) the occurrence of any error in a randomized sample may indicate poor pricing practices that would result in errors where additional items were sampled. For higher levels of enforcement only overcharges are considered.

10.2. Accuracy. - The accuracy requirement for a sample must be $98 \%$ or higher to "pass" a single inspection. See Column 4, Accuracy Requirements, in Table 1. Samples, Sample Collection, and Accuracy Requirements.

10.3. Ratio of Overcharges to Undercharges. - With large sample sizes, overcharges should not exceed the undercharges. A high rate of overcharges to undercharges (2 to 1, or 3 to 1$)$ may indicate systematic problems with a store's pricing practices.

NOTE: As the history of store compliance develops, the number of overcharges and undercharges may be evaluated to determine if systematic errors or other problems exist. This ratio should be maintained when at least 10 errors are found over several inspections, or in a single large sample size (e.g., the results of several 100-item inspections collected over a period of time or if 1000 items are sampled in one inspection.) 
Table 2. Price Errors

(This table shows the percentage of errors in different sample sizes)

Percentage of Errors

Sample Size

\begin{tabular}{ccccccc}
$\begin{array}{c}\text { No. of } \\
\text { Errors }\end{array}$ & $\mathbf{2 5}$ & $\mathbf{5 0}$ & $\mathbf{1 0 0}$ & $\mathbf{1 5 0}$ & $\mathbf{2 0 0}$ & $\mathbf{3 0 0}$ \\
\hline 1 & $4 \%$ & $2 \%$ & $1 \%$ & $0.67 \%$ & $0.50 \%$ & $0.33 \%$ \\
2 & $8 \%$ & $4 \%$ & $2 \%$ & $1.33 \%$ & $1.00 \%$ & $0.67 \%$ \\
3 & $12 \%$ & $6 \%$ & $3 \%$ & $2.00 \%$ & $1.50 \%$ & $1.00 \%$ \\
4 & $16 \%$ & $8 \%$ & $4 \%$ & $2.67 \%$ & $2.00 \%$ & $1.33 \%$ \\
5 & $20 \%$ & $10 \%$ & $5 \%$ & $3.33 \%$ & $2.50 \%$ & $1.67 \%$ \\
6 & $24 \%$ & $12 \%$ & $6 \%$ & $4.00 \%$ & $3.00 \%$ & $2.00 \%$ \\
7 & $28 \%$ & $14 \%$ & $7 \%$ & $4.67 \%$ & $3.50 \%$ & $2.33 \%$ \\
9 & $32 \%$ & $16 \%$ & $8 \%$ & $5.33 \%$ & $4.00 \%$ & $2.67 \%$ \\
10 & $36 \%$ & $18 \%$ & $9 \%$ & $6.00 \%$ & $4.50 \%$ & $3.00 \%$ \\
\hline & $40 \%$ & $20 \%$ & $10 \%$ & $6.67 \%$ & $5.00 \%$ & $3.33 \%$
\end{tabular}

NOTE: Random pricing errors are to be expected, but the ratio of overcharges to undercharges will rarely be exactly 1 to 1 (e.g., of 10 errors, 5 overcharges and 5 undercharges); the ratio will likely vary both ways over several inspections. If a store has more overcharges than undercharges (e.g., 2 to 1, or 3 to 1), it may indicate that the store is not following good pricing practices, but enough errors must be present in order to make this determination. (Consider the example of 12 pricing errors consisting of 8 overcharges and 4 undercharges: the ratio of overcharges to undercharges is 2 to 1. Similarly, 10 pricing errors consisting of 6 overcharges and 4 undercharges correspond to a ratio of 1.5 to 1; since all decimal values are truncated to whole numbers, 1.5 is truncated to 1 , and the ratio becomes 1 to 1.)

The one-to-one ratio should be applied to any sample size if at least 10 errors are present. For example, if 1000 items are verified and 10 items are found in error, the sample has an accuracy of $99 \%$. However, if 9 of the 10 errors are overcharges (i.e., a ratio of 9 overcharges to 1 undercharge), the store should be considered to have poor pricing practices or other problems; if 100 items are verified and a $90 \%$ accuracy is found, 10 items in error not meeting the overcharge to undercharge ratio can be used in enforcement action as evidence of poor pricing practices.

\section{Section 11. Enforcement Procedures}

\subsection{Enforcement Steps.}

(a) Compliance is based on the accuracy found on a sample collected according to this procedure.

(b) Errors should be corrected immediately, or if the correction cannot be made immediately, a stop-sale order shall be issued before you leave the business. If the errors are not corrected in your presence, a follow-up inspection may be made later in the day or the following day to ensure the store has corrected the error. If a store fails to correct the error by that time, higher level enforcement action should be taken. 
(c) Enforcement action for large monetary errors on individual items, confirmed overcharges on items verified in response to complaints, or errors found on follow-up inspection of items ordered corrected, should be taken independently from any sample, giving consideration to the magnitude of the violation, corrective action by the establishment, and any other relevant information. Action may be initiated at any time in the inspection process based on the facts of the individual case.

(d) Overcharges and undercharges are used to determine lower levels of enforcement actions, but higher levels of enforcement action (e.g., fines or penalties) are taken only on the overcharges found in the sample.

(Amended 2001)

NOTE: Many computer systems do not allow for the immediate correction of errors in the database. Downloading information throughout the day may not be possible. Therefore, for the purposes of this section, "immediate" correction of errors may entail the removal or correction of problem signs, manually changing marked prices, or communicating notice of the corrected price to all applicable stores through facsimile, e-mail, or any other appropriate medium to ensure that consumers are charged the correct price.

\subsection{Model Enforcement Levels.}

These recommendations do not modify the enforcement policy of any jurisdiction unless adopted by that jurisdiction.

(a) Ninety-Eight Percent or Higher. - If price accuracy is $98 \%$ or higher on a sample of 50 or more items, and if overcharges do not exceed undercharges on sample sizes of 100 or more items, and the store is on a normal inspection frequency:

(1) a notice of noncompliance is issued on violations, and the store is maintained on a normal inspection frequency; or

(2) if the store is on increased inspection frequency, it remains on this frequency until inspection results conform to Terms of Increased Inspection Frequency.

(b) Less Than Ninety-Eight Percent. - If price accuracy is less than $98 \%$ on a sample of 50 or more items and if overcharges do not exceed undercharges on large sample sizes, and the store is on normal inspection frequency:

(1) A notice of noncompliance is issued and the store is placed on an increased inspection frequency.

(2) A second inspection should be conducted within 30 business days. If the price accuracy then is not $98 \%$ or higher, a warning is issued.

(3) A third inspection should be made within 60 business days. If the price accuracy is again less than $98 \%$, higher level enforcement action should be taken.

(Amended 2001)

If the store is on increased inspection frequency, a warning should be issued and the store re-inspected within 30 business days. If price accuracy is less than $98 \%$, higher levels of enforcement action should be taken.

(Amended 2001)

Examples:

For the 100-item sample size:

- If 100 items are verified and three overcharges are found in the sample, the error rate is $3 \%$. In this example, higher levels of enforcement action should be taken. 
- If 100 items are verified and three overcharges and two undercharges are found, the error rate on the sample is $5 \%$, but overcharges are $3 \%$. In this example, higher levels of enforcement action should be taken.

- If 100 items are verified and two overcharges and three undercharges are found, the error rate is still $5 \%$, but overcharges are only $2 \%$ of the sample. In this example, a lower level enforcement action would be taken.

(c) Terms of Increased Inspection Frequency. - When a store is on increased inspection frequency, it shall remain at that frequency until two consecutive inspections reveal an accuracy of $98 \%$ or higher.

(d) Higher Levels of Enforcement Action. - Overcharges and undercharges are used to determine lower levels of enforcement actions, but higher levels of enforcement action (e.g., fines or penalties) are taken only on overcharges. A store's history of error rates, the time it takes a store to correct the errors, the difference in inaccuracy rates found between "regular" and "sale" priced items, the ratio of overcharges to undercharges, a record of valid consumer complaints, and the magnitude of the error(s) may be used to support enforcement action.

\section{Section 12. Post-Inspection Tasks}

(a) You should meet with the store representative to review your findings. Have the inspection report completed prior to the meeting and be prepared to briefly summarize your findings and recommended actions, and provide a copy to the store representative.

(b) Return borrowed safety, sanitation, and/or test equipment.

(c) If you removed items from display, ensure that the items are returned to their proper location on the store shelves unless the representative requests to have the items returned by a store employee, which is permitted.

(d) Advise the representative of your findings. Explain any violations and errors. Explain any orders issued and be sure the individual acknowledges understanding of what corrective action is expected, if any.

(e) If necessary, describe the implications of the inspection results and advise the store of the action that you intend to take. If an increased inspection frequency is called for due to the accuracy level found during the inspection, advise the firm that re-inspections will be made, but do not indicate when they may occur.

\section{Section 13. Supervisory Activities}

13.1. Baseline Surveys. - Price verification programs require management support so that the program's objectives and desired benefits can be incorporated into the enforcement agency's work plans and budget. Surveys to measure pre- and post-implementation accuracy should be used to establish a base from which to measure whether a cost/benefit has been obtained.

13.2. Follow-up Inspections. - Inspections that reveal errors exceeding the accuracy requirements recommended above must include follow-up action to ensure that the store fulfills its obligations regarding accurate prices.

13.3. Management Information Systems. - To ensure adequate control and follow-up, a database should be established in each jurisdiction to provide information on every store, including: 


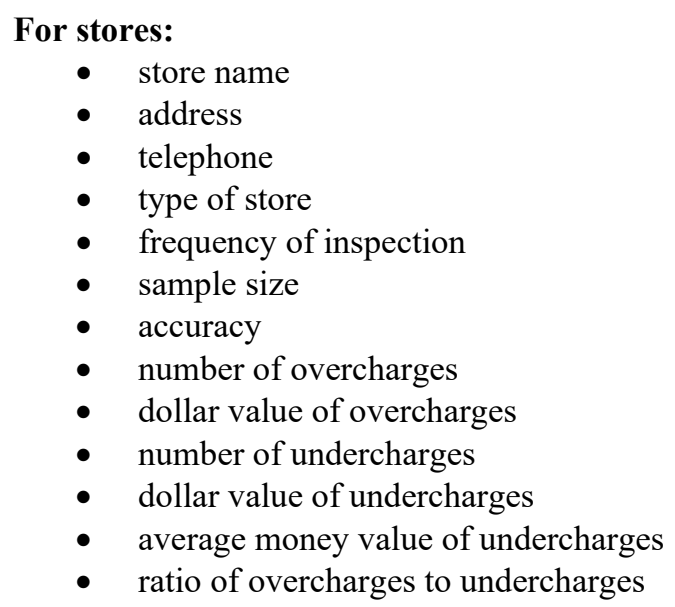

\section{For program review:}

- total number of undercharges

- total dollar value of undercharges

- $\quad$ average dollar value of undercharges

- percent undercharges of total

- ratio of overcharges to undercharges

- total error in percent

- accuracy levels of stores

- $\quad$ store type

- total stores tested

- $\quad$ total stores tested (each type)

- total items tested

- total number of overcharges

- total dollar value of overcharges

- average dollar value of overcharges

- $\quad$ percent of overcharges of total

\section{Section 14. Model Forms for Price Verification Inspections}

These models can be used to develop formal report forms, or they can be copied and used as worksheets for conducting inspections:

(a) Sample Tally Sheets: These forms can help you keep track of the number of items verified. They provide spaces to record the item's display location (e.g., aisle or department), a description of the item, and the shelf or advertised price. The worksheets are set up for the stratified sample collection described above to help identify the types of products to select.

(1) Price Verification Tally Sheet - Food Stores. (See page 229.)

(2) Price Verification Tally Sheet - Department Stores. (See page 230.)

(b) Model Inspection Form I: This can be used to document violations and record findings. A completed sample is provided.

(1) Price Verification Report I - sample blank form. (See page 231.)

(2) Price Verification Report I - completed sample form. (See page 232.)

(c) Model Inspection Form II: This can be used in stores where a hand-held scanning device is not available, or when it is inconvenient to take items (e.g., a large ladder in a hardware store) to a check-out register to verify the price. You can record an identity, the UPC or PLU code, and advertised price so that you can manually enter the codes to verify the price. The form can also be used to record findings. A completed sample is provided.

(1) Price Verification Report II - sample blank form. (See page 233.)

(2) Price Verification Report II - completed sample form. (See page 234.) 
Price Verification Tally Sheet - Food Stores

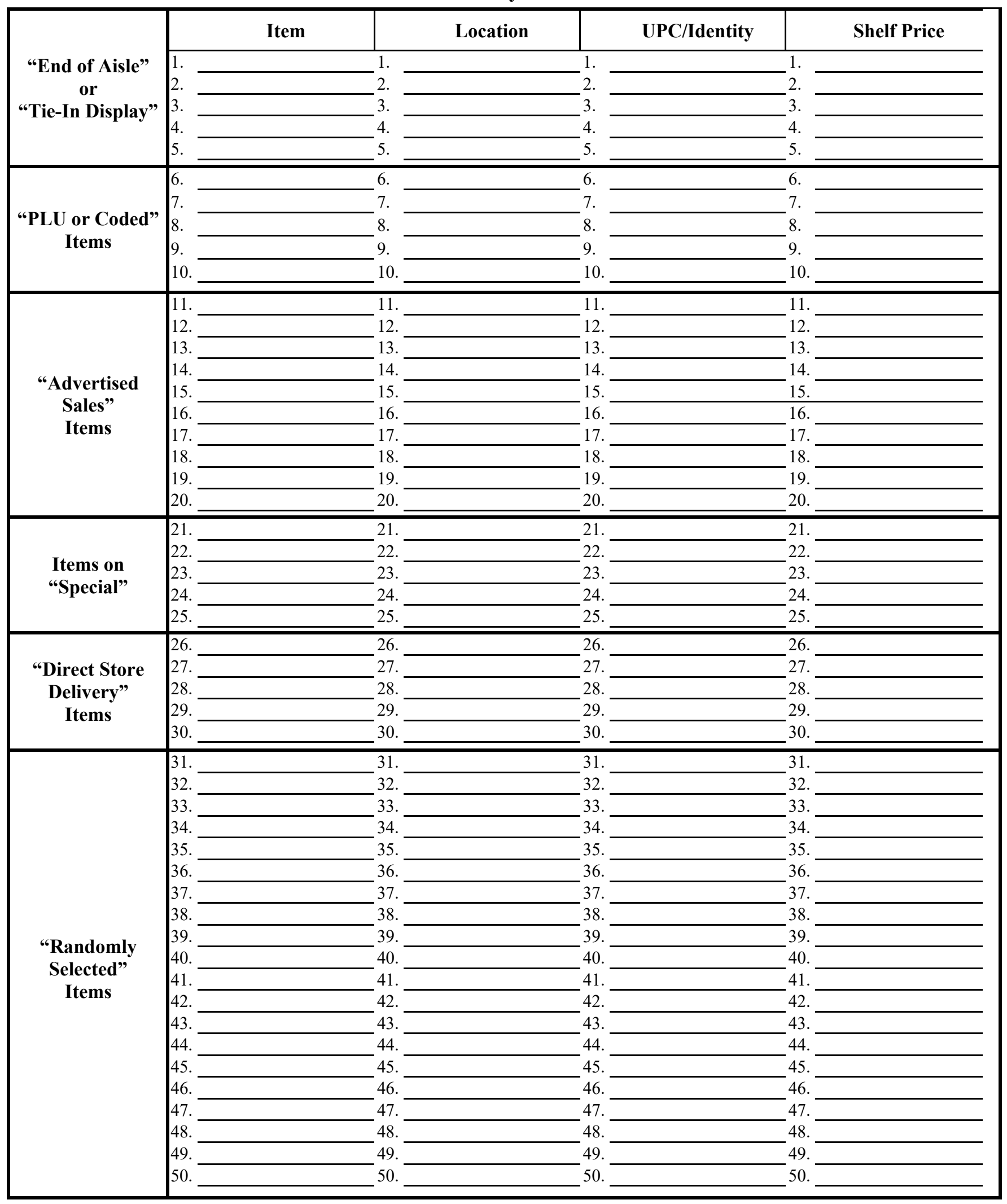


Price Verification Tally Sheet - Department Stores

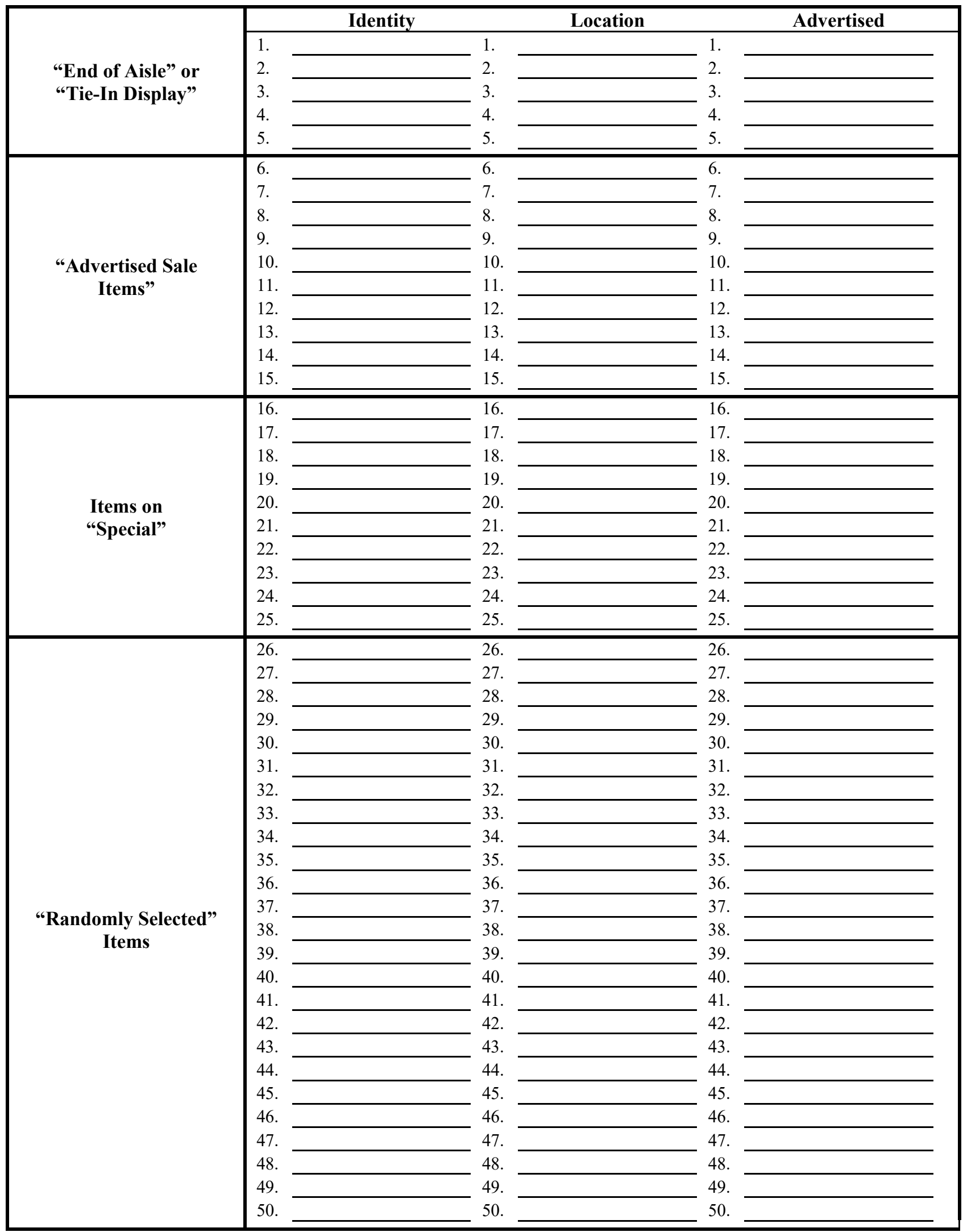




\section{Price Verification Report I}

Page _ of

Inspection: $\square 1^{\text {st }} \square 2^{\text {nd }} \square 3^{\text {rd }}$ Frequency: $\square$ Normal $\square$ Increased Complaint:

\begin{tabular}{|c|c|c|c|c|c|}
\hline \multicolumn{2}{|c|}{$\begin{array}{l}\text { Location of Test } \\
\text { (Store Name, Address, County, ZIP Code): }\end{array}$} & \multicolumn{2}{|l|}{\begin{tabular}{|l} 
Date: \\
Manager:
\end{tabular}} & \multicolumn{2}{|c|}{\begin{tabular}{|l|} 
Telephone: \\
Type of Store:
\end{tabular}} \\
\hline $\begin{array}{c}\text { Identity, Brand Name, Item } \\
\text { or Style Number }\end{array}$ & \multicolumn{2}{|c|}{$\begin{array}{c}\text { Number of Items, Size, } \\
\text { Location in Store, or UPC Code }\end{array}$} & $\begin{array}{l}\text { Offered } \\
\text { Price }\end{array}$ & $\begin{array}{c}\text { Price } \\
\text { Charged }\end{array}$ & Error $( \pm)$ \\
\hline \multicolumn{6}{|l|}{1.} \\
\hline $\begin{array}{l}\text { Stop Sale Issued } \\
\text { Corrected }\end{array}$ & \multicolumn{5}{|l|}{ Comments: } \\
\hline \multicolumn{6}{|l|}{2.} \\
\hline $\begin{array}{l}\text { Stop Sale Issued } \\
\text { Corrected }\end{array}$ & \multicolumn{5}{|l|}{ Comments: } \\
\hline \multicolumn{6}{|l|}{3 . } \\
\hline $\begin{array}{l}\square \text { Stop Sale Issued } \\
\square \text { Corrected }\end{array}$ & \multicolumn{5}{|l|}{ Comments: } \\
\hline \multicolumn{6}{|l|}{4.} \\
\hline $\begin{array}{l}\square \text { Stop Sale Issued } \\
\square \text { Corrected }\end{array}$ & \multicolumn{5}{|l|}{ Comments: } \\
\hline \multicolumn{6}{|l|}{5.} \\
\hline $\begin{array}{l}\text { Stop Sale Issued } \\
\text { Corrected }\end{array}$ & \multicolumn{5}{|l|}{ Comments: } \\
\hline \multicolumn{6}{|l|}{6.} \\
\hline $\begin{array}{l}\text { Stop Sale Issued } \\
\text { Corrected }\end{array}$ & \multicolumn{5}{|l|}{ Comments: } \\
\hline \multicolumn{6}{|l|}{7.} \\
\hline $\begin{array}{l}\text { Stop Sale Issued } \\
\text { Corrected }\end{array}$ & \multicolumn{5}{|l|}{ Comments: } \\
\hline \multicolumn{6}{|l|}{8.} \\
\hline $\begin{array}{l}\square \text { Stop Sale Issued } \\
\square \text { Corrected }\end{array}$ & \multicolumn{5}{|l|}{ Comments: } \\
\hline
\end{tabular}

\section{Inspection Results:}

(Sample Count) (\#Errors) $\div$ (ASC) $(\#$ Not on File $)=$ (Adjusted Sample Count [ASC])

(Accuracy Percentage $)=$

$$
=
$$
(Error Percentage)

\section{Inspector Name:}

Time In:

Comments/Remarks:

$\% \quad$ Overcharges $/$ Undercharges Ratio =

Time Out:

\section{Report Acknowledgement:}

Name/Title:

Comments/Remarks: 


\section{Price Verification Report I (completed sample)}

Inspection: $[\sqrt{ }] 1^{\text {st }} \square 2^{\text {nd }} \square 3^{\text {rd }} \quad$ Frequency: $[\sqrt{ }]$ Normal $\square$ Increased $\quad$ Type: $[\sqrt{ }]$ Stratified $\square$ Automated $\square$ Randomized

Complaint:

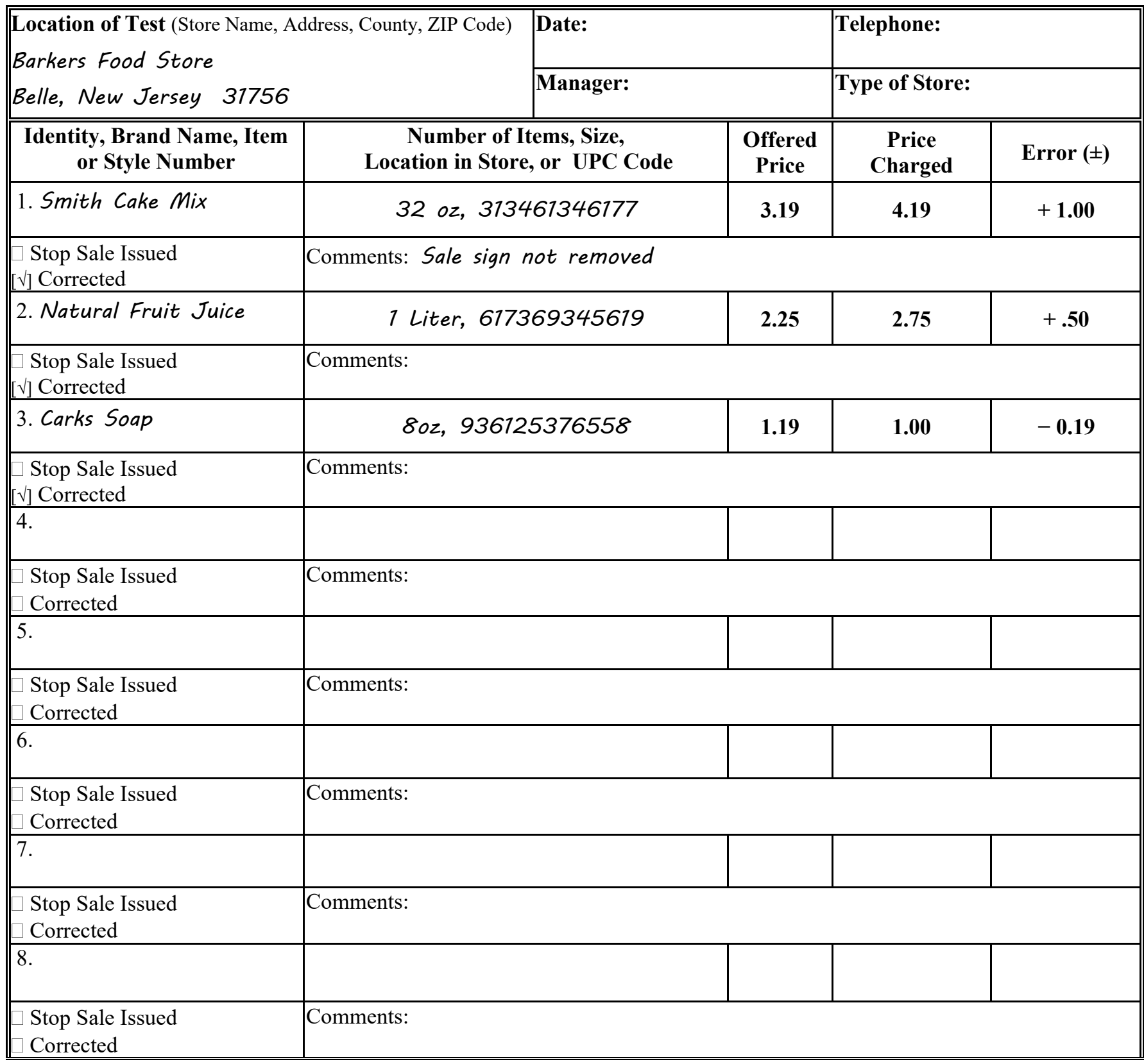

\section{Inspection Results}

100 (Sample Count $)-\underline{0}($ \#Not on File $)=\underline{100}$ (Adjusted Sample Count $[$ ASC $])$

3 (\#Errors) $\div \underline{100}($ ASC $)=3$ (Error Percentage $)$

$($ Accuracy Percentage $)=\quad 97 \% \quad$ Overcharges/Undercharges Ratio $=\underline{2: 1}$

Inspector Name: T. Price

Time In: $\quad$ 8:15 Time Out: 9:30

Comments/Remarks:
Report Acknowledgement:

Name/Title: Chris Barker

Comments/Remarks: 


\section{Price Verification Report II}

\begin{tabular}{|c|c|c|c|c|c|c|c|}
\hline \multirow{3}{*}{\multicolumn{3}{|c|}{$\begin{array}{l}\text { Inspection: } \square 1^{\text {st }} \square 2^{\text {nd }} \square 3^{\text {rd }} \\
\text { Location of Test: } \\
\text { (Store Name, Address, County, ZIP Code) }\end{array}$}} & \multicolumn{2}{|c|}{ quency: $\square$ Normal $\square$ Increased } & \multicolumn{3}{|c|}{ Complaint: $\square$} \\
\hline & & & \multicolumn{2}{|l|}{ Date: } & \multicolumn{3}{|c|}{ Telephone: } \\
\hline & & & \multicolumn{2}{|c|}{ Manager: } & \multicolumn{3}{|c|}{ Type of Store: } \\
\hline Item/Size or Style Number & $\begin{array}{l}\text { Offered } \\
\text { Price }\end{array}$ & \begin{tabular}{|c|} 
Price \\
Charged
\end{tabular} & $\begin{array}{c}\text { Price } \\
\text { Error } \\
( \pm)\end{array}$ & $\begin{array}{c}\text { Item, Brand, Description, } \\
\text { Code/Size }\end{array}$ & $\begin{array}{l}\text { Offered } \\
\text { Price }\end{array}$ & $\begin{array}{c}\text { Price } \\
\text { Charged }\end{array}$ & $\begin{array}{c}\text { Price } \\
\text { Error } \\
( \pm)\end{array}$ \\
\hline $\begin{array}{l}\text { 1. Identity: } \\
\text { UPC/PLU: } \\
\text { Comments: }\end{array}$ & & & & $\begin{array}{l}\text { 11. Identity: } \\
\text { UPC/PLU: } \\
\text { Comments: }\end{array}$ & & & \\
\hline $\begin{array}{l}\text { 2. Identity: } \\
\text { UPC/PLU: } \\
\text { Comments: }\end{array}$ & & & & $\begin{array}{l}\text { 12. Identity: } \\
\text { UPC/PLU: } \\
\text { Comments: }\end{array}$ & & & \\
\hline $\begin{array}{l}\text { 3. Identity: } \\
\text { UPC/PLU: } \\
\text { Comments: }\end{array}$ & & & & $\begin{array}{l}\text { 13. Identity: } \\
\text { UPC/PLU: } \\
\text { Comments: }\end{array}$ & & & \\
\hline $\begin{array}{l}\text { 4. Identity: } \\
\text { UPC/PLU: } \\
\text { Comments: }\end{array}$ & & & & $\begin{array}{l}\text { 14. Identity: } \\
\text { UPC/PLU: } \\
\text { Comments: }\end{array}$ & & & \\
\hline $\begin{array}{l}\text { 5. Identity: } \\
\text { UPC/PLU: } \\
\text { Comments: }\end{array}$ & & & & $\begin{array}{l}\text { 15. Identity: } \\
\text { UPC/PLU: } \\
\text { Comments: }\end{array}$ & & & \\
\hline $\begin{array}{l}\text { 6. Identity: } \\
\text { UPC/PLU: } \\
\text { Comments: }\end{array}$ & & & & $\begin{array}{l}\text { 16. Identity: } \\
\text { UPC/PLU: } \\
\text { Comments: }\end{array}$ & & & \\
\hline $\begin{array}{l}\text { 7. Identity: } \\
\text { UPC/PLU: } \\
\text { Comments: }\end{array}$ & & & & $\begin{array}{l}\text { 17. Identity: } \\
\text { UPC/PLU: } \\
\text { Comments: }\end{array}$ & & & \\
\hline $\begin{array}{l}\text { 8. Identity: } \\
\text { UPC/PLU: } \\
\text { Comments: }\end{array}$ & & & & $\begin{array}{l}\text { 18. Identity: } \\
\text { UPC/PLU: } \\
\text { Comments: }\end{array}$ & & & \\
\hline $\begin{array}{l}\text { 9. Identity: } \\
\text { UPC/PLU: } \\
\text { Comments: }\end{array}$ & & & & $\begin{array}{l}\text { 19. Identity: } \\
\text { UPC/PLU: } \\
\text { Comments: }\end{array}$ & & & \\
\hline $\begin{array}{l}\text { 10. Identity: } \\
\text { UPC/PLU: } \\
\text { Comments: }\end{array}$ & & & & $\begin{array}{l}\text { 20. Identity: } \\
\text { UPC/PLU: } \\
\text { Comments: }\end{array}$ & & & \\
\hline
\end{tabular}

\section{Inspection Results:}

(Sample Count) $(\#$ Not on File $)=$ (Adjusted Sample Count [ASC]) Stop-Sale Order Issued? [ ] (\#Errors) $\div$ $(\mathrm{ASC})=$ (Error Percentage)

(Accuracy Percentage $)=$ $\% \quad$ Overcharges $/$ Undercharges Ratio $=$

Inspector Name:

Time In:

Comments/Remarks:
Time Out:

\section{Report Acknowledgement:}

Name/Title:

Comments/Remarks: 


\section{Price Verification Report II (completed sample)}

Inspection: $[\sqrt{ }] 1^{\text {st }} \square 2^{\text {nd }} \square 3^{\text {rd }}$

Frequency: $[\sqrt{ }]$ Normal $\square$ Increased

Page 1 of 1

\begin{tabular}{|c|c|c|c|c|c|c|c|}
\hline \multicolumn{3}{|c|}{$\begin{array}{l}\text { Location of Test: (Store Name, Address, County, ZIP } \\
\text { Code) } \\
\text { Mark Downtown Department Store } \\
11650 \text { Main Street } \\
\text { Alice, MN } 61619\end{array}$} & \multicolumn{2}{|c|}{ Manager: } & \multicolumn{3}{|c|}{\begin{tabular}{|l|}
$\begin{array}{l}\text { Telephone: } \\
\text { (614) } 555-6746\end{array}$ \\
$\begin{array}{l}\text { Type of Store: } \\
\text { Department Store }\end{array}$
\end{tabular}} \\
\hline Item, Size, or Style Number & $\begin{array}{c}\text { Offered } \\
\text { Price }\end{array}$ & $\begin{array}{c}\text { Price } \\
\text { Charged }\end{array}$ & $\begin{array}{l}\text { Price } \\
\text { Error } \\
( \pm)\end{array}$ & $\begin{array}{c}\text { Item, Brand, Description, } \\
\text { Code, Size }\end{array}$ & $\begin{array}{l}\text { Offered } \\
\text { Price }\end{array}$ & $\begin{array}{c}\text { Price } \\
\text { Charged }\end{array}$ & $\begin{array}{l}\text { Price } \\
\text { Error } \\
( \pm)\end{array}$ \\
\hline $\begin{array}{l}\text { 1. Identity: Sony Color TV } \\
\text { UPC/PLU: } 38569 \\
\text { Comments: Model } 6136 \mathrm{X}\end{array}$ & 189.00 & 199.00 & +10.00 & $\begin{array}{l}\text { 11. Identity: } \\
\text { UPC/PLU: } \\
\text { Comments: }\end{array}$ & & & \\
\hline $\begin{array}{l}\text { 2. Identity: Moore Lawn Mower } \\
\text { UPC/PLU: } 31619 \\
\text { Comments: Shp with bagger }\end{array}$ & 96.00 & 91.00 & -5.00 & $\begin{array}{l}\text { 12. Identity: } \\
\text { UPC/PLU: } \\
\text { Comments: }\end{array}$ & & & \\
\hline $\begin{array}{l}\text { 3.Identity: Taft Rake } \\
\text { UPC/PLU: } 39916 \\
\text { Comments: Not on file }\end{array}$ & 8.99 & & & $\begin{array}{l}\text { 13. Identity: } \\
\text { UPC/PLU: } \\
\text { Comments: }\end{array}$ & & & \\
\hline $\begin{array}{l}\text { 4. Identity: Calendar } \\
\text { UPC/PLU: } \mathbf{6 1 5 1 9 1} \\
\text { Comments: }\end{array}$ & 5.50 & 7.10 & +1.60 & $\begin{array}{l}\text { 14. Identity: } \\
\text { UPC/PLU: } \\
\text { Comments: }\end{array}$ & & & \\
\hline $\begin{array}{l}\text { 5. Identity: } \\
\text { UPC/PLU: } \\
\text { Comments: }\end{array}$ & & & & $\begin{array}{l}\text { 15. Identity: } \\
\text { UPC/PLU: } \\
\text { Comments: }\end{array}$ & & & \\
\hline $\begin{array}{ll}6 . & \text { Identity: } \\
\text { UPC/PLU: } \\
\text { Comments: }\end{array}$ & & & & $\begin{array}{ll}\text { 16. Identity: } \\
\text { UPC/PLU: } \\
\text { Comments: }\end{array}$ & & & \\
\hline $\begin{array}{l}\text { 7. Identity: } \\
\text { UPC/PLU: } \\
\text { Comments: }\end{array}$ & & & & $\begin{array}{l}\text { 17. Identity: } \\
\text { UPC/PLU: } \\
\text { Comments: }\end{array}$ & & & \\
\hline $\begin{array}{ll}\text { 8. } & \text { Identity: } \\
& \text { UPC/PLU: } \\
& \text { Comments: } \\
\end{array}$ & & & & \begin{tabular}{|l} 
18. \\
Identity: \\
UPC/PLU: \\
Comments:
\end{tabular} & & & \\
\hline $\begin{array}{l}\text { 9. Identity: } \\
\text { UPC/PLU: } \\
\text { Comments: }\end{array}$ & & & & $\begin{array}{l}\text { 19. Identity: } \\
\text { UPC/PLU: } \\
\text { Comments: }\end{array}$ & & & \\
\hline $\begin{array}{l}\text { 10. Identity: } \\
\text { UPC/PLU: } \\
\text { Comments: }\end{array}$ & & & & $\begin{array}{l}\text { 20. } \text { Identity: } \\
\text { UPC/PLU: } \\
\text { Comments: }\end{array}$ & & & \\
\hline
\end{tabular}

\section{Inspection Results:}

$50($ Sample Count $)-\ldots$

$$
3(\# \text { Errors }) \div \quad 49(\mathrm{ASC})=6 \text { (Error Percentage })
$$

$($ Accuracy Percentage $)=\quad 94 \% \quad$ Overcharges $/$ Undercharges Ratio $=\underline{2: 1}$

Inspector Name: Tim Marlowe

Time In: 10:25 AM Time Out: $\underline{4: 45 \mathrm{PM}}$

Comments/Remarks:
Report Acknowledgement:

Name/Title: Jim Chester, Manager

Comments/Remarks: 


\section{NCWM Policy, Interpretations, and Guidelines}

\section{Excerpts from NCWM Publication 3 \\ Table of Contents}

Section $\quad$ Page

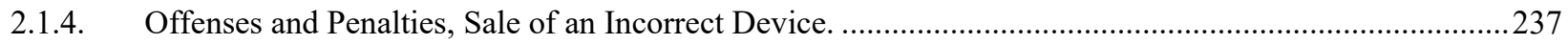

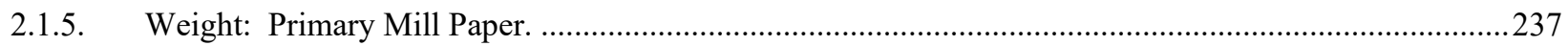

2.2.13. Declaration of Identity: Consumer Package (UPLR) and 1.5.1. In Combination with Other Foods

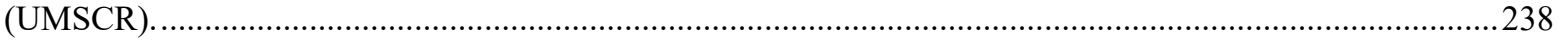

2.2.14. Typewriter and Computer Printer Ribbons and Tapes. ............................................................239

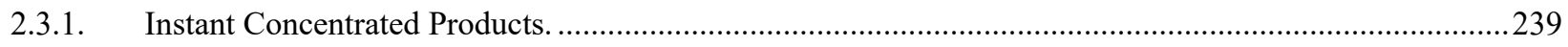

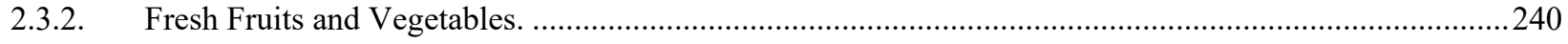

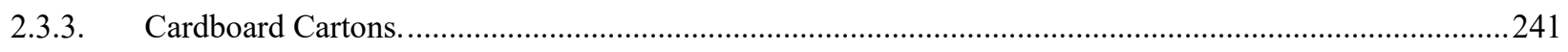

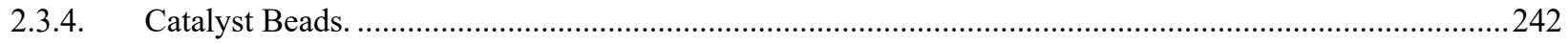

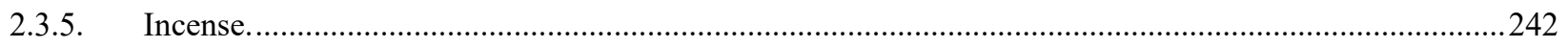

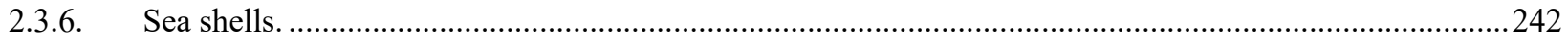

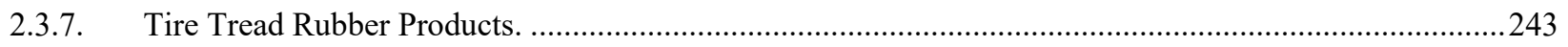

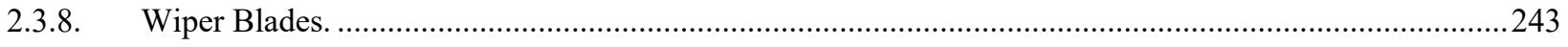

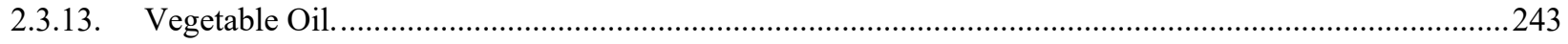

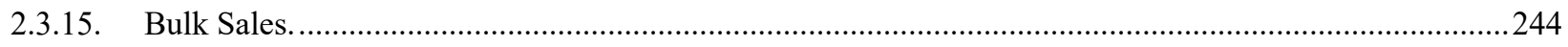

2.5.6. Guidelines for NCWM Resolution of Requests for Recognition of Moisture Loss in Other Packaged Products.

2.6.1. Retail Gas Sales and Metric Price Computations in General..........................................................248

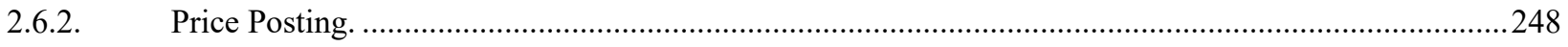

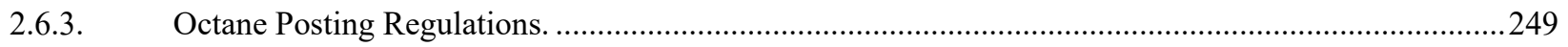

2.6.4. Multi-Tier Pricing: Motor Fuel Deliveries (Computing Pumps or Dispensers) $\quad$...............................250

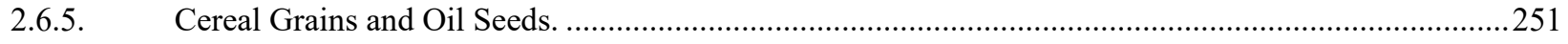

2.6.6. Basic Engine Fuels, Petroleum Products, and Lubricants Laboratory...........................................252

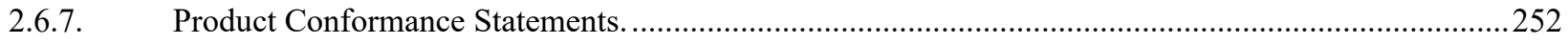


2.6.8. Commodities Under FTC Jurisdiction under the Fair Packaging and Labeling Act (FPLA) and Exclusions.

2.6.10. Model Guidelines for the Administrative Review Process. ..............................................................260

2.6.11. Good Quantity Control Practices. ……..........................................................................................263

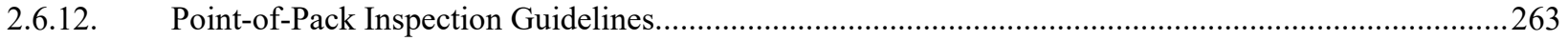

2.6.13. Guideline for Verifying the Labeled Basis Weight of Communication and Other Paper.....................266

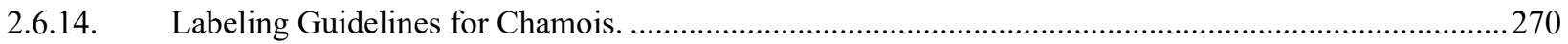

2.6.15. Labeling Guidelines for Natural and Synthetic Sponges. ...............................................................2273

2.6.16. Minimum Fuel Flush for Octane Verification...............................................................................278 


\section{NCWM Policy, Interpretations, and Guidelines}

\section{Introduction}

This section of the handbook includes NCWM interpretations, policies, recommendations, inspection outlines, and information on issues that have come before the Conference. Several sections include information on federal requirements related to the uniform laws and regulations presented in the handbook. The purpose of this section is to assist users in understanding and applying the uniform regulations and to guide administrators in implementing new programs or procedures. The guidelines or recommendations provided should not be construed to redefine any state or local law or limit any jurisdiction from enforcing any law, regulation, or procedure (unless the section describes a specific federal regulation that preempts local requirements).

(Added 1997)

\subsubsection{Offenses and Penalties, Sale of an Incorrect Device.}

(L\&R, 1987, p. 124)

A jurisdiction seeking to enforce the provision of the Uniform Weights and Measures Law that prohibits the sale of an incorrect device would have to show that the seller knowingly sold or offered for sale for use in commerce an incorrect weight or measure. Under Section 22, a seller would not be responsible for actions taken by the purchaser or distributor, in which the seller did not participate or have prior knowledge. Thus, the seller would not be liable:

(1) if a purchaser or distributor modified a scale obtained from a seller; or

(2) if a scale were used in trade after the seller informed the purchaser that the scale was not appropriate for that use.

In cases, such as those noted above, the Committee feels that the seller would be protected from prosecution. Only sellers who knowingly violate the provision would be subject to prosecution.

\subsubsection{Weight: Primary Mill Paper.}

(L\&R, 1990, p. 81)

\section{Interpretation}

Non-consumer sales of "primary mill paper" were discovered by weights and measures officials to be labeled and invoiced on what was called a "gross weight" basis. Primary mill paper is produced for commercial or industrial companies for subsequent additional processing, such as paper for newspaper or magazine publishers or sanitary tissue manufacturers. The primary mill paper is cut from "parent rolls" but is still a commercial-sized item weighing from several hundred to several thousands of pounds.

The key to understanding the longstanding trade practice is that the purchaser of such paper specifies not only the quality of the paper being purchased, such as the thickness, surface coating, etc., but the purchaser also specifies the core around which the paper is to be wound, the type of overwrap, the number of overwraps, and such other requirements that will ensure receipt of the primary mill paper in proper condition for subsequent processing. The weight of the core and wrapping is approximately $1 \%$ of the gross weight. It is recycled by the purchasers in their own or other paper recovery or reuse systems.

Having reviewed the practices in the industry in the specification and purchasing of primary mill paper, the Committee concludes that the true product is the paper plus the packaging (in order to assure maintenance of quality) and an appropriate core (to ensure a fit on the recipient's equipment). Therefore, in the Committee's opinion, the sale of primary mill paper is not at all on a gross weight basis. This is and has been a misnomer. The true identity of the purchased product has been misunderstood by weights and measures authorities, further compounded by the industry 
use of the term "gross weight." The product is the primary mill paper plus the core and overwrap specified by the purchaser.

The Committee, therefore, believes that the industry should review its invoicing and labeling to clarify that the weight of the specified product is the weight of the primary mill paper, core, and overwrap. Although this weight is the gross weight of the entire item as produced and shipped, it is the net weight of the item as specified by the purchaser.

This interpretation applies only to primary mill paper and is not intended to be applied to all non-consumer products ordered by specification; it is a narrow interpretation applying to the specific method of sale in this trade where the service of packaging and the packaging is part of the purchase.

\subsubsection{Declaration of Identity: Consumer Package (UPLR) and 1.5.1. In Combination with Other Foods (UM- SCR). \\ (L\&R, 1990, p. 93)}

\section{Background}

Many food products are made by the retail store and labeled with names that may or may not have standards of identity or standards of composition in federal regulation or policy (for example, chicken cordon bleu). Weights and measures officials need to know which names have standards of identity that must be followed in formulating the product and, therefore, in providing the ingredient statement.

\section{Food Standards}

The U.S. Department of Agriculture's Food Safety and Inspection Service (USDA - FSIS) and the U.S. Department of Health and Human Services' FDA share the responsibility of assuring truthful and accurate information on product labels. USDA - FSIS has responsibility for the development and application of the labeling requirements applicable to meat and poultry products containing more than $3 \%$ fresh meat or at least $2 \%$ cooked poultry meat. FDA oversees the labeling of most other food products.

\section{USDA Standards of Identity and Composition}

USDA has statutory authority to establish standards of identity for meat and poultry products. A standard of identity prescribes a manner of preparation and the ingredients of a product that is labeled with a particular name. A food that bears the name of a standardized food that does not satisfy the requirements of the applicable standard is misbranded. Examples of standardized products include: "Ham," "Ham Water Added," "Hot Dogs," "Chicken and Noodles," and "Spaghetti Sauce with Meatballs."

Almost all standards enforced by FSIS are called "standards of composition." These standards identify the minimum amount of meat or poultry required in a product's recipe. For example, the standard of composition for "beef a la king" states that, if a product carries this name on its label, at least $20 \%$ cooked beef must be used in the recipe.

But standards of composition do not prevent a manufacturer from increasing the meat or poultry content or adding other ingredients to increase a product's appeal. For instance, a processor has the option of using more than the required amount of beef in beef a la king and adding other ingredients to make the product unique. A listing of meat and poultry content and labeling requirement including terms that are further defined can be found in the USDA FSIS Food Standards and Labeling Policy book which is available at: www.fsis.usda.gov/wps/portal/fsis/topics/regulatory-compliance/labeling/Labeling-Policies

\section{Label Approval}

Food manufacturers are responsible for compliance with the FSIS labeling rules and adherence to the process maintained by FSIS for the evaluation and approval of meat and poultry product labels. This Guide provides the basic information necessary to devise a label for meat and poultry products and to understand the regulatory process administered by FSIS. A Guide to Federal Food Labeling Requirements for Meat and Poultry Products (2007) URL 
is located at: www.fsis.usda.gov/wps/portal/fsis/topics/regulatory-compliance/labeling/labeling-policies/basicsof-labeling/basics-labeling

\subsubsection{Typewriter and Computer Printer Ribbons and Tapes.}

(L\&R, 1991)

\section{Interpretation}

Typewriter and computer printer ribbons must be labeled by length. In addition, character yield information may be disclosed on the principal display panel.

\section{Background}

Packages of typewriter and computer printer ribbons and tapes have been found in the marketplace with no declaration of quantity of any kind. There is information on the package about the type of machine the ribbon or tape is designed to fit, but this is not a declaration of quantity. Purchasers have been misled as a result of the failure of some manufacturers to disclose the length; ribbons designated for a particular machine may be sold at a low price, but with substantially less length than ribbons ordinarily produced for the machine.

\subsubsection{Instant Concentrated Products.}

(L\&R, 1977, p. 219)

\section{Interpretation}

No additional net contents information (other than weight) is required for instant coffee, tea, and cocoa.

\section{Background}

It was proposed that certain products, such as instant coffee, tea, and cocoa, should have a dual statement of weight including the number of cups (e.g., makes ten 6 oz cups).

The National Coffee Association of U.S.A., Inc., offered the following comments:

1. The number of servings of instant coffee will depend upon the size of the cup involved and the taste of the individual consumer.

2. The size of a cup will vary widely, ranging from a small "demitasse" cup to a large coffee mug.

3. The taste of the individual consumer defies definition because it will vary as widely as the number of individuals considered. Market research shows many like it "strong and black" and others prefer it "mild and thin."

4. Any statement placed on a container of instant coffee that represents that the consumer will be able to obtain a specified number of servings would be arbitrary, confusing and, in a very sense, deceptive.

5. In view of the foregoing, any such requirements that the number of servings be listed on a container of instant coffee might expose the manufacturer to complaints from consumers that it was engaging in an unfair and deceptive practice.

Other issues that the Committee discussed included the authority to require precise directions (rather than, for example, two to three heaping teaspoons) and the issues of product variability and uniform enforcement. 
2.3.2. Fresh Fruits and Vegetables.

(L\&R, 1979, p. 176; 1980; 1982, p. 152; 2008)

\section{Guideline}

Recognizing the difficulty faced by consumers when more than one method of sale is employed in the same outlet for the same product, non-comparable methods of sale (e.g., weight and measure) for the same produce item in the same outlet should be minimized.

This guideline applies to all sales of fruits and vegetables. There are two tables, one for specific commodities and one for general commodity groups. Search the specific list first to find those commodities that either do not fit into any of the general groups or have unique methods of sale. If the item is not listed, find the general group in the second table. The item may be sold by any method of sale marked with an X.

(Amended 2008)

\begin{tabular}{|c|c|c|c|c|c|}
\hline \multicolumn{6}{|c|}{$\begin{array}{l}\text { Method of Retail Sale for Fresh Fruits and Vegetables } \\
\text { Specific Commodity }\end{array}$} \\
\hline Commodity & Weight & Count & $\begin{array}{l}\text { Head or } \\
\text { Bunch }\end{array}$ & $\begin{array}{c}\text { Dry } \\
\text { Measure } \\
\text { (any size) }\end{array}$ & $\begin{array}{c}\text { Dry } \\
\text { Measure } \\
\text { (1 dry qt } \\
\text { or larger) }\end{array}$ \\
\hline Artichokes & $\mathrm{X}$ & $\mathrm{X}$ & & & \\
\hline Asparagus & $\mathrm{X}$ & & $\mathrm{X}$ & & \\
\hline Avocados & & $\mathrm{X}$ & & & \\
\hline Bananas & $\mathrm{X}$ & $\mathrm{X}$ & & & \\
\hline Beans (green, yellow, etc.) & $\mathrm{X}$ & & & & $\mathrm{X}$ \\
\hline Brussels Sprouts (loose) & $\mathrm{X}$ & & & & \\
\hline Brussels Sprouts (on stalk) & & & $\mathrm{X}$ & & \\
\hline Cherries & $\mathrm{X}$ & & & $\mathrm{X}$ & $\mathrm{X}$ \\
\hline Coconuts & $\mathrm{X}$ & $\mathrm{X}$ & & & \\
\hline Corn on the Cob & & $\mathrm{X}$ & & & $\mathrm{X}$ \\
\hline Dates & $\mathrm{X}$ & & & & \\
\hline Eggplant & $\mathrm{X}$ & $\mathrm{X}$ & & & \\
\hline Figs & $\mathrm{X}$ & & & & \\
\hline Grapes & $\mathrm{X}$ & & & & \\
\hline Melons (cut in pieces) & $\mathrm{X}$ & & & & \\
\hline Mushrooms (small) & $\mathrm{X}$ & & & $\mathrm{X}$ & $\mathrm{X}$ \\
\hline Mushrooms (portobello, large) & $\mathrm{X}$ & $\mathrm{X}$ & & & \\
\hline Okra & $\mathrm{X}$ & & & & \\
\hline Peas & $\mathrm{X}$ & & & & $\mathrm{X}$ \\
\hline Peppers (bell and other varieties) & $\mathrm{X}$ & $\mathrm{X}$ & & & $\mathrm{X}$ \\
\hline Pineapples & $\mathrm{X}$ & $\mathrm{X}$ & & & \\
\hline Rhubarb & $\mathrm{X}$ & & $\mathrm{X}$ & & \\
\hline Tomatoes (except cherry/grape) & $\mathrm{X}$ & $\mathrm{X}$ & & & $\mathrm{X}$ \\
\hline
\end{tabular}




\begin{tabular}{|c|c|c|c|c|c|}
\hline \multicolumn{6}{|c|}{$\begin{array}{l}\text { Method of Retail Sale for Fresh Fruits and Vegetables } \\
\text { General Commodity Groups }\end{array}$} \\
\hline Commodity & Weight & Count & $\begin{array}{c}\text { Head } \\
\text { or } \\
\text { Bunch }\end{array}$ & $\begin{array}{c}\text { Dry } \\
\text { Measure } \\
\text { (any size) }\end{array}$ & $\begin{array}{c}\text { Dry } \\
\text { Measure } \\
\text { (1 dry qt } \\
\text { or larger) }\end{array}$ \\
\hline Berries and Cherry/Grape Tomatoes & $\mathrm{X}$ & & & $\mathrm{X}$ & \\
\hline $\begin{array}{l}\text { Citrus Fruits (oranges, grapefruits, lemons, } \\
\text { etc.) }\end{array}$ & $\mathrm{X}$ & $\mathrm{X}$ & & & $\mathrm{X}$ \\
\hline $\begin{array}{l}\text { Edible Bulbs (onions [spring or green], } \\
\text { garlic, leeks, etc.) }\end{array}$ & $\mathrm{X}$ & $\mathrm{X}$ & $\mathrm{X}$ & & $\mathrm{X}$ \\
\hline $\begin{array}{l}\text { Edible Tubers (Irish potatoes, sweet pota- } \\
\text { toes, ginger, horseradish, etc.) }\end{array}$ & $\mathrm{X}$ & & & & $\mathrm{X}$ \\
\hline $\begin{array}{l}\text { Flower Vegetables (broccoli, cauliflower, } \\
\text { Brussel sprouts, etc.) }\end{array}$ & $\mathrm{X}$ & & $\mathrm{X}$ & & \\
\hline $\begin{array}{l}\text { Gourd Vegetables (cucumbers, squash, } \\
\text { melons, etc.) }\end{array}$ & $\mathrm{X}$ & $\mathrm{X}$ & & & $\mathrm{X}$ \\
\hline $\begin{array}{l}\text { Leaf Vegetables (lettuce, cabbage, celery, } \\
\text { etc.) }\end{array}$ & $\mathrm{X}$ & & $\mathrm{X}$ & & \\
\hline $\begin{array}{l}\text { Leaf Vegetables (parsley, herbs, loose } \\
\text { greens) }\end{array}$ & $\mathrm{X}$ & & $\mathrm{X}$ & $\mathrm{X}$ & \\
\hline Pitted Fruits (peaches, plums, prunes, etc.) & $\mathrm{X}$ & $\mathrm{X}$ & & & $\mathrm{X}$ \\
\hline Pome Fruits (apples, pears, mangoes, etc.) & $\mathrm{X}$ & $\mathrm{X}$ & & & $\mathrm{X}$ \\
\hline $\begin{array}{l}\text { Root Vegetables (turnips, carrots, rad- } \\
\text { ishes, etc.) }\end{array}$ & $\mathrm{X}$ & & $\mathrm{X}$ & & \\
\hline
\end{tabular}

\subsubsection{Cardboard Cartons.}

(L\&R, 1974, p. 223)

\section{Guidelines and Interpretations}

Cardboard cartons should be sold by their dimensions. Identification numbers used in the trade do not correspond to these dimensions and could tend to mislead the uninformed purchaser (although there is no actual unit such as inches associated with the identification numbers). Sales or catalogue literature will have to be investigated to determine whether there is sufficient information upon which to make a purchasing decision.

\section{Background}

Copies of letters received by the New York Bureau of Weights and Measures regarding cardboard containers were forwarded to the Committee. These letters highlight the confusion that exists when these containers are sold to new businessmen by an identity number which is often mistaken for the size of the box. For example, a $30 \times 4$ identification number refers to a box whose actual size is $27 \times 3$ inches. It was suggested that a new section be added to the Method of Sale of Commodities Regulation so that these containers can be sold on a basis that will provide more accurate information.

An important argument in support of adding a new section is that small businessmen just getting started need as much assistance as can be provided in order to survive and grow. 
An argument opposing this change is that a table, similar to Table 1. of Section 2.9. (Softwood Lumber) of the Uniform Method of Sale Regulation, could be printed showing the relationship between identity and size; this would not solve the problem.

It is the consensus of the Committee that these containers should be sold by actual size. The Committee does not believe, however, that every trade practice must be controlled through the Uniform Laws and Regulations. This is particularly true where the item does not directly concern the retail consumer. The Committee, therefore, recommends that the appropriate trade associations be contacted and asked to correct this practice on a voluntary basis.

\subsubsection{Catalyst Beads.}

(L\&R, 1981, p. 100)

\section{Guideline and Interpretation}

The proper method of sale of catalyst beads used in automobile exhaust systems is by volume. It is appropriate for the quantity declaration to be supplemented by part number or other description of the specific converter for which the package of catalyst beads is intended.

\section{Background}

A communication from the General Motors Corporation AC Spark Plug Division was forwarded to the Committee which proposes discontinuing the labeling of their catalyst beads by weight. When the catalyst becomes contaminated by leaded gasoline or prolonged use, the catalytic converter in the exhaust system of recent GM cars and trucks (running on unleaded gasoline) must be emptied of its catalyst beads and be refilled by volume with replacement catalyst beads in order to meet emission standards. The beads are used by volume (to fill a catalytic converter), are hygroscopic, and vary in core material density. Therefore, packages of beads meeting a net weight label require an additional one-third pound (on the average) over the packages labeled by volume, cost about $\$ 7.50$ more per package, and the additional weight of beads will be discarded in actual use.

\subsubsection{Incense.}

(L\&R, 1978, p. 151)

\section{Interpretation}

Incense labeled by count is fully informative and sufficient.

\section{Background}

The State of Oregon raised the issue of proper quantity declarations for the sale of incense. The question is what, if any, information other than count, such as weight or volume or length, is necessary for an adequate description on packages of incense. The Committee is of the opinion that a statement of count as defined in Section 6.4.1(c) of the Uniform Packaging and Labeling Regulation is fully informative and is sufficient in this case.

\subsubsection{Sea shells.} (L\&R, 1976, p. 223)

\section{Guideline}

Sea shells shall be sold by count and weight for packages of 50 sea shells or less and by volume and weight for packages containing more than 50 sea shells. 


\subsubsection{Tire Tread Rubber Products.}

(L\&R, 1976, p. 233)

\section{Guideline}

Tire tread rubber products shall be sold by net weight. The polyethylene film protective backing shall be part of the product and included in the net weight. The core is part of the tare and must be deducted from the gross weight to determine the net weight.

\subsubsection{Wiper Blades.}

(L\&R, 1979, p. 182)

\section{Interpretation}

There is a trade custom of labeling automobile wiper blades by the length of the metal backing or vertebra, not the length of the blade. This is an acceptable method of sale and net contents declaration.

\section{Background}

The Committee received a request from a manufacturer of automobile wiper blades that had a problem with one state concerning the measurement of length as labeled on their packages. The state felt that the proper designation should be the length of the blade itself; the manufacturer said that traditionally the industry measured the length of the metal backing or vertebra.

The Committee, after some discussion, determined that since there was no intent to mislead customers, the traditional measurement of the metal backing or vertebra was acceptable.

\subsubsection{Vegetable Oil.}

(L\&R, 1983, p. 208)

\section{Guideline and Interpretation}

Packaged liquid vegetable oil must be labeled by liquid volume, although net weight may also be declared.

\section{Background}

Packages of liquid vegetable oil are being sold for restaurant and other small food business use labeled by weight. It has been brought to the attention of the Committee that containers of product labeled " 5 gal" look identical in dimensions to those labeled " $35 \mathrm{lb}$ " but the density of the vegetable oil is such that the $35 \mathrm{lb}$ cans contain only about $4 \frac{1}{2}$ gal. The Institute of Shortening and Edible Oils indicated that companies selling liquid vegetable oils often compete with those selling solid shortening, and that a net weight comparison is useful for these purposes. Recipes for food products in large sizes sometimes provide ingredient quantities by weight or volume.

It is the opinion of the members of the Committee that packaged liquid vegetable oil must be labeled by liquid volume although a net weight may be declared in addition to the net volume statement.

When a single manufacturer of vegetable oil packages the same oil in the same size container with two such widely different net quantity statements, this practice could easily be considered (a) misleading to the customer, and (b) nonfunctional slack fill. Weights and measures enforcement action should be taken. 


\subsubsection{Bulk Sales.}

(L\&R Committee, 1986, p. 140)

When packaged or wrapped items (such as individually wrapped candies) are sold from bulk displays by weight, the price must be based on the net weight, not the weight including the individual piece wrappings. This will require (1) subtracting the weight of the bag into which the customer puts the pieces plus (2) subtracting the weight of the piece wrappings (the latter is a percentage of the gross weight - that is, the tare increases as the customer selects more of the commodity).

\section{Background}

Retail food stores are merchandising prepackaged commodities such as candies, pet food, snack bars, and bouillon cubes from bulk displays. Some retailers sell these products by gross weight. Section 1.2. of the Uniform Weights and Measures Law reads in part: "The term 'weight' as used in connection with any commodity means net weight. .."

A workshop was held on June 20, 1986, at the U.S. Department of Commerce, Washington, D.C., to explore the issues and alternatives involved in the sale of prepackaged goods from the bulk food sales areas of supermarkets. Representatives of the packaging, supermarket, and small grocery industries, scale and point-of-sale (POS) systems manufacturers, the U.S. Food and Drug Administration, weights and measures agencies, and the National Institute of Standards and Technology attended. No final recommendations came from this meeting; however, the participants expressed an interest in meeting again after a written report of the June 20, 1986, meeting was made available and before the Interim Meetings of the NCWM in January 1987. The following issues were discussed:

1. Prepackaged commodities in bulk displays are being sold on a gross weight basis.

Federal regulations covering packaged goods and every state Weights and Measures Law require any sale by weight to be "net weight" (not including the weight of the wrapping materials). In some areas of the nation, many items are being sold on a gross weight basis in the supermarkets, for example, fresh fruit and vegetables in poly bags in the produce area. Perhaps because of the light weight of these bags (that is, the minimum size of the scale division on the ordinary supermarket checkout scale is large with respect to the weight of the poly bags), low priority is given to correcting this sales practice, and a lack of uniformity in enforcement of the net weight requirements results. Weights and measures officials have found tare amounting to over $40 \%$ of the gross weight in prepackaged items sold from bulk; the majority of cases seems to range from $3 \%$ to $12 \%$. Officials see the need to "draw the line" in a sales practice that appears to have evolved from other practices that were not heavily monitored and corrected at their inception.

2. Retailers face technical and administrative problems in properly deducting tare from the gross weight.

Automatic deduction of tare is preferable for large-scale retailers because of its speed. No equipment (either stand-alone scale or POS) is available at the present time that can: (1) subtract a percentage of the gross weight to represent the tare weight; or (2) subtract a fixed tare for the bag and a percentage tare for the wrapper on the prepackaged item. [Editor's Note: There is equipment now available that can deduct a tare that is a percentage of the gross weight.] Two POS system manufacturers said that new systems with percentage tare capability could be designed, but they could not definitely say whether retrofitting existing systems was possible. They said that the ability to retrofit declined with the age of the system. Supermarket representatives expressed concern that their in-store computer software would need modification above and beyond the retrofitting or software redesign that might be done by the POS manufacturers; their software is designed around current POS software.

Deduction of tare in the bulk food area using a scale other than the checkout scale can be done more easily than at checkout if a POS system is being used. A tare look-up table used in conjunction with the scale appears to be the only currently used method that meets the net weight requirements when packaged products are sold from bulk. (The procedure is to gross weigh the product, look up the tare, subtract it from the gross weight, and then determine a final net weight and total price.) 
Each retailer will have to consider the cost of additional manpower (as the weighing and marking of the purchase in the bulk food area might require), new equipment (purchasing scales or POS systems with percentage tare capability), or retrofit of existing equipment as compared with the value of the market share contributed by the bulk marketing of prepacked commodities. However, two supermarket chain representatives said that they expected some growth in this type of sale (because of the customers' perception of cleanliness of the product, for example).

3. Present methods of sale and advertising are often misleading.

Suggestions were made that advertising on a "wrapped weight" basis would properly inform the consumer. However, it was pointed out that a typical purchaser does not know what "wrapped weight" is (i.e., gross weight). Moreover, selling packaged goods on a gross weight basis is illegal; it thwarts value comparison with other products sold by net weight.

Bulk food sales advertising often includes claims of savings of, for example, $10 \%$ to $20 \%$ over a purchase of the same commodity in standard-pack form. These advertising claims can be exaggerated and misleading if the comparisons referenced are between standard-pack commodities sold net weight and products sold from bulk on a gross weight basis.

The possibility of advertising a net weight unit price, but actually weighing at the checkout on a gross weight basis (and charging at a lower gross weight unit price) was discussed. For example, a sign could be posted with the following:

" $\$ 1.50$ per pound, net weight. We are not able to weigh this packaged product on a net weight basis (that is, without the wrapper), and will therefore charge you $\$ 1.40$ per pound including the wrapper weight at the checkout."

Everyone agreed that advertising claims and appropriate wording would have to be chosen carefully if this is to be viable. However, those weights and measures officials present were generally opposed to this alternative based on the difficulty of enforcement and lack of assurance that a consumer would really understand explanatory signage.

\subsubsection{Guidelines for NCWM Resolution of Requests for Recognition of Moisture Loss in Other Packaged Products.}

(Exec, 1988, p. 94)

The Task Force on Commodity Requirements limited its work to only a few product categories, using these categories as models for addressing moisture loss. The gray-area concept is the result of this work.

Recognizing several candidates for future work in moisture loss, the Task Force recommends that the following guidelines for moisture loss be followed as far as possible by any industry requesting consideration:

1. There should be reasonable uniformity in the moisture content of the product category. For example, since pet food has final moisture contents ranging from very moist to very dry, some sub categorization of pet food needs to be defined by industry before the NCWM study of the issue.

2. The predominant type of moisture loss (whether into the atmosphere or into the packaging materials) must be specified.

3. Different types of packaging might make it necessary to subcategorize the product. For example, pasta is packaged in cardboard, in polyethylene, or other packaging more impervious to moisture loss. The industry should define the domain of packaging materials to be considered.

4. "Real-world" data is needed on the product as found in the retail marketing chain - not just laboratory moisture-loss data. 
5. The industry requesting consideration of moisture loss for its product should collect data on an industry-wide basis (rather than from only one or two companies).

Information concerning the relative fractions of imported and domestically produced product should be available, for example, in order to assess the feasibility of interacting with the manufacturer on specific problem lots.

6. Moisture loss may occur either:

- during manufacturing; or

- during distribution.

Data will be needed to show the relative proportion of moisture loss in these different locations since moisture loss is permitted only under good distribution practices. Geographical and seasonal variations may apply.

7. A description of the processing and packaging methods in use in the industry will be of great value, as will a description of the distribution system and time for manufacturing and distribution. A description of the existing net quantity control programs in place should be given, together with information on how compliance with NIST Handbook 133 is obtained. A description of maintenance and inspection procedures for the scales should be provided, together with information on suitability of equipment and other measurements under Handbook 44.

8. A description of federal and local agency jurisdiction and test should be given, as well as any regulatory history with respect to moisture loss and short weight. Has weights and measures enforcement generated the request? What efforts have addressed the moisture loss issue prior to approaching the NCWM? Are the appropriate federal agencies aware of the industry's request to the NCWM?

9. The industry should propose the type of compliance system and/or moisture determination methodology to be used. The compliance scheme, if it contains industry data components, should be susceptible to verification (examples: USDA net weight tests for meat; exchange of samples with millers for flour) and should state what the companies will do to provide data to field inspection agencies in an ongoing fashion (as the gray-area approach requires). If in-plant testing is to be combined with field testing, who is to do such testing, and how is this to be accomplished? It should be possible to incorporate the proposed testing scheme into Handbook 133 to be used with Category A or B sampling plans.

When all the preliminary information recommended above has been collected, a field test of the proposed compliance scheme should be conducted by weights and measures enforcement officials to prove its viability.

See the plan diagrammed on the next page. 


\section{Plan for NCWM Resolution of Individual Requests for Recognition of Moisture Loss}

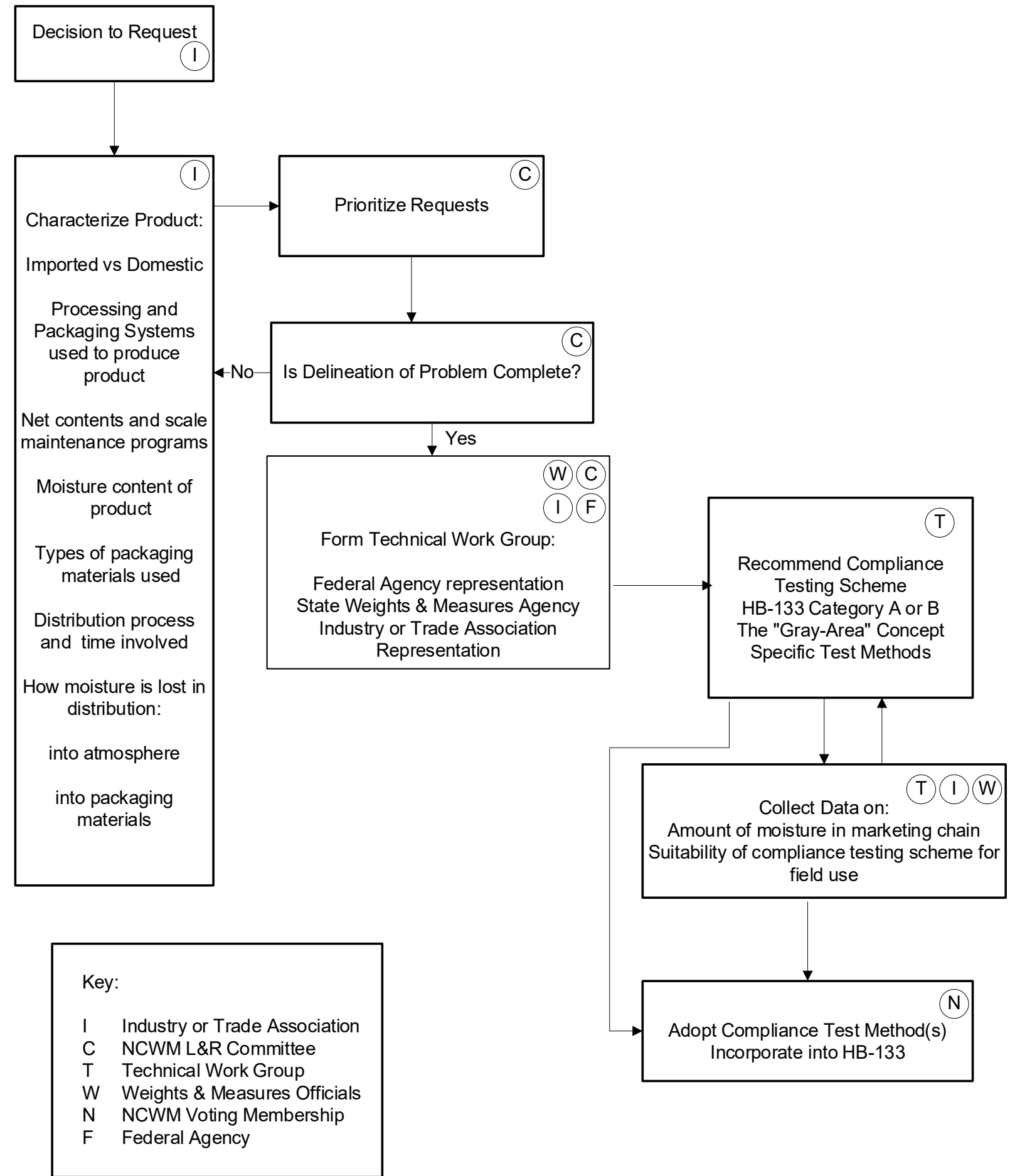




\subsubsection{Retail Gas Sales and Metric Price Computations in General.}

(S\&T, 1980, p. 227)

\section{Guideline}

The National Institute of Standards and Technology published equivalent rounded values for metric equivalents of U.S. customary units should be used. They are:

$$
\begin{aligned}
& 3.785411784 \text { liters = } 1 \text { gallon } \\
& 0.2641720524 \text { gallon = } 1 \text { liter }
\end{aligned}
$$

A "Rule of Reason" should apply to the corrected value so that the value used is consistent with the quantity of the transaction. The converted value should never have fewer than four significant digits and should have at least the same number of significant digits as the number of significant digits in the quantity of product being converted. For example, if a 1000 gal delivery were to be converted to liters the value would be $3785 \mathrm{~L}$; for $10000 \mathrm{gal}, 37854 \mathrm{~L}$; for 100 gal, $378.5 \mathrm{~L}$.

In the case of expressing a unit price equivalent for consumer value comparisons in retail gasoline sales, the following formula should be used: (advertised, posted, or computing device unit price per liter) $\times 3.785=$ (equivalent unit price per gallon, rounded to the nearest $1 / 10$ cent.)

\section{Examples:}

26.9 cents per liter $\times 3.785=\$ 1.018$ per gallon

26.8 cents per liter $\times 3.785=\$ 1.014$ per gallon

26.7 cents per liter $\times 3.785=\$ 1.011$ per gallon

26.5 cents per liter $\times 3.785=\$ 1.003$ per gallon

26.4 cents per liter $\times 3.785=\$ 0.999$ per gallon

This method is preferable to the alternative method of dividing the price per gallon by 3.785 , which results in the same price per liter for three or more different prices per gallon when rounded to the $1 / 10$ cent.

\subsubsection{Price Posting.}

(L\&R, 1981, p. 101)

\section{Guideline}

1. Street Signs.

a. Until such time as the sale of gasoline and other Engine fuels is predominately by metric measurement (liter), price per gallon information should be made readily available to all prospective customers.

b. All street, roadside, and similar advertising signs displaying product price should provide price per gallon information.

c. Signs showing the equivalent price per liter may also be used, but their use is optional and should not employ numerals larger than the equivalent gallon price display.

d. Signs should show complete dollar and cents numerals, and they should be clearly legible and of full size. An exception should be granted to street signs that were designed to display only three numerals (e.g., \$.899) and not four numerals as required for prices over \$1.00 per gallon (e.g., \$1.259). Until such signs can be replaced or modified, it would be acceptable:

(1) to attach an appropriate sign extension with the decimal fraction of a cent representation in alignment with the posted price; 
(2) to include a smaller fraction of a cent representation with the last numeral of the posted price; or

(3) to add the whole number "one" before the cents values.

e. The changeover to advertising prices by the liter as a single mode of pricing should be established when $75 \%$ of all retail outlets in a jurisdiction have converted their dispensers to metric measurement.

2. Posting of Prices at the Dispenser.

Each retail outlet should use exclusively only one measurement method of sale (gallon or liter). A change from one method to another should be carried out for all devices dispensing motor fuels in the retail outlet.

In the case of liter sales, suitable posting of per gallon and per liter prices at the device, service island, premises of the retail outlet, or any other locations must be in accordance with state and local laws, regulations, and ordinances, and in a manner that facilitates consumer comparisons between the per gallon price and the per liter price. Additional requirements may be necessary to avoid uncertainty as to nomenclature, location, and size of information on signs.

It is recommended that:

a. Current and accurate price comparisons between gallon and liter values be posted at the dispenser within easy view of the customer and visible from either side of the island.

b. The sign should show equivalent quantity and price information.

\section{Examples:}

$27.1 \varnothing$ per liter $=\$ 1.026$ per gallon

3.785 liters $=1$ gallon

c. Letters and numerals should be at least $3 / 4$ in $(19 \mathrm{~mm})$ in height and $1 / 8$ in $(3 \mathrm{~mm})$ in width of stroke.

3. Quantity and Price Display on Dispensers

It is required that dispensers be designed to clearly show all required quantity and price information on the face(s) of a motor fuel dispenser in accordance with NIST Handbook 44.

4. Dispenser Modification Kits

As an interim alternative to "half pricing," a number of computer modification kits have been installed to modify existing retail motor fuel dispensers that were not designed to compute and indicate prices over $99.9 \notin$ per gallon.

Some of the modification kits that have been referred to state weights and measures officials for approval have been rejected as failing to conform to NIST Handbook 44 requirements. It is recommended that all modification kits and future modifications of dispensers be so designed and made as to be in full compliance with all applicable requirements of NIST Handbook 44.

\subsubsection{Octane Posting Regulations.}

(Liaison, 1979, p. 240)

\section{Guideline}

Weights and Measures officials should report to the FTC any instances of failure to post octane ratings by service stations. These would most likely occur during routine inspections of service station gasoline dispensers. Reports should be made to the appropriate FTC regional offices as listed below. 


\section{Background}

As of June 1, 1979, the FTC requires the determination of octane ratings by refiners, the certification of octane ratings by refiners and distributors, and the posting of octane ratings by retailers on all gasoline pumps. The requirements are set forth in Public Law 95 297, the Petroleum Marketing Practices Act (PMPA), passed in June 1978 and the FTC's Octane Rule, 16 CFR 306. Although the octane posting rule has no effect on most FTC programs administered by state weights and measures officials with respect to checking gasoline dispensing devices for accuracy, the Liaison Committee feels that the Conference should be generally informed about the law and the FTC rule, if only to be prepared to answer inquiries about it or for some probable future enforcement demands. Keeping apprised of developments associated with the rule may be advisable. In addition, it will affect states which have octane certification and posting programs.

Information on the FTC Regional Offices can be obtained at www.ftc.gov/about-ftc/bureaus-offices/regionaloffices or by mail Consumer Response Center, Federal Trade Commission, 600 Pennsylvania Avenue, NW, Washington, DC 20580. Telephone: (202) 326-2222.

The preemption section of PMPA (204) reads as follows:

Section 204. To the extent that any provision of this title applies to any act or omission, no state or any political subdivision thereof may adopt, enforce, or continue in effect any provision of any law or regulation (including any remedy or penalty applicable to any violation thereof) with respect to such act or omission, unless such provision of such law or regulation is the same as the applicable provision of this title.

Section 204 prohibits states and other political subdivisions from enforcing requirements that are not the same as the applicable provisions of this law. Jurisdictions having octane requirements should carefully review with their legal advisors the effect of this law.

The FTC's Octane rule was published in final form on March 30, 1979, in the Federal Register (Vol. 44, No. 63, Part V, pp. 19160 19172). The rule became effective June 1, 1979.

The law requires that refiners determine octane ratings of their products, and certify them to their distributors. The distributors must pass along the certification to the retailer, unless he blends the gas, in which case he may have to certify his blend.

A similar procedure relating to the posting of octane ratings is set forth for the retailer. The FTC is responsible for enforcement with respect to the accuracy of the certified ratings. The FTC is also empowered to check records, which must be retained for one year by each link in the distribution chain.

The FTC is in need of help from the state and local jurisdictions in the area of surveillance and testing. Such assistance could occur at a number of levels. Notice of octane mislabeling and failure to post octane ratings is requested.

Other levels of assistance would concern jurisdictions that have octane testing programs and would be interested in cooperating with FTC in testing or in reporting discrepancies in octane rating.

2.6.4. Multi-Tier Pricing: Motor Fuel Deliveries (Computing Pumps or Dispensers). (L\&R, 1982, p. 150; L\&R, 1985, p. 100) (L\&R, 1988, p. 162)

\section{Policy}

Charging different prices for the same product depending upon the manner of payment, other purchases, amount of service, etc., is a management decision of the merchandiser. Those merchants who elect to offer multiple prices for motor fuel must comply with the state and local weights and measure laws and regulations, including Handbook 44. They must also make marketing decisions that comply with state truth in lending, cash discount, price advertising, and usury laws. All such laws are intended to prohibit deceptive, misleading, or misrepresentative information being given to the consumer. The following guidelines are intended to apply to price advertising or posting at the street side or 
highway as well as at the pump or dispenser, and to the price computed at the device. These guidelines are applicable to other discount or combination offers (such as combination purchases of car wash and gas, for example).

1. If a price is posted or advertised, it must be available to all qualified customers. If any condition or qualification is required to obtain the posted price, that condition must also be posted clearly and understandably, in conjunction with the price wherever it is posted.

2. The lowest price may be posted or advertised by itself as long as any restrictions for receiving that price (for example, "cash only") are also clearly posted or advertised in conjunction with the price and as long as other state requirements do not prohibit it. For example, certain states require that all prices available from a given retail location must be posted on street side signs if any prices are posted.

3. If the merchandiser elects to establish separate devices or islands for sale of the same product at different prices, the devices or islands shall be clearly identified as "cash," "credit," "self-serve," or other appropriate wording to avoid customer confusion.

4. The use of a single-price-computing dispenser for sale of motor fuel at multiple unit prices is inappropriate, facilitates fraud, and should be eliminated. The NCWM should adopt a plan and timetable for changeover to devices that can compute and display final money values for multiple prices.

\subsubsection{Cereal Grains and Oil Seeds.} (L\&R, 1981, p. 95; L\&R, 1996, p. 135)

\section{Interpretation}

The addition of water to grain for the purpose of adding weight prior to selling grain by weight is an illegal practice under federal laws.

NOTE: Effective February 11, 1995, the Federal Grain Inspection Service adopted a regulation in 7 CFR 800.61 prohibiting the application of water to grain except for milling, malting, or similar processing operations. See Volume 59, No. 198 for Friday, October 14, 1994, or page 52 071, for additional information.

\section{Background}

A letter from the Oklahoma Grain and Feed Association was forwarded to the Committee asking whether the addition of water to grain is legal. The request was prompted by an article reporting on methods of adding water to grain to bring the moisture content up to market standards. For example, when soybeans are sold at $8 \%$ moisture content, there is less weight sold (and less revenue for the soybeans to the seller) than if water were added to the same soybeans to bring them to $10 \%$ moisture content.

However, the Committee is greatly concerned about the ramifications of such practices. Many grain experts do not believe that over-dried grain should be valued as highly as grain at moisture contents close to market standards. Overly dry grain is more susceptible to breakage, for example.

Water added after harvest will not be taken up chemically the way that naturally moist grain binds water. Errors in adding water or the particular biochemical nature of the grain after addition of water can lead to spoiled grain. Studies on the long term keeping qualities of grain with water added have not been carried out. The calibration of moisture meters is based on naturally moist grain, and there is a known difference between the electrical properties of naturally moist grain and grain with moisture added.

Of a more basic nature, however, the Committee recognizes the fact that a grain buyer purchases grain expecting such grain to be naturally moist or dried, not to be with water added. The seller who adds water to grain solely to add weight, therefore, misrepresents his product. 
Both the FDA and USDA have sent letters to the Committee indicating that the addition of water to grain solely for the purpose of adding weight is an illegal practice. Because existing federal laws already prohibit this practice, the Committee recommends no further action on the part of the Conference at this time.

\subsubsection{Basic Engine Fuels, Petroleum Products, and Lubricants Laboratory.} (L\&R, 1994, p. 129-135; L\&R, 2006, p. L\&R-8) (Developed by the Petroleum Subcommittee.)

The petroleum fuels and lubricants laboratory is an integral element of an inspection program and is generally developed to satisfy the testing requirements as described in the laws and rules of the regulating agency. Guidelines have been developed to assist states in evaluating their options of employing a private lab or building or expanding their own lab. (Refer to NIST SP 1053 Report of the 91st NCWM Annual Meeting (2006) - refer to Appendix C., Item 250-1: Basic Engine Fuels, Petroleum Products, and Lubricants Laboratory Guidelines on L\&R C-1. (www.nist.gov/pml/weights-and-measures/publications/ncwm-annual-reports).

\subsubsection{Product Conformance Statements.}

(L\&R, 1992, p. 148)

\section{Interpretation}

References to a product's conformance with product standards (for example, "manufactured to standard EN235" or similar product conformance statements) on labels for wallcovering or other products, are not considered qualifying terms and do not violate Section 6.12.1. Supplementary Quantity Declarations of the Uniform Packaging and Labeling Regulation, provided the requirements of Section 8.1.4. Free Area is met.

\section{Background}

The Wallcovering Manufacturers Association (WMA) requested the Conference's position on the use of conformance statements on the labels of wallcovering and border material. This issue relates to wallcovering products that originate from manufacturers in Europe where a declaration of conformance to a specific government standard is required on consumer packages. Thousands of product "standards" or "Euronorms" are being established for the European Community. Conformance declarations are required to provide consumers and customs officials with information on the product. The issue relates to the use of such statements as "manufactured to standard EN235" on labels of wallcovering that are imported from Europe. The WMA requested the Committee's opinion on the use of this type of statement if a package is labeled in conformance with sections Section 6.12.1. Supplementary Quantity Declarations and Section 8.1.4. Free Area. One question is whether the display of the conformance statement would be permitted provided that it did not include an unacceptable quantity declaration. Another question concerns the need to comply with the requirement for adequate free area around the quantity declaration when the conformance declaration is placed on the label. It was the Committee's opinion that conformance statements on package labels would not violate any provisions of the UPLR if the requirements of Sections 6.12.1. Supplementary Quantity Declarations and 8.1.4. Free Area are met.

The Committee recommended this interpretation for inclusion in Handbook 130 because it is likely that this type of notice will become common as more and more free market trading areas are opened to expand international trade. This interpretation does not indicate acceptance or endorsement of any requirements contained in product conformance statements.

\subsubsection{Commodities Under FTC Jurisdiction under the Fair Packaging and Labeling Act (FPLA) and Exclu- sions. \\ (L\&R, 1993, p. 279; L\&R, 1994, p. 294)}

The following lists indicate the commodities and commodity groups that are and are not within the scope of the Fair Packaging and Labeling Act administered by the FTC. The following codes appear with each excluded commodity and designate the reason that the particular commodity has been excluded. 
CI (Commission Interpretation) - designates those categories that have been excluded by the Commission in the light of legislative history of the definition of "consumer commodity." By applying this definition to individual commodities, the Commission has more narrowly applied the latter term and set forth a list of items that do not meet the criteria of consumer commodities. On occasion the Commission is requested in both a formal and informal manner to consider individual products and to determine their status relative to the definition of "consumer commodity" as it is used in the Act.

EPA - designates commodities subject to the Federal Environmental Pest Control Act of 1972 administered by the Environmental Protection Agency.

FDA - designates those commodities which are subject to regulation by the FDA either under the portion of the FPLA administered by that agency or the Federal Food, Drug, and Cosmetic Act (Section 10(a)(3) and Section 7 of the FPLA). Following the code FDA will be a letter further designating the commodity as either a food (F), drug (D), cosmetic (C), or device (DV).

TTB (formerly known as BATF) - designates commodities subject to laws administered by the Alcohol, and Tobacco Tax, and Trade Bureau.

USDA - designates those commodities excluded from jurisdiction by Section 10(a) of the FPLA and represents a commodity within one of the following categories: meat or meat products, poultry or poultry products, or tobacco or tobacco products.

It may be of some help in ascertaining whether a particular product is or is not included within the FPLA definition of "consumer commodity" and thus subject to FTC jurisdiction under that Act, to refer to the following definition:

“. . Any article, product, or commodity of any kind or class which is customarily produced or distributed for sale through retail sales agencies or instrumentalities for consumption by individuals, or use by individuals for purposes of personal care or in the performance of services ordinarily rendered within the household, and which is usually consumed or expended in the course of such use."

By applying these criteria to the particular product in question and then reviewing the list of excluded commodities, the observer will be able, in most instances, to determine the status of the item. In the event, however, that the observer is unable to ascertain whether a particular commodity is covered or excluded from FTC jurisdiction, contact FTC for an opinion. 


\begin{tabular}{|c|c|}
\hline \multicolumn{2}{|c|}{ Commodities Included Under FTC Jurisdiction } \\
\hline Soaps and Detergents & $\begin{array}{l}\text { Powder, flakes, chips, etc. } \\
\text { Liquid } \\
\text { Paste, cake, or tablet }\end{array}$ \\
\hline Cleaning Compounds & $\begin{array}{l}\text { Liquid } \\
\text { Powder } \\
\text { Paste or cake } \\
\text { Solvent and cleaning fluids for home use }\end{array}$ \\
\hline Laundry Supplies & $\begin{array}{l}\text { Conditioners and softeners, ironing aids, distilled water } \\
\text { Sizings and starches } \\
\text { Bluings and bleaches } \\
\text { Pre-soaks, enzymes, etc. }\end{array}$ \\
\hline Cleaning Devices & $\begin{array}{l}\text { Sponges and chamois } \\
\text { Steel wool, scouring and soap pads }\end{array}$ \\
\hline Food Wraps & $\begin{array}{l}\text { Plastic and cellophane } \\
\text { Wax paper and paper } \\
\text { Foil (aluminum wrap) }\end{array}$ \\
\hline Paper Products & $\begin{array}{l}\text { Toweling } \\
\text { Napkins, table cloths, and place mats } \\
\text { Facial tissues } \\
\text { Bathroom tissues } \\
\text { Disposable diapers } \\
\text { Crepe paper } \\
\text { Other (e.g., shelf paper, wrapping paper, eye glass tissues) }\end{array}$ \\
\hline Waxes and Polishes & $\begin{array}{l}\text { Powder } \\
\text { Liquid } \\
\text { Paste and cake } \\
\text { Other (e.g., polish impregnated cloths, scratch removers) }\end{array}$ \\
\hline Household Supplies & $\begin{array}{l}\text { Matches } \\
\text { Candles } \\
\text { Toothpicks } \\
\text { Cordage (string, twine, rope, clothes line, etc.) } \\
\text { Drinking straws } \\
\text { Lighter and propane torch fuel, flints, pipe cleaners, etc. } \\
\text { Lubricants } \\
\text { Picnic supplies } \\
\text { Sandpaper and emery paper }\end{array}$ \\
\hline & $\begin{array}{l}\text { Charcoal briquets, chips, logs, etc. } \\
\text { Dyes and tints }\end{array}$ \\
\hline & Camera film, photo supplies and chemicals \\
\hline
\end{tabular}




\begin{tabular}{||l|l||}
\hline \multicolumn{2}{|c|}{ Commodities Included Under FTC Jurisdiction } \\
\hline \hline & Protective foil cooking utensils \\
& Aluminum foil cooking utensils \\
& Christmas decorations \\
& Solder \\
& LPG for other than home heating or cooking \\
& Waxes for home use \\
& Light bulbs \\
& Dry cell batteries \\
& Pressure sensitive tapes, excluding gift tapes \\
\hline Containers & Paper (plain, waxed, or plastic coated) \\
& Foil \\
& Plastic or Styrofoam \\
\hline Air Fresheners and Deodorizers & Potpourri \\
\hline Adhesives and Sealants & \\
\hline Cordage & \\
\hline \hline
\end{tabular}




\begin{tabular}{|c|c|c|}
\hline \multicolumn{3}{|c|}{ Commodities Excluded from FTC Jurisdiction } \\
\hline Term & Description & $\begin{array}{c}\text { FTC } \\
\text { Jurisdiction }\end{array}$ \\
\hline Adhesive Tape & & FDA-D \\
\hline Alcoholic Beverages & & TTB \\
\hline Aluminum Clothesline & Plastic clothesline with a steel core & $\mathrm{CI}$ \\
\hline Antifreeze & & $\mathrm{CI}$ \\
\hline $\begin{array}{l}\text { Artificial Flowers and } \\
\text { Parts }\end{array}$ & & $\mathrm{CI}$ \\
\hline Automotive Accessories & Floor mats, seat covers, spare parts, etc. & $\mathrm{CI}$ \\
\hline $\begin{array}{l}\text { Automotive Chemical } \\
\text { Products }\end{array}$ & $\begin{array}{l}\text { Auto polish, wax, and finish conditioner, rubbing compound, tire } \\
\text { paint, chrome polish, gasoline additives, etc. }\end{array}$ & $\mathrm{CI}$ \\
\hline $\begin{array}{l}\text { Bath Oil and Bubble } \\
\text { Bath }\end{array}$ & & FDA-C \\
\hline Bicycle Tires and Tubes & & $\mathrm{CI}$ \\
\hline Books & & $\mathrm{CI}$ \\
\hline Bottled Gas & Cooking or heating & $\mathrm{CI}$ \\
\hline Brushes & $\begin{array}{l}\text { Bristle, nylon, etc., including hair-brushes, toothbrushes, hand and } \\
\text { nail brushes, paint brushes, etc. }\end{array}$ & $\mathrm{CI}$ \\
\hline Brooms and Mops & Glass, floor, and dish mops, etc. & $\mathrm{CI}$ \\
\hline "Bug Proof" Shelf Paper & & EPA \\
\hline Candle Holders & Without candles & $\mathrm{CI}$ \\
\hline Cameras & & $\mathrm{CI}$ \\
\hline Chinaware & & $\mathrm{CI}$ \\
\hline Christmas Light Sets & Replacement or other bulbs sold separately are not excluded & $\mathrm{CI}$ \\
\hline Cigarette Lighters & & $\mathrm{CI}$ \\
\hline Clothespins & & $\mathrm{CI}$ \\
\hline $\begin{array}{l}\text { Clothing and Wearing } \\
\text { Apparel }\end{array}$ & Socks, gloves, shoelaces, underwear, etc. & $\mathrm{CI}$ \\
\hline Compacts and Mirrors & & $\mathrm{CI}$ \\
\hline Cosmetics & $\begin{array}{l}\text { Defined by Section 201(i) of the Food, Drug, and Cosmetic Act as } \\
\text { "(l) articles intended to be rubbed, poured, sprinkled, or sprayed on, } \\
\text { introduced into, or otherwise applied to the human body or any part } \\
\text { thereof for cleansing, beautifying, promoting attractiveness, or alter- } \\
\text { ing the appearance, and (2) articles intended for use as a component } \\
\text { of any such articles; except that such term shall not include soap." }\end{array}$ & FDA-C \\
\hline Cotton Puffs & Sterilized & FDA-D \\
\hline Crystalware & & $\mathrm{CI}$ \\
\hline $\begin{array}{l}\text { Detergent Bar with Any } \\
\text { Drug or Cosmetic Claim }\end{array}$ & $\begin{array}{l}\text { If the observer experiences difficulty in ascertaining whether or not } \\
\text { a given product is a soap or a detergent, contact the manufacturer or } \\
\text { FDA. }\end{array}$ & FDA-D or $\mathrm{C}$ \\
\hline Decorative Magnets & & $\mathrm{CI}$ \\
\hline
\end{tabular}




\begin{tabular}{|c|c|c|}
\hline \multicolumn{3}{|c|}{ Commodities Excluded from FTC Jurisdiction } \\
\hline Term & Description & $\begin{array}{c}\text { FTC } \\
\text { Jurisdiction }\end{array}$ \\
\hline Devices & $\begin{array}{l}\text { Defined by Section 201(h) of the Food, Drug, and Cosmetic Act as } \\
\text { "instruments, apparatus, and contrivances, including their compo- } \\
\text { nents, parts, and accessories, intended (1) for use in the diagnosis, } \\
\text { cure, mitigation, treatment, or prevention of disease in man or other } \\
\text { animals; or (2) to affect the structure or any function of the body of } \\
\text { man or other animals." This category includes trusses, syringes, } \\
\text { arch supports, etc. }\end{array}$ & FDA-DV \\
\hline Diaries and Calendars & & $\mathrm{CI}$ \\
\hline Disinfectants & & EPA \\
\hline Drugs & $\begin{array}{l}\text { Defined by Section 201(g)(1) of the Food, Drug, and Cosmetic Act } \\
\text { as "(a) articles recognized in the official United States Pharmaco- } \\
\text { peia, official Homeopathic Pharmacopeia, or official National For- } \\
\text { mulary, or any supplement to any of them; and (b) articles intended } \\
\text { for use in the diagnosis, cure, mitigation, treatment, or prevention of } \\
\text { disease in man or other animals; and (c) articles (other than food) } \\
\text { intended to affect the structure or any function of the body of man } \\
\text { or other animals; and (d) articles intended for use as a component of } \\
\text { any articles specified in clause (a), (b) or (c); but does not include } \\
\text { devices or their components, parts, or accessories." }\end{array}$ & FDA-D \\
\hline $\begin{array}{l}\text { Durable Articles or } \\
\text { Commodities }\end{array}$ & & $\mathrm{CI}$ \\
\hline EPA Covered Products & $\begin{array}{l}\text { Products subject to regulation under the Federal Environmental Pes- } \\
\text { ticide Control Act that is administered by the Environmental Protec- } \\
\text { tion Agency. }\end{array}$ & EPA \\
\hline Fingernail Files & & $\mathrm{CI}$ \\
\hline $\begin{array}{l}\text { Flowers, Flower Seeds, } \\
\text { Fertilizer, and Fertilizer } \\
\text { Materials, Plants or } \\
\text { Shrubs, Garden and } \\
\text { Lawn Supplies }\end{array}$ & & $\mathrm{CI}$ \\
\hline Food & $\begin{array}{l}\text { Defined by Section 201(f) of the Food, Drug, and Cosmetic Act as } \\
\text { "(1) articles used for food and drink for man or other animals, } \\
\text { (2) chewing gum, and (3) articles used for components of any such } \\
\text { article." }\end{array}$ & FDA-F \\
\hline $\begin{array}{l}\text { Fountain Pens, Mechani- } \\
\text { cal Pencils, and Kindred } \\
\text { Products }\end{array}$ & Ball point pens, lead pencils, and lead refills, etc. & $\mathrm{CI}$ \\
\hline Garden Tools & Hoses, trowels, grass clippers, etc. & $\mathrm{CI}$ \\
\hline $\begin{array}{l}\text { Germ Killing or Germ } \\
\text { Proofing Products }\end{array}$ & & EPA \\
\hline Gift Tape and Ties & Ribbon, tape, etc. & $\mathrm{CI}$ \\
\hline Gift Wrapping Material & Decorative wrapping foil, paper, cellophane, etc. & $\mathrm{CI}$ \\
\hline Glasses and Glassware & Disposable plastic glasses are not excluded & $\mathrm{CI}$ \\
\hline Gloves (of Any Type) & & $\mathrm{CI}$ \\
\hline
\end{tabular}




\begin{tabular}{|c|c|c|}
\hline \multicolumn{3}{|c|}{ Commodities Excluded from FTC Jurisdiction } \\
\hline Term & Description & $\begin{array}{c}\text { FTC } \\
\text { Jurisdiction }\end{array}$ \\
\hline Greeting Cards & & $\mathrm{CI}$ \\
\hline $\begin{array}{l}\text { Hair Combs, Nets, and } \\
\text { Pins }\end{array}$ & & FDA-DV \\
\hline Hand Tools & & $\mathrm{CI}$ \\
\hline $\begin{array}{l}\text { Handicraft and Sewing } \\
\text { Thread }\end{array}$ & Yarn, etc. & $\mathrm{CI}$ \\
\hline Hardware & $\begin{array}{l}\text { Extension cords, thumb-tacks, hose clamps, nails, screws, picture } \\
\text { hangers, etc. }\end{array}$ & $\mathrm{CI}$ \\
\hline $\begin{array}{l}\text { Household Appliances, } \\
\text { Equipment, or Furnish- } \\
\text { ings, Including Feather } \\
\text { and Down-Filled Prod- } \\
\text { ucts, Synthetic-Filled } \\
\text { Bed Pillows, Mattress } \\
\text { Pads and Patchwork } \\
\text { Quilts, Comforters, and } \\
\text { Decorative Curtains }\end{array}$ & & $\mathrm{CI}$ \\
\hline Ink & & $\mathrm{CI}$ \\
\hline Insecticides & Insect repellents in any form, mothballs, etc. & EPA \\
\hline Ironing Board Covers & & $\mathrm{CI}$ \\
\hline Jewelry & & $\mathrm{CI}$ \\
\hline Lambs Wool Dusters & & $\mathrm{CI}$ \\
\hline Luggage & & $\mathrm{CI}$ \\
\hline $\begin{array}{l}\text { Magnetic Recording } \\
\text { Tape }\end{array}$ & Reels, cassettes, and cartridges. & $\mathrm{CI}$ \\
\hline Meat and Meat Products & & USDA \\
\hline Metal Pails & & $\mathrm{CI}$ \\
\hline Motor Oil & Including additives. Household multi-purpose oil is not excluded. & $\mathrm{CI}$ \\
\hline Mouse and Rat Traps & & $\mathrm{CI}$ \\
\hline Mouthwash & & FDA-D \\
\hline Musical Instruments & & $\mathrm{CI}$ \\
\hline $\begin{array}{l}\text { Paints and Kindred Prod- } \\
\text { ucts }\end{array}$ & $\begin{array}{l}\text { Wallpaper, turpentine, putty, paint removers, caulking and glazing } \\
\text { compounds, wood fillers, etc. Note, however, that bathroom } \\
\text { caulking materials, patching plaster, spackling compound, and } \\
\text { plastic wood are not excluded. In the event of uncertainty, contact } \\
\text { FTC. }\end{array}$ & $\mathrm{CI}^{\prime}$ \\
\hline $\begin{array}{l}\text { Paintings and Wall } \\
\text { Plaques }\end{array}$ & & CI \\
\hline Pet Care Supplies & & $\mathrm{CI}$ \\
\hline Pewterware & & $\mathrm{CI}$ \\
\hline Photo Albums & & $\mathrm{CI}$ \\
\hline
\end{tabular}




\begin{tabular}{|c|c|c|}
\hline \multicolumn{3}{|c|}{ Commodities Excluded from FTC Jurisdiction } \\
\hline Term & Description & $\begin{array}{c}\text { FTC } \\
\text { Jurisdiction }\end{array}$ \\
\hline Pictures & & $\mathrm{CI}$ \\
\hline $\begin{array}{l}\text { Plastic Buckets and Gar- } \\
\text { bage Cans }\end{array}$ & & $\mathrm{CI}$ \\
\hline $\begin{array}{l}\text { Plastic Tablecloths, Plas- } \\
\text { tic Place Mats }\end{array}$ & & $\mathrm{CI}$ \\
\hline Plastic Shelf Lining & & $\mathrm{CI}$ \\
\hline $\begin{array}{l}\text { Pre-Moistened } \\
\text { Towelettes }\end{array}$ & & FDA-C \\
\hline Polishing Cloths & $\begin{array}{l}\text { Polishing cloths that are impregnated with polish or chemicals (sili- } \\
\text { cone, etc.) are not excluded. }\end{array}$ & $\mathrm{CI}$ \\
\hline $\begin{array}{l}\text { Poultry and Poultry } \\
\text { Products }\end{array}$ & & USDA \\
\hline Rubber Gloves & & $\mathrm{CI}$ \\
\hline Rubbing Alcohol & & FDA-D \\
\hline Safety Flares & & $\mathrm{CI}$ \\
\hline Safety Pins & & $\mathrm{CI}$ \\
\hline Sanitary Napkins & & FDA-D or C \\
\hline School Supplies & Rulers, crayons, paper, pencils, etc. & $\mathrm{CI}$ \\
\hline $\begin{array}{l}\text { Self-Stick Protective Felt } \\
\text { Tabs }\end{array}$ & & $\mathrm{CI}$ \\
\hline Seeds of All Kinds & & USDA \\
\hline Sewing Accessories & Needles of any type, thimbles, kindred articles, etc. & $\mathrm{CI}$ \\
\hline Shampoo & & $\begin{array}{l}\text { FDA-C } \\
\text { or D }\end{array}$ \\
\hline Shoelaces & & $\mathrm{CI}$ \\
\hline Small Arms Ammunition & & $\mathrm{CI}$ \\
\hline $\begin{array}{l}\text { Silverware, Stainless } \\
\text { Steelware, and Pewter- } \\
\text { ware }\end{array}$ & & $\mathrm{CI}$ \\
\hline Smoking Pipes & & $\mathrm{CI}$ \\
\hline $\begin{array}{l}\text { Soap Bars with a Drug } \\
\text { Claim }\end{array}$ & $\begin{array}{l}\text { Including any claim for removing facial blemishes, etc. Refer to } \\
\text { Detergent Bars for further discussion in this area. }\end{array}$ & FDA-D \\
\hline Soap Dishes & & $\mathrm{CI}$ \\
\hline Souvenirs & & $\mathrm{CI}$ \\
\hline Sporting Goods & & $\mathrm{CI}$ \\
\hline $\begin{array}{l}\text { Stationery and Writing } \\
\text { Supplies }\end{array}$ & Loose-leaf binders, paper tablets, etc. & $\mathrm{CI}$ \\
\hline $\begin{array}{l}\text { Textiles and Items of } \\
\text { Wearing Apparel }\end{array}$ & Cloth laundry bags, towels, cheese cloth, shoe shine cloths, etc. & $\mathrm{CI}$ \\
\hline
\end{tabular}




\begin{tabular}{||l|l|c||}
\hline \multicolumn{2}{|c|}{ Commodities Excluded from FTC Jurisdiction } \\
\hline \hline \multicolumn{1}{|c|}{ Term } & \multicolumn{1}{|c||}{ Description } & $\begin{array}{c}\text { FTC } \\
\text { Jurisdiction }\end{array}$ \\
\hline $\begin{array}{l}\text { Tobacco and Tobacco } \\
\text { Products }\end{array}$ & Pipes, cigarettes, etc. & TTB - USDA \\
\hline Toothpaste & & FDA-D \\
\hline Toys & & CI \\
\hline Typewriter Ribbon & & CI \\
\hline Wire of Any Type & & CI \\
\hline Woodenware & & CI \\
\hline \hline
\end{tabular}

\subsubsection{Size Descriptors for Raw, Shell-On Shrimp Products.}

(L\&R, 1995, p. 97)

\section{Guideline}

If size descriptor terms for shrimp (e.g., small, medium, large, or colossal) are used on packages, advertisements, or on signs when offering shrimp for sale from bulk, a statement of count-per-kilogram, if sold by kilogram, or countper-pound, if sold by pound, should be included adjacent to the size descriptor (e.g., medium-large, 31 to 40 shrimp per pound).

\subsubsection{Model Guidelines for the Administrative Review Process.}

\section{Purpose}

These guidelines are provided to assist weights and measures programs in establishing an administrative review process. They are not intended to be the only process an agency may use nor are they intended to supersede any agency's existing process. Before implementing ANY process, it should be approved by legal counsel.

These guidelines ensure that persons affected by "inspection findings" (e.g., price misrepresentations or shortweight packages), or who are deprived of the use of their property (devices or packages placed under "stop" or "off-sale" order), are provided a timely-independent review of the action. The process enables affected persons to provide evidence which could be relevant in determining whether the enforcement action was proper. The purpose of the process is to ensure that a person's ability to conduct business is not hindered by improper enforcement actions. This process is independent of any other action (e.g., administrative penalties, prosecutions, etc.) that may be taken by the enforcement agency.

\section{Background}

In the course of their work, weights and measures officials take enforcement actions that may prohibit the use of devices or the sale of packaged goods (e.g., "stop-sale" or "off-sale" orders for packages and "stop-use" or "condemnation" tags issued on devices). Improper actions (e.g., not following prescribed test procedures, enforcing labeling requirements on exempted packages, or incorrectly citing someone for a "violation") place the official and the jurisdiction in the position of being liable for the action if it is found that the action was "illegal." In some cases, weights and measures jurisdictions could be ordered to pay monetary damages to compensate the affected party for the improper action.

This process is one way to provide affected persons an opportunity to present evidence which may be relevant in determining whether the order or finding has been properly made to an independent party. The procedure enables business operators to obtain an independent review of orders or findings so that actions affecting their business can be evaluated administratively instead of through litigation. This ensures timely review, which is essential because of the 
impact that such actions may have on the ability of a business to operate and in cases where perishable products may be lost.

\section{Review Provisions}

Parties affected by enforcement actions must be given the opportunity to appeal enforcement actions.

Inspectors are the primary contacts with regulated firms and thus are in the best position to ensure that the enforcement actions they take are "proper." "Proper" means that inspections are conducted (1) within the scope of the authority granted by law, (2) according to recognized investigative or testing procedures and standards, and (3) that enforcement actions are lawful. The "burden" for proving that actions are "proper" falls on the weights and measures program, not on regulated firms.

Weights and measures officials are law enforcement officers. Therefore, they have the responsibility to exercise their authority within the "due process" provisions of the U.S. Constitution. As weights and measure programs carry-out their enforcement responsibilities in the future, more and more challenges to their actions and authority will occur. It is in the best interest of any program to establish strict operational procedures and standards of conduct to prevent the occurrence of improper actions which may place the jurisdiction in an untenable position in a court challenge of an enforcement action. The foundation for ensuring "proper" actions is training, clear and concise requirements, and adoption of, and adherence to uniform test procedures and legal procedures.

Prior to taking enforcement actions the inspector should recheck test results and determine that the information on which the action will be taken is accurate.

Inspections shall be conducted with the understanding that the findings will be clearly and plainly documented and reviewed with the store's representative.

During the review of the findings, the firm's representative may provide information which must be used by the inspector to resolve the problems and concerns before enforcement actions are taken. In some cases, the provided information may not persuade the inspector to forego the action. In some cases, the inspector and business representative may not understand the circumstances surrounding the violations, or there may be a conflict between the parties that they cannot resolve. In other cases, the owner or manufacturer may not learn that an enforcement action has occurred until long after the inspector leaves the establishment.

Steps:

1. Provide a framework that will help in resolving most of these situations where "due process" is of concern. Make sure that the responsible party (e.g., as declared on the package label) is notified of violations and receives copies of inspection reports. Establish standard operating procedures to assure the affected party of timely access to a representative of the weights and measures program so that the firm can provide the relevant information or obtain clarification of legal requirements.

2. Make the process as simple and convenient as possible. Especially in distant or rural areas where there are no local offices, the review should be conducted by a supervisor of the official taking the action if agreed to by the person filing the request for review.

3. The process should include notice that the firm can seek review at a higher level in the weights and measures program or an independent review by a third party. The following procedures are recommended:

(a) Any owner, distributor, packager, or retailer of a device ordered out of service, or item or commodity ordered "off-sale," or inspection finding (e.g., a price misrepresentation or a shortweight lot of packages) shall be entitled to a timely review of such order, to a prompt, impartial, administrative review of such off-sale order or finding. 
A notice of the right to administrative review should be included on all orders or reports of findings or violations and should be communicated to the responsible firm (e.g., person or firm identified on the product label):

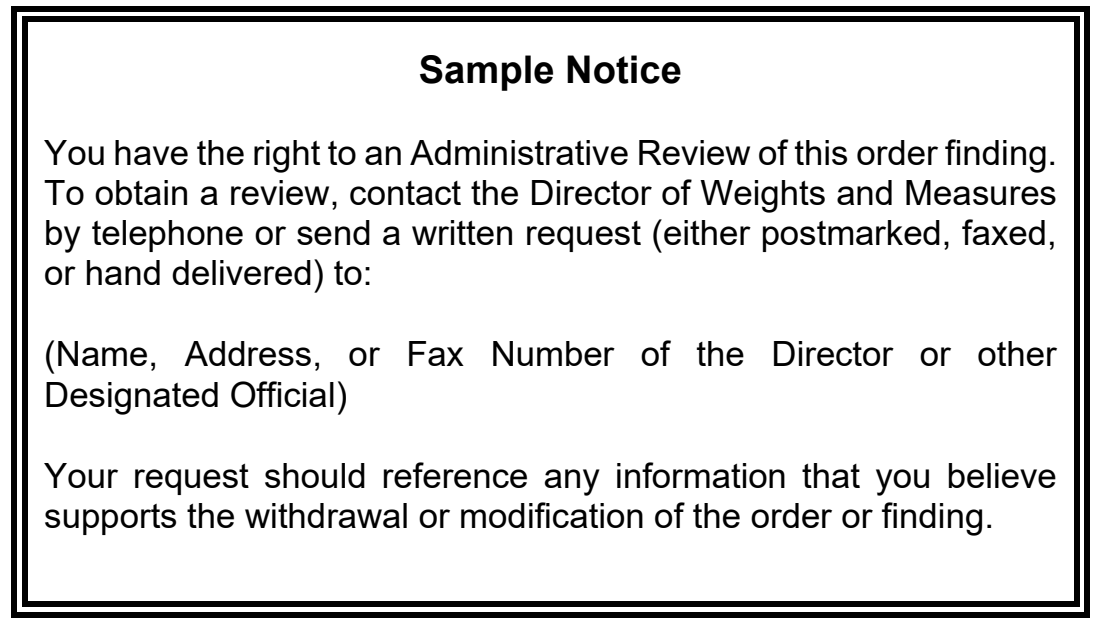

(b) The administrative review shall be conducted by an independent party designated by the Director or before an independent hearing officer appointed by the Department. The officer shall not be a person responsible for weights and measures administration or enforcement.

(c) No fees should be imposed for the administrative review process.

(d) The firm responsible for the product or the retailer may introduce any record or other relevant evidence.

\section{For example:}

i. Commodities subject to the off-sale action or other findings were produced, processed, packaged, priced, or labeled in accordance with applicable laws, regulations or requirements.

ii. Devices subject to the "stop-use" order or "condemnation" were maintained in accordance with applicable laws, regulations or requirements.

iii. Prescribed test procedures or sampling plans were not followed by the inspector.

iv. Mitigating circumstances existed which should be considered.

(e) The reviewer must consider the inspector's report, findings, and actions as well as any evidence introduced by the owner, distributor, packager, or retailer as part of the review process.

(f) The reviewer must provide a timely written recommendation following review unless additional time is agreed to by the department and the petitioner.

(g) The reviewer may recommend to the Department that an order be upheld, withdrawn or modified. If justified the reviewer may recommend other action including a reinspection of the device or commodity based upon information presented during the review.

(h) All actions should be documented and all parties advised in writing of the results of the review. The report of action should be detailed in that it provides the reasons for the decision. 


\subsubsection{Good Quantity Control Practices.}

Good Quantity Control Practices means that the plant managers should take all reasonable precautions to ensure the following quantity control standards or their equivalent are met:

1. A formal quantity control function is in place with authority to review production processes and records, investigate possible errors, and approve, control, or reject lots.

2. Adequate facilities (e.g., equipment, standards, and work areas) for conducting quantity control functions are provided and maintained.

3. A quantity control program (e.g., a system of statistical process control) is in place and maintained.

4. Sampling is conducted at a frequency appropriate to the product process to ensure that the data obtained is representative of the production lot.

5. Production records are maintained to provide a history of the filling and net content labeling of the product.

6. Each "production lot" contains on the average the labeled quantity and the number of packages exceeding the specified maximum allowable variation (MAV) value in the inspection sample shall be no more than permitted in Table 2-1. Sampling Plans for Category A and Table 2-2. Sampling Plans for Category B found in NIST Handbook 133, Appendix A.

7. Packaging practices are appropriate for specific products and measurement procedures (e.g., quantity sampling, density and tare determinations) and guidelines for recording and maintaining test results are documented.

8. Personnel responsible for quantity control follow written work instructions and are competent to perform their duties (e.g., background, education, experience and training). Training is conducted at sufficient intervals to ensure good practices.

9. Recognized procedures are used for the selection, maintenance, adjustment, and testing of filling equipment to insure proper fill control.

10. Weighing and measuring devices are suitable for their intended purpose. Recognized policies and procedures are established and followed to maintain metrological traceability to the International System of Units (SI) through the NIST. This includes a system of equipment maintenance and calibration to include recordkeeping procedures.

(Amended 2019)

11. Controls over automated data systems and software used in quantity control ensure that information is accessible, but changeable only by authorized personnel.

12. Tare materials are monitored for variation. Label changes are controlled to ensure net quantity matches labeled declaration.

\subsubsection{Point-of-Pack Inspection Guidelines.}

\section{A. Weights and Measures Officials' Responsibilities.}

1. Conduct inspections during hours when the plant is normally open for business. Open the inspection by making contact with the plant manager or authorized representative (e.g., the quality assurance manager or the production manager). 
2. Present the proper credentials and explain the reason for the visit (e.g., routine or follow-up inspection or consumer complaint).

3. Request access to quantity measurement equipment in the packing room, moisture testing equipment in the laboratory or in the packing room, and product packed on premise or stored in warehouse areas.

4. Obtain permission from a plant representative prior to using a tape recorder or a camera.

5. Conduct inspection related activities in a professional and appropriate manner and, if possible, work in an area that will not interfere with normal activities of the establishment.

6. Abide by all the safety and sanitary requirements of the establishment and clean the work area upon completion of the inspection/test. Return borrowed equipment and materials.

7. To close the inspection, recheck inspection reports in detail and ascertain that all information is complete and correct.

8. Sample questions and tasks for Inspectors:

(a) Inside Buildings and Equipment.

i. Is all filling and associated equipment in good repair?

ii. Are net content measurement devices suitable for the purpose being used?

iii. Are standards used by the firm to verify device accuracy traceable to NIST?

(b) Packing Room Inspection.

i. Observe if the program for net quantity of content control in the packing room is actually being carried out.

ii. Ensure that the weighing systems are suitable and tare determination procedures are adequate. If there are questions regarding tare determination, weigh a representative number of tare and/or filled packages.

iii. For products labeled and filled by volume and then checked by weight, ensure that proper density is used.

(c) Warehouse Inspection.

If an inspection is conducted:

i. Select lot(s) to be evaluated.

ii. Determine the number of samples to be inspected. Use the appropriate sampling plan as described in NIST Handbook 133, "Checking the Net Content of Packaged Goods."

iii. Randomly select the number of samples or use a mutually agreed on plan for selecting the samples.

iv. Determine the average net quantity of the sample and use the standard deviation factor to compute the Sample Error Limit (SEL) to evaluate the lot.

v. Look for individual values that exceed the applicable Maximum Allowable Variation as found in NIST Handbook 133. 
vi. Apply moisture allowances, if applicable.

vii. Review the general condition of the warehouse relevant to package integrity, good quantity control, and distribution practices.

viii. Prepare an inspection report to detail findings and actions.

9. Close the inspection - Review findings with Plant Representative.

After the inspection, meet with the management representative to discuss inspection findings and observations. Provide additional information as needed (e.g., information on laws and regulations or explanations of test procedures used in the inspection). Be informative, courteous and responsive. If problems/violations are found during the inspection/test, bring them to the attention of the appropriate person.

\section{B. Plant Management Responsibilities.}

1. Recognize that inspectors are enforcing a federal, state or local law.

2. Assist the official in conducting inspection activities in a timely and efficient manner.

3. During the initial conference with the inspector, find out whether the inspection is routine, a follow-up, or the result of a consumer complaint. If a complaint, obtain as much information as possible concerning the nature of the complaint, allowing for an appropriate response.

4. The plant manager, quality assurance manager, or any designated representative should accompany the inspector.

5. Plant personnel should take note of the inspector's comments during the inspection and prepare a detailed write-up as soon as the inspection is completed.

6. When an official presents an inspection report, discuss the observations and, if possible, provide explanations for any changes deemed necessary as a result of the inspection/test.

Plant Management: information that must be shared with the inspector.

1. Establishment name and address.

2. Type of firm and information on related firms or applicable information (e.g., sub-contractor, servant, or agent).

3. General description and location of shipping and storage areas where packaged goods intended for distribution are stored.

4. Commodities manufactured by or stored at the facility.

5. Names of responsible plant officials.

Plant Management: information that may be shared with the inspector.

1. Simple flow sheet of the filling process with appropriate net content control checkpoints.

2. Weighing or measuring device maintenance and calibration test records.

3. Type of quantity control tests and methods used. 
4. Net content control charts for any lot, shipment, or delivery in question or lots which have previously been cited.

5. Method of date coding the product to include code interpretation.

6. Laboratory reports showing the moisture analysis of the products which are in question or have been previously cited.

7. Product volume of lot sizes or related information.

8. Distribution records related to a problem lots including names of customers.

\subsubsection{Guideline for Verifying the Labeled Basis Weight of Communication and Other Paper.} (L\&R, 1998, p. 27)

2.6.13.1. Equipment. - Linear measure recommended in Section 5.3.1. Equipment in the third edition of NIST Handbook 133 "Checking the Net Contents of Packaged Goods."

- Scale with a minimum division of $0.5 \mathrm{~g}(0.001 \mathrm{lb})$ or less.

- Scientific calculator with a sample standard deviation function.

2.6.13.2. Scope and Recommended Enforcement Approach. - Paper is manufactured in various "basis weights" for use in different applications (e.g., copy paper can have a basis weight of 18 or $20 \mathrm{lb}$ ). Basis weight is part of the product identity and not a declaration of net contents. This procedure is used to audit the basis weight declared on package labels. If the tested packages in a sample do not have an average basis weight equal to or greater than the labeled basis weight, the inspection lot may be in violation. A potentially violative lot should be placed "off-sale" until the owner provides documentation to confirm that the labeled basis weight corresponds to the basis weight declared by the original manufacturer. If documentation is not provided, the inspection lot should remain "off-sale" until the basis weight declaration is corrected.

2.6.13.3. Determine Target Net Weight for Common Types of Paper. - The basis weight of paper is the designated weight (measured in grams or pounds per specified area) of one ream in basic sheet size for the type of paper being tested. This procedure permits the confirmation of basis weight by linear measurement and gravimetric testing. This procedure is designed to test the various types, size, count, and basis weights of packaged paper currently in the marketplace. Table 1 lists the "area of basic sheet size" for common types of paper. A "ream" equals 500 sheets of basic sheet size for all types of paper other than tissue paper. A "ream" of tissue paper equals 480 sheets. Each of the standard categories of paper products shown in Table 1 has a different standard basic sheet size. Although there are basic sheet sizes, paper is packaged and marketed in various sizes and counts. The net weight of packaged paper can be determined from the label information using the General Formula for Sheet Paper. For roll paper, use one (1) for the sheet count

\section{General Formula for Sheet Paper}

$$
\frac{P A \times B W}{B S S} \times \frac{S C}{500}=T N W
$$

Where:

$\begin{array}{lll}\mathrm{PA} & = & \text { measured area of one sheet of paper } \\ \mathrm{BW} & = & \text { labeled basis weight } \\ \mathrm{BSS} & = & \text { area of basic sheet size from Table 1 } \\ \text { SC } & = & \text { labeled package sheet count } \\ \text { TNW } & = & \text { target net weight of paper }\end{array}$


2.6.13.4. Test Procedure. - The following gravimetric, measuring, and counting procedures shall be used to determine if packages are accurately labeled. Procedures are also provided for verifying net quantity of content declarations for count and dimensions (e.g., length and width.)

2.6.13.4.1. Sample Selection. - Select a sample from an inspection lot using Table 2-1 Sampling Plans of Category A (page A-2) in the fourth edition of NIST Handbook 133, "Checking the Net Contents of Packaged Goods." Determine an average tare weight in accordance with Section 2 of the fourth edition of NIST Handbook 133.

\subsection{Determine Target Net Weight of Common Types of Paper Packaged in Various Sizes or Counts.}

Verify the basis weight declared on a package using the following gravimetric procedure:

a. Record the following information from the package label on a worksheet. (see Figure 1 for a sample label.)

1. Type of Paper (TP)

2. Length (L)

3. Width (W)

4. Package Sheet Count (PSC)

5. Basis Weight (BW)

6. Basic Size Sheet (BSS)

b. Compute the Target Net Weight (TNW) for the sample packages using the General Formula for Sheet Paper. TNW is what the paper should weigh if the labeled properties of the packaged paper are accurate.)

c. Determine the average net weight of the sample packages. (Do not use sample error limit calculations.) If the average net weight is not equal to or more than the Target Net Weight, go to Section 2.6.14.3. to determine if the labeled basis weight (BW) is correct. If the average net weight is equal to or more than the labeled basis weight, the sample passes.

\section{Basis Weight Worksheet (see Figure 1)}

$\begin{array}{ll}\text { Type of Paper (TP): } & \text { Copy Paper } \\ \text { Length (L): } & 11 \text { in } \\ \text { Width (W): } & 8 \frac{1 / 2}{\text { in }} \\ \text { Area (PA) of Sheet }(\mathrm{L} \times \mathrm{W}): & 93.5 \mathrm{in}^{2} \\ \text { Package Sheet Count }(\mathrm{PSC}): & 500 \\ \text { Basis Weight (BW): } & 20 \mathrm{lb} \\ \text { Basic Sheet Size (BSS): } & 17 \mathrm{in} \times 22 \mathrm{in} \\ \text { Area of BSS from Table } 1 \text { or } & 374 \mathrm{in}^{2} \\ \quad \text { by calculation: } & \end{array}$

Use the General Formula to compute Target Net Weight (TNW):

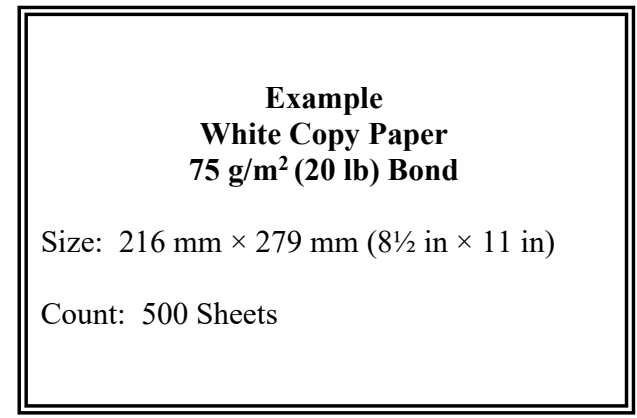

Figure 1. Sample Label

Target Net Weight $(\mathrm{TNW})=5 \mathrm{lb}$

NOTE: Three factors will cause actual sample weights to differ from the TNW:

Actual sheet count in package

Actual basis weight of paper being tested

Actual dimensions of the paper being tested 


$$
\frac{93.5 \mathrm{in}^{2} \times 20 \mathrm{lb}}{374 \mathrm{in}^{2}} \times \frac{500}{500}=5 \mathrm{lb}
$$

\subsection{Determine Basis Weight.}

This procedure is used to identify potentially violative packages. If the Average Basis Weight (ABW) for the sample determined by this procedure is not equal to or greater than the labeled basis weight, other steps must be taken. Moisture affects the weight of paper, but the moisture content of paper can only be determined in a measurement laboratory according to the Technical Association of the Pulp and Paper Industry (TAPPI) (www.tappi.org/) TAPPI - T410 om-08, "Grammage of Paper and Paperboard (Weight per Unit Area)."

a. Verify the basis weight for each package according to the following steps:

i. Identify the paper type from Column 1 in Table 1 and record the area for the paper type from Column 2.

ii. Select a sample of paper from each of the tare sample packages. Use a sample of exact count to eliminate the possibility that the packages are short count.

- For packages with more than 100 sheets, use 100 sheets; or

- For packages with 100 sheets or less, verify the sheet count and use all of the sheets.

iii. Use a basis weight work sheet and determine the number of basic size sheets the paper sample represents with the following formula:

$$
\frac{P A}{A} \times E C=E N B S S
$$

Where:

$\begin{array}{lll}\mathrm{A} & = & \text { area of basic sheet size from Table } 1 \\ \mathrm{PA} & = & \text { area }(1 \times \mathrm{w}) \text { of one sheet of paper } \\ \mathrm{EC} & = & \text { exact sheet count of sample } \\ \text { ENBSS } & = & \text { equivalent number of basic size sheets }\end{array}$

iv. Determine the average basis weight,

Where:

$\mathrm{BW} \quad=\quad$ basis weight for each package

$\mathrm{ABW} \quad=\quad$ average basis weight

ENBSS $=$ equivalent number of basic size sheets from step iii

$\mathrm{NW} \quad=\quad$ net weight of sample

RC $=$ Ream Count (500; for tissue paper, use 480)

v. Repeat this step for each paper package from the tare sample and average the basis weights to obtain an Average Basis Weight (ABW). If the ABW is less than the labeled basis weight, or if the difference between the basis weight of the sample packages is more than 1 scale division, measure and compute the basis weight for each of the remaining packages.

vi. Weigh each sample. If the basis weight from step iv is less than the labeled basis weight, recalculate the target net weight by using the general formula for sheet paper. 


\begin{tabular}{||l|c||}
\hline \multicolumn{1}{||c||}{ Table 1. Common Types of Paper and Area of Basic Sheet Size } \\
\hline \hline \multicolumn{1}{|c||}{ Pape } & Area \\
\hline $\begin{array}{l}\text { Bond, Ledger, Thin, Writing, and } \\
\text { Track Feed Printer Paper }\end{array}$ & $2412 \mathrm{~cm}^{2}\left(374 \mathrm{in}^{2}\right)$ \\
\hline Manuscript Cover & $3599 \mathrm{~cm}^{2}\left(558 \mathrm{in}^{2}\right)$ \\
\hline Blotting & $2941 \mathrm{~cm}^{2}\left(456 \mathrm{in}^{2}\right)$ \\
\hline Cover & $3354 \mathrm{~cm}^{2}\left(520 \mathrm{in}^{2}\right)$ \\
\hline Blanks & $3974 \mathrm{~cm}^{2}\left(616 \mathrm{in}^{2}\right)$ \\
\hline Printing Bristols & $4135 \mathrm{~cm}^{2}\left(641 \mathrm{in}^{2}\right)$ \\
\hline $\begin{array}{l}\text { Wrapping, Tissue, Waxed, Newsprint } \\
\text { and Tag Stock }\end{array}$ & $5574 \mathrm{~cm}^{2}\left(864 \mathrm{in}^{2}\right)$ \\
\hline Book, Offset, and Text & $6129 \mathrm{~cm}^{2}\left(950 \mathrm{in}^{2}\right)$ \\
\hline Index Bristol & $5019 \mathrm{~cm}^{2}\left(778 \mathrm{in}^{2}\right)$ \\
\hline
\end{tabular}

vii. Use the target net weight computed in step vi and re-weigh the inspection lot samples using the Section 2. of the fourth edition of NIST Handbook 133. If inspection sample weights differ from the target net weight computed using the average basis weight determined in step vi, the label sheet count is probably inaccurate.

b. Verify the label sheet count by counting the number of sheets in each package.

c. Verify sheet dimensions (length $\times$ width) for each package of the sample.

$$
\frac{N W \times R C}{E N B S S}=B W
$$

\subsection{Other Types of Packaged Paper.}

1. Roll Paper. - When testing rolled paper, cut a length of paper from the roll equal to 9350 divided by the width of the paper in inches. Make sure the ends of this length of paper are square. Proceed to Section 2.6.14.3. step a. Disregard the exact sheet count in step iii.

2. Continuous Track Feed Printer Paper:

i. Count out a sample of 100 sheets from each tare sample package of the inspection lot.

ii. Weigh each 100-sheet sample and record the weights.

iii. Calculate an average weight.

iv. Remove printer track feed strips from each sample.

v. Re-weigh each sample after the tractor feed has been removed and record the weights.

vi. Calculate an average weight from step v.

vii. Calculate percentage (\%) difference in the average weights in steps iii and vi. 
viii. After the track feed strips have been removed, use the samples to verify the basis weight for the packages of the inspection lot using the formula in 2.6.14.2. Declaration of Net Quantity of Contents. If the basis weight is less than the labeled basis weight, refer to 2.6.13.2. Scope and Recommended Enforcement Approach.

ix. If the basis weight established in step viii is the same as the labeled basis weight, weigh the remaining packages from the sample and compare the actual net weights with the TNW. (Remember to adjust the TNW up by the percentage established in step vii.)

x. If the adjusted weights of the remaining samples is less than the TNW, the deficiency may have been caused by:

a. the sheet count in the package.

b. the basis weight of the paper.

c. the dimensions of the paper.

d. combinations of the above.

This procedure is for use in verifying that the basis weight included in a statement of identity is not misleading or deceptive. It is not intended to be used as the final criterion on which enforcement action is taken. Instead, the test procedure is only used to identify potentially volatile lots. There are two alternative actions that can be taken if the test results indicate that a lot is potentially volatile. The first is to review the documentation supplied by the original manufacturer to the converter to determine if any misrepresentation has occurred. The second is to collect packages of the paper and test them according to the latest version of ASTM International Method D646 for "Grammage of Paper and Paperboard."

\subsubsection{Labeling Guidelines for Chamois. (L\&R, 1999, p. L\&R 25)}

These requirements are based on the Uniform Packaging and Labeling Regulation in the 1999 edition of NIST Handbook 130, "Uniform Laws and Regulations" and regulations and guidelines of the Federal Trade Commission.

\section{General}

The following information must be declared on the principal display panel of the chamois package. The principal display panel is the tag, or label that consumers can examine under normal and customary conditions of display.

- $\quad$ Identity - what the package contains

- Net Quantity of Contents - how many items the package contains and the area of the item(s)

The following information may appear anywhere on the package.

- $\quad$ Responsibility - the party responsible for packaging or distributing the product.

2.6.14.1. Declaration of Identity. - Chamois is a natural product made of sheepskin which has been oil tanned. In 1964, the FTC issued an advisory opinion stating that using the word "chamois" on a product (e.g., "Artificial" Chamois, "Synthetic" Chamois, "Pig Chamois" or "Man Made" Chamois) that is not made from oil tanned sheepskin is unlawful and deceptive. Packages are required to declare identity in terms of: 
i. the name specified in or required by any applicable federal or state law or regulation or, in the absence of this,

ii. the common or usual name or, in the absence of this,

iii. the generic name or other appropriate description, including a statement of function.

\section{Example:}

Chamois, Natural Chamois Leather

2.6.14.2. Declaration of Net Quantity of Contents. - The following information is to appear on the lower $30 \%$ of the principal display panel of all packages:

Count

- $\quad$ The package must include a count declaration (e.g., 1 Chamois) unless the statement of identity clearly expresses the fact that only one unit is contained in the package. A package containing two or more units shall bear a statement in terms of count (e.g., 2 Chamois).

Area

- Chamois packages must have area declarations in both U.S. customary and metric units.

Metric

- For areas that measure less than $1 \mathrm{~m}^{2}$, the area should be stated in square decimeters and decimal fractions of a square decimeter or in square centimeters and decimal fractions of a square centimeter;

- For areas that measure $1 \mathrm{~m}^{2}$ or more, the area should be stated in square meters and decimal fractions to not more than three places.

To facilitate value comparison and simplify the measurement process, chamois should be measured in one quarter square foot (2.322 57 decimeter) increments. Dimensions should be rounded down to avoid overstating the area.

For example: 2 square feet (18.5 square decimeters) or $2 \mathrm{ft}^{2}\left(18.5 \mathrm{dm}^{2}\right)$

\section{Conversion Factors:}

$$
\begin{aligned}
& 1 \mathrm{ft}^{2}=9.29030 \mathrm{dm}^{2} \\
& 1 \mathrm{in}^{2}=6.4516 \mathrm{~cm}^{2} \\
& 1 \mathrm{yd}^{2}=83.6127 \mathrm{dm}^{2}
\end{aligned}
$$

\section{U.S. Customary Units}

- For areas that are less than $1 \mathrm{ft}^{2}\left(929 \mathrm{~cm}^{2}\right)$, the area declaration shall be expressed in square inches and fractions of square inches;

- For areas of $1 \mathrm{ft}^{2}\left(929 \mathrm{~cm}^{2}\right)$, or more, but less than $4 \mathrm{ft}^{2}\left(37.1 \mathrm{dm}^{2}\right)$, the area shall be expressed in square feet with any remainder expressed in square inches or in fractions of a square foot;

- For areas of $4 \mathrm{ft}^{2}\left(37.1 \mathrm{dm}^{2}\right)$ or more, the area should be expressed in terms of the largest whole unit (e.g., square yards, square yards and square feet, or square feet) with any remainder expressed in square inches and fractions of a square inch or in fractions of the square foot or square yard. 
Chamois labeled for retail sale is exempt from these requirements if (a) the area of a full skin is expressed in terms of square feet with any remainder in terms of the common or decimal fraction of the square foot $\left(929 \mathrm{~cm}^{2}\right)$, or (b) the area for cut skins of any configuration is expressed in terms of square inches and fractions thereof. Where the area of a cut skin is at least one square foot $\left(929 \mathrm{~cm}^{2}\right)$ or more, the statement of square inches shall be followed in parentheses by a declaration in square feet with any remainder in terms of square inches or common or decimal fractions of the square foot.

\section{Prohibited Labeling Practices}

- Do not use qualifying terms or phrases (e.g., "Approximate Size," "Size when Wet," "Up to 20 \% Larger When Wet").

- Do not use unacceptable symbols (e.g., using (") as a symbol for inches is not acceptable).

2.6.14.3. Declaration of Responsibility. - The name and address of the manufacturer, packer, or distributor must be conspicuously specified on the label of any package that is kept, offered, exposed for sale, or sold anywhere other than the premises where packed. The name shall be the actual corporate name, or, when not incorporated, the name under which the company does business. This declaration does not have to appear on the principal display panel.

\section{Example:}

Chamois Tanning Company

8190 Main Road

Tarpon Springs, FL 34568

The address shall include street address, city, state (or country if outside the United States), and ZIP Code (or the postal code, if any, used in countries other than the United States); however, the street address may be omitted if it is shown in a current city directory or telephone directory.

\section{Sample Labels}

1. If one natural chamois is in a see-through package, the following label would be acceptable:

\begin{tabular}{|c|}
\hline Natural Chamois Leather \\
Distributed by: \\
Chamois Leather Co. \\
8190 Main Road \\
Tarpon Springs, FL 34568 \\
$\mathbf{7} \mathrm{ft}^{2}\left(\mathbf{6 5} \mathbf{d m}^{\mathbf{2}}\right)$ \\
\hline
\end{tabular}

2. The next sample would apply if one chamois is in a package and the statement of identity does not clearly express the fact the package only contains one unit.

\begin{tabular}{|c|}
\hline Chamois \\
Chamois Leather Company \\
8190 Main Road \\
Tarpon Springs, FL 34568 \\
One Chamois \\
$\mathbf{3} \mathrm{ft}^{2}\left(\mathbf{2 7 . 8} \mathbf{d m}^{\mathbf{2}}\right)$ \\
\hline
\end{tabular}




\subsubsection{Labeling Guidelines for Natural and Synthetic Sponges.} (L\&R, 1999, p. L\&R 31)

These requirements are based on the Uniform Packaging and Labeling Regulation in NIST Handbook 130, "Uniform Laws and Regulations" and regulations and guidelines of the Federal Trade Commission. All indicated dimensions and conversions from metric to U.S. customary units are approximate only and are used for illustration purposes only.

\section{General}

The following information must be declared on the principal display panel (PDP) of a package of sponge(s). The PDP is the part of label (or package) most likely to be displayed, presented, shown to or examined by consumers. A tag or spot label may be used.

- Identity - what the package contains

- Net Quantity of Contents - how many items in the package and the dimensions of the item(s)

The following information may appear anywhere on the package.

- Responsibility - the name of the processor or distributor

\subsubsection{Declaration of Identity.}

a. A declaration of identity that clearly describes the origin and other relevant information about the sponge must appear on the label of each package. The identity of a sponge must include information about its origin (i.e., is it a natural or synthetic sponge). The identity shall be in terms of (i) the name specified in or required by applicable federal or state law or regulation, or (ii) the common or usual name, or (iii) the generic name or other appropriate description.

\section{Example:}

Sea Wool Sponge, Rock Island Sponge, Sea Grass Sponge, Sea Yellow Sponge, or Atlantic Silk Sponge

- Origin - Natural or Synthetic

- For natural sponges, the label must specify if they are "Cut" or "Form." "Cut" sponges are those that have been cut into halves, quarters, or fourths while "forms" are whole sponges.

- For natural sponges, indicate type of sponge (e.g., "silk," "seawool," or "yellow")

b. Identifiers

- Terms which indicate locations of origin on some natural sponges (e.g., "Atlantic Sea Sponge") are permitted to be used for identification if they accurately describe the source of the sponge.

- Use of terms that may be interpreted by consumers to imply quality, durability, or "expert" endorsement (e.g., "professional quality sponge") are permitted as identifiers if they are not misleading. However, terms that imply quality should be used with care if they are not based on a recognized grading system. Use of terms to describe sponge texture such as "fine," "medium," or "coarse" are acceptable. 
2.6.15.2. Declaration of Net Quantity of Contents. - The following information must appear on the lower $30 \%$ of the principal display panel of all packages:

- Count

The package must include a count declaration (e.g., 1 sponge) unless the statement of identity clearly expresses the fact that only one unit is contained in the package. A package containing two or more units shall bear a statement in terms of count (e.g., 2 sponges).

\section{- Dimensions}

The package must include the dimensions of the sponges in inches and centimeters.

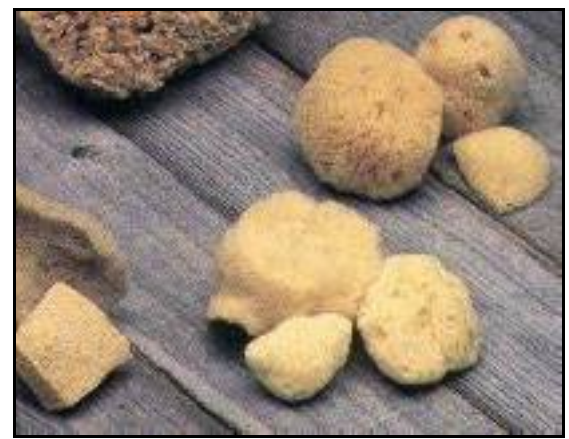

To facilitate value comparison and simplify the measurement process, sponges should be measured in $1 / 2$ in $(1 \mathrm{~cm})$ increments. Dimensions should be rounded down to avoid overstating the size of a sponge.

\section{Example:}

- 6 in, $6 \frac{1}{2}$ in, and 7 in for inch declarations;

- $\quad 15 \mathrm{~cm}, 16 \mathrm{~cm}$, and $17 \mathrm{~cm}$ for metric declarations

- Synthetic sponges: the dimensions shall include length $\times$ width $\times$ height (thickness). Either unit of measure can be the primary declaration (e.g., the metric or U.S. customary units can be presented first).

$$
1 \text { sponge } 17 \times 10 \times 5 \mathrm{~cm}(7 \times 4 \times 2 \text { in })
$$

- Natural sponges: the declaration shall be a single measurement representing the maximum dimension of one axis of a sponge that is passed through a circular template. When measured, the sponge is "classified" as a specific size when at least three (including two opposing) points of the sponge touch the template (e.g., see graphic on the following page where the sample sponge is designated as a 7 in $[17 \mathrm{~cm}]$ sponge).

As the following pictures show, natural sponges are irregular in size and shape and have traditionally been measured using this procedure. It is difficult to develop a meaningful or cost-effective measurement process that would provide a means of direct comparison between synthetic and natural sponges based on dimensions. Requiring declarations, such as average height, length, or width of natural sponge procedures would increase the costs for industry and consumers. 


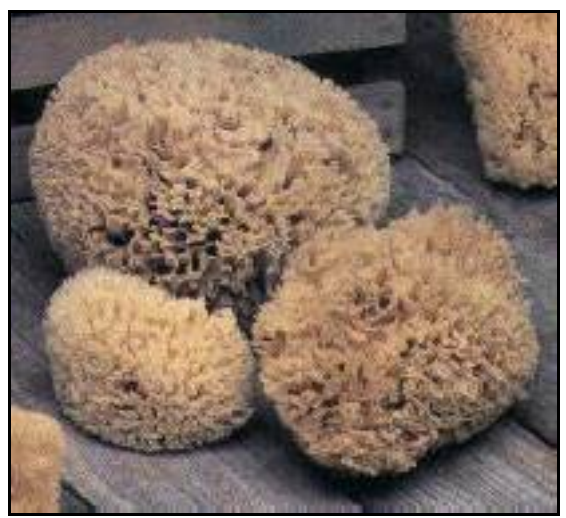

Sea Wool Sponges

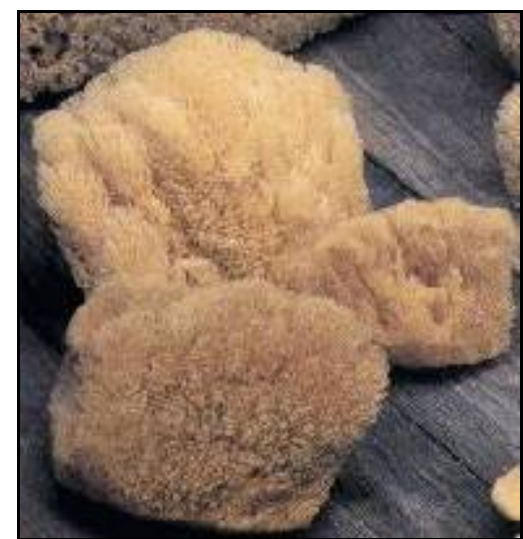

Sea Grass Sponges

This graphic illustrates an irregular form of a natural sponge passing through a $17 \mathrm{~cm}$ (7 in) template and touching at least two opposite points. This sponge could be labeled 7 in.

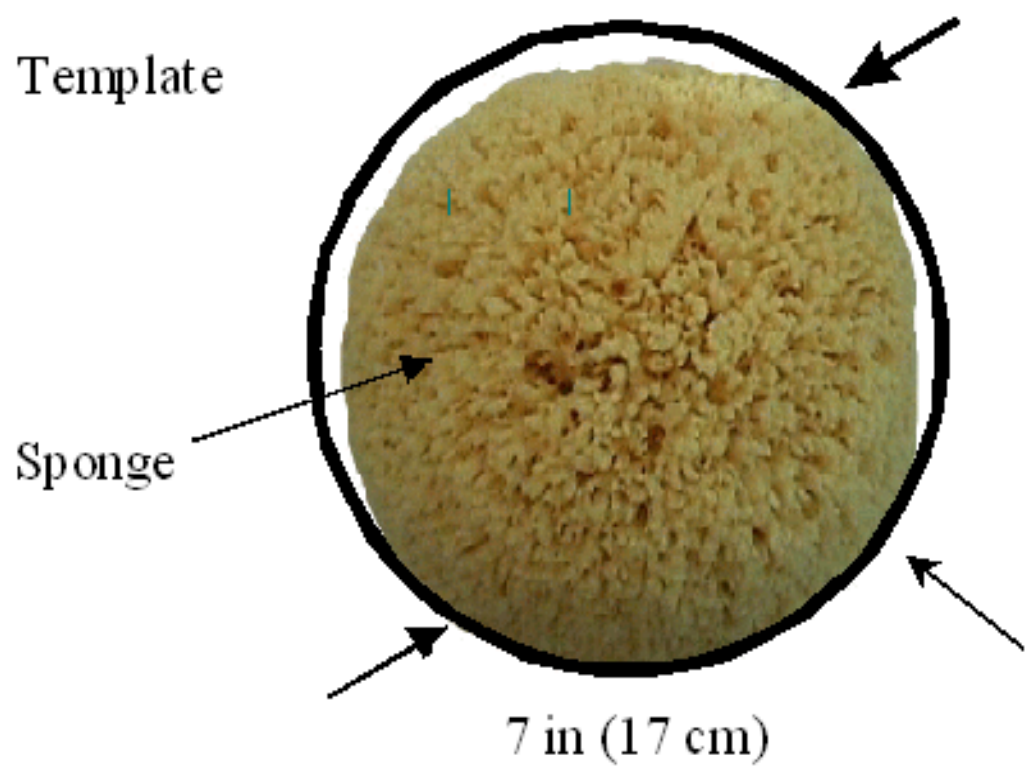

- For banana sponges the size will be determined as shown below. This sponge is $17 \mathrm{~cm}$ (7 in). 


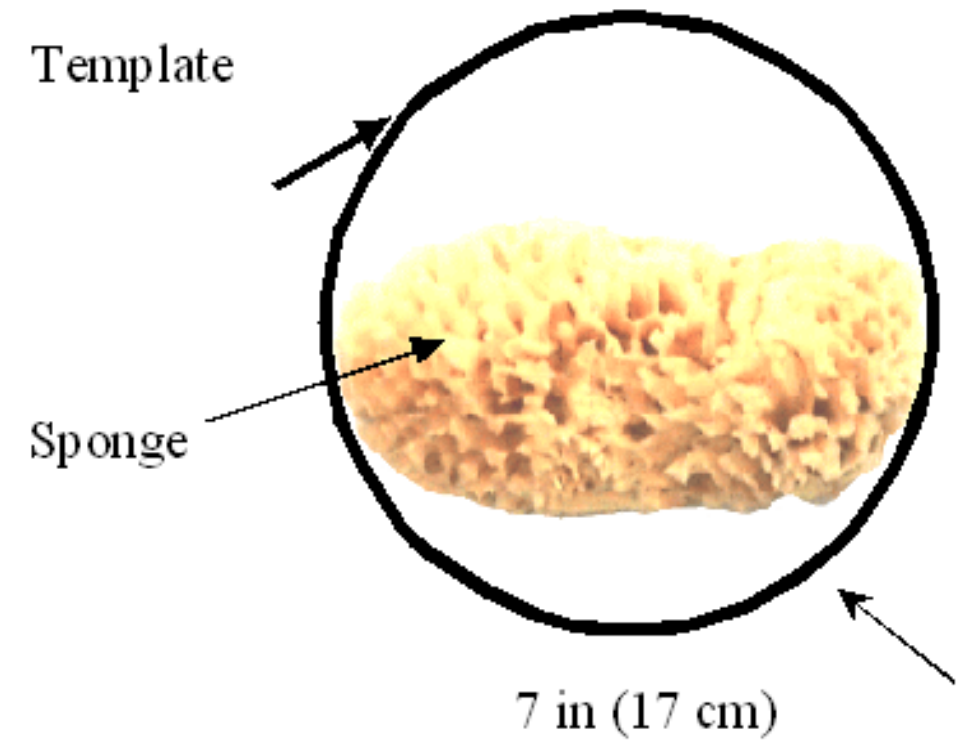

Good Measurement Practice

- Dimensions are determined with the sponge wet.

- Measuring templates (see photo below for the currently used type templates):

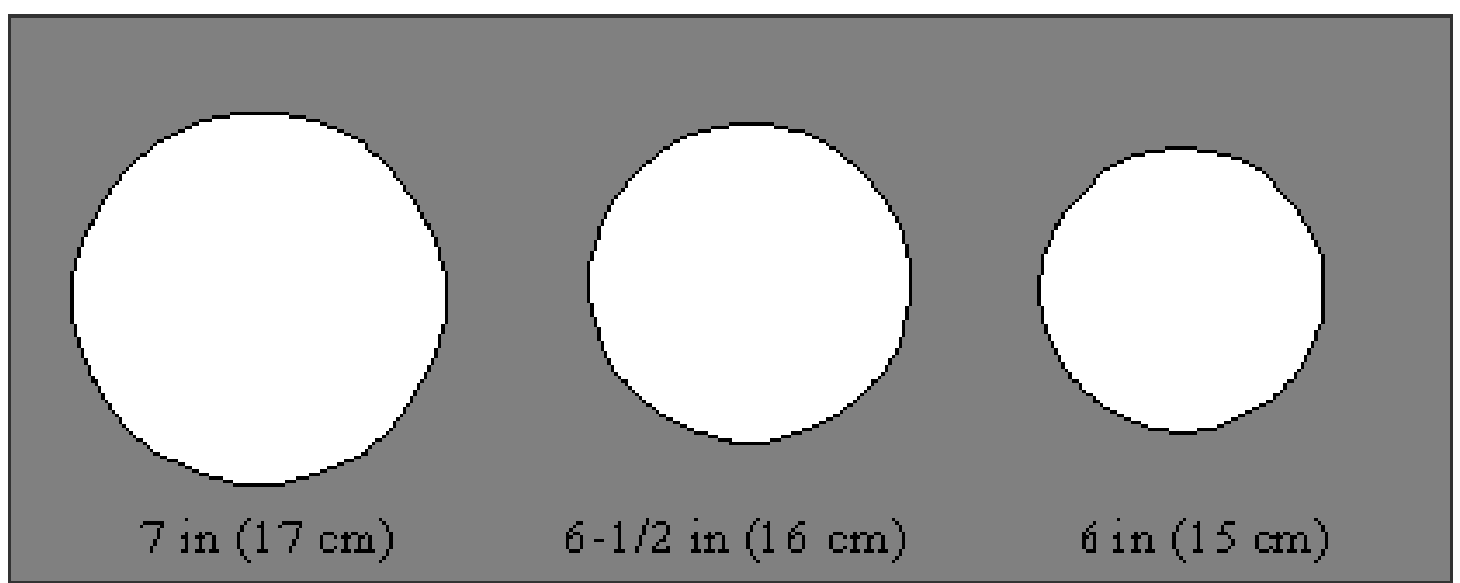

- $\quad$ should be constructed of rigid metal or plastic material.

- circular openings should graduate in increments of one-half inch (one centimeter).

- The error in the circular openings shall not be greater than $\pm 1 / 32$ in $( \pm 0.79 \mathrm{~mm})$ as specified in Table 2 . Tolerances in Section 5.52. Linear Measures of NIST Handbook 44 "Specifications, Tolerances, and Technical Requirements for Weighing and Measuring Devices."

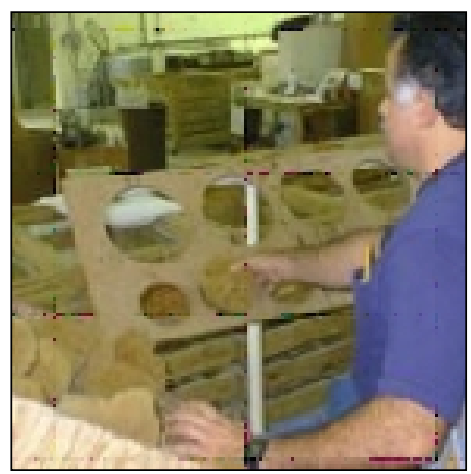


Prohibited Labeling Practices

- $\quad$ Stating country of origin declarations that are not accurate.

- Declaring ranges of dimensions (e.g., 4"- 5" in) or using terms such as "half or semi form" instead of either "cut" or "form."

• Using qualifying terms. (e.g., "Wet Size," “Approximate” or "Jumbo")

- “Anti-bacterial” claims must meet EPA requirements.

- $\quad$ Using type size that does not meet minimum height requirements.

- $\quad$ Using unacceptable symbols (e.g., using (") as a symbol for inches is not acceptable).

2.6.15.3. Declaration of Responsibility. - The name and address of the processor or distributor must be specified on the label of any package that is kept, offered, or exposed for sale, or sold anywhere other than the premises where packed. The name shall be the actual corporate name or, when not incorporated, the name under which the business is conducted.

\section{Example:}

Processed by

Argonaut Sponge Company

8190 Main Road

Tarpon Springs, Florida 34568

The address shall include street address, city, state (or country if outside the United States), and ZIP Code (or the postal code, if any, used in countries other than the United States); however, the street address may be omitted if this is shown in a current city directory or telephone directory.

\section{Sample Labels}

\section{Yellow Sponge Cut}

Argonaut Sponge Company 8190 Main Road

Tarpon Springs, FL 34568

$$
\text { One }-17.5 \mathrm{~cm} \text { (7 in) }
$$

\section{Synthetic Sponge}

Made by: Argonaut Sponge Company 8190 Main Road Tarpon Springs, FL 34568

$17.7 \times 10 \times 5 \mathrm{~cm}(7 \times 4 \times 2$ in $)$
If a natural sponge is in a box, carton, or package that does not permit consumers to see how many sponges are in the box, the package must include a count declaration (e.g., 1 sponge) unless the statement of identity clearly expresses the fact that only one unit is contained in the package. A package containing two or more units shall bear a statement in terms of count (e.g., 2 sponges). The following sample label would apply.

Synthetic Sponge
Made by:
Argonaut Sponge Company
8190 Main Road
Tarpon Springs, FL 34568

$\mathbf{1}$ - Sponge $\mathbf{1 7 . 7} \mathbf{~ c m ~} \times \mathbf{1 0} \times \mathbf{5} \mathbf{~ c m ~}(\mathbf{7}$ in $\times \mathbf{4}$ in $\times \mathbf{2}$ in $)$

If a package does not permit the consumer to see how many sponges are the box, it must include a count declaration (e.g., 1 sponge) unless the statement of identity clearly expresses the fact that only one unit is contained in the package. A package containing two or more units shall bear a statement in terms of count (e.g., 2 sponges). 
A transparent bag of small pieces of sponge may be sold on the basis of count if the words "Irregular Dimensions" appear in conjunction with the declaration of count (e.g., 10 Sponges - Irregular Dimensions).

\subsubsection{Minimum Fuel Flush for Octane Verification.}

(L\&R, 2000, p. L\&R 13)

A minimum of $1.2 \mathrm{~L}(0.3 \mathrm{gal})$ of motor fuel shall be flushed from a dispenser before taking a sample for octane verification. The flush shall be returned to the storage tank containing the lowest octane.

To find the history on the following Sections, please refer to "Reports of the National Conference on Weights and Measures" at www.nist.gov/pml/weights-and-measures/publications/ncwm-annual-reports

\subsubsection{Weight(s) and/or Measure(s).}

2.1.2. Section 19(a), Identity.

2.1.3. Definition of Net Weight.

2.2.1. Gift Packages.

2.2.2. Sand.

2.2.3. Sold by $4 / 5$ Bushel.

2.2.5. Lot, Shipment, or Delivery.

2.2.6. Aerosols and Similar Pressurized Containers.

2.2.7. Aerosol Packaged Products.

2.2.8. Variety and Combination Packages.

2.2.9. Textile Products.

2.2.10. Yarn.

2.2.11. Tint Base Paint.

2.2.12. Reference Temperature for Refrigerated Products: When a Product is Required to be Maintained Under Refrigeration.

2.3.9. Fireplace Logs.

2.3.11. Packaged Foods or Cosmetics Sold from Vending Machines.

2.3.12. Movie Films, Tapes, Cassettes. 


\section{Index}

\section{A}

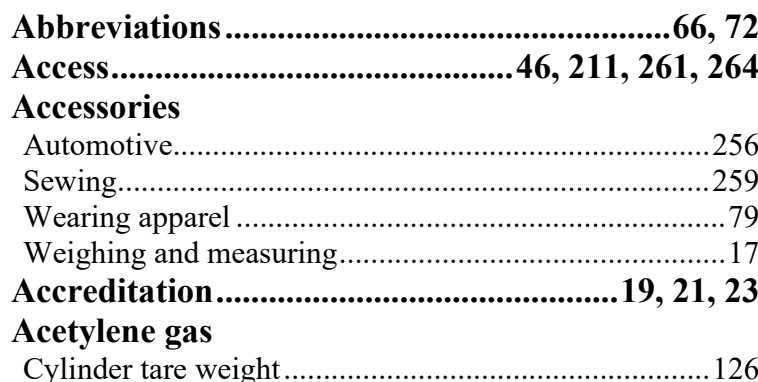

Addition of water to grain.........................251, 252

Administrative hearing ....................26, 38, 47, 208

Advertising ...............................................25, 45

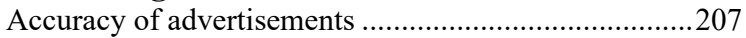

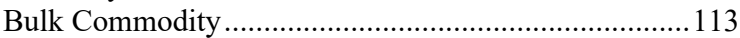

Bulk Food Commodities .................................................108

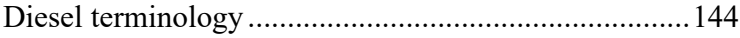

Home Food Service Plans ............................................... 113

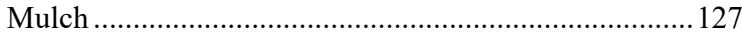

Price ….................................................. 133, 144, 250

Prohibited terms ........................................................ 115

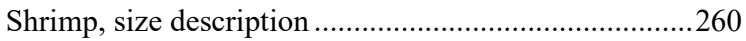

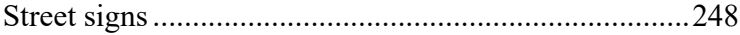

Turf .......................................................................... 117

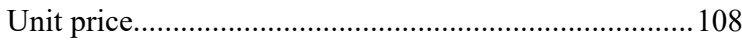

Aerosol..............................................61, 75, 278

Afghans ................................................................79

Alcohol..........................................................59, 180

Alcoholic beverages ....................................... 82, 95, 256

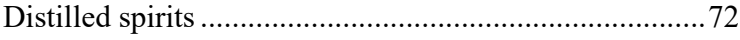

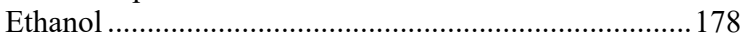

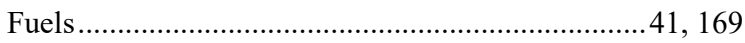

Gasoline-alcohol blends ..........................................41, 199

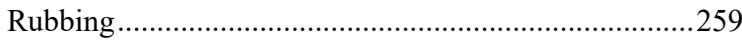

Alcoholic Beverages............................................63

Allowable difference

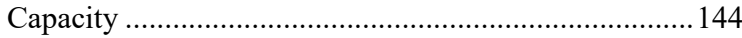

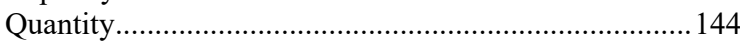

Tare weight .................................................. 125, 126

Railroad cars ......................................................... 145

Animal Bedding

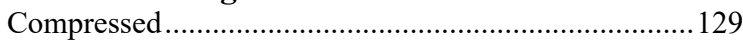

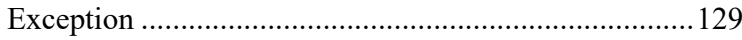

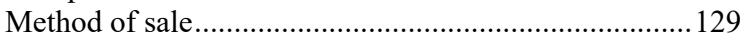

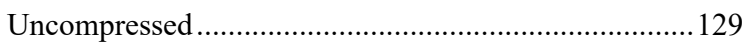

Animal food .........................................................95

Anthracite............................................................125

Antifreeze ....................................................59, 256

Antiknock index.......................................187, 201

Appliance

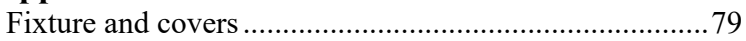

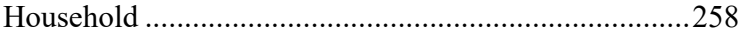

Weighing and measuring.............................................. 17
Area...................................................................65, 67

Asphalt paints ..................................................113

ASTM International.......................41, 45, 169, 177

Automotive lubricants.................41, 45, 46, 47, 169

Automotive Lubricants Inspection Act................48

Automotive Lubricants Inspection Law ..............42

Aviation

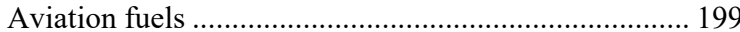

Gasoline ............................................177, 184, 189, 199

Labeling of grade required......................................... 189

Turbine fuels............................................... 177, 183, 189

Avoirdupois (pound or ounce).......... 66, 72, 80, 278

\section{B}

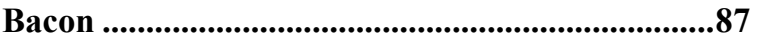

Barbeque ................................................109, 114

Bath mats................................................................79

Bedding

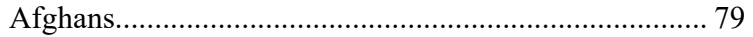

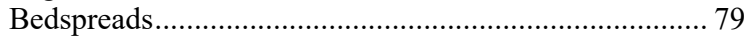

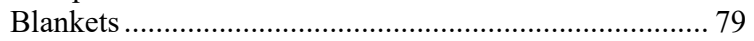

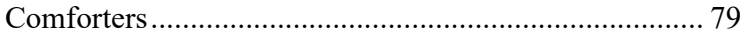

Mattress covers ............................................................. 79

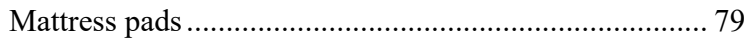

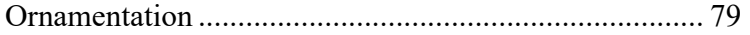

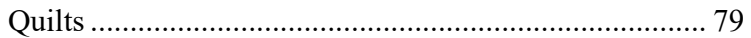

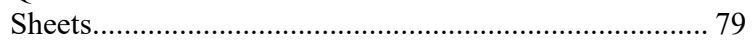

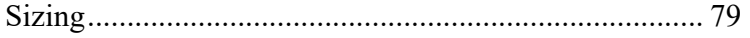

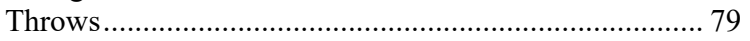

Beef

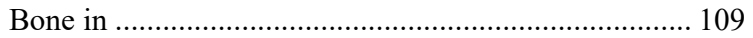

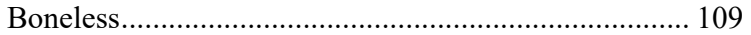

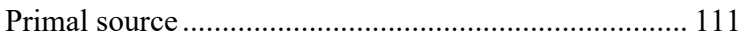

Beer ................................................63, 82, 95, 207

Beverageware ..........................................................144

Bi-dimensional commodities ...............................68

Biodiesel....................................................See Fuels

Bituminous ...............................................................125

Bonus offer ..............................................................207

Brake fluid.......................................................59

Bread.................................................................106

Bulk deliveries........................................................24

Bulk Delivery .............................................................197

Bulk sales......................................................24, 244

Sand, rock, gravel, stone, paving stone, similar materials

Butane

128, 180, 191

Butanol .................................................................177

Butter and butter-like spreads .............................106

\section{C}

Camping fuels .59 
Candy, exemption from labeling ............................82

Cardboard cartons ........................... See Containers

Carpets .........................................................79, 80, 119

Catalyst beads ................................................................242

Catfish

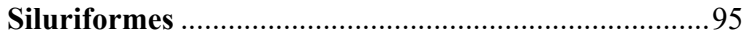

Cents-off Representation......................................207

Cereal grains and oil seeds..................................251

Certificate of Conformance

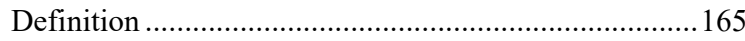

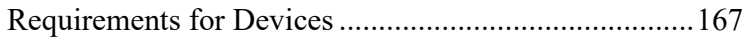

Certificate of Registration............................157, 158

Cetane number........................................See Fuels

Chamois .................................................................270

Cigarettes.................................................................82

Cigars.....................................................................882

Citrus

Sold by $4 / 5$ Bushel .........................................................2 278

Civil action ..............................................26, 38, 48

Civil penalty .....................................26, 38, 47, 48

Cleaning solvents ..................................................59

Cloths, wiping ......................................................130

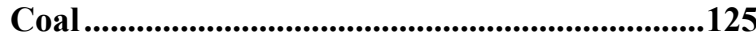

Coated seed...............................................................881

Cocoa, instant....................................................239

Coffee, instant ....................................................239

Combination package

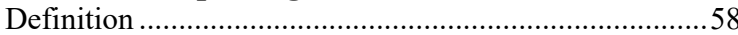

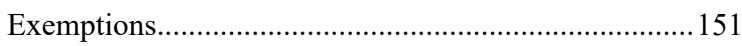

Labeling, interpretation .............................................. 76

Comforters ......................................................79, 85

Commercial and law enforcement equipment .165, 166

Commercial and law enforcement weighing and measuring devices ..............................................157

Commercial vehicle ..............................................23

Commodity ............................................................86

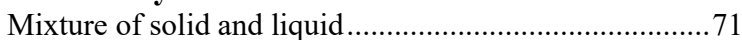

Packaged

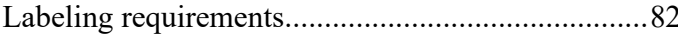

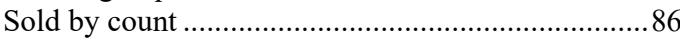

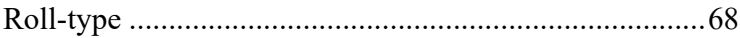

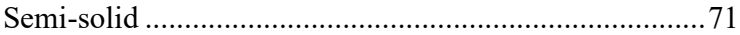

U.S. customary units exemptions .................................... 87

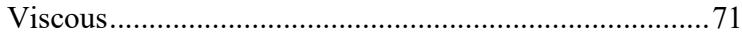

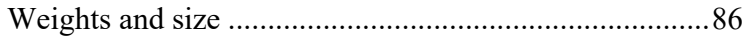

Commodity excluded from Federal Trade

Commission jurisdiction ...................................256

Commodity under Federal Trade Commission jurisdiction ..........................................252, 254

Commodity, liquid form, method of sale .............24

Common fraction................................................74

Common fractions ..........................................69, 116

Compressed gases ................................................126

Computer printer ribbons and tapes, guidelines

.....................................................................239

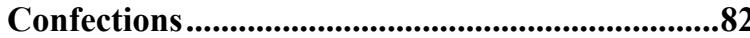

Confidentiality .............................................................210

Consumer package .....................................58, 60, 61

Containers

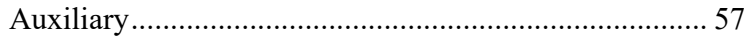

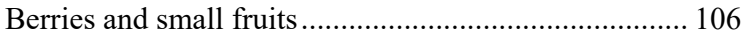

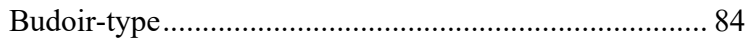

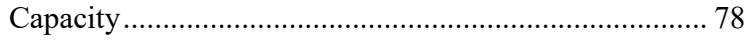

Cardboard cartons ....................................................... 241

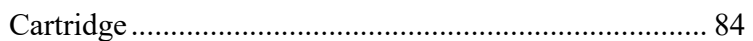

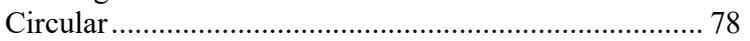

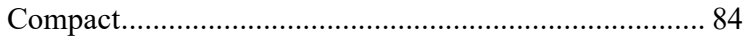

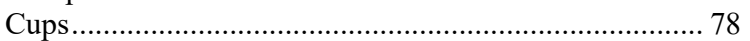

Cylindrical …......................................... 72, 73, 77

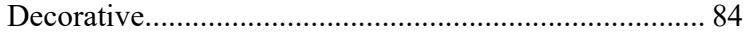

Dry measure............................................................. 78

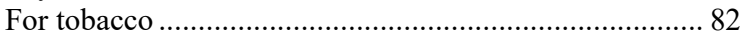

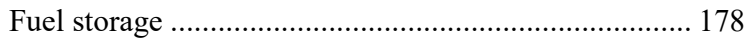

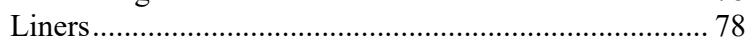

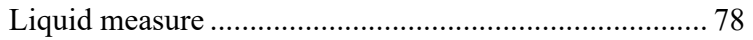

Milk, ice cream, etc. …..................................... 82, 83

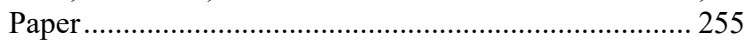

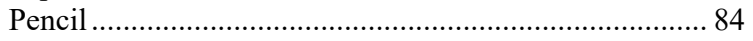

Pre-pressurized …................................................. 61, 75

Pressurized................................................. 61, 75, 278

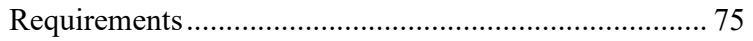

Retail tray pack displays ................................................ 57

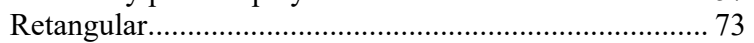

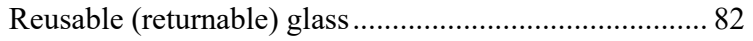

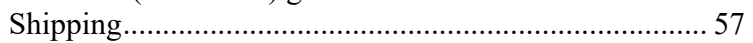

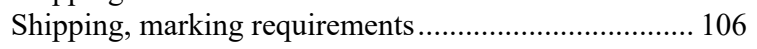

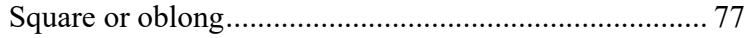

Tint base paint ......................................................... 85

Vegetable oil, guideline .............................................. 243

Contract and disclosure requirements...............112

Conversions ...................................................91, 94

Copier machine dispersant ..................................55

Corn flour...............................................................84

Corn meal ...............................................................84

Cosmetics.............................................84, 87, 95, 278

Cost per unit information ....................................22

Count .............................................................69, 86

Criminal penalties....................................................26

Crustaceans ...................................................106

Cubic measure .....................................................65

Curtains ................................................79, 80

$\begin{aligned} & \text { Dairy products } \\ & \text { Containers } \\ & \text { Milk, ice cream, etc. }\end{aligned}$ Cottage cheese
Fream
Ice cream
Pelletized ice cream 


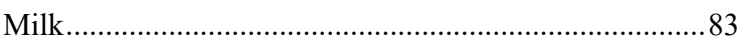

Other milk products....................................................... 107

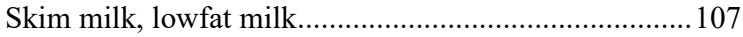

Yogurt

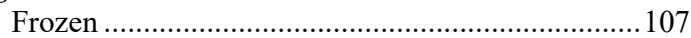

Deceptive dealing .....................................................21

Decimal fractions .......................................61, 69

Declaration of quantity ...........................62, 65, 66

Declarations of unit price.....................................25

Definitions

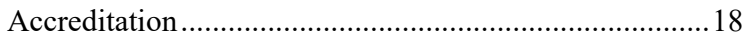

Aisle stacks or end-of-aisle displays ............................207

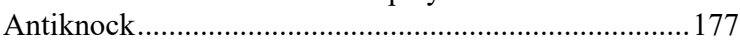

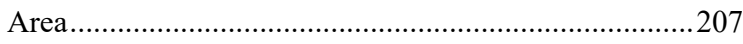

ASTM International ................................................... 177

Automated inspection.............................................208

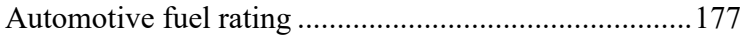

Automotive gasoline, automotive gasoline-oxygenate

$$
\text { blend...... }
$$

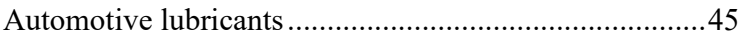

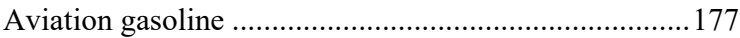

Aviation turbine fuel ................................................. 177

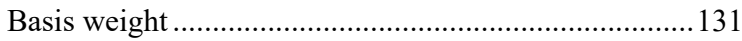

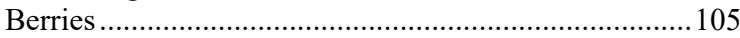

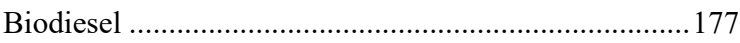

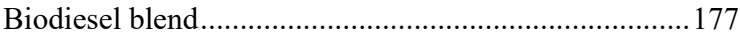

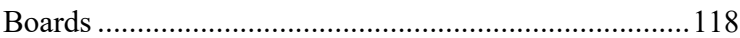

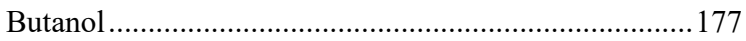

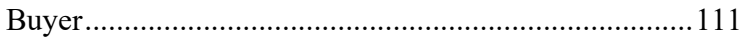

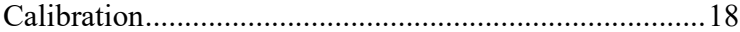

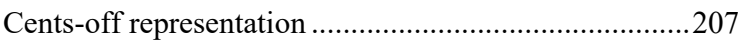

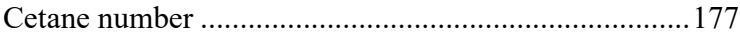

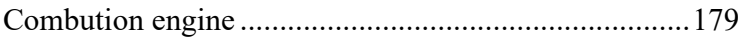

Commercial weighing and measuring equipment ...........18

Communication paper ............................................... 131

Compressed animal bedding .........................................129

Compressed natural gas (CNG) ............................130, 178

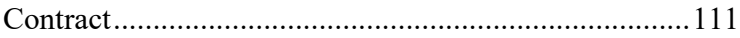

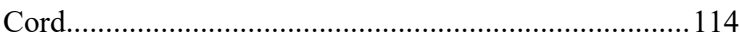

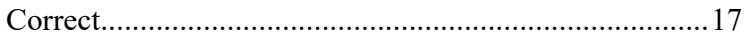

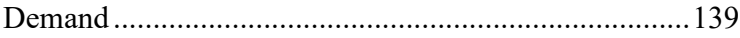

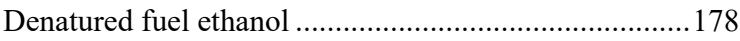

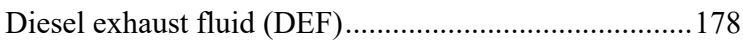

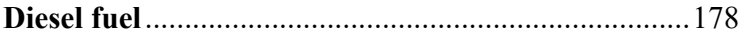

Diesel gallon equivalent (DGE) .................................. 130

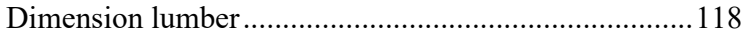

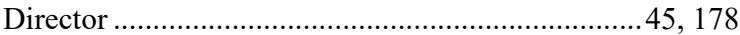

Direct-store-delivery (DSD) item..................................207

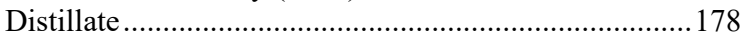

Electric vehicle suppy equipment (EVSE) ...................135

Electricity Metering System.........................................139

Electricity sold as vehicle fuel...................................... 134

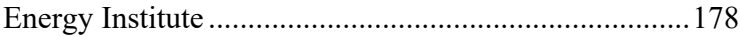

Engine fuel .......................................................45, 178

Engine fuel designed for special use .............................. 45

Engine fuels designed for special use ............................. 178

Environments Protection Agency (EPA) ...................... 178

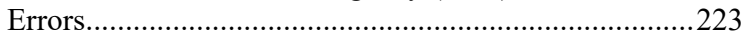

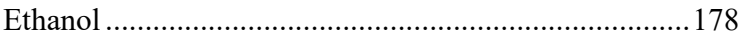

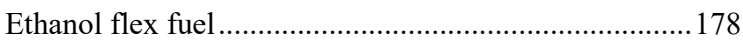

Fireplace and stove wood .......................................... 114

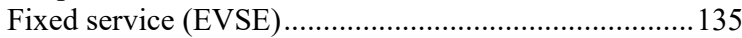

Flavoring chips …………............................................. 114

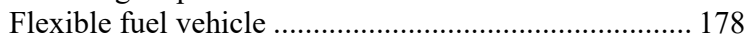

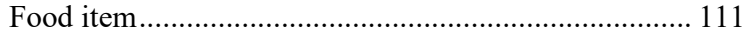

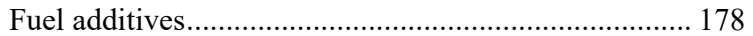

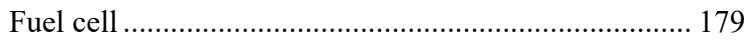

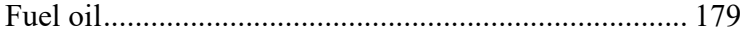

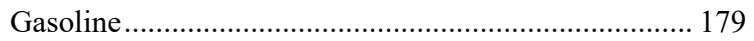

Gasoline gallon equivalent (GGE) .............................. 130

Gasoline-oxygenate blends ........................................ 179

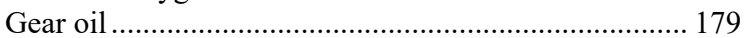

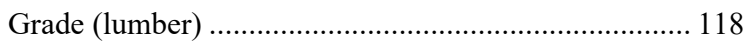

Hand-held scanning device ......................................... 207

Header strip ............................................................... 59

Home food service plan .............................................. 111

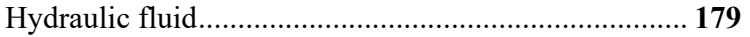

Hydrogen fuel ................................................... 132, 179

Increased inspection frequency................................... 208

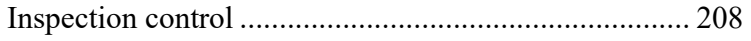

Inspection frequency................................................. 208

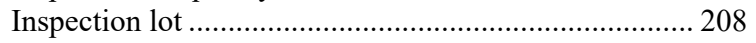

Intentional undercharge ............................................... 209

International Organization for Standardization (ISO) ... 179

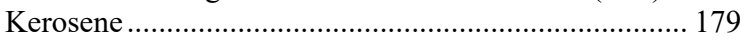

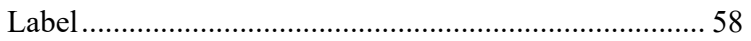

Lead substitute ..................................................... 179

Lead substitute engine fuel ........................................... 179

Liquefied natural gas (LNG).................................... 179

Liquefied petroleum gas (LPG) ..................................... 180

Low temperature operability...................................... 180

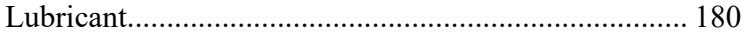

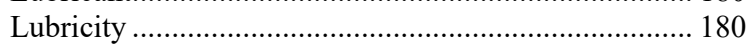

M85 fuel methanol.................................................... 180

Manual inspection...................................................... 208

Matched lumber............................................................. 118

Merchandise group ..................................................... 208

Minimum dressed sizes (width and thickness)............. 118

Misrepresented price.................................................. 209

Motor octane number.................................................... 180

Motor oil.................................................................... 180

MTBE, Methyl tertiary-butyl ether .............................. 180

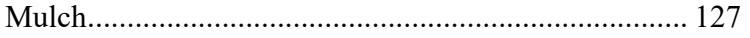

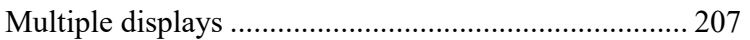

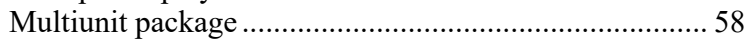

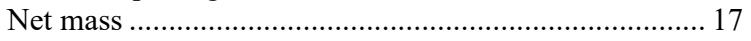

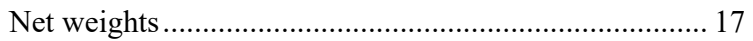

Nominal power (EVSE) ............................................. 135

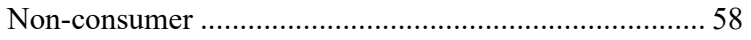

Non-consumer package..................................................... 58

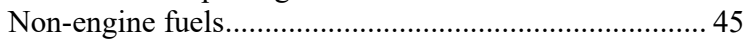

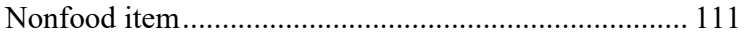

No-on-file item ......................................................... 208

Normal inspection frequency...................................... 208

Notification of noncompliance .................................. 208

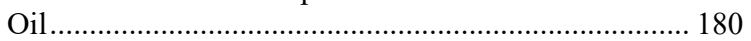

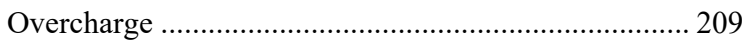

Oxygen content of gasoline ...................................... 180

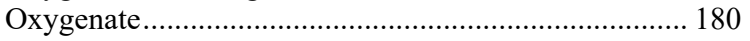

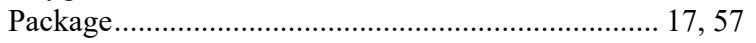

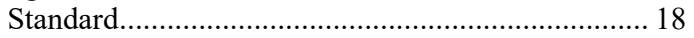

Patterned lumber................................................... 118

Person ….................................................... 17, 45, 58

Petroleum Products....................................................... 59 
Precious metals.............................................................. 126

Price charged ...............................................................209

Price look-up code (PLU)...........................................208

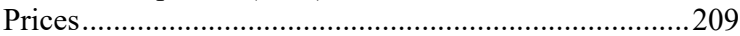

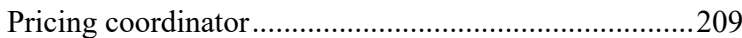

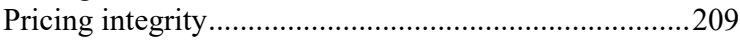

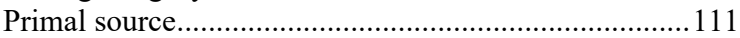

Principal Display Panel or Panels...................................58

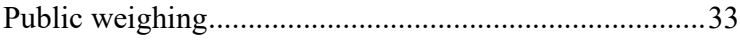

Public weighmaster ........................................................ 33

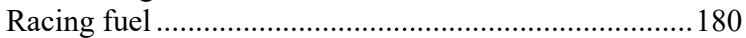

Random weight package ............................................ 17

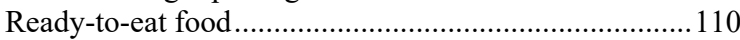

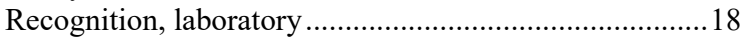

Representation............................................ 114, 118

Research octane number................................................ 180

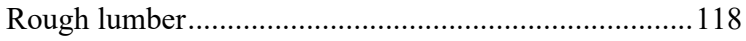

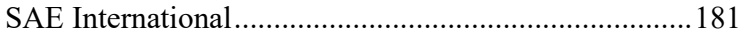

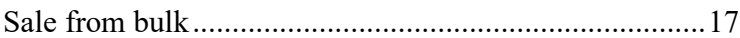

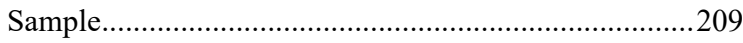

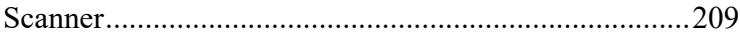

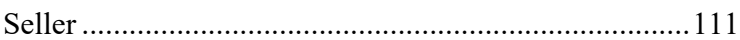

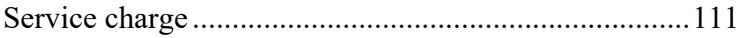

Shiplapped lumber .................................................... 118

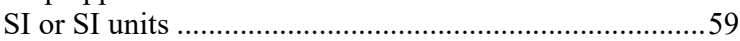

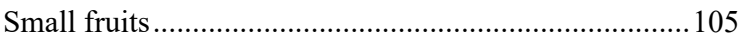

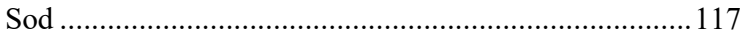

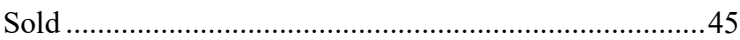

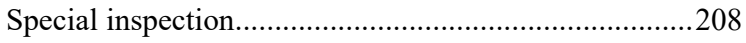

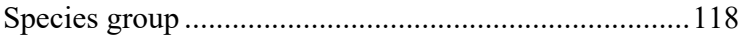

Species, trees ……..................................................... 118

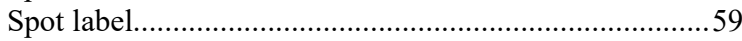

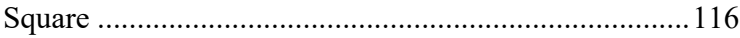

Square foot ............................................................... 116

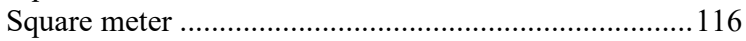

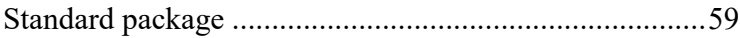

Standard, field ......................................................... 18

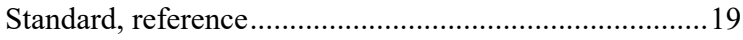

Standard, working ........................................................ 19

Stock-keeping unit (SKU) ..........................................209

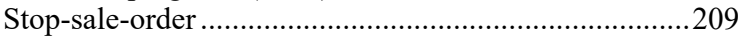

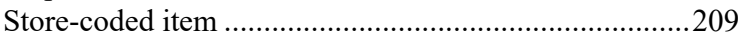

Surfaced (dressed) lumber........................................... 117

Thermal stability .......................................................... 181

Ticketed merchandise................................................209

Tie-in displays ..............................................................207

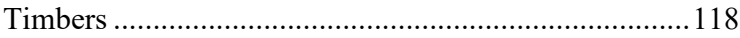

Traceability ............................................................ 18, 19

Tractor hydraulic fluid ................................................. 181

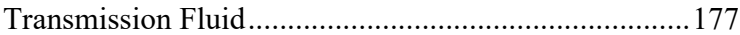

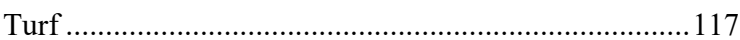

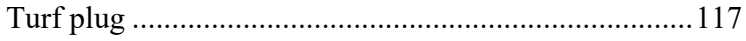

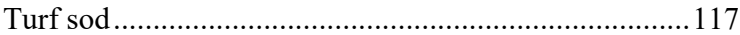

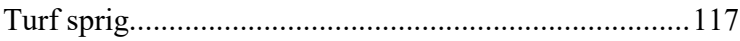

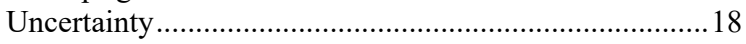

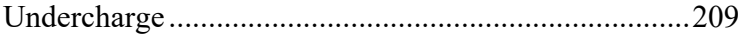

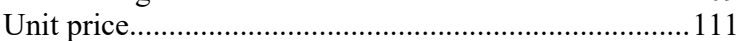

Universal product code (UPC) .....................................209

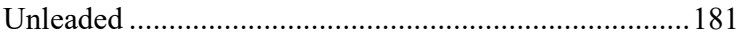

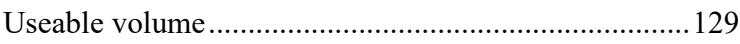

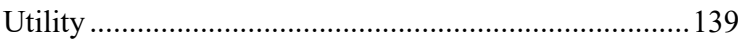

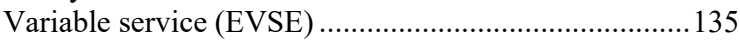

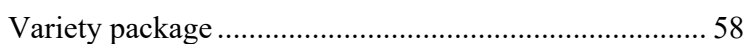

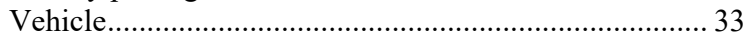

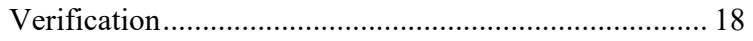

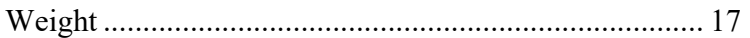

Weights and measures ................................................. 17

Wholesale purchaser consumer......................................... 181

Delivery ticket .......................................................24

Desserts, frozen .....................................................82

Diapers, nonrectuangular .....................................79

Diesel exhaust fluid (DEF) ...................136, 186, 196

Bulk ............................................................ 136, 196

Dispenser ....................................................................... 196 Labeling........................................................... 136

Documentation................................................ 136, 196

Labeling ...................................................... 137, 196

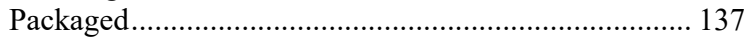

Diesel fuel ...................................................See Fuels

Direct sales ................................................. See Sales

Director................................ 17, 21, 33, 186, 199, 200

Dish cloths ..............................................................79

Dish towels......................................................79, 80

Dispenser

Labeling ....................................................... 128, 190

Liquefied natural gas .................................................... 131

Displays...................................................................207

Distilled spirits ................................71, See Alcohol

Drained weight ..................................................17, 107

Drapes.................................................................79, 80

Drugs...................................................84, 87, 96, 257

Dry measure ...............................62, 65, 68, 71, 72

Dual declaration of quantity ...................................70

\section{E}

\section{Electric vehicles}

Electric vehicle supply equipment ................................ 135

Electricity sold as vehicle fuel .................................... 134

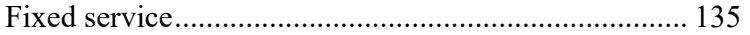

Method of sale ...................................................... 134

Nominal power .......................................................... 135

Retail electric vehicle supply equipment (EVSE) labeling

135

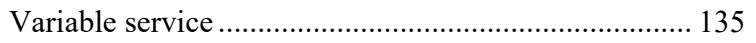

Electrical Energy

Non-Utility Transactions .............................................. 139

Electricity Metering System................................139

Encapsulated seed.................................................81

Energy Institute ...................................................178

Enforcement ............................. 2, 157, 201, 207, 225

Engine Fuels, Petroleum Products, and Automotive Lubricants Inspection Law ..........41

English language, packaging..........................72, 75

Entertainment value, media.................................85

Ethanol flex fuel.......................... See Fuels:Ethanol

Exaggerate the amount ..........................................70

Exemptions

To labeling regulations ............................................ 51, 81

To Uniform Weights and Measures Law ........................ 22 
Exposure variations..............................................88

\section{$\mathbf{F}$}

Face cloths 79,80

Facilitate fraud.............................................................27

Fair Packaging and Labeling Act

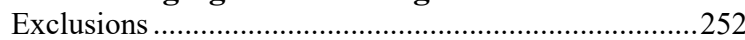

Federal Fair Packaging and Labeling Act .....3, 51, 61, 86, 105

Felony $.27,38,48$

Fence wire products............................................113

Firewood

Artifical compressed or processed logs .........................114

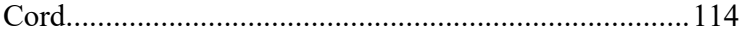

Delivery ticket or sales invoice ......................................115

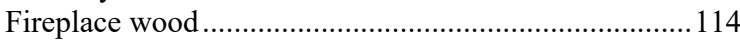

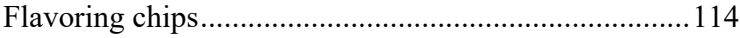

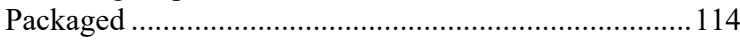

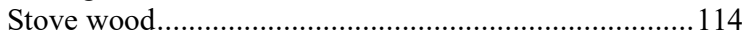

Stovewood pellets or chips.............................................114

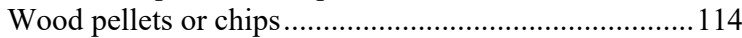

Fish...............................................................106

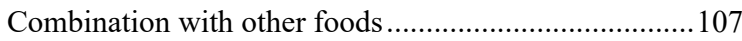

Flags ...................................................................79, 80

Flavoring chips.....................................................114

Flexible fuel vehicle ...........................................178

Flour ...................................................................106

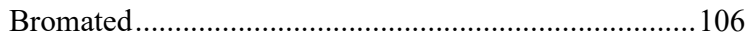

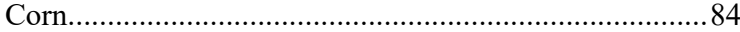

Exemption from labeling regulation.............................. 84

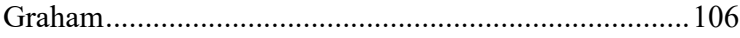

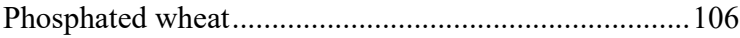

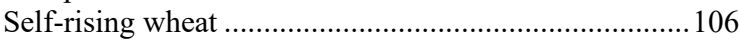

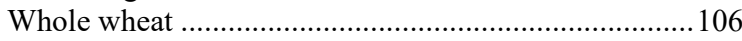

Food Products ..................................................... 105

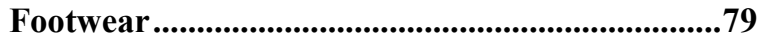

Fraction of a cent .....................................144, 248

Free area, labeling ......................................81, 86

Fruit ..................................................................240

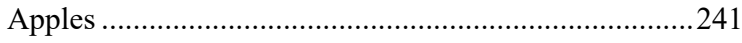

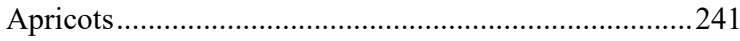

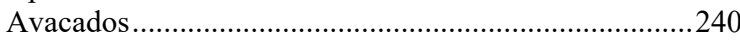

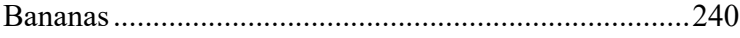

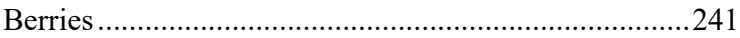

Cantaloupes ...................................................240, 241

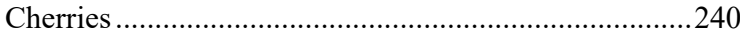

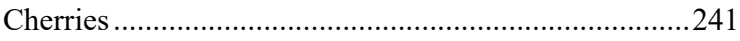

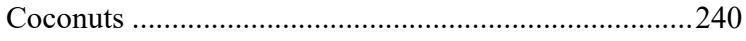

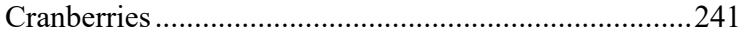

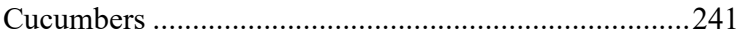

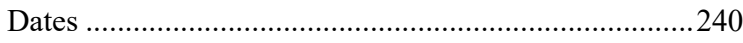

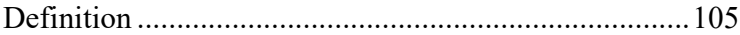

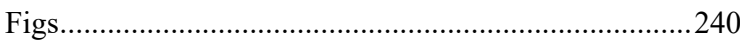

Grapefruit .............................................................. 241

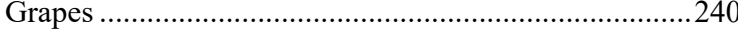

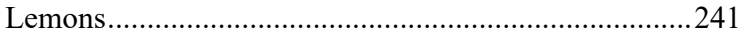

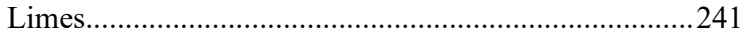

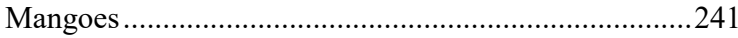

Melons......................................................2. 240, 241
Method of sale ………….................................. 240, 241

Nectarines ................................................................. 241

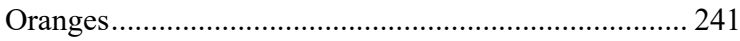

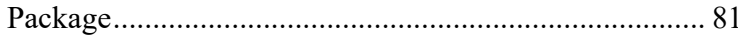

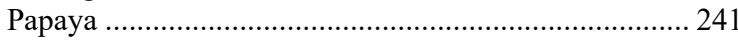

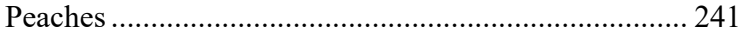

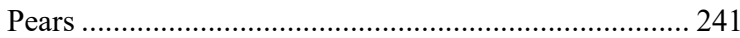

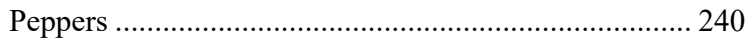

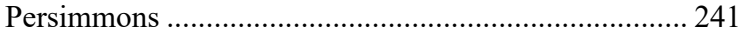

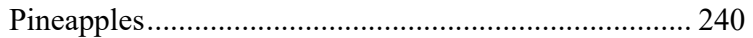

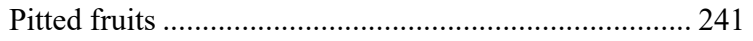

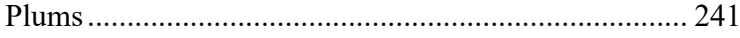

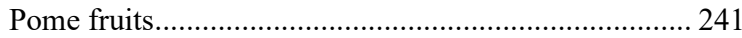

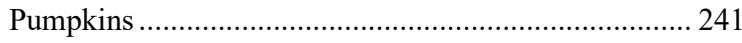

Tomatoes …................................................. 240, 241

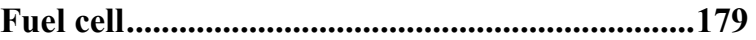

Fuels ........................................................41, 178

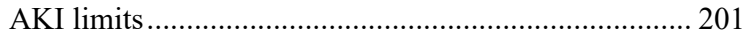

Antiknock ........................................................ 177, 181

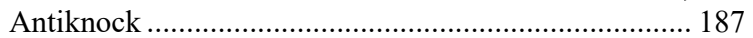

Automotive lubricants ................................ 45, 46, 169

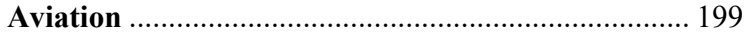

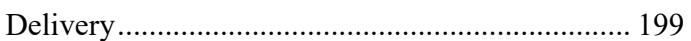

Gasoline........................................... 177, 184, 189

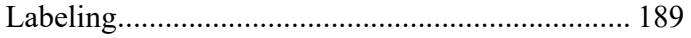

Product storage ....................................................... 199

Turbine fuels ................................... 177, 183, 199

Biodiesel.........................................132, 177, 186, 195

Blends....................................................... 132, 195

Dispenser................................................. 195, 196

Exemption ............................................. 132, 196

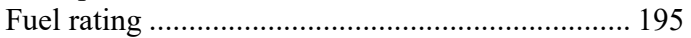

Indentification of product .................................... 132

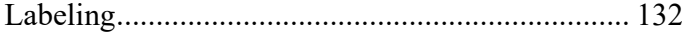

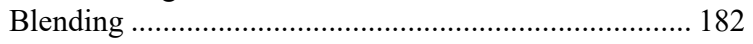

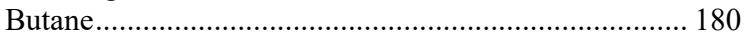

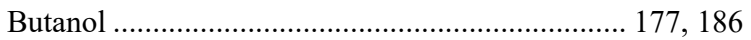

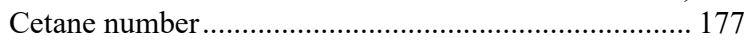

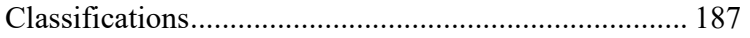

Compressed natural gas (CNG) ............................... 130 Identification ....................................................... 191

Method of sale ..................................................... 130

Computing pumps or dispensers .................................. 250

Condemned product................................................... 200

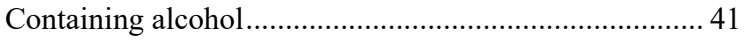

Denatured fuel ethanol.................................................... 184

Designed for special use ................................... 46, 200

Diesel....................................................... 144, 189, 201

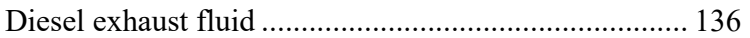

Diesel fuel....................................59, 143, 178, 182, 189

Dimethyl ether ..................................................... 186

Dispenser .......................................130, 188, 191, 199

Filters................................................................ 199

Labeling............................................ 132, 187, 191

Documentation.......................................................... 187

Enforcement ........................................................... 201

Engine Designed for special use ................................. 178

EPA labeling............................................... 132, 188

Ethanol...................................................... 178, 184

Ethanol flex fuel .........................132, 178, 184, 190, 199

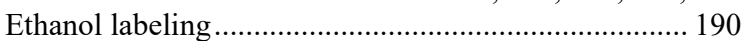

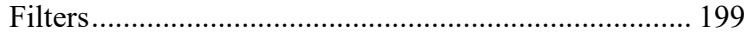




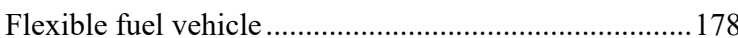

Fuel flush for octane verification .................................278

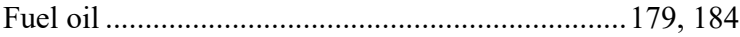

Fuel rating .................................................... 132, 177, 189

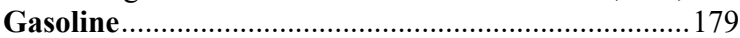

Oxygenate blends ................................................ 179

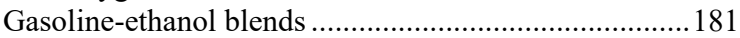

Gasoline-oxygenate blends....................................127, 181

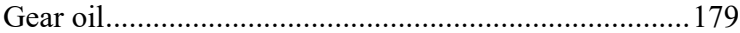

Grade name .................................................................. 187

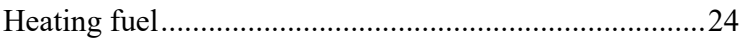

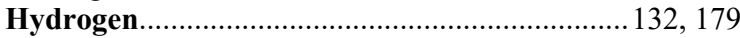

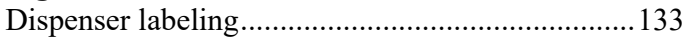

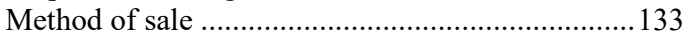

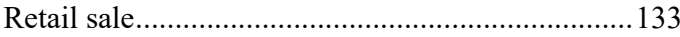

Kerosene............................................. 59, 127, 179, 190

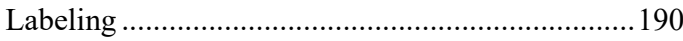

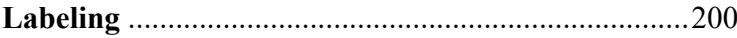

FTC labeling requirements................................... 132

Lead substitute ........................................... 179, 182, 187

Liquefied natural gas (LNG) ....................................191

Identification .......................................................191

Liquefied natural gas(LNG) .........................................179

Liquefied petroleum gas (LPG)................. 180, 184, 191

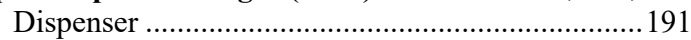

Low temperature operability ....................................... 180

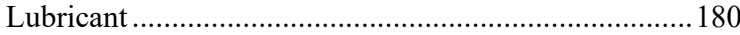

Lubricating tractors ................................................ 186

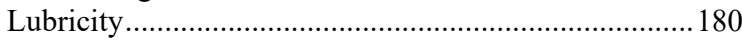

M85 methanol ............................................... 180, 184, 190

Method of sale............................................. 41, 187, 188

Motor fuel deliveries ...................................................250

Motor octane number ................................................... 180

Motor octane number, minimum................................... 182

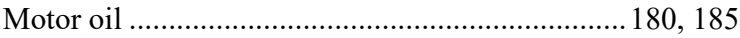

Multi-tier pricing ........................................................... 250

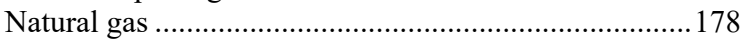

Natural gas (CNG) …............................................... 184

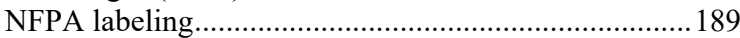

Non-engine ............................................................ 45

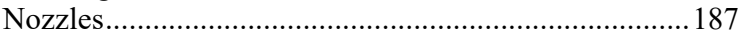

Octane posting regulations ............................................249

Oil ............................................................... 180, 190

Oxygen content of gasoline ........................................ 180

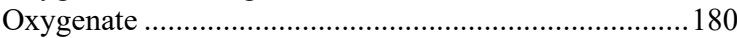

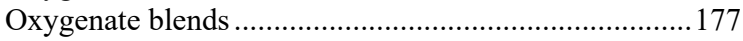

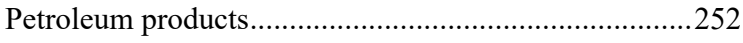

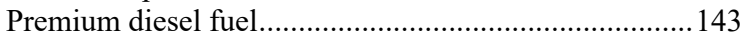

Price posting...................................................248, 249

Product registration .................................................200

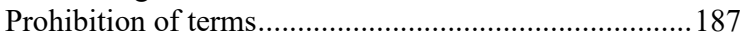

Racing fuel ........................................................... 180

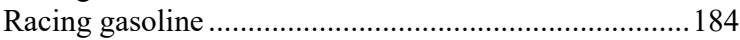

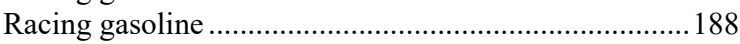

Reproducibility limits...............................................201

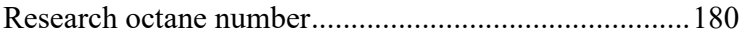

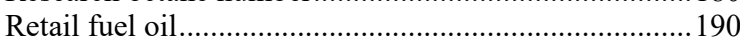

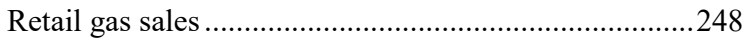

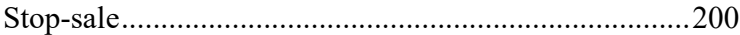

Test methods ........................................................ 201

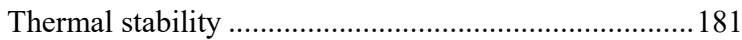

Tractor hydraulic fluid additives .........................140, 186
Uniform Fuels and Automotive Lubricants Law ............ 41

Uniform Regulation for Fuels, Petroleum Products, and

Automotive Lubricants.................................................. 3

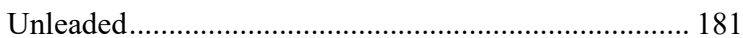

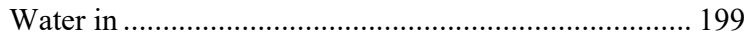

Furniture scarves............................................79

\section{G}

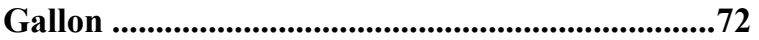

Gasoline ...........................................................179

Metric price computations .......................................... 248

Oxygenate blends...................................... 127, 179, 181

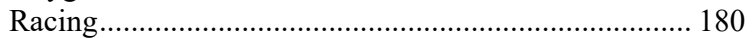

General consumer usage ........................................62

Generally parallel to the declaration, labeling ....60

Giant, package size .................................................70

Gloves .....................................................................79

Gold................................. 126, See Precious metals

Good distribution practice..........................87, 246

Good manufacturing practice................................23

H

Hand lettering ............................................72, 75

Hand script ............................................................72

Handbooks

HB130 ...... 3, 5, 13, 17, 20, 23, 35, 51, 57, 106, 111, 252, 270,273

HB133 ….................22, 88, 126, 246, 263, 264, 266, 269

HB44 ...... 13, 20, 36, 37, 82, 128, 158, 159, 165, 166, 167, $211,246,249,250,276$

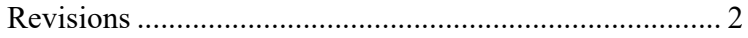

Health and Safety...............................................210

Heating fuel, bulk deliveries ................................24

Hold orders..............................................................23

Home food service plans.......................................111

Hosiery ......................................................................79

Hydraulic Fluid.....................................................179

Hydrogen ............................ 126, 132, 133, See Fuels

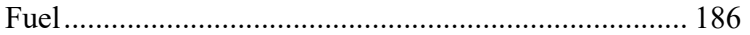

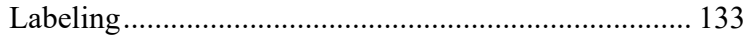

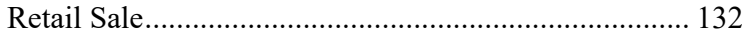

Ice cream products ................... See Dairy products Ice milk ...................................... See Dairy products Identification on Documentation..........................197 Identification on Service Provider Documentation

\section{Identity}

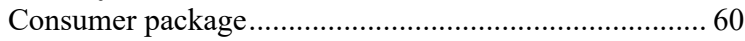

Declaration ................................................................ 120

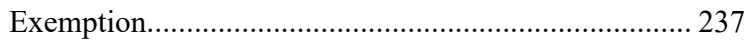

Interpretation, meat and poultry ................................... 237

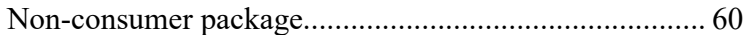

Principal display panels ............................................... 58 
Inch, units of measure ...See U.S. Customary Units Incorrect weights or measures...............................22 Indirect sales ................................................... See Sales Individual servings .......................................................82

Infant formula.....................................................151

Information required on Package ............................25

Injunction ........................................................................27

Inner wrappings.................................................................57

Inspection frequency ............................................208

Increased inspection frequency .....................................208

Normal inspection frequency .........................................208

Special inspection..........................................................208

Term of increased inspection frequency.........................208

Install weighing or measuring devices .................157

Instant concentrated products, interpretation..239

Instruments for weighing and measuring.............17

Insulation ...................................................................124

Batt and blanket.............................................................. 124

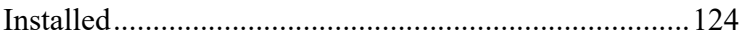

Loose-fill (except cellulose)........................................124

Loose-fill cellulose ..........................................................124

Insulin, drugs containing ........................................84

International Organization for Standardization (ISO)

International Organization. 179

International System of Units . .19

Internet Sales See Sales

Intrastate commerce 23,87

Investigations

$22,23,222$

\section{J}

Jumbo, package size . .70

\section{K}

Kerosene 127, See Fuels

$\mathbf{L}$

\section{Label}

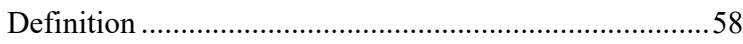

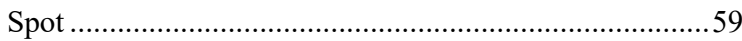

\section{Labeling}

Confections

Dispenser. $132,190,191$

Exemptions ....81

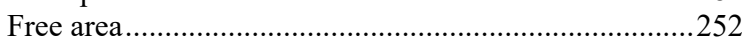

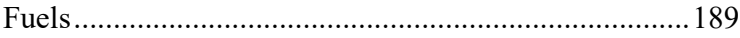

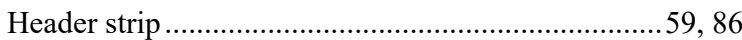

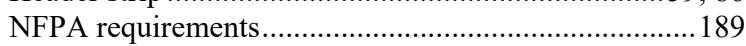

Requirements ............................... 20, 82, 189, 190, 191

Labeling and Identification of Tractor Hydraulic

Fluid

$.141,196$

Lamb, primal source ............................................111

Largest whole unit ..............................................61

Leather goods.........................................................79

Letters, labeling style.............................................72

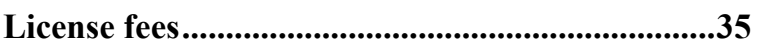

Lignite coal .............................................................125

Linear measure .....................................................667

Liquefied natural gas (LNG) .....................See Fuels

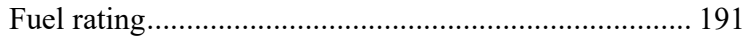

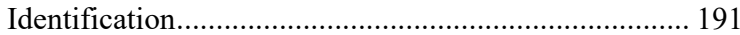

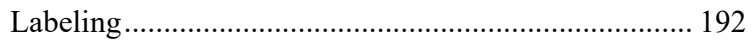

Liquefied petroleum gas (LPG) ...........................180

Liquid measure .........................................24, 62, 71

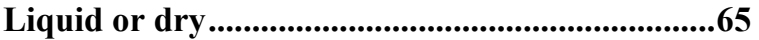

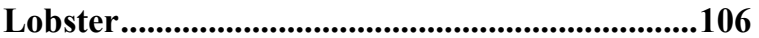

Local officials, powers and duties.........................24

Logs

Artificial compressed or processed ............................... 114

For flavoring foods .................................................... 114

Lot shipment or delivery, interpretation ............278

Lubricant

Transmissions, gears or axles ......................................... 185

Lumber

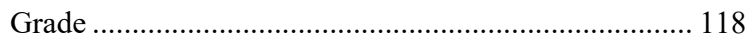

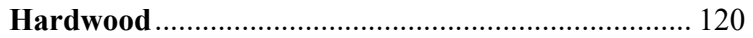

Board foot.......................................................... 120

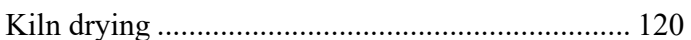

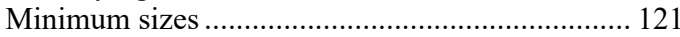

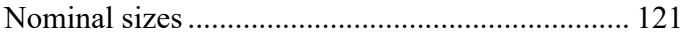

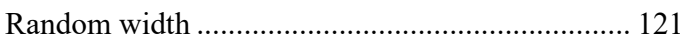

Surface measure ….............................................. 120

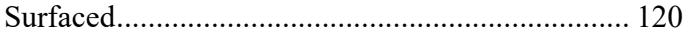

Surfaced sizes for kiln dried ................................. 121

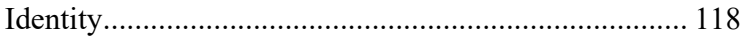

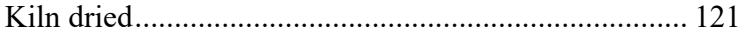

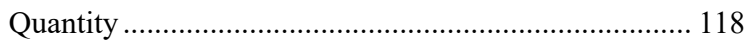

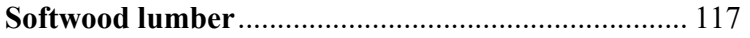

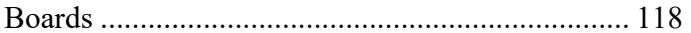

Dimension lumber .................................................. 118

Dry..........................................................118, 119

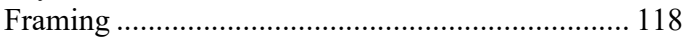

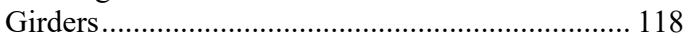

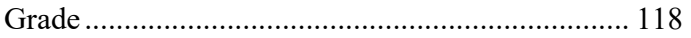

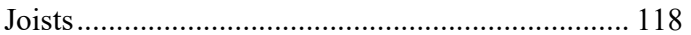

Matched........................................................... 118

Minimum dressed sizes ...................................... 118

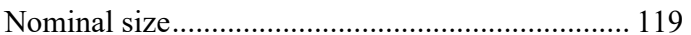

Patterned...................................................... 118

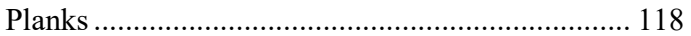

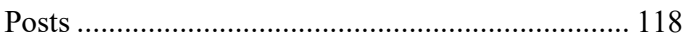

Purlins ................................................................ 118

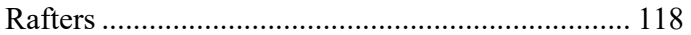

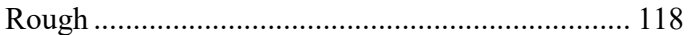

Shiplapped ............................................................. 118

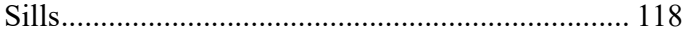

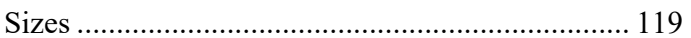

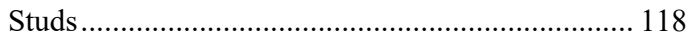

Surfaced (dressed) ............................................ 117

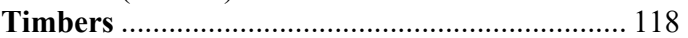

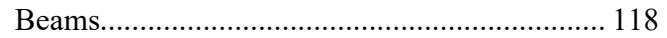

Caps …........................................................... 118

Unseasoned (green) .................................. 118, 119 


\section{M}

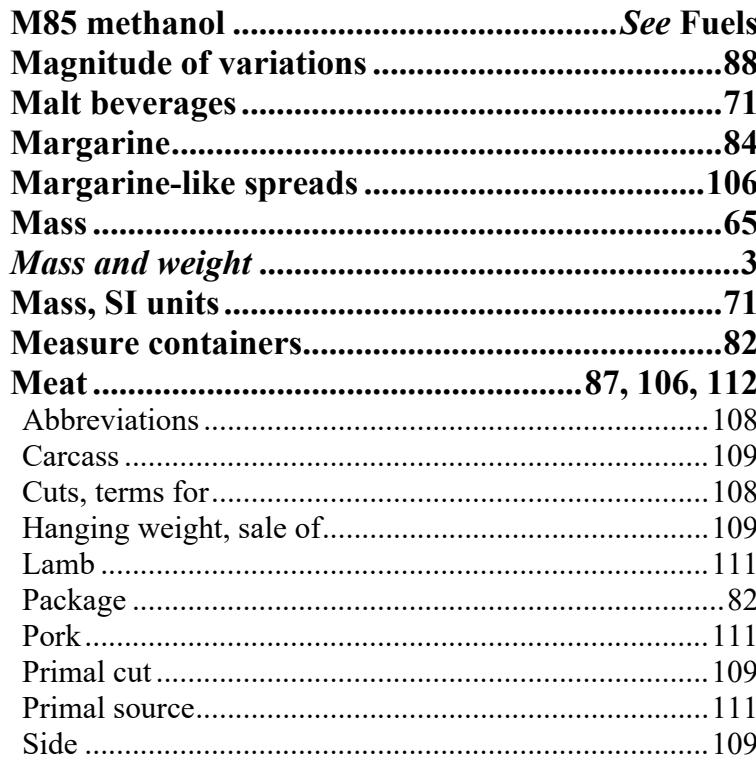

Medical Device ........................................................96

Method of Retail Sale for Fresh Fruits and Vegetables.............................. See Method of sale

Method of sale ....................................131, 135, 140

Allowable difference ..................................................... 144

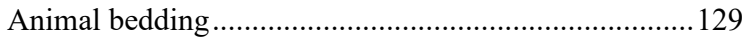

Apples ......................................................................... 241

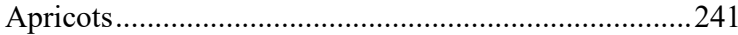

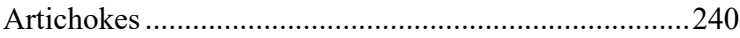

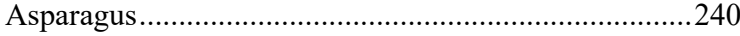

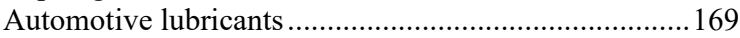

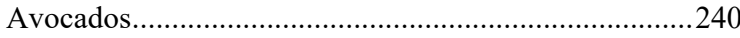

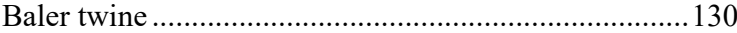

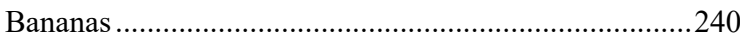

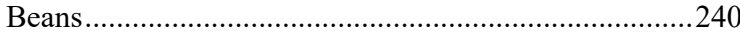

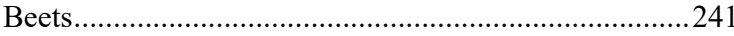

Berries ........................................................................ 241

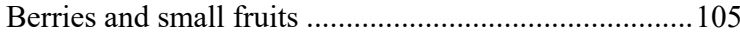

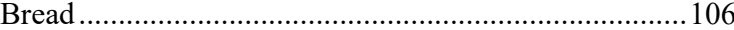

Broccoli.....................................................................241

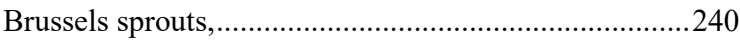

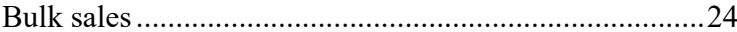

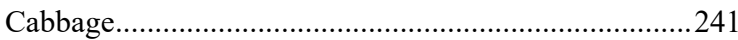

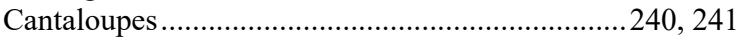

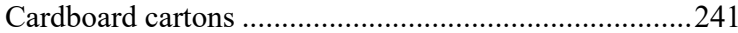

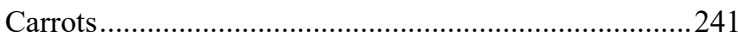

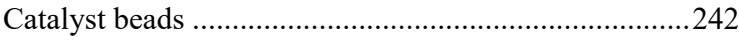

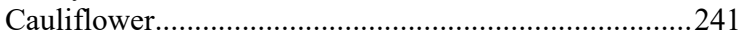

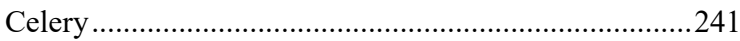

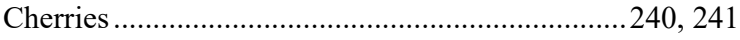

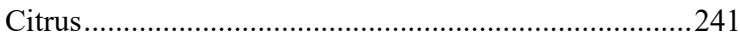

Coconuts ............................................................... 240

Commodity ….......................... 20, 41, 98, 99, 105, 241

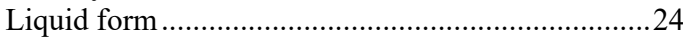

non liquid form ................................................... 24

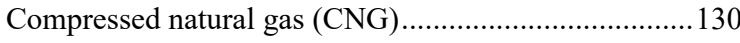

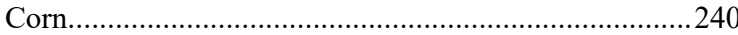

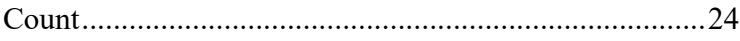

Cranberries ................................................................ 241

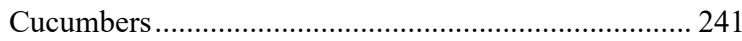

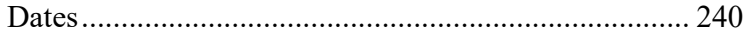

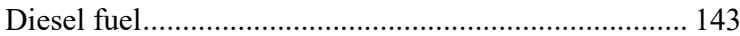

Edible bulbs ............................................................. 241

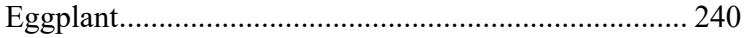

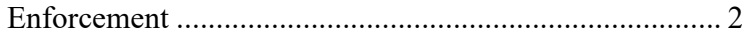

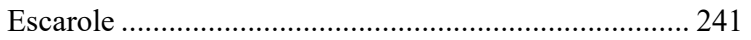

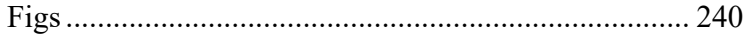

Firewood................................................ 114, 115, 278

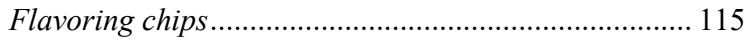

Flower vegetables ........................................................ 241

Fluid milk products................................................... 107

Fruits and vegetables ................................................. 240

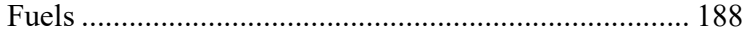

Fuels and automotive lubricants ..................................... 41

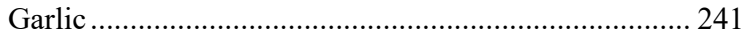

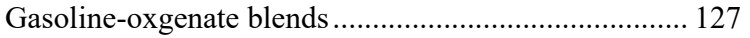

General concepts............................................................ 97

Gourd Vegetables .................................................... 241

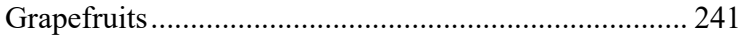

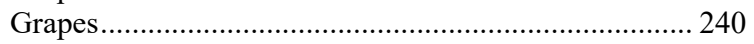

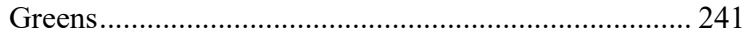

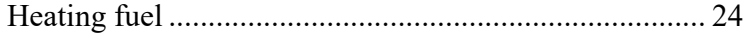

Hydrogen fuel ........................................................ 133

Ice cream, similar frozen products ....................... 107, 108

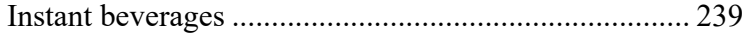

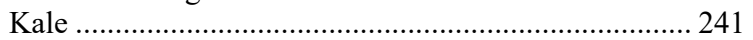

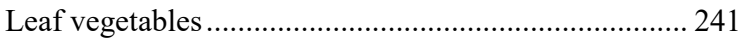

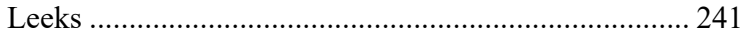

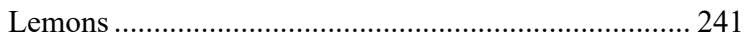

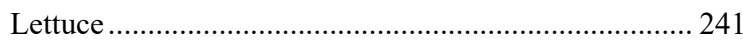

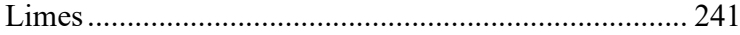

Liquefied natural gas .................................................. 131

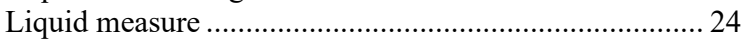

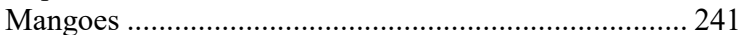

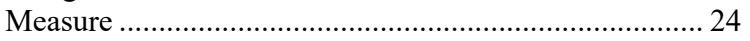

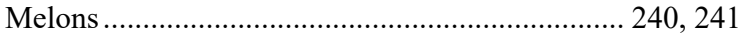

Model state method of sale ............................................. 97

Mushrooms ............................................................... 240

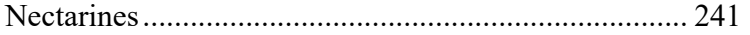

Non-utility transactions of electrical energy ................. 139

Oil ........................................................................... 133

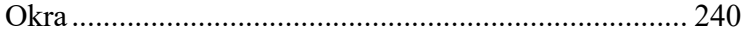

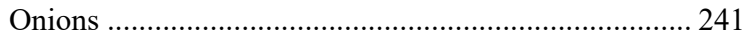

Oranges.................................................................. 241

Packaged foods or cosmetics

Vending machines .................................... 278

Papaya .................................................................. 241

Paper .................................................. 131, 237, 238

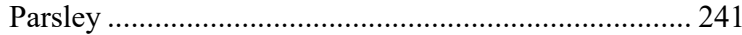

Parsnips..................................................................... 241

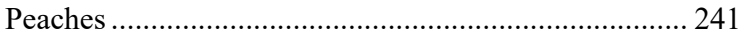

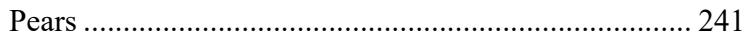

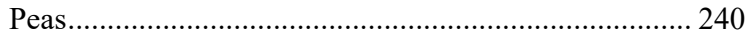

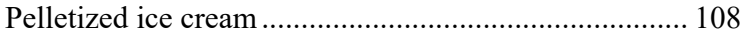

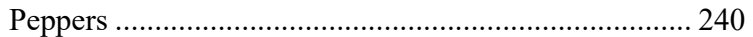

Persimmons ……..................................................... 241

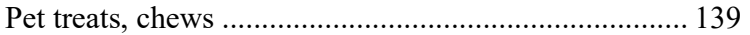

Petroleum products ............................................ 41, 187

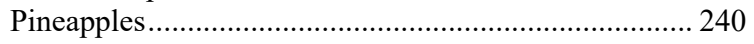

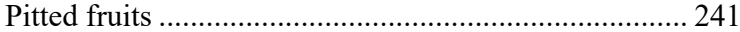


Plums.......................................................................... 241

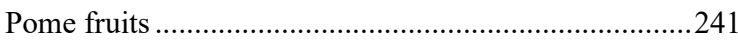

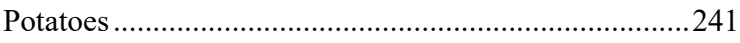

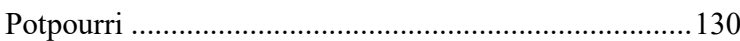

Precious metals............................................................ 126

Premium diesel fuel.................................................. 143

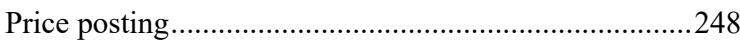

Pumpkins............................................................. 241

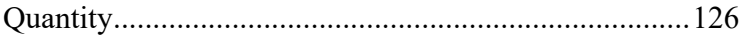

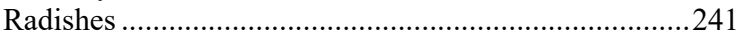

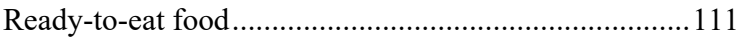

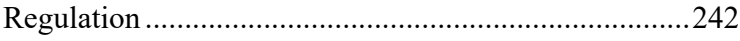

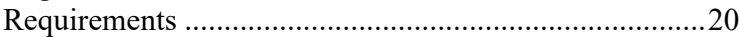

Retail sale for fresh fruits and vegetables......................240

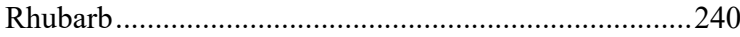

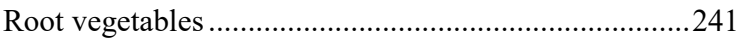

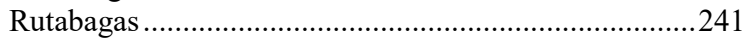

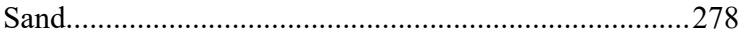

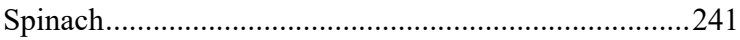

Street sign prices and other advertisements..................136

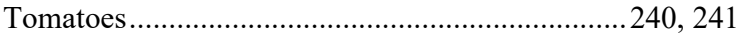

Tractor hydraulic fluid ............................................... 140

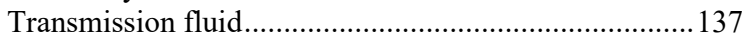

Uniform Engine Fuels and Automotive Lubricants

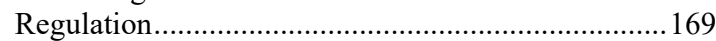

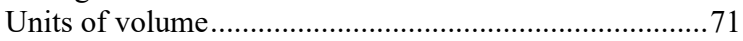

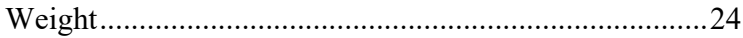

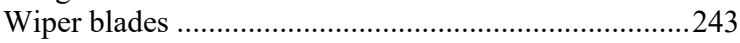

Wiping cloths .......................................................... 130

Method of Sale

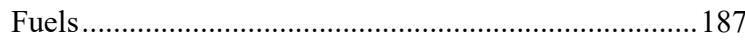

Metric equivalents ...............................................248

Metric System (SI) .................................................19

Metric system of weights and measures...............19

Milligram, SI Units ...............................................65

Misrepresentation of pricing ...................................24

Moisture, loss or gain of .......................................23

Mollusks........................................ 107, See Shellfish

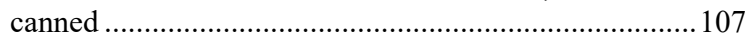

Motor octane number...........................................180

Motor oil ....................................................85, 180

Movie film.............................................................85

Mulch

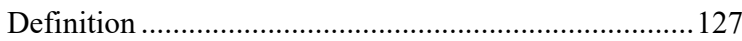

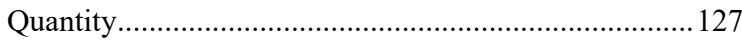

Multiunit package.................................58, 75, 83

$\mathbf{N}$

Napkins

$68,76,79$

National Type Evaluation ..................3, 21, 161, 165

National Type Evaluation Program 161, 165, 166, 168

Natural gas .....................................................See Fuels

Net mass.................................................3, 17, 61

Net quantity..................................................61, 87

Net weight .......................................................3, 17, 61

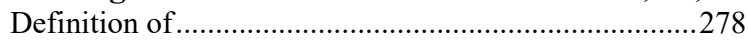

Non-food products ...............................................113

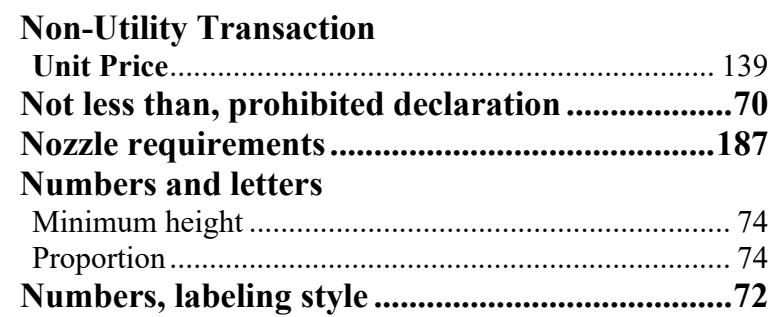

Octane posting regulation ..........................See Fuels

Oil..............................................................180, 192

Brand ……................................................... 133, 192

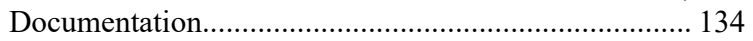

Engine service category ...................................... 133, 192

Inactive or obsolete service categories......................... 134

Labeling ...................................................... 192, 193

Rail cars …................................................... 134, 193

Recreational ................................................................ 193

Service categories ............................................ 192, 193

Tank trucks ...................................................... 134, 193

Use ......................................................................... 193

Vehicle or engine manufacturer standard ......................... 134

Viscosity ......................................................... 133, 193

Oleomargarine ........................................................106

Open carriers ...............................................................57

Open multiunit retail food packages.......................76

Ordinary and customary exposure .......................87

Ornamentation....................................................88

Ounce, unit of measure ......................................67

Oysters ..........................................................107

\section{P}

Package .................................................................70

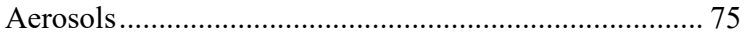

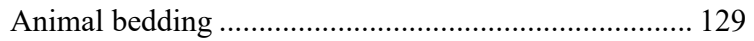

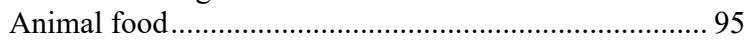

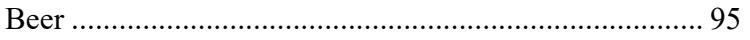

Catfish

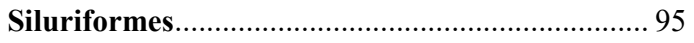

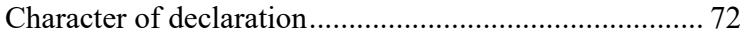

Color contrast, labeling................................................ 73

Combination ............................................. 58, 76, 278

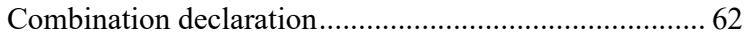

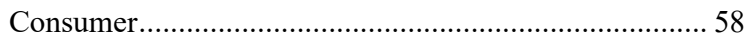

Container-type commodity ........................................... 77

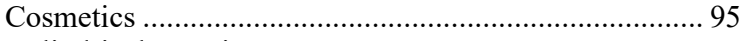

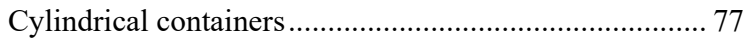

Declaration of quantity ........................................ 62, 70

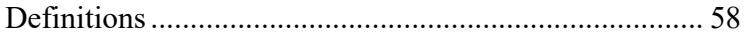

Display card package ................................................... 75

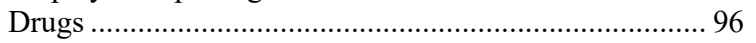

Egg cartons .................................................................. 75

Exemptions, combination package .............................. 151

Exemptions, infant formula ....................................... 151

Exemptions, single item............................................. 151

Exemptions, small ........................................................ 151

Exemptions, variety package ....................................... 151 
Free area, labeling ....................................................... 73

Gift ............................................................. 278

Header strip .....................................................59, 86

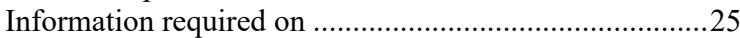

Labeling, consumer information ..................................... 72

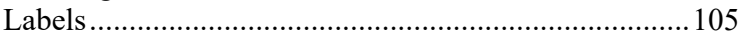

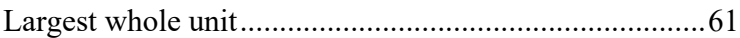

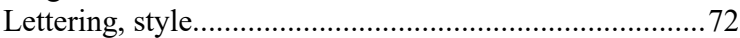

Location of declarations ................................................ 72

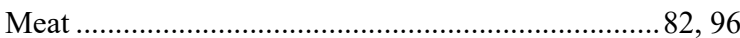

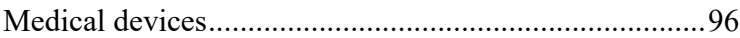

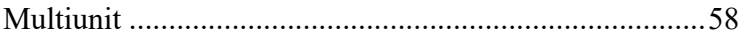

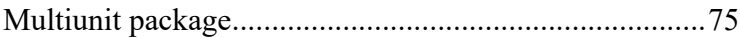

Non-consumer ................................................... 58, 71, 75

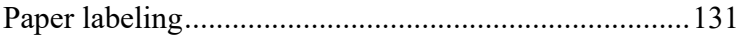

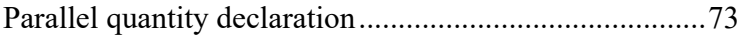

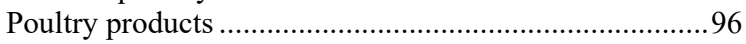

Principal display panel

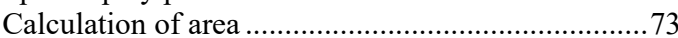

Qualifications of declaration prohibited ......................... 70

Random ................................... 17, 57, 58, 70, 81, 82

Random weight ....................................................... 17

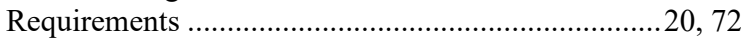

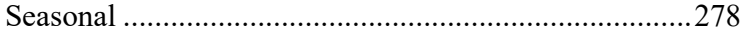

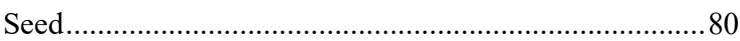

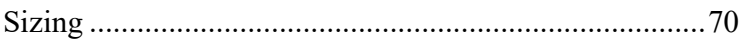

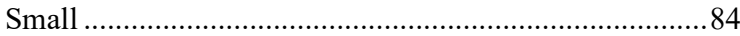

Standard ….................................. 17, 18, 25, 57, 59

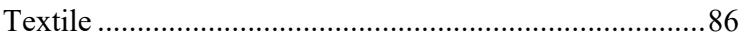

Tobacco and Tobacco Products.........................................96

Unreasonable shortage ................................................... 72

Variety.................................................... 58, 76, 278

Vending machine food and cosmetics ..........................2278

Weight....................................................................... 71

Paint

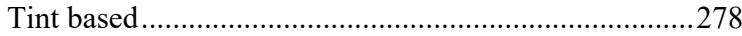

Paper .....................................................................268

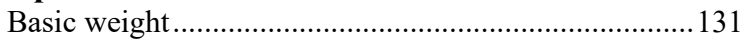

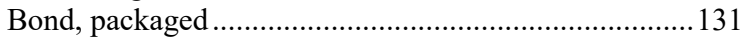

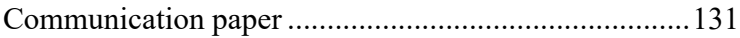

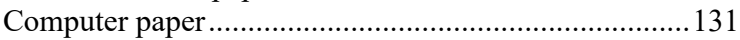

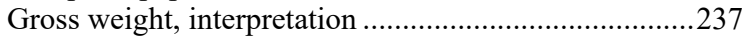

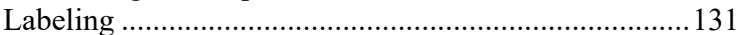

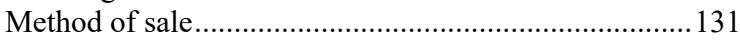

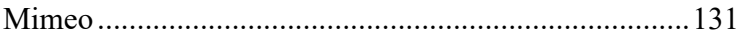

Net weight, interpretation................................................238

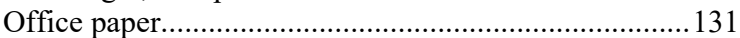

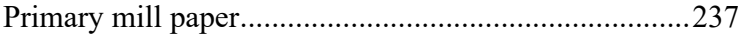

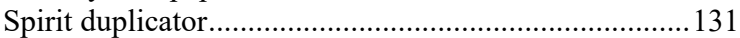

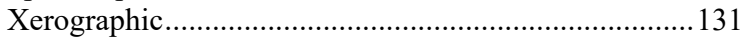

Parallel to the base, labeling ...............................60

Participating Laboratory ...................................161

Passenger carrier servings ......................................82

Peat and peat moss .............................................115

Pelletized frozen desserts ....................................108

Pelletized ice cream .............................................108

Pelletized seed .....................................................81

Performance requirements, personnel.................23

Pet chews ..........................................................139

Pet treats.......................................................139

Petroleum products ...............41, 59, 169, See Fuels
Petroleum Subcommittee's name to the Fuels and Lubricants Subcommittee (FALS) ..................41

Pickles ......................................................................108

Pillow ...................................................................79

Pillowcases.................................................................79

Placed in Service Reports....................................159

Plastics ................................................................113

Platinum .................................See Precious Metals

Police powers........................................................23

Polyethylene products ............................................122

Sheeting and film ....................................................... 122

Pork.

109, 111

Pot holders.......................................................79

Pot roast..................................................................109

Potpourri, method of sale.....................................130

Poultry 25, 82, 87, 106, 110, 111, 112, 237, 238, 253, 259

Combinations with other foods

Pound ..................................................................667

Pound, units of measure See U.S. Customary Units

Power Factor (PF). ...........................................140

Powers and duties

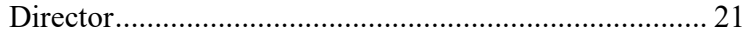

Local officials ....................................................... 24

Precious metals

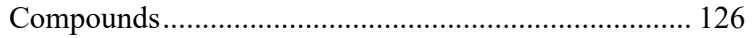

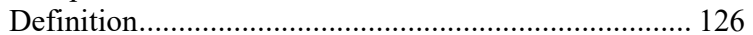

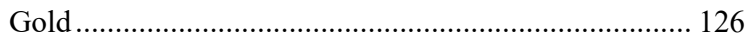

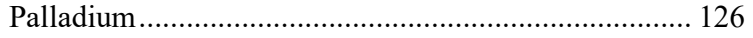

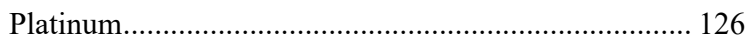

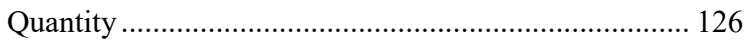

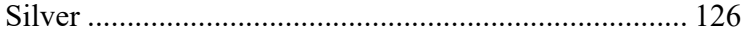

Prefabricated utility buildings..............................115

Preplanters ..............................................................81

Prescription drugs ...................................................884

Presumptive evidence .............................................27

Price computing of bulk commodities.................113

Price posting

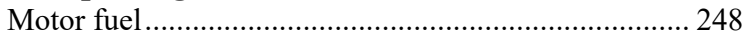

Price verification..................................................207

Examination procedure ............................... 23, 203, 207

Inspections ......................................207, 219, 221, 228

Program ............................................................... 227

Reports........................221, 223, 228, 231, 232, 233, 234

Tally sheets........................210, 219, 221, 228, 229, 230

Working Group.......................................................... 203

Principal display panel............................................55

Printer ribbons and tapes, guidelines ................239

Prohibited Acts .

26, 37, 47, 167

Prohibition of terms

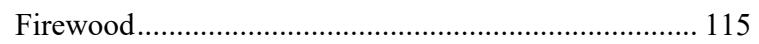

Promoting uniformity............................................21

Propane........................................................128, 191

Qualifying terms, prohibited $.272,277$

Quality representation . .25 


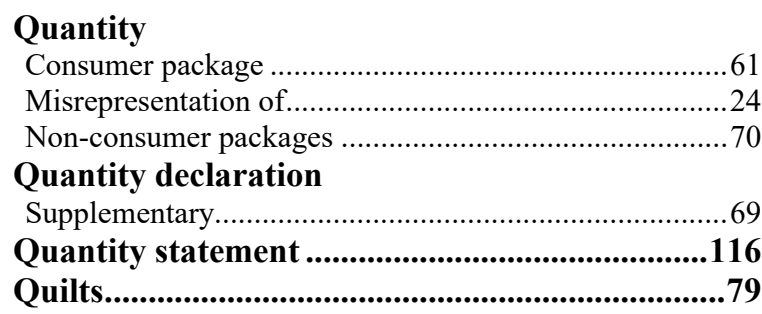

\section{$\mathbf{R}$}

\section{Railroad cars}

Covered hopper cars..................................................... 145

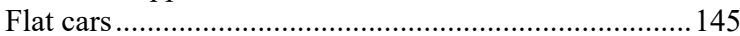

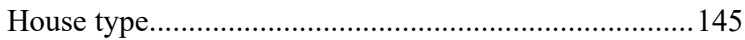

Refrigerator cars, mechanical..................................... 145

Tank trucks or rail cars................................................. 193

Ready-to-eat food................................................110

Refrigerated products, reference temperature .278

Registered service agency.....................................157

Registered serviceperson......................................157

Regulation, for National Type Evaluation.161, 165

Relishes ..................................................................108

Removal orders ......................................................23

Representation .......................................114, 118, 121

Restaurant servings .............................................82

Restraining order...................................................27

Retail price ..................................................................25

Revocation

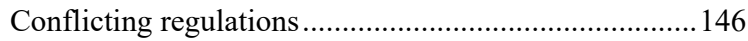

Revocation of conflicting regulations..................88

Ribbon, typewriter...............................................239

Right of cancellation ......................................110, 112

Roast .............................................................109

Roofing material .................................................116

Rounding .............................................................69

Rounding and significant digits ......................91, 92

Rounding rules........................................................92

Rounding, units of measure .................................70

Rugs ...........................................................79, 80

Rule of 1000 .............................................................71

\section{$\mathbf{S}$}

SAE International............................................181

Sale from bulk...................................................24

Sales

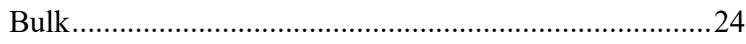

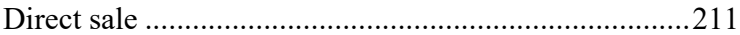

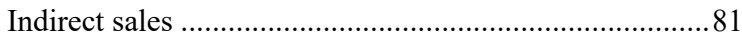

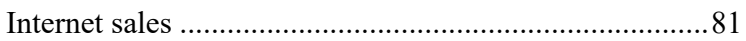

Temperature compensated.............................................25

Sampling procedures ..........................................207

Sand ................................................................278

Scallops .................................................................106

Seafood .................................................106, 111, 112

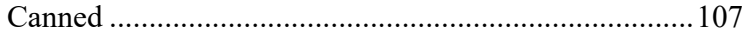

Combination with other foods ...................................... 107

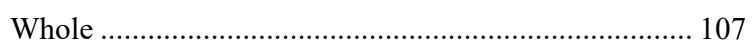

Sealants

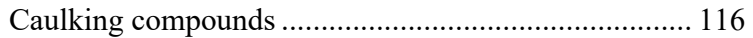

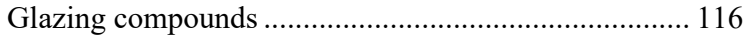

Putty...................................................................... 116

Rope caulk .......................................................... 116

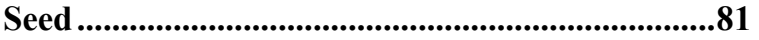

Seed tapes .....................................................................81

Seeds ...............................................................80

Semi-anthracite..................................................125

Semi-bituminous .................................................125

Service agencies, registration.............................157

Sewing machine lubricants ..................................59

Shellfish ............................................................106, 107

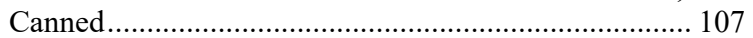

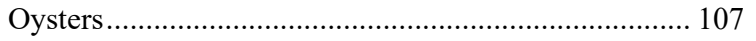

Shellfood

Clams, mussels, oysters, others........................................ 107

Shoes ......................................................................79

Shoulder...................................................109, 111

Shrimp .......................................................106, 260

SI units

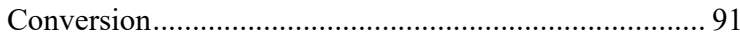

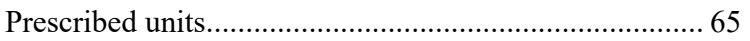

SI Units ..........................................59, 61, 62, 86

SI, fractions and prefixes ........................................64

SI/U.S. Customary Units conversion factors .......89

Silver ..........................................See Precious Metals

Slip covers.....................................................................79

Society of Automotive Engineers..........................47

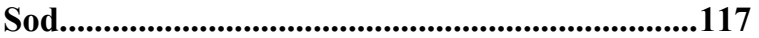

Softwood lumber...............................................117

Species

Fireplace and stove wood ............................................... 114

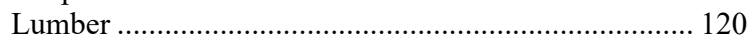

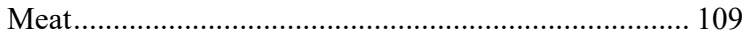

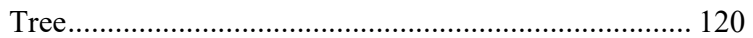

Species group ..........................................118, 120

Species tree .............................................................118

Specifications..........................................................201

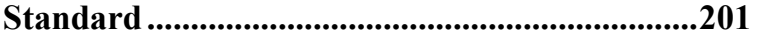

Standard lengths ......................................................120

Standard package .................................See Package

Standards of fill.......................................................22

Standards of weights .................................................19

Steak ..........................................................109

Storage Tank Labeling ..........................................197

Stove wood...............................................................114

Stove wood, chips or pellets .................................114

Symbols.........................................See Abbreviations

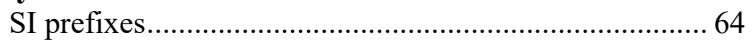

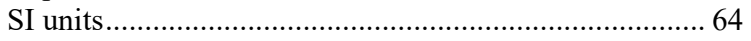

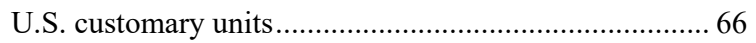

System of weights and measures in customary use

.19 


\section{$\mathbf{T}$}

Tablecloths .............................................................79

Tank cars............................................................145

Tapes, typewriter ....................................................239

Tare weight

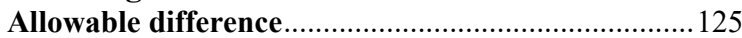

Railroad cars ..................................................... 145

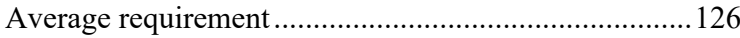

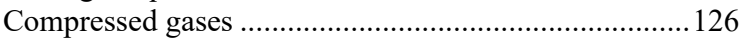

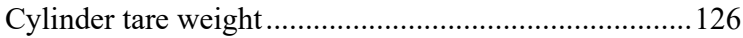

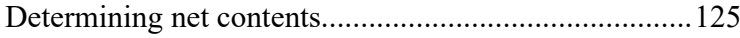

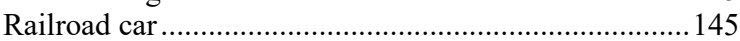

Stamped or stenciled .............................................. 125

Stenciled tare weights

Railroad car.......................................................... 145

Verification or change ...................................................... 145

Tea, instant .........................................................2239

Tear away tag.............................................................88

Temperature compensated sales...........................25

Textiles...........................................................79, 80

Thread

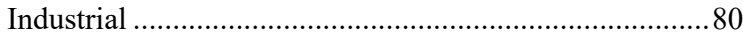

Threads ....................................................................8 80

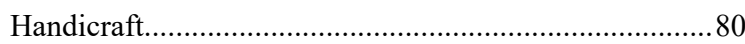

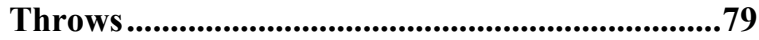

Tint base paint, labeling, interpretation ..............85

Tobacco

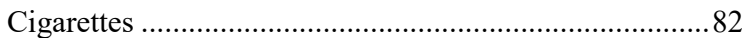

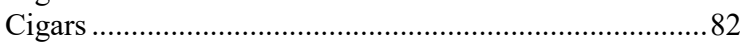

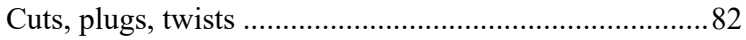

Tobacco and Tobacco Products.........................................96

Tobacco, cuts, plugs, and twists.............................82

Tractor Hydraulic Fluid .......................................140

Bulk Delivery .......................................................... 142

Conformance ....................................................... 140, 186

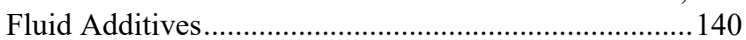

Identification on Documentation ...................................... 141

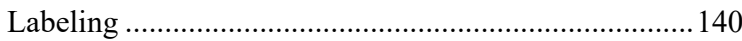

Trademark .............................................................80

Training, weights and measures personnel .........23

Transmission fluid ................................137, 177, 193

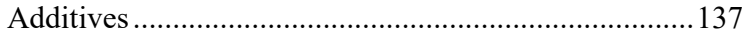

Bulk delivery..................................................139, 195

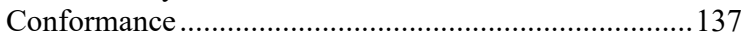

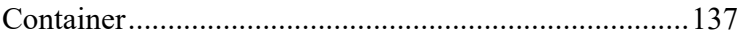

Documentation .......................................... 138, 194, 195

Labeling .......................................... 137, 139, 193, 194

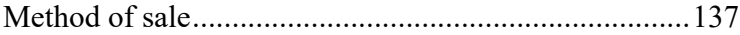

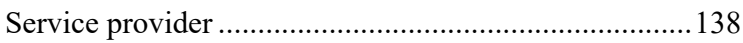

Storage tank ................................................... 139, 195

Transparent wrappers ...........................................57

Turf ...............................................................117

Type evaluation....................... 21, 161, 165, 166, 168

Type evaluation, requirements for .....................21

Typewriter ribbons and tapes............................239
U

U.S. Customary Units $61,65,66,67,68,72$

Unapproved weight or measure ...........................23

Unavoidable deviations

In good manufacturing practice ...................................... 23

In weighing, measuring, or counting .............................. 87

Uniform Packaging and Labeling Regulation 2, 17, 20

Uniform Regulation for Fuels, Petroleum

Products, and Automotive Lubricants...............3

Uniform Regulation for National Type Evaluation

Uniform Regulation for the Method of Sale of

Commodities .105

Uniform Regulation for the Registration of Servicepersons and Service Agencies...............21

Uniform Regulation for the Voluntary Registration of Servicepersons and Service Agencies.

Uniform Retail Meat Identity Standards...........108

Uniform Unit Pricing Regulation.20, 111, 147, 148

Uniform Weighmaster Law See Weighmaster Law Uniformity ...................................................5, 21

Unit pricing .......... 3, 20, 25, 147, 148, 151, 152, 211

Requirements ............................................................... 20

Units of two or more meanings.............................67

Unreasonable shortage .................................70, 87

Utility cloths .............................................79, 80

\section{V}

Variations to be allowed.........................................887

Variety packages..........................................................84

Vegetables..........................................................240

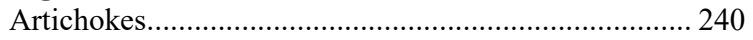

Asparagus ........................................................... 240

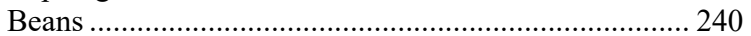

Beets .......................................................................... 241

Broccoli ......................................................... 240, 241

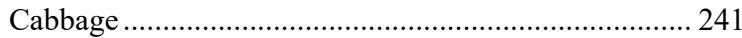

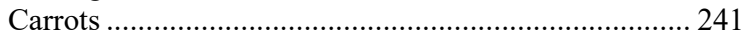

Cauliflower ............................................................ 241

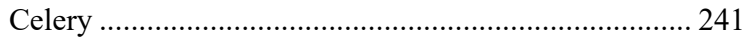

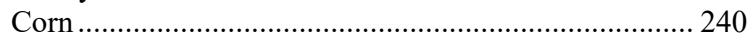

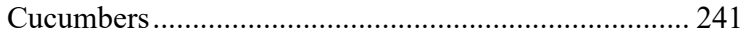

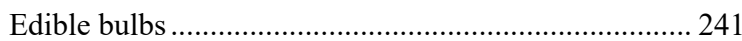

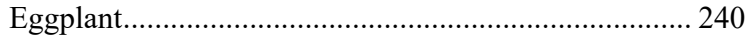

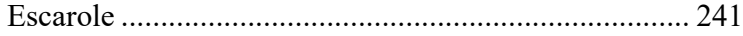

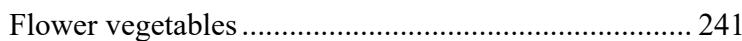

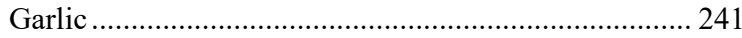

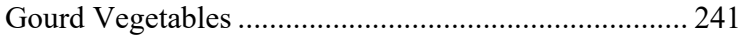

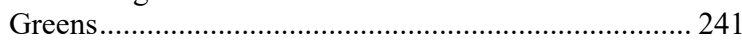

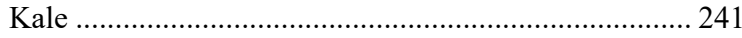

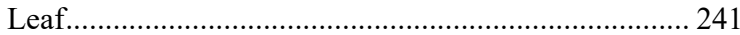

Leaf vegetables ...................................................... 241

Leeks ................................................................... 241

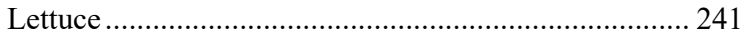

Method of sale ................................................ 240, 241 


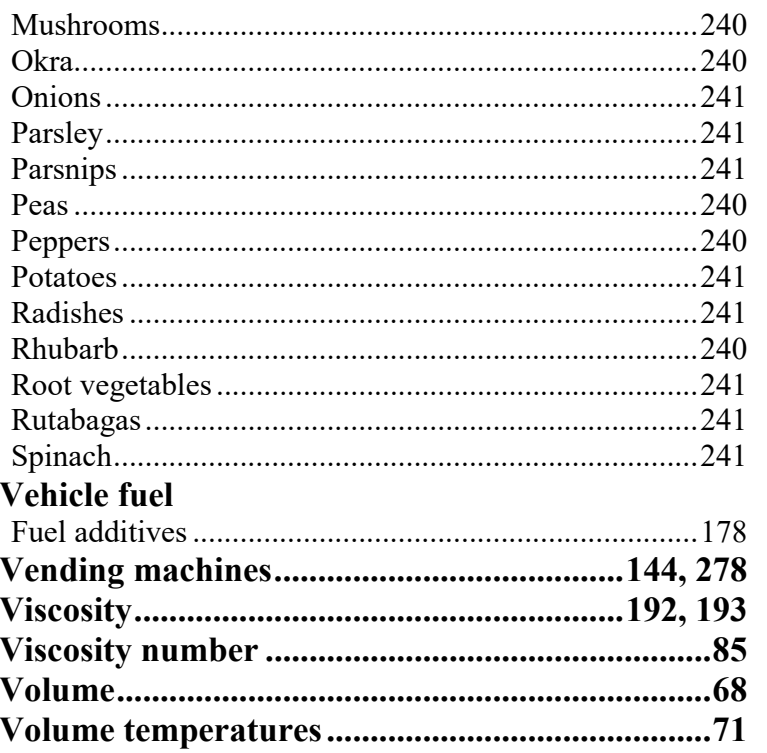

Voluntary registrant, privileges and responsibilities...................................................158

Voluntary registration..............................................3

\section{w}

Weighmaster 34, 35, 36

Qualifications for 34

Weighmaster Act ....................................................39

Weighmaster Law........................................8, 29, 33

Weight......................................................................67

Weight(a) and/or Measure(s) ...............................2278

Wiper blades ..........................................................243

Wood.....................................................See Firewood

Y

Yarn ....................................................80, 278 Yogurt

Frozen ....................................................See Dairy Products 


\section{THIS PAGE INTENTIONALLY LEFT BLANK}

